\title{
ZOOPLÂNCTON DOS LAGOS DO PARQUE ESTADUAL DAS FONTES DO IPIRANGA (SP) E RELAÇÕES ENTRE ESPÉCIES ZOOPLANCTÔNICAS E ESTADO TRÓFICO EM CORPOS D'ÁGUA DO ESTADO DE SÃO PAULO
}

\author{
STELA APARECIDA EID PIVA-BERTOLETTI
}

\begin{abstract}
TESE APRESENTADA AO DEPARTAMENTO DE SAÚDE AMBIENTAL DA FACULDADE DE SAÚDE PÚBLICA DA UNIVERSIDADE DE SÃO PAULO PARA OBTENÇÃO DO GRAU DE DOUTOR EM SAÚDE PÚBLICA
\end{abstract}

ÁREA DE CONCENTRAÇÃO: SAÚDE AMBIENTAL

ORIENTADORA:

DOUTORA SUZANA SENDACZ

São Paulo

2001 
Autorizo, exclusivamente para fins acadêmicos e científicos, a reprodução total ou parcial desta tese, por processos fotocopiadores.

Assinaturas.

Data: 


\section{AGRADECIMENTOS}

A Dra. Suzana Sendacz, pela orientação, dedicação, incentivo e participação constante na concretização deste trabalho

Ao Centro de Estudos de Bacias Hidrograficas do Instituto de Pesca da Secretaria da Agricultura e Abastecimento do Estado de São Paulo, pela infraestrutura e facilidades concedidas.

Aos funcionários e estagiários do Laboratório de Ecologia Aquática da Seção de Ecologia do Instituto de Botânica da Secretaria do Meio Ambiente do Estado São Paulo, pela realização das coletas e análises físicas, químicas e biológicas.

Aos colegas do Centro de Estudos de Bacias Hidrográficas do Instituto de Pesca, em especial aos amigos Msc. Edison Kubo e Msc. Adalberto Monteiro Júnior pela amizade, ajuda constante e convivência no decorrer destes anos, e à Dra. Cacilda Thais Janson Mercante pela amizade e incentivo.

Ao Prof. Dr. Aristides Almeida Rocha, pelo incentivo, apoio e principalmente pela amizade e compreensão em todos os momentos.

A Dra. Denise de Campos Bicudo, pela amizade e pelas valiosas informações que contribuiram para a realização deste trabalho.

A Dra. Marcia Janete Coelho Botelho pelas informações concedidas, apoio e incentivo constante.

A Fundação de Amparo à Pesquisa do Estado de São Paulo (FAPESP) (processo $\mathrm{n}^{\circ}$ 98/01673-7), e Conselho Nacional de Desenvolvimento Científico e Tecnológico $(\mathrm{CNPq})$ pelas bolsas de estudo concedidas.

Ao meu pai Vasco, e em especial à minha mãe Edith pela compreensão, e por estar sempre presente na minha ausència.

As minhas filhas Juliana e Luana, por terem compreendido os meus momentos de ansiedade e impaciència.

Ao Eduardo, pela ajuda e sugestões. 


\section{RESUMO}

Piva - Bertoletti SAE. Zooplâncton dos lagos do Parque Estadual das Fontes do Ipiranga (SP) e relações entre espécies zooplanctônicas e estado trófico em corpos d'água do Estado de São Paulo. São Paulo; 2001. [Tese de Doutorado Faculdade de Saúde Pública da Universidade de São Paulo].

Este trabalho teve como objetivo avaliar a utilização de organismos zooplanctônicos como indicadores da qualidade da água, através da caracterização da comunidade zooplanctônica de lagos do Parque Estadual das Fontes do Ipiranga (PEFI) (SP) (23 $39^{\prime} \mathrm{S} ; 46^{\circ} 37^{\prime} \mathrm{W}$ ), de diferentes estados tróficos, e de estudos realizados no Estado de São Paulo. Desta maneira, a composição, estrutura, abundância e diversidade do zooplâncton e sua associação ao gradiente trófico foram caracterizadas nos três lagos, através de coletas mensais de zooplâncton realizadas de janeiro a dezembro de 1997. Foram compilados dados de ocorrência de espécies zooplanctônicas e sua associação ao estado trófico em corpos d'água do Estado de São Paulo; foi calculado, o Índice de Estado Trófico (IET) de Carlson modificado a partir das concentrações de clorofila a total. Nos lagos do PEFI, constatou-se o predomínio de microzooplâncton; ciclopóides foram mais importantes no lago das Garças, cladóceros no lago do IAG, e calanóides nos lagos do IAG e das Ninféias. Evidenciou-se associações específicas de acordo com o estado trófico como também táxons cuja ocorrência foi independente das condições tróficas. A composição, estrutura, abundância e diversidade do zooplâncton nos três lagos variaram de acordo com o estado trófico, dependendo também das diferentes estratégias alimentares de cada grupo zooplanctônico. Foram evidenciados táxons que podem ser utilizados como indicadores da qualidade da água, assim como táxons que não devem ser utilizados para tal finalidade por não mostrarem uma clara associação ao estado trófico.

Descritores: Zooplâncton. Estado trófico. Lagos. Indicadores. Qualidade da água 


\section{SUMMARY}

Piva - Bertoletti SAE. Zooplâncton dos lagos do Parque Estadual das Fontes do Ipiranga (SP) e relações entre espécies zooplanctônicas e estado trófico em corpos d'água do Estado de São Paulo [Zooplankton of the Parque Estadual das Fontes do Ipiranga lakes (SP) and zooplanktonic species and trophic state relationships in São Paulo State aquatic environments]. São Paulo (BR); 2001. [Tese de Doutorado - Faculdade de Saúde Pública da Universidade de São Paulo].

The purpose of this study was to evaluate the use of zooplankton organisms as indicators of the water quality through the characterization of the zooplanktonic community of lakes of the Parque Estadual das Fontes do Ipiranga (PEFI) (SP) (230 $39^{\prime} \mathrm{S} ; 46^{\circ} 37^{\prime} \mathrm{W}$ ), of different trophic status, and through studies undertaken at São Paulo State. The zooplankton composition, structure, abundance and diversity and its association to the trophic gradient of the three studied lakes were evaluated through the collection and analysis of zooplankton monthly samples, from January to December 1997. Data of the occurrence of zooplanktonic species of São Paulo State related to the trophic state were summarized in tables and maps; the modified Carlson's Trophic State Index (TSI) was determined from concentrations of total chlorophyll $a$. Microzooplankton dominated the PEFI lakes; cyclopoids were important at Garças Lake, cladocerans at IAG Lake, and calanoids at IAG and Ninféias Lakes. Specific associations of species occurred according to the trophic state, as well as taxa which occurred independently of this condition. The zooplanktonic composition, structure, abundance and diversity of the studied lakes changed with the trophic state, also depending on the different feeding strategies of each zooplankton group. Taxa that may be used as indicators of the water quality were pointed out, as well as taxa that should not be used for such purposes due to a lack of its association to the trophic state.

Descriptors: Zooplankton. Trophic state. Lakes. Indicators. Water quality. 


\section{ÍNDICE}

1. INTRODUÇÃO

2. OBJETIVOS 4

3. ÁREA DE ESTUDO 4

3.1. Lago do IAG 6

3.2. Lago da Ninféias 7

3.3. Lago das Garças

4. MATERIAL E MÉTODOS 10

$\begin{array}{ll}\text { 4.1. Dados climatológicos } & 10\end{array}$

4.2. Variáveis físicas, químicas e biológicas $\quad 10$

4.3. Zooplâncton 11

4.4. Ocorrência de espécies zooplanctônicas nas Unidades de Gerenciamento de Recursos Hídricos (UGRHIs) do Estado de São Paulo

$\begin{array}{ll}\text { 5. TRATAMENTO DOS DADOS } & 16\end{array}$

5.1. Densidade numérica (D) 16

5.2. Abundância relativa (AR) 16

5.3. Freqüência de ocorrència $(F) \quad 16$

$\begin{array}{ll}\text { 5.4. Diversidade }\left(\mathrm{H}^{\prime}\right) & 16\end{array}$

$\begin{array}{ll}\text { 5.5. Riqueza (S) } & 17\end{array}$

$\begin{array}{ll}\text { 5.6. Equitatividade ou uniformidade (E) } & 17\end{array}$

$\begin{array}{ll}\text { 5.7. Análise multivariada } & 17\end{array}$

5.8. Estado trófico dos corpos d'água das Unidades de Gerenciamento de Recursos Hídricos (UGRHIs) do Estado de São Paulo 20

5.9. Espécies zooplanctônicas como indicadoras da qualidade da água nas Unidades de Gerenciamento de Recursos Hídricos (UGRHIs) do Estado de São Paulo

6. RESULTADOS 21

6.1. Dados climatológicos 21

6.2. Variáveis fĩsicas, químicas e biológicas 22 
6.3. Zooplâncton 26

6.3.1. Composição da comunidade 26

$\begin{array}{ll}\text { 6.3.2. Estrutura da comunidade } & 27\end{array}$

6.3.3. Flutuação da comunidade 33

6.3.4. Riqueza, equitatividade e diversidade $\quad 45$

6.3.5. Análise multivariada $\quad 47$

6.3.6. Ocorrência de espécies zooplanctônicas e estado trófico das Unidades de Gerenciamento de Recursos Hidricos (UGRHIs) do Estado de São Paulo 53

$\begin{array}{ll}\text { 7. DISCUSSÃO } & 116\end{array}$

7.1. Composição da comunidade 116

$\begin{array}{ll}\text { 7.2. Estrutura da comunidade } & 125\end{array}$

$\begin{array}{ll}\text { 7.3. Flutuação da comunidade } & 139\end{array}$

$\begin{array}{ll}\text { 7.4. Riqueza, equitatividade e diversidade } & 148\end{array}$

$\begin{array}{ll}\text { 7.5. Análise multivariada } & 151\end{array}$

7.6. Espécies zooplanctônicas como indicadoras da qualidade da água 153

8. CONCLUSÕES 164

9. REFERÊNCIAS BIBLIOGRÁFICAS 168

$\begin{array}{ll}\text { TABELAS } & 196\end{array}$ 


\section{LISTA DE FIGURAS}

Figura

Página

1 Localização da Reserva Biológica do Parque Estadual das Fontes do Ipiranga $\left(23^{\circ} 39^{\prime} \mathrm{S} 46^{\circ} 37^{\prime} \mathrm{W}, 798 \mathrm{~m}\right)$

2 Localização dos lagos do IAG, das Ninféias e Garças na Reserva Biológica do Parque Estadual das Fontes do Ipiranga $\quad 8$

3 Lago do IAG 9

4 Lago das Ninféias 9

5 Lago das Garças 9

6 Localização das Unidades de Gerenciamento de Recursos Hídricos (UGRHIs) do Estado de São Paulo

7 Variação das médias de precipitação total $(\mathrm{mm})$ de janeiro a dezembro de 1997

8 Variação da transparência da água (m) nos lagos do IAG, das Ninféias e Garças de janeiro a dezembro de 1997

9 Variação das médias de condutividade elétrica $(\mu \mathrm{S} / \mathrm{cm})$ nos lagos do IAG, das Ninféias e Garças de janeiro a dezembro de 1997

10 Variação das médias de sólidos totais em suspensão $(\mathrm{mg} / \mathrm{L})$ nos lagos do IAG, das Ninféias e Garças de janeiro a dezembro de 1997

11 Variação das médias de fósforo total $(\mu \mathrm{g} / \mathrm{L})$ nos lagos do IAG, das Ninféias e Garças de janeiro a dezembro de 1997

12 Variação das médias de clorofila $a$ total $(\mu \mathrm{g} / \mathrm{L})$ nos lagos do IAG, das Ninféias e Garças de janeiro a dezembro de 1997

13 Abundâncias relativas (\%) de rotiferos, copépodos ciclopóides, copépodos calanóides e cladóceros no lago do IAG de janeiro a 30 dezembro de 1997. 
14 Abundâncias relativas $(\%)$ de rotiferos, copépodos ciclopóides, copépodos calanóides e cladóceros no lago das Ninféias de janeiro a dezembro de 1997

15 Abundâncias relativas (\%) de rotíferos, copépodos ciclopóides, copépodos calanóides e cladóceros no lago das Garças de janeiro a dezembro de 1997

16 Densidades numéricas da comunidade zooplanctônica $\left(\mathrm{n}^{\circ} \mathrm{org} / \mathrm{m}^{3}\right)$ nos lagos do IAG, das Ninféias e Garças de janeiro a dezembro de 1997.

17 Densidades numéricas da comunidade zooplanctônica $\left(\mathrm{n}^{\circ} \mathrm{org} / \mathrm{m}^{3}\right)$ e precipitação total $(\mathrm{mm})$ no lago do IAG de janeiro a dezembro de 1997.

18 Densidades numéricas da comunidade zooplanctônica $\left(\mathrm{n}^{\circ} \mathrm{org} / \mathrm{m}^{3}\right)$ e precipitação total $(\mathrm{mm})$ no lago das Ninféias de janeiro a dezembro de 1997.

19 Densidades numéricas da comunidade zooplanctônica $\left(\mathrm{n}^{\circ} \mathrm{org} / \mathrm{m}^{3}\right)$ e precipitação total $(\mathrm{mm})$ no lago das Garças de janeiro a dezembro de 1997.

20 Densidades numéricas dos grupos zooplanctônicos $\left(\mathrm{n}^{\circ} \mathrm{org} / \mathrm{m}^{3}\right)$ no lago do IAG de janeiro a dezembro de 1997.

21 Densidades numéricas dos grupos zooplanctônicos $\left(\mathrm{n}^{\circ} \mathrm{org} / \mathrm{m}^{3}\right)$ no lago das Ninféias de janeiro a dezembro de 1997.

22 Densidades numéricas dos grupos zooplanctônicos $\left(\mathrm{n}^{\circ} \mathrm{org} / \mathrm{m}^{3}\right)$ no lago das Garças de janeiro a dezembro de 1997.

23 Densidades numéricas de rotíferos $\left(\mathrm{n}^{\circ} \mathrm{org} / \mathrm{m}^{3}\right)$ no lago do IAG de janeiro a dezembro de 1997.

24 Densidades numéricas de rotíferos $\left(\mathrm{n}^{\circ} \mathrm{org} / \mathrm{m}^{3}\right)$ no lago das Ninféias de janeiro a dezembro de 1997.

25 Densidades numéricas de rotíferos $\left(\mathrm{n}^{\circ} \mathrm{org} / \mathrm{m}^{3}\right)$ no lago das Garças de janeiro a dezembro de 1997.

26 Densidades numéricas de copépodos ciclopóides $\left(\mathrm{n}^{\circ} \mathrm{org} / \mathrm{m}^{3}\right)$ no lago do IAG de janeiro a dezembro de 1997. 
27 Densidades numéricas de copépodos ciclopóides $\left(\mathrm{n}^{\circ} \mathrm{org} / \mathrm{m}^{3}\right)$ no lago das Ninféias de janeiro a dezembro de 1997.

28 Densidades numéricas de copépodos ciclopóides $\left(\mathrm{n}^{\circ} \mathrm{org} / \mathrm{m}^{3}\right)$ no lago das Garças de janeiro a dezembro de 1997.

29 Densidades numéricas de copépodos calanóides $\left(\mathrm{n}^{\circ} \mathrm{org} / \mathrm{m}^{3}\right)$ no lago do IAG de janeiro a dezembro de 1997.

30 Densidades numéricas de copépodos calanóides $\left(\mathrm{n}^{\circ} \mathrm{org} / \mathrm{m}^{3}\right)$ no lago das Ninféias de janeiro a dezembro de 1997.

31 Densidades numéricas de cladóceros $\left(\mathrm{n}^{\circ} \mathrm{org} / \mathrm{m}^{3}\right)$ no lago do IAG de janeiro a dezembro de 1997.

32 Densidades numéricas de cladóceros $\left(\mathrm{n}^{\circ} \mathrm{org} / \mathrm{m}^{3}\right)$ no lago das Ninféias de janeiro a dezembro de 1997.

33 Densidades numéricas de cladóceros $\left(\mathrm{n}^{\circ} \mathrm{org} / \mathrm{m}^{3}\right)$ no lago das Garças de janeiro a dezembro de 1997.

34 Valores médios de diversidade (bits/ind), equitatividade e riqueza da comunidade zooplanctônica no lago do IAG de janeiro a dezembro de 1997.

35 Valores médios de diversidade (bits/ind), equitatividade e riqueza da comunidade zooplanctônica no lago das Ninféias de janeiro a dezembro de 1997.

36 Valores médios de diversidade (bits/ind), equitatividade e riqueza da comunidade zooplanctônica no lago das Garças de janeiro a dezembro de 1997.

37 Biplot da ACP para as variáveis físicas, químicas e biológicas nos lagos do IAG, das Ninféias e Garças de janeiro a dezembro de 1997.

38 Dendrograma da análise de agrupamento dos táxons da comunidade zooplanctônica nos lagos do IAG, das Ninféias e Garças.

39 Biplot da ACP para as densidades numéricas dos táxons da comunidade zooplanctônica nos lagos do IAG, das Ninféias e 
Garças de janeiro a dezembro de 1997.

40 Ocorrência de rotíferos e Índice de Estado Trófico (IET) de Carlson modificado do reservatório de Paraibuna (UGRHI 02 Paraíba do Sul)

41 Ocorrência de microcrustáceos e Índice de Estado Trófico (IET) de Carlson modificado dos reservatórios de Paraibuna, Santa Branca, Jaguari, Borba, Itapeva e Funil (UGRHI 02 Paraíba do Sul)

42 Ocorrència de rotíferos e Índice de Estado Trófico (IET) de Carlson modificado dos reservatórios Graminha, Euclides da Cunha, Limoeiro e lago Monte Alegre (UGRHI 04 - Pardo)

43 Ocorrência de microcrustáceos e Índice de Estado Trófico (IET) de Carlson modificado dos reservatórios Graminha, Euclides da Cunha, Limoeiro e lago Monte Alegre (UGRHI 04 - Pardo)

44 Ocorrência de rotíferos e Índice de Estado Trófico (IET) de Carlson modificado do reservatório de Americana (UGRHI 05 - Piracicaba, Capivari e Jundiaí)

45 Ocorrência de microcrustáceos e Índice de Estado Trófico (IET) de Carlson modificado dos reservatórios de Atibainha, Cachoeira e Americana (UGRHI 05 - Piracicaba, Capivari e Jundiai)

46 Ocorrência de rotíferos e Índice de Estado Trófico (IET) de Carlson modificado dos reservatórios Rio Grande (década de 80) e Guarapiranga (década de 90) (UGRHI 06 - Alto Tietê)

47 Ocorrência de rotíferos e Índice de Estado Trófico (IET) de Carlson modificado do Complexo Billings e reservatório Guarapiranga (dados recentes), e dos lagos do PET e PEFI (UGRHI 06 - Alto Tietê)

48 Ocorrência de microcrustáceos e Índice de Estado Trófico (IET) de Carlson modificado do Complexo Billings e reservatórios Guarapiranga, Ponte Nova, Ribeirão do Campo, 
Taiaçupeba, Parque Ecológico, Cabuçu, Águas Claras, Juqueri e Pedro Beicht (1979) (UGRHI 06 - Alto Tietê)

49 Ocorrència de microcrustáceos e Índice de Estado Trófico (IET) de Carlson modificado dos reservatórios Rio Grande (década de 80) e Guarapiranga (década de 90) (UGRHI 06 Alto Tietê)

50 Ocorrência de microcrustáceos e Índice de Estado Trófico (IET) de Carlson modificado do Complexo Billings $\mathrm{e}$ reservatório Guarapiranga (dados recentes), e dos lagos do PET e PEFI (UGRHI 06 - Alto Tietê)

51 Ocorrência de rotíferos e Índice de Estado Trófico (IET) de Carlson modificado dos reservatórios Estreito, Jaguará e Volta Grande (UGRHI 08 - Sapucaí/Grande)

52 Ocorrência de microcrustáceos e Índice de Estado Trófico (IET) de Carlson modificado dos reservatórios Estreito, Jaguará e Volta Grande (UGRHI 08 - Sapucai/Grande)

53 Ocorrência de rotíferos e Índice de Estado Trófico (IET) de Carlson modificado do reservatório de Barra Bonita (década de 80) (UGRHI 10 - Sorocaba/Médio Tietê)

54 Ocorrência de rotíferos e Índice de Estado Trófico (IET) de Carlson modificado do reservatório de Barra Bonita (década de 90) (UGRHI 10 - Sorocaba/Médio Tietê)

55 Ocorrência de rotíferos e Índice de Estado Trófico (IET) de Carlson modificado do reservatório de Barra Bonita (dados recentes) (UGRHI 10 - Sorocaba/Médio Tietê)

56 Ocorrência de microcrustáceos e Índice de Estado Trófico (IET) de Carlson modificado dos reservatórios de Itupararanga (1979) e Barra Bonita (década de 80) (UGRHI 10 Sorocaba/Médio Tietê)

57 Ocorrência de microcrustáceos e Índice de Estado Trófico (IET) de Carlson modificado do reservatório de Barra Bonita (década de 90) (UGRHI 10 - Sorocaba/Médio Tietê) 
58 Ocorrència de microcrustáceos e Índice de Estado Trófico (IET) de Carlson modificado do reservatório de Barra Bonita (dados recentes) (UGRHI 10 - Sorocaba/Médio Tietê)

59 Ocorrència de microcrustáceos e Índice de Estado Trófico (IET) de Carlson modificado dos reservatórios França, Fumaça, Alecrim e Serraria (UGRHI 11 - Ribeira de Iguape/Litoral Sul)

60 Ocorrência de rotiferos e Índice de Estado Trófico (IET) de Carlson modificado dos reservatórios Porto Colombia e Marimbondo (UGRHI 12 - Baixo Pardo/Grande)

61 Ocorrência de microcrustáceos e Índice de Estado Trófico (IET) de Carlson modificado dos reservatórios Porto Colombia e Marimbondo (UGRHI 12 - Baixo Pardo/Grande)

62 Ocorrència de rotiferos e Índice de Estado Trófico (IET) de Carlson modificado dos reservatórios Bariri, Lobo (Broa), Monjolinho e Jacaré-Pepira, e lagoas Dourada e da Pedreira (UGRHI 13 - Tietê/Jacaré)

63 Ocorrência de microcrustáceos e Índice de Estado Trófico (IET) de Carlson modificado dos reservatórios Bariri, Ibitinga, Lobo (Broa), Monjolinho e Jacaré-Pepira, e lagoas Dourada e da Pedreira (UGRHI 13 - Tietê/Jacaré)

64 Ocorrência de rotiferos e Índice de Estado Trófico (IET) de Carlson modificado dos reservatórios Jurumirim, Xavantes e Piraju, e lagoas do Coqueiral e do Camargo (UGHRI 14 - Alto Paranapanema)

65 Ocorrência de microcrustáceos e Índice de Estado Trófico (IET) de Carlson modificado dos reservatórios Jurumirim, Xavantes, Piraju, Batista e São José, e lagoas do Coqueiral e Camargo (UGHRI 14 - Alto Paranapanema)

66 Ocorrència de rotiferos e Índice de Estado Trófico (IET) de Carlson modificado do reservatório de Água Vermelha (UGHRI 15 - Turvo/Grande) 
67. Ocorrência de microcrustáceos e Índice de Estado Trófico (IET) de Carlson modificado do reservatório de Água Vermelha (UGHRI 15 - Turvo/Grande)

68 Ocorrência de rotiferos e Índice de Estado Trófico (IET) de Carlson modificado do reservatório de Promissão (UGHRI 16 - Tietê/Batalha)

69 Ocorrência de microcrustáceos e Índice de Estado Trófico (IET) de Carlson modificado do reservatório de Promissão (UGHRI 16 - Tietê/Batalha)

70 Ocorrência de rotíferos e Índice de Estado Trófico (IET) de Carlson modificado dos reservatórios Capivara, Salto Grande, Rio Pari e Rio Novo (UGHRI 17 - Médio Paranapanema) 105

71 Ocorrência de microcrustáceos e Índice de Estado Trófico (IET) de Carlson modificado dos reservatórios Capivara, Salto Grande, Rio Pari e Rio Novo (UGHRI 17 - Médio Paranapanema)

72 Ocorrência de rotíferos e Índice de Estado Trófico (IET) de Carlson modificado do reservatório de Ilha Solteira (UGHRI 18 - São José dos Dourados)

73 Ocorrência de microcrustáceos e Índice de Estado Trófico (IET) de Carlson modificado do reservatório de Ilha Solteira (UGHRI 18 - São José dos Dourados)

74 Ocorrència de rotiferos e Índice de Estado Trófico (IET) de Carlson modificado dos reservatórios Jupiá e Nova Avanhandava (UGHRI 19 - Baixo Tietê)

75 Ocorrência de microcrustáceos e Índice de Estado Trófico (IET) de Carlson modificado dos reservatórios Jupiá e Nova Avanhandava (UGHRI 19 - Baixo Tietê)

76 Ocorrência de rotíferos e Índice de Estado Trófico (IET) de Carlson modificado das lagoas Jota e Comprida (UGHRI 22 Pontal do Paranapanema)

77 Ocorrência de microcrustáceos e Índice de Estado Trófico 
(IET) de Carlson modificado das lagoas Jota e Comprida (UGHRI 22 - Pontal do Paranapanema) 


\section{LISTA DE TABELAS}

Tabela

Página

1 Temperaturas do ar $\left({ }^{\circ} \mathrm{C}\right)$ e precipitação total $(\mathrm{mm})$ (médias mensais) de janeiro a dezembro de 1997

2 Valores e médias mensais das variáveis físicas, químicas e biológicas no lago do IAG de janeiro a dezembro de 1997

3 Valores e médias mensais das variáveis físicas, químicas e biológicas no lago das Ninféias de janeiro a dezembro de 1997

4 Valores e médias mensais das variáveis físicas, químicas e biológicas no lago das Garças de janeiro a dezembro de 1997

5 Composição de rotiferos nos lagos do IAG, das Ninféias e Garças de janeiro a dezembro de 1997

6 Composição de microcrustáceos nos lagos do IAG, das Ninféias e Garças de janeiro a dezembro de 1997

7 Densidades numéricas $\left(\mathrm{n}^{\circ} \mathrm{org} / \mathrm{m}^{3}\right)$ e abundâncias relativas $(\%)$ de rotíferos, copépodos ciclopóides e calanóides, e cladóceros no lago do IAG de janeiro a dezembro de 1997

8 Densidades numéricas $\left(\mathrm{n}^{\circ} \mathrm{org} / \mathrm{m}^{3}\right)$ e abundâncias relativas $(\%)$ de rotíferos, copépodos ciclopóides e calanóides, e cladóceros no lago das Ninféias de janeiro a dezembro de 1997

9 Densidades numéricas $\left(\mathrm{n}^{\circ} \mathrm{org} / \mathrm{m}^{3}\right)$ e abundâncias relativas $(\%)$ de rotíferos, copépodos ciclopóides e calanóides, e cladóceros no lago das Garças de janeiro a dezembro de 1997

10 Densidades numéricas $\left(\mathrm{n}^{\circ} \mathrm{org} / \mathrm{m}^{3}\right)$ de rotiferos e microcrustáceos no lago do IAG de janeiro a dezembro de 1997

11 Densidades numéricas $\left(\mathrm{n}^{\circ} \mathrm{org} / \mathrm{m}^{3}\right)$ de rotíferos e microcrustáceos no lago das Ninféias de janeiro a dezembro de 1997

12 Densidades numéricas $\left(\mathrm{n}^{\circ} \mathrm{org} / \mathrm{m}^{3}\right)$ de rotíferos no lago das Garças de janeiro a dezembro de 1997

13 Densidades numéricas $\left(\mathrm{n}^{\circ} \mathrm{org} / \mathrm{m}^{3}\right)$ de microcrustáceos no lago das 
Garças de janeiro a dezembro de 1997

14 Valores mensais de diversidade (bits/ind) e diversidade média ( $\mathrm{H}^{\prime}$ média) nos lagos do IAG, das Ninféias e Garças de janeiro a dezembro de 1997

15 Valores mensais de equitatividade e equitatividade média ( $E$ média) nos lagos do IAG, das Ninféias e Garças de janeiro a dezembro de 1997

16 Valores mensais de riqueza e riqueza média ( $\mathrm{S}$ média) nos lagos do IAG, das Ninféias e Garças de janeiro a dezembro de 1997

17 Correlação das variáveis físicas, químicas e biológicas $(n=36)$ com os eixos 1 e 2

18 Correlações das densidades numéricas dos táxons da comunidade zooplanctônica $(n=36)$ com os eixos 1 e 2

19 Relação dos autores e ano de publicação dos estudos realizados nos corpos d'água das Unidades de Gerenciamento de Recursos Hídricos (UGRHIs) do Estado de São Paulo

20 Ocorrência de rotíferos, média das concentrações de clorofila $a$ total $(\mu \mathrm{g} / \mathrm{L})$ e Índice de Estado Trófico (IET) de Carlson modificado, em cada corpo d'água, com o respectivo autor $e$ época de estudo, por Unidade de Gerenciamento de Recursos Hídricos (UGRHI) do Estado de São Paulo

21 Ocorrência de copépodos ciclopóides, média das concentrações de clorofila $a$ total $(\mu \mathrm{g} / \mathrm{L})$ e Índice de Estado Trófico (IET) de Carlson modificado, em cada corpo d'água, com o respectivo autor e época de estudo, por Unidade de Gerenciamento de Recursos Hidricos (UGRHI) do Estado de São Paulo

22 Ocorrência de copépodos calanóides, média das concentrações de clorofila $a$ total $(\mu \mathrm{g} / \mathrm{L})$ e Índice de Estado Trófico (IET) de Carlson modificado, em cada corpo d'água, com o respectivo autor e época de estudo, por Unidade de Gerenciamento de Recursos Hídricos (UGRHI) do Estado de São Paulo

23 Ocorrência de cladóceros, média das concentrações de clorofila $a$ 
total $(\mu \mathrm{g} / \mathrm{L})$ e Índice de Estado Trófico (IET) de Carlson modificado, em cada corpo d'água, com o respectivo autor e época de estudo, por Unidade de Gerenciamento de Recursos Hídricos (UGRHI) do Estado de São Paulo

24 Relação das espécies de rotíferos registradas nas Unidades de Gerenciamento de Recursos Hídricos (UGRHIs) do Estado de São Paulo e seu respectivo número de identificação

25 Relação das espécies de copépodos ciclopóides, calanóides e cladóceros registradas nas Unidades de Gerenciamento de Recursos Hídricos (UGRHIs) do Estado de São Paulo e seu respectivo número de identificação 


\section{INTRODUÇÃO}

Com o aumento da complexidade de impactos antrópicos no meio ambiente, a necessidade de manejo de sistemas naturais torna-se cada vez mais necessária. A avaliação de mudanças nas comunidades e ecossistemas e o diagnóstico de problemas e agentes causadores das mesmas constitui um método "top-down". Em contraste, métodos "bottom-up" testam no laboratório efeitos em sistemas simples para modelar mudanças em ecossistemas mais complexos. Observações periódicas da saúde de comunidades no ambiente natural proporcionam mecanismos para implementar ações corretivas; tal abordagem, de natureza "top-down", é descrita como monitoramento biológico, ou seja, a avaliação conjunta das condições ambientais que garantam que os objetivos formulados em relação à qualidade ambiental de um ecossistema sejam mantidos (CAIRNS et al., 1993).

Em estudos de ecossistemas de águas continentais, a análise das comunidades planctônicas reveste-se de grande importância para que se obtenha uma compreensão adequada das condições existentes no ambiente aquático, pois as espécies que constituem estas comunidades são sensores muito precisos das propriedades do manancial (BRANCO 1991).

Em sistemas pelágicos continentais a estrutura das comunidades biológicas é complexa, sendo regulada através de mecanismos bióticos e abióticos (CARPENTER et al., 1985). De acordo com ARCIFA et al. (1992), é necessário conhecer os fatores bióticos e abióticos dos corpos d'água e suas variações a curto e longo prazo, pois a falta de dados impede que se chegue a conclusões mais amplas sobre as comunidades planctônicas e suas relações com o ambiente.

A estrutura e o funcionamento das comunidades bióticas, a composição de espécies e os processos que controlam mudanças nas abundâncias relativas de cada espécie ou grupo são influenciadas pela natureza e disponibilidade de fontes alimentares e predação (NORTHCOTE 1988).

A comunidade zooplanctônica ocupa uma posição intermediária na cadeia alimentar de ambientes aquáticos, sendo grandemente afetada por mudanças no aporte de nutrientes, que alteram por sua vez a quantidade e qualidade de fontes alimentares disponiveis (efeito "bottom-up"), assim como é controlada pela predação (efeito "top-down") (CAIRNS et al., 1993). 
Apesar da intensificação de estudos limnológicos no Brasil nas últimas décadas, é menos frequente a caracterização de lagos urbanos e reservatórios com usos múltiplos (abastecimento, irrigação, recreação e outros).

Pode-se citar, no entanto, quanto ao zooplâncton, estudos realizados no complexo Billings e reservatório Guarapiranga (Alto Tietê) por SENDACZ (1978), ROCHA (1984), SENDACZ et al. (1984, 1985), CABIANCA e SENDACZ (1986), ROCHA e MERIGHI (1986, 1987), KUBO (1989), DOMINGOS (1993), CALEFFI (1994), LAMPARELLI et al. (1996), SENDACZ e KUBO (1999), CALEFFI (2000) e COELHO-BOTELHO et al. (2001).

No Médio Tietê, FONSECA (1990), GÁVILAN-DIAZ (1990), MATSUMURA-TUNDISI et al. (1990), TUNDISI e MATSUMURA-TUNDISI (1990, 1994), ESPÍNDOLA (1994), RIETZLER (1995), WISNIEWSKI (1998) e COELHO-BOTELHO et al. (2001) caracterizaram o zooplâncton do reservatório de Barra Bonita.

A comunidade zooplanctônica de reservatórios do Estado de São Paulo do Projeto "Tipologia de Reservatórios do Estado de São Paulo" foi estudada por SENDACZ e KUBO (1982), ARCIFA (1984), SENDACZ et al. (1985) e ESTEVES e SENDACZ (1988).

Em relação a lagos urbanos, o lago Paranoá (DF) e o lago da Pampulha (MG) são exceções, pois têm sido estudados sob vários aspectos. O lago Paranoá, situado na região urbana de Brasília, formado artificialmente, recebeu por um longo período um aporte contínuo de nutrientes decorrente dos lançamentos de esgotos sanitários brutos e/ou tratados (ALVES et al., 1988). A partir de 1993, 80\% dos esgotos estão sendo tratados, e somente $1 \%$ são lançados sem tratamento no lago Paranoá (CAVALCANTI et al., 1997). Estudos sobre diversos aspectos ecológicos da comunidade zooplanctônica deste lago foram realizados por FREITAS (1983), PINTO-COELHO (1983, 1987), GIANI (1984), ALVES et al. (1988), TOLEDO et al. (1988), BRANCO (1991), FONSECA e ROCHA (1997) e ROCHA e FONSECA (1997).

O lago da Pampulha, periurbano, considerado área de lazer e patrimônio cultural da cidade de Belo Horizonte, como a maioria dos reservatórios urbanos brasileiros está hoje ameaçado pela contaminação por esgotos domésticos (GIA VI 
et al., 1988). Vários aspectos relacionados à comunidade zooplanctônica foram abordados por SILVA e PINTO-COELHO (1986), PINTO-COELHO et al. (1988), REID et al. (1988) e PINTO-COELHO e GRECCO (1997). Ainda na região metropolitana de Belo Horizonte, FREIRE e PINTO-COELHO (1986) verificaram a distribuição espacial do zooplâncton e sua relação com as variáveis físicas e químicas no lago de Vargem das Flores.

Apesar da degradação ambiental, estudos limnológicos em lagos urbanos na região metropolitana de São Paulo são raros, podendo-se citar trabalhos efetuados na Raia Olímpica da Cidade Universitária (SCHADEN 1970), nos lagos do Parque Zoológico (ROCHA e NARDUZZO, 1975) e nos lagos do Parque Ecológico do Tietê (EYSINK et al. 1985; BEYRUTH 1993; BEYRUTH et al. 1993; DEKER, 2000).

No lago Taquaral, hipereutrófico, localizado em Campinas (SP) foram abordados por MATSUMURA-TUNDISI et al. (1986) diversos aspectos relacionados à comunidade zooplanctônica.

Os organismos zooplanctônicos respondem rapidamente às mudanças ambientais, podendo se constituir em importantes indicadores das eventuais mudanças tróficas no ecossistema (GANNON e STEMBERGER 1978; BLANCHER 1984; BRANCO 1991); a proporção entre as abundâncias relativas dos grupos que compõem esta comunidade - rotíferos, copépodos ciclopóides e calanóides, e cladóceros - pode refletir o estado trófico de determinado corpo d'água devido às diferentes estratégias alimentares e reprodutivas de cada grupo.

Os ecossistemas aquáticos do PEFI vêm sofrendo acelerado processo de eutrofização, principalmente de origem antrópica, através do lançamento de várias fontes de esgoto "in natura", de água servida de excrementos e de água de lavagem de animais (BICUDO 1996)

Até o presente momento, vários estudos já foram realizados nos lagos do PEFI referentes a diversos aspectos das comunidades de algas planctônicas e perifiticas (BICUDO 1983, 1984, 1989, 1990; SANT'ANNA et al. 1989, 1997; AZEVEDO et al. 1994; MOURA 1996, 1997; RAMIREZ 1996; NOGUEIRA 1997; BICUDO CEM et al. 1999; FERRAGUT 1999; LOPES 1999; GENTIL 2000). 
Pesquisas relacionadas a aspectos ecológicos e limnológicos nos lagos em questão, foram realizadas por NOGUEIRA e RAMIREZ (1998), BICUDO DC et al. (1999), HENRY (1999), MERCANTE e TUCCI-MOURA (1999), BUENO (2000), CARMO (2000) e MERCANTE (2000).

O presente estudo faz parte do projeto integrado "Tipologia, monitoramento e recuperação dos corpos d'água da Reserva Biológica do Parque Estadual das Fontes do Ipiranga", que tem como objetivo a caracterização limnológica, biológica e geomorfológica, com a finalidade de elaborar modelos ecológicos e propor ações de recuperação e monitoramento destes corpos d'água. Este trabalho contribui com dados da comunidade zooplanctônica, a fim de subsidiar a caracterização ecológica dos lagos do PEFI.

\section{OBJETIVOS}

Såo objetivos do presente trabalho:

a) Caracterizar a composição, estrutura, densidade e diversidade da comunidade zooplanctônica nos três lagos estudados e sua associação ao gradiente evidenciado pelas condições tróficas;

b) Estabelecer relações entre o zooplâncton e variáveis físicas, quimicas e biológicas de cada lago estudado;

c) Compilar dados de ocorrência de espécies zooplanctônicas em corpos d'água do Estado de São Paulo e verificar sua associação com o estado trófico;

d) Comparar a composição, estrutura, densidade e diversidade da comunidade zooplanctônica dos lagos do PEFI com outros lagos urbanos e reservatórios;

e) Avaliar a utilização de organismos zooplanctônicos como indicadores da qualidade da água.

\section{3. ÁREA DE ESTUDO}

O Parque Estadual das Fontes do Ipiranga (PEFI) existe, como área física, desde setembro de 1893. Originou-se da desapropriação de terrenos da bacia do Ribeirão do Ipiranga, que foram declarados como de utilidade pública, sobretudo com a função de manter o abastecimento de água para a região sudeste da capital do Estado. Em agosto de 1969, teve sua denominação mudada para "Parque Estaciual 
das Fontes do Ipiranga" e definidos seus limites em função da natureza da cobertura vegetal e dos seus usos que, até então, lhes eram atribuídos (STRUFFALDI-DEVUONO 1985; BARBOSA 1993, apud BICUDO 1996).

O PEFI situa-se na região sudeste do Município de São Paulo, entre os paralelos $23^{\circ} 39^{\prime} \mathrm{S}$ e $46^{\circ} 37^{\prime} \mathrm{W}$ (Figura 1). Este Parque trata-se, na realidade, de uma reserva biológica com área total de 549,3 ha e uma altitude média de $798 \mathrm{~m}$.

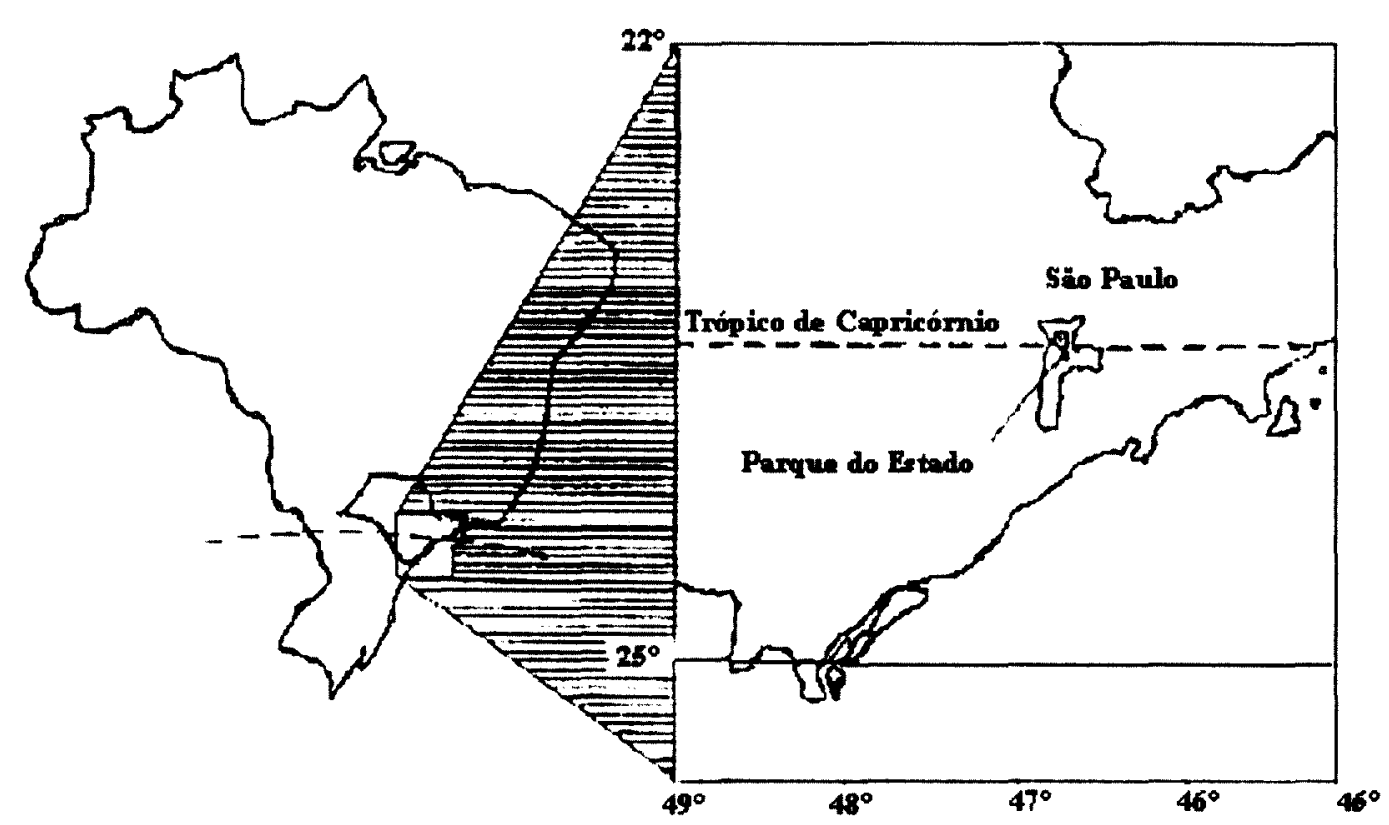

Eecale 1:4.000.000

FONTE: Seção de Urbanização e Paisagismo - Instituto de Botânica

FIGURA 1 - Localizą̧ão da Reserva Biológica do Parque Estadual das Fontes do Ipiranga $\left(23^{\circ} 39^{\prime} \mathrm{S}, 46^{\circ} 37^{\prime} \mathrm{W}, 798 \mathrm{~m}\right)$.

É uma área de grande importância ambiental e social, destacando-se seu papel como rota migratória de aves aquáticas, repositório de biodiversidade, fator moderador do microclima local, fator mantenedor do lençol freático, laboratório natural para pesquisas básicas e aplicadas e para o desenvolvimento de programas de 
Educação Ambiental, e área de lazer essencial para a comunidade do entorno (BARBOSA 1993, apud FERRAGUT 1999).

As áreas preservadas de vegetação natural constituem um dos últimos remanescentes de Mata Atlântica em meio a uma região densamente urbanizada da cidade de São Paulo, compreendendo uma das maiores áreas verdes metropolitanas da América Latina (STRUFFALDI-DE-VUONO 1985).

O clima da área enquadra-se no tipo Cwb, segundo o Sistema Internacional de Classificação Climática de Köppen, ou seja, é mesotérmico de inverno seco, com temperatura média anual de $19^{\circ} \mathrm{C}$, precipitação anual de $1400 \mathrm{~mm}$ e ventos mais frequentes no quadrante sul-leste, com a direção SE predominante (SANT'ANNA et al., 1989).

A reserva inclui três sub-bacias que fazem parte da grande bacia hidrográfica do rio Tietê. Nela localizam-se as nascentes que constituem a cabeceira do riacho Ipiranga, as quais abastecem, em seu trajeto, nove reservatórios localizados no PEFI, dos quais os três estudados neste trabalho estão representados na figura 2. Após abastecer tais lagos artificiais, suas águas juntam-se sob a Rodovia dos Imigrantes para percorrer cerca de $7 \mathrm{~km}$ sob duas avenidas, aflorando em frente ao Museu do Ipiranga. O Riacho do Ipiranga deságua no Rio Tamanduateí que, por sua vez, é afluente do Rio Tietê (BICUDO 1996).

Neste trabalho, foram selecionados três corpos d'água : lago do IAG, lago das Ninféias e lago das Garças.

\subsection{Lago do IAG}

O lago do Instituto Astronômico e Geofísico da Universidade de São Paulo (IAG) (Figuras 2 e 3) tem caracteristicas oligotróficas e, assim, é o que melhor representa as condições pretéritas desta área de preservação, constituindo-se em um sistema de referência; é um lago urbano, raso (profundidade máxima de $4,7 \mathrm{~m}$ ) e foi construido por volta de 1930 com fins paisagísticos (FERRAGUT 1999). 


\subsection{Lago das Ninféias}

É um lago mesotrófico, raso (profundidade máxima de 3,3m), e, também, foi construido na década de 30 para compor a paisagem de ambientes do Jardim Botânico de São Paulo (Figuras 2 e 4).

Apresenta extensa região litorânea com grande desenvolvimento das macrófitas aquáticas Cyperus papyrus L., Hydrocleis nymphoides (Willd.) Buch, Nymphaea elegans Hook, Macaya fluviatilis Aubl., Vallisneria spiralis L., Salvinia herzogii de La Sota e Nitella translucens (Pers.) C. Agardh emend. R.D. Wood (MOURA 1997).

\subsection{Lago das Garças}

É o maior corpo d'água localizado no PEFI e foi formado pelo represamento de vários córregos (SANT'ANNA et al., 1989) (Figuras 2 e 5). Apresenta profundidade máxima de $4,7 \mathrm{~m}$ e foi construído em 1930, para fins de abastecimento de água para a população local (BICUDO CEM et al., 1999).

Embora localizado em uma área de preservação ambiental, no lago das Garças são lançados despejos orgânicos "in natura" provenientes de diferentes instituições governamentais existentes em suas proximidades (Secretaria de Agricultura e Abastecimento do Estado de São Paulo, Fundação Parque Zoológico, Instituto Agronômico e Geofísico da Universidade de São Paulo e do próprio Instituto de Botânica) (SANT'ANNA et al.,1989), principalmente do Parque Zoológico, que despeja em suas águas uma elevada carga de nutrientes como nitratos e fósforo solúvel reativo (NOGUEIRA e RAMIREZ, 1998). De acordo com BICUDO et al. (1998), este lago apresenta sete entradas pontuais, duas das quais responsáveis pelas maiores cargas médias de nitrogênio $(63 \%)$ e/ou fósforo (34 e $48 \%$ ), e uma saída.

Como consequência, este lago vem sofrendo, há várias décadas, um processo contínuo de eutrofização artificial, confirmado por florações periódicas de Microcystis aeruginosa, e que foram inicialmente constatadas por SANT'ANNA et al. (1989) nos períodos de dezembro/82-março/83 e novembro-dezembro/83. Posteriormente, SANT'ANNA et al. (1997) registraram floração de $M$. aeruginosa 
desde o final da primavera até o início do verão (setembro a dezembro de 1991) e RAMIREZ (1996) e NOGUEIRA (1997) nos meses de outubro e novembro de 1994.

No lago das Garças, Eichhornia crassipes (Mort.) Solms e Pistia sp. são as principais macrófitas flutuantes (BICUDO CEM et al., 1999).

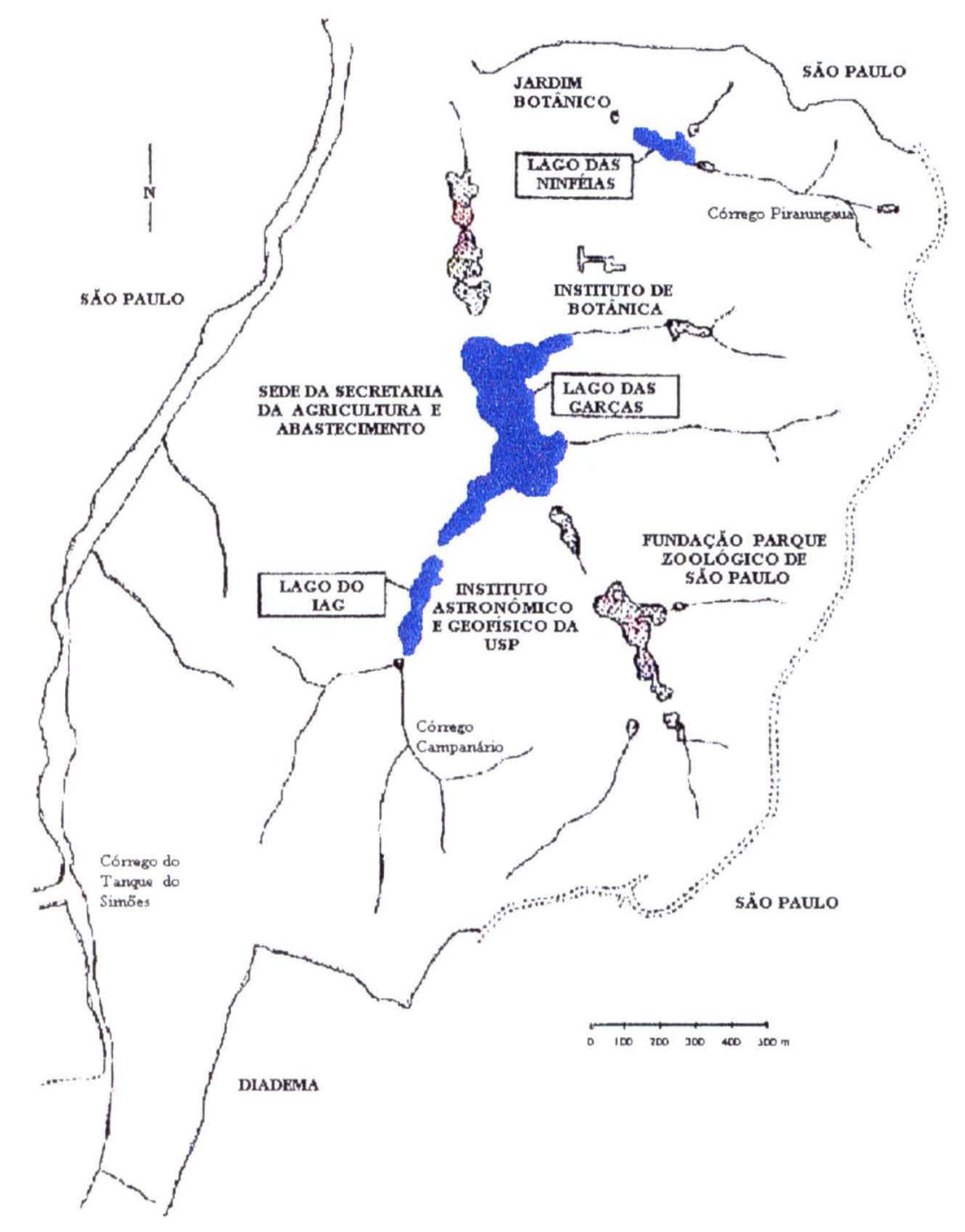

FIGURA 2 - Localização dos lagos do IAG, das Ninféias e Garças na Reserva Biológica do Parque Estadual das Fontes do Ipiranga (Fonte: Seção de Urbanização e Paisagismo - Instituto de Botânica). 


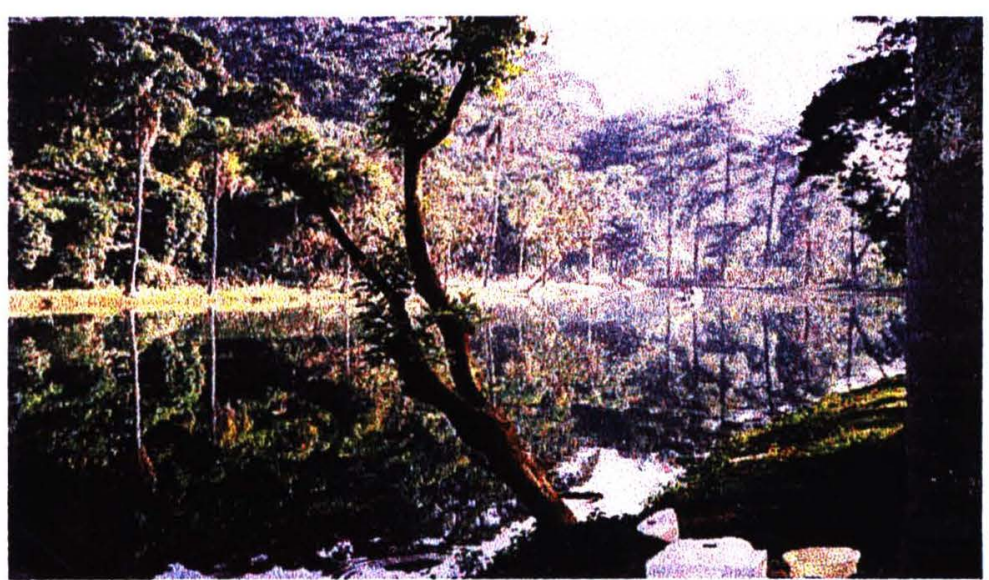

FIGURA 3 - LAGO DO IAG

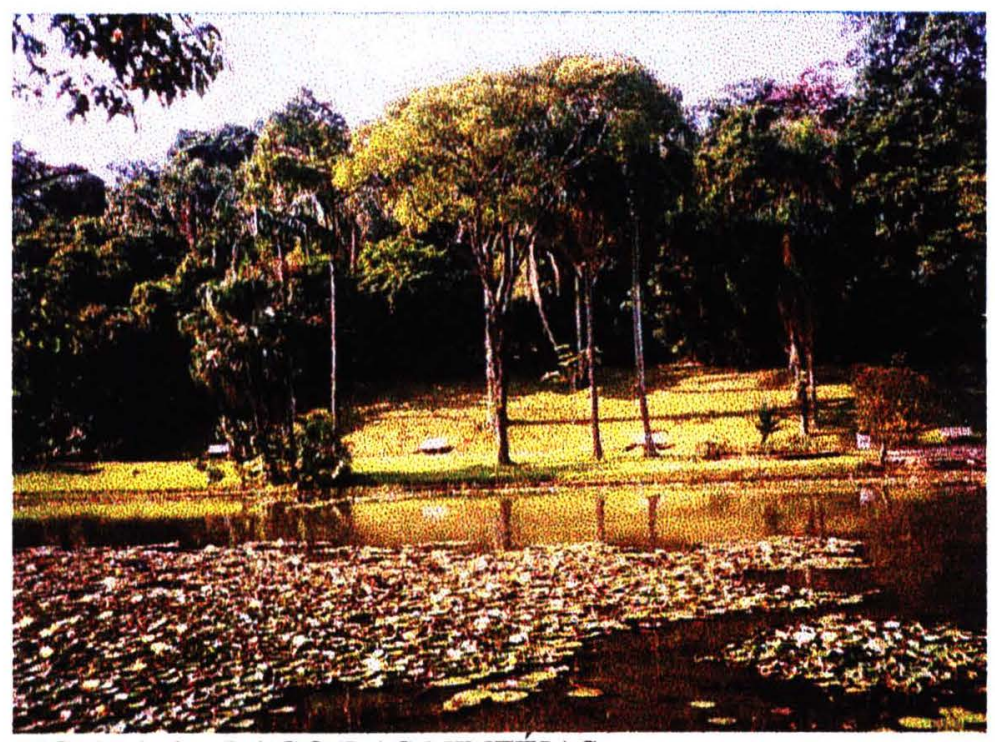

FIGURA 4 - LAGO DAS NINFEIAS

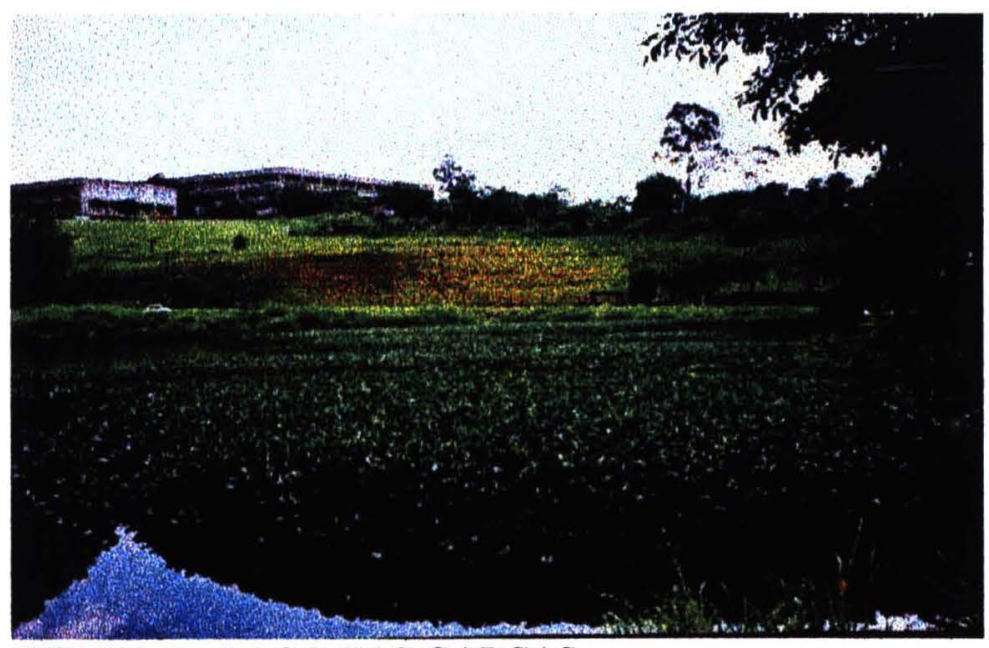

FIGURA 5 - LAGO DAS GARÇAS 


\section{MATERIAL E MÉTODOS}

\subsection{Dados climatológicos}

Os dados climatológicos (temperatura do ar e precipitação total) foram fornecidos pelo Observatório "Alexandre Postoiev" (ex-Observatório de São Paulo, Instituto Astronômico e Geofísico, USP) situado a distâncias que variam de $50 \mathrm{~m}$ a no máximo 200m dos locais de amostragem (BICUDO 1996).

\subsection{Variáveis físicas, químicas e biológicas}

De janeiro a dezembro de 1997 foram realizadas coletas mensais de amostras de água, nos lagos estudados, nos períodos chuvoso-quente (janeiro-março e outubro-dezembro) e estiagem-frio (abril-setembro), para determinação de variáveis fisicas, químicas e biológicas, ao longo da coluna d'água (superfície, $1 \mathrm{~m}, 2 \mathrm{~m}, 3 \mathrm{~m}$ e fundo) nos lagos do IAG e das Garças, e na superfície, $1 \mathrm{~m}, 2 \mathrm{~m}$ e fundo, no lago das Ninféias.

As amostras de água foram coletadas com garrafa de Van Dorn e acondicionadas em frascos apropriados, sendo os dados de transparência, perfis térmicos, condutividade elétrica, turbidez e pH obtidos em campo, e os demais processados no Laboratório de Ecologia Aquática da Seção de Ecologia do Instituto de Botânica (SP).

As seguintes variáveis físicas, químicas e biológicas foram determinadas através de métodos específicos:

. Transparência da água: disco de Secchi branco, de $20 \mathrm{~cm}$ de diâmetro.

Perfis térmicos: termistor digital portátil, marca FAC, modelo 400, com acuracidade de $0,1^{\circ} \mathrm{C}$.

- Condutividade elétrica: condutivímetro Digimed digital, modelo CD-21, leitura direta em $\mu \mathrm{S} / \mathrm{cm}$.

Turbidez: turbidímetro marca Micronal, modelo B250, leitura em UNT (unidades nefelométricas de turbidez).

$\mathrm{pH}$ : potenciômetro Micronal digital, modelo B-378. 
Oxigênio dissolvido: método clássico de "Winkler" (modificado pela azida), descrito em GOLTERMAN et al. (1978). Os valores de oxigênio dissolvido foram expressos em unidades de concentração $(\mathrm{mg} / \mathrm{L})$.

. Concentrações de nitrogênio e fósforo totais $(\mu \mathrm{g} / \mathrm{L})$ : espectrofotometria, segundo a técnica de VALDERRAMA (1981).

Sólidos totais em suspensão (mg/L): técnica gravimétrica descrita em WETZEL e LIKENS (1991).

Clorofila $a(\mu \mathrm{g} / \mathrm{L})$ : segundo as técnicas de NUSCH e PALME (1975) e SARTORY e GROBBELAAR (1984) apud BICUDO DC et al. (1999).

$\mathrm{Na}$ interpretação dos resultados, com exceção da transparência, foi considerada a média mensal dos dados obtidos ao longo da coluna d'água.

\subsection{Zooplâncton}

As coletas mensais de amostras para análise da comunidade zooplanctônica foram realizadas com rede de $25 \mathrm{~cm}$ de diâmetro de boca e malha de $68 \mu \mathrm{m}$ de abertura. Foram efetuados arrastos verticais nos compartimentos limnéticos dos três lagos considerados, filtrando-se toda coluna de água, de $0,5 \mathrm{~m}$ do fundo até a superficie. As amostras foram acondicionadas em frascos de vidro, com capacidade de $200 \mathrm{~mL}$, preservadas em solução de formalina $10 \%$ ou formaldeído $4 \%$, e coradas com algumas gotas de Rosa de Bengala. Foram realizadas análises quantitativas das amostras de zooplâncton coletadas, através de subamostragens, após homogenização.

Os rotiferos foram contados em câmaras de Sedgwick-Rafter, de $1 \mathrm{ml}$ de capacidade, sob microscópio óptico Olympus. Para os crustáceos (copépodos ciclopóides e calanóides, e cladóceros), foram retiradas subamostras com uma pipeta Stempel de $1 \mathrm{ml}$, e os organismos foram contados em placas de acrilíco quadriculadas, sob microscopio esteoroscópico Zeiss até atingir o mínimo de 300 individuos para cada grupo taxonòmico; quando a amostra apresentava um número de organismos abaixo do estabelecido, foi contada em quadrantes ou na sua totalidade (SENDACZ et al., 1985).

Os organismos zooplanctônicos foram identificados, sempre que possivel, em nível de espécie, através de literatura especializada (PAGGI 1973; KOSTE 1978; PAGGI 1978; SENDACZ e KUBO 1982; DUSSART 1984; MATSUMUPA- 
TUNDISI 1984; REID 1985; KOSTE e SHIEL 1986; ELMOOR-LOUREIRO 1988, 1997).

4.4. Ocorrência de espécies zooplanctônicas nas Unidades de Gerenciamento de Recursos Hídricos (UGRHIs) do Estado de São Paulo

De acordo com CETESB (1999b), a Lei Estadual n 7663 de dezembro de 1991, que institui a Política Estadual de Recursos Hídricos e o Sistema de Gerenciamento de Recursos Hídricos, dividiu o Estado de São Paulo em 22 Unidades de Gerenciamento de Recursos Hídricos (UGRHIs) (Figura 6).

Deste total, levando-se em consideração a existência de dados sobre a comunidade zooplanctônica no Estado de São Paulo, foram selecionados 64 corpos d'água presentes em 16 UGRHIs, relacionados a seguir:

1) UGRHI 02 - PARAÍBA DO SUL

Reservatórios: Paraibuna, Santa Branca, Jaguari, Itapeva e Funil

2) UGRHI 04 - PARDO

Reservatórios: Graminha, Euclides da Cunha e Limoeiro

Lago Monte Alegre

3) UGRHI 05 - PIRACICABA, CAPIVARI e JUNDIAÍ

Bacia do rio Piracicaba

Reservatórios: Atibainha, Cachoeira e Americana

4) UGRHI 06 - ALTO TIETÊ

4.1. Bacia do rio Tietê Alto - Cabeceiras

Reservatórios: Ribeirão do Campo, Ponte Nova e Taiaçupeba

4.2. Bacia do rio Tietê Alto - Zona Metropolitana

Reservatórios : Cabuçu, Parque Ecológico, Águas Claras e Juqueri

Lagos: Parque Ecológico do Tietê (PET), do IAG (Instituto Astronômico e Geofisico da USP), das Ninféias e Garças (Parque Estadual das Fontes do Ipiranga - PEFI) 


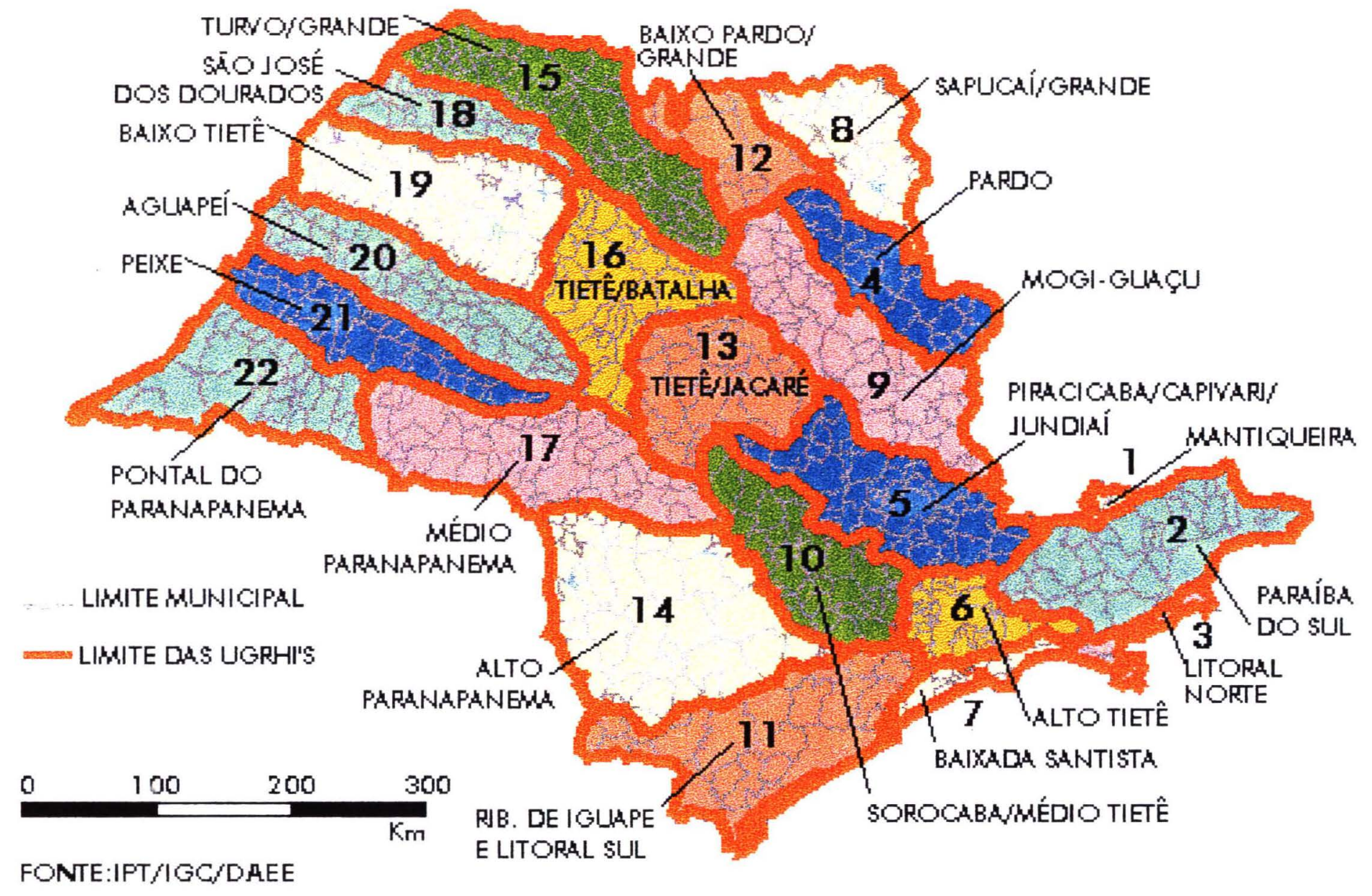

FIGURA 6 - Localização das Unidades de Gerenciamento de Recursos Hídricos (UGRHIs) no Estado de São Paulo. 


\subsection{Bacia do reservatório Billings}

Complexo Billings : Braços Taquacetuba e Rio Pequeno, reservatórios Rio Grande e Rio das Pedras

\subsection{Bacia do rio Cotia}

Reservatório Pedro Beicht

\subsection{Bacia do reservatório Guarapiranga}

Reservatório Guarapiranga

\section{UGRHI 08 - SAPUCAİ/GRANDE}

Reservatórios: Estreito, Jaguará e Volta Grande

6. UGRHI 10 - SOROCABA/MÉDIO TIETÊ

\subsection{Bacia do rio Tietê Médio Superior}

Reservatório de Barra Bonita

\subsection{Bacia do rio Sorocaba}

Reservatório Itupararanga

\section{UGRHI 11 - RIBEIRA DE IGUAPE/LITORAL SUL}

Reservatórios: França, Fumaça, Alecrim e Serraria

\section{UGRHI 12 - BAIXO PARDO/GRANDE}

Reservatórios: Porto Colombia e Marimbondo

\section{UGRHI 13 - TIETÊ/JACARÉ}

Reservatórios: Bariri, Ibitinga, Lobo (Broa), Monjolinho e Jacaré-Pepira Lagoas: Dourada : da Pedreira

\section{UGRHI 14 - ALTO PARANAPANEMA}

Reservatórios: Jurumirim, Xavantes, Piraju, São José e Batista Lagoas: do Camargo e do Coqueiral

\section{UGHRI 15 - TURVO/GRANDE}

Reservatório Água Vermelha

\section{UGRHI 16 - TIETÊ/BATALHA}

Reservatório Promissão

\section{UGRHI 17 - MÉDIO PARANAPANEMA}

Reservatórios: Capivara, Rio Pari, Salto Grande e Rio Novo

\section{UGRHI 18 - SÃO JOSÉ DOS DOURADOS}

Reservatório de Ilha Solteira 


\section{UGRHI 19 - BAIXO TIETÊ}

Reservatórios: Nova Avanhandava (Salto de Avanhandava) e Jupiá

\section{UGHRI 22 - PONTAL DO PARANAPANEMA}

Lagoas Comprida e Jota

Os dados sobre a ocorrência de espécies zooplanctônicas foram compilados por UGRHI. Os rotiferos foram representados separadamente dos microcrustáceos (copépodos ciclopóides e calanóides, e cladóceros), e para cada espécie foi atribuído um número de identificação.

Em relação aos rotíferos, não foram considerados no presente estudo os dados referentes aos reservatórios Santa Branca, Jaguari, Borba, Itapeva e Funil (UGRHI 02), Atibainha e Cachoeira (UGRHI 05), Ribeirão do Campo, Ponte Nova, Taiaçupeba, Cabuçu, Parque Ecológico, Águas Claras, Juqueri, Rio das Pedras e Pedro Beicht (UGRHI 06), Itupararanga (UGRHI 10), França, Fumaça, Alecrim e Serraria (UGRHI 11) e reservatório Ibitinga (UGRHI 13) já que a identificação dos organismos foi em nível de gênero (SENDACZ e KUBO 1982; ARCIFA 1984; CABIANCA e SENDACZ 1985; SENDACZ et al. 1985; MATSUMURA-TUNDISI $1997 b)$.

Representações cartográficas adicionais foram elaboradas para os reservatórios Rio Grande (Complexo Billings), Guarapiranga e Barra Bonita, sujeitos a regras operacionais dos sistemas Alto e Médio Tietê, com o objetivo de evidenciar mudanças na composição zooplanctônica de acordo com as alterações do estado trófico.

Os corpos d'água cuja localização não constava nas representações cartográficas da SMA (1999) foram representados por um símbolo independentemente de escala. Os corpos d'água cujas concentrações de clorofila $a$ total não estavam disponiveis foram representados pela cor azul. 


\section{TRATAMENTO DOS DADOS}

\subsection{Densidade numérica (D)}

É a grandeza relativa da população em uma unidade de espaço, expressa em número de organismos por metro cúbico $\left(\mathrm{n}^{\circ} \mathrm{org} / \mathrm{m}^{3}\right)$. Foi calculada a partir da fórmula $\mathbf{D}=\mathbf{N} / \mathbf{V}$, onde $\mathbf{D}$ é a estimativa da densidade, $\mathbf{N}$ é o número de indivíduos capturados e $\mathbf{V}$ é o volume de água filtrado pela rede. $\mathrm{O}$ volume filtrado é calculado pela fórmula $\mathbf{V}=\mathbf{a} . \mathbf{h}$, onde $\mathbf{a}$ é a área da boca da rede, e $\mathbf{h}$ a distância percorrida.

\subsection{Abundância relativa ( $(\mathrm{AR})$}

Foi estimada considerando-se o número de individuos de um determinado táxon em relação ao total de individuos do correspondente grupo zooplanctônico; foi expressa em porcentagem $(\%)$.

\subsection{Frequência de ocorrência (F)}

Número de vezes que o táxon esteve presente durante o período de amostragem; foi expressa em \%.

\subsection{Diversidade ( $\left.\mathrm{H}^{\prime}\right)$}

É uma medida da composição de espécies de um ecossistema, em termos de número e abundância relativa destas espécies (LEGENDRE e LEGENDRE, 1983), expressa em bits/ind. Foi utilizado o Índice de Shannon, baseado na teoria da informação (SHANNON-WEAVER 1949 apud MARGALEF 1991), que é uma medida do grau de "incerteza" em predizer a qual espécie pertencerá um individuo escolhido aleatoriamente, de uma coleção de $\mathbf{s}$ espécies e $\mathbf{N}$ indivíduos (LUDWIG e REYNOLDS, 1988). Utilizou-se a fórmula

$$
H=-\sum_{i=1}^{s} \frac{N i}{N} \log _{2} \frac{N i}{N}
$$

onde s é o número de espécies; Ni o número de indivíduos em cada espécie e $\mathbf{N}$ o número total de indivíduos. A diversidade de espécies é composta por dois 
componentes que devem ser interpretados separadamente (LEGENDRE e LEGENDRE, 1983): a riqueza e a equitatividade.

\subsection{Riqueza (S)}

Foi considerada como o número de táxons presentes em cada amostra.

\subsection{Equitatividade ou uniformidade (E)}

A equitatividade ou uniformidade refere-se à distribuição dos dados de abundâncias entre os táxons (LUDWIG e REYNOLDS, 1988). É uma medida importante para auxiliar na compreensão do aumento ou diminuição da diversidade de uma comunidade (ODUM 1971). Foi calculada através do Índice de PIELOU (1975, apud LEGENDRE e LEGENDRE 1983), cuja fórmula é $\mathbf{E}=\mathbf{H} / \mathbf{H}$ máx, onde H é a diversidade de espécies obtida pelo Índice de Shannon, e $\mathbf{H}$ máx é a diversidade de espécies obtida sob condições de máxima equitatividade, obtida do logarítmo do número de espécies da amostra.

A equitatividade varia de 0 a 1 , onde 1 representa a distribuição uniforme de todos os táxons na amostra.

\subsection{Análise multivariada}

A ecologia numérica tem por objetivo a análise de grandes tabelas de dados, visando descrever sua estrutura, quantificando o grau de associação entre variáveis e objetos, definindo assim comunidades biológicas e áreas ou períodos de mesmas caracteristicas ecológicas. As técnicas oferecidas pela ecologia numérica permitem também evidenciar e hierarquizar os fatores responsáveis pela variabilidade dos dados e da estrutura do sistema estudado (VALENTIN 1995).

Em pesquisas limnológicas, quase sempre utiliza-se uma grande variedade de variáveis ambientais que, juntamente com os dados específicos da comunidade, irão possibilitar o conhecimento das características dos corpos d'água. Frequentemente, com a quantificação das observações ecológicas, procura-se avaliar a semelhança entre amostras, pontos de coleta, espécies e entre variáveis físicas e químicas (BRANCO 1991) 
Foram elaboradas, para cada lago estudado, matrizes de correlação dos valores mensais de densidades numéricas dos táxons mais frequentes, e dos valores das seguintes variáveis ambientais: profundidade, transparência, e as médias dos valores de temperatura da água, $\mathrm{pH}$, condutividade elétrica, turbidez, oxigênio dissolvido, nitrogênio e fósforo totais, sólidos totais em suspensão e clorofila $a$ total, obtidos ao longo da coluna d'água (superfície, $1 \mathrm{~m}, 2 \mathrm{~m}, 3 \mathrm{~m}$ e fundo, de acordo com a profundidade de cada corpo d'água considerado). No presente trabalho, em cada lago estudado, foram considerados frequentes os táxons cuja frequência de ocorrência $(F)$ foi maior ou igual a $25 \%$ ( $F \geq 25 \%$ ), por serem importantes quantitativamente na comunidade zooplanctônica dos corpos d'água estudados.

Após os valores das matrizes de correlação biótica (táxons) e abiótica (variáveis ambientais) serem transformados em $\log (\mathrm{x}+1)$ para normalização, aplicaram-se duas técnicas de estatística multivariada: a análise de agrupamento ou "cluster analysis", e a análise de componentes principais.

A análise de agrupamento tem como objetivo evidenciar as associações entre espécies, ou seja, reconhecer entre as mesmas um grau de similaridade suficiente para reuni-las em um mesmo conjunto, visando descrever, da maneira mais clara e sintética possivel, a estrutura de um corpo d'água, determinando a composição e a extensão das suas unidades funcionais (VALENTIN 1995).

É um método de agrupamento politético não probabilístico, por aglomeração sequencial hierárquica; a aglomeração é por ligação simples e é baseada na matriz de associação entre os táxons mais frequentes (VALENTIN 1995).

Com o objetivo de determinar o grau de semelhança entre os táxons mais frequentes, utilizou-se o coeficiente de similaridade de SORENSEN (1948, apud LEGENDRE e LEGENDRE 1983), baseado em dados de presença ou ausência (qualitativo).

$\mathrm{Na}$ análise de agrupamento, os grupos são formados a partir dos pares de táxons mais similares, e em seguida, os táxons ou grupos já formados vão se reunir em função de similaridades decrescentes. A cada ciclo de fusão, a similaridade diminui e o resultado é visualizado sob a forma de uma estrutura hierárquica semelhante a uma "árvore", denominada dendrograma. 
As técnicas de ordenação, partindo de um problema multidimensional, simplificam e condensam uma série de dados em um espaço reduzido, com o objetivo de elucidar os fatores biológicos e ambientais que podem ser importantes na determinação da estrutura das comunidades biológicas.

Um dos métodos de ordenação muito utilizado em ecologia é a análise de componentes principais (ACP); é basicamente uma técnica estatística multivariada que trabalha com a estrutura interna de matrizes, e consiste em um método de fracionar uma matriz de associação em um conjunto de eixos ortogonais (perpendiculares) ou componentes (LUDWIG e REYNOLDS, 1988).

Para a composição das matrizes de correlação entre as densidades numéricas dos táxons mais frequentes $(F \geq 25 \%)$ e entre os dados das variáveis ambientais, utilizou-se o coeficiente de correlação linear de Pearson, de uso comum na determinação de relações entre variáveis.

Cada eixo da ACP corresponde a um autovalor da matriz, que representa a variância responsável pelo eixo. O primeiro plano fatorial, formado pelos dois primeiros eixos, representa a maior porcentagem de explicabilidade da variância total dos dados. O resultado é um sistema reduzido de coordenadas, que fornece informações sobre as similaridades ecológicas entre táxons e/ou amostras.

São também calculadas as contribuições absolutas dos objetos (amostras) e descritores (táxons e/ou variáveis), que consistem na contribuição de cada ponto à variância de cada eixo, permitindo visualizar quais as variáveis que mais contribuem à sua formação, e com isso facilitar sua interpretação ecológica.

A análise de componentes principais ordena, de forma independente, os objetos (amostras) e descritores (táxons e/ou variáveis). No diagrama da ACP as unidades amostrais são marcadas por pontos e os descritores por flechas (vetores), recebendo o nome de "biplot"; a direção dessas flechas aponta para a variação máxima dessa variável e o comprimento é proporcional à taxa máxima de mudança. Assim, os descritores de borda do diagrama são os mais importantes para indicar as diferenças entre as unidades amostrais e as próximas do centro do diagrama as de menor importância. 
O programa estatístico empregado, nas análises de agrupamento e de componentes principais, foi o PC-ORD, versão 3.0 para Windows (McCUNE e MEFFORD, 1997).

\subsection{Estado trófico dos corpos d'água das Unidades de Gerenciamento de}

\section{Recursos Hídricos (UGRHIs) do Estado de São Paulo}

O Índice de Estado Trófico (IET) de Carlson modificado por TOLEDO Jr. et al. (1983) foi calculado a partir das concentrações de clorofila a total (clorofila e feofitina), de acordo com a seguinte fórmula:

$$
\operatorname{IET}(C L)=10\left(6-\frac{2,04-0,695 \ln C L}{\ln 2}\right)
$$

onde:

$$
\mathbf{C L}=\text { concentração de clorofila } a \text { total }
$$

Neste trabalho, o IET de Carlson modificado foi calculado, a partir da média das concentrações de clorofila $a$ total obtidas ao longo do período de estudo, em cada corpo d'água considerado.

Os critérios adotados neste trabalho, para a aplicação do IET de Carlson modificado, nos corpos d'água das UGRHIs foram os seguintes:

- Oligotrófico: IET $<44$

- Mesotrófico: $44<$ IET $<54$

- Eutrófico: $54<$ IET $<64$

$$
\begin{aligned}
& 64<\text { IET }<74 \\
& 74<\text { IET }<84 \\
& \text { IET }>84
\end{aligned}
$$

$\mathrm{Na}$ categoria eutrófico, foram consideradas quatro sub-divisões, levando-se em consideração a grande amplitude de variação do IET. 


\subsection{Espécies zooplanctônicas como indicadoras da qualidade da água nas} Unidades de Gerenciamento de Recursos Hídricos (UGHRIs) do Estado de São Paulo

Com o objetivo de evidenciar indicadores da qualidade da água no Estado de São Paulo, foram considerados dados de densidades numéricas e a frequência de ocorrência das espécies zooplanctônicas nos corpos d'água considerados.

\section{RESULTADOS}

\subsection{Dados climatológicos}

As médias mensais de precipitação e temperatura do ar, registradas durante o período estudado, encontram-se na Tabela 1. Temperaturas mais elevadas (igual ou superior a $20^{\circ} \mathrm{C}$ ) ocorreram nos meses de janeiro a março e novembro a dezembro, no período chuvoso-quente.

As maiores precipitações foram registradas em janeiro $(341,4 \mathrm{~mm})$ e dezembro $(206,5 \mathrm{~mm})$, e as menores em julho $(9,4 \mathrm{~mm})$ e agosto $(38,7 \mathrm{~mm})$ (Tabela 1 ; Figura 7).

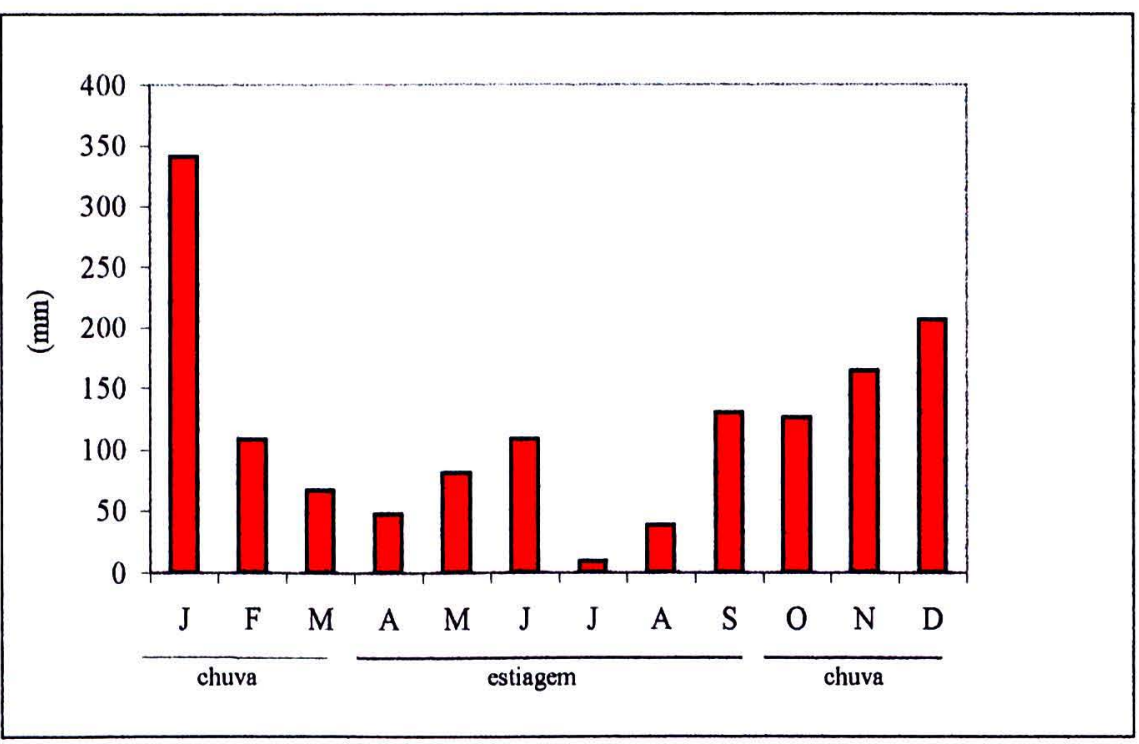

FIGURA 7 - Variação das médias de precipitação total (mm), de janeiro a dezembro de 1997. 


\subsection{Variáveis físicas, químicas e biológicas}

Os valores mensais de profundidade $(\mathrm{m})$ e transparência da água $(\mathrm{m})$, e os valores mensais por profundidade de coleta, e médias ao longo da coluna d'água, de temperatura $\left({ }^{\circ} \mathrm{C}\right)$, oxigênio dissolvido $(\mathrm{mg} / \mathrm{L}), \mathrm{pH}$, condutividade elétrica $(\mu \mathrm{S} / \mathrm{cm})$, sólidos totais em suspensão (mg/L), turbidez (UNT), nitrogênio total $(\mu \mathrm{g} / \mathrm{L})$, fósforc total $(\mu \mathrm{g} / \mathrm{L})$ e clorofila $a$ total $(\mu \mathrm{g} / \mathrm{L})$, em cada lago estudado, encontram-se nas tabelas 2, 3 e 4 .

No lago do IAG, cuja profundidade máxima foi $4,7 \mathrm{~m}$, foram registrados valores mais elevados de transparència $(1,10$ a $2,15 \mathrm{~m})$ e oxigênio dissolvido $(0,51$ a $8,24 \mathrm{mg} / \mathrm{L})$, e baixos valores de $\mathrm{pH}(5,38$ a 6,10$)$, condutividade elétrica $(30,5$ a 48,7 $\mu \mathrm{S} / \mathrm{cm})$, sólidos totais em suspensão (1,0 a $8,6 \mathrm{mg} / \mathrm{L})$, turbidez $(3,1$ a 8,3 UNT), fósforo total $(10,58$ a $35,41 \mu \mathrm{g} / \mathrm{L})$ e clorofila $a$ total $(1,56$ a $7,96 \mu \mathrm{g} / \mathrm{L})$; valores intermediários entre os demais lagos estudados foram constatados para o nitrogênio total $(35,19$ a $958,88 \mu \mathrm{g} / \mathrm{L})$ (Tabela 2; Figuras 8 a 12).

A menor profundidade entre os corpos d'água estudados $(3,5 \mathrm{~m})$, foi constatada no lago das Ninféias, que apresentou valores intermediários de transparência $(0,55$ a $1,90 \mathrm{~m}), \mathrm{pH}(5,96$ a 6,04$)$, condutividade elétrica $(48,1$ a 88,1 $\mu \mathrm{S} / \mathrm{cm})$, sólidos totais em suspensão (6,2 a 14,0 mg/L), turbidez (4,8 a 17,0 UNT), fósforo total $(13,28$ a $50,45 \mu \mathrm{g} / \mathrm{L})$ e clorofila $a$ total $(2,56$ a $17,80 \mu \mathrm{g} / \mathrm{L})$, e baixos valores de oxigênio dissolvido $(0,41$ a $5,49 \mathrm{mg} / \mathrm{L})$ e nitrogênio total $(124,44$ a 532,08 $\mu \mathrm{g} / \mathrm{L}$ ) (Tabela 3; Figuras 8 a 12).

O lago das Garças, com a maior profundidade entre os corpos d'água estudados (4,9m), apresentou valores mais elevados de $\mathrm{pH}(6,63$ a 7,81), condutividade elétrica (138,3 a $164,1 \mu \mathrm{S} / \mathrm{cm})$, sólidos totais em suspensão $(6,5$ a 20,9 $\mathrm{mg} / \mathrm{L})$, turbidez (6,2 a 27,3 UNT), nitrogênio e fósforo totais $(226,59$ a $1864,97 \mu \mathrm{g} / \mathrm{L}$ e 75,92 a $178,80 \mu \mathrm{g} / \mathrm{L}$, respectivamente) e clorofila $a$ total $(13,65$ a $110,16 \mu \mathrm{g} / \mathrm{L})$.

Neste corpo d'água foram registrados valores intermediários de oxigênio dissolvido $(0,44$ a $6,13 \mathrm{mg} / \mathrm{L})$, e valores mais baixos de transparência $(0,10$ a $0,95 \mathrm{~m})$ (Tabela 4; Figuras 8 a 12).

No lago do IAG, no período estiagem-frio a estrutura da coluna d'água foi homogênea em relação ao oxigênio dissolvido; já nos lagos das Ninféias e Garças, a 
coluna d'água se mostrou estratificada, com condições anóxicas no fundo, principalmente no período chuvoso-quente (Tabelas 2,3 e 4 ).

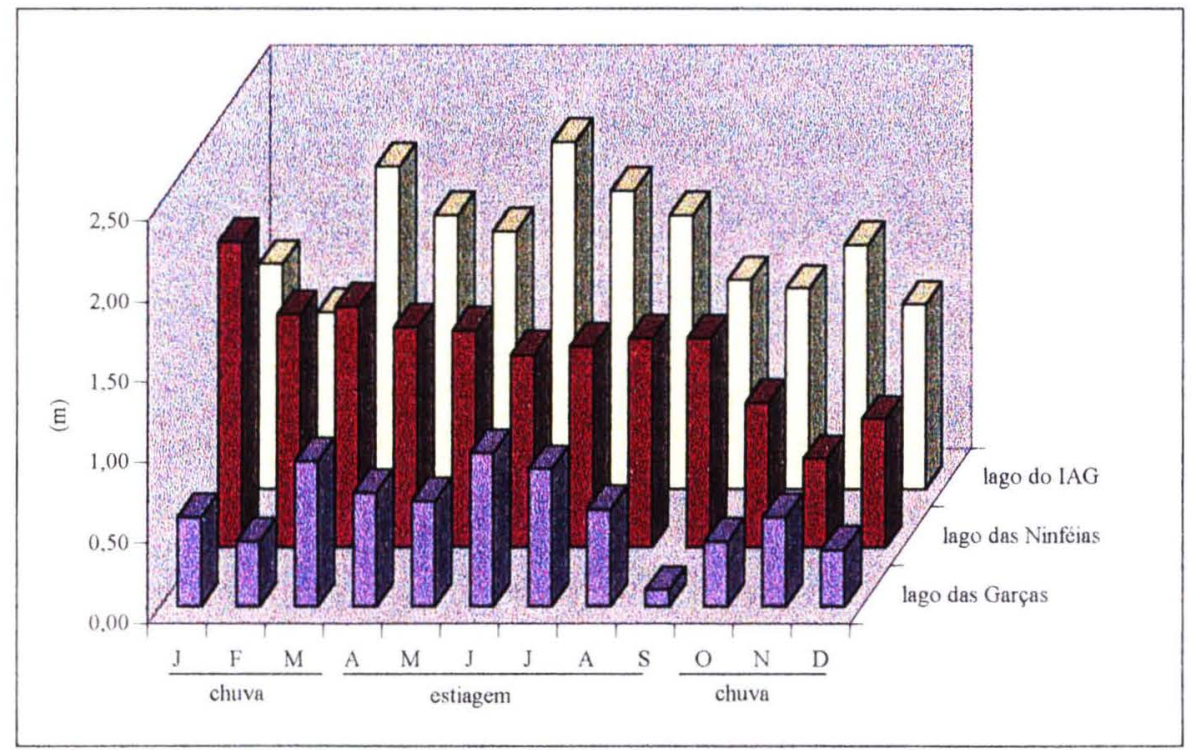

FIGURA 8 - Variação da transparência da água (m) nos lagos do IAG, das Ninféias e Garças, de janeiro a dezembro de 1997. 


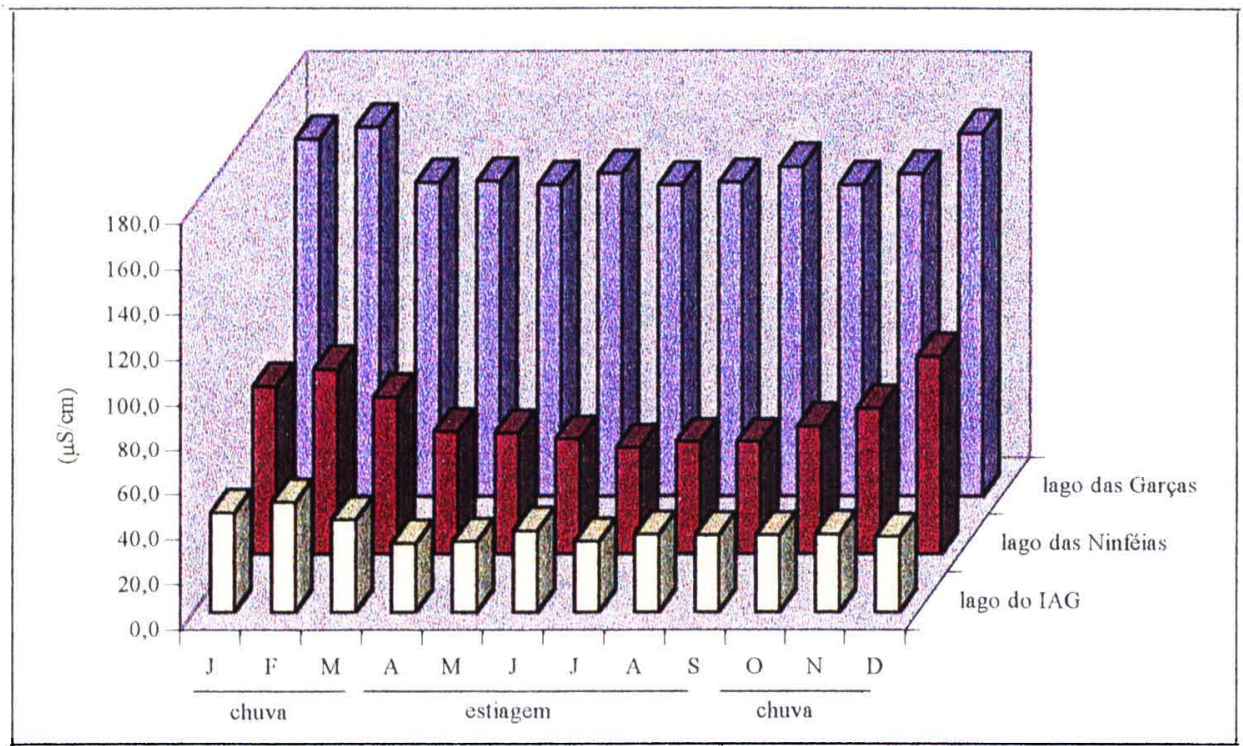

FIGURA 9 - Variação das médias de condutividade elétrica $(\mu \mathrm{S} / \mathrm{cm})$ nos lagos do IAG, das Ninféias e Garças, de janeiro a dezembro de 1997.

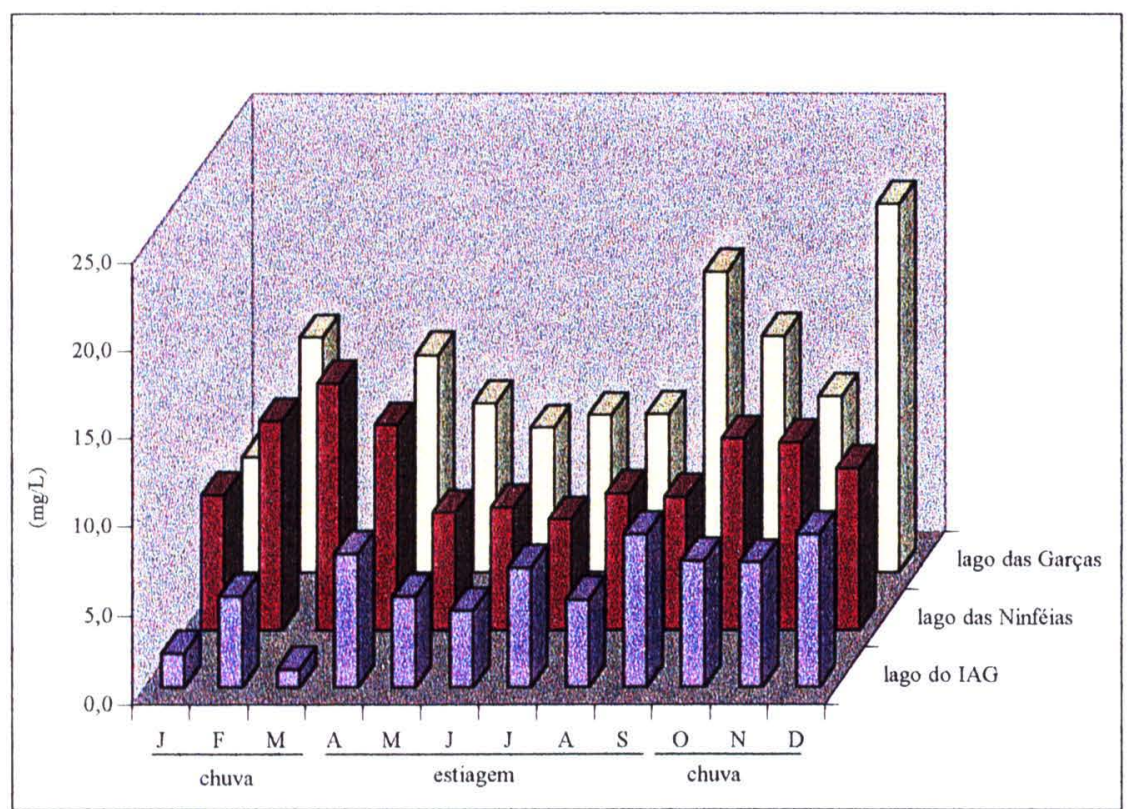

FIGURA 10 - Variação das médias de sólidos totais em suspensão $(\mathrm{mg} / \mathrm{L})$ nos lagos do IAG, das Ninféias e Garças, no período de janeiro a dezembro de 1997. 


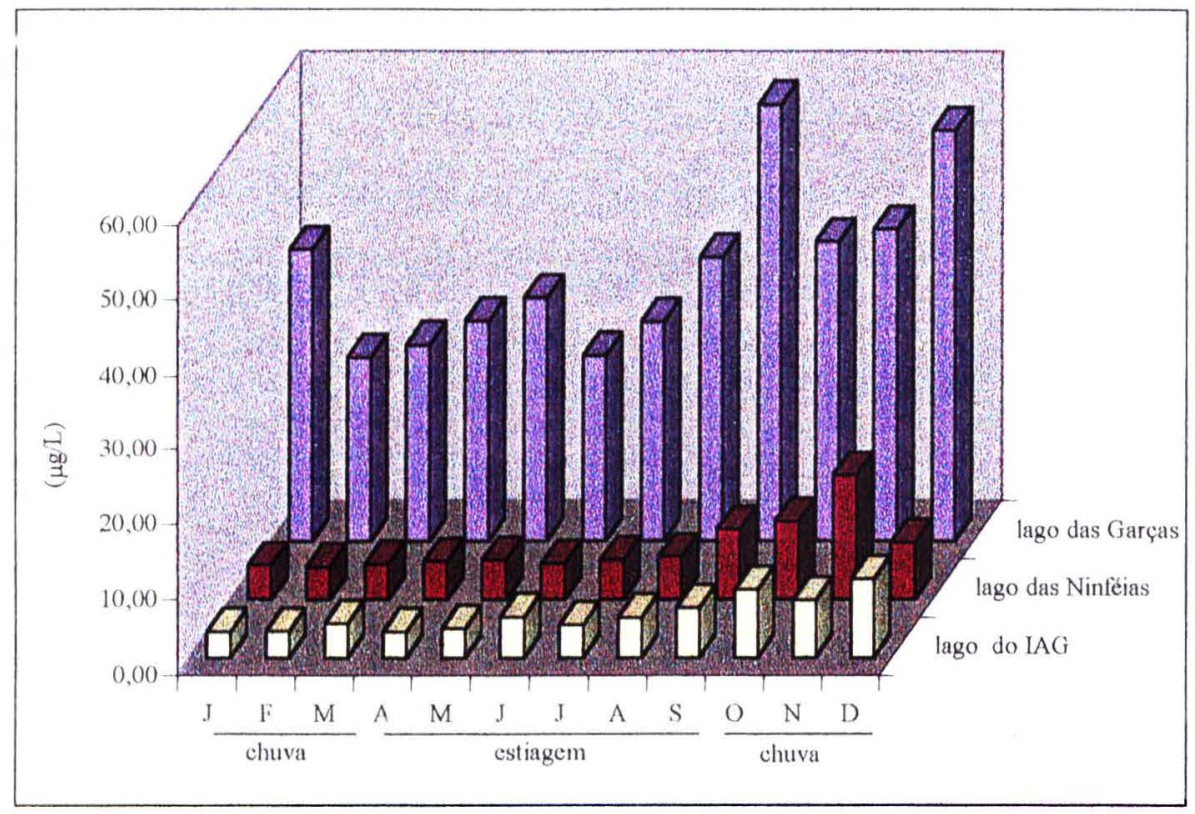

FIGURA 11 - Variação das médias de fósforo total $(\mu \mathrm{g} / \mathrm{L})$ nos lagos do IAG, das Ninféias e Garças, no período de janeiro a dezembro de 1997.

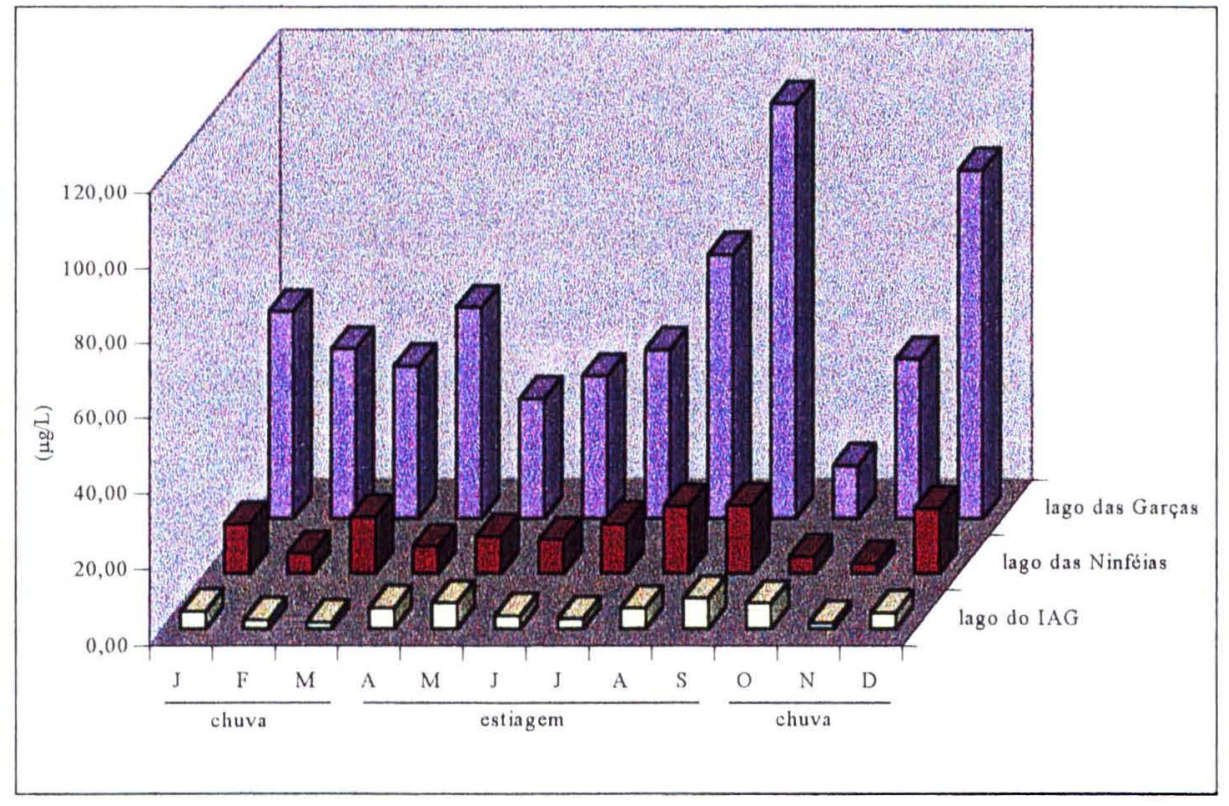

FIGURA 12 - Variação das médias de clorofila $a$ total $(\mu \mathrm{g} / \mathrm{L})$ nos lagos do IAG, das Ninféias e Garças, no período de janeiro a dezembro de 1997. 


\subsection{Zooplâncton}

\subsubsection{Composição da comunidade}

A composição das comunidades de rotiferos e crustáceos, nos lagos do IAG, das Ninféias e das Garças, encontra-se nas tabelas 5 e 6 . Em relação aos rotíferos, Collotheca spp., Conochilus dossuarius, Keratella cochlearis, Polyarthra vulgaris e Trichocerca spp. ocorreram nos três lagos estudados (Tabela 5), e Anuraeopsis fissa foi comum aos lagos das Ninféias e Garças.

Por outro lado, constatou-se que vários táxons foram restritos a determinado corpo d'água. No lago do IAG, foram registrados Anuraeopsis sp., Ascomorpha ecaudis, A. saltans, Ascomorpha sp., Hexarthra intermedia brazliensis, $H$. intermedia intermedia, Hexarthra spp. e Trichocerca stylata, além da ocorrência esporádica de Dissotrocha aculeata e Macrochaetus sp.

Certos táxons de ocorrência esporádica foram registrados exclusivamente no lago das Ninféias, como Dipleuchlanis propatula, Lepadella patella, Monommata sp., Sinantherina sp., Trichocerca cf. bidens, além de espécies de Lecane (L. doryssa e $L$. leontina).

Várias espécies pertencentes aos gêneros Brachionus ( $B$. angularis bidens, $B$. angularis chelonis, B. bidentatus, B. calyciflorus, B. caudatus, B. falcatus e B. mirus), Keratella (K. americana, K. tecta e K. tropica) e Trichocerca ( $T$. cf. mus, T. pusilla e T. similis) foram registradas somente no lago das Garças, além de Cephalodella catellina, (ephalodella sp., Conochilus unicornis, Conochilus spp., Euchlanis dilatata, Filinia opoliensis, $F$. terminalis, Mytilina bisulcata e Polyarthra sp. Rotíferos predadores tais como Asplanchna girodi e Synchaeta pectinata também ocorreram exclusivamente neste corpo d'água.

Em relação aos copépodos ciclopóides (Tabela 6), Tropocyclops prasinus ocorreu nos três corpos d'água estudados, e a co-ocorrência de Thermocyclops decipiens e Metacyclops mendocinus foi constatada somente no lago das Garças; esta última espécie foi de ocorrência esporádica no lago do IAG, não sendo registrada no lago das Ninféias.

Alguns taxons tais como liucyclops pseudoensifer, Eucyclops sp., Macrocyclops sp., Mesocyclops longisetus e Microcyclops sp. foram registrados esporadicamente nos lagos do PEFI. Eucyclops sp. foi comum aos lagos do IAG c das 
Ninféias; já Macrocyclops sp. ocorreu exclusivamente no lago das Ninféias. Quanto a Microcyclops sp., foi registrado nos lagos do IAG e das Garças, e Eucyclops pseudoensifer e Mesocyclops longisetus, somente no lago das Garças. Scolodiaptomus corderoi foi a espécie de copépodo calanóide registrada nos três lagos (Tabela 6).

Bosminopsis deitersi, Daphnia ambigua e Moina micrura foram comuns aos três corpos d'água estudados. O mesmo foi observado para Alona guttata, Alona spp., Biapertura spp., (amptocercus dadayi, Chydorus sphaericus, Chydorus spp., Disparalona dadayl, llyocryptus spinifer e Macrothrix spinosa, táxons não euplanctônicos componentes das famílias Chydoridae, Ilyocryptidae e Machrotricidae, associados ao sedimento e/ou regiões litorâneas (Tabela 6).

Por outro lado, somente no lago das Garças constatou-se a co-ocorrência de Daphnia ambigua e D. gessneri, e Moina micrura e M. minuta. Ceriodaphnia cornuta cornuta, C. cornuta rigaudi e C. cf. reticulata também foram registradas exclusivamente neste corpo d'água, porém sua ocorrência foi esporádica.

Bosmina hagmanni, B. tubicen, Bosmina sp. e Diaphanosoma birgei foram táxons comuns aos lagos do IAG e das Garças, não ocorrendo no lago das Ninféias.

\subsubsection{Estrutura da comunidade}

A comunidade zooplanctônica foi caracterizada pelo predomínio de rotíferos nos lagos do IAG, das Ninféias e Garças, representando respectivamente, $67 \%$, 76\% e $78 \%$ da comunidade zooplanctônica. As abundâncias relativas deste grupo de organismos se mantiveram elevadas durante quase todo o periodo estudado (Tabelas 7,8 e 9 ).

No lago do IAG, observou-se a co-ocorrência de Conochilus dossuarius (41\%) e Keratella cochlearis (25\%), seguido por Polyarthra vulgaris (13\%) e Ascomorpha ecaudis, A. saltans e Collotheca spp. (4\%) (Figura 13).

Polyarthra vulgaris constituiu $41 \%$ do total de espécies de rotíferos no lago das Ninféias, seguido por C. dossuarius (20\%), K. cochlearis (16\%), Anuraeopsis fissa (8\%) e Trichocerca spp. (7\%) (Figura 14).

No lago das Garças, as abundâncias relativas das espécies de rotíferos registradas foram semelhantes; $A$. fissa representou $13 \%$ do total deste grupo, seguida por Keratella americana (10\%), P. vulgaris, K. cochlearis e Keratella tropica ( $5 \%)$, 
Brachionus angularts chelonts e Keratella tecta (8\%) e finalmente Polyarthra sp. $(7 \%)$ (Figura 15).

Copépodos ciclopóides representaram $12 \%$ e $4 \%$ da comunidade zooplanctônica nos lagos do IAG e das Ninféias, respectivamente, apresentando abundâncias relativas mais elevadas no lago das Garças ( $21 \%)$.

Ciclopóides foram representados principalmente por náuplios, cujas abundâncias relativas foram elevadas, $75 \%, 69 \%$ e $71 \%$ do total deste grupo, respectivamente nos lagos do IAG, das Ninféias e Garças. Os copepoditos constituiram $9 \%$ no lago do IAG, $23 \%$ no lago das Ninféias, e $20 \%$ no lago das Garças.

Tropocyclops prasinus apresentou abundância relativa mais elevada no lago do IAG ( $16 \%$ ), constituindo no lago das Ninféias $8 \%$ e no lago das Garças $4 \%$ do total de ciclopóides. Thermocyclops decipiens e Metacyclops mendocinus foram registrados no lago das Garças, com abundâncias relativas baixas ( $3 \%$ e $2 \%$, respectivamente).

Nos lagos do PEFI, Scolodiaptomus corderoi foi a única espécie de copépodo calanóide observada, representando 8 e $15 \%$ da comunidade zooplanctônica nos lagos do IAG e das Ninféias, respectivamente. Já no lago das Garças, esta espécie apresentou abundâncias relativas muito baixas $(0,01 \%)$, não ocorrendo na maioria das amostras analisadas (Figuras 13, 14 e 15).

Scolodiaptomus corderot também foi representada principalmente por formas larvais; nauplios e copepoditos constituiram no lago do IAG, 44 e $41 \%$ do total de organismos desta espécie, no lago das Ninféias, 82 e 13\%, respectivamente, e no lago das Garças, na maioria das amostras analisadas, observou-se somente a ocorrência de copepoditos com abundâncias relativas baixas. Adultos de $S$. corderoi apresentaram abundância relativa mais elevada no lago do IAG (15\%), representando somente $5 \%$ do total de organismos desta espécie no lago das Ninféias.

Os cladóceros apresentaram abundâncias relativas mais elevadas (13\%) no lago do IAG; nos lagos das Ninféias e Garças, representaram $5 \%$ e $1 \%$ respectivamente, da comunidade zooplanctônica.

Bosminopsis deiterst foi a principal espécie de cladócero nos lagos do IAG e das Ninféias, correspondendo a 31 e $56 \%$ do total deste grupo. No lago do IAG foram 
também importantes Diaphanosoma birget (29\%), Daphnia ambigua (19\%) e Moina micrura (12\%) (Figura 13). No lago das Ninféias, além de Bosminopsis deitersi, foram importantes D. ambigua (15\%) e Disparalona dadayi (14\%) (Figura 14). Daphnia gessneri, que ocorreu exclusivamente no lago das Garças, representou 33\% do total de cladóceros, seguida por Daphnia sp. (jovem) $(20 \%), D$. birgei $(14 \%), D$. ambigua (9\%) e B. deitersi (7\%) (Figura 15). 


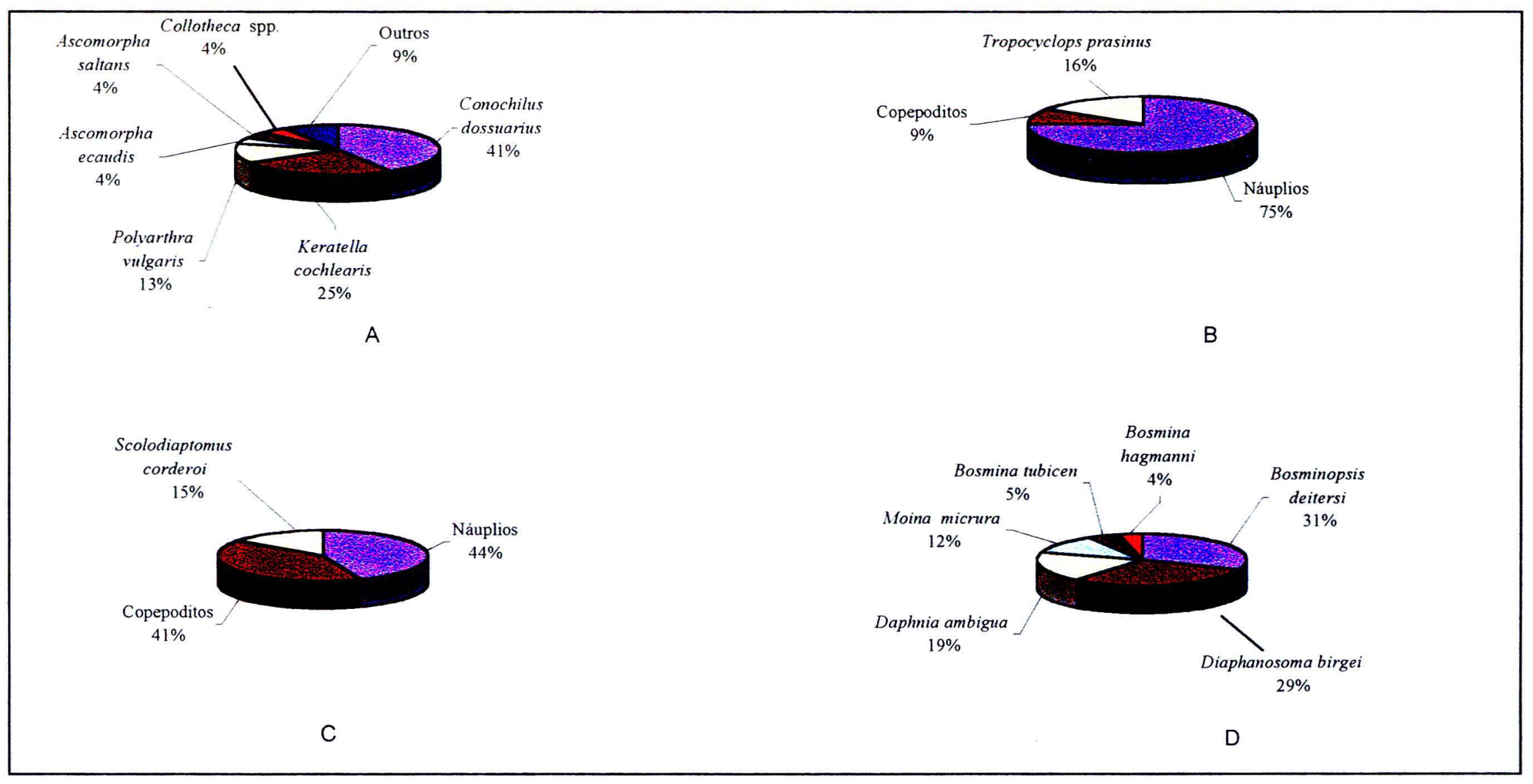

FIGURA 13 - Abundâncias relativas (\%) de rotíferos (A), copépodos ciclopóides (B), copépodos calanóides (C), e cladóceros (D), no lago do IAG, de janeiro a dezembro de 1997.

$\ddot{o}$ 


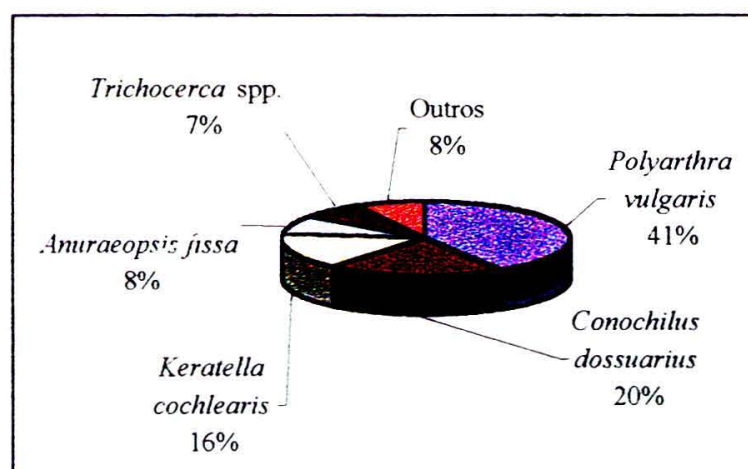

A

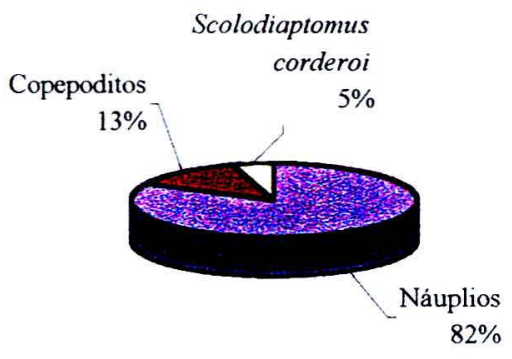

C

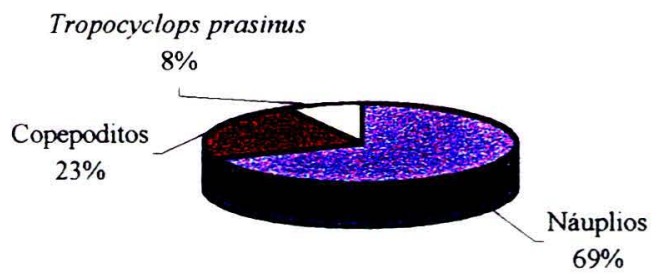

B

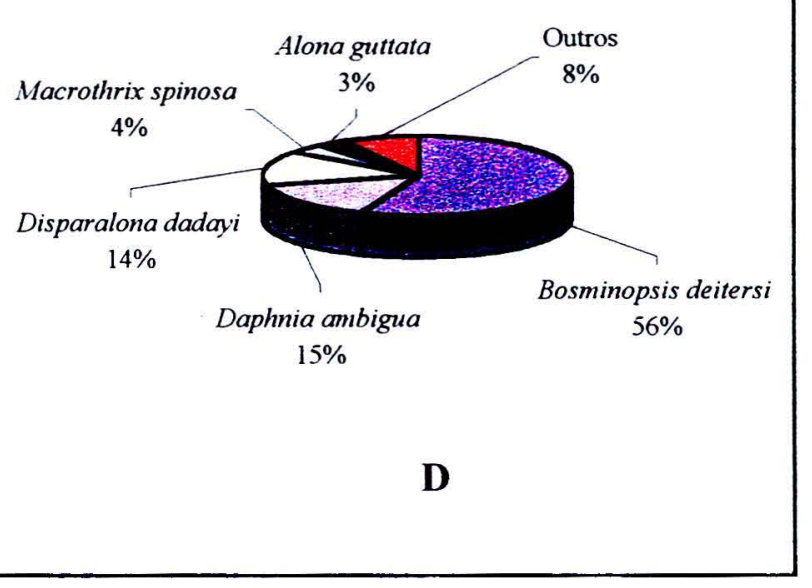

$\underline{\omega}$

FIGUKंA 14 - Abundâncias relativas (\%) de rotíferos (A), copépodos ciclopóides (B), copépodos calanóides (C) e cladóceros (D), no lago das Ninféias, de janeiro a dezembro de 1997. 


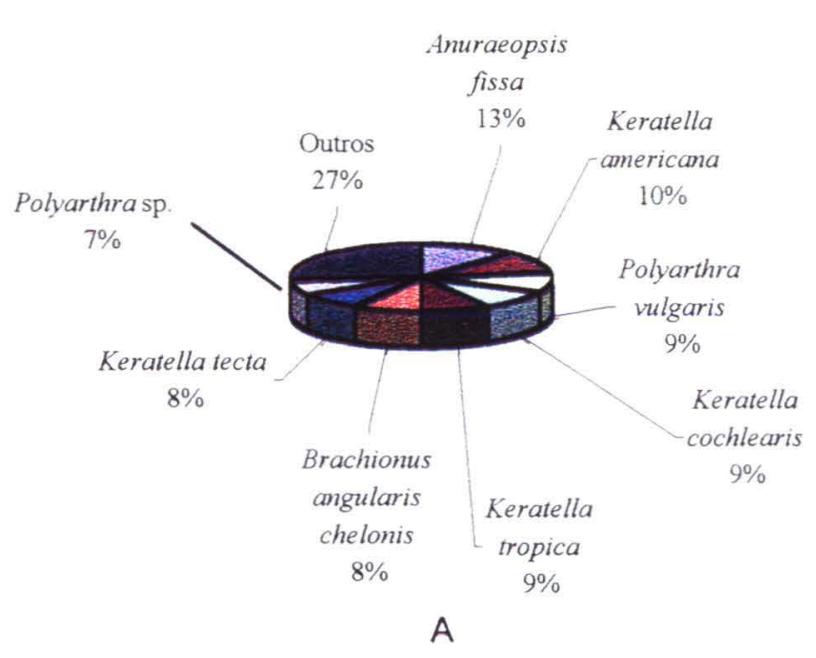

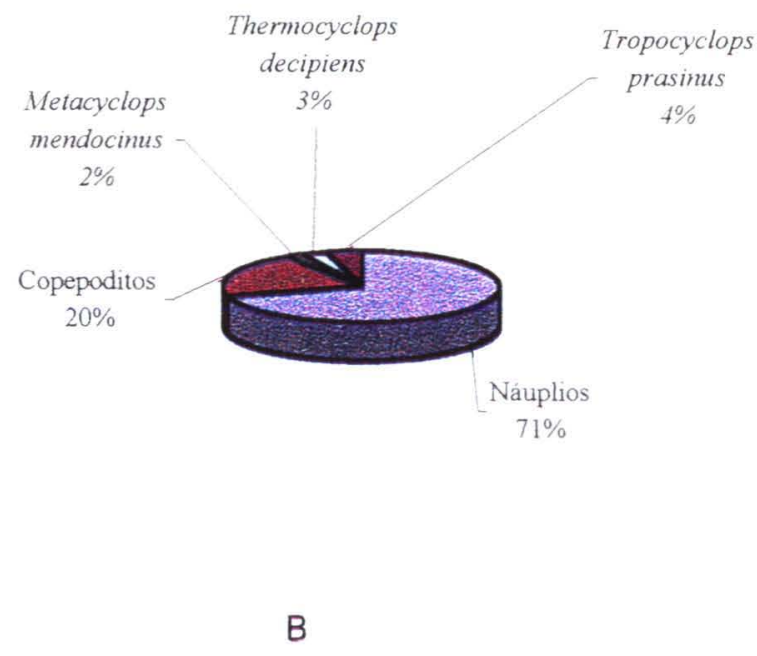

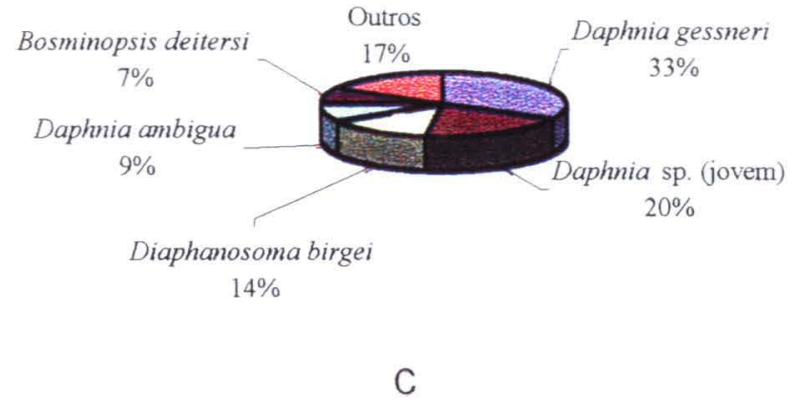

FIGURA 15 - Abundâncias relativas (\%) de rotíferos (A), copépodos ciclopóides (B) e cladóceros (C), no lago das Garças, de janeiro a dezembro de 1997.

$\omega$ 


\subsubsection{Flutuação da comunidade}

De janeiro a dezembro de 1997, a densidade numérica da comunidade zooplanctônica, de uma maneira geral, foi mais elevada no lago das Garças, e mais baixa no lago do IAG; no lago das Ninféias registrou-se densidades intermediárias em relação aos demais corpos d'água estudados (Tabelas 7, 8 e 9; Figura 16).

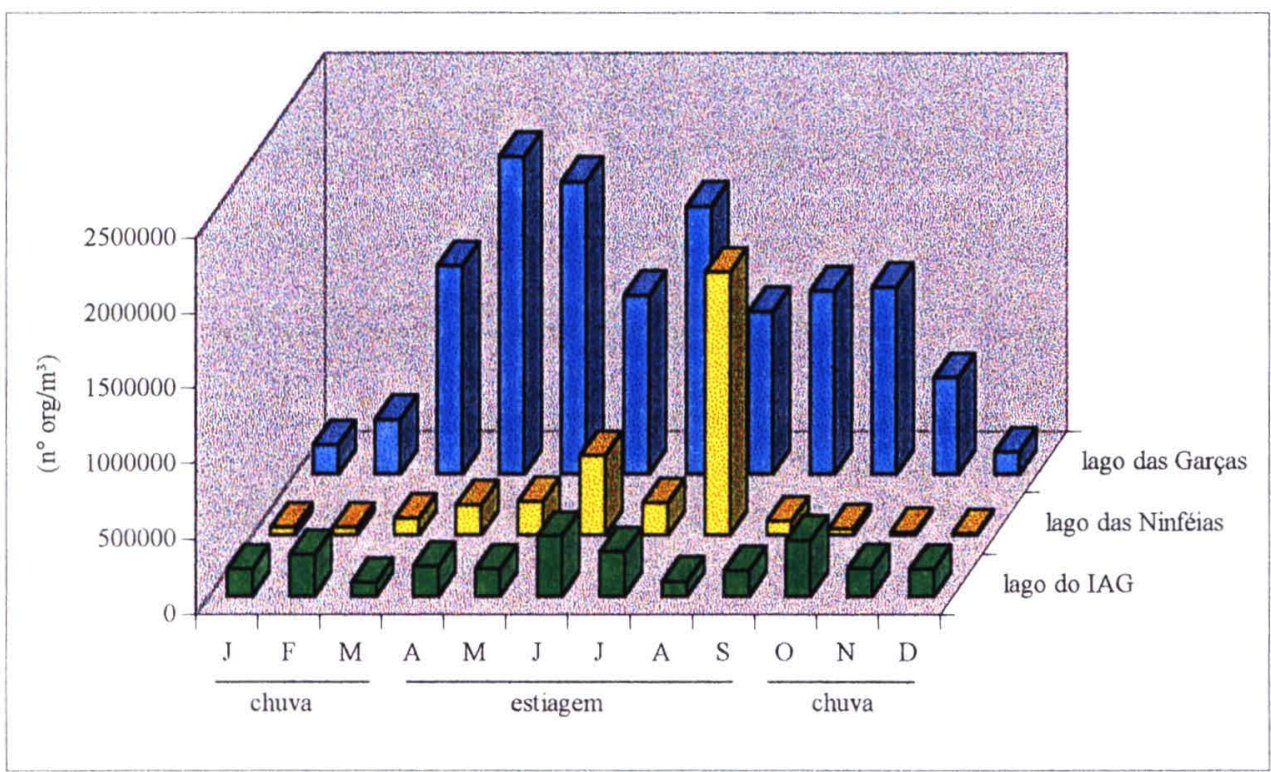

FIGURA 16 - Densidades numéricas da comunidade zooplanctônica $\left(\mathrm{n}^{\circ} \mathrm{org} / \mathrm{m}^{3}\right)$, nos lagos do IAG, das Ninféias e Garças, de janeiro a dezembro de 1997.

Nos lagos das Ninféias e Garças, a densidade numérica da comunidade zooplanctônica foi mais elevada no período estiagem-frio, com picos em agosto $\left(1.749 .345 \mathrm{org} / \mathrm{m}^{3}\right)$ e abril $\left(2.102 .565 \mathrm{org} / \mathrm{m}^{3}\right)$, respectivamente; as densidades numéricas mais baixas foram registradas em dezembro $\left(7.710 \mathrm{org} / \mathrm{m}^{3}\right.$, no lago das Ninféias, e $141.512 \mathrm{org} / \mathrm{m}^{3}$, no lago das Garças) (Tabelas 8 e 9; Figuras 18 e 19).

Já no lago do IAG, não foi observada uma aparente relação entre a flutuação da densidade dos organismos zooplanctônicos e os periodos chuvoso-quente e estiagem-frio; a densidade mais elevada foi constatada em junho $\left(399.569 \mathrm{org} / \mathrm{m}^{3}\right)$ e a mais baixa em março ( $94.463 \mathrm{org} / \mathrm{m}^{3}$ ) (Tabela 7; Figura 17). 


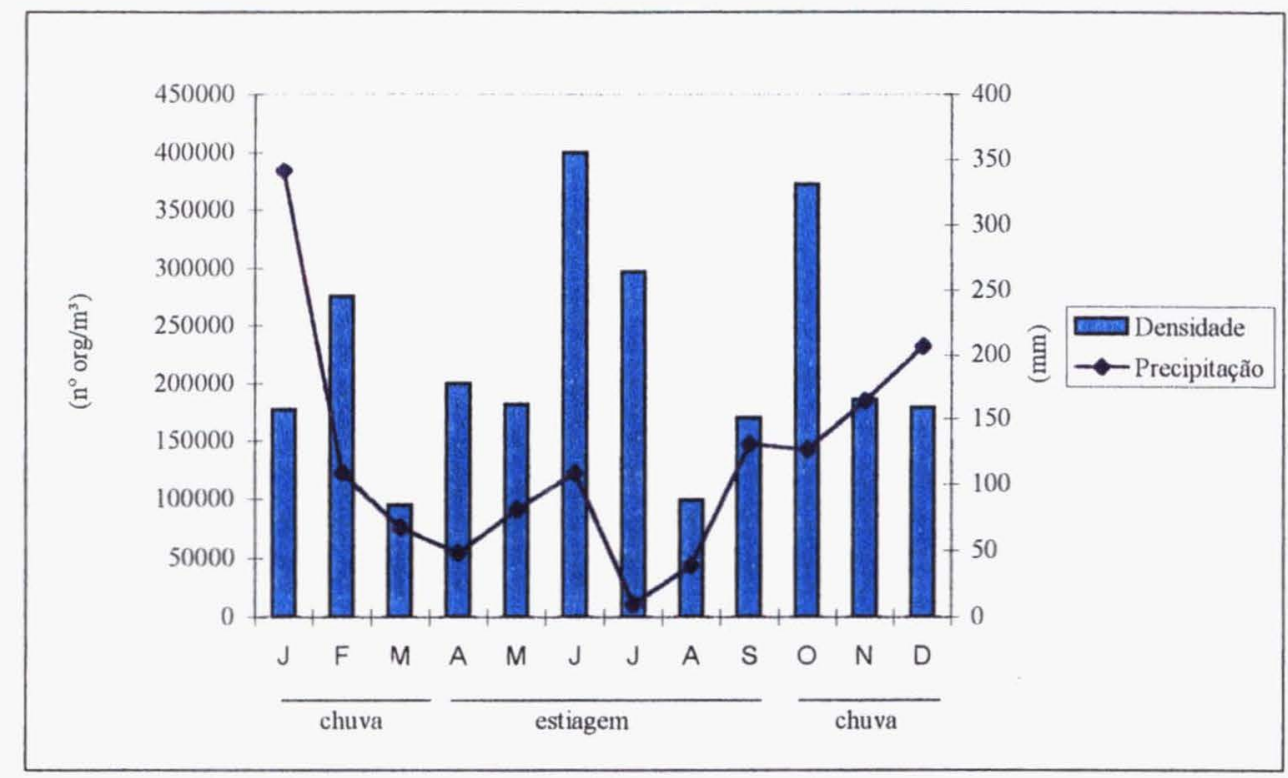

FIGURA 17 - Densidades numéricas da comunidade zooplanctônica $\left(n^{\circ} \mathrm{org} / \mathrm{m}^{3}\right)$ e precipitação total $(\mathrm{mm})$ no lago do IAG, de janeiro a dezembro de 1997.

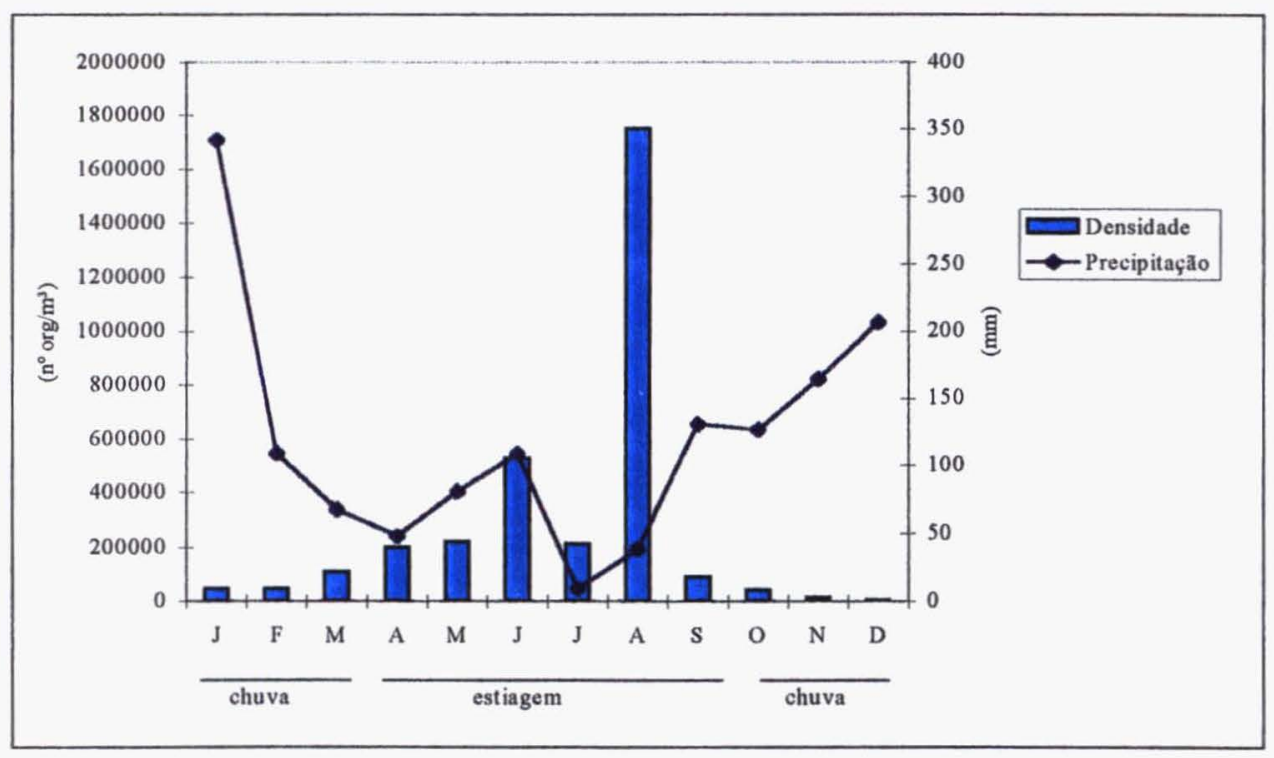

FIGURA 18 - Densidades numéricas da comunidade zooplanctônica $\left(\mathrm{n}^{\circ} \mathrm{org} / \mathrm{m}^{3}\right)$ e precipitação total $(\mathrm{mm})$ no lago das Ninféias, de janeiro a dezembro de 1997. 


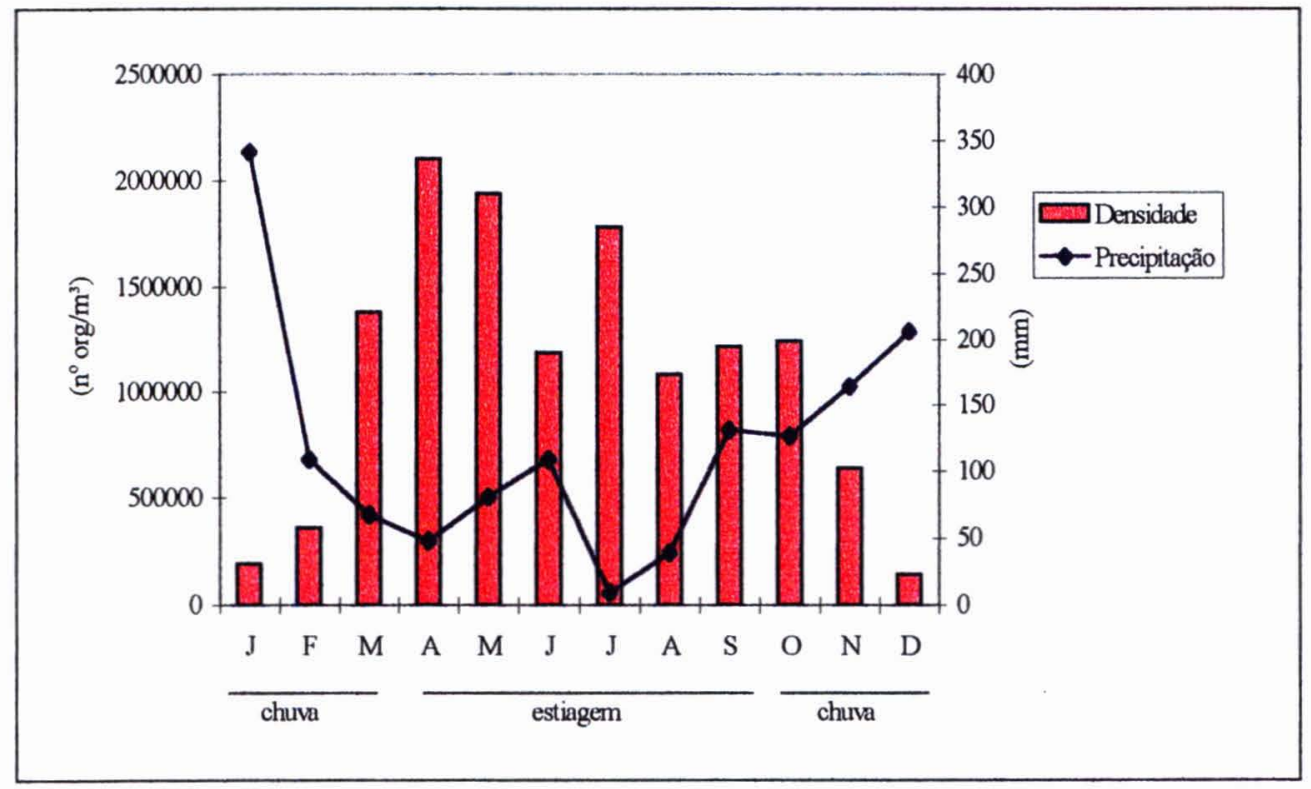

FIGURA 19 - Densidades numéricas da comunidade zooplanctônica ( $\left.\mathrm{n}^{\circ} \mathrm{org} / \mathrm{m}^{3}\right)$ e precipitação total ( $\mathrm{mm}$ ) no lago das Garças, de janeiro a dezembro de 1997.

e rganismos zooplanctônicos, independentemente do estado trófico dos lagos studados (Tabelas 7, 8 e 9; Figuras 20, 21 e 22).

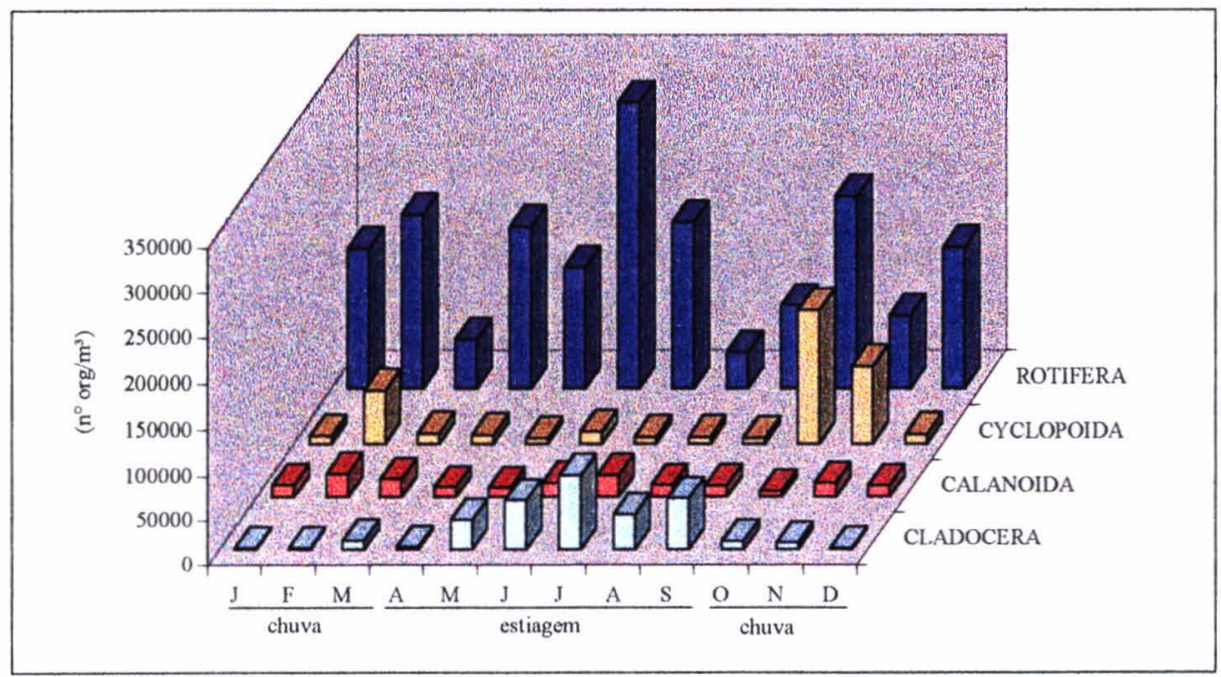

FIGURA 20 - Densidades numéricas dos grupos zooplanctônicos $\left(\mathrm{n}^{\circ} \mathrm{org} / \mathrm{m}^{3}\right)$, no lago do IAG, de janeiro a dezembro de 1997. 


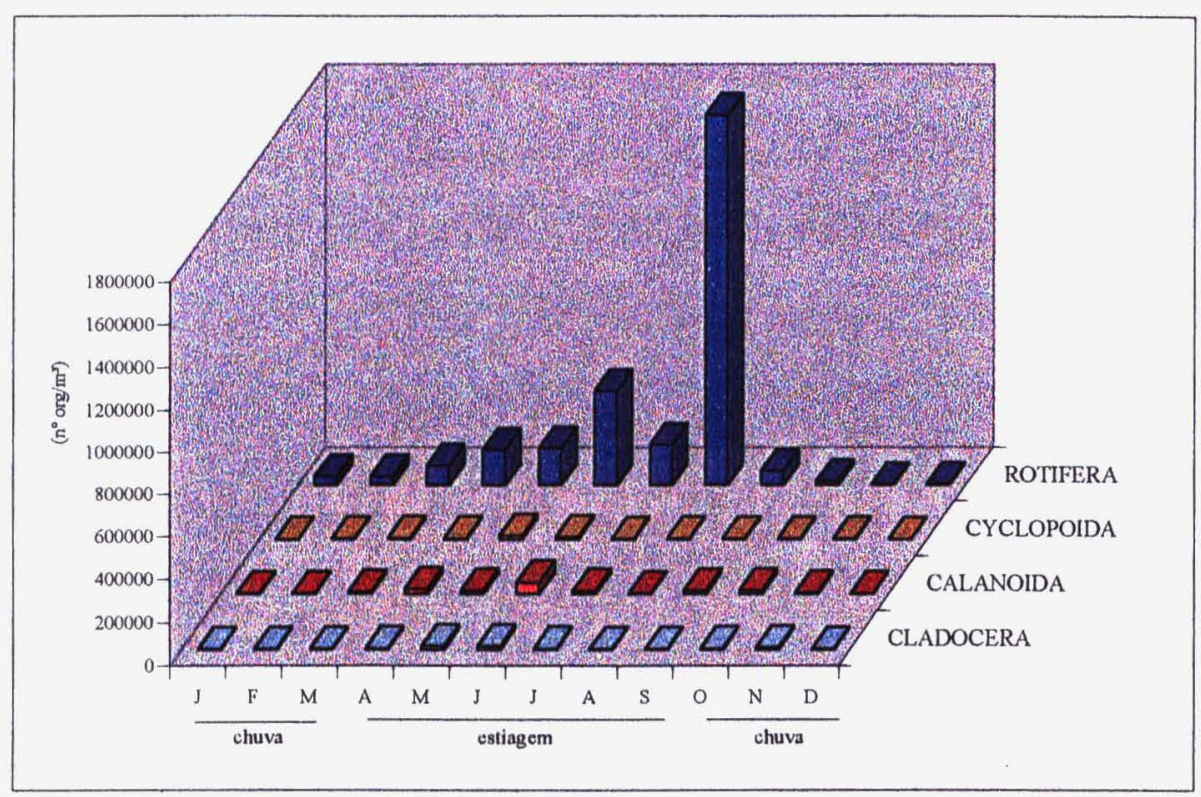

FIGURA 21 - Densidades numéricas dos grupos zooplanctônicos $\left(\mathrm{n}^{\circ} \mathrm{org} / \mathrm{m}^{3}\right)$, no lago das Ninféias, de janeiro a dezembro de 1997.

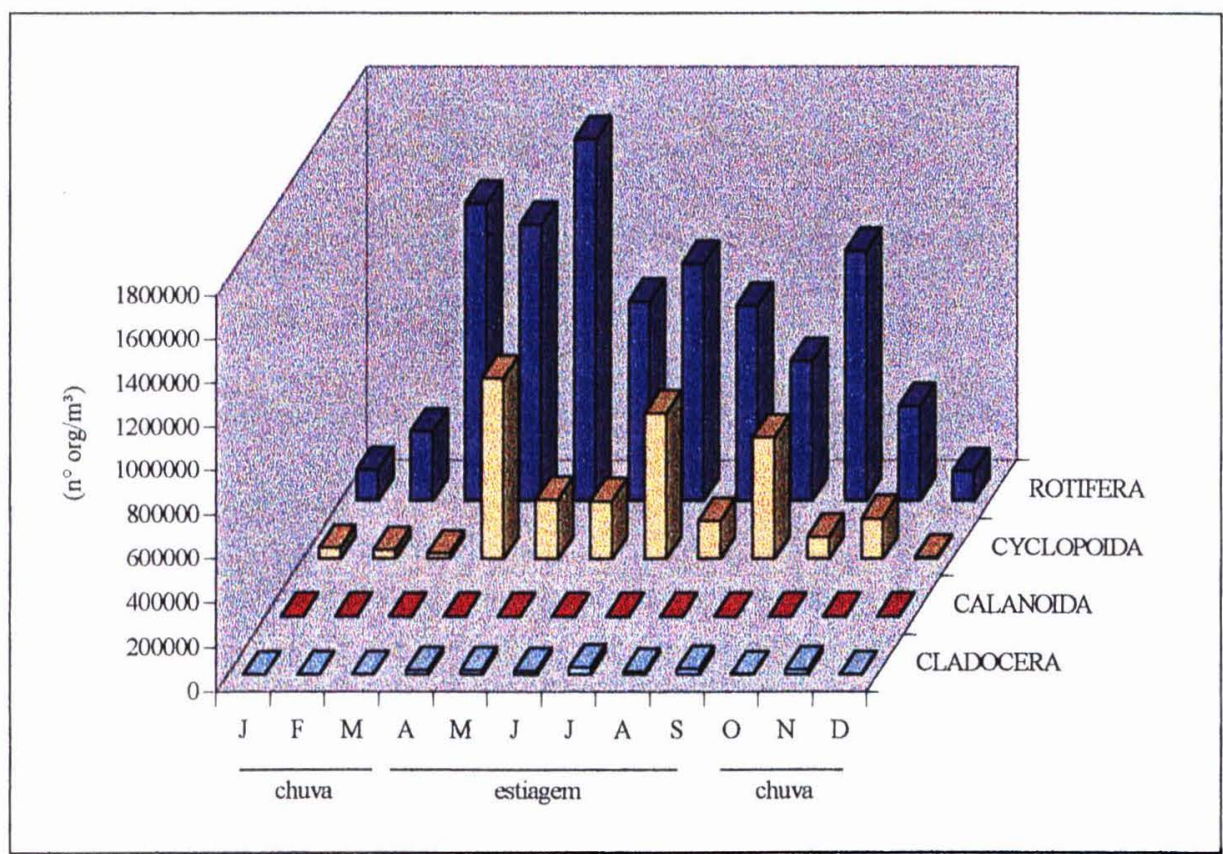

FIGURA 22- Densidades numéricas dos grupos zooplanctônicos ( $\mathrm{n}^{\circ} \mathrm{org} / \mathrm{m}^{3}$ ) no lago das Garças, de janeiro a dezembro de 1997. 
No lago do IAG, Ascomorpha ecaudis, A. saltans, Collotheca spp. e Polyarthra vulgaris apresentaram densidades numéricas mais elevadas no período estiagem-frio, ocorrendo o inverso com Keratella cochlearis; já Conochilus dossuarius não mostrou um padrão sazonal de flutuação de densidades (Tabela 10; Figura 23).

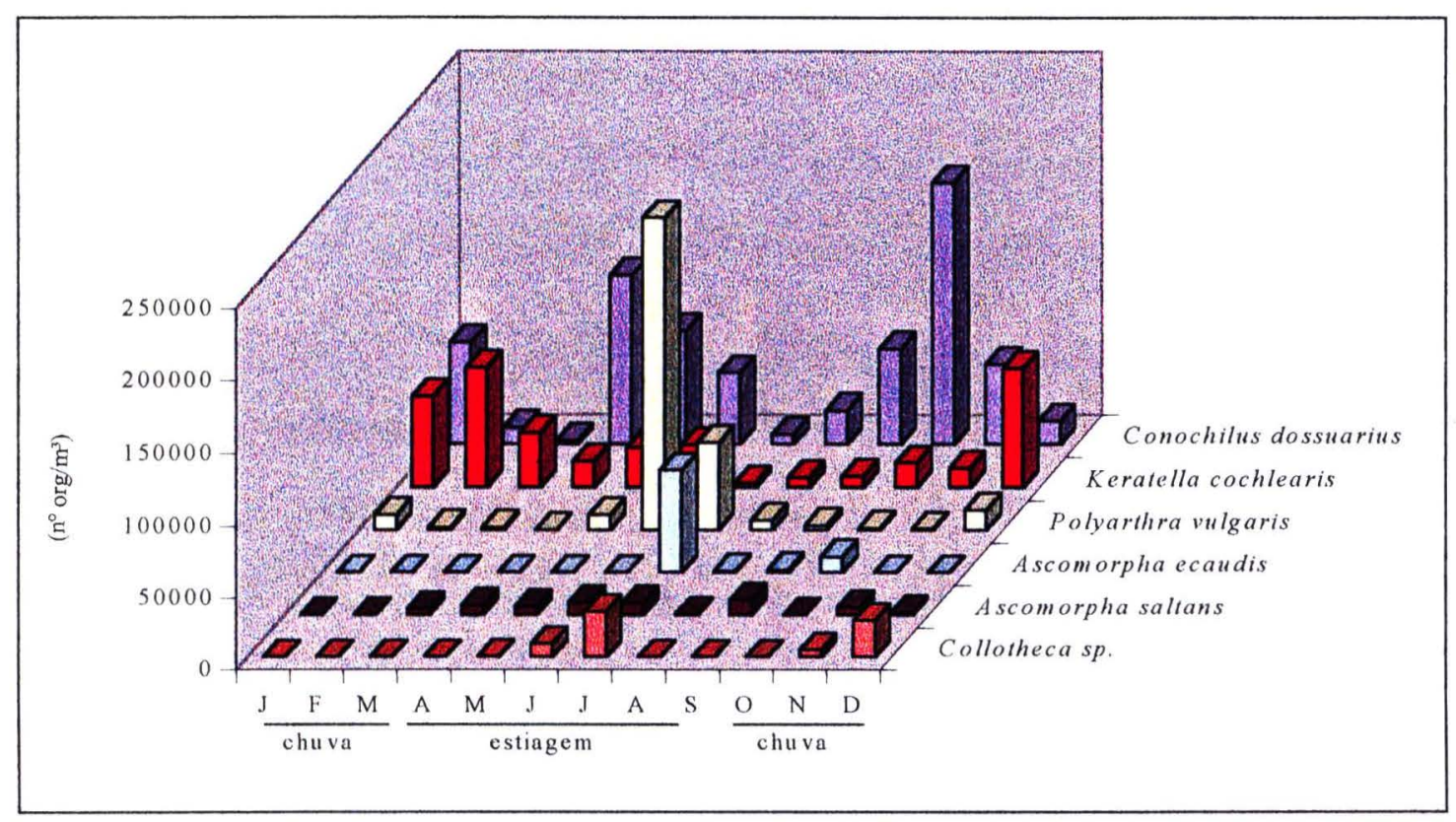

FIGURA 23 - Densidades numéricas de rotíferos $\left(\mathrm{n}^{\circ} \mathrm{org} / \mathrm{m}^{3}\right)$ no lago do IAG, de janeiro a dezembro de 1997.

No lago das Ninféias, as densidades mais elevadas de $C$. dossuarius, $K$. cochlearis e $P$. vulgaris também foram registradas no período estiagem-frio; Anuraeopsis fissa apresentou pico de densidade em agosto (1.380.952 org $/ \mathrm{m}^{3}$ ), representando a densidade numérica mais elevada da comunidade de rotíferos de todo o período amostrado; Trichocerca spp. ocorreu somente de janeiro a abril (Tabela 11; Figura 24). 


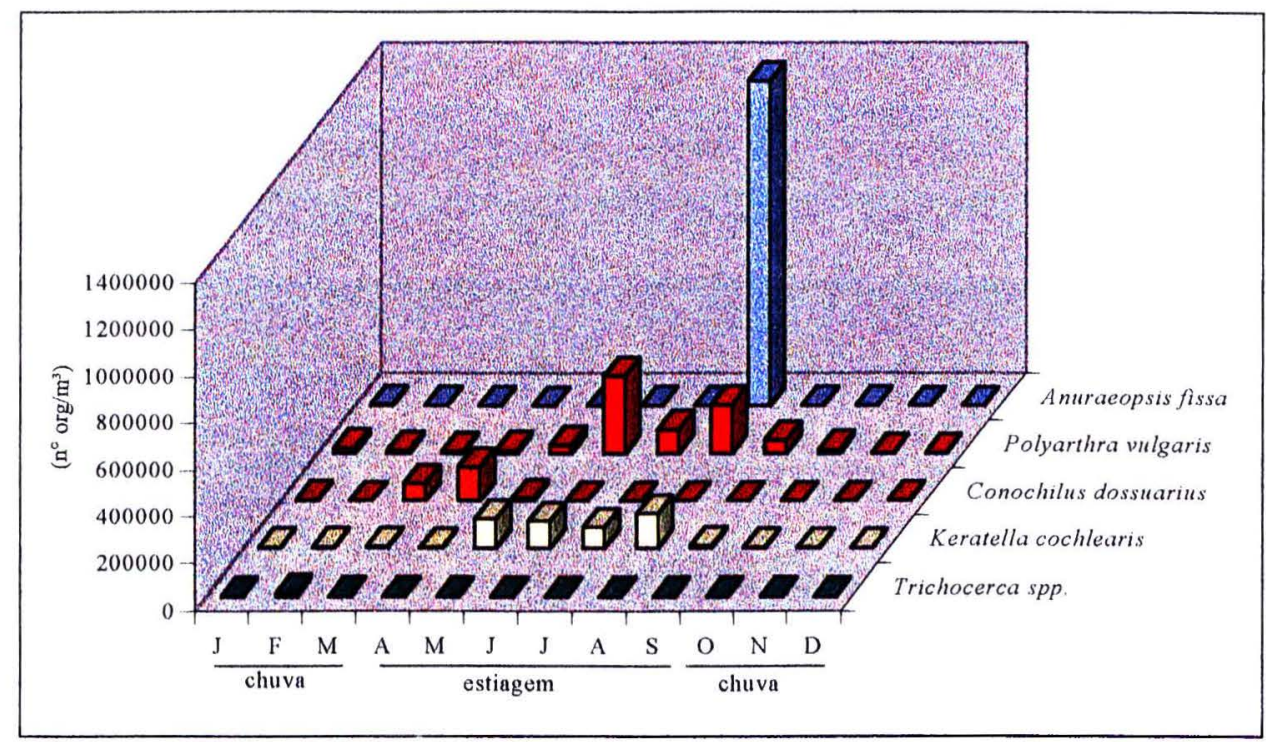

FIGURA 24 - Densidades numéricas de rotíferos $\left(\mathrm{n}^{\circ} \mathrm{org} / \mathrm{m}^{3}\right)$ no lago das Ninféias, de janeiro a dezembro de 1997.

Brachionus angularis chelonis e Keratella americana, no lago das Garças apresentaram densidades mais elevadas no período chuvoso-quente, ocorrendo o inverso com Anuraeopsis fissa, Keratella cochlearis, K. tecta, K. tropica e Polyarthra vulgaris; Polyarthra sp. só ocorreu no período de outubro a dezembro (Tabela 12; Figura 25).

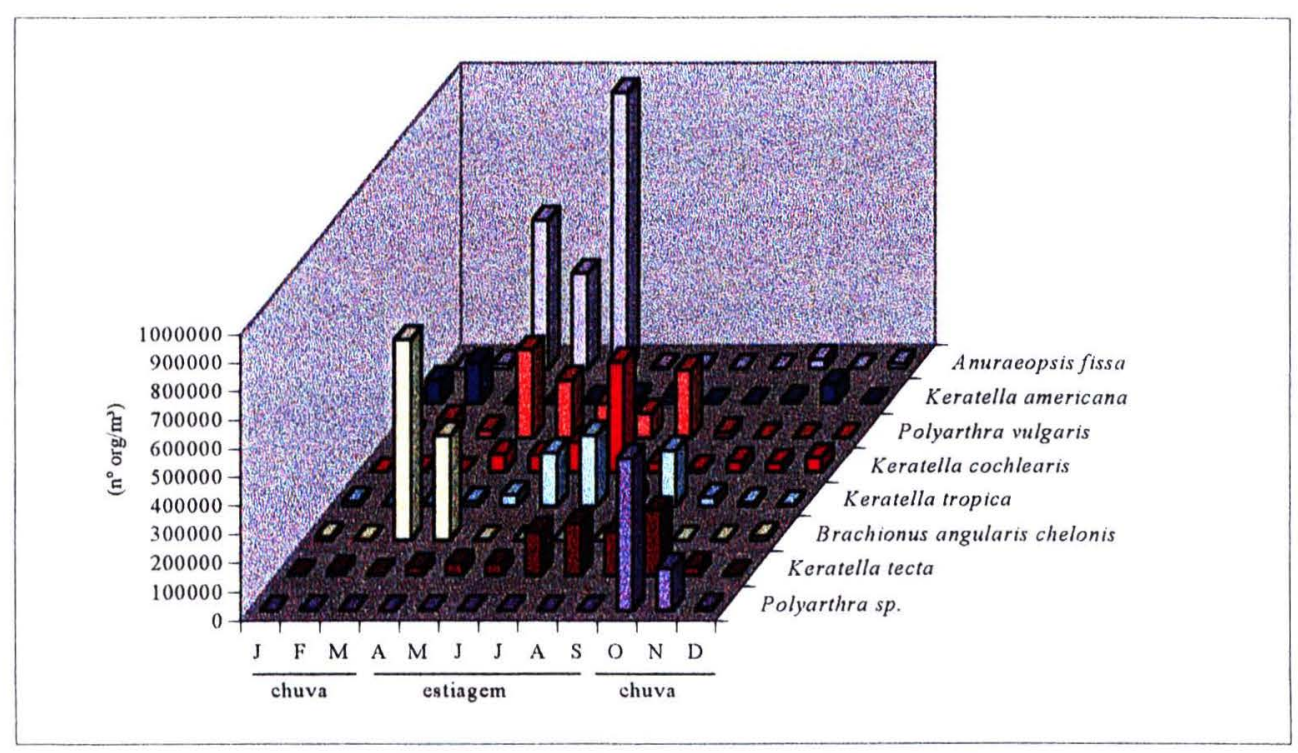

FIGURA 25 - Densidades numéricas de rotíferos $\left(\mathrm{n}^{\circ} \mathrm{org} / \mathrm{m}^{3}\right)$ no lago das Garças, de janeiro a dezembro de 1997. 
As densidades numéricas de copépodos ciclopóides foram mais elevadas no lago das Garças e mais baixas no lago das Ninféias; no lago do IAG constatou-se densidades intermediárias em relação aos demais corpos d'água considerados (Tabelas 7, 8 e 9; Figuras 20, 21 e 22).

No período estiagem-frio, no lago do IAG, os ciclopóides apresentaram as menores densidades numéricas. Um comportamento inverso foi observado nos lagos das Ninféias e Garças; densidades mais elevadas de ciclopóides foram registradas no periodo estiagem-frio.

Observou-se um predomínio de formas imaturas de ciclopóides nos três corpos d'água considerados; náuplios apresentaram densidades mais elevadas que copepoditos (Tabelas 10; 11 e 13; Figuras 26, 27 e 28).

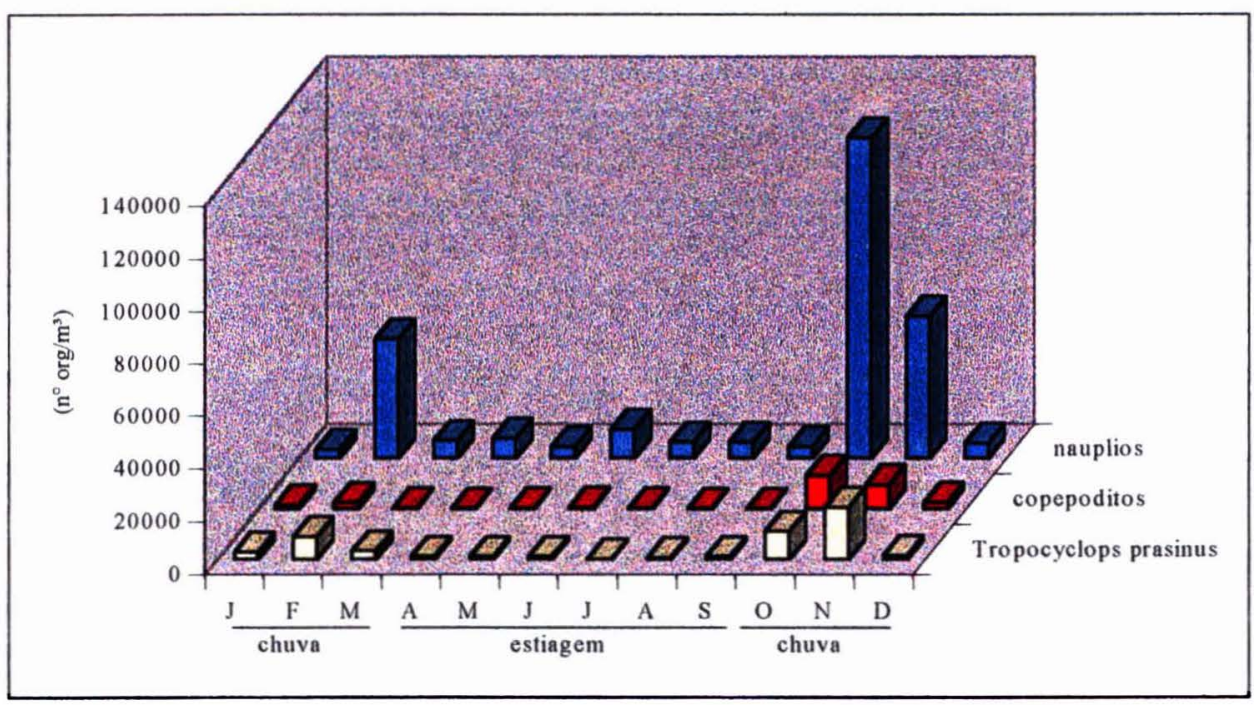

FIGURA 26 - Densidades numéricas de copépodos ciclopóides $\left(\mathrm{n}^{\circ} \mathrm{org} / \mathrm{m}^{3}\right)$, no lago do IAG, de janeiro a dezembro de 1997. 


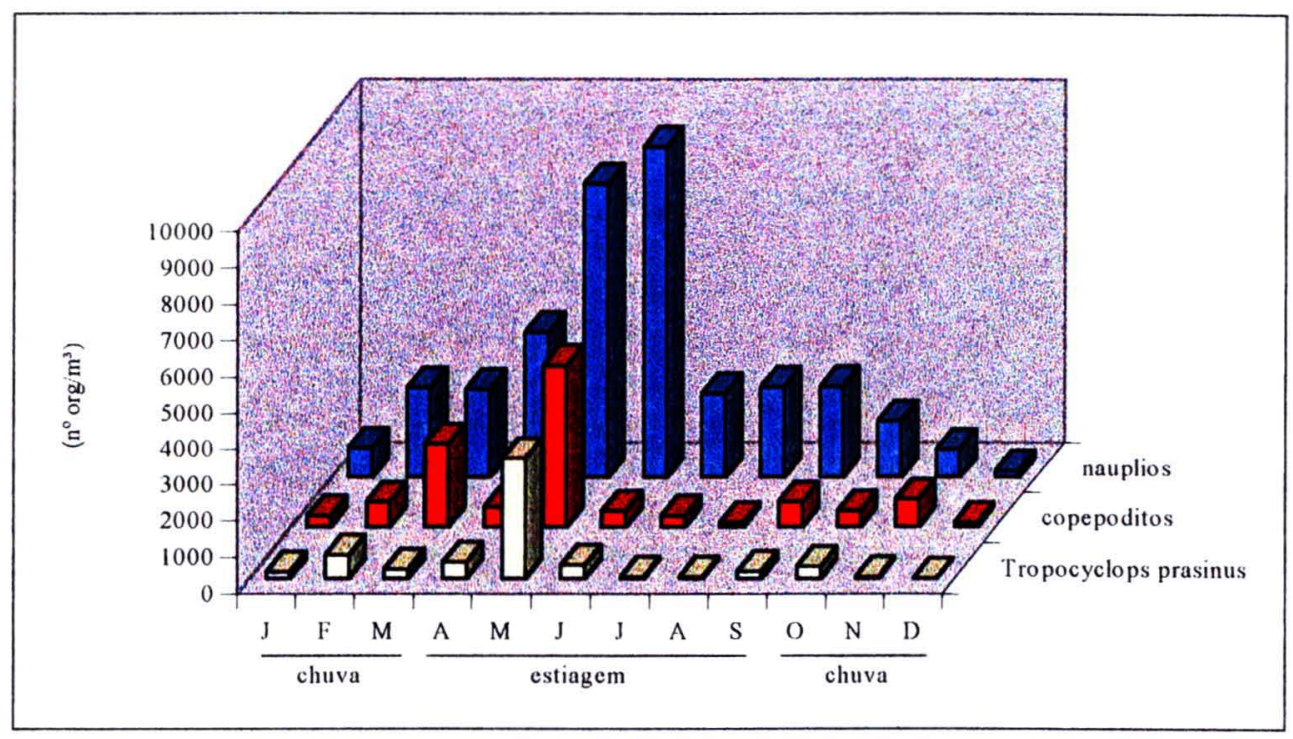

FIGURA 27 - Densidades numéricas de copépodos ciclopóides $\left(\mathrm{n}^{\circ} \mathrm{org} / \mathrm{m}^{3}\right)$, no lago das Ninféias, de janeiro a dezembro de 1997.

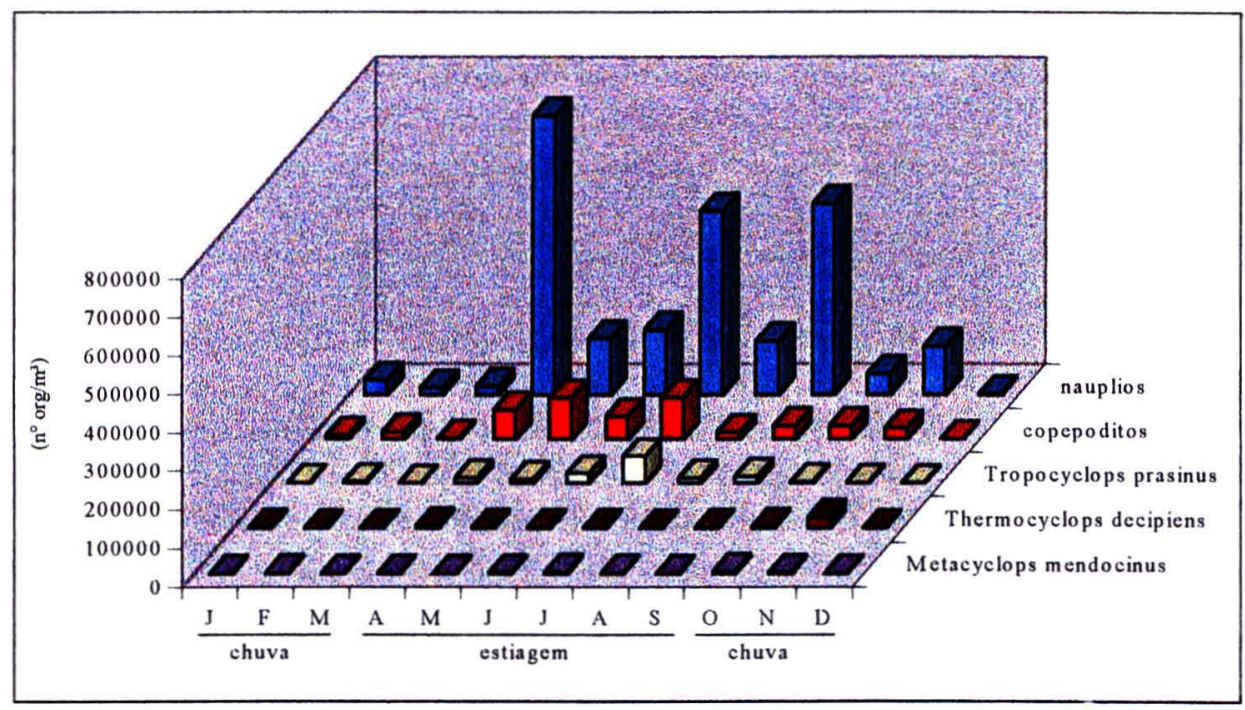

FIGURA 28 - Densidades numéricas de copépodos ciclopóides $\left(\mathrm{n}^{\circ} \mathrm{org} / \mathrm{m}^{3}\right)$, no lago das Garças, de janeiro a dezembro de 1997. 
Nos lagos do IAG e das Ninféias Tropocyclops prasinus predominou entre as formas adultas; no lago das Garças, T. prasinus, Thermocyclops decipiens e Metacyclops mendocinus apresentaram densidades numéricas semelhantes. Thermocyclops decipiens apresentou densidades mais elevadas no período chuvosoquente; já $M$. mendocinus não mostrou um comportamento sazonal de flutuação.

Quanto aos copépodos calanóides, Scolodiaptomus corderoi apresentou densidades mais elevadas nos lagos do IAG e Ninféias. Observou-se uma flutuação sazonal desta espécie somente no lago das Ninféias; densidades mais elevadas ocorreram no período estiagem-frio. No lago das Garças foi de ocorrência esporádica (Tabelas 7, 8 e 9; Figuras 20, 21 e 22).

Em geral, as formas larvais predominaram em relação aos adultos de $S$. corderoi (Tabelas 10 e 11; Figuras 29 e 30). No lago do IAG, náuplios apresentaram densidades mais elevadas que copepoditos, de janeiro a abril e novembro; $S$. corderoi apresentou pico de densidade em julho (9082 org $/ \mathrm{m}^{3}$ ), superando os valores de densidades das formas imaturas. Já no lago das Ninféias, náuplios e copepoditos desta espécie apresentaram densidades mais elevadas no período estiagem-frio, e os adultos predominaram somente nos meses de abril a junho.

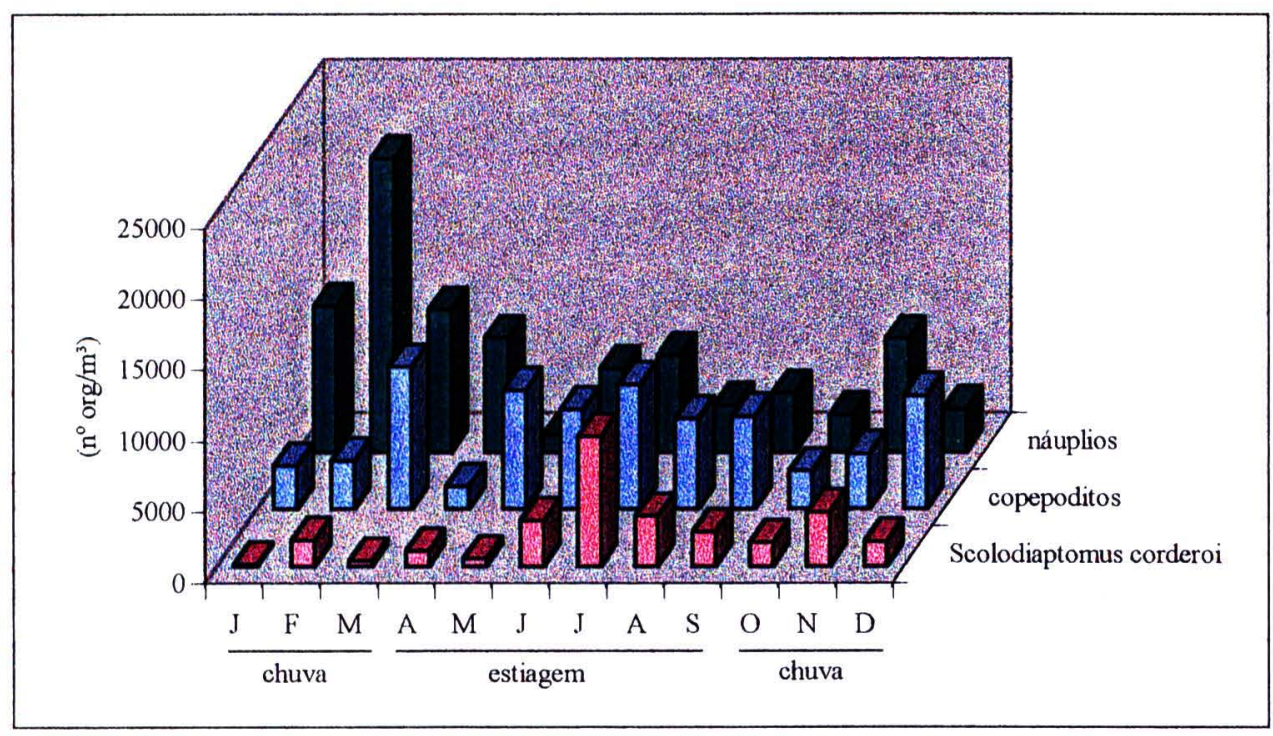

FIGURA 29 - Densidades numéricas de copépodos calanóides $\left(\mathrm{n}^{\circ} \mathrm{org} / \mathrm{m}^{3}\right)$ no lago do IAG, de janeiro a dezembro de 1997. 


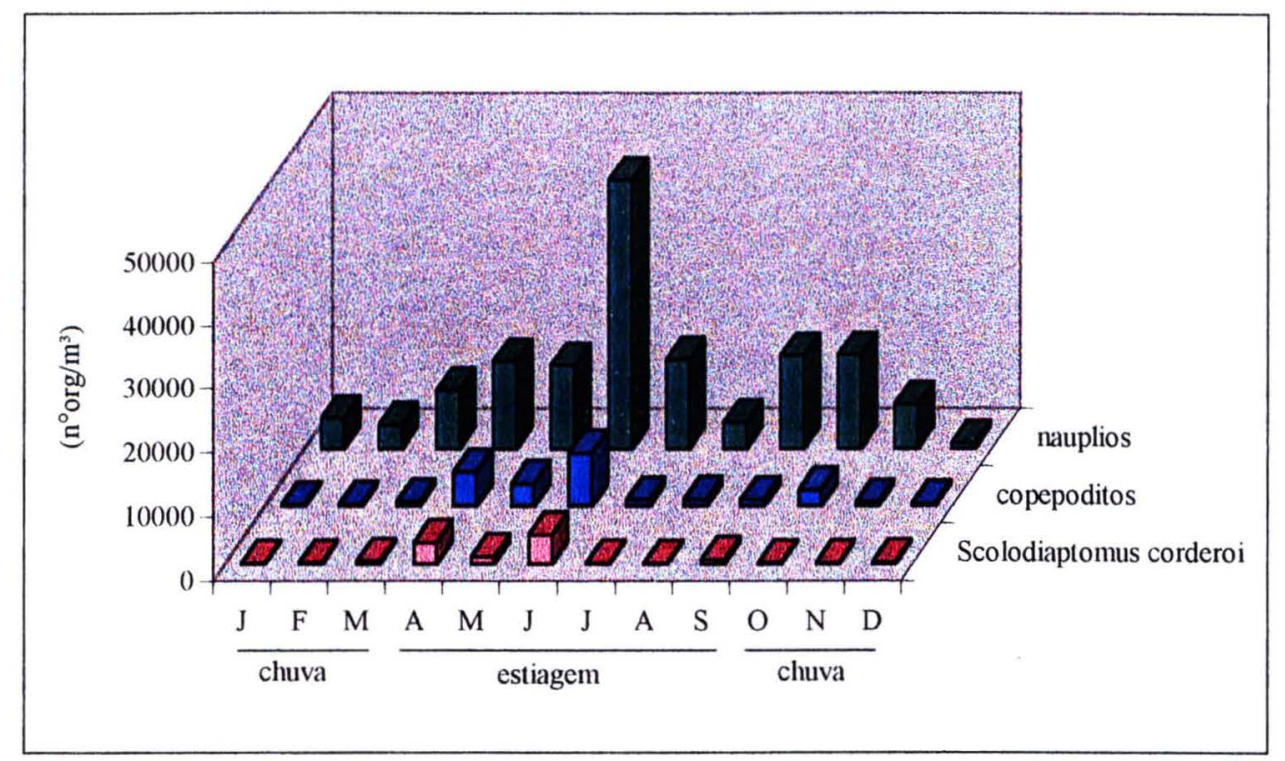

FIGURA 30 - Densidades numéricas de copépodos calanóides $\left(\mathrm{n}^{\circ} \mathrm{org} / \mathrm{m}^{3}\right)$ no lago das Ninféias, de janeiro a dezembro de 1997.

Os cladóceros apresentaram densidades mais elevadas no lago do IAG e mais baixas no lago das Ninféias; no lago das Garças foram registradas densidades intermediárias em relação aos demais corpos d'água estudados (Tabelas 7, 8 e 9; Figuras 20, 21 e 22). No período estiagem-frio, nos lagos do IAG e das Garças, os cladóceros apresentaram as mais elevadas densidades numéricas.

Bosminopsis deitersi, Bosmina hagmanni, B. tubicen, Daphnia ambigua e Diaphanosoma birgei apresentaram densidades mais elevadas no lago do IAG, e mais baixas no lago das Garças. No lago das Ninféias, foram registradas densidades intermediárias, em relação aos demais lagos considerados, para $B$. deitersi e $D$. ambigua, enquanto que as demais espécies não ocorreram neste corpo d'água. Moina micrura apresentou densidades numéricas mais elevadas no lago do IAG, intermediárias no lago das Garças, e foi de ocorrência esporádica no lago das Ninféias. 
No lago do IAG, Bosminopsis deitersi, Diaphanosoma birgei e Daphnia ambigua apresentaram picos de densidade no período estiagem-frio, respectivamente em setembro (43.633 org $\left./ \mathrm{m}^{3}\right)$, julho $\left(22.066 \mathrm{org} / \mathrm{m}^{3}\right)$, e também em julho $(57.526$ org $/ \mathrm{m}^{3}$ ). Quanto a Moina micrura, ocorreu exclusivamente neste mesmo período, apresentando densidade mais elevada em junho (36.898 org $/ \mathrm{m}^{3}$ ). A flutuação das densidades de Bosmina hagmanni e B. tubicen não mostrou relação aparente com os períodos chuvoso-quente e estiagem-frio (Tabela 10; Figura 31).

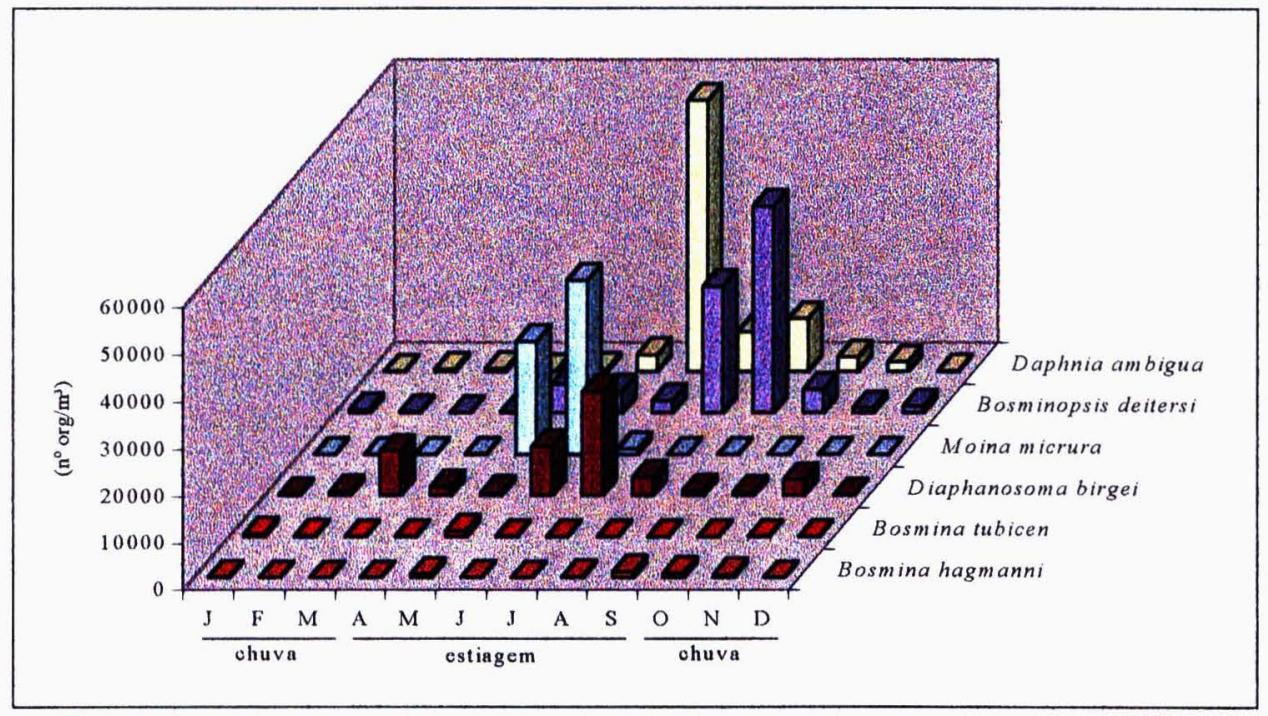

FIGURA 31 - Densidades numéricas de cladóceros $\left(\mathrm{n}^{\circ} \mathrm{org} / \mathrm{m}^{3}\right)$ no lago do IAG, de janeiro a dezembro de 1997.

No lago das Ninféias, densidades mais elevadas de $B$. deitersi foram registradas no período chuvoso-quente; já $D$. ambigua, em geral ocorreu praticamente no período estiagem-frio, com picos de densidade em maio e junho (Tabela 11; Figura 32).

No lago das Garças, D. ambigua e Daphnia gessneri apresentaram densidades elevadas no período estiagem-frio. Neste mesmo período, foram registrados picos de densidades de B. deitersi (setembro) e D. birgei (agosto e setembro) (Tabela 13; Figura 33). 


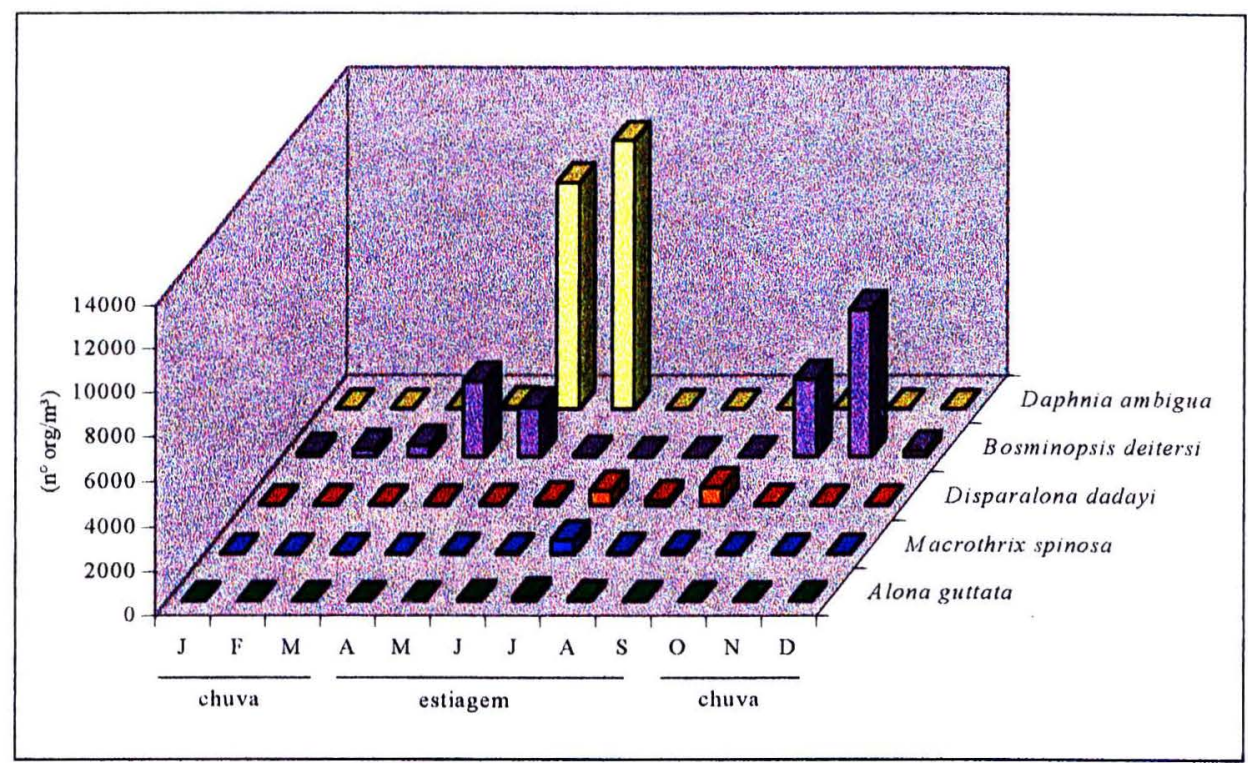

FIGURA 32 - Densidades numéricas de cladóceros $\left(\mathrm{n}^{\circ} \mathrm{org} / \mathrm{m}^{3}\right)$ no lago das Ninféias, de janeiro a dezembro de 1997.

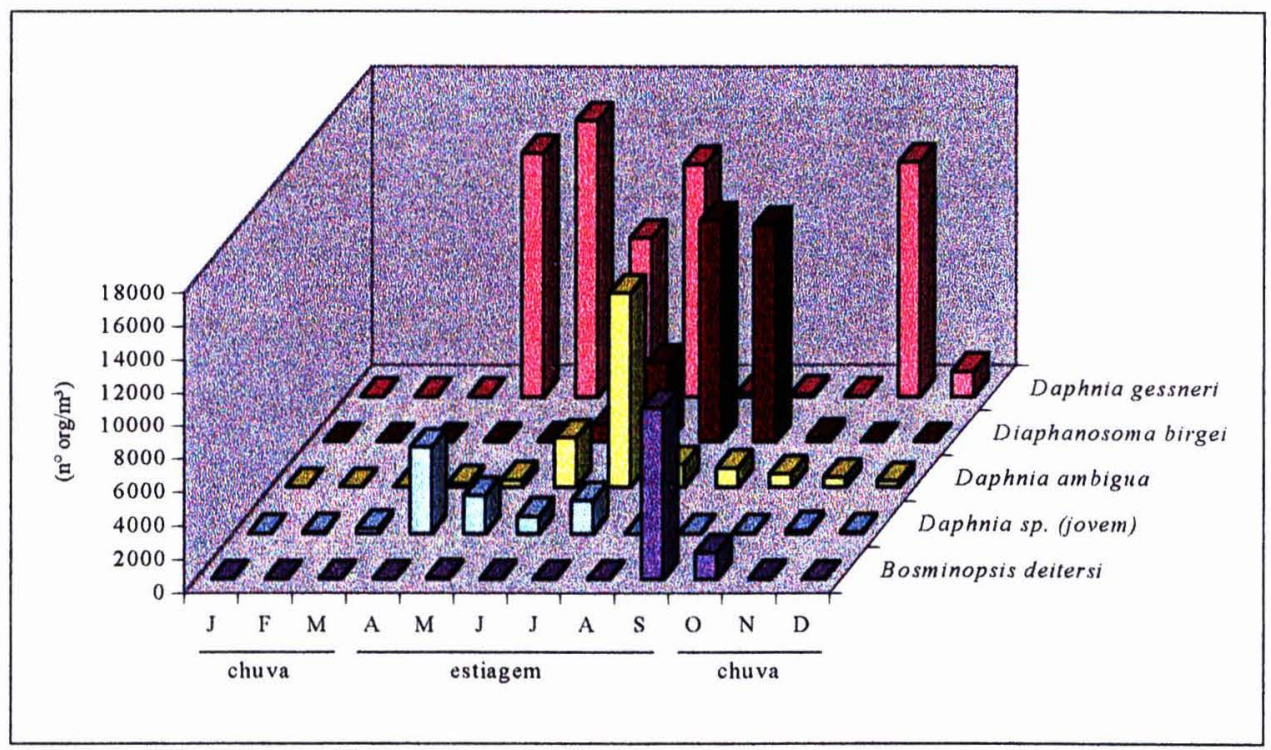

FIGURA 33 - Densidades numéricas de cladóceros $\left(\mathrm{n}^{\circ} \mathrm{org} / \mathrm{m}^{3}\right)$ no lago das Garças, de janeiro a dezembro de 1997. 
Larvas de Chaoboridae apresentaram densidades mais elevadas no lago das Garças; nos lagos do IAG e das Ninféias, as densidades foram semelhantes. Nos três corpos d'água estudados, as maiores densidades destes organismos foram registradas no periodo chuvoso-quente (Tabelas 10,11 e 13 ).

\subsubsection{Riqueza, equitatividade e diversidade}

A maior riqueza da comunidade zooplanctônica foi observada no lago das Garças ( 75 táxons); nos lagos do IAG e das Ninféias foram registrados um total de 46 e 48 táxons, respectivamente (Tabelas 5 e 6).

Em relação aos rotíferos, a mais elevada riqueza foi registrada também no lago das Garças (41), seguindo-se o lago das Ninféias (25) e do IAG (22). O gênero Trichocerca esteve representado pelo maior número de táxons (9), seguido por Brachionus (8), Keratella (5) e Hexarthra (4).

Quanto aos crustáceos, o maior número de táxons de copépodos ciclopóides foi observado no lago das Garças (6), seguido pelos lagos do IAG (4) e das Ninféias (3). A maior riqueza de cladóceros (28 táxons) também ocorreu no lago das Garças; nos lagos do IAG e das Ninféias foram registrados 20 táxons.

Os dados mensais de diversidade, equitatividade e riqueza, assim como suas médias nos lagos do IAG, das Ninféias e Garças encontram-se nas tabelas 14, 15 e 16 e figuras 34,35 e 36 . As médias anuais dos indices de diversidade, equitatividade e riqueza foram mais baixas no lago das Ninféias e mais elevadas no lago das Garças, e intermediárias no lago do IAG.

Os dados obtidos para o indice de diversidade variaram de 1,74 a 3,56 bits/ind no lago das Garças; nos lagos do IAG e Ninféias estiveram compreendidos entre 2,07 e 3,15 bits/ind, e entre 1,02 e 3,12 bits/ind, respectivamente.

Nos corpos d'água estudados, o padrão de flutuação dos valores de diversidade e equitatividade foi semelhante, evidenciando ser a equitatividade o componente principal da diversidade. Quando houve queda da diversidade, esta foi atribuída a um declínio da equitatividade, devido às densidades numéricas elevadas de certos táxons, dependendo do lago considerado. 


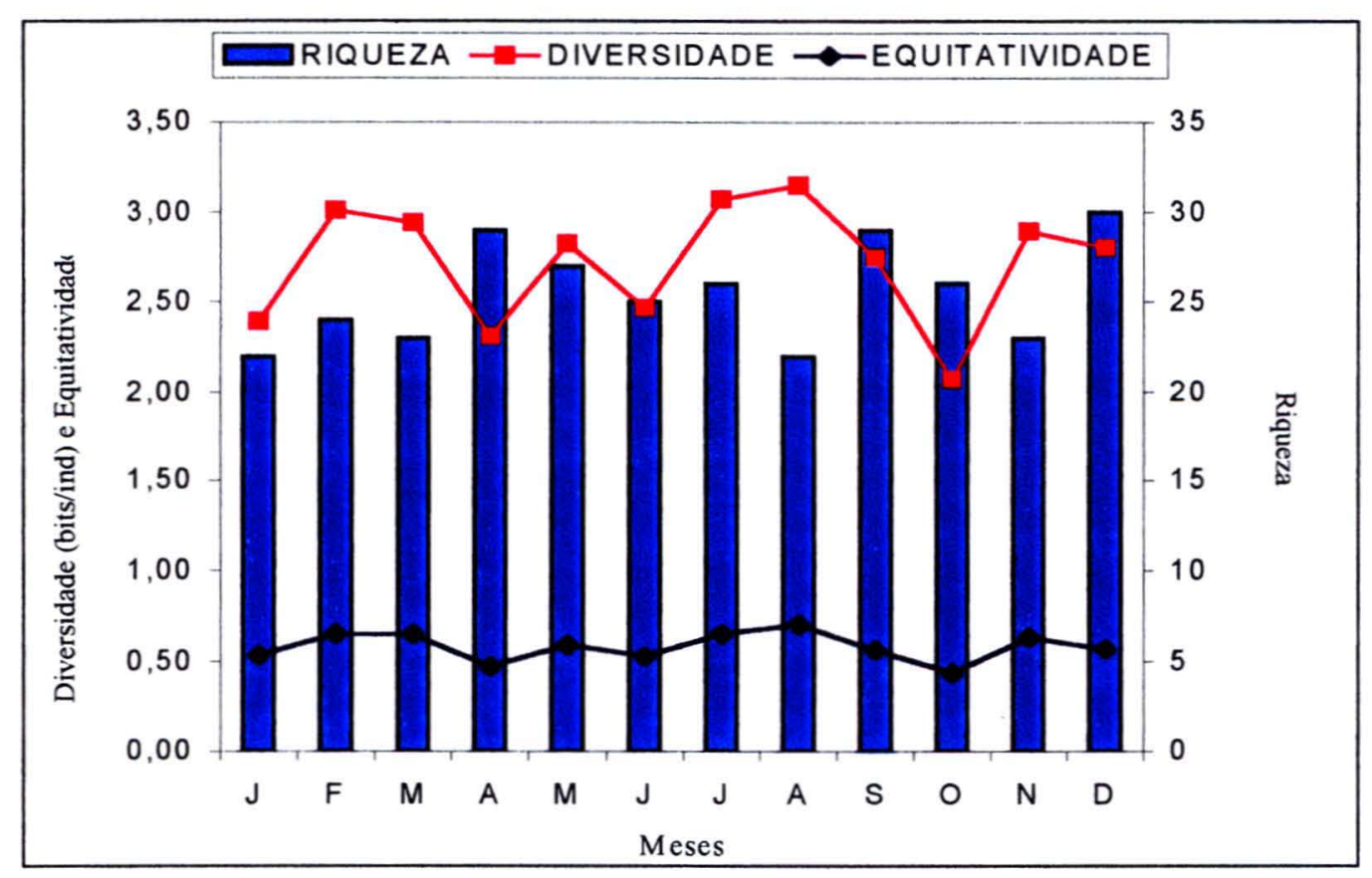

FIGURA 34 - Valores médios de diversidade (bits/ind), equitatividade e riqueza da comunidade zooplanctônica no lago do IAG, de janeiro a dezembro de 1997.

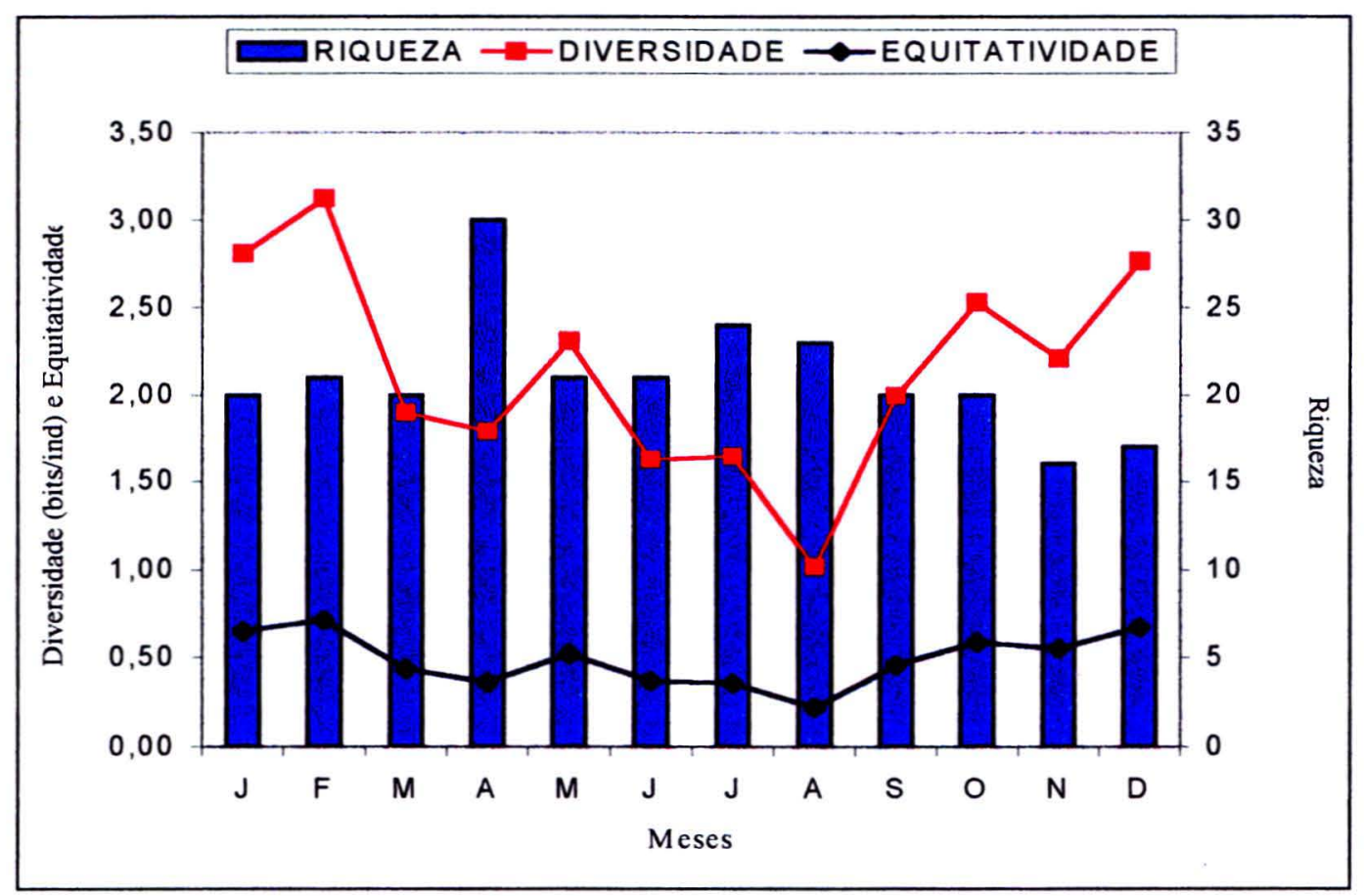

FIGURA 35 - Valores médios de diversidade (bits/ind), equitatividade e riqueza da comunidade zooplanctônica no lago das Ninféias, de janeiro a dezembro de 1997. 


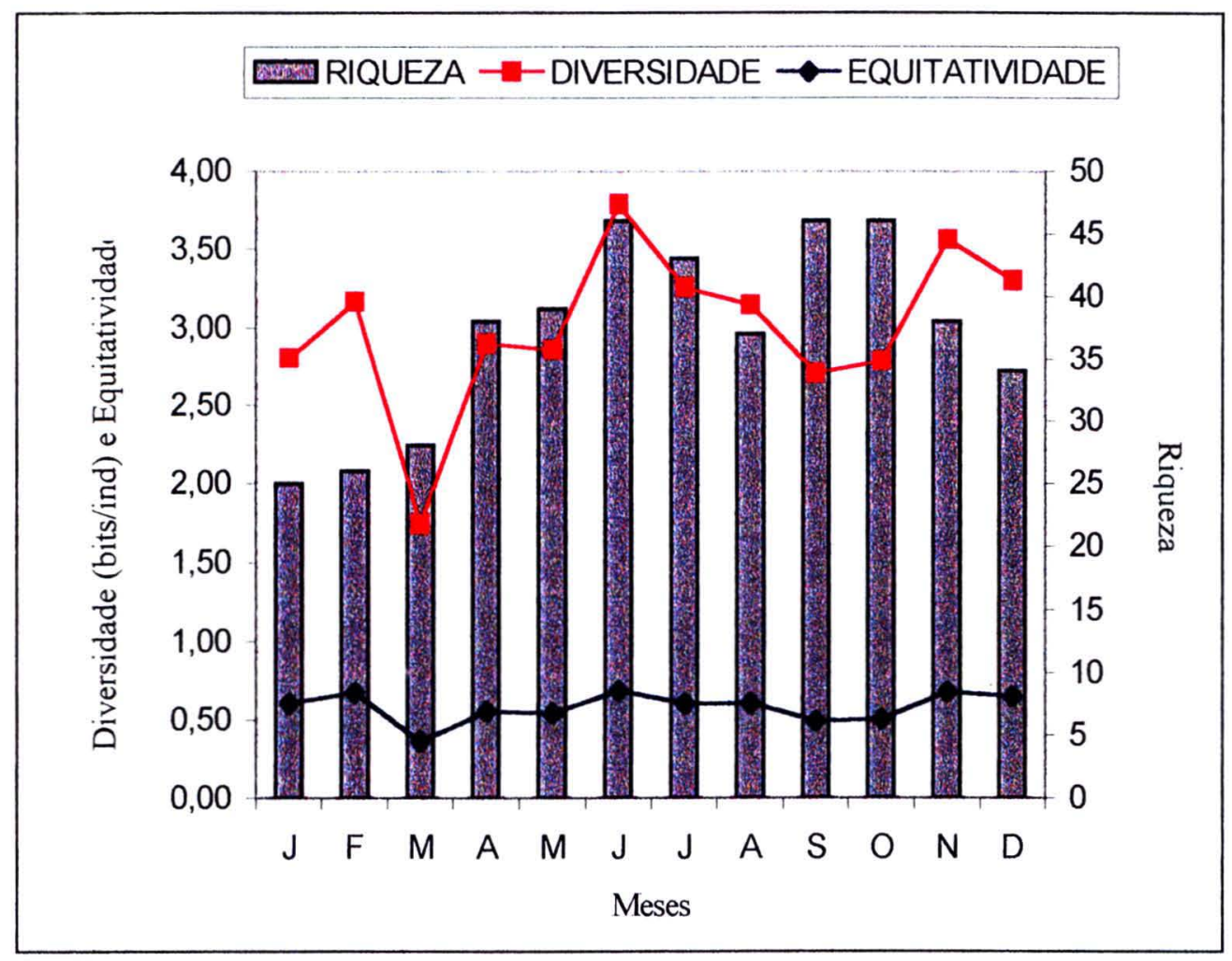

FIGURA 36 - Valores médios de diversidade (bits/ind), equitatividade e riqueza da comunidade zooplanctônica no lago das Garças, de janeiro a dezembro de 1997.

No lago do IAG, os menores valores de diversidade e equitatividade ocorreram em outubro/97, quando se registrou picos de densidades numéricas de Conochilus dossuarius e náuplios de ciclopóides. Declínios de diversidade e equitatividade também coincidiram, no lago das Ninféias, com densidade numérica elevada de Anuraeopsis fissa em agosto/97, e no lago das Garças com picos de densidade numérica de Brachionus angularis chelonis, em março/97.

\subsubsection{Análise multivariada}

Os resultados da análise de componentes principais da matriz de correlação das variáveis físicas (profundidade e transparência da água), químicas (oxigênio dissolvido, $\mathrm{pH}$, condutividade elétrica, sólidos totais em suspensão, turbidez, 
nitrogênio e fósforo totais) e biológica (clorofila $a$ total) dos lagos do IAG, Ninféias e Garças, evidenciaram dois eixos responsáveis por $75,3 \%$ da variância total dos dados.

A figura 3 representa o plano fatorial 1-2, onde encontram-se representados os vetores-variáveis ambientais e os 36 pontos-observações referentes a amostragens mensais efetuadas em cada lago estudado, nos períodos chuvoso-quente e estiagemfrio.

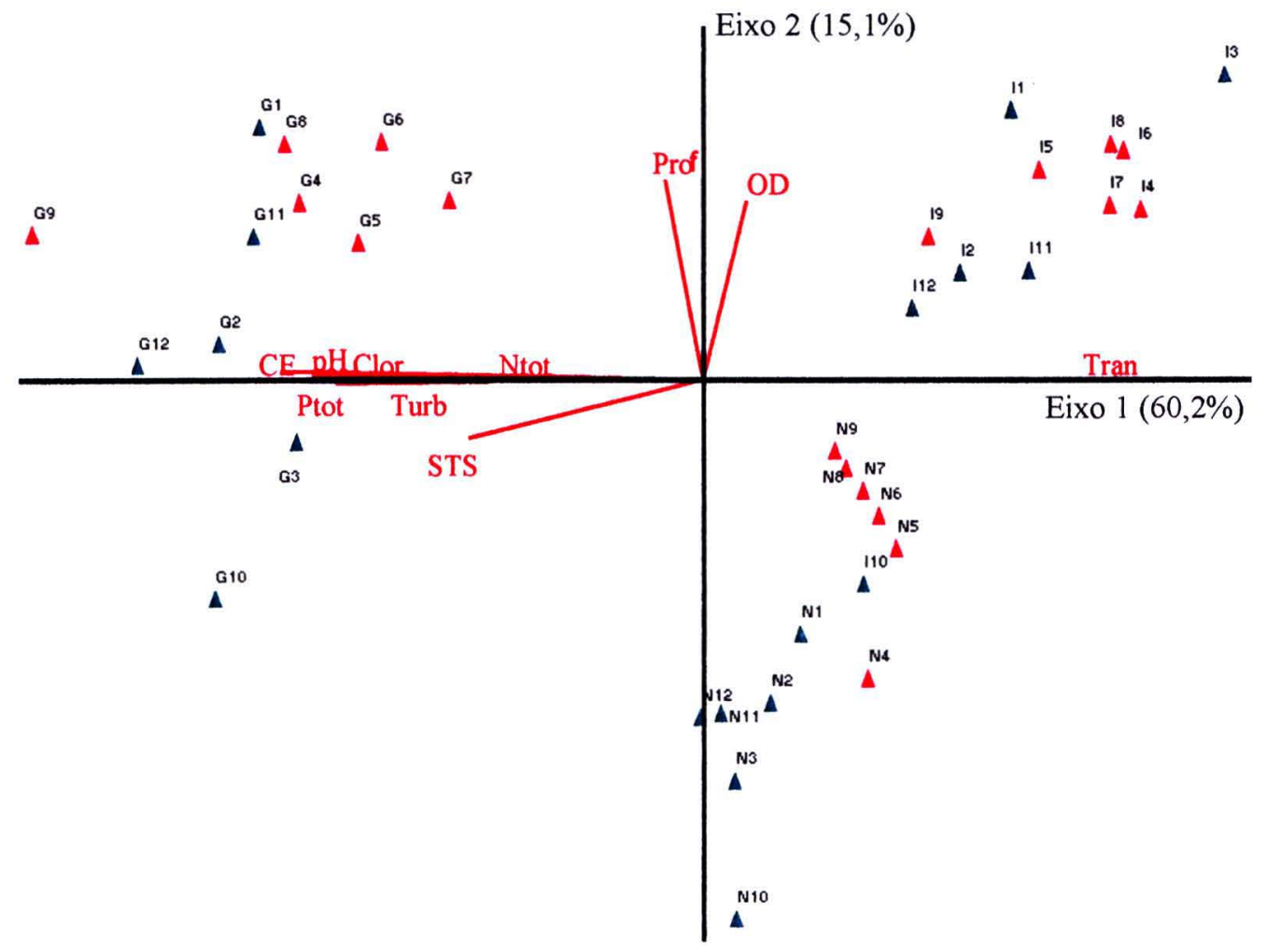

$\Delta$ Período chuvoso-quente

$\Delta$ Período estiagem-frio

FIGURA 37 - Biplot da ACP para as variáveis físicas, químicas e biológicas nos lagos do IAG (I), das Ninféias (N) e Garças (G), de janeiro (1) a dezembro (12) de 1997 (abreviações conforme tabela 17). 
O eixo 1, que explica $60,2 \%$ da variància dos dados, está formado positivamente pela transparència da água $(\mathrm{r}=0,903)$. Negativamente, o eixo é formado pelas contribuições da condutividade elétrica $(r=-0,952)$, fósforo total $(r=$ $-0,934), \quad \mathrm{pH}(\mathrm{r}=-0,898), \quad$ clorofila $a(\mathrm{r}=-0,890)$, turbidez $(\mathrm{r}=-0,870)$, sólidos totais em suspensão $(r=-0,694)$ e nitrogênio total $(r=-0,649)$ (Tabela 17).

A distribuição dos pontos-observações evidenciou que as amostragens que correspondem ao lago das Garças encontram-se associadas negativamente ao eixo 1 , e as do lago do IAG, positivamente. Este eixo representa um gradiente nas condiçð̃es tróficas, separando o lago das Garças, eutrófico, do lago do IAG, oligotrófico.

O eixo 2, com $15,1 \%$ da variância explicada, é formado pelas contribuições positivas da profundidade $(r=0,807)$ e oxigênio dissolvido $(r=0,767)$ (Tabela 17). Pela distribuição dos pontos-observações verificou-se que os pontos associados positivamente ao eixo 2 correspondem aos lagos do IAG e das Garças, que apresentaram valores mais elevados de profundidade e oxigênio dissolvido; valores mais baixos destas variáveis ocorreram no lago das Ninféias, cujos pontos se situaram na extremidade oposta deste eixo. Constatou-se que os pontos-observações referentes ao período chuvoso-quente no lago das Ninféias estão associados a este eixo, devido a valores mais baixos de oxigênio dissolvido que aí ocorreram.

A análise de agrupamento aplicada aos 32 táxons mais frequentes, nas 36 amostras analisadas, encontra-se na figura 38 , e evidenciou os seguintes grupos com maiores afinidades ecológicas:

GRUPO A: Ascomorpha ecaudis (Aeca), Daphnia ambigua (Damb), Ascomorpha saltans (Asal), náuplios e copepoditos de calanóides (naCa e coCa), Scolodiaptomus corderol (Scor), Diaphanosoma birget (Dbir) e Bosminopsis deiterst (Bdei).

GRUPO B: (ollotheca sp. (Cosp), Keratella cochlearis (Kco), Polyarthra vulgaris (Pvul), Keratella tecta (Kcot), Keratella tropica (Ktro), náuplios e copepoditos de ciclopóides (naCy e coCy) e Tropocyclops prasinus (Tpra).

GRUPO C: Metacyclops mendocinus (Mmen), Thermocyclops decipiens (Tdec), Daphnia gessnerl (Dges) e Daphnia sp. (Dasp).

GRUPO D: Anuraeopsis fissa (Afis) e Brachionus angularis chelonis (Banc). 
GRUPO E: Alona guttata (Agut), Disparalona dadavi (Dida) e Macrothrix spinosa (Mspi).

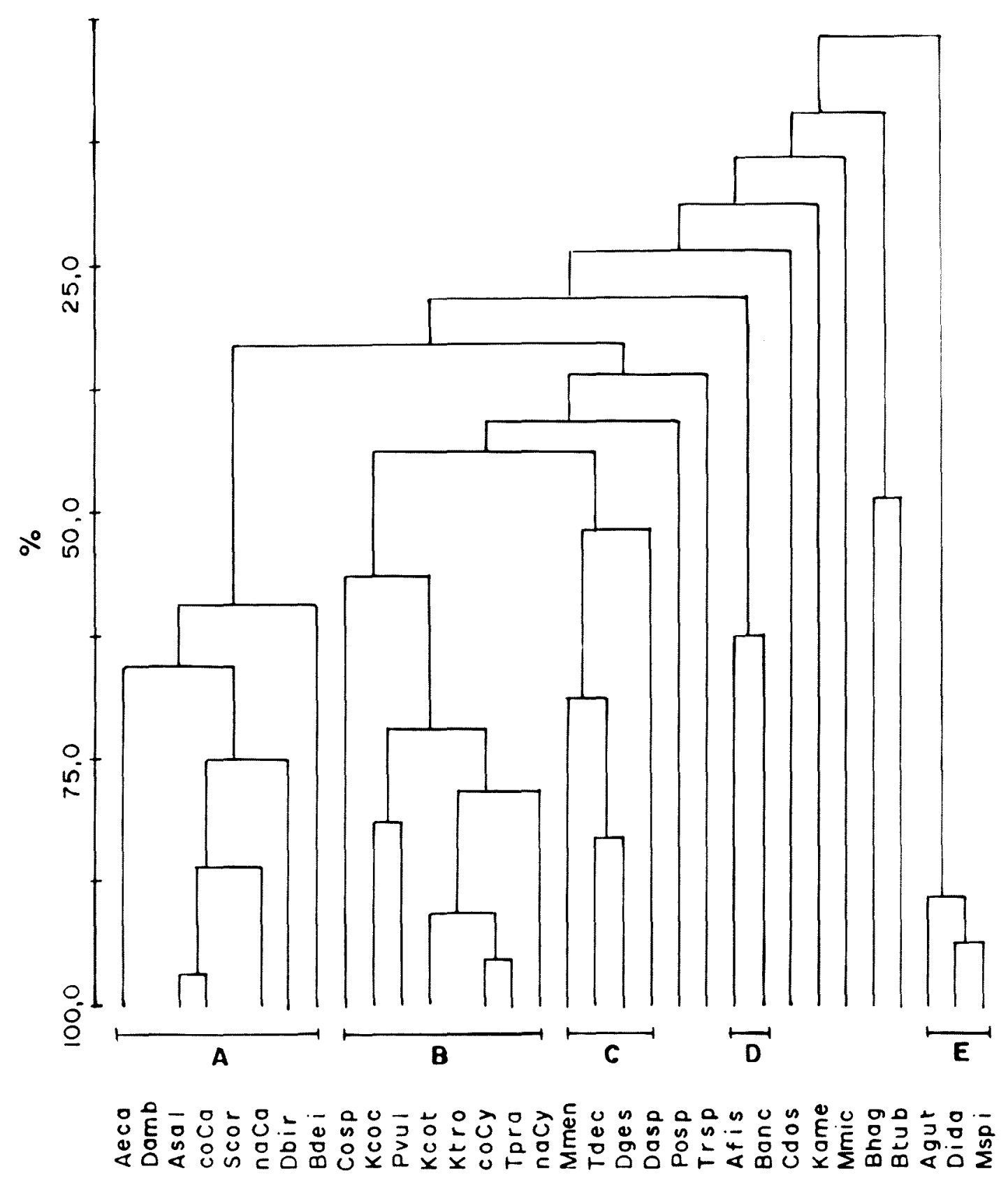

FIGURA 38 - Dendrograma da análise de agrupamento dos táxons da comunidade zooplanctônica nos lagos do IAG. das Ninféias e Garças. 
O grupo A foi composto por 6 táxons mais importantes nos lagos do IAG e Ninféias; 2 táxons ocorreram exclusivamente no lago do IAG (Ascomorpha ecaudis e A. saltans). O grupo B foi constituido por táxons que, apesar de serem registrados nos três lagos estudados, apresentaram densidades numéricas mais elevadas no lago das Garças. Keratella tecta e $K$. tropica ocorreram exclusivamente no lago das Garças.

Os grupos $\mathrm{C}$ e $\mathrm{D}$ também foram compostos por táxons que ocorreram exclusivamente no lago das Garças, com exceção de Anuraeopsis fissa, registrado também no lago das Ninféias. $\mathrm{O}$ grupo $\mathrm{E}$ foi constituido por cladóceros não euplanctônicos, que apresentaram densidades numéricas mais elevadas no lago das Ninféias.

A análise fatorial de componentes principais da matriz de correlação dos valores de densidades numéricas de 20 táxons mais frequentes da comunidade zooplanctônica, para um total de 36 observaç̃es ( 12 correspondentes a cada lago estudado) encontra-se na figura 39.

Os dois primeiros eixos foram responsáveis por $73,3 \%$ da variância total dos dados. O primeiro componente (eixo 1), com $46,9 \%$ da variância total explicada, é formado positivamente por alguns táxons que compõem o grupo $\mathrm{A}$, tais como náuplios e copepoditos de calanóides $(r=0,955$ e $r=0,874$, respectivamente), Scolodiaptomus corderoi $(\mathrm{r}=0,738)$ e Bosminopsis deitersi $(\mathrm{r}=0,601)$ (Tabela 18). Os pontos-observações que correspondem aos lagos do IAG e Ninféias encontram-se também associados positivamente ao eixo 1 , indicando que estes táxons atingiram densidades numéricas mais elevadas nestes corpos d'água.

Keratella tropica $(\mathrm{r}=-0,972)$, K. tecta $(\mathrm{r}=-0,971)$, Thermocyclops decipiens $(r=-0,943)$, Metacyclops mendocinus $(r=-0,878)$, Daphnia gessneri $(r=$ - 0,833), náuplios e copepoditos de ciclopóides $(r=-0,747$ e $r=-0,818$, respectivamente), A. fissa $(\mathrm{r}=-0,716)$ e Brachionus angularis chelonis $(\mathrm{r}=-0,639)$ associaram-se negativamente ao eixo 1 (Tabela 18), onde também se projetam os pontos-observações que se relacionam ao lago das Garças. Tais táxons apresentaram densidades mais elevadas no lago das Garças e mais baixas ou ausência nos lagos do IAG e Ninféias. 


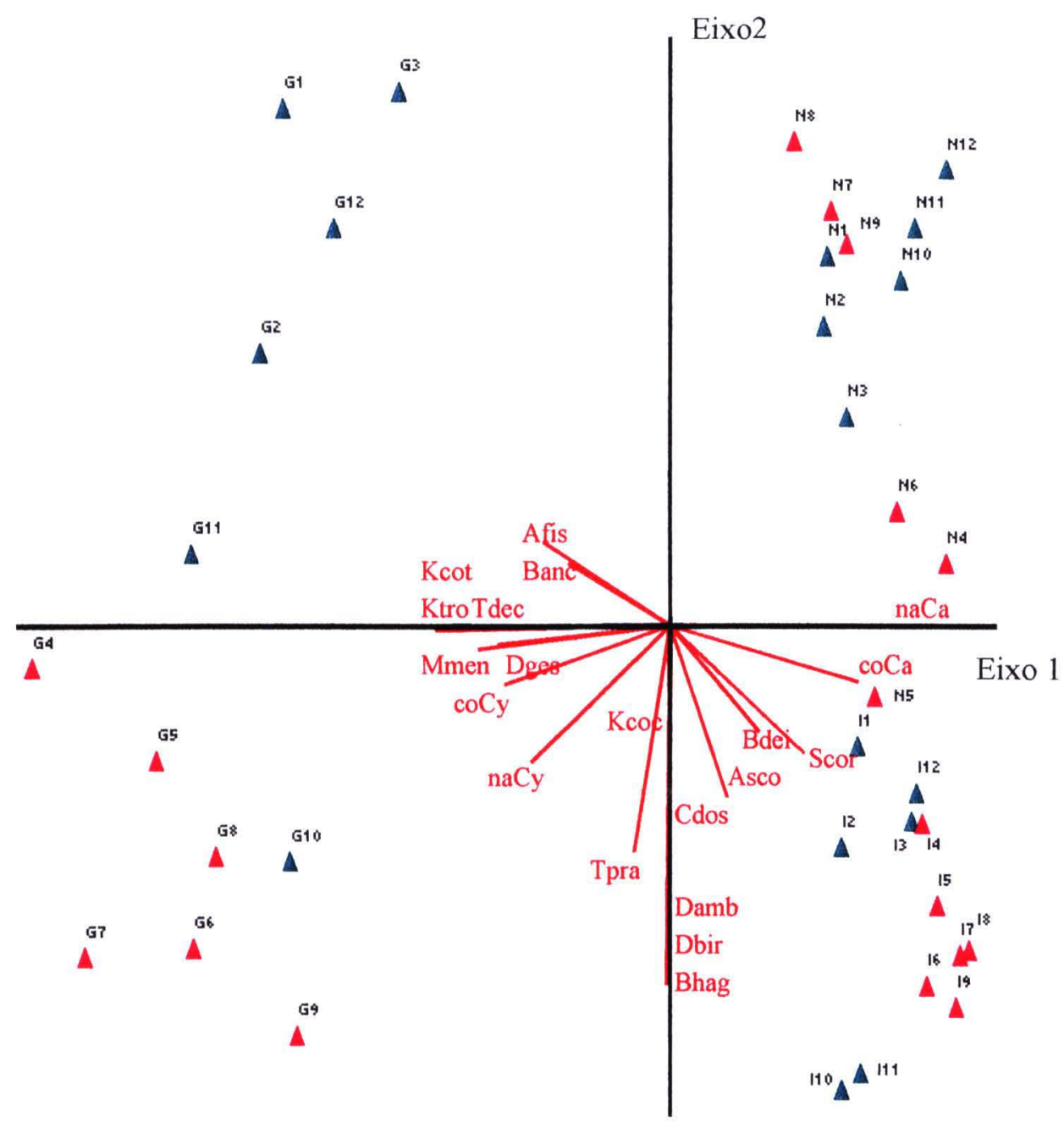

- Período chuvoso-quente

$\Delta$ Período estiagem-frio

FIGURA 39 - Biplot da ACP para as densidades numéricas dos táxons da comunidade zooplanctônica, nos lagos do IAG (I), das Ninféias (N) e Garças (G), de janeiro (1) a dezembro (12) de 1997 (abreviações conforme tabela 18). 
Como o eixo 1 é responsável pela maior explicabilidade dos dados, pode-se evidenciar, em relação à comunidade zooplanctônica, que a maior diferença entre os lagos estudados está relacionada com as variações das densidades numéricas desses 13 táxons.

O eixo 2, explicando $26,5 \%$ da variância dos dados, é formado pelas coordenadas negativas de Bosmina hagmanni $(\mathrm{r}=-0,883)$, Diaphanosoma birgei $(\mathrm{r}=$ - 0,877), Duphnia ambigua $(\mathrm{r}=-0,848)$, Tropocyclops prasinus $(\mathrm{r}=-0,698)$, Conochilus dossuarius $(\mathrm{r}=-0,656)$, Ascomorpha spp. $(\mathrm{r}=-0,609)$, náuplios de Cyclopoida $(\mathrm{r}=-0,540)$, Scolodiaptomus corderot $(\mathrm{r}=-0,526)$ e Keratella cochlearis $(\mathrm{r}=-0,520)($ Tabela 18$)$.

\subsubsection{Ocorrência de espécies zooplanctônicas e estado trófico das Unidades de Gerenciamento de Recursos Hídricos (UGRHI) do Estado de São Paulo}

A tabela 19 mostra a relação dos autores e ano de publicação dos estudos realizados sobre a comunidade zooplanctônica nos corpos d'água das Unidades de Gerenciamento de Recursos Hídricos (UGRHI) do Estado de São Paulo.

As tabelas 20 a 23 , mostram a ocorrência de espécies zooplanctônicas, as concentrações de clorofila $a$ total $(\mu \mathrm{g} / \mathrm{L})$, e dados do Índice de Estado Trófico (IET) de Carlson modificado, em cada corpo d'água, com o respectivo autor e época de estudo, por Unidade de Gerenciamento de Recursos Hídricos (UGRHI) considerada. As tabelas 24 e 25 mostram o número de identificação de espécies zooplanctônicas registradas nas UGRHIs, e as figuras 40 a 77 a ocorrência destas espécies e sua relação à qualidade da água.

\section{UGRHI 02 - PARAÍBA DO SUL}

Na UGRHI do rio Paraíba do Sul estão localizados os reservatórios de Paraibuna, Santa Branca, Borba, Itapeva e Funil.

Em relação aos rotíferos, no reservatório de Paraibuna foram registrados Brachonus angularis, Filinia pejleri. Trichocerca capucina. T. pusilla. T. similis, entre outras (Tabela 20; Figura 40). 
Thermocyclops dectpiens foi registrado no primeiro estudo realizado neste reservatorio, e posteriomente, foi evidenciada a co-ocorrência de Thermocyclops minutus e T. decipiens, juntamente com Mesocyclops meridianus. Scolodiaptomus corderot representou os calanóides inicialmente neste reservatório, sendo substituido por Odontodiaptomus paulıstanus posteriormente (Tabelas 21, 22, Figura 41).

Quanto aos cladóceros, no primeiro estudo efetuado em Paraibuna foram registradas Bosminopsis deiterst e ceriodaphnia cornuta; posteriomente, foi evidenciado o aparecimento de Bosmina hagmanni. B. longirostris. Ceriodaphnia reliculata. Daphnia ambigua, D. gessneri, Diaphanosoma birgei e Moina minuta (Tabela 23; Figura 41).

Em relação aos demais corpos d'água desta UGRHI, foi verificado que $T$. decipiens foi registrado em Santa Branca, Borba, Itapeva e Funil, e a co-ocorrència de $T$. decipiens a Metacyclops mendocinus, e Mesocyclops longisetus, foi evidenciada nos reservatórios de Funil e Itapeva. Esta última espécie também ocorreu em Santa Branca e Borba (Tabela 21; Figura 41). A co-ocorrència de $T$. deciptens e T. minutus foi constatada nos reservatórios Borba e Funil, e neste último também foi registrada Tropocyclops prasinus.

Quanto aos calanoides, Notodiaptomus theringt foi registrada nos reservatorios de Itapeva e Funil, O. paulistanus em Santa Branca, e no reservatório de Jaguari só ocorreu S. corderoi (Tabela 22; Figura 41).

Bosminopsis detters ocorreu em Santa Branca, Borba, Itapeva e Funil, C. cornuta, D. gessnert e 1 . hirget em Borba, Itapeva e Funil, e M. minuta ocorreu em Itapeva e Funil. Já no reservatório Jaguari, as únicas espécies registradas foram $C$. cornuta e ('. retkulata (Tabela 23; Figura 41).

Quanto ao estado trofico, o IET nesta UGRHI variou de 58,8 (Paraibuna) a 68,7 (Itapeva); jả para o reservatório do Borba, este indice não foi determinado devido à ausência de dados de clorofila a (Tabelas 20 a 23; Figuras 40; 41 ). 


\section{LFGENDA}

IFT $<4$

$44<$ IET $<54$

$54<$ IET $<64$

$64 \div$ IET $<74$

$74 \div$ IET $\div 84$

IFT $>84$

IET NÃo DE TERNIINADO

LIITE DE UGRHI
$\ldots$ IMITE INTERESTADUAL
CURSO D AGUA
LAGO OU RESERVATÓRIO

LAGO OU RESERVATÓRIO

SEDE MUUMTIPAL

FONTE SMIA (1999)

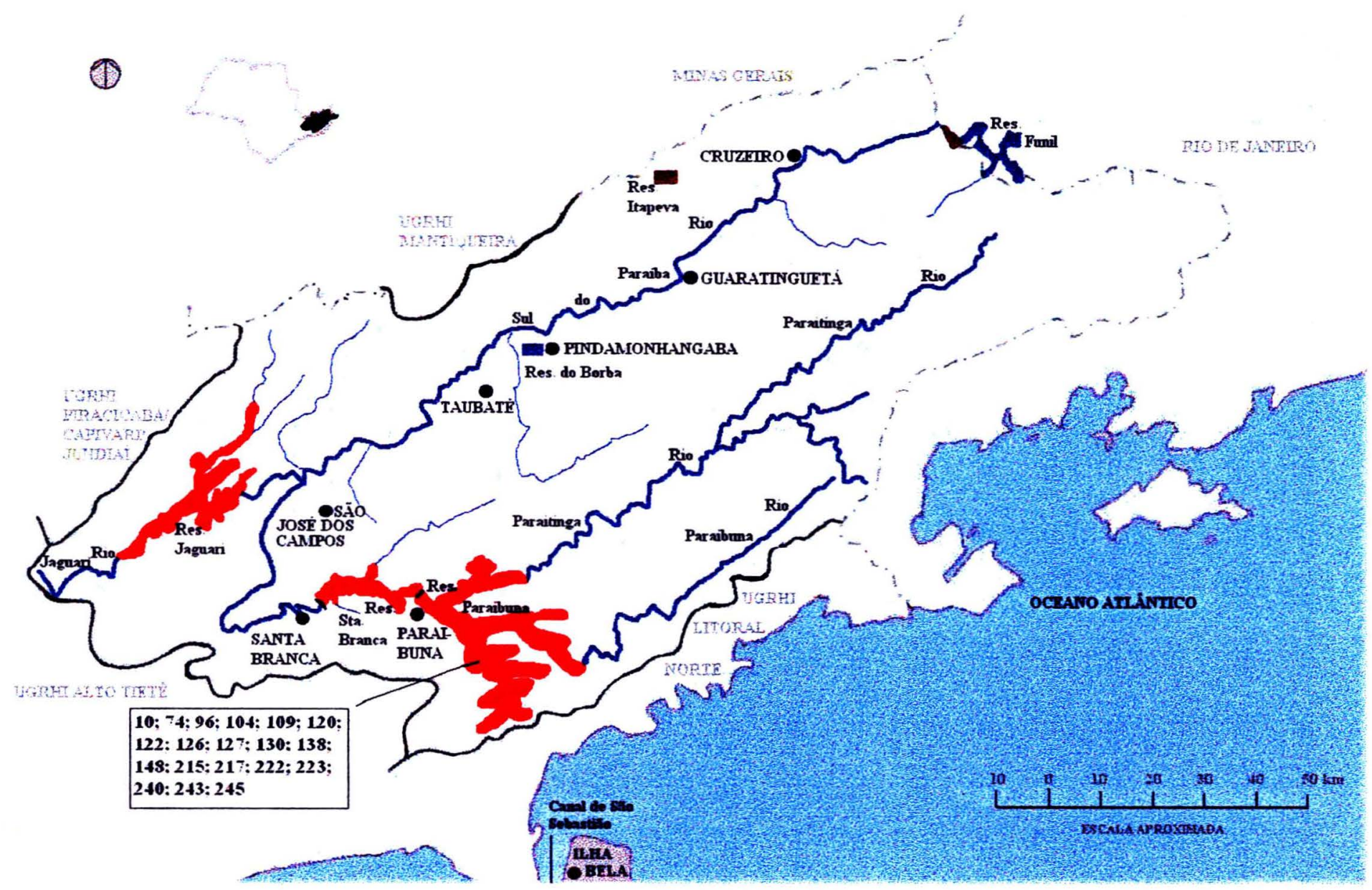

FIGURA 40 - Ocorrência de rotíferos e Índice de Estado Trófico (IET) de Carlson modificado do reservatório Paraibuna (UGRHI 02 Paraíba do Sul) (Números representam as espécies que constam na tabela 24). 


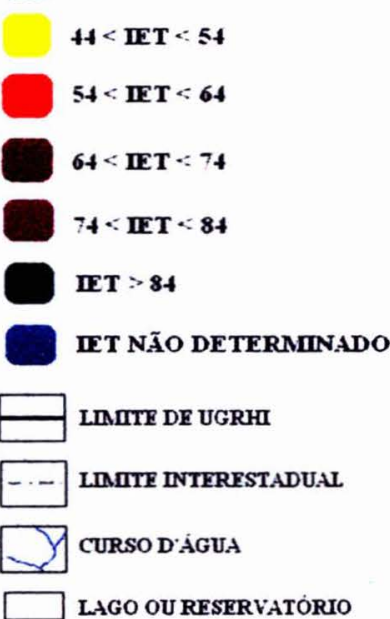

SEDF MUNICPAI.

FONTE: SMA (1999)

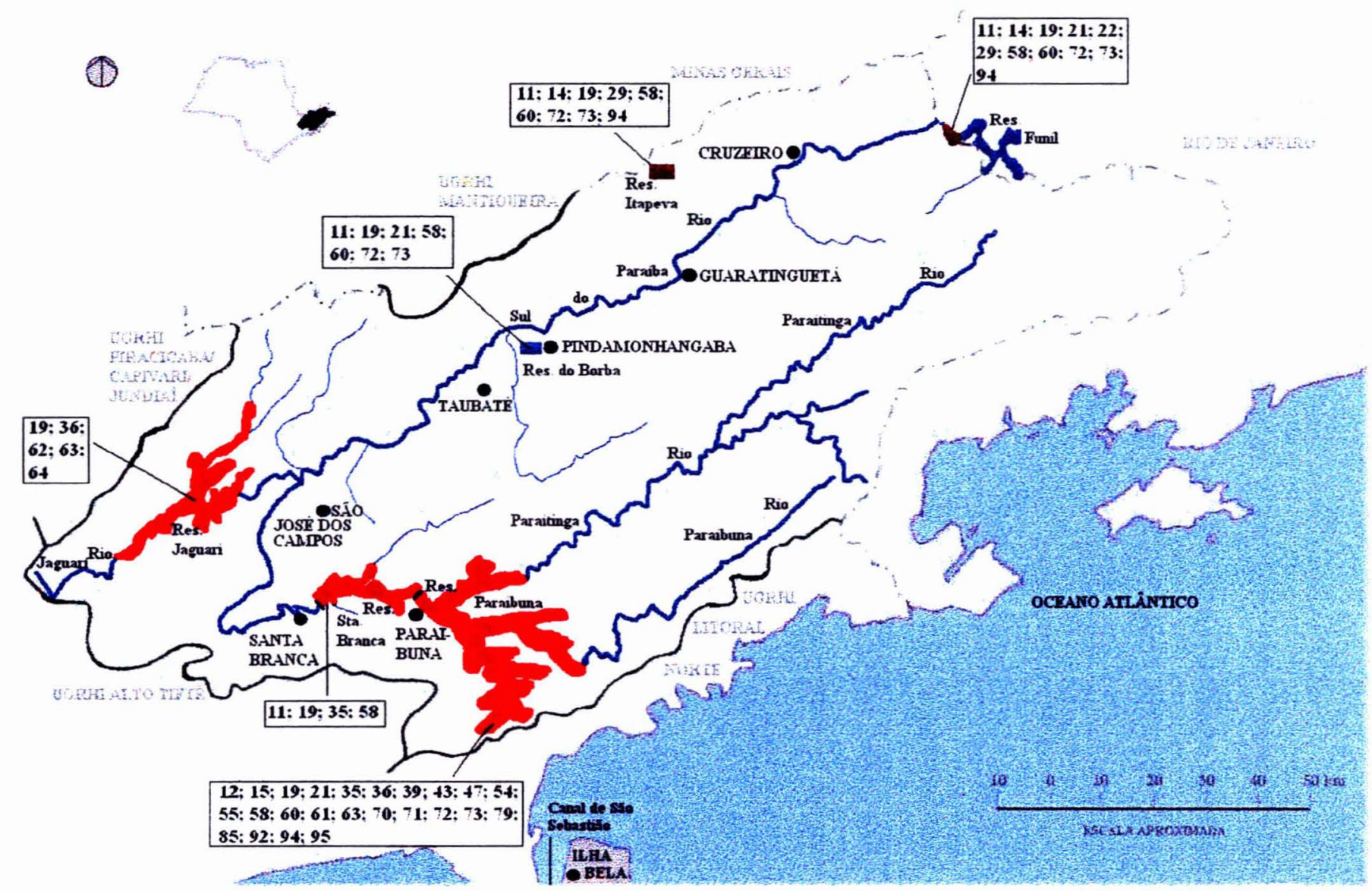

FIGURA 41 - Ocorrência de microcrustáceos e Índice de Estado Trófico (IET) de Carlson modificado dos reservatórios de Paraibuna, Santa Branca, Jaguari, Borba, Itapeva e Funil (UGHRI 02 - Paraíba do Sul) (Números representam as espécies que constam na tabela 25). 


\section{UGRHI O4 - PARDO}

Os reservatórios de Limoeiro, Euclides da Cunha e Graminha, como também o lago Monte Alegre, pertencem à UGRHI do rio Pardo.

Entre as especies registradas, Hexarthra mira ocorreu nos reservatórios de Limoeiro e Graminha, Plationus patulus em Euclides da Cunha e Limoeiro, Conochilus coenobasis, Collotheca ornata e Ptygura libera somente em Graminha, e Conochilus cf. dossuarius, Epiphanes macrourus, Keratella tecta e Trichocerca pusilla, no lago Monte Alegre (Tabela 20; Figura 42).

Em relação aos ciclopóides, Thermocyclops decipiens e Tropocyclops prasinus ocorreram nos reservatórios de Graminha e Limoeiro, e no lago Monte Alegre. A co-ocorrência de T. decipiens e Mesocyclops longisetus foi registrada no reservatório de Graminha, e de Thermocyclops minutus e T. decipiens em Graminha e Limoeiro. Mesocyclops longisetus e T. minutus também estiveram presentes no reservatório Euclides da Cunha (Tabela 21; Figura 43).

Scolodiaptomus corderoi foi a única espécie de calanóide registrada nesta UGRHI, ocorrendo nos reservatórios de Graminha e Euclides da Cunha (Tabela 22; Figura 43).

Quanto aos cladóceros, Diaphanosoma birgei e Moina minuta ocorreram em todos os corpos d'água considerados, Bosminopsis deitersi foi registrada em Euclides da Cunha, Limoeiro e Monte Alegre, e Daphnia gessneri em Euclides da Cunha e Monte Alegre. Já Bosmina tubicen foi registrada exclusivamente no lago Monte Alegre, e Bosmina hagmanni no reservatório de Graminha. No lago Monte Alegre, foi evidenciada a co-ocorrência de Ceriodaphnia cornuta e C. reticulata, Daphnia ambigua e D. gessneri, e Moina minuta e M. micrura (Tabela 23; Figura 43).

Na UGRHI Pardo, o IET variou de 36,5 (reservatório Euclides da Cunha) a 59,9 (lago Monte Alegre) (Tabelas 20 a 23; Figuras 42; 43). 
IET $>84$

IET Não DETERMIINADo $\square$ LIIITE DF UGRHI

L... LIITE INTERESTADUAL Y CURSO DAGUA

$\square$ LAGO OU RESERVATORIO

- SEDE MUNICIPAL

FONTE SNLA (1999)

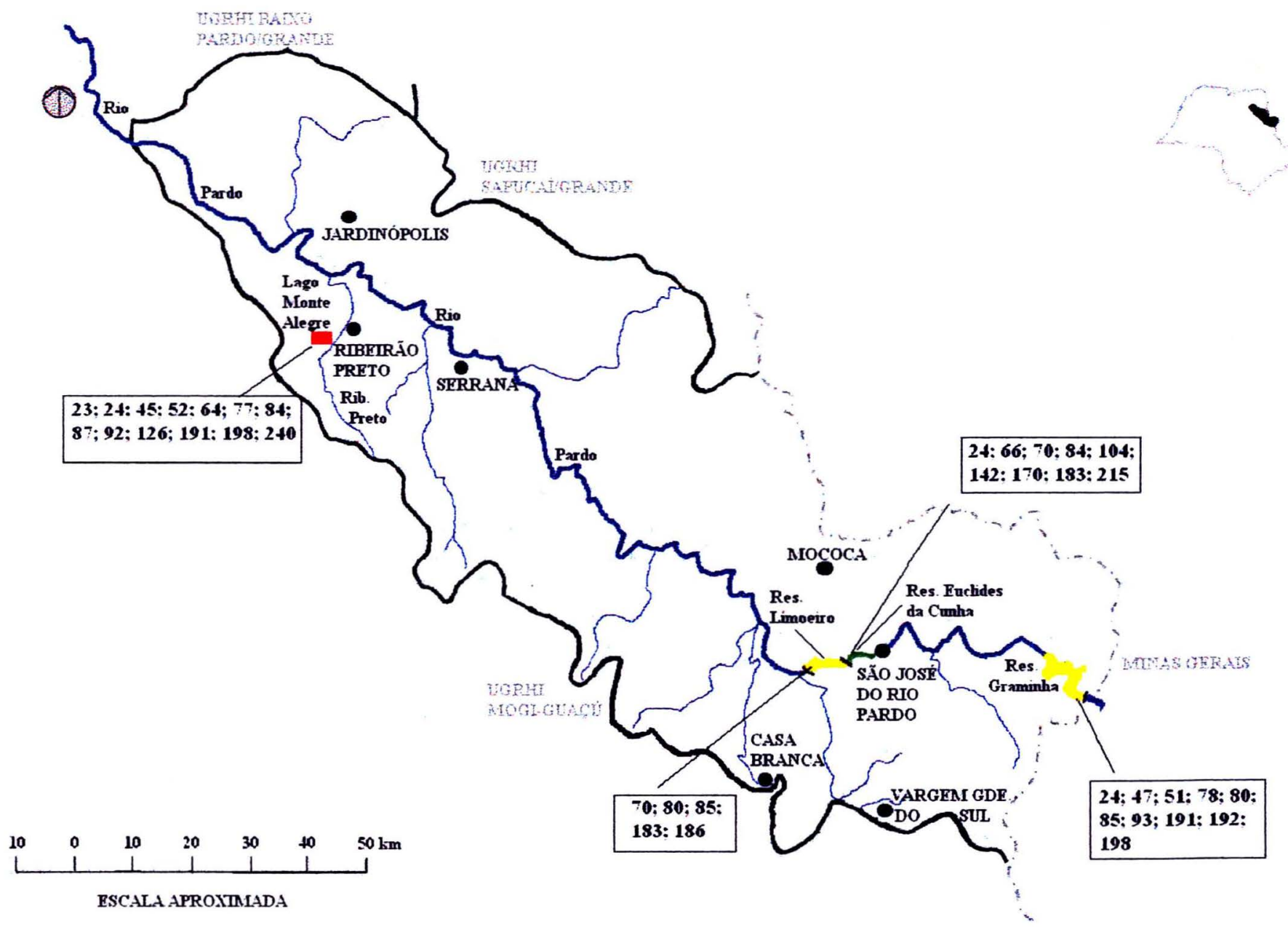

FIGURA 42 - Ocorrência de rotíferos e Índice de Estado Trófico (IET) de Carlson modificado dos reservatórios Graminha, Euclides da Cunha, Limoeiro e lago Monte Alegre (UGRHI 04 - Pardo) (Números representam as espécies que constam na tabela 24). 
LFGENDA

IET $\div 4$

$44<$ IET $<54$

S4 $<$ IET $<64$

$64<$ IET $<74$

$74<$ IET $<8$

IET $>84$

IET Não DETERAIINADO

$\square$ LIMTTE DE UGRHI

-... LINITE INTERESTADUAI

DURSO D AGUA

$\square$ LAGO OU RESERVATÓRIO

- SEDE MUNICIPAI

FONTE: SMLA (1999)

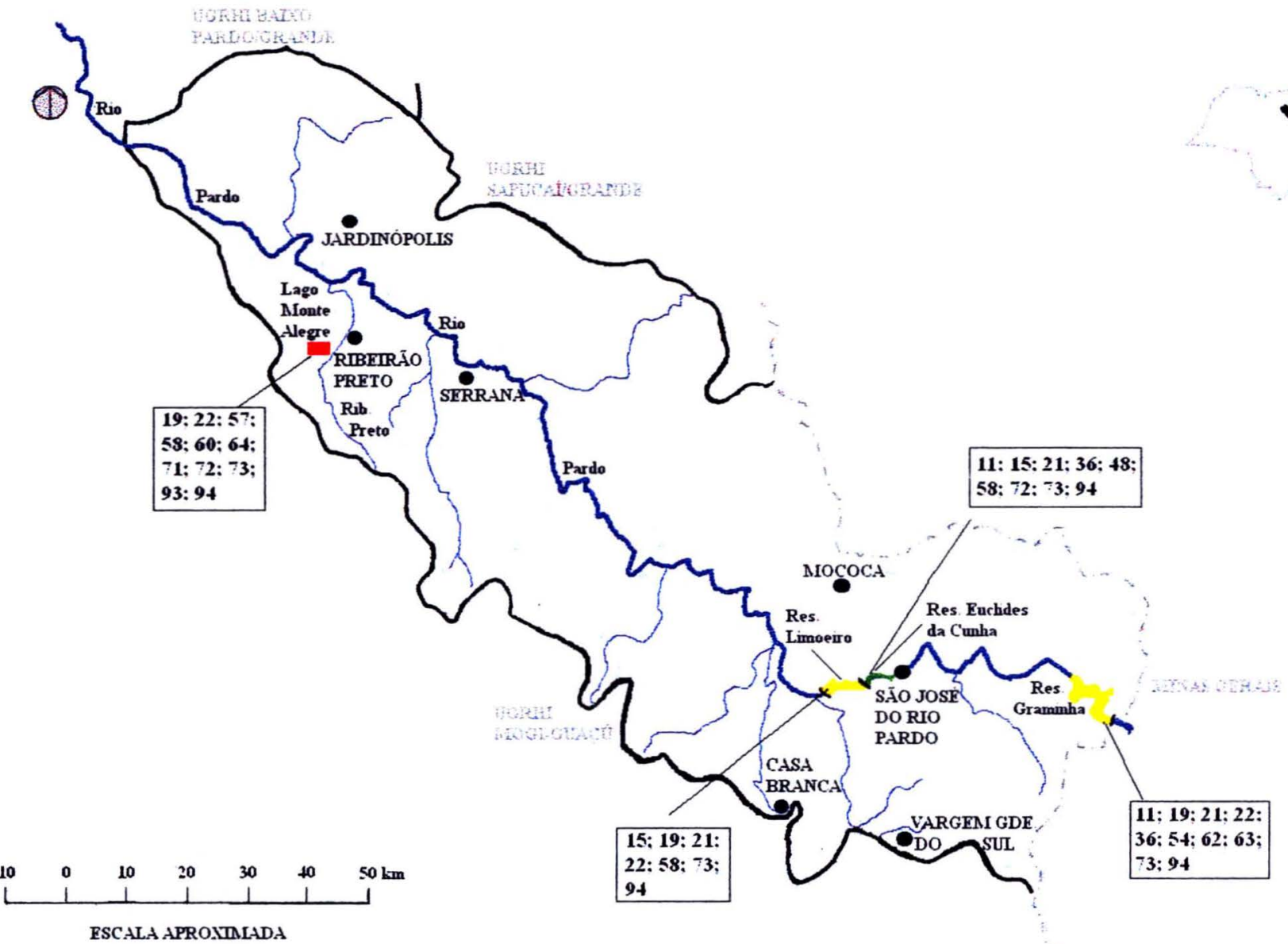

FIGURA 43 - Ocorrência de microcrustáceos e Índice de Estado Trófico (IET) de Carlson modificado dos reservatórios Graminha, Euclides da Cunha, Limoeiro e lago Monte Alegre (UGRHI 04 - Pardo) (Números representam as espécies que constam na tabela 25 ). 


\section{UGRHI 05 - PIRACICABA, CAPIVARI E JUNDIAÍ}

Na UGRHI dos rios Piracicaba, Capivari e Jundiaí estão localizados os reservatórios de Americana, Atibainha e Cachoeira.

Ocorreram no reservatório de Americana Brachionus angularis, $B$. calyciflorus, ('onochllus unicornis, Keratella cochlearis, K. tropica, Polyarthra major e $P$. vulgaris ( Tabela 20; Figura 44).

Tropocyclops prasinus foi comum aos três reservatórios desta UGRHI, onde também foi registrada a co-ocorrência de Thermocyclops decipiens e Metacyclops mendocinus. No reservatório de Americana, T. decipiens também co-ocorreu com Mesocyclops longisetus (Tabela 21; Figura 45). Não foram registrados calanóides nestes reservatórios.

Quanto aos cladóceros, no primeiro estudo realizado no reservatório de Americana foi constatada a ocorrència de Bosmina longirostris, Bosminopsis deitersi, (eriodaphnia cornuta, (. rettculata, Daphnia gessneri e Diaphanosoma brevireme (Tabela 23; Figura 45). Posteriormente, só ocorreram C. cornuta e $D$. gessneri.

Estudos recentes (Tabela 23; Figura 45) evidenciaram o aparecimento de Bosmina hagmanni, Ceriodaphnia silvestrii, Diaphanosoma birget e Moina minuta, até então não registradas neste reservatório. Bosminopsis deitersi, $C$. cornuta, $C$. reticulata e $D$. gessneri também foram registradas nos reservatórios de Atibainha e Cachoeira.

Quanto às condições tróficas, nos reservatórios de Americana e Cachoeira o IET foi elevado ( 78,1 e 76,5 , respectivamente), e no reservatório de Atibainha, o IET obtido foi 67,2 (Tabelas 20 a 23; Figuras 44; 45). 
(1)

LFGENDA

IET $<4$

$44:$ IET $\div 54$

$54<$ IET $<64$

$64<$ IET $<74$

$74<$ IET $\approx 84$

IET $>84$

IET NÃo DETERNIINADO

$\square$ LINITE DE UGRHI
LINITT INTERESTADUAL
CURSO D AGUA
LAGO OU RESERVATORIO

LAGO OU RFSERVATÓRIO

- SEDF MUUNCIPAL

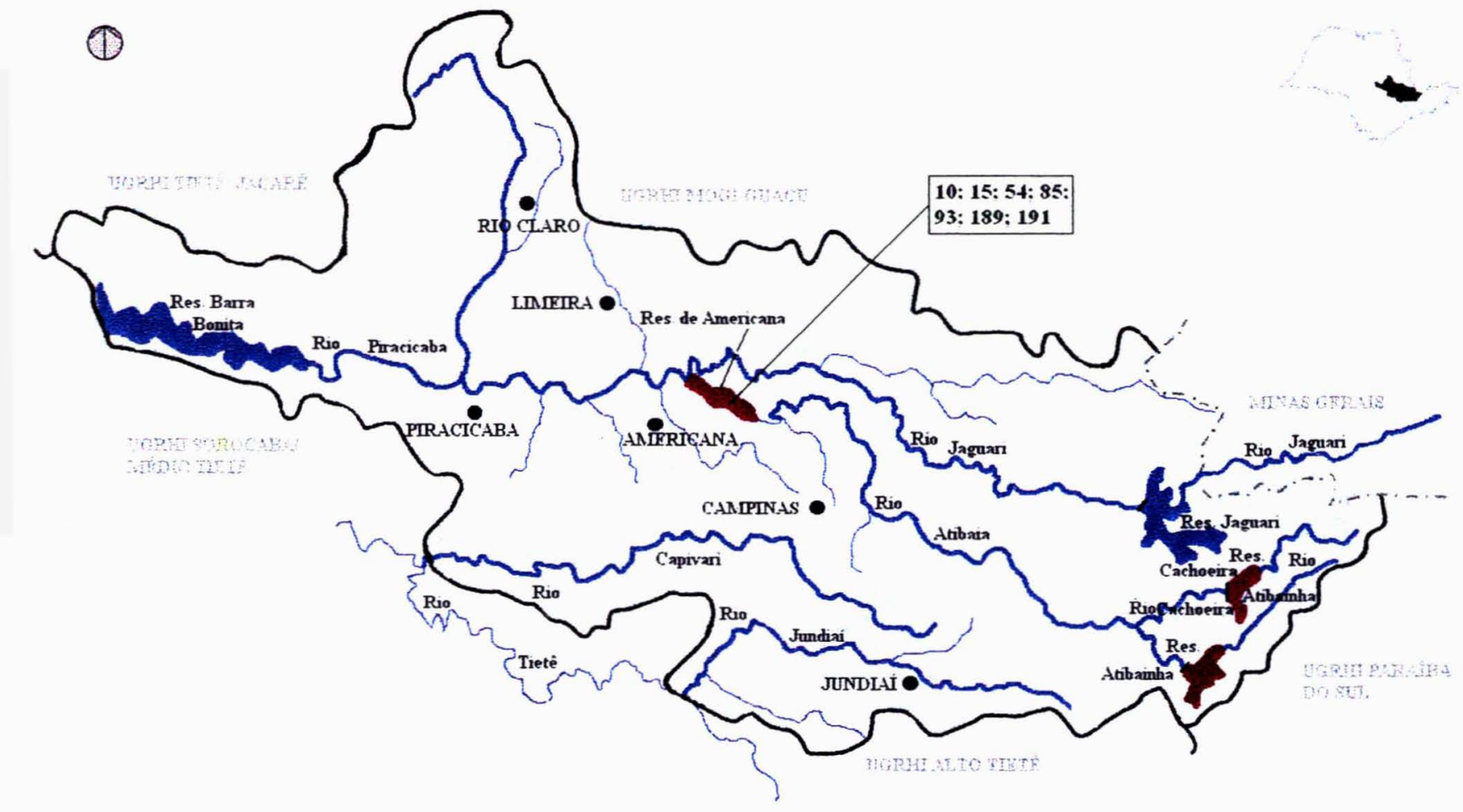

FONTE. SNIA (1999)

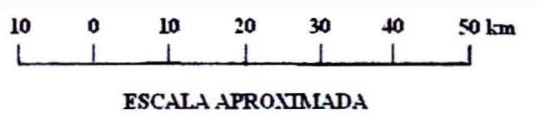

FIGURA 44 - Ocorrência de rotíferos e Índice de Estado Trófico (IET) de Carlson modificado do reservatório de Americana (UGRHI 05 - Piracicaba, Capivari e Jundiaí) (Números representam as espécies que constam na tabela 24). 
(1)

I.EGENDA

IET $<4$

$\boldsymbol{t +}<$ IFT $<54$

$54<$ IET $<64$

$64<$ IET $<74$

$74<$ IET $<84$

IET $>84$

IET NÃO DETERMIINADO
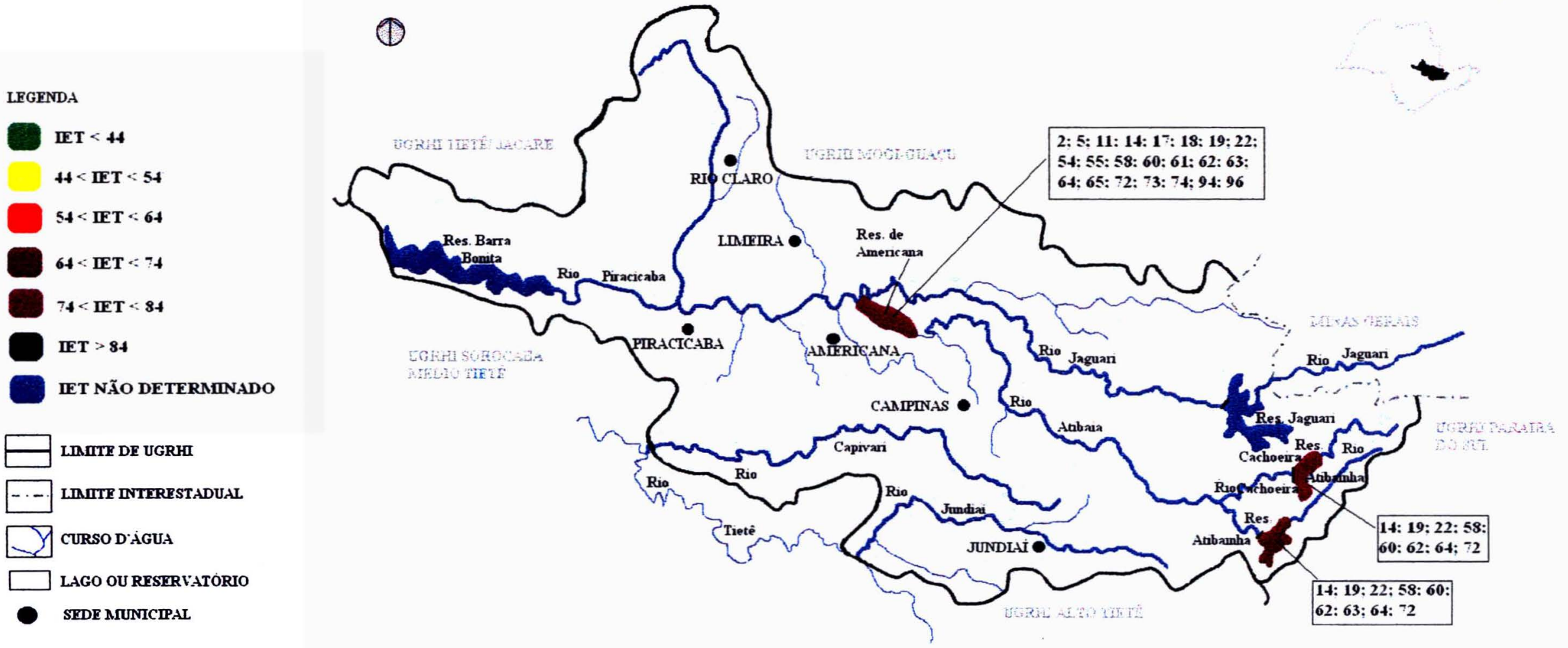

SEDE MUNICIPAI

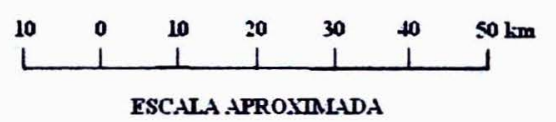

FIGURA 45 - Ocorrência de microcrustáceos e Índice de Estado Trófico (IET) de Carlson modificado dos reservatórios Atibainha, Cachoeira e Americana (UGRHI 05 - Piracicaba, Capivari e Jundiai) (Números representam as espécies que constam na tabela 25). 


\section{UGRHI 06 - ALTO TIETÊ}

\section{Bacia do rio Tietê Alto-Cabeceiras}

A bacia do rio Tietê Alto Cabeceiras engloba os reservatórios Ribeirão do Campo, Taiaçupeba e Ponte Nova

Tropocyclops prasinus ocorreu nos três reservatórios, Thermocyclops decipiens, em Ribeirão do Campo, e Mesocyclops longisetus em Ponte Nova; a coocorrência destas duas espécies foi evidenciada em Taiaçupeba (Tabela 21; Figura 48).

Odontodiaptomus paulistanus foi registrada em Ribeirão do Campo e Ponte Nova e Scolodiaptomus corderoi ocorreu exclusivamente em Taiaçupeba (Tabela 22; Figura 48).

Em relação aos cladóceros, Bosminopsis deitersi e Ceriodaphnia cornuta foram registradas nos três corpos d'água considerados; já Daphnia gessneri ocorreu em Ribeirão do Campo e Ponte Nova, Ceriodaphnia reticulata em Ribeirão do Campo e Taiaçupeba, e Diaphanosoma birgei e Moina minuta estiveram presentes neste último reservatório (Tabela 23; Figura 48).

$\mathrm{Na}$ bacia do rio Tietê Alto - Cabeceiras, o IET variou de 57,8 (Ribeirão do Campo) a 70,9 (Taiaçupeba) (Tabelas 21 a 23; Figura 48).

\section{Bacia do rio Tietê Alto - Zona Metropolitana}

$\mathrm{Na}$ bacia do rio Tietê Alto-Zona Metropolitana estão localizados os reservatórios Cabuçu, Águas Claras, Juqueri, Parque Ecológico, o lago do Parque Ecológico do Tietê (PET), e os lagos do Parque Estadual das Fontes do Ipiranga (PEFI) (IAG, das Ninféias e Garças).

No lago do PET e nos lagos do PEFI foram registradas 50 espécies de rotiferos, pertencentes principalmente aos gêneros Brachionus (11), Keratella (6), Trichocerca (6) e Lecane (5). Do total de espécies, somente Conochilus dossuarius e Keratella cochlearis ocorreram nos quatro lagos estudados (Tabela 20; Figura 47).

Brachionus angularis, B. calyciflorus, B. falcatus, Conochilus unicornis, Filinia opoliensis, F. terminalis, Keratella americana, K. tecta, Synchaeta pectinata, Trichocerca pusilla e T. similis ocorreram no lago das Garças e no lago do PET, e Brachionus havanaensis só foi registrada no PET. 
Em relação aos ciclopóides, Themocyclops decipiens e Tropocyclops prasinus foram registradas nos reservatórios Cabuçu, Águas Claras e Juqueri. A co-ocorrência de $T$. decipiens e Metacyclops mendocinus foi evidenciada em Águas Claras e Juqueri; em Águas Claras, Thermocyclops minutus co-ocorreu com T. decipiens, e Mesocyclops longisetus (Tabela 21; Figura 48).

No Parque Ecológico, a única espécie de ciclopóide registrada foi $M$. mendocinus. Tropocyclops prasinus ocorreu nos três corpos d'água do PEFI, e a coocorrência de $T$. decipiens e $M$. mendocinus foi registrada somente no lago das Garças, que apresentou IET mais elevado que os lagos do IAG e das Ninféias (Tabela 21; Figuras 48; 50). Thermocyclops decipiens e M. longisetus co-ocorreram nos lagos das Garças e no PET; neste último, também foi registrado Thermocyclops inversus.

Em relação aos calanóides, Odontodiaptomus paulistanus e Scolodiaptomus corderoi ocorreram nos reservatórios de Águas Claras e Juqueri; S. corderoi também esteve presente nos três lagos do PEFI e no Parque Ecológico. Notodiaptomus iheringi foi a única espécie registrada no lago do PET (Tabela 22; Figuras 48; 50).

Nos reservatórios Cabuçu, Águas Claras e Juqueri foi constatada a ocorrência de Bosminopsis deitersi e Ceriodaphnia cornuta. Daphnia gessneri, Diaphanosoma birgei e Moina minuta ocorreram em Águas Claras e Juqueri.

Nos lagos urbanos, B. deitersi ocorreu no Parque Ecológico e nos três lagos do PEFI, D. gessneri nos lagos do PET e Garças, D. birgei no Parque Ecológico, nos lagos do PET, IAG e Garças, e M. minuta no Parque Ecológico e no lago das Garças (Tabela 23; Figuras 48; 50).

Quanto ao IET, variou de 45,2 (lago do IAG) a 75,9 (lago do PET) (Tabelas 20 a 23 ; Figuras $47 ; 48 ; 50$ ).

\section{Bacia do reservatório Billings}

Esta bacia, também denominada de Complexo Billings, é formada pelos reservatórios Billings (braço Taquacetuba e braço Rio Pequeno), Rio Grande e Rio das Pedras. Nos braços Taquacetuba e Rio Pequeno ocorreram, entre os rotíferos principalmente Brachionus calyciflorus, B. dolabratus, B. havanaensis, Conochilus dossuarius, Filinia opoliensis, Hexarthra mira, Keratella tropica, Trichocerca 
similis. Já Anuraeopsis fissa foi registrada exclusivamente em Taquacetuba. e Kellicottia bostoniensis, Keratella tecta e Ptygura libera no Rio Pequeno ITabela 20; Figura 47).

No primeiro estudo realizado no reservatório Rio Grande, a comunidade de rotiferos foi constituída basicamente por várias espécies de Brachionus, dentre elas B. angularis e B. calyciflorus, além de espécies de Keratella, Plationus patulus e Trichocerca similis. Estudos posteriores evidenciaram a ocorrência de A. fissa. $B$. calyciflorus, $C$. dossuarius, $F$. opoliensis, $K$. bostoniensts, $K$. tecta. K. troptca, Trichocerca capucina, T. pusilla e T. similis, entre outras (Tabela 20; Figuras 46; 47).

Em estudo recente realizado no braço do Rio Pequeno, foi constatado o aparecimento de Mesocyclops aspericornis, M. ogunnus, Thermocyclops inversus e T. minutus, até então não registradas neste corpo d'água, assim como a co-ocorrència de Thermocyclops decipiens e Metacyclops mendocinus, juntamente com Tropocyclops prasinus, já verificadas no primeiro estudo. Recentemente, no braço Taquacetuba, estas três últimas espécies de ciclopóides e $M$. ogunnus também foram registradas (Tabela 21; Figura 50).

No reservatório Rio Grande foi constatada a co-ocorrència de T. dectiplens e M. mendocinus, juntamente com T. prasinus; já Mesocyclops longısetus só foi registrada nos primeiros estudos. Thermocyclops decipiens, M. mendocinus e $T$. prasinus foram as únicas espécies de ciclopóides registradas no reservatório Rio das Pedras (Tabela 21; Figuras 48 a 50).

Em relação aos calanóides, no primeiro estudo realizado no braço do Rio Pequeno, ocorreu somente Scolodiaptomus corderoi; recentemente, esta espécie foi substituida por Notodiaptomus iheringi, que também ocorreu no braço Taquacetuba (Tabela 22; Figuras 48; 50).

Argyrodiaptomus furcatus e $S$. corderol ocorreram no reservatóno Rio Grande, em todos os estudos realizados; recentemente, $A$. furcatus não foi registrado neste corpo d'água. No reservatório Rio das Pedras não foi constatada a ocorrência de calanóides (Tabela 22; Figuras 48 a 50).

Quanto aos cladóceros, em estudo recente realizado nos braços Taquacetuba e Rio Pequeno foram registradas Bosminopsis deitersi, ('eriodaphnia cur 'lla, 
Daphnia ambigua, D. gessneri, Diaphanosoma birgei e D. spinulosum. No braço Rio Pequeno ocorreram Bosmina hagmanni, B. tubicen, Moina micrura e M. minula, e no braço Taquacetuba foram registradas B. hagmanni e M. minuta (Tabela 23: Figura $50)$.

Bosmina hagmanni, B. longirostris, B. tubicen, Bosminopsis ditterst. Ceriodaphnia cornuta, C. reticulata, D. ambigua, D. gessneri, Diaphanosoma brevireme, D. birgei e $M$. minuta foram registradas em todos os estudos realizados no reservatório Rio Grande. Ceriodaphnia cornuta, D. gessneri, D. birge! e $M$. minuta representaram os cladóceros no reservatório Rio das Pedras (Tabela 23: Figuras 48 a 50$)$.

Em relação às condições tróficas, nos braços Rio Pequeno e Taquacetuba o IET obtido foi 50,9 e 61,9 respectivamente; no reservatório Rio Grande o IET variou de 49,3 a 86,2 e, no reservatório Rio das Pedras, foi 87,5 (Tabelas 20 a 23; Figuras 46 a 50$)$.

\section{Bacia do rio Cotia}

No reservatório Pedro Beicht, a única espécie de ciclopóide registrada foi Tropocyclops prasinus, e entre os cladóceros, ocorreu B. deiterst, não foram registrados calanóides. O valor obtido para o IET foi 72,5 (Tabelas 21; 23; Figura 48).

\section{Bacia do reservatório Guarapiranga}

A comunidade zooplanctônica do reservatório Guarapiranga foi constituida por 104 espécies, sendo 72 de rotíferos, 18 de cladóceros, 8 de ciclopóides e 6 de calanóides.

Os rotíferos foram representados principalmente por 16 espécies de Brachionus, 13 de Lecane, 10 de Trichocerca, 5 de Keratella e 4 de Filinia (Tabela 20; Figuras 46; 47).

No primeiro estudo realizado, ocorreram Brachionus angularls, $B$. calyciflorus, B. falcatus, B. quadridentatus, Collotheca ornata, Keratella americanc. K. cochlearis, K. lenzi, K. tropica, Polyarthra longiremis, I'. vulgaris, l'ngura libera, Trichocerca longiseta, T. similis, entre outras. Posteriormente. foi 
evidenciado o aparecimento de Anuraeopsis fissa. ('onochilus dossuarius, Epiphanes macrourus, Keratella tecta, Plationus patulus, Trichocerca capucina e $T$. stylata, entre outras espécies.

Em estudo mais recente, apesar de se constatar uma diminuição do número de espécies de rotiferos, foi verificado o aparecimento de Brachionus dolabratus, B. cf. forficula, Filinia opoliensis, Kellicottia bostoniensis e Trichocerca chattoni, até então não registradas em Guarapiranga.

Somente Brachionus calyciflorus, B. falcatus, Conochilus unicornis, Filinia longiseta, Keratella americana e $K$. tropica foram registradas em todos os estudos realizados neste reservatório.

Quanto aos ciclopóides, no primeiro estudo realizado foi constatada a coocorrência de Thermocyclops decipiens e Metacyclops mendocinus, juntamente com Mesocyclops longisetus e Tropocyclops prasinus. Posteriomente, foi evidenciada a co-ocorrência de $T$. decipiens e $M$. longisetus, e o aparecimento de Thermocyclops inversus. Em estudo mais recente, $T$. decipiens e $M$. mendocinus co-ocorreram novamente, constatando-se o aparecimento de Thermocyclops minutus $\mathrm{e}$ Mesocyclops ogunnus, além de T. prasinus (Tabela 21; Figuras 48 a 50).

Em relação aos calanóides, Odontodiaptomus paulistanus e Scolodiaptomus corderoi foram as únicas espécies observadas no primeiro estudo realizado no reservatório Guarapiranga. Posteriomente, foram registrados Argyrodiaptomus furcatus, Notodiaptomus iheringi e $S$. corderoi, não sendo constatada a ocorrência de $O$. paulistanus. Recentemente, foi registrada a ocorrência de Notodiaptomus cf. cearensıs; já $S$. corderoı não foi observado neste corpo d'água (Tabela 22; Figuras 48 a 50$)$.

Quanto aos cladóceros, foram registradas no primeiro estudo Bosminopsis deitersi, Ceriodaphnia cornuta, Daphnia gessneri, Diaphanosoma birgei e Moina minuta. Posteriomente, além destas espécies, foram registradas Bosmina hagmanni, B. longirostris, B. Iubicen. Ceriodaphnia cf. reticulata, Daphnia ambigua e Diaphanosoma brevireme. Em estudo mais recente, foi constatada a co-ocorrência de B. hagmanni e B. tubicen. e D. ambigua e D. gessneri (Tabela 23; Figuras 48 a 50).

Quanto às condições tróficas, o IET no reservatório de Guarapiranga esteve compreendido entre 51,2 a 59,7 (Tabelas 20 a 23; Figuras 46 a 50). 
IET $<4$

44 $<$ IET $<54$

$54<$ IET $<64$

D $64<$ IET $<: 7$

$74<\mathrm{IET}<8 \mathrm{~s}$

IET $>84$

IET NÃo DETERMIINAdO

$\square$ LAITI DE UGRH

-.- LDITIE INTIRESTADUAI

CURSO D ÁGUA

$\square$ LAGO OU RESERVATORIO

- SIDE MUNCIPAI

FONIR SALA (159)

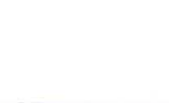
1: 10: 11: 14; 15: 16; 17: 18:
19; 21: 24; 27; 28; 32; 60 51; 52; 54; 59; $64: 67$; $70 ; 70$ : 51 ;

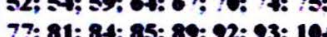
77; 81: 24. 85; 89; 92; 93; 104 106: 108: 109; 119: 122: 126; 128; 130: 132: 141; 142; 143: 159; 171: 176; 183; 186: 188: 191: 193; 198; 208; 212: 213: 234; 236: 237; 243; 245; 247

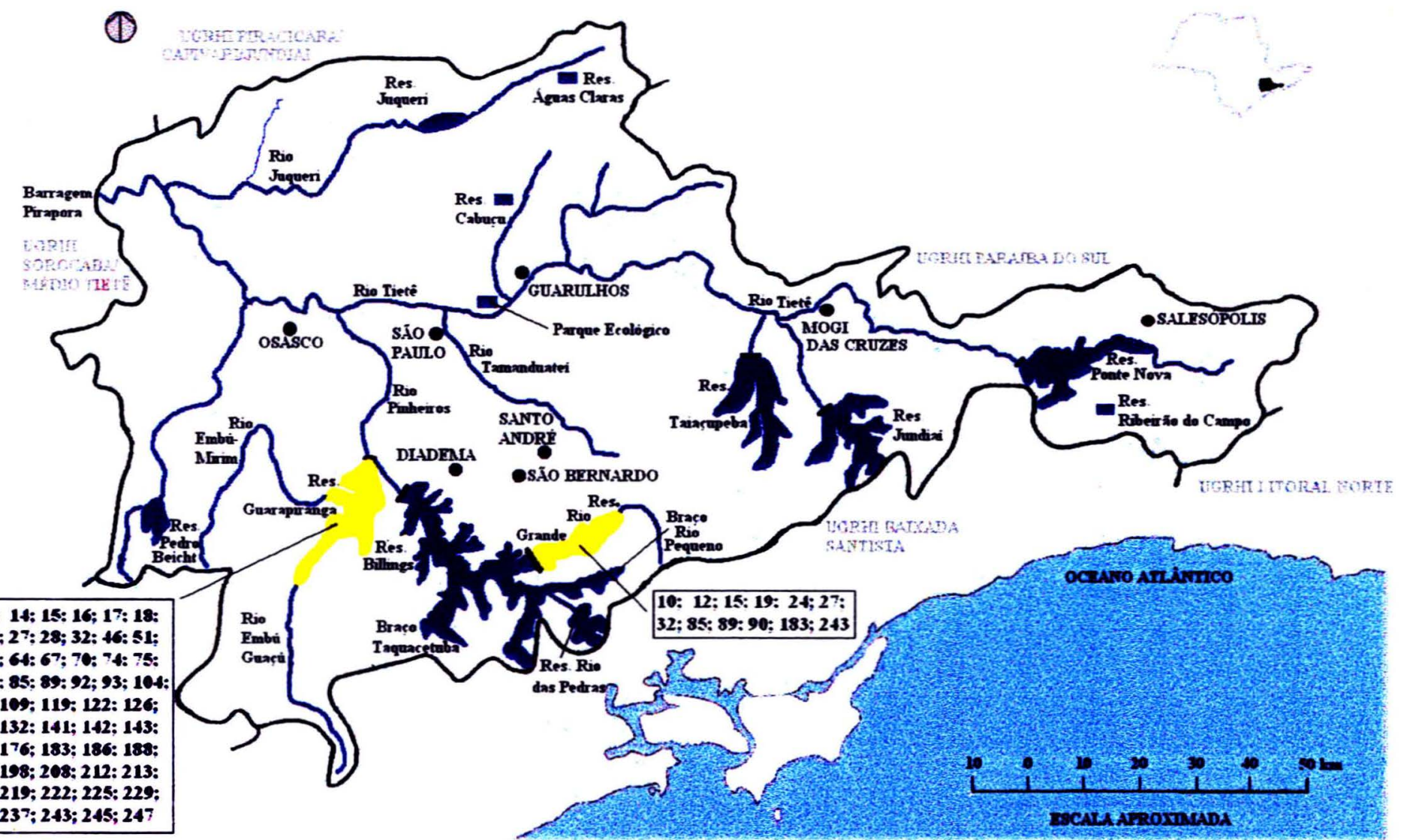

FIGURA 46 - Ocorrência de rotíferos e Índice de Estado Trófico (IET) de Carlson modificado dos reservatórios Rio Grande (década de 80) e Guarapiranga (década de 90) (UGRHI 06 - Alto Tietê) (Números representam as espécies que constam na tabela 24). 
IET NÃo DETERMInADO

IMITT DE UGRHI
IMITR INTERESTADUAI
CURSO D'AGUA
LAGO OU RESERVATOBIO
SEDE MUNCIPAI

FONTR: SALA (1899)

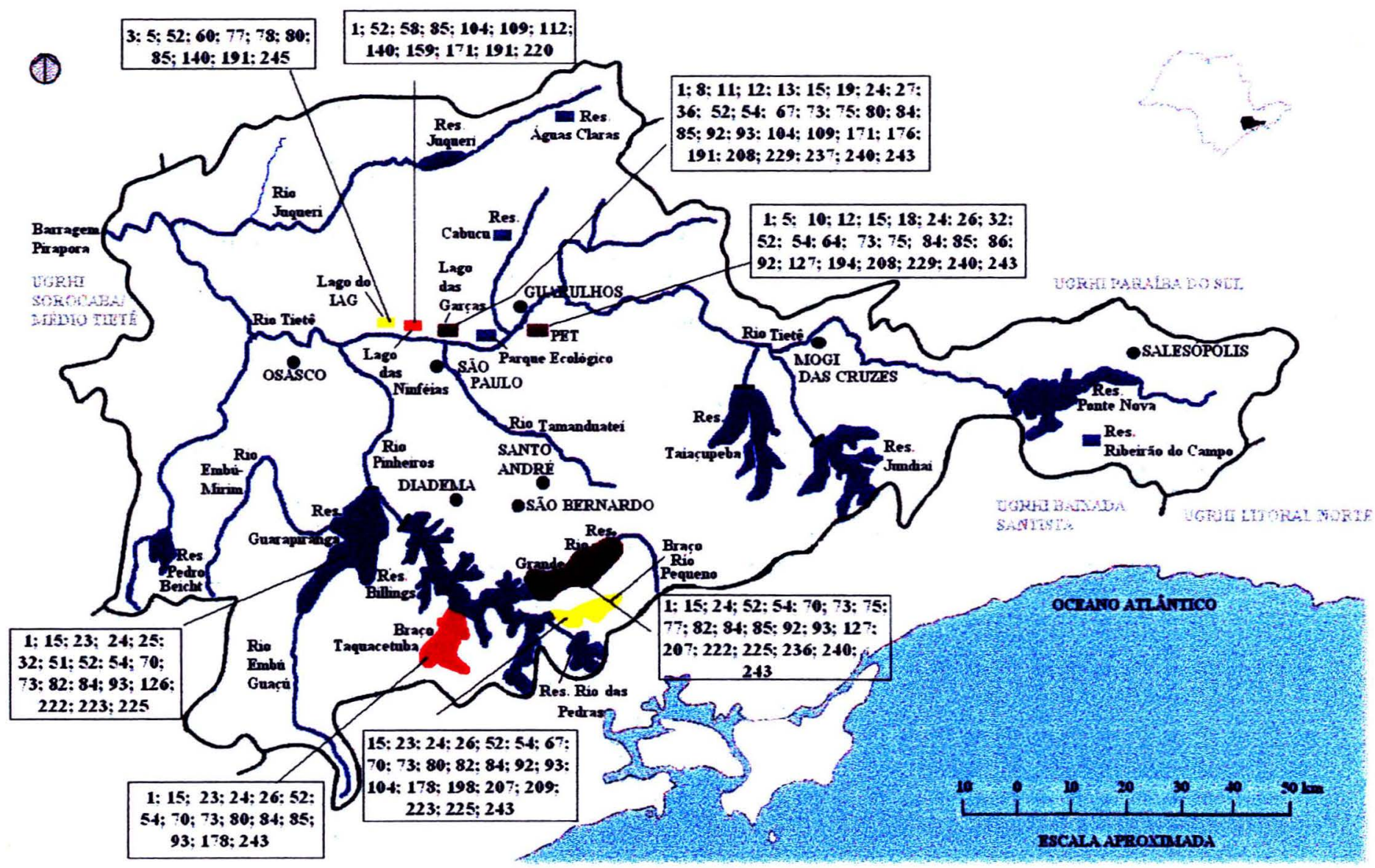

FIGURA 47 - Ocorrência de rotíferos e Índice de Estado Trófico (IET) de Carlson modificado do Complexo Billings e reservatório Guarapiranga (dados recentes), e dos lagos do PET e PEFI (UGRHI 06 - Alto Tietê) (Números representam as espécies que constam na tabela 24). 
IET NÃO DETERMIINADO

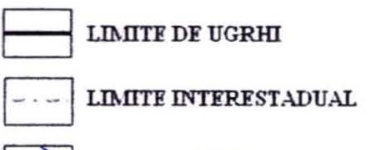

\section{CURSO D AGUA}

$\square$ LAGO OU RESERVATORIO

- SEDE MUNICIPAL

FONTE SALA (1999)

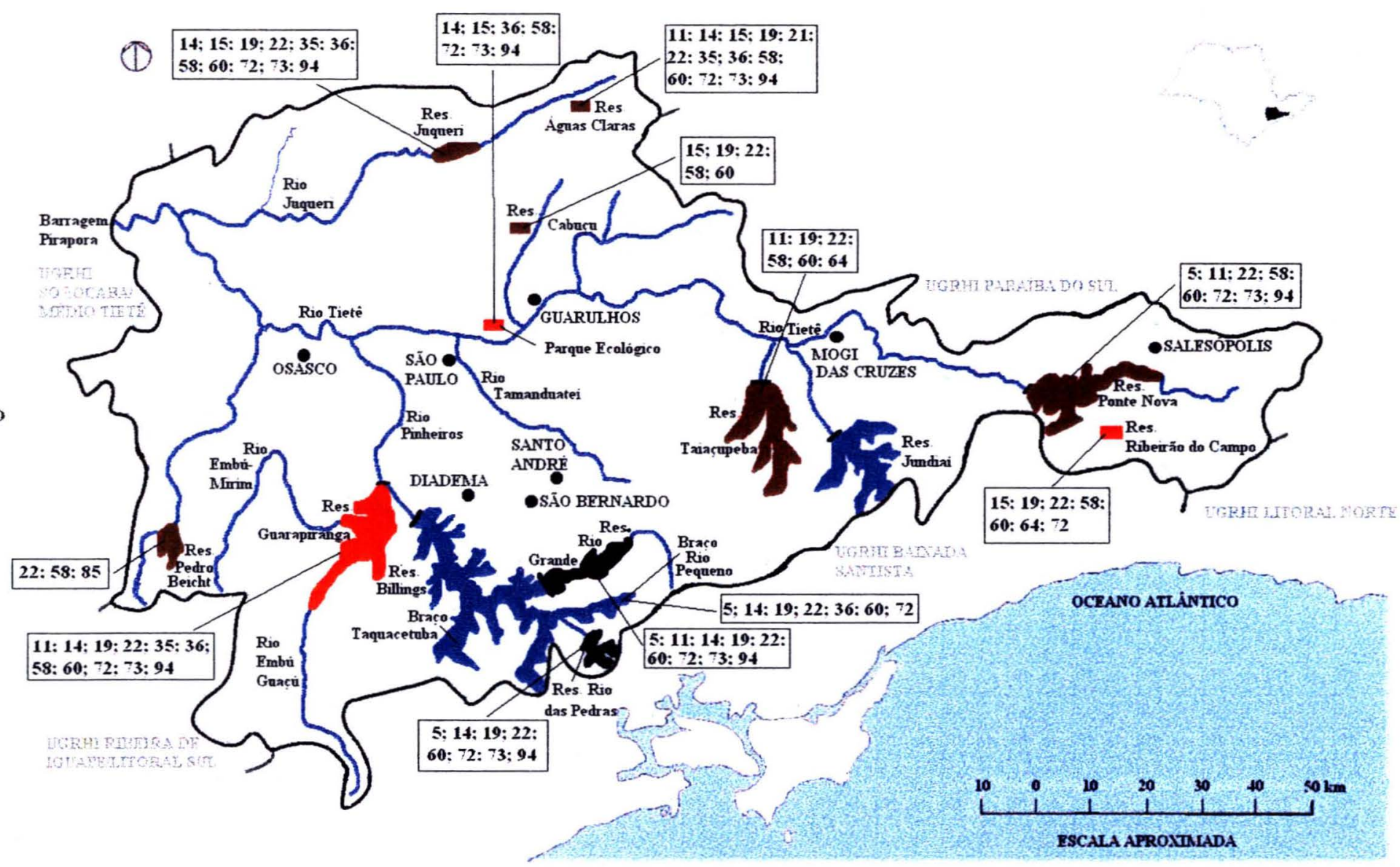

FIGURA 48 - Ocorrência de microcrustáceos e Índice de Estado Trófico (IET) de Carlson modificado do Complexo Billings e reservatórios Guarapiranga, Ponte Nova, Ribeirão do Campo, Taiaçupeba, Parque Ecológico, Cabuçu, Águas Claras, Juqueri e Pedro Beicht (1979) (UGRHI 06 - Alto Tietê) (Números representam as espécies que constam na tabela 25). 
IET $>84$

IET NÃO DETERMIINADO $\square$ LIMTTE DE UGRHI

- D. LIITE INTFRESTADUAL

9 CURSO DiaUt

LAGO OU RESERVATORIO

SEDF MUUNICIPAL

FONTE: SNA (1999)

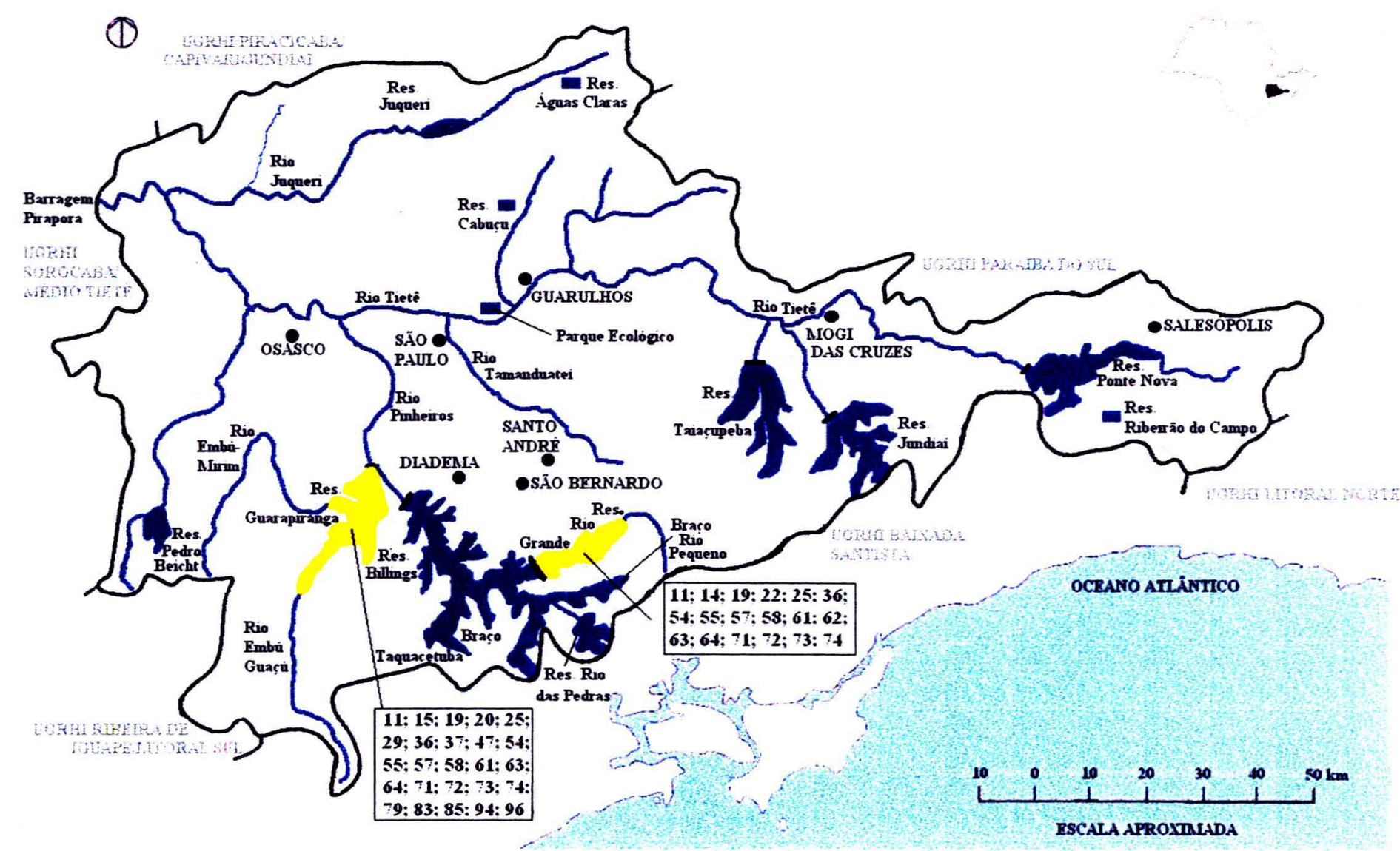

FIGURA 49 - Ocorrência de microcrustáceos e Índice de Estado Trófico (IET) de Carlson modificado dos reservatórios Rio Grande (década de 80) e Guarapiranga (década de 90) (UGHRI 06 - Alto Tietê) (Números representam as espécies que constam na tabela 25). 
IET Não DETERMIINADO

LINITE DE UGRHI
- LIIITE INTERESTADUAL
CURSO D AGUA

LAGO OU RESERVATORIO

- SEDE MUUNCIPAI

FONTF SNAA (1\$S9)

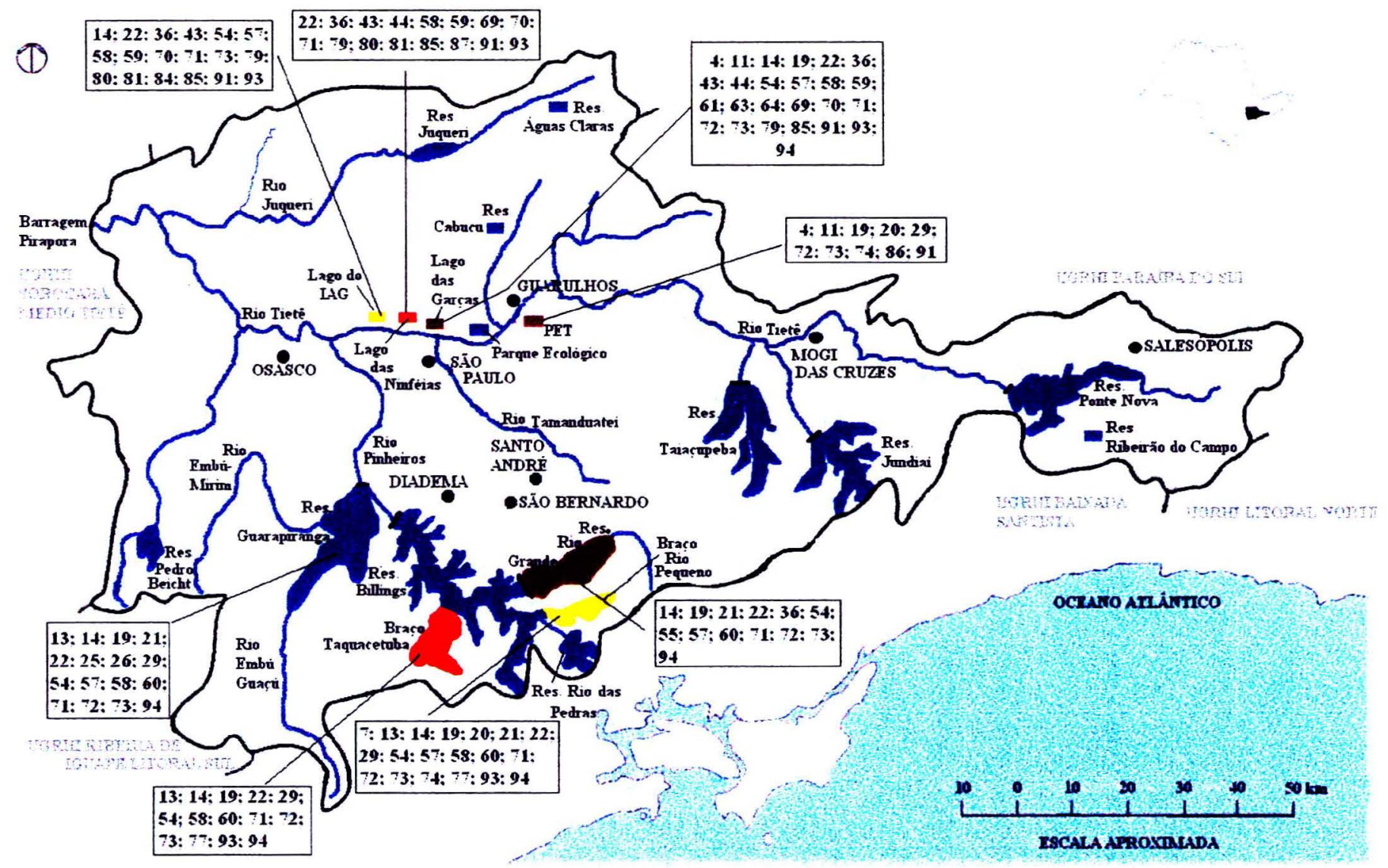

FIGURA 50-Ocorrência de microcrustáceos e Índice de Estado Trófico (IET) de Carlson modificado do Complexo Billings e reservatório Guarapiranga (dados recentes), e dos lagos do PET e PEFI (UGRHI 06 - Alto Tietê) (Números representam as espécies que constam na tabela 25). 


\section{UGRHI 08 - SAPUCAÍ/GRANDE}

Na bacia dos rios Sapucaí e Grande estão localizados os reservatórios Estreito, Jaguará e Volta Grande.

No primeiro estudo realizado no reservatório Volta Grande foram registradas Anuraeopsis fissa, Brachionus angularis, B. dolabratus, B. falcatus, Collotheca ornata, Conochilus coenobasis, C. natans, Hexarthra intermedia braziliensis, $H$. mira, Keratella americana, K. cochlearis, Polyarthra trigla, P. vulgaris e Ptygura libera, entre outras.

Posteriormente, foram constatadas algumas modificações na composição de rotiferos, como o aparecimento de Brachionus calyciflorus, Conochilus unicornis, Keratella lenzi, Plationus patulus, Trichocerca pusilla e T. similis, não sendo registrada a ocorrência de $C$. coenobasis, $H$. intermedia braziliensis, $H$. mira e $P$. libera, entre outras (Tabela 20; Figura 51).

Collotheca ornata, $C$. coenobasis, $H$. mira, $K$. americana, $K$. cochlearis e $P$. libera foram comuns aos reservatórios de Estreito e Jaguará; já B. angularis, $B$. dolabratus, B. falcatus, C. natans e P. vulgaris ocorreram exclusivamente em Estreito (Tabela 20; Figura 51).

Quanto aos ciclopóides, em ambos estudos realizados no reservatório Volta Grande, e no estudo efetuado em Estreito, foi evidenciada a co-ocorrência de Thermocyclops decipiens e T. minutus, e Mesocyclops longisetus; já no reservatório Jaguará, foram registrados $M$. longisetus, T. minutus e Tropocyclops prasinus (Tabela 21; Figura 52).

Argyrodiaptomus furcatus e Scolodiaptomus corderoi foram registradas nos três reservatórios desta UGRHI; já Notodiaptomus iheringi ocorreu no reservatório de Volta Grande no estudo realizado na década de 90 (Tabela 22; Figura 52).

Em ambos os estudos realizados no reservatório de Volta Grande, a composição de cladóceros permaneceu praticamente a mesma, registrando-se a ocorrência de Bosmina longirostris, Bosminopsis deitersi, Ceriodaphnia cornuta, Daphnia gessneri e Moina minuta; já Bosmina hagmanni e Diaphanosoma birgei foram registradas somente no primeiro estudo (Tabela 23; Figura 52). 
Bosmina hagmanni, Bosminopsis deitersi e Diaphanosoma birgei ocorreram nos reservatórios de Jaguará e Estreito; já Moina minuta foi registrada exclusivamente em Jaguará, e Ceriodaphnia cornuta e Daphnia gessneri em Estreito (Tabela 23; Figura 52).

$\mathrm{Na}$ UGRHI Sapucaí / Grande os valores obtidos para o IET foram de 32,8 em Estreito, 38,1 em Jaguará, e 43,8 em Volta Grande (Tabelas 20 a 23; Figuras 51; 52). 
SEDE MUNICIPAI

FONTE SMA (1999)

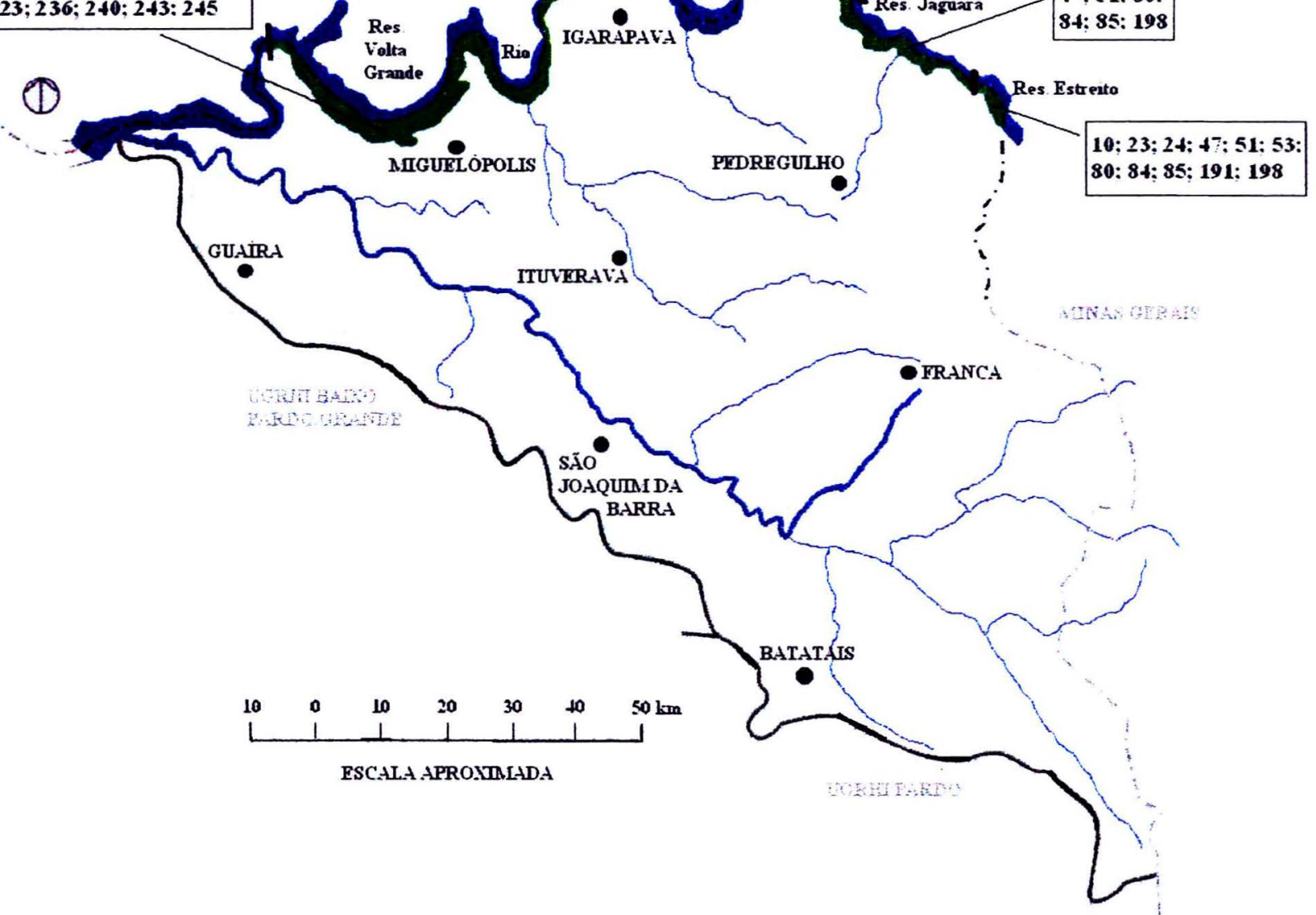

FIGURA 51 - Ocorrência de rotíferos e Índice de Estado Trófico (IET) de Carlson modificado dos reservatórios Estreito, Jaguará e Volta Grande (UGRHI 08 - Sapucaí / Grande) (Números representam as espécies que constam na tabela 24). 
LFGENDA

IET $<4$

$44 \div$ IET $<54$

St $<$ IET $<64$

$64<$ IET $<74$

$74<$ IET $\div 84$

IET $:>4$

IET NÃO DETERAINADO

LIMITE DF UGRHI

- . . LIMIITE INTFRESTADUAL

CURSO D:AGUA

LAGO OU RESERVATÓRIO

- SEDF AIUNTCIPAI

FONTE SMA (1999)

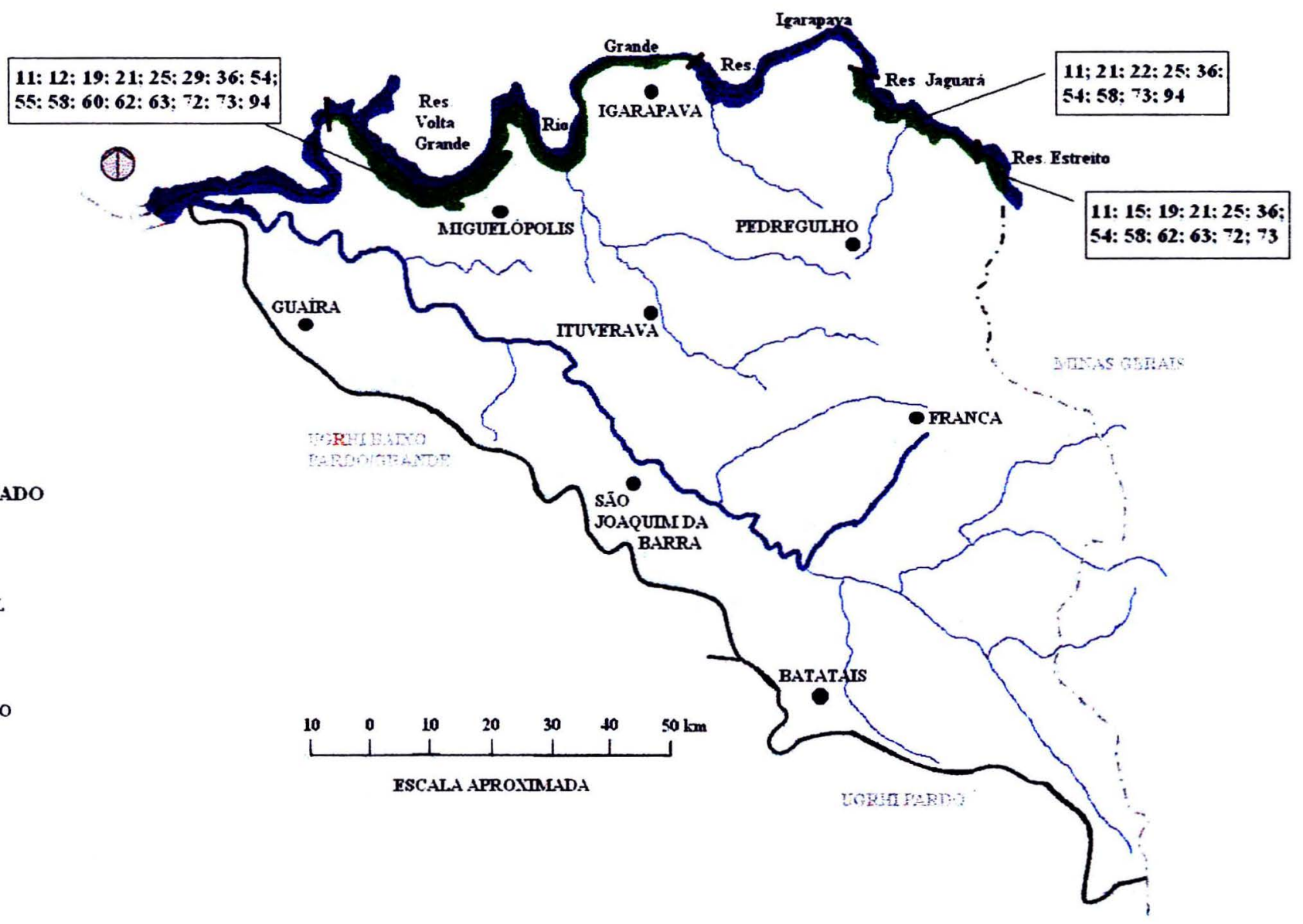

FIGURA 52 - Ocorrência de microcrustáceos e Índice de Estado Trófico (IET) de Carlson modificado dos reservatórios Estreito, Jaguará e Volta Grande (UGHRI 08 - Sapucai / Grande) (Números representam as espécies que constam na tabela 25 ). 


\section{UGRHI 10 - SOROCABA/MÉDIO TIETÊ}

\section{Bacia do rio Tietê Médio Superior}

No reservatório de Barra Bonita, localizado na bacia do rio Tietê Médio Superior, os rotíferos foram representados por 67 espécies, principalmente dos gêneros Brachionus (12), Trichocerca (10), Lecane (8) e Keratella (5) (Tabela 20; Figuras 53 a 55).

Nos estudos realizados na década de 80 , publicados em 90 , foram registradas Ascomorpha ovalis, Asplanchna sieboldi, Brachionus angularis, B. calyciflorus, B. falcatus, Conochilus coenobasis, C. unicornis, Keratella americana, K. cochlearis, K. tropica, Plationus patulus, Polyarthra vulgaris, Ptygura libera, Synchaeta stylata, Trichocerca capucina, T. pusilla, T. similis, entre outras.

Posteriormente, evidenciou-se algumas alterações na composição de rotiferos; foi observada a ocorrência de Filinia opoliensis, Keratella lenzi, não sendo registradas $K$. americana e $P$. libera, entre outras.

Mais recentemente, ocorreram Anuraeopsis fissa, Brachionus havanaensis, Conochilus dossuarius, Epiphanes macrourus, Hexarthra intermedia, H. mira, Kellicottia bostoniensis, P. patulus, Trichocerca cylindrica e $T$. dixon-nutalli, entre outras. Brachionus calyciflorus, $C$. unicornis, $K$. cochlearis, S. stylata e $T$. capucina foram registradas no reservatório de Barra Bonita em todos os estudos realizados.

Em relação aos ciclopóides, Thermocyclops decipiens, Metacyclops mendocinus e Mesocyclops longisetus co-ocorreram em todos os estudos efetuados (Tabela 21; Figuras 56 a 58); recentemente $M$. longisetus não foi registrado neste reservatório. A co-ocorrência de Thermocyclops minutus e T. decipiens, embora não tenha sido observada na década de 80 , ocorreu em grande parte do período estudado.

Mesocyclops aspericornis, M. ogunnus e Thermocyclops inversus foram registradas recentemente. Mesocyclops brasilianus e $M$. kieferi, cuja ocorrência foi constatada em estudos anteriores, não foram registradas.

Quanto aos calanóides, Notodiaptomus iheringi foi a única espécie registrada desde o início dos estudos realizados em Barra Bonita; já as demais espécies, tais como Argyrodiaptomus furcatus, Notodiaptomus conifer, N. cearensis, Notodiaptomus sp.n., N. cf. henseni e Scolodiaptomus corderoi ocorreram somente em determinados periodos (Tabela 22; Figuras 56 a 58). 
Entre os cladóceros, Bosmina hagmanni, Ceriodaphnia cornuta, C. silvestrii, Daphnia ambigua, D. gessnerı e Diaphanosoma birgel foram registradas em todos os estudos efetuados; recentemente, não foi observada a ocorrència de $C$. silvestrii e $D$. ambigua. Bosmina longirostris, Bosminopsis deitersi, Diaphanosoma spinulosum, Moina micrura e $M$. minuta foram registradas em certas épocas de estudo (Tabela 23; Figuras 56 a 58).

No reservatório de Barra Bonita, constatou-se uma variação nas condições tróficas; o IET variou de 46,8 a 65,4 (Tabelas 20 a 23; Figuras 53 a 58).

\section{Bacia do rio Sorocaba}

No reservatório de Itupararanga, localizado na bacia do rio Sorocaba foram registradas 5 espécies de ciclopóides, 2 de calanóides e 4 de cladóceros. A comunidade de microcrustáceos foi constituída por Mesocyclops longisetus, Metacyclops mendocinus, Thermocyclops decipiens, T. minutus, Tropocyclops prasinus, Argyrodiaptomus furcatus, Notodiaptomus conifer, B. deitersi, C. cornuta, D. gessneri e M. minuta. O IET obtido neste reservatório foi 58,3 (Tabelas 21 a 23; Figura 56). 
LEGENDA

IET $<4$

$4+<$ IET $<54$
$54<$ IIT $<64$
$64<$ IET $<74$
$74<$ IET $<84$
IET $>84$
IET NÃO DETERMIINADO
LIMITE DE UGRHI
LIIITIE INTERESTADUAL
CURSO D AGUA
LAGO OU RESERVATORIO

- SEDR MUUNICIPAL

FONTE: SMA (1999)

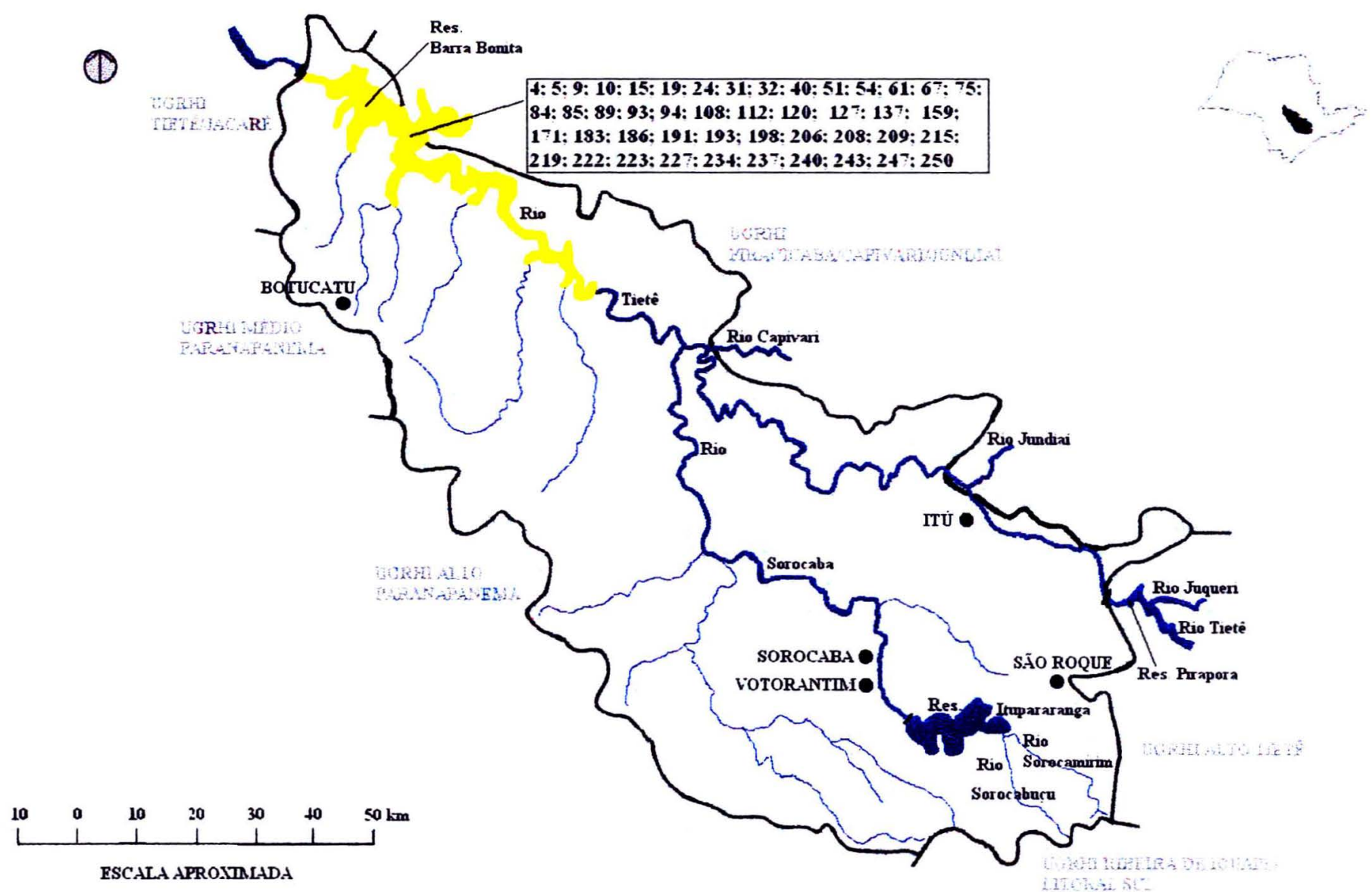

FIGURA 53 - Ocorrência de rotíferos e Índice de Estado Trófico (IET) de Carlson modificado do reservatório de Barra Bonita (década de 80) (UGRHI 10 - Sorocaba / Médio Tietê) (Números representam as espécies que constam na tabela 24). 
LFGENDA

IET

$44 \div$ IET $\div 54$

$54<$ IET $<6+$

$64 \div$ IET $\div-7$

$7 t<$ IET $<8 t$

IET $>8$

IET NÃo DETERMIINADO

\section{LIMITE DE UGRHI}

LIMITT INTERESTADUAI

DURSO D AGUA

LAGO OU RESERVATORIO

SEDF AUNICTPAI

PONTE SMIA (1099)

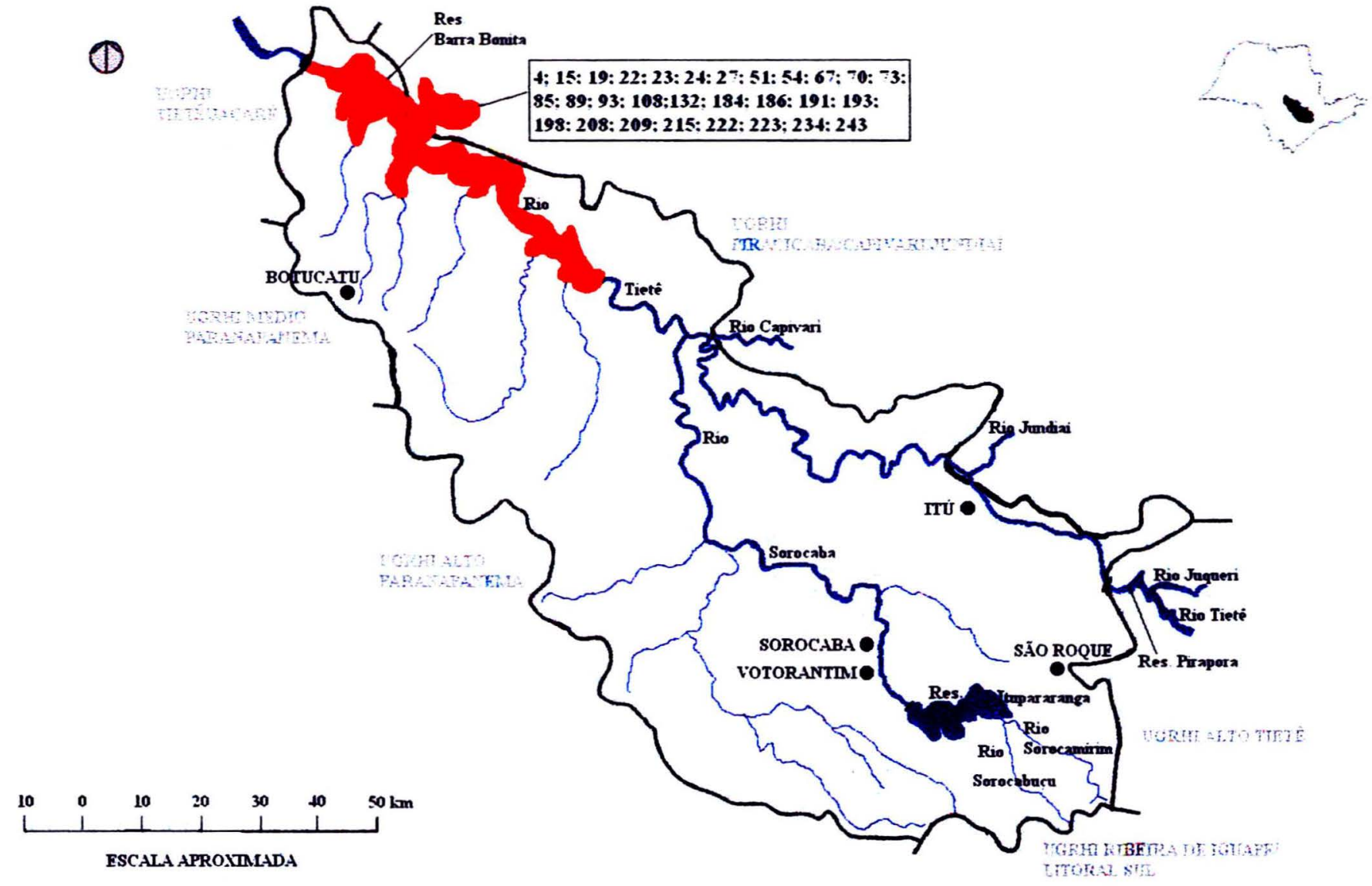

FIGURA 54 - Ocorrência de rotíferos e Índice de Estado Trófico (IET) de Carlson modificado do reservatório de Barra Bonita (década de 90) (UGRHI 10 - Sorocaba / Médio Tietê) (Números representam as espécies que constam na tabela 24). 


\section{LEGENDA}

IET $:$ :

H $<$ IET $<54$

5t $:$ IET $<64$

$64<$ IFT $<$ it

$74<$ IET $<84$

IET $>84$

IET NÃo DETERRIINADO

LIIITE DE UGRHI

LIMITE INTKRESTADUAL

D CURSO D AGUA

LAGO OU RESERVATORIO

SEDE MUNICIPAL

FONTF: SALA (1999)

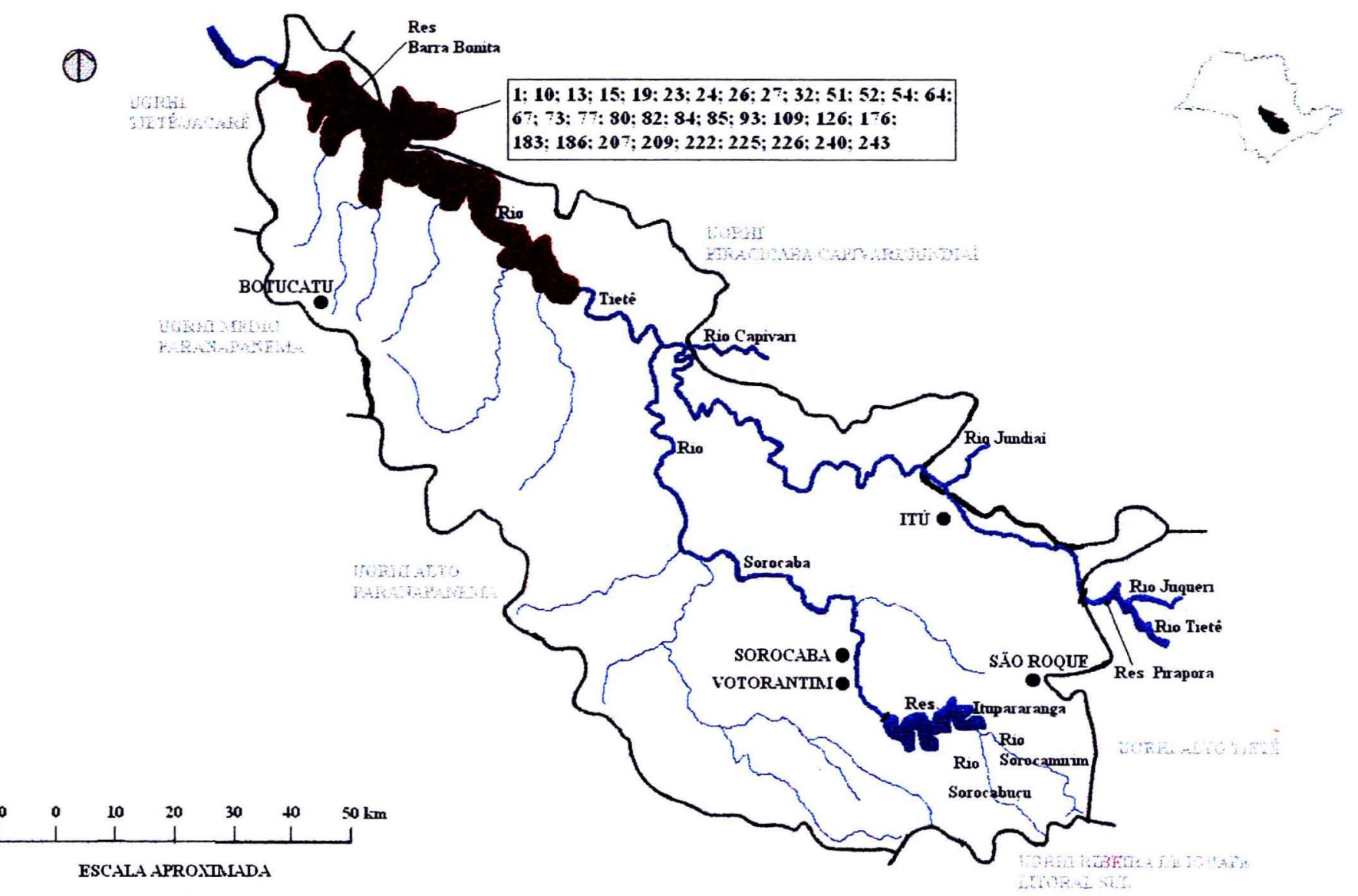

(1)

FIGURA 55 - Ocorrência de rotíferos e Índice de Estado Trófico (IET) de Carlson modificado do reservatório de Barra Bonita (dados recentes) (UGRHI 10 - Sorocaba / Médio Tietê) (Números representam as espécies que constam na tabela 24). 
LFGENDA

IET $\div 4$

$44:$ IET $<54$

$54<\operatorname{IET}<64$

C64 IET $\div-7$

$7+<$ IET $: 84$

IET $>84$

IET NÃo DETERMIINADO

$\square$ LIMTTE DF UGRH

-... LIMITTE INTERESTADUAL

YURSO D AGUA

LAGO OU RESERVATORIO

- SEDE MUUNCIPAL

FONTE: SNLA (1999)

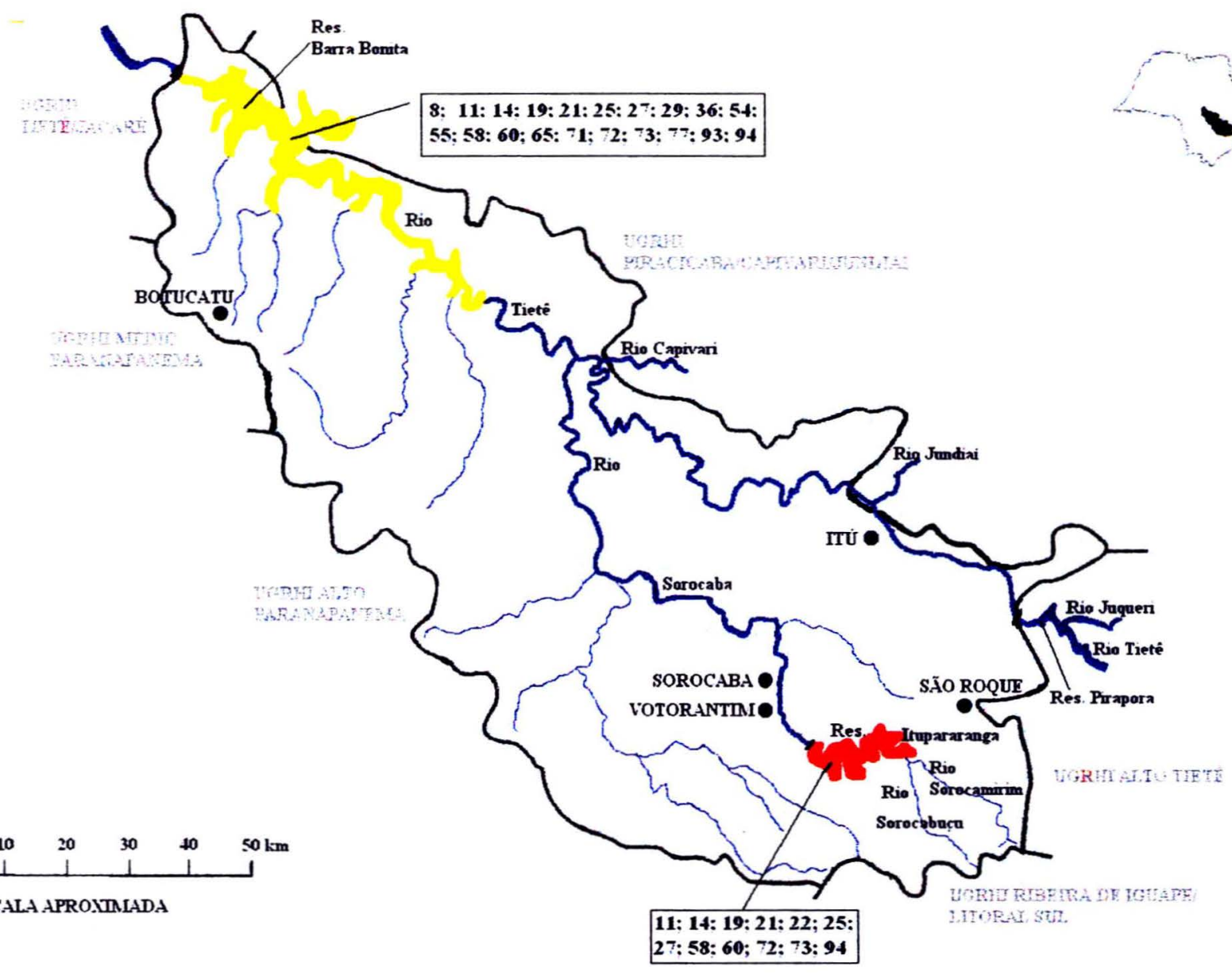

FIGURA 56 - Ocorrência de microcrustáceos e Índice de Estado Trófico (IET) de Carlson modificado dos reservatórios de Itupararanga (1979) e Barra Bonita (década de 80) (UGHRI 10 - Sorocaba / Médio Tietê) (Números representam as espécies que constam na tabela 25 ). 


\section{LFGENDA}

IET $<4$

$4+<\operatorname{IET}<5+$

$54:$ IET $<6+$

$64<$ IET $<74$

$74<\operatorname{IET}<84$

IET $>84$

IET NÃO DETERMINADO

$\square$ LMITIE DE UGRHI

-.- LIMITE INTERESTADUAL

CURSO D iguA

LAGO OU RFSERVATÓRIO

SEDr amunctral

FONTE: SMA (1959)

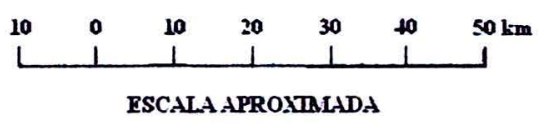

ISCALA APROXTMLDA
0

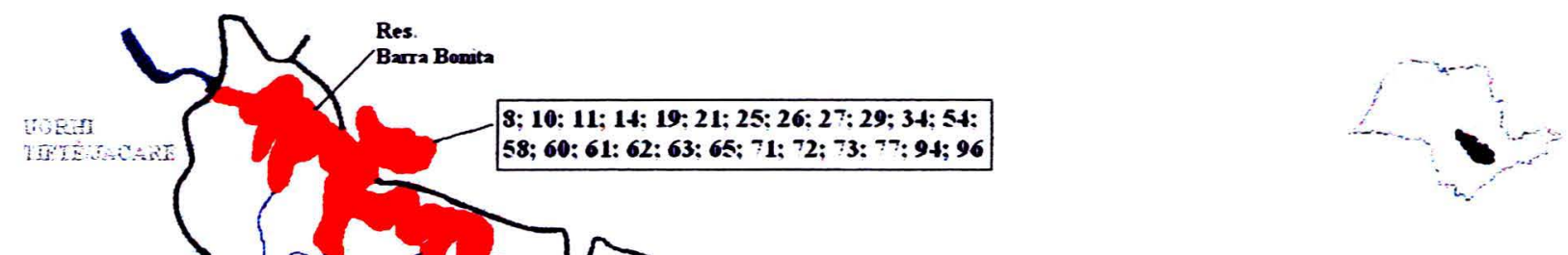

FIGURA 57 - Ocorrência de microcrustáceos e Índice de Estado Trófico (IET) de Carlson modificado do reservatório de Barra Bonita (década de 90) (UGRHI 10 - Sorocaba / Médio Tietê) (Números representam as espécies que constam na tabela 25). 
LEGENDA

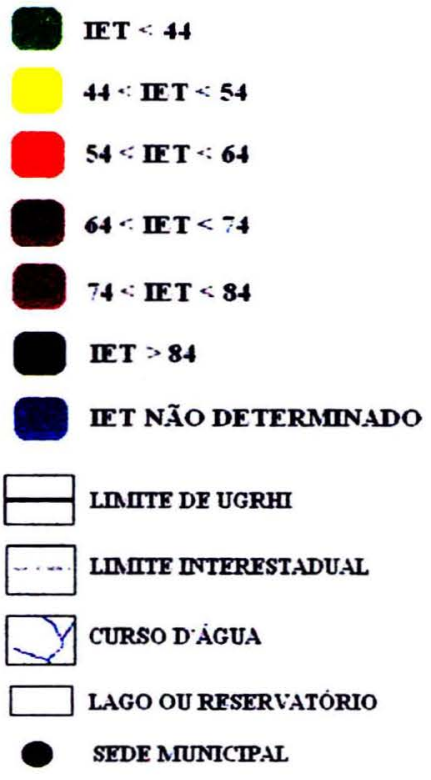

FONTY SNA (1999)

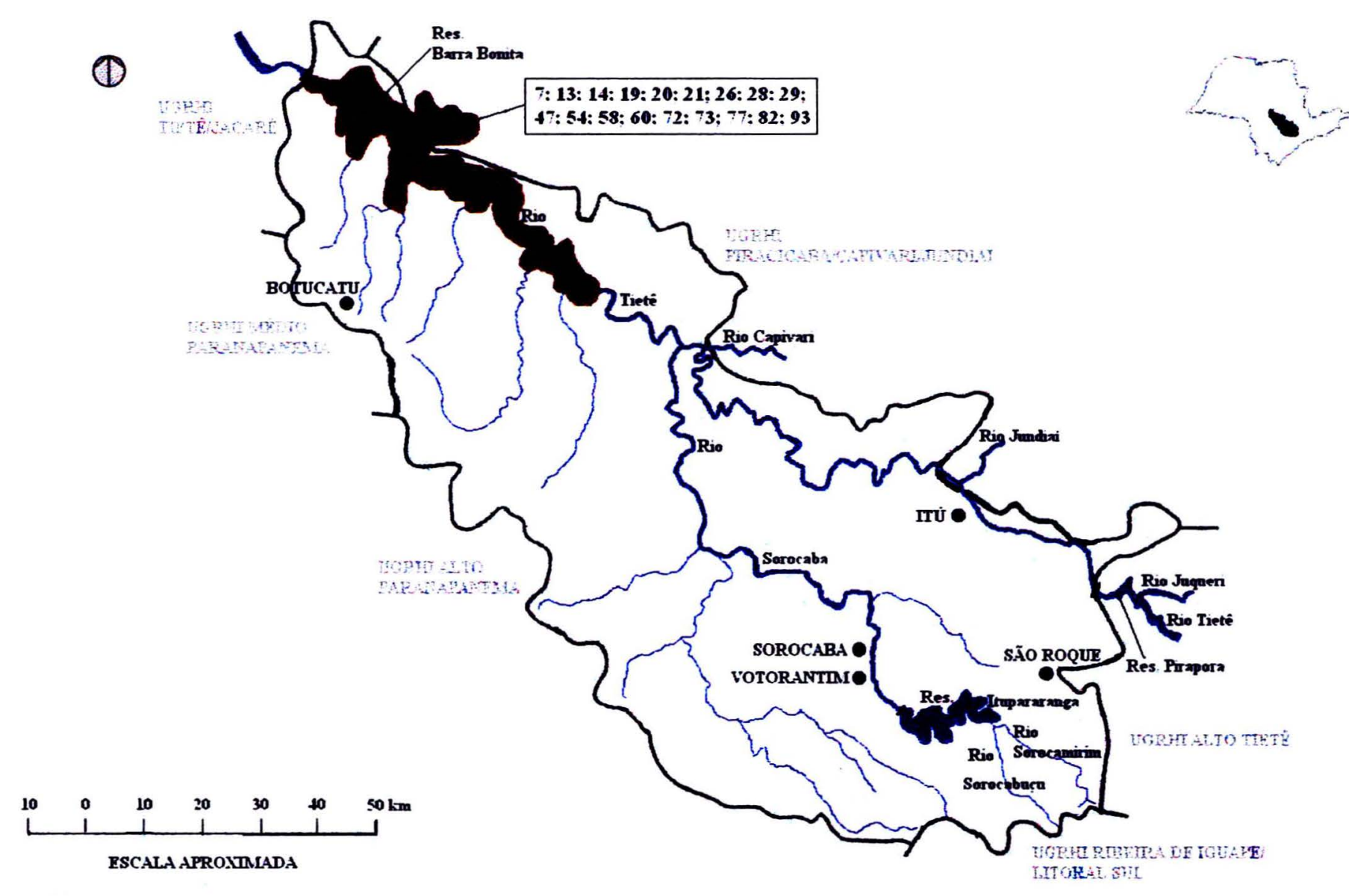

FIGURA 58 - Ocorrência de microcrustáceos e Índice de Estado Trófico (IET) de Carlson modificado do reservatório de Barra Bonita (dados recentes) (UGRHI 10 - Sorocaba / Médio Tietê) (Números representam as espécies que constam na tabela 25 ). 


\section{UGRHI 11 - RIBEIRA DE IGUAPE/LITORAL SUL}

Os reservatórios França, Fumaça, Alecrim e Serraria, localizados na bacia do rio Ribeira de Iguape, apresentaram a mesma composição de microcrustáceos. Em relação aos ciclopóides, foi constatada a ocorrência de Mesocyclops longisetus, Metacyclops mendocinus, Thermocyclops decipiens, T. minutus e Tropocyclops prasinus. Odontodiaptomus paulistanus foi a única espécie de calanóide registrada, e os cladóceros foram representados por Bosminopsis deitersi, Ceriodaphnia cornuta, Daphnia gessneri e Moina minuta (Tabelas 21a 23; Figura 59). Quanto ao estado trófico, o IET variou de 58,8 em Alecrim, a 68,7 em Serraria (Tabelas 21 a 23; Figura 59).

\section{UGRHI 12 - BAIXO PARDO/GRANDE}

Na UGRHI do Baixo Pardo/Grande, onde estão localizados os reservatórios Porto Colombia e Marimbondo, ocorreram 11 espécies de rotíferos, 3 de ciclopóides, 4 de calanóides e 10 de cladóceros (Tabelas 20 a 23; Figuras 60; 61).

Em relação aos rotíferos, em Porto Colombia foram registradas Brachionus angularis, Conochilus coenobasis, Hexarthra intermedia braziliensis, H. mira, Keratella americana, $K$. cochlearis e Ptygura libera, entre outras espécies. Já em Marimbondo, evidenciou-se a presença de Collotheca ornata, C. coenobasis, H. mira e $K$. cochlearis.

Thermocyclops decipiens, T. minutus e M. longisetus co-ocorreram em Porto Colombia; já em Marimbondo, a única espécie registrada foi T. minutus. Quanto aos calanóides, em Marimbondo foi evidenciada a co-ocorrência de Argyrodiaptomus azevedoi e A. furcatus, e a presença de Notodiaptomus spinuliferus e Scolodiaptomus corderol, e em Porto Colombia, A. furcatus e S. corderoi co-ocorreram.

Em Porto Colombia, os cladóceros foram representados por Bosmina hagmanni, B. longirostris, B. deitersi, C. cornuta, D. gessneri, Diaphanosoma birgei e M. minuta; já em Marimbondo foi registrada a ocorrência de C. cornuta, $D$. gessneri e D. hirgei. Quanto às condições tróficas, o IET obtido em Marimbondo foi 40,7 e em Porto Colombia foi 45,2 (Tabelas 20 a 23; Figuras 60; 61). 


\section{(1)}

LFGENDA

IET $<4$

$H<$ IFT $<s t$

$54:$ IET $<64$

$64:$ IET $<74$

$7 t<$ IET $<84$

IET $>84$

IET NÃO DETERMINADO

$\square$ LIMITE DE UGRHI

- - . LIMTEE INTERESTADUAL

DCURSO D AGUA

LAGO OU RESERVATÓRIO

- SEDE MUNICIPAL

FONTI : SMA (1099)

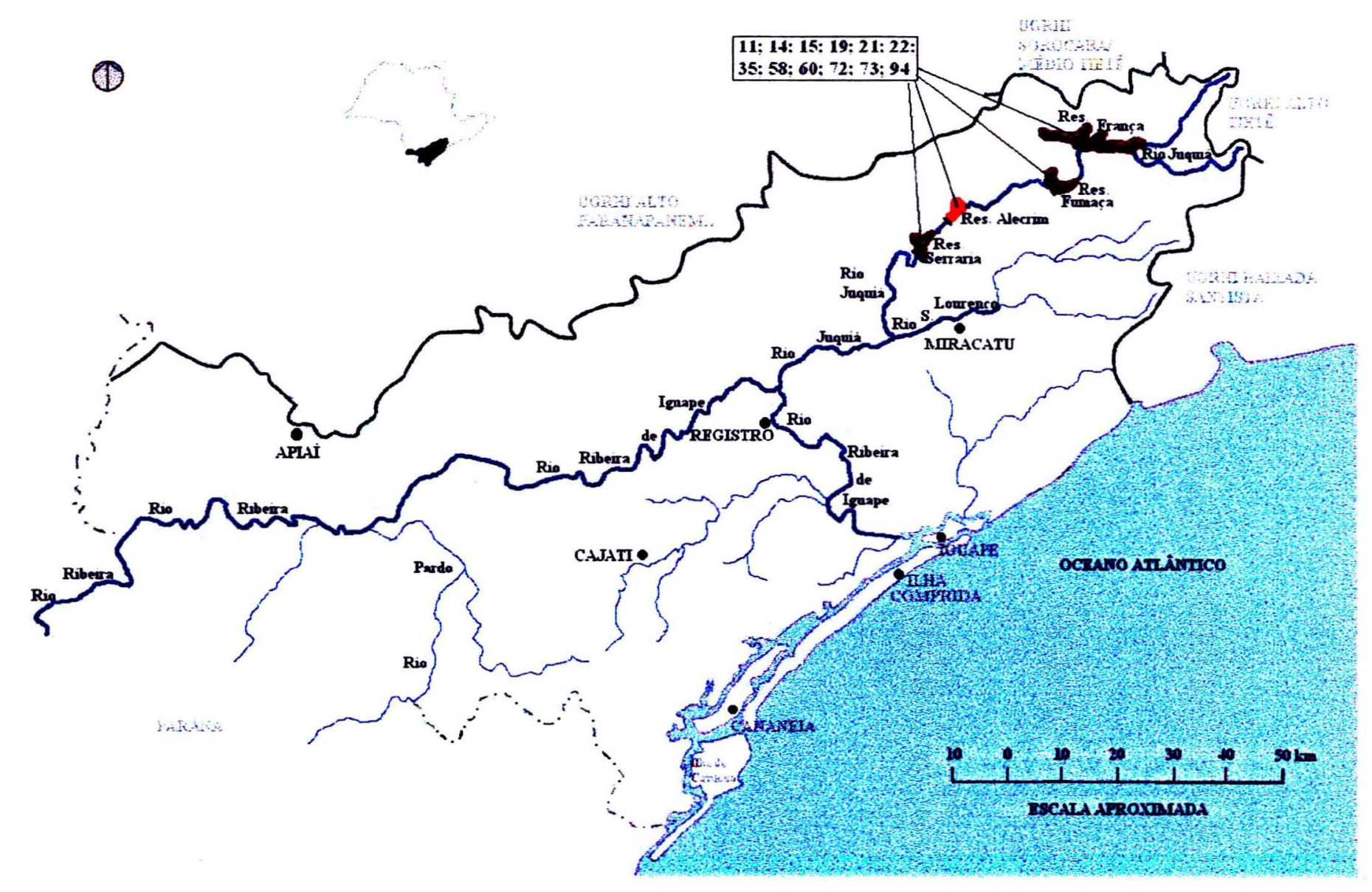

FIGURA 59 - Ocorrência de microcrustáceos e Índice de Estado Trófico (IET) de Carlson modificado dos reservatórios França, Fumaça, Alecrim e Serraria (UGHRI 11 - Ribeira de Iguape / Litoral Sul) (Números representam as espécies que constam na tabela 25). 


\section{$\square$ LINITE DF UGRHI \\ - . L LIITTE INTEREST.ADUAL \\ C CURSO D AGUA \\ LAGO OU RFSERVATORIO \\ SEDR MUNICIPAL}

FONTE SALA (1999)

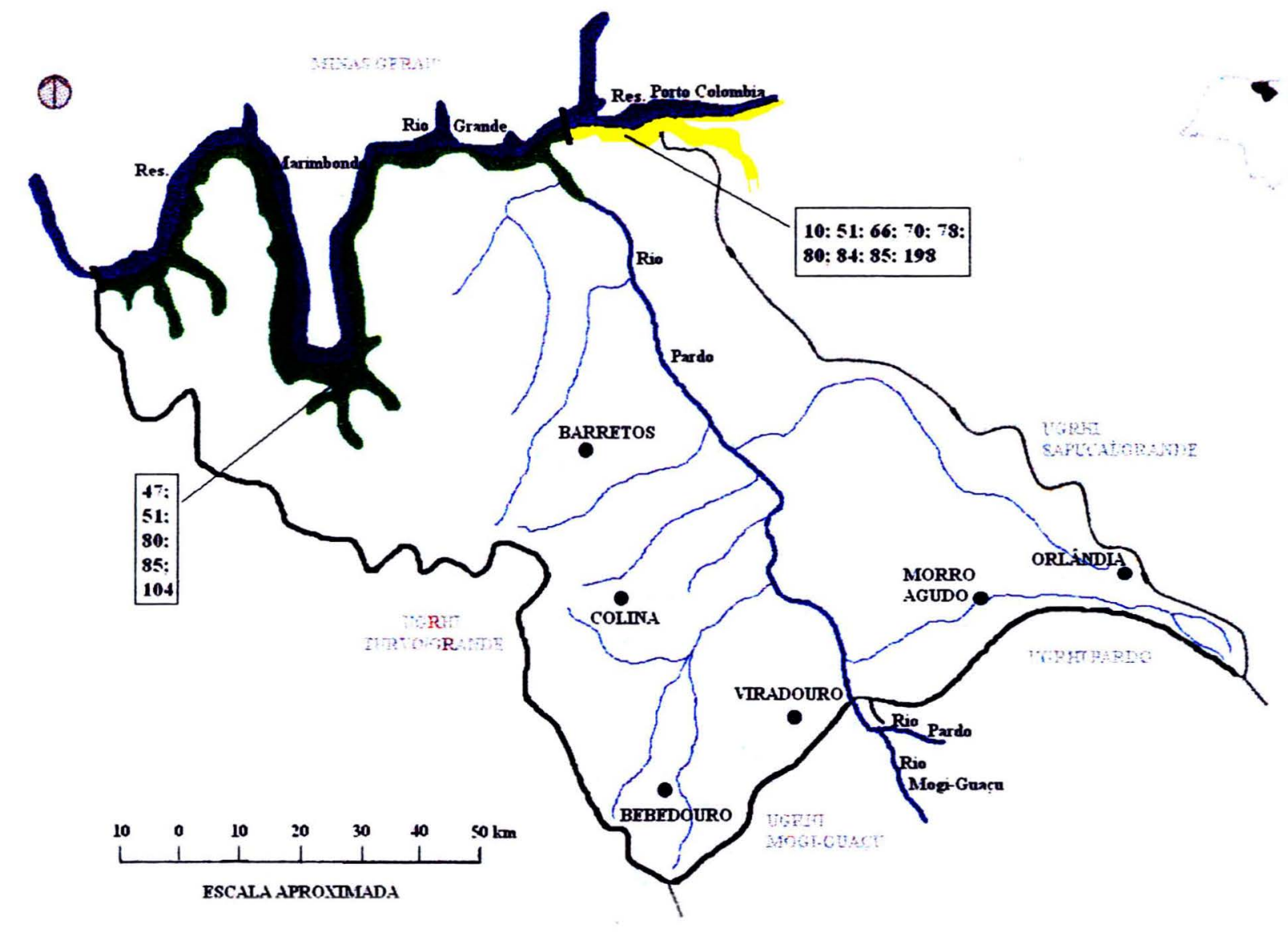

FIGURA 60- Ocorrência de rotíferos e Índice de Estado Trófico (IET) de Carlson modificado dos reservatórios Porto Colombia e Marimbondo (UGRHI 12 - Baixo Pardo / Grande) (Números representam as espécies que constam na tabela 24). 
LEGENDA

IET $<4$

$44<$ IET $<54$
$54<$ EET $<64$
$64<$ IET $<74$
$74<$ IET $<84$
EET $>84$
IET NÃO DETERNINADO

$\square$ LMTIR DE UGRHI

-.. LINTIE INTERESTADUAL

D CURSO D'AGUA

$\square$ LAGO OU RESERVATORIO

- SEDF MUNICTPAI

FONTE: SMA (1999)

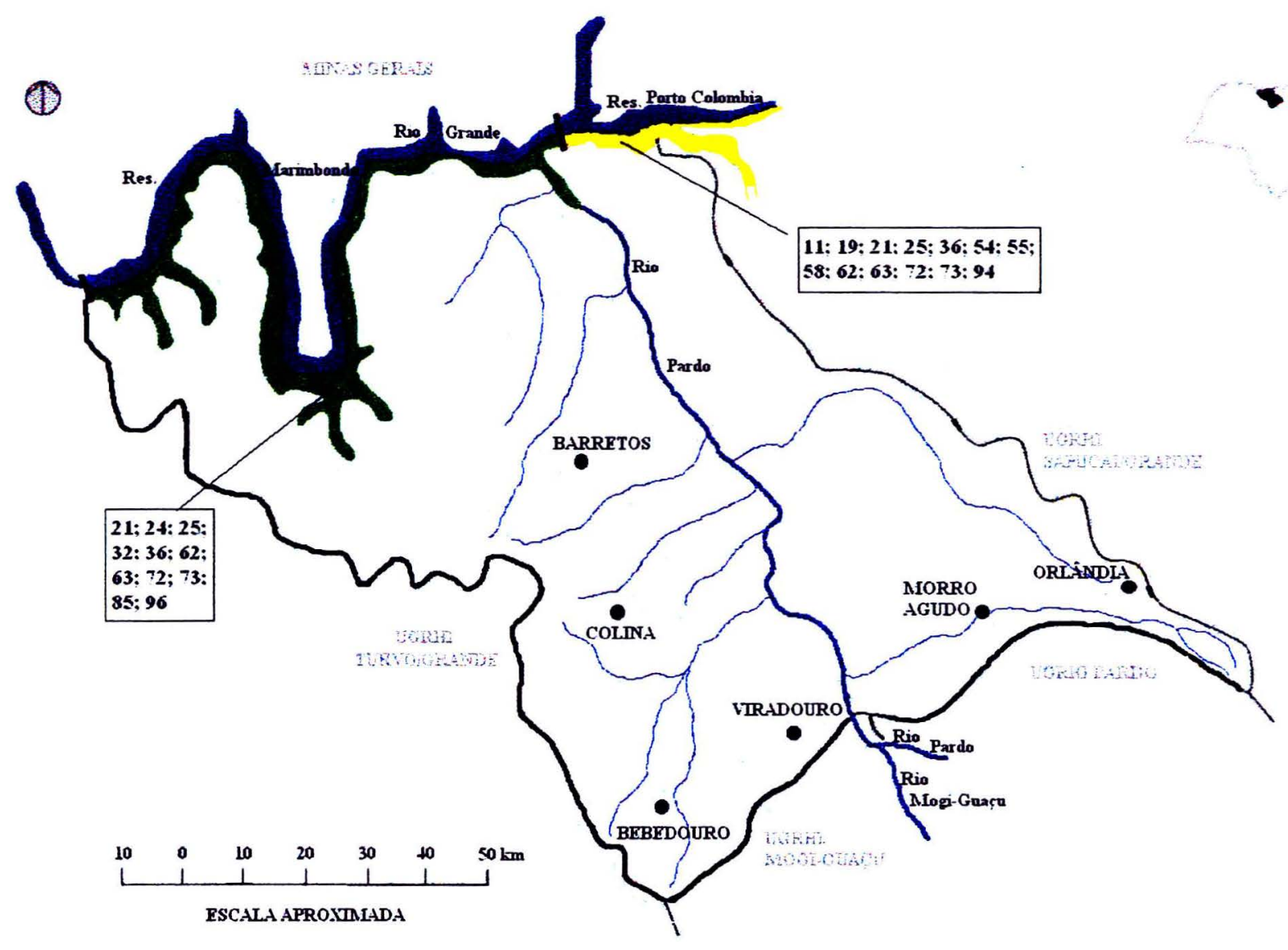

FIGURA 61 - Ocorrência de microcrustáceos e Índice de Estado Trófico (IET) de Carlson modificado dos reservatórios Porto Colombia e Marimbondo (UGRHI 12 - Baixo Pardo / Grande) (Números representam as espécies que constam na tabela 25). 


\section{UGRHI 13 - TIETÊ/JACARÉ}

A UGRHI Tietê/Jacaré engloba os reservatórios Lobo (Broa), Monjolinho, Jacaré-Pepira, Bariri e Ibitinga, e as lagoas Dourada e da Pedreira; foram registradas nesta bacia 173 espécies de rotiferos, 13 de ciclopóides, 3 de calanóides e 52 de cladóceros.

No reservatório do Broa ocorreram 131 espécies de rotiferos, 8 de ciclopóides, 2 de calanóides, e 43 de cladóceros. Em relação aos rotiferos, nos primeiros estudos realizados foram registradas Brachionus falcatus, $B$. quadridentatus, Collotheca ornata e Keratella cochlearis (Tabela 20; Figura 62)

Posteriormente, em 93, foram registradas Anuraeopsis fissa, Conochilus coenobasis. (: unicornis, Hexarthra mira, Keratella americana, K. cochlearis, Polyarthra vulgaris, Ptygura libera. Trichocerca capucina, T. pusilla, entre outras (Tabela 20; Figura 62).

No estudo efetuado em 95 , na região limnética e litorânea do Broa, ocorreram 45 espécies de rotíferos; deste total, 30 espécies do gênero Lecane, 12 de Lepadella, 12 de Trichocerca, 6 de Cephalodella, entre outras, além da ocorrência de uma nova espécie, Ascomorpha tundisii. Recentemente, foram registradas Brachionus mirus, Filinia pejleri e Hexarthra longicornicula, entre outras (Tabela 20; Figura 62).

Asplanchna sieboldi, $B$. falcatus, Filinia longiseta, $K$. americana, $K$. cochlearis, P. vulgaris e Synchaeta stylata foram comuns a ambos os estudos efetuados no reservatório Monjolinho. Já Brachionus angularis, B. calyciflorus, $H$. mira, Plationus patulus e $P$. libera só foram registradas no primeiro estudo.

Na lagoa Dourada, foram registradas K. cochlearis, P. vulgaris, Trichocerca collaris e T. longiseta; já B. calyciflorus, B. falcatus, F. longiseta e Keratella tropica só ocorreram no primeiro estudo, e nos subsequentes, ocorreram Hexarthra intermedia e Trichocerca similis, entre outras espécies da região litorànea (Tabela 20; Figura 62).

No reservatório de Jacaré-Pepira, no primeiro estudo foi registrada $T$. capucina, entre outras: posteriomente, ocorreram B. falcatus, K. americana, $K$. cochlearts, K. tropica, H. mira, P. patulus, P. vulgaris, P. libera, entre outras. 
Na lagoa da Pedreira, situada na região urbana do município de São Carlos, foram registradas Brachionus falcatus, Hexarthra intermedia braziliensis, $H$. intermedia, Keratella americana, K. cochlearis, Polyarthra vulgaris, Ptygura libera, entre outras. No reservatório de Bariri, foi constatada a ocorrência de Anuraeopsis fissa, Asplanchna sieboldi, H. intermedia braziliensis, Keratella tropica e Trichocerca capucina (Tabela 20; Figura 62).

Quanto aos ciclopóides, no reservatório do Broa ocorreram Mesocyclops longisetus e Thermocyclops minutus, e no reservatório Jacaré-Pepira, no primeiro estudo foram registradas $M$. longisetus e Tropocyclops prasinus; posteriormente, foi evidenciada a co-ocorrência de Thermocyclops decipiens e M. longisetus (Tabela 21; Figura 63).

No reservatório de Monjolinho, no primeiro estudo realizado, $T$. decipiens foi a única especie registrada; posteriormente, ocorreram modificações na composição de ciclopóides, constatando-se a co-ocorrência de $T$. decipiens e Metacyclops mendocinus, juntamente com M. longisetus e T. prasinus (Tabela 21; Figura 63).

Como em Monjolinho, a composição de ciclopóides também sofreu algumas alterações na lagoa Dourada. No início dos estudos, evidenciou-se a co-ocorrência de T. decipiens e $M$. longisetus, e a presença de Tropocyclops schubarti; posteriormente, $M$. longisetus foi a única espécie registrada, e mais recentemente, constatou-se o aparecimento de $T$. prasinus. Já na lagoa da Pedreira, a única espécie registrada foi $T$. decipıens. Nos reservatórios de Bariri e Ibitinga, $T$. decipiens, $T$. minutus e $M$. longisetus co-ocorreram.

Quanto aos calanóides, nos primeiros estudos realizados no reservatório do Broa Argyrodiaptomus furcatus foi a única espécie registrada, sendo substituída ocasionalmente por Notodiaptomus iheringi (Tabela 22; Figura 63). No reservatório Jacare-Pepira, foi registrada somente a ocorrència de $A$. furcatus, e nos reservatórios Bariri e Ibitinga estiveram presentes Notodiaptomus conifer e $N$. iheringi. Nas lagoas Dourada e da Pedreira não ocorreram calanóides.

No reservatório do Broa, os cladóceros foram representados por Bosmina coregoni, B. hagmanni, B. longirostris, B. tubicen, Bosminopsis deitersi, Ceriodaphnia cornuta, ( . silvestrii, Daphnia ambigua, Diaphanosoma hirget, D. chilensi, D. fliviatile e Moina minuta (Tabela 23; Figura 63). 
No primeiro estudo realizado no reservatório Monjolinho foram registradas Bosmina hagmanni, Bosminopsis deitersi, Daphnia ambigua e Moina minuta; posteriormente, Moina micrura substituiu $M$. minuta, não sendo observada a ocorrência de $B$. hagmanni. No reservatório Jacaré-Pepira, os cladóceros foram representados por B. hagmanni, B. deitersi, Ceriodaphnia cornuta, C. silvestrii, Daphnia gessneri, Diaphanosoma birget e M. minuta.

Bosmina hagmanni, B. deitersi, C. cornuta e D. ambigua ocorreram na lagoa Dourada, e Bosmina tubicen, B. hagmanni, B. deitersi, C. cornuta, D. ambigua e $M$. micrura na lagoa da Pedreira.

A composição de cladóceros nos reservatórios Bariri e Ibitinga foi semelhante, onde foram registradas Bosmina longirostris, C. cornuta, D. gessneri e D. birgei; já B. hagmanni ocorreu somente no reservatório de Bariri, e C. silvestrii no reservatório de Ibitinga.

Nos corpos d'água da UGRHI Tietê/Jacaré evidenciou-se uma grande amplitude de variação das condições tróficas; no reservatório Jacaré-Pepira o IET variou de 35,8 a 39,7, na lagoa Dourada foi 48,2, nos reservatórios Bariri e Monjolinho foi 50,7 e 53,0 respectivamente, e no reservatório de Ibitinga o valor obtido foi 54,1. Já nos reservatórios do Broa e na lagoa da Pedreira, o IET não foi determinado devido à ausência de dados de clorofila $a$ (Tabelas 20 a 23; Figuras 62; 63). 


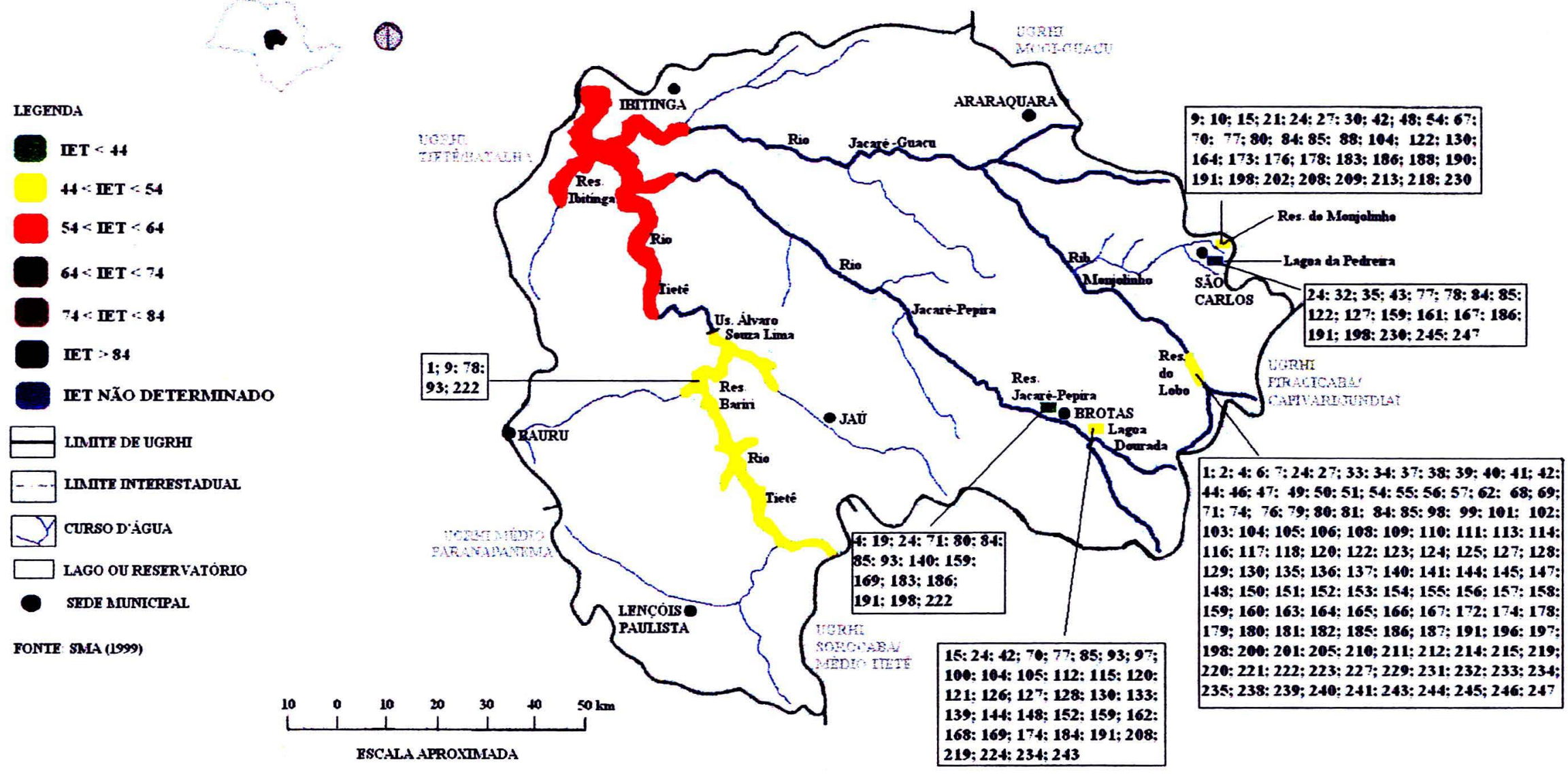

FIGURA 62 - Ocorrência de rotíferos e Índice de Estado Trófico (IET) de Carlson modificado dos reservatórios Bariri, Lobo (Broa), Monjolinho e Jacaré-Pepira, e lagoas Dourada e da Pedreira (UGRHI 13 - Tietê / Jacaré) (Números representam as espécies que constam na tabela 24). 


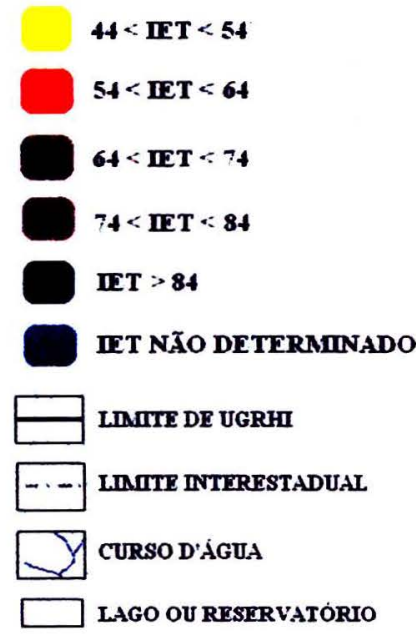

- SEDE MUNICIPAL

FONTE: SMLA (1999)

\section{(1)}

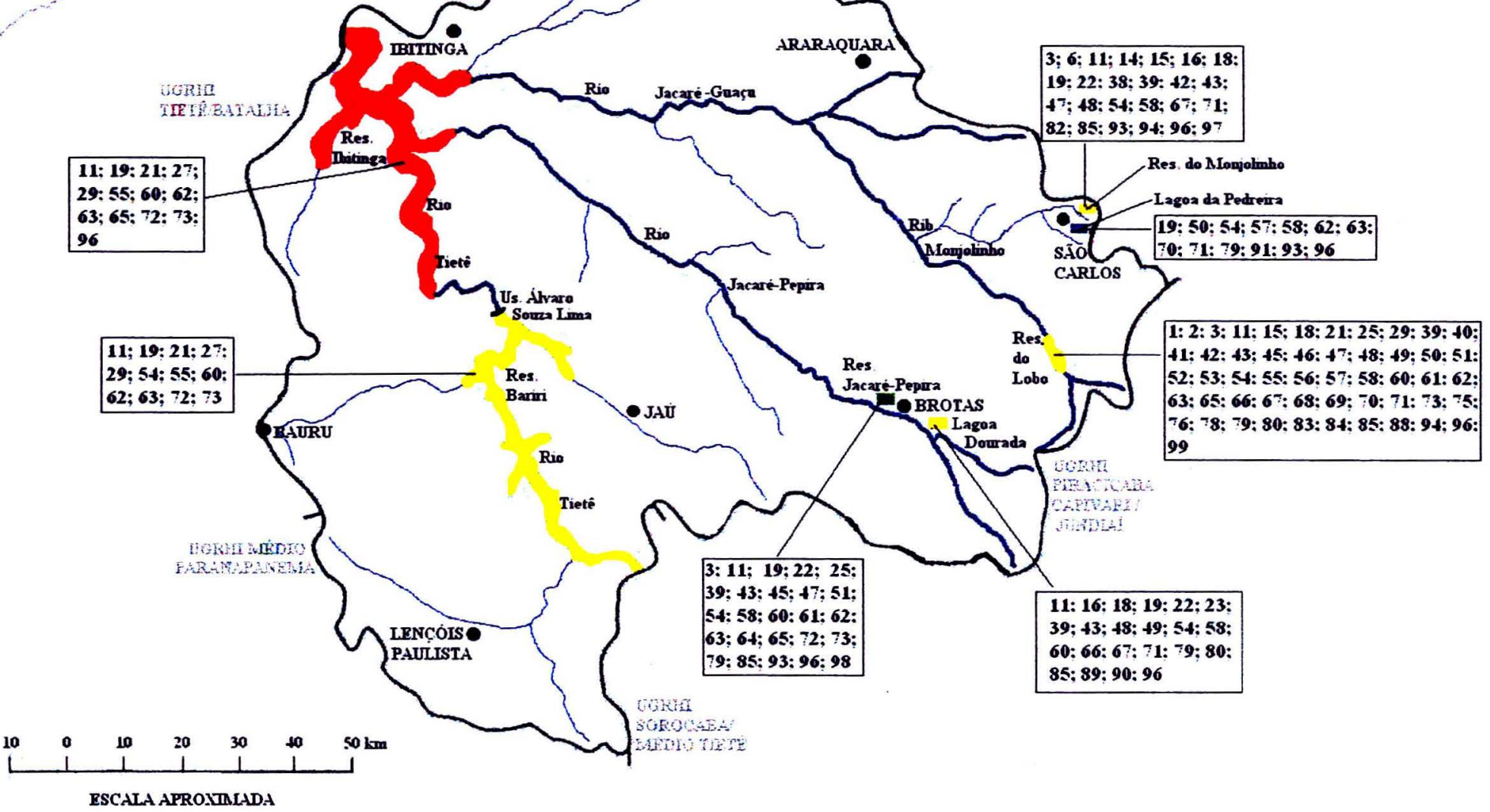

FIGURA 63 - Ocorrência de microcrustáceos e Índice de Estado Trófico (IET) de Carlson modificado dos reservatórios Bariri, Ibitinga, Lobo (Broa), Monjolinho e Jacaré-Pepira, e lagoas Dourada e da Pedreira (UGRHI 13 - Tietê / Jacaré) (Números representam as espécies que constam na tabela 25). 


\section{UGRHI 14 - ALTO PARANAPANEMA}

A UGRHI do Alto Paranapanema engloba os reservatórios Jurumirim, Piraju, Xavantes, São José e Batista e as lagoas do Camargo e do Coqueiral.

Em relação aos rotíferos, no reservatório de Jurumirim foram registradas 52 espécies pertencentes principalmente aos gêneros Lecane (11), Trichocerca (8), Brachionus (4), Keratella (4), Conochilus (3) e Filinia (3). No primeiro estudo realizado neste reservatório foram registradas Asplanchna sieboldi, Conochilus coenobasis, Keratella americana e Trichocerca capucina (Tabela 20; Figura 64).

Posteriormente, em 96, foi constatada a ocorrência de Brachionus calyciflorus, B. falcatus, Conochilus unicornis, K. americana, Keratella cochlearis, K. lenzi, K. tropica, Plationus patulus e Polyarthra vulgaris, entre outras espécies registradas (Tabela 20; Figura 64). Deve-se ressaltar que este estudo considerou a ocorrência de espécies zooplanctônicas tanto no reservatório Jurumirim como nos tributários.

Estudos efetuados em 98 evidenciaram alterações na composição de rotíferos; foi constatado o aparecimento de Ascomorpha ecaudis, C. coenobasis, Conochilus natans, Filinia longiseta, $F$. opoliensis, $F$. terminalis, Hexarthra intermedia, Polyarthra cf. major, Trichocerca cylindrica, T. dixon-nutalli e T. similis, além de outras espécies (Tabela 20; Figura 64).

Em estudo mais recente, em 99, evidenciou-se que Brachionus angularis substituiu B. calyciflorus, além do aparecimento de B. falcatus, Collotheca mutabilis, C. ornata, Hexarthra intermedia braziliensis, Synchaeta pectinata, S. stylata, além de várias espécies de Lecane e Trichocerca (Tabela 20; Figura 64). Conochilus unicornis, $K$. americana, $K$. cochlearis, $K$. tropica e $P$. vulgaris também foram registradas em todos os estudos realizados no reservatório de Jurumirim.

A composição de rotíferos das lagoas do Camargo e do Coqueiral foi semelhante; foi constatada a ocorrência de espécies de Brachionus (B. angularis, $B$. bidentata, B. dolabratus, B. falcatus, B. forficula), de C. coenobasis, C. unicornis, $F$. longiseta, F. terminalis, K. americana, K. cochlearis, K. lenzi, e T. capucina (Tabela 20; Figura 64).

Nos reservatórios Piraju e Xavantes, foram registradas Filinia longıseta e Keratella americana; já Conochilus coenobasis e Keratella cochlearis ocorreram 
somente no reservatório Piraju, e Asplanchna sieboldi e Trichocerca capucina no reservatório Xavantes.

Quanto aos ciclopóides, em todos os estudos efetuados no reservatório de Jurumirim, foi constatada a co-ocorrência de Thermocyclops decipiens e T. minutus, e Mesocyclops longisetus. No estudo realizado em 96, também foram registradas Mesocyclops brasilianus e $M$. kieferi. Nas lagoas do Coqueiral e do Camargo, $T$. decipiens e T. minutus co-ocorreram (Tabela 21; Figura 65).

Em relação aos demais reservatórios desta UGRHI, $M$. longisetus e $T$. minutus foram registradas em Piraju; já em Xavantes, a única espécie registrada foi T. minutus. Em São José, foi evidenciada a co-ocorrência de $T$. decipiens e Metacyclops mendocinus, juntamente com M. longisetus, e Tropocyclops prasinus; estas duas últimas espécies foram registradas no reservatório Batista.

Argyrodiaptomus furcatus, Notodiaptomus conifer e $N$. iheringi ocorreram no reservatório Jurumirim; recentemente não foi constatada a ocorrência de $N$. conifer neste reservatório, que por sua vez foi a única espécie registrada na lagoa do Coqueiral (Tabela 22; Figura 65).

Nos reservatórios Piraju e Xavantes ocorreram A. furcatus e $N$. conifer, sendo esta última espécie também registrada no reservatório Batista. Não ocorreram calanóides no reservatório São José.

A composição de cladóceros no reservatório Jurumirim permaneceu praticamente a mesma, em todos os estudos efetuados; foram registradas Bosmina hagmanni, B. longirostris, Ceriodaphnia cornuta, C. silvestrii, Daphnia gessneri, Diaphanosoma birgei. D. fluviatile e D. spinulosum (Tabela 23; Figura 65).

Nas lagoas do Coqueiral e do Camargo, a composição de cladóceros foi semelhante, registrando-se B. hagmanni, B. longirostris, Bosminopsis deitersi, $C$. cornuta, Daphnia ambigua, D. birget, D. fluviatile e Moina minuta. Na lagoa do Coqueiral ocorreram C. silvestru, D. ambigua, D. gessneri, D. birgei, Diaphanosoma brevireme. D. fluviatile e D. spinulosum, e na lagoa do Camargo foi registrada Bosmina cf tubicen.

Nos reservatórios Piraju e Xavantes, os cladóceros foram representados pelas mesmas espécies; foram registradas Bosmina hagmanni, B. longirostris, Ceriodaphnia cornuta, C. silvestril, Daphnia gessneri, Diaphanosoma birg.i e 
Moina minuta. Em São José e Batista, ocorreram Bosminopsis deitersi, C. cornuta, D. birgei e $M$. minuta; já em Batista, também foi registrada $D$. gessneri.

O IET do reservatório Jurumirim variou de 31,3 a 41,4; nos reservatórios Xavantes e Piraju, o IET obtido foi 35,5 e 40,0, respectivamente. Nas lagoas do Camargo e do Coqueiral o IET obtido foi 51,2 e 54,2, respectivamente; no reservatório São José foi 67,5 e no reservatório Batista, 69,6 (Tabelas 20 a 23; Figuras $64 ; 65$ ). 
SEDR MUUNCTPAI

FONTE SNA (1999)

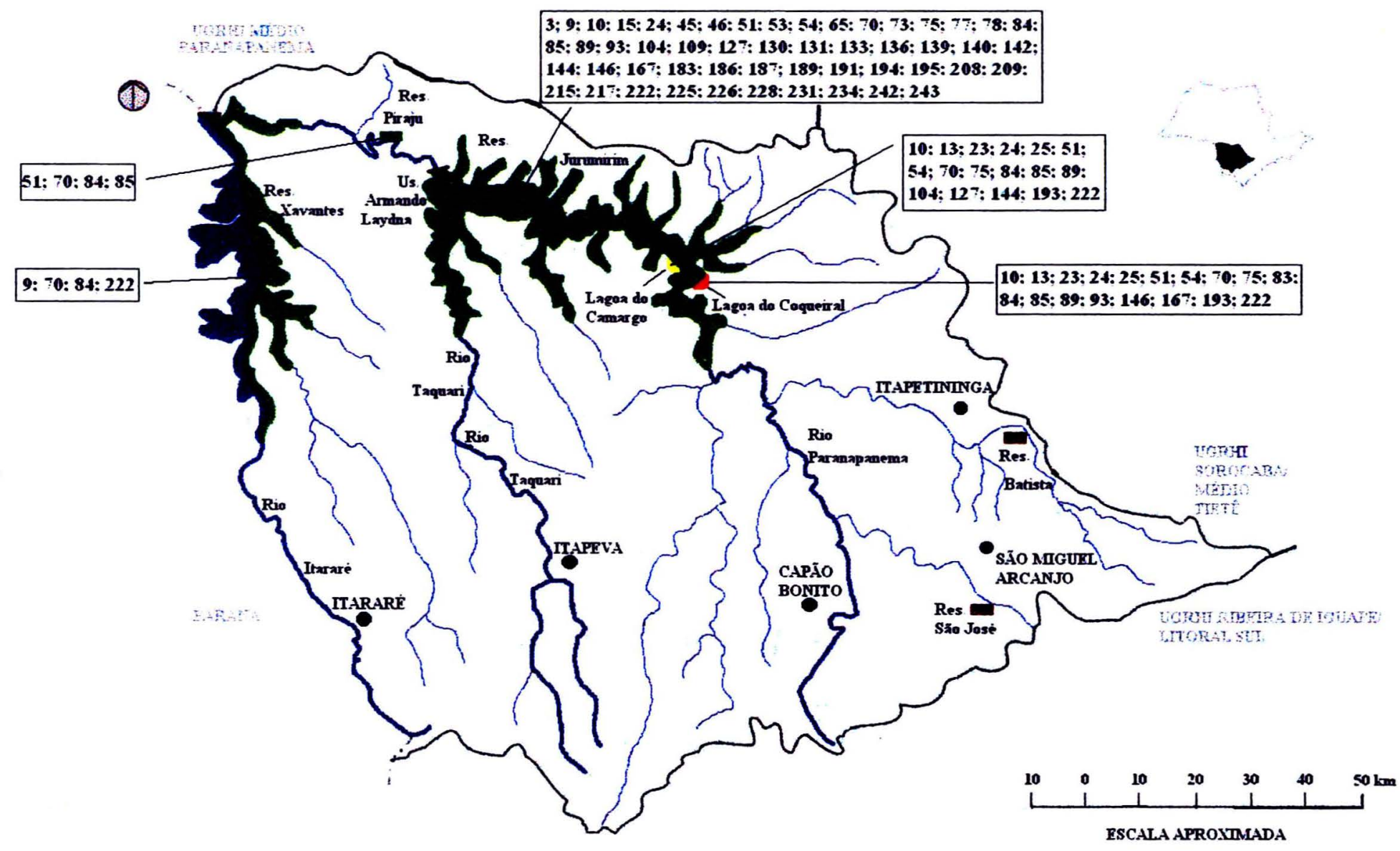

FIGURA 64 - Ocorrência de rotíferos e Índice de Estado Trófico (IET) de Carlson modificado dos reservatórios Jurumirim, Xavantes e Piraju, e lagoas do Coqueiral e do Camargo (UGRHI 14 - Alto Paranapanema) (Números representam as espécies que constam na tabela 24). 
$\square$ LAGO OU RESERVATORIO - SEDE MUNICIPAI

FONTE: SNAA (1999)

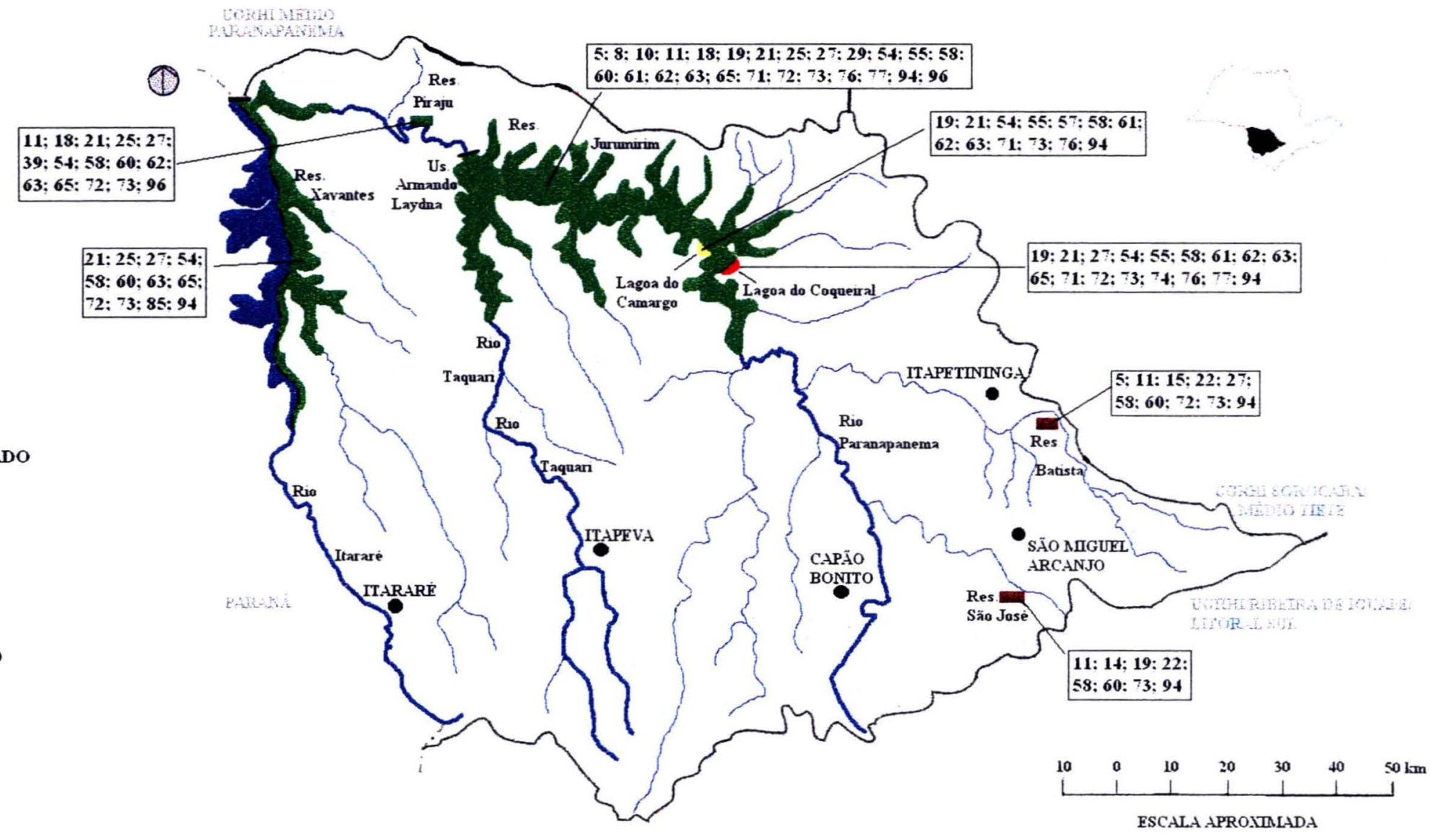

FIGURA 65 - Ocorrência de microcrustáceos e Índice de Estado Trófico (IET) de Carlson modificado dos reservatórios Jurumirim, Xavantes, Piraju, Batista e São José, e lagoas do Coqueiral e do Camargo (UGRHI 14 - Alto Paranapanema) (Números representam as espécies que constam na tabela 25). 


\section{UGRHI 15 - TURVO/GRANDE}

No reservatório Água Vermelha, localizado na UGRHI dos rios Turvo e Grande, foram registrados entre os rotiferos Asplanchna sieboldi, Keratella cochlearis, Hexarthra mira e Lecane curvicornis. Quanto aos calanóides, foi constatada a presença de Argyrodiaptomus furcatus, Notodiaptomus conifer e $N$. transitans; não ocorreram ciclopóides. Em relação aos cladóceros, foram registradas Bosmina hagmanni, Daphnia gessneri e Diaphanosoma birgei. O IET obtido para este reservatório foi 40,6 (Tabelas 20; 22, 23; Figuras 66; 67).

\section{UGRHI 16 - TIETÊ/BATALHA}

Na UGRHI Tietê/Batalha, onde está localizado o reservatório de Promissão, foi evidenciada a ocorrência de $K$. cochlearis, Ptygura libera e Trichocerca capucina (Tabela 20; Figura 68). Os ciclopóides foram representados por Mesocyclops longisetus, Thermocyclops minutus e Tropocyclops prasinus, e os calanóides por A. furcatus, N. conifer e N. transitans (Tabelas 21; 22; Figura 69).

Quanto aos cladóceros, foram registradas B. hagmanni, Ceriodaphnia cornuta, D. gessneri e D. birgei, entre outras (Tabela 23; Figura 69). Em relação ao estado trófico, o IET obtido no reservatório de Promissão foi 52,2 (Tabelas 20 a 23; Figuras $68 ; 69$ ). 


\section{$\square$ LIIITE DE UGRHI \\ - ... LIIITE INTERESTADUAL \\ DCURO D AGUA \\ LAGO OU RESERVATÓRIO}

- SEDE MUUNCTPAI

FONTE SALA (1099)

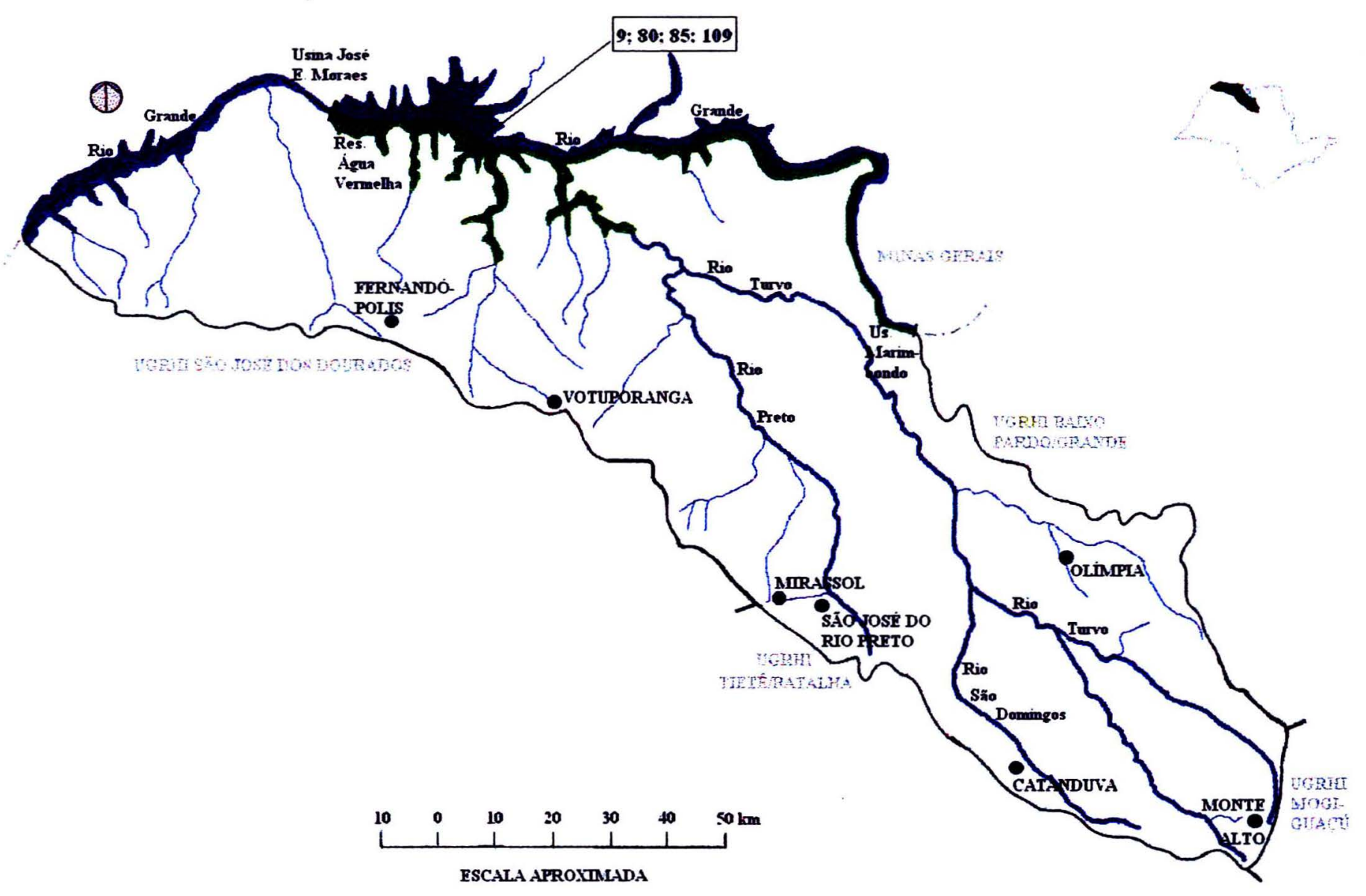

FIGURA 66 - Ocorrência de rotíferos e Índice de Estado Trófico (IET) de Carlson modificado do reservatório de Água Vermelha (UGHRI 15 - Turvo / Grande) (Números representam as espécies que constam na tabela 24). 


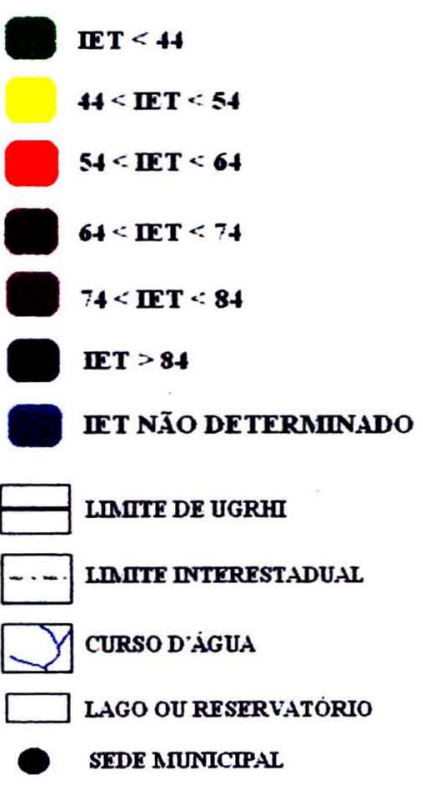

FONTR SAIA (1959)

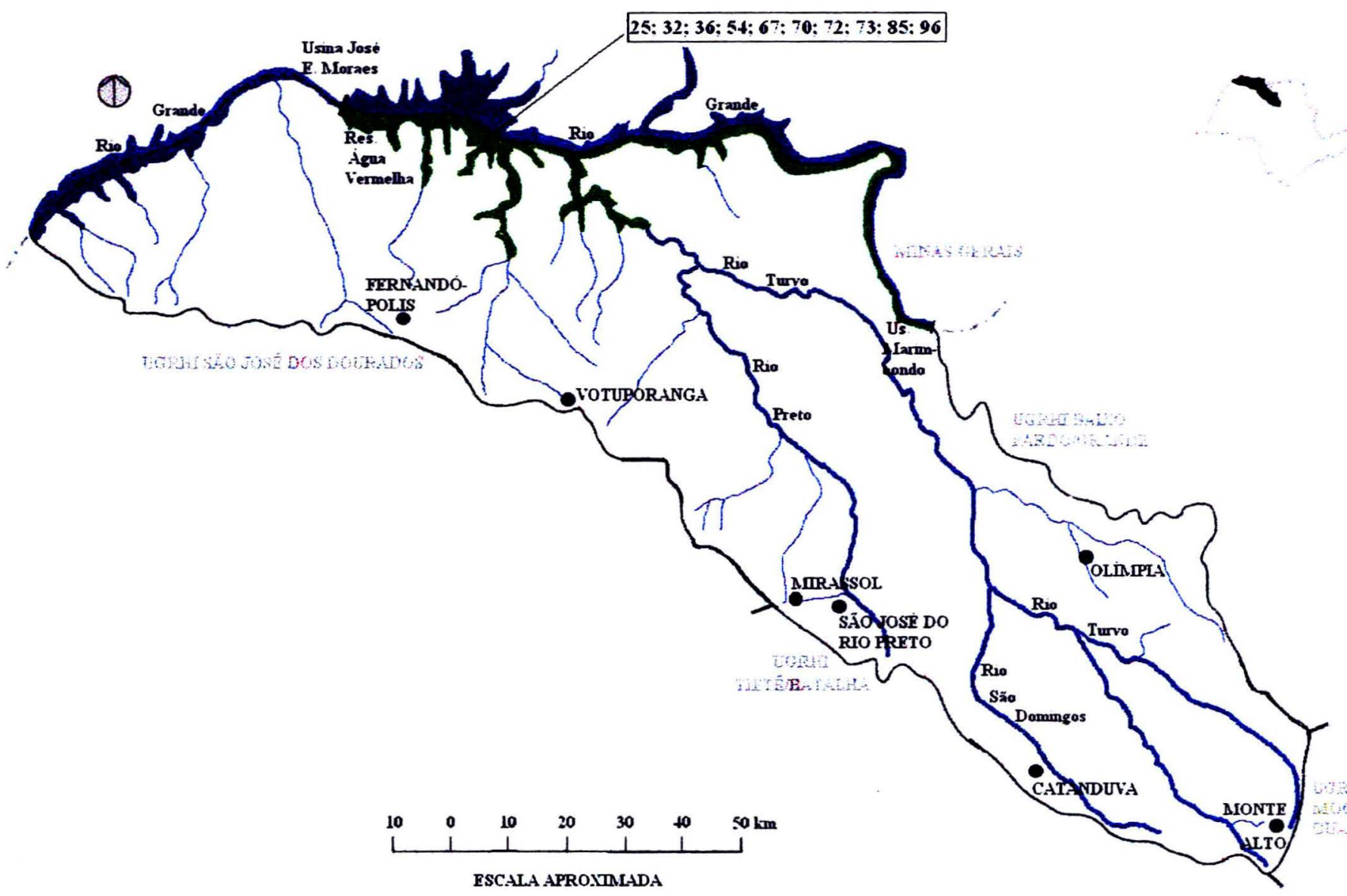

ESCALA APRONMLADA

FIGURA 67 - Ocorrência de microcrustáceos e Índice de Estado Trófico (IET) de Carlson modificado do reservatório de Água Vermelha (UGHRI 15 - Turvo / Grande) (Números representam as espécies que constam na tabela 25). 
(1)

LEGPNDA

IET $<4$

44 $\therefore$ IET $<54$

$54<$ IET $<64$

64: IET $<7$

$74<\operatorname{IET}<84$

IET $>84$

IET NÃo DETERMIINADO

$\bigoplus$ IMITIF DE UGRHI

.... IMITE INTEREstaDU.AL

D CURSO DiGUA

$\square$ LAGO OU RESERVATORIO

- SEDF MUUNCIPAL

PONTE: SNLA (1999)

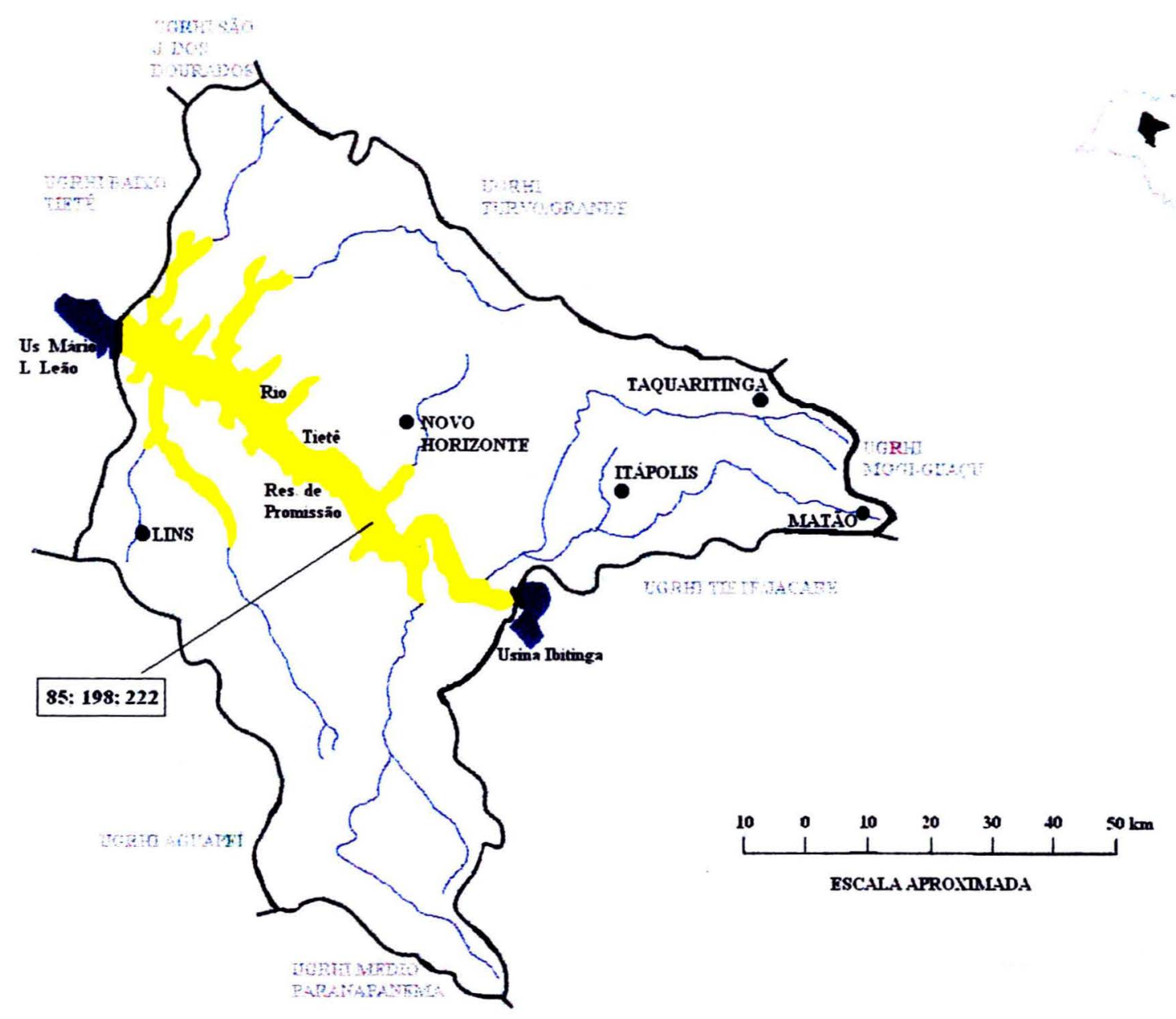

FIGURA 68 - Ocorrência de rotíferos e Índice de Estado Trófico (IET) de Carlson modificado do reservatório de Promissão (UGRHI 16 - Tietê / Batalha) (Números representam as espécies que constam na tabela 24). 
(1)

LFGENDA

IET $<+$

H4 $<$ IFT $<54$

$54<$ IET $<6 t$

D $64<$ IET $<74$

$74<$ IET $<84$

IET $>84$

IET NÃo DETERAIINADO

$\square$ LRIITR DR UGRHI

-... LIMTIE INTERESTADUAI

CURSO D AGUA

LAGO OU RESERVATORIO

- SEDE MUNICIPAL

FONTE : SMA (105)

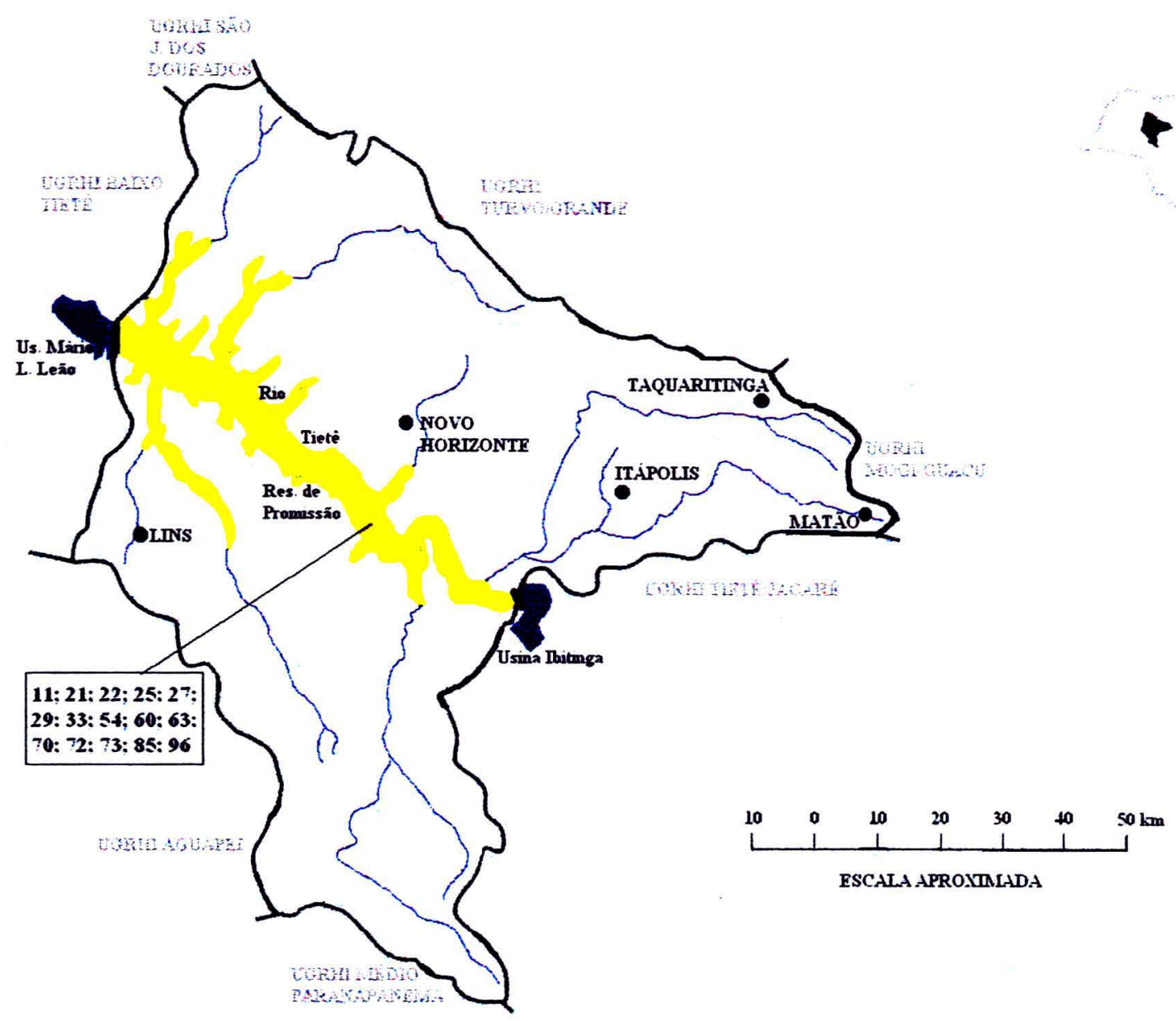

FIGURA 69 - Ocorrência de microcrustáceos e Índice de Estado Trófico (IET) de Carlson modificado do reservatório de Promissão (UGRHI 16 - Tietê / Batalha) (Números representam as espécies que constam na tabela 25). 


\section{UGRHI 17 - MÉDIO PARANAPANEMA}

Nos reservatórios Salto Grande, Rio Pari, Capivara e Rio Novo ocorreram 11 espécies de rotíferos, 4 de ciclopóides, 3 de calanóides e 11 de cladóceros.

Em relação aos rotíferos, nos reservatórios Rio Pari e Rio Novo foi evidenciada a ocorrência de Conochilus coenobasis, Hexarthra intermedia braziliensis e $H$. mira; neste último reservatório também foram registradas Brachionus falcatus, Collotheca ornata, Filinia longiseta e Keratella cochlearis. Asplanchna sieboldi esteve presente nos reservatórios de Salto Grande e Capivara; já Trichocerca capucina ocorreu exclusivamente em Capivara (Tabela 20; Figura 70).

Quanto aos ciclopóides, a co-ocorrência de Thermocyclops decipiens e $T$. minutus, e Mesocyclops longisetus foi evidenciada nos reservatórios Capivara e Rio Novo; já no reservatório Rio Pari, $T$. decipiens foi a única espécie registrada (Tabela 21; Figura 71).

Notodiaptomus conifer foi registrada nos reservatórios Salto Grande, Rio Pari, e Capivara; neste último ocorreu também Notodiaptomus transitans; já Argyrodiaptomus furcatus foi registrada exclusivamente no reservatório Salto Grande; calanóides não ocorreram no reservatório Rio Novo (Tabela 22; Figura 71).

Quanto aos cladóceros, no reservatório Capivara foram registradas Bosmina hagmanni, B. longirostris, Ceriodaphnia cornuta, Daphnia gessneri, Diaphanosoma birgei e Moina minuta. No reservatório de Salto Grande ocorreram C. cornuta e Ceriodaphnia silvestrii, D. gessneri e M. minuta (Tabela 23; Figura 71).

Bosmina hagmanni, C. cornuta, C. silvestrit, D. gessneri e D. birgei ocorreram no reservatório Rio Pari, e B. hagmanni, Bosminopsis deitersi, C. cornuta e $M$. minuta no reservatório Rio Novo (Tabela 23; Figura 71).

No Médio Paranapanema, os valores obtidos para o IET estiveram compreendidos entre 36,4 (Salto Grande) a 42,5 (Rio Novo) (Tabelas 20 a 23; Figuras $70 ; 71)$. 
(1)

LEGENDA

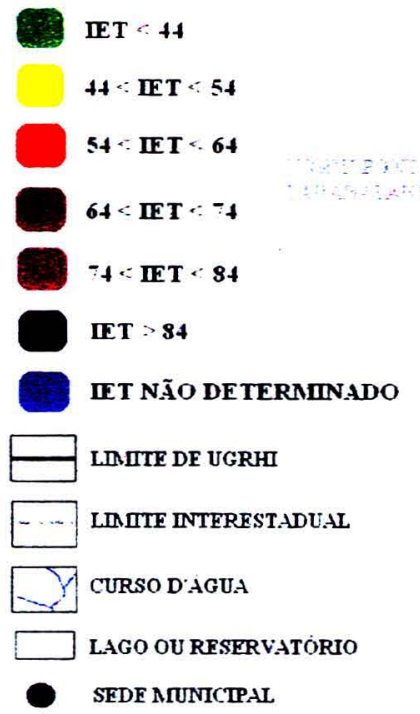

FONTE: SMA (1999)
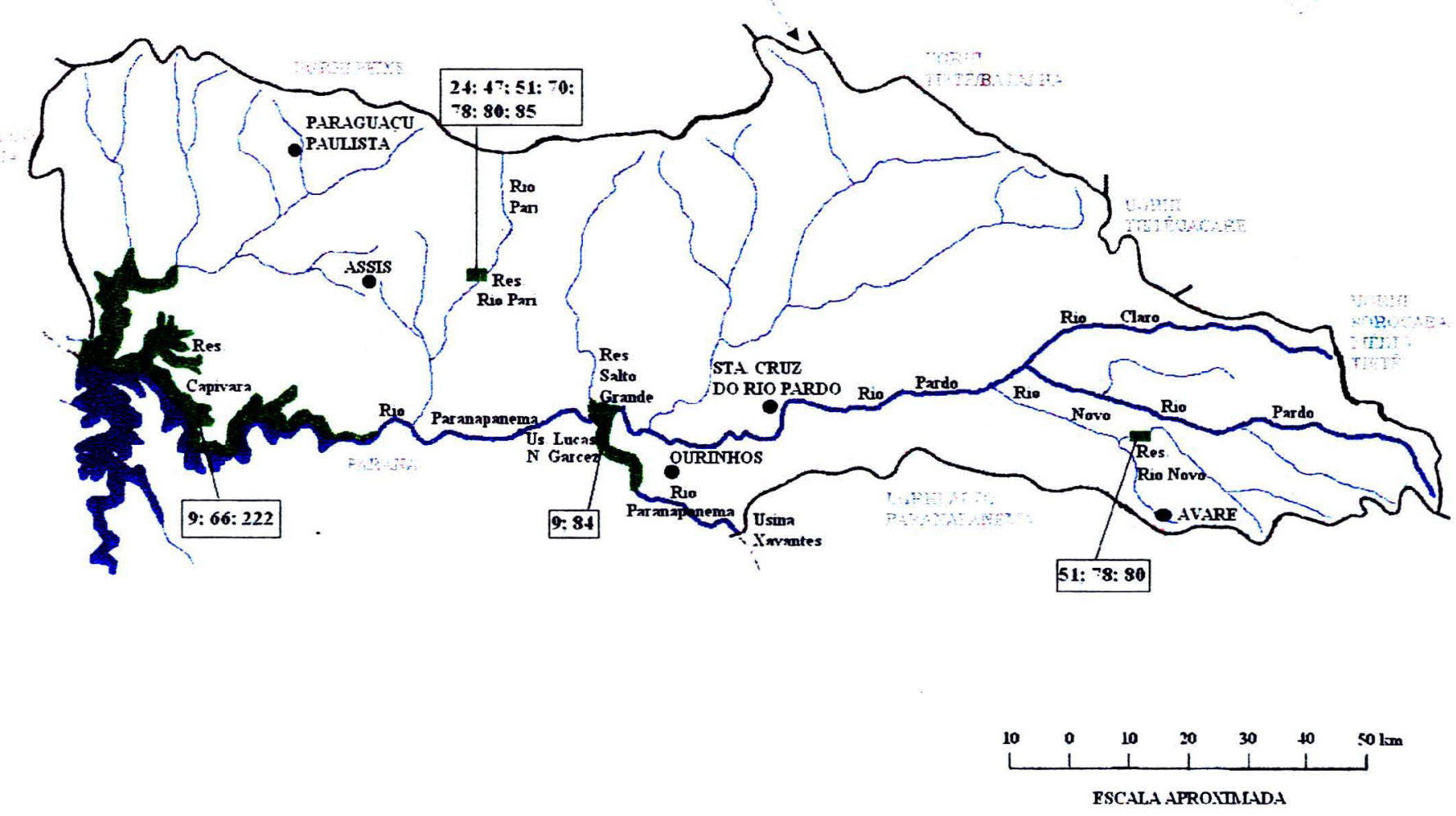

FIGURA 70 - Ocorrência de rotíferos e Índice de Estado Trófico (IET) de Carlson modificado dos reservatórios Capivara, Salto Grande, Rio Pari e Rio Novo (UGRHI 17 - Médio Paranapanema) (Números representam as espécies que constam na tabela 24). 
(1)

IFGENDA

IITT $<4$

$44 \div$ IFT $<54$

$54 \div$ IET $<64$

D $64:$ IET $<74$

$74<$ IET $<84$

IET $>84$

IET NÃo DETERMIINADO

$\square$ LMIIE DE UGRHI

LDITE INTERESTADUAL
CURSO D AGUA
$\square$ LAGO OU RESERVATORIO

- SEDf MUUMictar

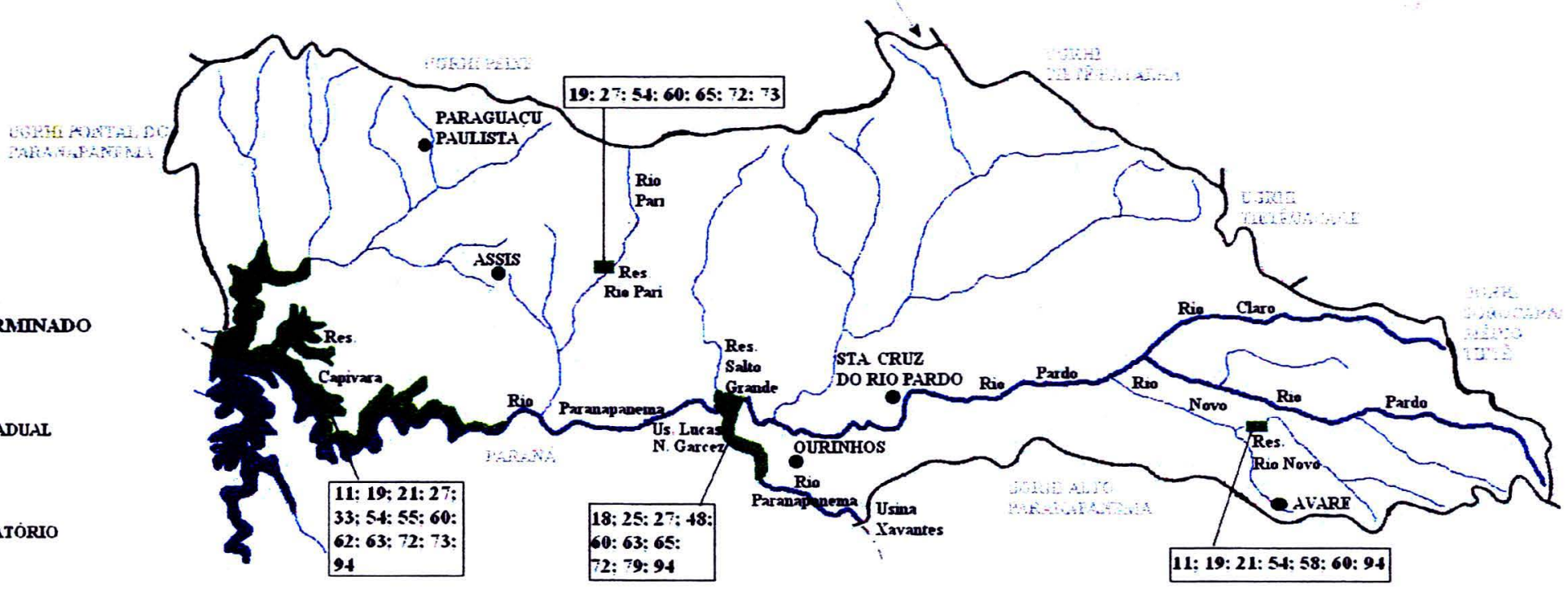

FONTE: SMA (1599)

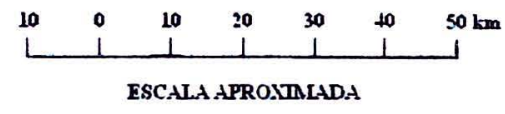

FIGURA 71 - Ocorrência de microcrustáceos e Índice de Estado Trófico (IET) de Carlson modificado dos reservatórios Capivara, Salto Grande, Rio Pari e Rio Novo (UGRHI 17 - Médio Paranapanema) (Números representam as espécies que constam na tabela 25). 


\section{UGRHI 18 - SÃO JOSÉ DOS DOURADOS}

No reservatório de llha Solteira, localizado na bacia do rio São José dos Dourados, a comunidade de rotiferos foi representada, no primeiro estudo realizado, por Keratella cochlearis e Polyarthra trigla. Posteriomente, ocorreram Conochilus coenobasis, C. dossuarius, C. unicornis, Keratella americana, K. cochlearis, K. lenzi e Ptygura libera, dentre outras espécies (Tabela 20; Figura 72).

Em relação aos ciclopóides, no primeiro estudo foi evidenciada a coocorrência de Thermocyclops decipiens e T. minutus, e Mesocyclops longisetus, e posteriormente, T. decipiens foi a única espécie registrada (Tabela 21, Figura 73).

No reservatório de Ilha Solteira ocorreram Argyrodiaptomus azevedoi, A. furcatus e Notodiaptomus spinuliferus; mais recentemente, foram constatados Notodiaptomus theringi e N. jatobensis (Tabela 22; Figura 73).

A comunidade de cladóceros, em ambos os estudos realizados, foi representada por Bosmina hagmanni, Daphnia gessneri, Diaphanosoma birgei e Moina minuta. Mais recentemente, foi constatada a ocorrência de Diaphanosoma brevireme e D. spinulosum (Tabela 23; Figura 73).

No reservatório de Ilha Solteira o valor do IET foi 37,7 (Tabelas 20 a 23; Figuras $72 ; 73$ ). 
LFGENDA

IET $\div 4$

$44<$ IET $<54$
$54<$ IET $<64$
$64<$ IET $<74$
$74<$ IET $<84$
IET $>84$
IET NÃO DETERNIINADO
LIMTIF DE UGRHI
LIIITE INTERESTADU.II
CURSO D AGUA
LAGO OU RESERVATORIO

- SEDF ATUNCIPAL

FONTE SMA (1999)
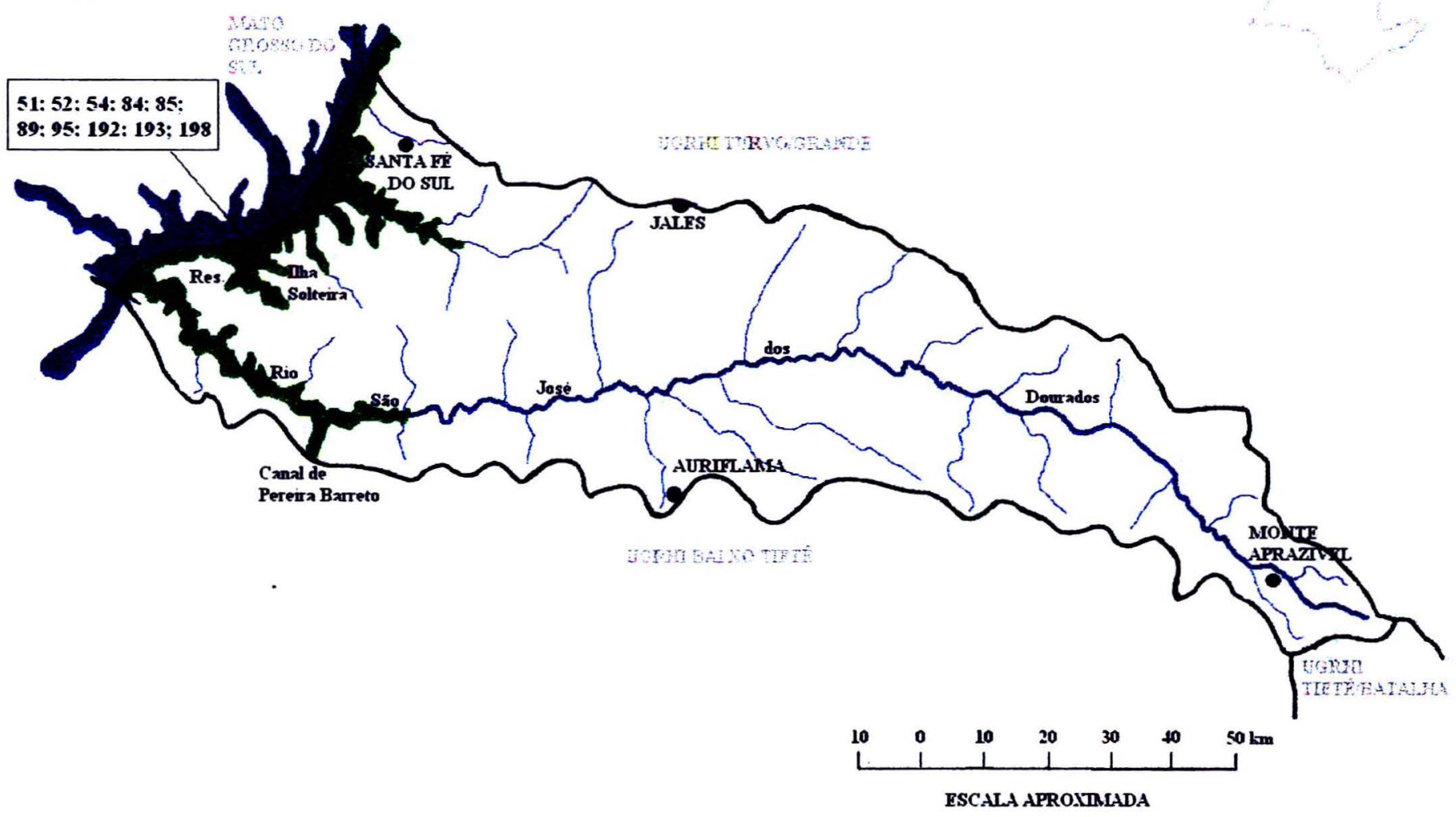

FIGURA 72 - Ocorrência de rotíferos e Índice de Estado Trófico (IET) de Carlson modificado do reservatório de Ilha Solteira (UGRHI 18 - São José dos Dourados) (Números representam as espécies que constam na tabela 24). 
LEGENDA

IET $<4$

$H<$ IET $<54$

$54<$ IET $<64$

$64<$ IET $<74$

$74<$ IET $<84$

IET $>84$

IET NÃo DETERMIINADO

LIMIIT DE UGRHI

-. - L LMITIE INTERESTADUAL

Y CURSO D AGUA

LAGO OU RESERVATORIO

- SEDE MUNICIPAI

FONTE: SMA (1999)

\section{(1)}

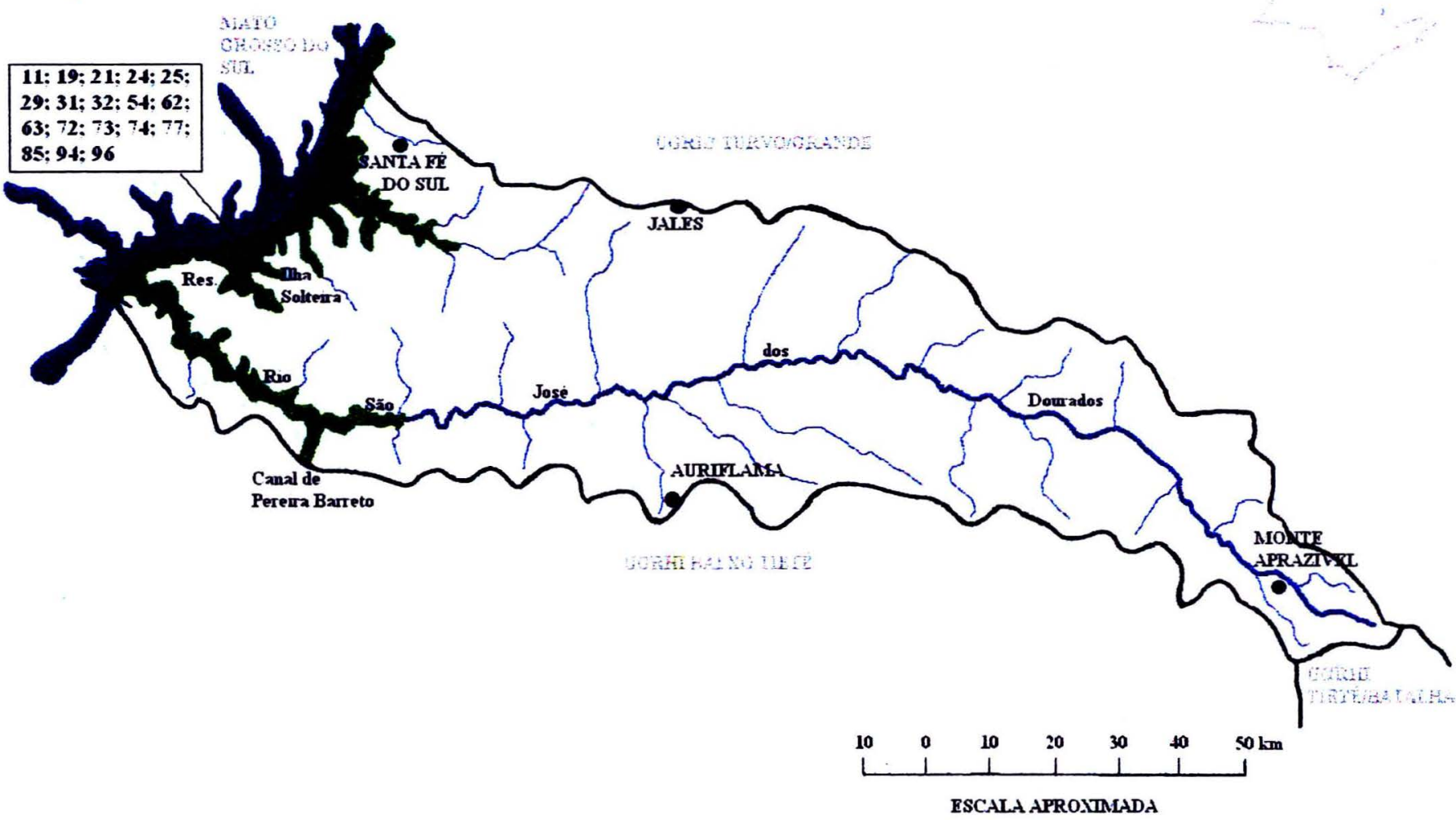

FIGURA 73- Ocorrência de microcrustáceos e Índice de Estado Trófico (IET) de Carlson modificado do reservatório de Ilha Solteira (UGRHI 18 - São José dos Dourados) (Números representam as espécies que constam na tabela 25). 


\section{UGRHI 19 - BAIXO TIETÊ}

Na UGRHI do Baixo Tietê estão localizados os reservatórios Jupiá e Salto de Avanhandava ou Nova Avanhandava. Asplanchna sieboldi, Brachionus falcatus, Hexarthra mira. Keratella cochlearis, K. tropica e Plationus patulus, dentre outras espécies, foram registradas no primeiro estudo realizado no reservatório Jupiá (Tabela 20; Figura 74).

Posteriormente, foi constatado que a composição de rotiferos sofreu algumas alterações; ocorreram Brachionus angularis, B. calyciflorus, Conochilus coenobasis, C. dossuarius e ( $:$ unicornis, Keratella americana, K. lenzi e K. tropica, entre outras (Tabela 20; Figura 74).

Quanto aos ciclopóides, em ambos os estudos registrou-se a co-ocorrência de Thermocyclops decıpiens e T. minutus; em estudos posteriores não foi constatada a presença de Mesocyclops longisetus (Tabela 21; Figura 75).

Em relação aos calanóides, em ambos os estudos foram registrados Argyrodiaptomus azevedol, A. furcatus, e Notodiaptomus spinuliferus. No estudo mais recente, foi constatada a ocorrência de Notodiaptomus iheringi e $N$. jatobensis (Tabela 22; Figura 75).

Os cladóceros, no primeiro estudo realizado no reservatório Jupiá, foram representados por Daphnia gessneri, Diaphanosoma birgei e Moina minuta. Posteriormente, ocorreram também Bosmina hagmanni, Bosminopsis deitersi, Ceriodaphnia cornuta e Diaphanosoma brevireme (Tabela 23; Figura 75).

No reservatório de Salto de Avanhandava ou Nova Avanhandava, foram registradas Trichocerca capucina, M. longisetus, Tropocyclops prasinus, A. furcatus, Notodiaptomus conter, N. transitans, B. hagmanni, C. cornuta e Diaphanosoma birgei (Tabelas 20 a 23; Figuras 74; 75).

O IET obtido para o reservatório Jupiá foi 42,3 , sendo o IET de Nova Avanhandava 53.5 (Tabelas 20 a 23; Figuras 74; 75). 


$$
f^{1}+x
$$


IET Não DETERAIINADO

LMITI DE UGRHI
LAITT INTERESTADUAI
CURSO DAGUA
LAGO OU RESERVATORIO

SEDF AMUNTCIPAL

FONTR SMLA (1099)

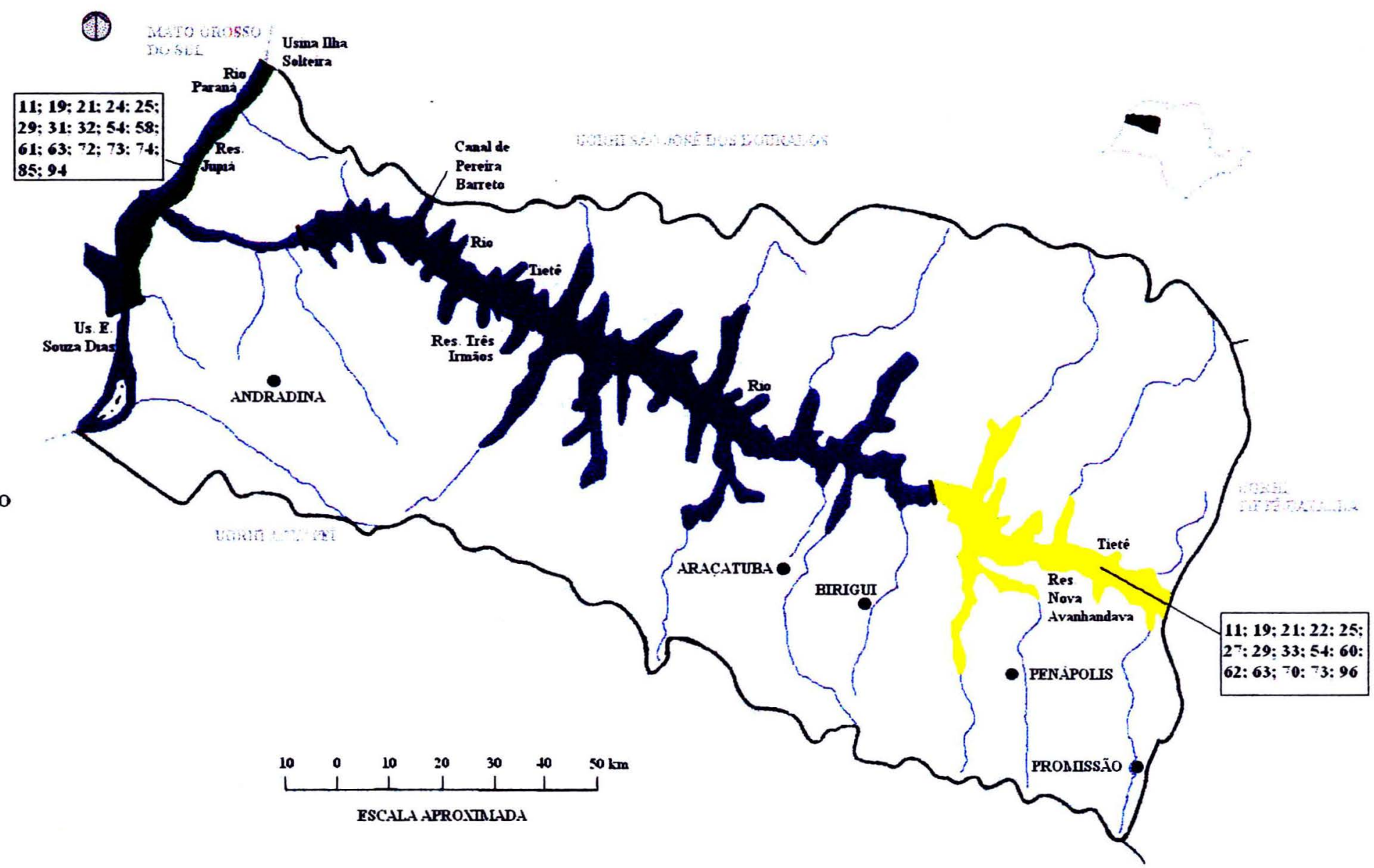

FIGURA 75 - Ocorrência de microcrustáceos e Índice de Estado Trófico (IET) de Carlson modificado dos reservatórios Jupiá e Nova Avanhandava (UGRHI 19 - Baixo Tietê) (Números representam as espécies que constam na tabela 25). 


\section{UGRHI 22 - PONTAL DO PARANAPANEMA}

No Pontal do Paranapanema, onde estão localizadas as lagoas Comprida e Jota, foram registradas 36 espécies de rotíferos, 4 de ciclopóides, 4 de calanóides e 11 de cladóceros (Tabelas 20 a 23; Figuras 76; 77).

Os rotiferos estiveram representados principalmente por espécies de Brachionus (10), Keratella (4), Lecane (4), Filinia (3) e Trichocerca (3). Foram registradas em ambas as lagoas, Anuraeopsis fissa, Brachionus calyciflorus, B. dolabratus, B. falcatus, B. mirus, Conochilus dossuarius, C. unicornis, Filinia pejleri, F. opoliensis, Keratella americana, K. cochlearis, K. tropica, Ptygura libera, Trichocerca similis e T. stylata, entre outras espécies. Já Brachionus angularis e Epiphanes macrourus ocorreram exclusivamente na lagoa Jota, e Plationus patulus e Trochosphaera aequatorialis, na lagoa Comprida.

Quanto aos ciclopóides foi constatada a co-ocorrência de Thermocyclops decipiens e T. minutus, e a presença de Mesocyclops ellipticus e M. meridianus. Nas lagoas associadas ao rio Paraná, os calanóides foram representados por Argyrodiaptomus furcatus, Notodiaptomus iheringi e N. isabelae; já Notodiaptomus conifer foi registrado somente na lagoa Comprida.

A composição de cladóceros destas duas lagoas foi semelhante; foram registradas Bosmina hagmanni, B. tubicen, Bosminopsis deitersi, Ceriodaphnia cornuta, Daphnia gessneri, Diaphanosoma birgei, D. spinulosum e Moina minuta; na lagoa Jota, Moina micrura e M. minuta co-ocorreram.

Em relação às condições tróficas, o IET obtido na lagoa Comprida foi de 57,8 e na lagoa Jota de 68,6 (Tabelas 20 a 23; Figuras 76; 77). 


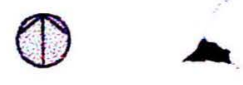

LEGENDA

IET $: 4$

$44 \div$ IET $<54$

$54 \div \operatorname{IET}<64$

$64<$ IET $\div$ ?

$7+<$ IET $: 84$

IET $>84$

IET NÃo DETERMINADO

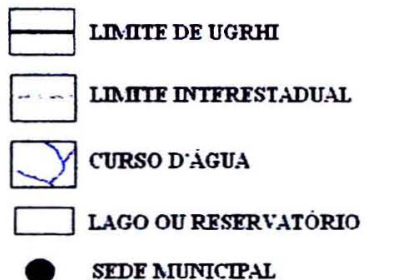

FONTE: SALA (1999)
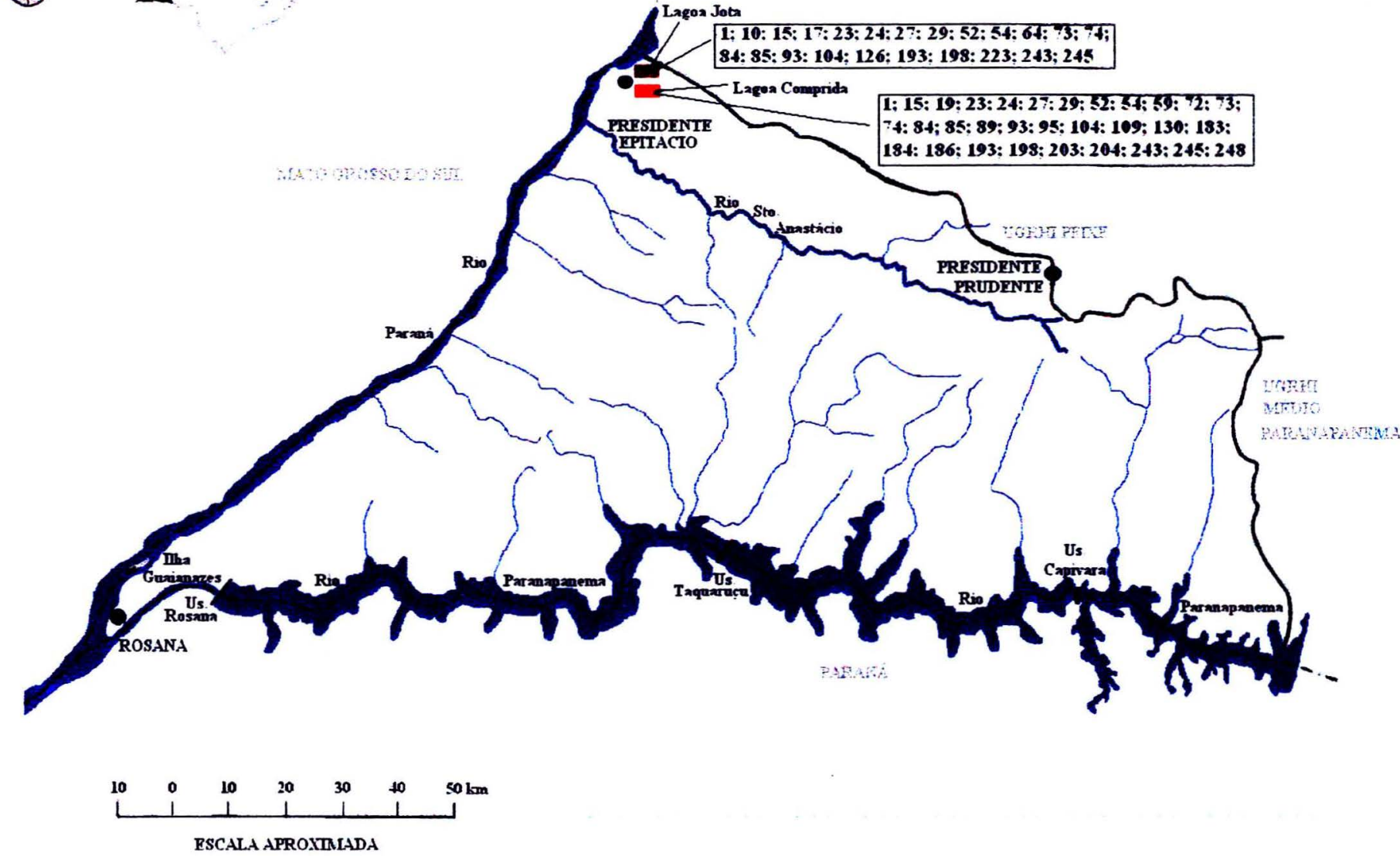

FIGURA 76 - Ocorrência de rotíferos e Índice de Estado Trófico (IET) de Carlson modificado das lagoas Jota e Comprida (UGRHI 22 - Pontal do Paranapanema) (Números representam as espécies que constam na tabela 24). 


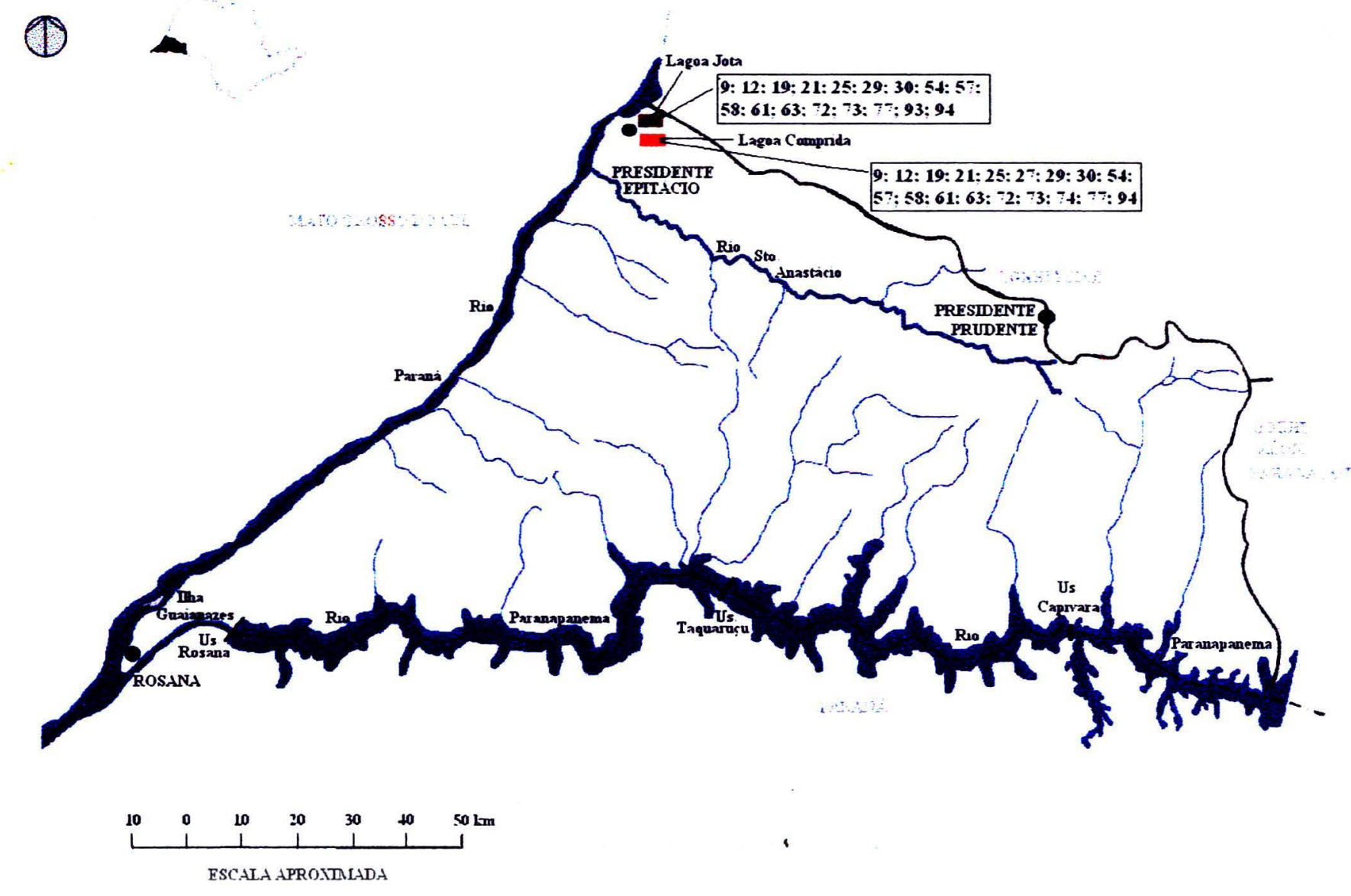

FIGURA 77 - Ocorrência de microcrustáceos e Índice de Estado Trófico (IET) de Carlson modificado das lagoas Jota e Comprida (UGRHI 22 - Pontal do Paranapanema) (Números representam as espécies que constam na tabela 25). 


\section{DISCUSSÃO}

\subsection{Composição da comunidade}

Os lagos estudados foram caracterizados como oligotrófico (lago do IAG), mesotrófico (lago das Ninféias) e eutrófico (lago das Garças) por BICUDO et al. (1997), a partir da determinação do Índice de Estado Trófico (IET) de Carlson modificado por TOLEDO Jr. et al. (1983).

A comunidade fitoplanctônica do lago do IAG em 97, foi representada principalmente por cloroficeas pertencentes às espécies Chlamydomonas planctogloea e Oocystis lacustris, e pela cianobactéria Synechococcus cf. nidulans (LOPES 1999).

No lago das Ninféias, em 97, foi constatado o predomínio de cloroficeas, dos gêneros Monoraphidium e Scenedesmus; também foram importantes as algas flageladas Cryptomonas, Peridinium e Trachelomonas (FONSECA comunicação pessoal).

De acordo com GENTIL (2000), no lago das Garças, em 97, o fitoplâncton esteve representado principalmente por cianobactérias pertencentes às espécies Merismopedia glauca, M. trolleri, Sphaerocavum brasiliensis e Cylindropermopsis raciborskii, além da ocorrência de Microcystis aeruginosa.

Conochilus dossuarius, Keratella cochlearis e Polyarthra vulgaris foram comuns aos três lagos do PEFI, independentemente das condições tróficas. Keratella cochlearis e $P$. vulgaris foram também consideradas espécies ubíquas por PINELALLOUL et al. (1989) e PONTIN e LANGLEY (1993) na zona temperada.

No Estado de São Paulo, C. dossuarius, K. cochlearis e P. vulgaris também foram registradas independentemente das condições tróficas por diversos autores (SILVA 1989; MATSUMURA-TUNDISI et al. 1990; ARCIFA et al. 1992, 1998; DOMINGOS 1993; OLIVEIRA-NETO 1993; SENDACZ 1993; CALEFFI 1994, 2000; FONSECA 1996; MITSUKA 1998; PANARELLI 1999; COELHO-BOTELHO et al. 2001).

O fato de $K$. cochlearis ter ocorrido nos lagos estudados associada tanto a concentrações mais elevadas como mais baixas de oxigênio dissolvido, corrobora o verificado por MIKSCHI (1989), na Áustria: segundo este autor, esta espécie apresentou tolerância em relação às variações de oxigênio dissolvido. 
No presente estudo, Keratella cochlearis e Polyarthra vulgaris também apresentaram tolerância em relação à variação de $\mathrm{pH}$, confirmando as constatações de BERZINS e PEJLER (1987) e DUMONT e DeRIDDER (1987).

Em relação ao alimento, GILBERT e BOGDAN $(1981,1984)$ consideraram $K$. cochlearis "generalista", por ingerir uma variedade de células (bactérias, cloroficeas, flagelados e criptoficeas), devido ao tipo de coroa de cílios, que parece permitir a entrada de ampla variedade de partículas, com baixo grau de seletividade. É uma espécie k-estrategista, ou seja, suas baixas taxas de nascimento e crescimento são compensadas por baixas taxas de mortalidade, alocando mais energia na reprodução; parece ser capaz de utilizar concentrações muito baixas de alimento em relação a rotiferos r-estrategistas (WALZ 1987).

('onochilus dossuarius foi também designada "generalista" em relação ao alimento por GILBERT e BOGDAN (1984), ingerindo vários tipos de células, incluindo aflageladas de tamanho relativamente pequeno.

Apesar de P. vulgaris ser considerada "especialista" em relação ao alimento, ingerindo preferencialmente flagelados a pequenas células algais, fungos ou bactérias (GILBERT e BOGDAN, 1984), sua ocorrência independentemente do estado trófico neste estudo pode estar relacionada com a presença de flagelados do gênero Cryptomonas, comum aos três lagos estudados. Este fato também foi constatado por BRANCO (1991) no lago Paranoá (DF), eutrófico, e por FONSECA (1996), no reservatório Jacaré-Pepira, oligotrofico.

De acordo com GILBERT e BOGDAN (1984), uma comunidade de rotíferos composta por $C$. dossuarius e $K$. cochlearis, ou $P$. vulgaris pode provocar diferentes alterações na cadeia alimentar dos corpos d'água, pois os rotiferos planctônicos podem diferir em relação às suas preferências ou habilidades de ingerir vários itens alimentares. Estes autores sugerem que as duas primeiras espécies provocam uma redução nitida de uma variedade de partículas em suspensão incluindo detritos, bactérias e um amplo espectro de células flageladas e aflageladas, enquanto que a última pode influenciar somente a abundância de certos flagelados.

Por outro lado, foram evidenciadas associações especificas ao estado trófico de cada corpo d'água estudado, como por exemplo, Ascomorpha ecaudis, A. saltans e Hexarthra intermedia exclusivamente no lago do IAG, oligotrófico. 
SLÁDECEK (1983) registrou na zona temperada Ascomorpha ecaudis em corpos d'água oligotroficos; o mesmo foi constatado no Estado de São Paulo por ROLLA et al. (1990) e MITSUKA (1998). Já Ascomorpha saltans foi registrada por FONSECA (1990) em condições mesotróficas, e por DEKER (2000) em condições eutróficas.

Segundo BERZINS e PEJLER (1987), espécies de rotiferos indicadoras de condições oligotróficas foram registradas em valores de $\mathrm{pH}$ abaixo de 7,0, e espécies indicadoras de condições eutróficas, em valores acima de 7,0. No presente estudo, $A$. ecaudis e $A$. saltans ocorreram exclusivamente no lago do IAG, cujos valores de $\mathrm{pH}$ foram abaixo de 7,0 .

A ocorrência de $A$. saltans associada a baixos valores de $\mathrm{pH}$ e a baixas concentrações de nutrientes confirma o verificado em lagos da Polônia por RADWAN (1984).

Ascomorpha ecaudis foi associada no lago do IAG a concentrações mais elevadas de oxigênio em relação aos demais lagos estudados. De acordo com MIKSCHI (1989), apesar desta especie preferir concentrações elevadas de oxigênio dissolvido, pode migrar em direção a locais mais profundos (região anóxica) com a finalidade de utilizar bactérias como recurso alimentar.

Hexarthra intermedia também foi associada a condições oligotróficas por MATSUMURA-TUNDISI (1997a) no lago Dom Helvécio (MG), e por MELÃO (1997) na lagoa Dourada (SP). LEWIS (1979 apud MELÃO 1997) constatou que $H$. intermedia consumiu criptoficeas e dinoflagelados no lago Lanao (Filipinas). Portanto, a ocorrência desta espécie no lago do IAG pode estar relacionada à presença destes grupos de algas constatadas neste corpo d'água por LOPES (1999).

Asplanchna girodi, Brachonus angularis, B. calvciflorus, Conochilus unicornis, Euchlanis dilatata, Filinia terminalis, Keratella americana, K. tecta, K. tropica, Synchaeta pectinata, Trichocerca pusilla e T. similis foram registradas exclusivamente no lago das Garças, eutrófico.

Brachionus angularis e $B$. calyciflorus foram também associadas a corpos d'água eutroficos, na zona temperada, por GANNON e STEMBERGER (1978), PEJLER (1983) e SLÁDECEK (1983), e no Estado de São Paulo por diversos autores 
(KUBO 1989; MATSUMURA-TUNDISI et al. 1990; DOMINGOS 1993; SENDACZ 1993; CALEFFI 1994, 2000; COELHO-BOTELHO et al. 2001).

De acordo com WALZ (1987), Brachionus angularis parece ser uma especie r-estrategista, apresentando elevada taxa de crescimento populacional; é adaptada a explorar uma grande variedade de recursos alimentares, condições estas mais comuns em corpos d'água eutróficos. Especies de Brachionus são consideradas "generalistas" (GILBERT e BOGDAN, 1984), com alimentação aparentemente não seletiva, porém não se alimentam eficientemente de bactérias livres ou de picoplâncton fototrófico (ROTHHAUPT 1990).

No lago Valencia (Venezuela), Brachionus calyciflorus foi mais importante em locais próximos à contribuição de despejos orgânicos (INFANTE 1980 apud INFANTE 1993). É uma espécie que pode estar associada a florações de cianobactérias; pode consumir Microcystis aeruginosa como fonte de alimento, além de ser tolerante às suas toxinas (FULTON e PAERL, 1987b). Esta espécie pode utilizar outras fontes nutricionais associadas a colônias de M. aeruginosa, tais como bactérias, protozoários e algas eucariontes (PAERL 1984; KILHAM et al. 1986 apud FULTON e PAERL 1987b).

Keratella tecta foi registrada exclusivamente em corpos d'água eutróficos no Estado de São Paulo (SILVA 1989; ARCIFA et al. 1992; CALEFFI 1994; ARCIFA et al. 1998; CALEFFI 2000; DEKER 2000; COELHO-BOTELHO et al. 2001). Na região temperada, GANNON e STEMBERGER (1978), BERZINS e PEJLER (1987) e PONTIN e LANGLEY (1993) consideraram esta espécie como indicadora de condições eutróficas.

A ocorrência de B. angularts e $K$. tecta no lago das Garças, aliada a baixos valores de transparência e elevadas concentrações de nutrientes, confirma o verificado por RADWAN (1984).

No lago das Garças, $K$. tecta foi também associada a elevados valores de condutividade elétrica, corroborando as constatą̧ões de KUCZYNSKI (1987), e a valores de $\mathrm{pH}$ em geral acima de 7,0 confirmando o verificado por BERZINS e PEJLER (1987).

A co-ocorrència de Keratella tropica e $K$. cochlearis observada no lago das Garças foi também constatada por GREEN (1987) nos lagos da África; segundo sste 
autor, provavelmente estas espécies podem ocorrer conjuntamente por apresentarem requerimentos alimentares diferentes, evitando assim a competição interespecífica.

Apesar de algumas espécies estarem associadas neste estudo a determinadas condiçòes tróficas, como por exemplo, a ocorrência de Hexarthra intermedia somente no lago do IAG, Anuraeopsis fissa, nos lagos das Ninféias e Garças, e Conochilus unicornis, Euchlanis dilatata, Filinia terminalis, Keratella americana, K. tropica, Synchaeta pectinata, Trichocerca pusilla e T. similis exclusivamente no lago das Garças, estas foram relacionadas por diversos autores independentemente do estado trófico (MATSUMURA-TUNDISI et al. 1990; ROLLA et al. 1990; ARCIFA et al. 1992; DOMINGOS 1993; OLIVEIRA-NETO 1993; SENDACZ 1993; CALEFFI 1994; OKANO 1994; FONSECA 1996; MELÃO 1997; MITSUKA 1998; PANARELLI 1999; COELHO-BOTELHO et al. 2001).

Certos táxons, tais como Dipleuchlanis propatula, Lecane doryssa, L. leontina, Lepadella patella, Monommata sp., Sinantherina sp., Trichocerca cf. bidens ocorreram esporadicamente no lago das Ninféias relacionados à presença de bancos de macrófitas.

Quanto aos microcrustáceos, Tropocyclops prasinus foi a única espécie de ciclopóide comum aos três lagos do PEFI. No lago do IAG co-ocorreu com Eucyclops sp., Metacyclops mendocinus e Microcyclops sp., e no lago das Ninféias com Eucyclops sp. e Macrocyclops sp. Já no lago das Garças, T. prasinus co-ocorreu com Thermocyclops decipiens, M. mendocinus, Mesocyclops longisetus, Eucyclops pseudoensifer e Microcyclops sp.

Tropocyclops prasinus é uma das espécies de copépodos mais frequentes nos reservatórios do Estado de São Paulo, e em muitos deles chega a ser quantitativamente importante (SENDACZ e KUBO 1982; ARCIFA 1984; SENDACZ et al. 1985). Diversos autores (CARVALHO 1975; SENDACZ 1978; CLARO 1981; SENDACZ et al. 1984; KUBO, 1989; SILVA, 1989; ARCIFA et al. 1992; OKANO 1994; MELÃO 1997; SENDACZ e KUBO 1999; COELHO-BOTELHO et al. 2001) registraram T. prasinus independentemente das condições tróficas.

A ocorrència desta espécie associada tanto a concentrações mais elevadas de oxigênio dissolvido no lago do IAG, como a concentrações mais baixas de oxigênio dissolvido nos lagos das Ninféias e Garças, foi também verificada, por 
MATSUMURA-TUNDISI et al. (1997a) no lago Dom Helvécio (MG), onde Tropocyclops prasinus foi registrada em baixas concentrações de oxigênio dissolvido; já na lagoa Dourada ocorreu em águas bem oxigenadas (MELÃO e ROCHA, 1999).

No presente estudo, a co-ocorrência de Thermocyclops decipiens e Metacyclops mendocinus só foi constatada no lago das Garças, eutrófico. No Estado de São Paulo estas espécies co-ocorreram em corpos d'água eutróficos (CARVALHO 1975; SENDACZ 1978; SENDACZ e KUBO 1982, 1999; ARCIFA 1984; SENDACZ et al. 1984; KUBO 1989; GÁVILAN-DIAZ 1990; DOMINGOS 1993; CALEFFI 1994, 2000; TUNDISI e MATSUMURA-TUNDISI 1994; RIETZLER 1995; WISNIEWSKI 1998; COELHO-BOTELHO et al. 2001).

No lago das Garças, T. decipiens foi associada a baixos valores de transparência da água e maiores concentrações de nitrogènio total, com elevada biomassa algal e predominio de cianobactérias, corroborando os resultados obtidos no lago Paranoá (DF) por PINTO-COELHO (1987). Esta espécie também ocorreu em corpos d'água com valores elevados de condutividade elétrica, confirmando o verificado por RIETZLER (1995) no reservatório de Barra Bonita (SP); já no reservatório Vargem das Flores (MG) (FREIRE e PINTO-COELHO, 1986) e no lago Paranoá (DF) (BRANCO 1991) a ocorrência de T. decipiens foi aliada a valores mais baixos de condutividade elétrica. Portanto, a condutividade elétrica parece não ser um fator determinante na ocorrência de $T$. decipiens.

A associação de $M$. mendocinus a condições eutróficas constatadas no lago das Garças confïrma o observado por SENDACZ et al. (1985) em estudo realizado em dezessete reservatórios do Estado de São Paulo; segundo estes autores, $M$. mendocinus foi registrada em corpos d'água que apresentaram valores elevados de condutividade elétrica, elevadas concentrações de nutrientes (nitrogênio e fósforo totais) e clorofila $a$, e baixos valores de transparência.

A ocorrència esporádica de Mesocyclops longisetus no lago das Garças também foi verificada por SENDACZ e KUBO (1982), ARCIFA (1984) e SENDACZ et al. (1985); segundo estes autores, esta espécie, embora em geral esteja presente no zooplàncton, não é importante quantitativamente. Eucyclops pseudoensifer, Eucyclops sp., Microcyclops sp. e Macrocyclops sp. também foram pouco importantes e de ocorrência esporádica. 
A única espécie de copépodo calanóide registrada nos lagos do PEFI foi Scolodiaptomus corderot. A associação desta espécie a condições oligo e mesotróficas evidenciadas nos lagos do IAG e das Ninféias confirma o verificado por diversos autores (SENDACZ 1978; SENDACZ et al. 1984; KUBO 1989; TUNDISI e MATSUMURA - TUNDISI 1990; DOMINGOS 1993; CALEFFI 1994, 2000; SENDACZ e KUBO 1999). Scolodiaptomus corderol também predominou entre os calanóides no lago Dom Helvécio (MG), oligotrófico (MATSUMURA-TUNDISI 1997a).

Esta espécie foi associada nos lagos do IAG e das Ninféias a baixos valores de condutividade elétrica, baixas concentrações de nutrientes, sólidos totais em suspensão e clorofila $a$, e valores elevados de transparência, confirmando o verificado por ROLLA et al. (1990) no reservatório Volta Grande (SP).

Apesar de calanóides geralmente não ocorrerem em corpos d'água eutróficos, $S$. corderol foi registrada esporadicamente no lago das Garças, e em reservatórios do Estado de São Paulo em processo de eutrofização, tais como Águas Claras, Juqueri e Guarapiranga (SENDACZ e KUBO 1982; SENDACZ et al. 1985), Jaguari e Taiaçupeba (ARCIFA 1984). Scolodiaptomus corderoi foi também associada a condições eutróficas evidenciadas nos lagos da Pampulha (MG) (PINTO-COELHO et al., 1988), e no reservatório de Pontal (MG) (DABÉS et al., 1990), sujeitos à contaminação por esgotos domésticos.

FREIRE e PINTO-COELHO (1986) constataram que $S$. corderoi foi registrada em locais do reservatorio Vargem das Flores (MG) onde se verificou maiores valores de transparência e menores valores de condutividade elétrica em relação aos locais que recebem esgotos domésticos.

Bosminopsis deitersi, Daphnia ambigua e Moina micrura foram comuns aos corpos d'água estudados. De acordo com NOGUEIRA (1996), B. deitersi é sujeita à influência da velocidade da corrente, e portanto associada a corpos d'água com caracteristicas semi-lóticas.

Daphnia ambigua e $M$. micrura foram também registradas independentemente das condições tróficas por diversos autores (CLARO 1981; SILVA 1989; KUBO 1989; GÁVILAN-DIAZ 1990; NOGUEIRA 1990; ARCIFA et al., 1992; SENDACZ 1993; CALEFFI 1994, 2000; OKANO 1994; FONSECA 1996; 
WISNIEWSKI 1998; SENDACZ e KUBO 1999; CASANOVA 2000; COELHOBOTELHO et al. 2001).

A ocorrência de Daphnia ambigua em lagos de diferentes estados tróficos também foi observada na Flórida por BLANCHER (1984). Já MATSUMURATUNDISI (1984) constatou que a ocorrência desta espécie no reservatório do Broa (SP), oligotrófico, pode ser associada a períodos de eutrofização.

No lago das Garças, a ocorrência de Daphnia gessneri associada a baixas concentrações de oxigênio dissolvido, e a valores de $\mathrm{pH}$ próximos de 7,0 , confirma o observado por MATSUMURA-TUNDISI et al. (1984), e PINEL-ALLOUL et al. (1989), respectivamente.

Esta espécie também foi associada a valores elevados de condutividade elétrica evidenciados no lago das Garças; o mesmo foi constatado em Barra Bonita (SP) (TUNDISI e MATSUMURA-TUNDISI, 1990) e Salto Grande (SP) (ESPÍNDOLA et al., 1998).

O fato de D. gessneri ter ocorrido exclusivamente no lago das Garças, onde também foram registradas as mais elevadas concentrações de sólidos totais em suspensão em relação aos demais lagos estudados, pode evidenciar que talvez esta espécie não seja desfavorecida pela presença de sólidos em suspensão.

Segundo KIRK (1991), entre os cladóceros, a interferência de partículas inorgânicas em suspensão depende do tamanho do corpo, ou seja, os organismos maiores são menos influenciados que os de menor porte. Os cladóceros maiores, como é o caso de $D$. gessneri, provavelmente capturam sólidos em suspensão com menor eficiência que os de menor porte, e, como consequência exibem uma maior seletividade para as algas, com pequena redução nas taxas de ingestão de células algais de elevado valor nutricional, aumentando suas taxas de crescimento e reprodução.

Ainda no lago das Garças, evidenciou-se a co-ocorrência de D. ambigua e $D$. gessneri, constatada em condições meso e eutróficas por diversos autores no Estado de São Paulo (KUBO 1989; SILVA 1989; GÁVILAN-DIAZ 1990; ROCHA e MATSUMURA-TUNDISI, 1990; TUNDISI e MATSUMURA, 1990, 1994; CALEFFI 1994, 2000; ARCIFA et al. 1998; WISNIEWSKI 1998; SENDACZ e KUBO, 1999; CASANOVA 2000; COELHO-BOTELHO et al. 2001). 
A co-ocorrència de Moina micrura e $M$. minuta também foi registrada exclusivamente no lago das Garças. No Estado de São Paulo, a co-ocorrência destas espécies foi constatada em corpos d'água meso e eutróficos (SILVA 1989; GÁVILAN-DIAZ 1990; NOGUEIRA 1990; ARCIFA et al. 1992, 1998; SENDACZ 1993: COELHO-BOTELHO et al. 2001).

Cerlodaphnia cornuta cornuta, (. cornuta rigaudi e $($. cf. reticulata são comuns em lagos e reservatórios do Estado de São Paulo, tendo sido citadas por vários autores; neste estudo ocorreram esporadicamente no lago das Garças.

Os representantes das familias Chydoridae, Ilyocryptidae e Macrothricidae Alona guttata, Alona spp., Biapertura spp., Camptocercus dadayi, Chydorus sphaericus, (hydorus spp., Disparalona dadayi, llyocryptus spinifer e Macrothrix spinosa ocorreram nos três lagos estudados, independentemente das condições tróficas.

Chydorus sphaericus é considerada por DUMONT (1980) a espécie mais ubiqua entre os cladóceros; de acordo com GANNON e STEMBERGER (1978), é indicadora de corpos d'água eutróficos. Segundo GELLER e MÜLLER (1981), C. sphaericus alimenta-se eficientemente de bactérias.

A composição da comunidade zooplanctônica dos lagos do PEFI evidenciou espécies comuns aos lagos estudados, independentemente das condições tróficas, tais como Conochilus dossuarius, Keratella cochlearis, Polyarthra vulgaris, Tropocyclops prasinus, Daphnia ambigua e M. micrura.

No entanto, constatou-se associações especificas de acordo com o estado trófico de cada corpo d'água. A ocorrência de Ascomorpha ecaudis, A. saltans e Hexarthra intermedia somente no lago do IAG, e de Brachionus angularis, $B$. calyciflorus, Keratella americana, K. tecta, K. tropica, Trichocerca pusilla e $T$. similis exclusivamente no lago das Garças, provavelmente pode estar relacionada às diferentes estratégias alimentares e refletem, desta maneira, o estado trófico característico de cada lago estudado.

Em relação aos microcrustáceos, somente no lago das Garças evidenciou-se as associações de Thermocyclops decipıens e Metacyclops mendocinus, Daphnia ambigua e D. gessneri, M. micrura e M. minuta. 
De acordo com MATSUMURA-TUNDISI et al. (1990), em corpos d'água eutróficos a maior amplitude de recursos alimentares permite uma maior especialização de nichos, evitando consequentemente a interação competitiva entre os organismos zooplanctônicos.

\subsection{Estrutura da comunidade}

A estrutura da comunidade zooplanctônica é o produto do crescimento, reprodução e competição interespecifica por recursos alimentares disponiveis (BLANCHER 1984).

A comunidade zooplanctônica nos lagos estudados foi caracterizada pelo predomínio de rotiferos, durante quase todo o periodo de estudo, independentemente do estado trófico.

O predominio de rotíferos na comunidade zooplanctônica de lagos e reservatórios pode ser atribuído principalmente à reprodução partenogenética e ciclo de vida curto, o que propicia o desenvolvimento de grandes populações transitórias. De acordo com PORTER et al. (1988), os requerimentos alimentares dos rotíferos incluem o picoplâncton algal e bacteriano, e o fitoplâncton; consomem preferencialmente nanoflagelados, exercendo uma menor pressão de "grazing" nas bactérias (SANDERS et al. 1989 apud SANDERS et al. 1994).

Rotíferos são oportunistas, de um modo geral r-estrategistas, cujo desenvolvimento é favorecido em ambientes instáveis; a natureza e origem dos lagos, e interações biológicas como produção e competição interespecífica por alimentos também influenciam o predomínio deste grupo zooplanctônico (MATSUMURA-TUNDISI et al., 1990).

Em ambientes tropicais e subtropicais, o predomínio de rotiferos no zooplâncton tem sido observado por diversos autores; no Estado de São Paulo, tal fato foi constatado por MATSUMURA-TUNDISI e TUNDISI (1976), ARCIFA (1984), CABIANCA (1991), SENDACZ et al. (1985), NOGUEIRA (1990), DOMINGOS (1993), CALEFFI (1994), OKANO (1994), TALAMONI (1995), MELÃO (1997) e COELHO-BOTELHO et al. (2001). 
Por outro lado, BLANCHER (1984) observou que os rotiferos apresentaram baixas abundâncias relativas (20 a 37\%) em lagos oligo e mesotróficos na Flórida, e mais elevadas ( 70 a 98\%) nos lagos eutróficos; nos corpos d'água menos eutróficos predominaram os copépodos.

O mesmo foi verificado em três lagos no Vale do Rio Doce (MG), de diferentes condições tróficas. Nos lagos Dom Helvécio, oligotrófico, e Carioca, mesotrófico, predominaram os copépodos; já na lagoa Amarela, eutrófica, os rotíferos foram mais importantes (MATSUMURA-TUNDISI e TUNDISI 1986 apud ROCHA et al. 1995).

Apesar de Keratella cochlearis ter ocorrido nos três lagos estudados independentemente do estado trófico, suas abundâncias relativas variaram de acordo com o corpo d'água considerado. Esta espécie apresentou abundâncias relativas mais elevadas no lago do IAG, e mais baixas no lago das Garças; abundâncias relativas intermediárias entre os corpos d'água estudados foram registradas no lago das Ninféias.

$O$ fato de $K$. cochlearis ter sido menos importante no lago das Garças pode talvez estar relacionado à presença de Microcystis neste corpo d'água. Nos lagos da África, GREEN (1987) constatou que um dos fatores desfavoráveis ao desenvolvimento de $K$. cochlearis foi a ocorrência de florações de Microcystis, que compete por nutrientes com pequenos flagelados utilizados como alimento por esta espécie (LINDSTRON 1983).

Durante as florações de cianobactérias, uma combinação de temperaturas elevadas, baixa disponibilidade de partículas alimentares e toxicidade destas algas pode acarretar condições adversas aos rotíferos, devido à habilidade das cianobactérias em competir por nutrientes com outras algas mais palatáveis ou de maior valor nutricional (GILBERT 1996).

No lago do IAG evidenciou-se o predomínio de Conochilus dossuarius, e no lago das Ninféias, de Polyarthra vulgaris. A primeira espécie apresentou abundâncias relativas mais baixas no lago das Garças, e no lago das Ninféias foram registradas densidades intermediárias em relação aos demais lagos estudados.

No lago das Garças, Anuraeopsis fissa, Keratella americana, K. cochlearis, K. tropica, P. vulgaris, Brachionus angularis chelonis e Keratella tecta apresentaram 
abundâncias relativas semelhantes, não se constatando o predominio de uma espécie de rotífero, como verificado nos lagos do IAG e das Ninféias. Em corpos d'água eutróficos, como é o caso do lago das Garças, há uma maior e constante disponibilidade de recursos alimentares, evitando a competição interespecífica.

Anuraeopsis fissa foi comum aos lagos das Ninféias e Garças; apresentou abundâncias relativas mais elevadas neste último corpo d'água. A sua ocorrência no lago das Garças foi coincidente com valores de $\mathrm{pH}$ próximos de 7,0, confirmando o verificado por BERZINS e PEJLER (1987). Anuraeopsis fissa foi associada a elevadas concentrações de fósforo total e valores elevados de condutividade elétrica (BERZINS e PEJLER, 1989), característicos de corpos d'água eutróficos. É uma espécie micrófaga, que se alimenta de algas, bactérias e detritos (BRANCO 1991).

Quanto aos copépodos, as abundâncias relativas de calanóides foram mais elevadas que as de ciclopóides no lago das Ninféias, mesotrófico; já o predomínio de ciclopóides em relação aos calanóides no lago das Garças, eutrófico, corrobora as observações constatadas em outros corpos d'água também eutróficos (SENDACZ et al. 1985; TUNDISI e MATSUMURA-TUNDISI 1994; RIETZLER 1995; WISNIEWSKI 1998).

Por outro lado, no lago do IAG, oligotrófico, ciclopóides apresentaram abundâncias relativas mais elevadas que os calanóides; este fato também foi constatado por TUNDISI et al. (1997) no lago Anibal (MG), também de características oligotróficas.

Apesar de calanóides serem geralmente associados a condições oligo e mesotróficas, não foram registrados por ROCHA e SAMPAIO (1991) e MELÃO (1997) na lagoa Dourada, de características oligotróficas. Segundo estes autores, a ausência deste grupo zooplanctônico pode ser relacionada às condições ecológicas deste corpo d'água, que restringiu a fauna a um pequeno número de espécies, excluindo grupos mais sensiveis, como é o caso dos calanóides.

A proporção entre as abundâncias relativas de ciclopóides e calanóides reflete o estado trófico de determinado corpo d'água. Nos Grandes Lagos, GANNON e STEMBERGER (1978) verificaram que ciclopóides foram mais abundantes que calanóides em corpos d'água eutróficos. Nos corpos d'água do Estado de São Paulo, ARCIFA (1984), SENDACZ et al. (1985), ESTEVES e SENDACZ (1988) e 
ARCIFA et al. (1992) verificaram que calanóides apresentaram baixas abundâncias relativas ou mesmo não ocorreram em condições eutróficas. De acordo com TUNDISI et al. (1988), em lagos e reservatórios eutróficos frequentemente a razão calanóides/ciclopóides é < 1

No presente estudo, o fato de ciclopóides terem apresentado abundâncias relativas mais elevadas no lago das Garças, provavelmente pode estar relacionado à sua omnivoria. De acordo com RIETZLER (1995), cianobactérias e detritos podem constituir uma fonte alternativa de alimento para este grupo zooplanctônico em corpos d'água eutróficos, diminuindo a competição intra e interespecifica. Os ciclopóides apresentam um amplo espectro alimentar; são predadores de uma grande variedade de organismos, incluindo o próprio grupo, cladóceros, rotíferos, turbelários, larvas de insetos e de peixes: entretanto, quando a disponibilidade de presas diminui, podem também consumir organismos mortos e detritos, além de algas. Portanto, por apresentarem hábito raptorial, tornam-se mais versáteis em sua alimentação (RIETZLER 1995).

De acordo com ESTEVES e SENDACZ (1988), ciclopóides provavelmente não seriam desfavorecidos com a eutrofização por serem predadores e não filtradores. RIETZLER (1995) constatou que ciclopóides freqüentemente ingerem colônias de Microcystis e detritos (em grande parte de Microcystis), não se observando uma discriminação entre algas vivas e mortas da mesma espécie, como também preferência por algas que não sejam cianobactérias.

Tropocyclops prasinus, a única espécie de ciclopóide registrada nos três lagos do PEFI, apresentou abundâncias relativas mais elevadas no lago do IAG, e mais baixas no lago das Garças; no lago das Ninféias, foram registradas abundâncias relativas intermediárias entre os lagos estudados.

No lago Anibal (MG), oligotrófico, esta espécie também predominou entre os copépodos, onde a comunidade fitoplanctônica foi constituida principalmente por cloroficeas e cianobactérias (TUNDISI et al., 1997). Segundo estes autores, tal fato pode ser devido ao acréscimo do material detrital da decomposição das cianobactérias ou do bacterioplâncton (bactérias fotossintéticas ou quimiosintéticas) que podem fornecer uma fonte de alimento para T. prasinus. 
O fato de Tropocyclops prasinus também ter sido registrada no lago das Garças pode talvez estar relacionado ao seu comportamento alimentar quimiosensorial altamente seletivo; esta espécie pode evitar a captura de Microcystis aeruginosa na presença de partículas alimentares de maior valor nutricional, e desta forma suas taxas de filtração não são afetadas pela presença desta cianobactéria (FULTON e PAERL, 1987b). Desta maneira, T. prasinus não seria desfavorecido em corpos d'água eutróficos.

Em lagos e reservatórios neotropicais eutróficos que tendem a ser dominados por uma ou várias espécies de cianobactérias, Thermocyclops decipiens frequentemente predomina em relação a outros copépodos herbívoros utilizando essas algas como fonte nutricional, recurso alimentar que a maioria de outros ciclopóides, assim como calanóides, não são capazes de explorar efetivamente (REID 1989). Nessas condições, esta espécie é favorecida na competição interespecífica com calanóides e outros ciclopóides.

INFANTE (1993) verificou que $T$. decipiens foi uma das espécies mais abundantes no lago Valencia (Venezuela), onde predominavam as cianobactérias $M$. aeruginosa. Synechocystis aquatilis e Cylindrospermopsis raciborskii.

Thermocyclops decipiens apresentou, no reservatório de Barra Bonita (SP), características tanto de r-estrategista, agindo como colonizadora, podendo aumentar rapidamente a sua representatividade na comunidade zooplanctônica, como de kestrategista, apresentando uma alta capacidade de manter suas abundâncias relativas sob condições competitivas (RIETZLER 1995).

De acordo com PINTO-COELHO (1983) e GIANI (1984), T. decipiens seria a única espécie do zooplâncton do lago Paranoá (DF) apta a consumir a cianobactéria $C$. raciborskii, que por sua vez também foi registrada no lago das Garças (GENTIL 2000). Já BRANCO (1991), também no lago Paranoá (DF), não evidenciou uma associação entre T. decipiens e esta cianobactéria.

Dados recentes obtidos por RIETZLER (1995), a partir da análise do conteúdo digestivo de $T$. decipiens no reservatório de Barra Bonita (SP), revelaram que esta espécie apresentou um maior consumo de detritos de origem basicamente orgànica e diatomáceas, tendo sido observada uma baixa porcentagem de cianobactérias, independente de sua abundância no ambiente. Desta maneira, a ingestão de mạterial 
detrital pode constituir um importante, senão fundamental complemento em sua dieta, considerada potencialmente omnivora.

No lago Paranoá (DF), BRANCO e CAVALCANTI (1999) verificaram que, devido ao predomínio de Cylindrospermopsis raciborskil, há redução da disponibilidade de alimentos, pois as cianobactérias são menos palatáveis e digestivas, e até mesmo tóxicas a certas espécies da comunidade zooplanctônica (FULTON e PAERL, 1987b). Ainda segundo BRANCO e CAVALCANTI (1999), o zooplâncton existente neste corpo d'água não exerce pressão de predação sobre esta cianobactéria; como consequência, grande parte da biomassa fitoplanctônica produzida neste lago fica acumulada e inacessivel ao zooplâncton, pois as cianobactérias maiores só podem ser utilizadas como detritos pelos organismos zooplanctônicos após sua destruição parcial.

Metacyclops mendocinus apresentou baixas abundâncias relativas no lago das Garças, ocorrendo esporadicamente no lago do IAG. SENDACZ e KUBO (1982) constataram que esta espécie foi importante nos reservatórios eutróficos do Estado de São Paulo; após o isolamento do braço do Rio Grande do corpo central do reservatório Billings, diminuições nas abundâncias relativas de $M$. mendocinus foram associadas a uma melhoria da qualidade da água (SENDACZ et al., 1984).

No lago das Garças, apesar de C. raciborskii ter sido uma das espécies de cianobactérias predominantes (GENTIL 2000), provavelmente por ser potencialmente tóxica (ZAGATTO 1998), talvez não tenha sido utilizada como recurso alimentar por T. decipiens e $M$. mendocinus, que apresentaram baixas abundâncias relativas; desta forma, estas espécies devem ter consumido detritos como fonte alimentar alternativa. Neste sentindo, torna-se necessária a realização de maiores estudos no sentido de esclarecer o consumo de C. raciborskii por estas espécies de copépodos.

Scolodiaptomus corderoi foi mais importante em condições oligo e mesotróficas, apresentando abundâncias relativas mais elevadas no lago das Ninféias; esteve pouco representado no lago das Garças. SENDACZ et al. $(1984,1985)$ e ESTEVES e SENDACZ (1988) também associaram calanóides a melhores condições da qualidade da água; este grupo não foi registrado nos reservatórios Rio Grande (previamente ao seu isolamento do corpo central do reservatório Billings) e Rio das Pedras (Complexo Billings, SP), que apresentavam avançado processo de 
eutrofização, com predominio de cianobactérias (SENDACZ et al., 1985). Calanóides também não ocorreram nos lagos Paranoá (DF) (BRANCO 1991) e Monte Alegre (SP) (ARCIFA et al., 1992), de características eutróficas.

Calanóides não utilizam como recurso nutricional cianobactérias filamentosas e coloniais, presentes em corpos d'água sujeitos à eutrofização, e que predominaram no lago das Garças. Este fato talvez seja responsável pelo declínio ou desaparecimento de macrofiltradores (SENDACZ 1984; SENDACZ et al. 1984).

MATSUMURA-TUNDISI e TUNDISI (1986 apud ROCHA et al. 1995) verificaram que no lago Carioca (Vale do Rio Doce, $M G$ ) calanóides foram pouco importantes; o fitoplâncton foi representado principalmente por cianobactérias de maior porte, tais como Botryococcus sp. e Lyngbia limnetica, uma fonte inadequada de alimento para macrofiltradores. Por outro lado, calanóides foram importantes no lago Dom Helvécio (MG), oligotrófico, onde predominou o nanofitoplâncton.

SCAVIA e FAHNENSTIEL (1988), baseados nos estudos de VANDERPLOEG e SCAVIA (1979) e VANDERPLOEG et al. (1984), verificaram que diaptomídeos não consomem bactérias e apresentam baixas taxas de filtração de pequenos "micrograzers" tais como flagelados heterotróficos e mixotróficos. Tais fatores poderiam também explicar a baixa representatividade de calanóides em condições eutróficas.

De acordo com PRICE et al. (1983 apud De MOTT e MOXTER 1991) e VANDERPLOEG e PAFFENHÖFER (1985 apud De MOTT e MOXTER 1991), calanóides apresentam dois mecanismos de alimentação: a captura raptorial de partículas maiores e filtração passiva de partículas menores, e portanto, não são sujeitos ao entupimento do aparelho filtrador ocasionado por cianobactérias. São filtradores seletivos (RICHMAN e DODSON, 1983), selecionando algas palatáveis e rejeitando cianobactérias tóxicas (FULTON e PAERL 1987a; DeMOTT e MOXTER 1991).

Calanóides também são capazes de distinguir fitoplâncton, detritos e particulas inorgânicas (KERFOOT e KIRK, 1991), demonstrando uma forte preferência por células vivas (DeMOTT 1988 apud KERFOOT e KIRK 1991). São considerados detritívoros facultativos quando predominam partículas alimentares de baixo valor nutricional (KERFOOT e KIRK, 1991). 
Portanto, o fato de Scolodiaptomus corderol ter sido mais importante nos lagos do IAG e das Ninféias, talvez esteja relacionado à composição fitoplanctônica, com predomínio de partículas alimentares de tipos e tamanhos mais adequados. Já no lago das Garças, $S$. corderoi foi pouco importante, talvez pelo predomínio de cianobactérias, uma fonte alimentar pouco adequada para esta espécie.

A baixa representatividade de S. corderoi no lago das Garças talvez possa estar relacionada ao seu mecanismo passivo de alimentação, que pode provocar decréscimos nas suas taxas de filtração na presença de cianobactérias. De acordo com FULTON e PAERL (1987b) as taxas de filtração de Diaptomus reighardi, espécie de regiões temperadas, foram inibidas por Microcystis aeruginosa, pois o mecanismo passivo de alimentação agrega as formas unicelulares desta cianobactéria, que consequentemente são rejeitadas por $D$. reighardi. Ainda segundo estes autores, cianobactérias nas formas coloniais ou filamentosas podem ter menos efeito inibitório nas taxas de filtração desta espécie, por serem previamente rejeitadas.

Os cladóceros apresentaram uma variação nas abundâncias relativas de acordo com o gradiente trófico observado nos lagos do PEFI; abundâncias relativas mais elevadas foram registradas no lago do IAG, e mais baixas no lago das Garças. BLANCHER (1984) também constatou que as abundâncias relativas de cladóceros foram baixas na maioria dos lagos eutróficos na Flórida.

Segundo ESTEVES e SENDACZ (1988), cladóceros foram importantes nos reservatórios do Estado de São Paulo com baixos Índices de Estado Trófico. De acordo com as autoras, este fato possa talvez ser explicado pelas estratégias alimentares diversificadas apresentadas pelos cladóceros; como a partícula filtrada é diretamente proporcional ao tamanho, componentes deste grupo zooplanctônico poderiam ser considerados microfiltradores ou macrofiltradores, apresentando diferenças específicas também em relação à qualidade de alimento ingerido.

Bosminopsis deitersi predominou nos lagos do IAG e das Ninféias; as mais elevadas abundâncias relativas desta espécie foram registradas no lago das Ninféias, que apresentou baixo tempo de residência médio ( 7,2 dias) (BICUDO DC comunicação pessoal). Ainda de acordo com esta autora, no lago do IAG, que também apresentou baixo tempo de residência médio ( 9,5 dias $), B$. deiterst apresentou abundâncias relativas intermediárias entre os lagos estudados. Já no lago das Garças, 
onde o tempo de residència médio foi maior (45,4 dias) (BICUDO DC comunicação pessoal), houve uma diminuição das abundâncias relativas desta espécie. Portanto, constatou-se que Bosminopsis deitersi foi mais importante nos lagos do IAG e das Ninféias, de caracteristicas semi-lóticas, confirmando o verificado por (NOGUEIRA 1996).

O predomínio de cianobactérias também poderia explicar a baixa representatividade de cladóceros no lago das Garças, bem como em lagos eutróficos de uma maneira geral. Cianobactérias são favorecidas na competição com outros produtores primários devido às suas adaptações fisiológicas; sua inadequabilidade como fonte nutricional as torna menos susceptíveis ao "grazing" pelos cladóceros e

ocorrência de florações de cianobactérias filamentosas devido à redução de suas taxas de alimentação e assimilação e aumento das taxas de respiração; como em geral, não são filtradores seletivos, utilizam energia na rejeição de partículas não desejáveis, ocasionando uma drástica redução nas taxas de crescimento e reprodução.

A inadequabilidade das cianobactérias como alimento para os cladóceros está relacionada com a interferência mecânica, eficiência de assimilação, qualidade nutricional das partículas alimentares e toxicidade (De BERNARDI e GIUSSANI, 1990).

A interferência mecânica de filamentos e colônias de cianobactérias, aliada a obstrução do aparelho filtrador, é um importante fator que controla o consumo destas algas pelos cladóceros (BOON et al., 1994).

Cianobactérias coloniais e filamentosas, ao provocar o entupimento nos apêndices filtradores dos cladóceros de maior tamanho, reduzem suas taxas de filtração ou aumentam suas taxas de respiração (GLIWICZ 1977), porém estas taxas são mais afetadas na presença de filamentos (RICHMAN e DODSON, 1983). No entanto, INFANTE e RIEHL (1984) observaram que florações periódicas de Microcystis aeruginosa não foram prejudiciais aos cladóceros no lago Valencia (Venezuela). 
Segundo GLIWICZ (1990) os cladóceros são desfavorecidos nas florações de cianobactérias, mais frequentemente pela interferência mecânica, do que pela toxicidade destas algas.

Apesar de cianobactérias serem consideradas, de uma maneira geral, de baixo valor nutricional para os organismos zooplanctônicos, podem, por outro lado representar um recurso nutricional, dependendo do seu estado fisiológico; quando entram em decomposição, há um acréscimo no crescimento bacteriano (GLIWICZ 1990), tornando-se então uma fonte de alimento mais adequada para o zooplâncton. O mesmo foi observado por HANAZATO e YASUNO (1985) em relação à utilização pelos cladóceros de células de Microcystis decompostas ou em decomposição.

A toxicidade de cianobactérias também depende do estado fisiológico; LAMPERT (1987) constatou que cepas tóxicas de Microcystis parecem não ter efeito nos organismos zooplanctònicos quando vivas, uma vez que não são consumidas, mas podem ser deletérias quando a floração começa a se decompor.

A ocorrência de cianobactérias tóxicas tem o potencial de alterar a dinâmica populacional dos organismos zooplanctônicos mais susceptiveis e modificar a estrutura da comunidade a favor das espécies que não ingerem cianobactérias, ou não são afetadas pelas toxinas das mesmas. O impacto de cianobactérias tóxicas no zooplâncton certamente é uma função da densidade das mesmas; este impacto também pode depender de fatores ambientais que modificam a resposta dos organismos zooplanctônicos (GILBERT 1996).

Assim, somente para os organismos zooplanctônicos de maior porte as cianobactérias podem ser uma fonte nutricional inadequada quando a forma ou tamanho da colônia interfere mecanicamente no processo de filtração. Além disso, a toxicidade de algumas espécies, e em particular de algumas cepas de cianobactérias, pode ser a principal razão para a inadequabilidade das mesmas. Em muitos casos, os organismos zooplanctônicos evitam ou rejeitam, ou ambos, com base na palatabilidade das cianobactérias, que, se ingeridas, geralmente são de baixo valor nutricional (De BERNARDI e GIUSSANI, 1990).

Desta forma, os organismos zooplanctônicos parecem ter desenvolvido mecanismos tanto para evitar a ingestão de cianobactérias tóxicas como para tolerar as toxinas ingeridas (DeMOTT e MOXTER, 1991). Por outro lado, a produção de 
toxinas pelas cianobactérias pode ser interpretada como um mecanismo evolutivo para amenizar a pressão do "grazing" pelo zooplâncton (LAMPERT 1987; DeMOTT e MOXTER 1991).

Apesar de Daphnia ambigua ter sido registrada nos três corpos d'água estudados, foi mais importante nos lagos do IAG e das Ninféias, associada a condições oligo e mesotróficas. Um dos fatores que talvez poderia explicar a ocorrência de baixas abundâncias relativas de D. ambigua no lago das Garças pode estar relacionado às mais elevadas concentrações de sólidos totais em suspensão. KIRK e GILBERT (1990 apud KIRK 1991) demonstraram experimentalmente reduções nas taxas de crescimento populacional de D. ambigua na presença de partículas inorgânicas em suspensão.

A inadequabilidade de cianobactérias como alimento para esta espécie talvez possa também explicar a sua baixa representatividade no lago das Garças. FULTON e PAERL (1987b) constataram que uma cepa unicelular de Microcystis aeruginosa foi tóxica a D. ambigua, e De BERNARDI e GIUSSANI (1990) verificaram que a morfologia colonial desta alga interferiu mecanicamente na taxas de assimilação de D. ambigua.

Apesar de existirem poucas evidências a respeito do consumo preferencial de cianobactérias tóxicas em relação a cepas não tóxicas, BENNDORF e HENNING (1989 apud DeMOTT e MOXTER 1991) demonstraram que a toxicidade de $M$. aeruginosa foi positivamente relacionada com a abundância relativa de Daphnia e a pressão de "grazing".

Alterações na estrutura da comunidade zooplanctônica, incluindo o desaparecimento de cladóceros maiores, e aumento na importância de cladóceros de menor porte são em geral associadas a florações de cianobactérias filamentosas ou coloniais. Verificou-se neste estudo que, no lago das Garças, não foi observada a substituição de cladóceros maiores (Daphnia) por cladóceros de menor porte (Bosmina), provavelmente devido ao curto periodo de duração da floração de Microcystis sp., talvez relacionada com a cobertura de macrófitas.

Daphnia gessneri foi predominante no lago das Garças, apesar de ser um cladócero de maior porte, e talvez mais vulnerável à presença de cianobactérias que os 
cladóceros menores (GLIWICZ 1990). Este fato pode ser explicado pela grande eficiência desta espécie em utilizar a cadeia microbiana como recurso alimentar.

Daphnia é o mais ubíquo cladócero em lagos meso-eutróficos na zona temperada, agindo como um predador "chave" que exerce grande influência na estrutura e função das cadeias alimentares microbianas (WEISSE e STOCKNER, 1993).

Espécies desse gênero são os únicos organismos do macrozooplâncton que têm amplo espectro alimentar, consumindo todos os componentes da comunidade microbiana variando de 1 a $50 \mu \mathrm{m}$ (STOCKNER e PORTER, 1988), desde bactérias até algas relativamente grandes (STERNER 1989 apud WEISSE 1994); são mais eficientes na captura de partículas do tamanho dos nanoflagelados, em relação às do bacterioplâncton (PORTER et al. 1983; DeMOTT 1985 apud SANDERS e PORTER 1990).

A maioria das espécies de Daphnia tem a habilidade de se alimentar de bactérias a taxas suficientes para remover a maior parte ou toda a produção diária bacteriana (GURTZ-HANSEN 1987; KANKAALA 1988; PACE et al. 1990 apud WEISSE e STOCKNER 1993); durante periodos de elevada abundância relativa de Daphnia, as cadeias alimentares microbianas são suprimidas em lagos meso e eutróficos (WEISSE e STOCKNER, 1993). O mesmo pode acontecer durante florações de grandes colônias de cianobactérias quando Daphnia se torna o bacterivoro dominante (CHRISTOFFERSEN et al. 1990 apud WEISSE e STOCKNER 1993).

Por outro lado, os demais organismos zooplanctônicos consomem bactérias, na maioria das vezes, com baixa eficiência, porém podem se alimentar facilmente de organismos maiores, tais como os ciliados, que consomem flagelados heterotróficos, que por sua vez consomem bactérias (PINTO-COELHO 2000). Desta forma, de acordo com o modelo de rotas tróficas proposto pelo elo microbiano, o zooplâncton é o principal agente remineralizador de nutrientes na zona pelágica de lagos e reservatórios (PINTO-COELHO 2000).

A baixa representatividade de Moina micrura no lago das Garças também pode estar relacionada à presença de cianobactérias. PORTER e ORCUTT (1980) confirmaram experimentalmente a toxicidade de certas cepas de Microcustis 
aeruginosa a esta espécie. O mesmo foi observado por HANAZATO e YASUNO (1987), que verificaram que Moina micrura não se reproduziu e apresentou baixas taxas de assimilação e crescimento quando cultivadas com cepas tóxicas de Microcystis aeruginosa, somente utilizada como alimento quando em decomposição.

No lago das Ninféias, densamente coberto por macrófitas submersas, Disparalona dadayl, componente típico de região litorânea, invadiu a região limnética e tornou-se uma das espécies de cladóceros predominantes; o mesmo foi verificado por ROCHA e SAMPAIO (1991) na lagoa Dourada (SP).

Bosmina hagmanni e $B$. tubicen apresentaram abundâncias relativas mais elevadas no lago do IAG, onde foram registrados em geral valores de $\mathrm{pH}$ abaixo de 6,0. PINEL-ALLOUL et al. (1989) constataram que microfiltradores não eficientes, pertencentes ao gênero Bosmina, apresentaram abundâncias relativas mais elevadas nos lagos mais ácidos.

A associação de $B$. hagmanni e $B$. tubicen a condições oligotróficas pode também estar relacionada à composição fitoplanctônica do lago do IAG. De acordo com DeMOTT e KERFOOT (1982), Bosmina é mais adaptada a ingerir nanoplâncton que bactérias, e WEISSE e STOCKNER (1993) constataram que espécies deste gênero são consideradas bacterivoros ineficientes, não exercendo pressão de "grazing" na cadeia microbiana.

Bosmina apresenta dois mecanismos de alimentação, combinando a filtração passiva com a captura ativa de particulas (DeMOTT e KERFOOT, 1982), o que as torna capazes de discriminar cianobactérias e outras particulas alimentares (LAMPERT 1987).

Na ocorrência de florações de cianobactérias, Bosmina é menos afetada pela interferência mecânica de colônias de Microcystis, em relação aos cladóceros de maior porte, podendo desta maneira manter elevadas abundâncias relativas (De BERNARDI e GIUSSANI, 1990). Tal fato não foi evidenciado no lago das Garças, e desta forma $B$. hagmanni e $B$. Iubicen podem ter utilizado detritos provenientes da decomposição de cianobactérias como recurso alimentar suplementar.

Diaphanosoma birget foi uma das espécies predominantes no lago do IAG, apresentando abundâncias relativas mais baixas no lago das Garças. O predominio desta espécie no lago do IAG também pode estar relacionado à comprcição 
fitoplanctônica; BLANCHER (1984) constatou que Diaphanosoma brachyurum (*) consome preferencialmente nanoplâncton nos lagos da Flórida.

O fato de Diaphanosoma birgei apresentar baixas abundâncias relativas no lago das Garças pode estar relacionado a concentrações elevadas de sólidos totais em suspensão; HERZIG (1975 apud KIRK e GILBERT 1990) evidenciou uma correlação positiva entre a taxa de mortalidade desta espécie e turbidez.

De acordo com HART (1988), com o aumento de turbidez as fontes convencionais de algas disponiveis ao zooplâncton tendem a declinar; consequentemente, a redução na disponibilidade de algas como alimento é combinada à interferência de partículas em suspensão inertes, com pouco ou nenhum valor nutriticional, influenciando a captura de alimento por filtradores zooplanctônicos (ARRUDA et al., 1983).

Os resultados obtidos neste trabalho evidenciam que é muito difícil identificar um padrão geral válido para todas as espécies de cianobactérias e organismos zooplanctônicos, pois são vários os fatores envolvidos afetando a utilização, digestão, assimilação e toxicidade deste grupo de algas. No entanto, parece que se as cianobactérias estiverem presentes em formas ou tamanhos adequados que não interfiram mecanicamente nos processos de filtração, e forem de cepas não tóxicas, podem representar uma importante fonte complementar de alimento para os zooplanctontes herbívoros (De BERNARDI e GIUSSANI, 1990).

No presente estudo, verificou-se que a estrutura da comunidade zooplanctônica variou de acordo com o estado trófico dos lagos estudados, dependendo também das estratégias alimentares de cada grupo zooplanctônico. Portanto, a associação de certas espécies a condições oligo e mesotróficas provavelmente pode estar relacionada à composição fitoplanctônica dos lagos do IAG e das Ninféias; já no lago das Garças, dois fatores podem ter influenciado a maior

* De acordo com Korovchinsky (1986) a designação Diaphanosoma brachyurum na América do Sul foi proveniente de uma traduçào errônea a partir do trabalho de Daday (1905). Portanto, de acordo com Korinek (1981. apud Korovchinsky, 1986) a espécie que ocorre nas Américas é Diaphanosoma birgei. 
representatividade de certas espécies: oferta diversificada de recursos alimentares e estratégias apresentadas pelos organismos zooplanctônicos que minimizam os efeitos deletérios das cianobactérias.

\subsection{Flutuação da comunidade}

Em estudos sobre a comunidade zooplanctônica, torna-se necessária a distinção entre dois padrões que podem estar superpostos, o padrão de evolução sucessional que reflete as condições tróficas dos corpos d'água, e o padrão sazonal (PINTO-COELHO 1987).

De um modo geral, as mais elevadas densidades numéricas do zooplâncton estiveram associadas a valores mais baixos de transparência da água, a valores elevados de condutividade elétrica e a concentrações elevadas de sólidos totais em suspensão, nitrogênio e fósforo totais, e clorofila $a$ total, condições estas verificadas no lago das Garças, ocorrendo o inverso no lago do IAG. Já no lago das Ninféias foram registradas densidades numéricas intermediárias, como também valores intermediários destas variáveis ambientais, em relação aos outros lagos estudados.

O gradiente evidenciado em relação à variação das densidades numéricas dos organismos zooplanctônicos, aliado à flutuação das variáveis que refletem as condições tróficas nos lagos estudados, corrobora os resultados obtidos por BICUDO et al. (1997) a partir dos Índices de Estado Trófico (IET) de Carlson modificado por TOLEDO Jr. et al. (1983), que consideraram o lago do IAG como oligotrófico, o lago das Ninféias, mesotrófico e o lago das Garças, eutrófico. Nos lagos da Flórida, BLANCHER (1984) também observou que a densidade numérica da comunidade zooplanctônica mostrou uma forte correlação positiva com o aumento do estado trófico.

Em corpos d'água tropicais e sub-tropicais a sazonalidade observada na densidade de organismos zooplanctônicos depende dos padrões de precipitação; nos lagos estudados, as densidades numéricas da comunidade zooplanctônica foram em geral mais baixas no periodo chuvoso-quente. Resultados semelhantes foram obtidos por SENDACZ (1978) no reservatório Billings (SP), e por PINTO-COELHO (1987) 
no lago Paranoá (DF). Este último autor atribuiu a ocorrência de menores densidades numéricas dos organismos zooplanctônicos neste período ao efeito diluidor provocado pelas chuvas.

MATSUMURA-TUNDISI e TUNDISI (1976), CABIANCA (1991) e ARCIFA et al. (1992) verificaram a ocorrência de picos de densidade de organismos zooplanctônicos no período chuvoso-quente, e decréscimo no período estiagem-frio. Segundo estes autores, com o início da estação chuvosa, os nutrientes são carreados para os reservatórios, favorecendo o crescimento do fitoplâncton, provocando consequentemente um aumento significativo nas densidades do zooplàncton.

O mesmo foi verificado por MELÃO (1997) na lagoa Dourada, constatando que no período chuvoso-quente ocorreu um maior aporte de sólidos em suspensão, parte de origem orgânica, que deve ter favorecido o desenvolvimento de bactérias, que por sua vez foram consumidas pelos organismos zooplanctônicos.

Já BRANCO (1991) e CALEFFI (1994) verificaram que picos de densidades numéricas da comunidade zooplanctônica foram obtidos tanto nos períodos chuvosoquente como estiagem-frio.

No lago das Garças, as mais elevadas densidades de organismos zooplanctônicos constatadas no periodo estiagem-frio foram relacionadas a concentrações mais elevadas de clorofila $a$ também registradas neste periodo. Assim, aumentos ou decréscimos das densidades numéricas do zooplâncton neste corpo d'água provavelmente estejam relacionados à maior ou menor biomassa algal disponivel.

As concentrações mais baixas de clorofila $a$ registradas no lago das Garças, no período chuvoso-quente, foram coincidentes com elevados valores de turbidez e concentrações mais elevadas de sólidos totais em suspensão e nutrientes, principalmente nitrogênio total. De acordo com FONSECA (1996), a resposta do fitoplâncton ao aumento das concentrações de nutrientes na água, em corpos d'água eutróficos, nem sempre é imediata e direta. DOKULIL e PADISÁK (1994 apud FONSECA 1996) verificaram, em um reservatório eutrófico, que o aumento da biomassa algal em relação ao aumento das concentrações de fósforo foi moderado, devido à limitação de luz causada pela elevada turbidez. 
No lago das Ninféias, densidades mais elevadas de organismos zooplanctônicos foram também registradas no periodo estiagem-frio, apesar das concentrações de clorofila $a$ não apresentarem uma aparente sazonalidade, indicando talvez que estes organismos possam utilizar detritos como fonte nutricional suplementar.

De acordo com CANFIELD e JONES (1984 apud MERCANTE e TUCCIMOURA, 1999), em lagos onde há a presença de macrófitas, a relação entre as concentrações de clorofila $a$ e nutrientes não é tão direta, pois as mudanças na abundância de macrófitas influenciam as características estruturais e funcionais de tais corpos d'água.

As macrófitas nos lagos das Ninféias e Garças atuaram ao mesmo tempo como fornecedoras de nutrientes, liberando matéria orgânica a ser utilizada pelos decompositores, assim como potentes competidoras na assimilação e estocagem dos mesmos.

Não se observou um padrão de flutuação sazonal no lago do IAG, tanto de densidades de organismos zooplanctônicos, como de concentrações de clorofila $a$. Estudos realizados neste lago por FERRAGUT (1999), LOPES (1999) e MERCANTE (2000) também evidenciaram que as concentrações de clorofila $a$ não apresentaram variação sazonal.

Em relação aos lagos das Ninféias e Garças, concentrações de nutrientes foram de uma forma geral também mais elevadas no periodo chuvoso-quente, provavelmente por serem carreados pelas chuvas. No entanto, nesta época do ano, mais especificamente no lago das Garças, houve uma diminuição da biomassa algal, provavelmente ocasionada pela sedimentação dos nutrientes no fundo e/ou devido à presença de macrófitas aquáticas. De acordo com REDDY et al. (1989 apud GOODWIN e GIANI 1998), macrófitas são conhecidas pela rápida assimilação de nitrogênio e fósforo, tornando-se assim competidoras eficazes por estes nutrientes, contra as próprias algas e cianobactérias.

No presente estudo, as flutuações das densidades numéricas da comunidade zooplanctônica foram devidas aos rotíferos, nos três lagos estudados. Lagos e reservatórios favorecem o desenvolvimento de espécies oportunistas, razão pela qual 
os rotiferos predominam nesses corpos d'água em relação a outros grupos zooplanctônicos (MATSUMURA-TUNDISI et al., 1990).

Nos lagos estudados, rotíferos apresentaram as mais baixas densidades numéricas no lago do IAG, onde foram registradas concentrações mais elevadas de oxigênio dissolvido; já no lago Valencia (Venezuela), INFANTE (1993) constatou uma diminuiçào das densidades deste grupo zooplanctônico com o decréscimo dac concentrações de oxigênio dissolvido.

Já no lago das Garças, rotíferos apresentaram elevadas densidades numéricas aliadas a concentrações mais elevadas de sólidos totais em suspensão, ocorrendo o inverso no lago do IAG. De acordo com KIRK (1991), rotíferos talvez sejam capazes de rejeitar sólidos em suspensão, devido ao hábito alimentar seletivo, e provavelmente são menos vulneráveis à interferência mecânica dos sólidos em suspensão.

No lago das Garças, são lançados esgotos domésticos "in natura"; segundo INFANTE (1993), densidades mais elevadas de rotiferos também foram registradas nos locais de maior contribuição de despejos orgânicos no lago Valencia.

Nos lagos das Ninféias e Garças, densidades numéricas de rotíferos foram mais elevadas no período estiagem-frio, porém somente no lago das Garças estas foram relacionadas à maior biomassa algal; nos lagos do IAG e das Ninféias, as concentrações de clorofila $a$ não apresentaram uma variação sazonal. No lago Paranoá (DF), PINTO-COELHO (1983), GIANI (1984) e PINTO-COELHO (1987) também constataram densidades elevadas de rotiferos no periodo estiagem-frio.

BRANCO (1991) observou que em alguns locais do lago Paranoá (DF), durante o periodo estiagem-frio, as densidades numéricas elevadas de rotíferos relacionaram-se com uma maior disponibilidade e variedade de alimentos, como algas cloroficeas e bactérias heterotróficas. Já no período chuvoso-quente, a elevação das densidades de rotíferos foi devida à elevada biomassa de Cylindrospermopsis raciborskiı. Segundo a autora, nas florações de cianobactérias existem decompositores ativos, havendo contínua produção de pequenas partículas, correspondendo a uma fonte autógena de detritos. Esse material, juntamente com as substàncias produzidas e excretadas pelas cianobactérias, pode constituir alimento adequado para espécies filtradoras micrófagas. 
As densidades numéricas de copépodos ciclopóides foram mais elevadas no lago das Garças, aliadas a baixos valores de transparència da água, valores elevados de condutividade elétrica, baixas concentrações de oxigênio dissolvido, e concentrações elevadas de nutrientes e clorofila $a$, confirmando as observações de SENDACZ et al. (1985) em reservatórios eutróficos do Estado de São Paulo. No lago Valencia (Venezuela), INFANTE (1993) também constatou que ciclopóides podem tolerar concentrações muito baixas de oxigênio dissolvido.

As densidades numéricas de ciclopóides foram mais baixas nos lagos do IAG e das Ninféias, confirmando as observações de ESTEVES e SENDACZ (1988), que verificaram correlações estatísticas positivas e significativas entre as densidades de ciclopóides e o estado trófico de vários reservatórios no Estado de São Paulo.

A flutuação das densidades numéricas de ciclopóides mostrou um comportamento sazonal; no lago do IAG essas densidades foram em geral mais elevadas no período chuvoso-quente, ocorrendo o inverso nos lagos das Ninféias e Garças. SENDACZ (1978) observou que as maiores densidades de ciclopóides no reservatório Billings (SP) ocorreram nos meses que antecedem o periodo chuvosoquente.

No lago das Garças, as maiores densidades numéricas de ciclopóides registradas no período estiagem-frio foram coincidentes com a maior biomassa algal, e provavelmente relacionada ao consumo de detritos e bactérias associadas às cianobactérias. RIETZLER (1995) constatou que os ciclopóides do reservatório de Barra Bonita (SP) provavelmente consomem Microcystis e/ou bactérias associadas à sua camada de mucilagem, levantando a hipótese de que estes organismos atuem como fator de interferència no elo microbiano.

O predominio de formas larvais de ciclopóides nos lagos estudados também foi verificada no Estado de São Paulo por diversos autores (CLARO 1981; SENDACZ et al. 1985; SILVA 1989; FONSECA 1990; BRANCO 1991; RIETZLER 1995; NUNES et al. 1996; MITSUKA 1998; PANARELLI 1999; CASANOVA 2000).

O fato de nauplios serem mais importantes que copepoditos pode estar relacionado as interações biológicas; segundo SOTO e HULBERT (1991), entre 
náuplios, a competição talvez seja a principal interação, e entre os copepoditos, ocorre a competição, predação e canibalismo.

Ainda de acordo com estes autores, a ontogenia dos copépodos envolve grandes mudanças no tamanho do corpo, comportamento e alimentação; condições favoráveis para determinado estágio do ciclo de vida são muitas vezes desfavoráveis a outro estágio.

No lago do IAG, Tropocyclops prasinus apresentou densidades numéricas mais elevadas no periodo chuvoso-quente, ocorrendo o inverso nos lagos das Ninféias e Garças. Somente no lago das Garças foi possivel estabelecer uma aparente relação entre a flutuação sazonal das densidades desta espécie e a variação das concentrações de clorofila $a$, densidades mais elevadas de $T$. prasinus foram coincidentes com maiores concentrações de clorofila $a$ no periodo estiagem-frio, representando uma maior disponibilidade alimentar.

As densidades numéricas de Thermocyclops decipiens no lago das Garças foram em geral mais elevadas no periodo chuvoso-quente, corroborando as observações de SENDACZ et al. (1984) e PINTO-COELHO (1987). Já no lago Paranoá (DF), BRANCO (1991) constatou que populações dessa espécie apresentaram pouca variação das densidades ao longo do periodo de estudo. No lago Valencia (Venezuela), T. decipiens apresentou densidades mais elevadas no período estiagem-frio, quando diatomáceas e criptoficeas foram mais abundantes (INFANTE 1993).

No periodo chuvoso-quente, GENTIL (2000) também constatou o predominio de cianobactérias no lago das Garças, porém as espécies predominantes e abundantes, tais como (ylindrospermopsis raciborski, Microcystis aeruginosa e Sphaerocavum brasiliensis, de uma maneira geral não apresentaram variação sazonal em relação às densidades numéricas. Pelo fato da sazonalidade observada nas densidades de $T$. decipiens provavelmente não estar relacionada com a flutuação das densidades destas cianobactérias, talvez esta espécie de ciclopóide não utilize estas algas na sua dieta alimentar.

Metacyclops mendocinus não apresentou um padrão de flutuação sazonal no lago das Garças; já no reservatório do Rio Grande (Complexo Billings, SP), foi mais comum durante o período estiagem-frio (SENDACZ et al., 1984). 
Em relação à Scolodiaptomus corderot, nos lagos do IAG e das Ninféias nauplios foram mais importantes que copepoditos; de acordo com THRELKELD (1976 apud BURNS 1988) e BURNS (1985 apud BURNS 1988), nauplios podem sobreviver à fome por periodos mais longos em comparação a outros organismos zooplanctônicos.

No presente estudo, verificou-se que calanóides apresentaram densidades numéricas mais elevadas nos lagos do IAG e das Ninféias, e ciclopóides predominaram no lago das Garças. Segundo MATSUMURA-TUNDISI e TUNDISI (1976), o desaparecimento de calanóides pode estar relacionado com a gradual substituição destes organismos pelos ciclopóides, o que normalmente ocorre com a eutrofização. Em condições eutróficas, o sucesso de ciclopóides pode estar relacionado à disponibilidade alimentar; de acordo com SENDACZ (1993), este grupo zooplanctônico utiliza um amplo espectro de fontes alimentares, como consequência das mudanças ontogenéticas mais extremas, na dieta.

Quanto aos cladóceros, as mais elevadas densidades constatadas no lago do IAG foram coincidentes com concentrações mais baixas de sólidos totais em suspensão. A presença de partículas em suspensão provoca grandes reduções nas taxas de assimilação de algas, e, consequentemente, há gastos de energia, provocando decréscimos na taxa de crescimento populacional de cladóceros (KIRK 1991).

Apesar dos cladóceros utilizarem pequenas particulas como alimento, tais como bactérias e nanofitoplâncton, a presença de sólidos totais em suspensão é desvantajosa, devido à incapacidade destes organismos em separar as partículas nutritivas das não-nutritivas. Portanto, a presença de sólidos em suspensão tem um papel importante na flutuação das densidades numéricas de cladóceros na comunidade zooplanctônica (KIRK e GILBERT, 1990).

Nos lagos do IAG e Garças, Bosmina hagmanni e B. tubicen nào mostraram um padrão de flutuação sazonal de suas densidades ao longo do periodo de estudo; já no lago Paranoá (DF), B. hagmannı ocorreu com maior abundância no periodo chuvoso-quente, apesar da menor oferta de alimento, o que pode evidenciar uma maior sensibilidade desta espécie a condições eutróficas constatadas na seca (BRANCO 1991). 
Pelo fato de não ocorrer uma aparente variação sazonal nas concentrações de clorofila a nos lagos do IAG e das Ninféias, só foi possivel estabelecer no lago das Garças uma aparente relação entre a variação das densidades numéricas de certas espécies de cladóceros e as concentrações de clorofila $a$. No período estiagem-frio, Bosminopsis deitersi, Daphnia ambigua, D. gessnert e Diaphanosoma birgei apresentaram densidades numéricas mais elevadas provavelmente associadas à elevada biomassa algal registrada, representando uma maior oferta de alimento.

No lago das Garças, observou-se uma drástica redução das abundâncias relativas de $D$. gessneri no período de agosto a outubro, ou seja, próximo à ocorrência da floração de Microcystis sp., que no ano de 1997 foi registrada no mês de setembro*. Esta constatação corrobora os resultados obtidos por SENDACZ et al. (1984) no braço do Rio Grande (SP), onde as abundâncias relativas de $D$. gessnerl também diminuiram com o aumento das densidades de Microcystis aeruginosa.

Neste sentido, a sazonalidade da comunidade zooplanctônica pode ter sido influenciada pelo efeito "bottom-up"; assim, alterações nas concentrações de nitrogènio e fósforo podem provocar mudanças na composição e biomassa fitoplanctònica, que consequentemente podem ou não ser favoráveis a certos "grazers" zooplanctònicos (SMITH 1983 apud CROWDER et al. 1988). Segundo LAZZARO (1997), lagos tropicais e subtropicais são predominantemente controlados pelo efeito "bottom-up".

De acordo com GLIWICZ (1994), a limitação do alimento, que é um efeito "bottom-up", controla as densidades do zooplâncton herbívoro através da reprodução; por outro lado, a predação, considerada um efeito "top-down", controla as densidades de componentes da comunidade zooplanctônica através da mortalidade.

As larvas de Chaoboridae são consideradas predadores planctônicos muito importantes (ARCIFA 1997). Ainda segundo esta autora, (haoborus é um predador potencial durante todo o ano, decrescendo sua pressão de predação de acordo com as

* No ano de 1997, a cobertura de macrótitas provavelmente pode ter dificultado a ocorrència de florações de cianobacterias, no lago das Garças, que geralmente foram observadas nos anos anteriores por um periodo mais longo (primavera e início do verão) 
flutuações sazonais de suas densidades numericas, e migração vertical. Durante o dia, as larvas migram em direção ao sedimento, e a noite, em direção à superficie.

Apesar desse fato, nos très lagos do PEFI, densidades mais elevadas de larvas de Chaoboridae foram constatadas no período chuvoso-quente, corroborando o verificado por ARCIFA et al. (1992) no lago Monte Alegre (SP).

No lago das Garças, larvas de Chaoboridae provavelmente exerceram pressão de predação sobre Keratella tecta e $K$. tropica, uma vez que estas espécies apresentaram as menores densidades no período chuvoso-quente. De acordo com MOORE e GILBERT (1987), a presença de espinhos na lórica de rotíferos não parece ser um recurso efetivo contra a predação por Chaoborus.

Não foi possivel determinar a possivel utilização de Bosmina hagmanni e $B$. lubicen como presa pelas larvas de Chaoboridae, uma vez que estas espécies não mostraram uma aparente flutuação sazonal de suas densidades nos lagos do IAG e das Garças; já Daphnia gessneri, no lago das Garças, por apresentar densidades mais baixas no período chuvoso-quente, provavelmente sofreu a pressão de predação por estas larvas. De acordo com ARCIFA et al. (1992), a predação por larvas de Chaoboridae parece ser o maior controlador das populações de D. gessneri.

Deve-se levar em consideração que a predação de larvas de Chaoboridae sobre certas espécies do zooplâncton depende dos estágios de desenvolvimento. No lago Monte Alegre (SP), ARCIFA et al. (1992) e ARCIFA (1997) verificaram que o primeiro e segundo estágios larvais predaram o gênero Keratella, uma vez que ambos estágios larvais não migram e säo encontrados na coluna d'água durante o dia e noite; já o terceiro e quarto estágios larvais exerceram pressão de predação sobre B. tubicen e D. gessneri.

Vários autores (LEWIS 1977; CHIMMEY et al. 1981; NEILL 1985 apud MOORE e GILBERT 1987) verificaram que os estagios mais jovens de ('haoborus também se alimentam de rotíferos; já os estágios III e IV provavelmente são predadores de Bosmina, Daphnia e Moina (HANAZATO e YASUNO, 1990). Por outro lado, MOORE e GILBERT (1987) constataram que estes dois últimos estágios podem consumir grandes densidades de rotíferos quando outras espécies de microcrustáceos utilizadas como presas, tais como copépodos e cladóceros, não estão disponiveis nos corpos d'água. 
As diferenças na preferência de certas presas entre os estágios de Chaoborus, ou entre os dois primeiros ou os dois últimos, podem reduzir a competição intraespecifica por alimento (MOORE e GILBERT, 1987).

Apesar da inexistência de estudos referentes à caracterização da ictiofauna nos lagos do PEFI até o presente momento, é provável que nestes corpos d'água, como nos demais lagos e reservatórios tropicais e subtropicais predomine o efeito "bottomup", ou seja, o padrão de flutuação das densidades numéricas da comunidade zooplanctònica é mais influenciado pela qualidade e quantidade das fontes alimentares disponiveis do que pela predação (efeito "top-down").

\subsection{Riqueza, equitatividade e diversidade}

O conhecimento da riqueza. equitatividade e diversidade da comunidade zooplanctònica é um instrumento de grande valia para a caraterização ou tipificação de um lago; são atributos desta comunidade que podem ser alterados pela eutrofização e, consequentemente, essas mudanças podem até levar à exclusão de determinadas espécies, e a um elevado crescimento populacional de outras (PINTO-COELHO et al., 1999). Ainda segundo estes autores, é provável que a comunidade zooplanctônica apresente diferentes padrões de diversidade de espécies de acordo com o estado trófico dos corpos d'água.

No presente estudo, o número total de táxons registrado na comunidade zooplanctônica foi mais baixo nos lagos do IAG e das Ninféias, e mais elevado no lago das Garças, confirmando o verificado por RADWAN e POPIOLEK (1989); segundo estes autores, o número total de táxons aumentou com o estado trófico nos lagos da Polônia.

O maior número de táxons de rotíferos (41) foi também registrado no lago das Garças; foi mais elevado em comparação a outros corpos d'água eutróficos, como os reservatórios Billings (SP) (SENDACZ et al., 1985) e Vargem das Flores (MG) (FREIRE e PINTO-COELHO, 1986), lagos Paranoá (DF) (PINTO-COELHO 1987; BRANCO 1991) e Monte Alegre (SP) (ARCIFA et al., 1992), e reservatório Guarapiranga (SP) (DOMINGOS 1993). Foi inferior somente em relação aos reservatórios Barra Bonita (SP) (MATSUMURA-TUNDISI 1999) e Guarapiranga (CALEFFI 2000). 
Nos lagos do IAG e das Ninféias registrou-se também um maior número de táxons de rotiferos, quando comparado aos de outros corpos d'água oligo e mesotróficos, tais como os lagos Dom Helvécio (MG) (MATSUMURA-TUNDISI 1997a) e Anibal (MG) (TUNDISI et al., 1997), e reservatório de Nova Ponte (MG) (SILVA 1998). O número de táxons foi menor em relação aos reservatórios de Jurumirim (SP) (NOGUEIRA 1990) e Broa (SP) (OLIVEIRA-NETO 1993), e lagoa Dourada (SP) (MELÃO 1997).

Copépodos ciclopóides também apresentaram maior riqueza no lago das Garças, em comparação a outros corpos d'água eutróficos. Nos lagos do IAG e das Ninféias, o baixo número de espécies de ciclopóides foi semelhante ao de outros corpos d'água de características oligo e mesotróficas (ROCHA et al. 1995, 1999).

A baixa riqueza de copépodos calanóides é um fato comum em reservatórios eutróficos (ROCHA et al. 1995, 1999), observando-se a ocorrência de uma ou duas espécies (ARCIFA 1984; SENDACZ et al., 1985), ou mesmo ausência deste grupo (SENDACZ et al., 1985).

Nos lagos estudados, a única espécie registrada foi Scolodiaptomus corderol; o mesmo foi verificado nos reservatórios Billings (SP) (SENDACZ 1978) e Vargem das Flores (MG) (FREIRE e PINTO-COELHO, 1986). Por outro lado, no reservatório de Guarapiranga (SP) constatou-se a presença de Argyrodiaptomus furcatus, Notodiaptomus iheringi, Scolodiaptomus corderoi e Trichodiaptomus coronatus (CALEFFI 1994), e no reservatório de Barra Bonita (SP) a associação de Notodiaptomus cearensis, $N$. conifer, $N$. iheringi e Notodiaptomus sp.n. (ESPINDOLA 1994). Tal fato talvez esteja relacionado ao contínuo processo de eutrofização destes corpos d'água, ou mais especificamente no caso de Barra Bonita, aos efeitos dos mecanismos operacionais de funcionamento da barragem sobre a dinâmica das populações, interferindo nas comunidades biológicas e favorecendo a colonização por novas espécies.

Nos três lagos do PEFI, o número de táxons de cladóceros foi mais elevado em relação a outros corpos d'água de diferentes condições tróficas (ROCHA et al. 1995, 1999), devido à contribuição de táxons associados ao sedimento e/ou região litorânea. A presença de macrófitas, além de oferecer refúgio da predação para as 
espécies zooplanctônicas, aumenta a disponibilidade de alimento (ROCHA et al., 1999).

Em relação ao indice de diversidade, os valores obtidos no lago das Garças (1,74 a 3,56 bits/ind) foram semelhantes aos constatados por DOMINGOS (1993) no reservatório de Guarapiranga (SP) (1,20 a 3,90 bits/ind), e mais elevados que os valores registrados no lago Paranoa (DF) $(0,43$ - 1,08 bits/ind) (BRANCO 1991), e nos reservatórios Guarapiranga (0,37 - 3,69 bits/ind) (CALEFFI 1994) e Barra Bonita (SP) $(1,20$ - 2,80 bits/ind) (WISNIEWSKI 1998), também de características eutróficas.

Os valores do índice de diversidade nos lagos do IAG $(2,07-3,15$ bits/ind $)$ e das Ninféias (1,02 - 3,12 bits/ind) foram superiores aos obtidos nos reservatórios Jacaré-Pepira (SP) (FONSECA 1996), Jurumirim (SP) (NOGUEIRA 1996) e Nova Ponte (MG) (SILVA 1998), de características oligotróficas.

No presente estudo, as médias anuais de riqueza e do indice de diversidade foram mais elevadas no lago das Garças e mais baixas nos lagos do IAG e das Ninfëias, confirmando o verificado por MARGALEF et al. (1976 apud ROCHA et al. 1999) na Espanha; estes autores constataram que a diversidade foi mais elevada em corpos d'água eutróficos.

PINTO-COELHO et al. (1999) constataram que em duas regiões no reservatório da Pampulha ( $\mathrm{MG}$ ), de diferentes condições tróficas, os valores do índice de diversidade foram semelhantes. Segundo estes autores, a diversidade, calculada a partir do Índice de Shannon, provavelmente refletiu que a riqueza foi pouco afetada pela eutrofização, não sendo portanto muito adequado para tal finalidade.

A simples comparação de indices de diversidade entre corpos d'água de condições tróficas semelhantes não é muito conclusiva, pois sob o aspecto ecológico a diversidade considera, além da riqueza, a equitatividade ou uniformidade. De acordo com MATSUMURA-TUNDISI (1999), ao se comparar dois corpos d'água que apresentam a mesma riqueza, porém um deles com uma ou duas espécies predominantes, e o outro praticamente sem predomínio de espécies, o primeiro terá uma diversidade menor que o segundo.

Nos lagos estudados, a queda dos valores dos índices de diversidade, atribuida a um declínio da equitatividade, como consequência do predomínio de certos 
táxons, corrobora as observações de PAYNE (1986 apud CALEFFI 1994); segundo este autor, o predominio de um pequeno número de espécies indica uma baixa uniformidade na distribuição dos recursos, típica de baixa diversidade. Por outro lado, de acordo com ODUM (1985 apud SENDACZ 1993), quando existe o predomínio de um táxon, uma perturbação generalizada ou moderada pode causar um aumento da diversidade, em vez de declinio.

\subsection{Análise multivariada}

A análise de componentes principais (ACP) foi aplicada com a finalidade de evidenciar os fatores que controlam a abundância e distribuição dos organismos zooplanctônicos, assim como as associações de táxons especificas para cada corpo d'água, e sua relação ao gradiente do estado trófico dos lagos estudados.

O lago das Garças apresentou condições tróficas peculiares, com concentrações mais elevadas de sólidos totais em suspensão, fósforo e nitrogênio totais e clorofila a total, assim como valores também mais elevados de condutividade elétrica e turbidez; tais caracteristicas permitiram considerar este lago como eutrófico.

Já no lago do IAG foram evidenciados valores mais baixos destas variáveis, assim como elevadas concentrações de oxigênio dissolvido, e valores também mais elevados de transparência, refletindo condições oligotróficas. O lago das Ninféias ocupou uma posição intermediária entre os lagos do IAG e das Garças em relação às condições tróficas, sendo considerado mesotrófico.

A ACP confirmou, desta maneira, os resultados obtidos a partir dos Índices de Estado Trófico (IET) de Carlson modificado por TOLEDO Jr. et al. (1983), considerando os corpos d'água como oligotrófico (lago do IAG), mesotrófico (lago das Ninféias) e eutrófico (lago das Garças) (BICUDO et al., 1997).

A transparência da água, por apresentar a maior correlação positiva com o principal eixo extraído na $\mathrm{ACP}$, foi a variável mais importante na discriminação entre os corpos d'água considerados

Quanto às densidades numéricas dos táxons zooplanctônicos, foi observado um gradiente semelhante ao constatado em relação ao estado trófico específico de cada lago. Densidades numéricas mais elevadas ocorreram no lago das Garças, verificando- 
se o inverso no lago do IAG; densidades numéricas intermediárias entre os corpos d'água estudados foram observadas no lago das Ninféias.

As análises de agrupamento e de componentes principais evidenciaram grupos de táxons associados às condições tróficas, como também táxons cuja ocorrência independe do estado trófico dos lagos do PEFI.

Nos lagos do IAG e das Ninféias, através da ACP, constatou-se uma maior importância de náuplios e copepoditos de calanóides, Scolodiaptomus corderoi e Bosminopsis dettersi. Evidenciou-se que Anuraeopsis fissa, Brachionus angularis chelonis, Keratella tecta, K. tropica, náuplios e copepoditos de ciclopóides, Metacyclops mendocinus, Thermocyclops decipiens e Daphnia gessneri foram importantes no lago das Garças.

Conochilus dossuarius, Keratella cochlearis, Tropocyclops prasinus, Daphnia umbigua, Bosmina hagmannı e Diaphanosoma birgei não mostraram uma clara associação a condições tróficas, com exceção de Ascomorpha spp., registrada somente no lago do IAG.

Conochilus dossuarius, $K$. cochlearis, $T$. prasinus e D. ambigua ocorreram nos três lagos estudados, independentemente do estado trófico, e B. hagmanni e D. birgei foram comuns aos lagos do IAG e das Garças.

Portanto, através da ACP foram evidenciados táxons que podem ser utilizados como indicadores da qualidade da água, tais como A. fissa, B. angularis chelonis, $K$. tecta, K. troptca, náuplios e copepoditos de calanóides, S. corderol, náuplios e copepoditos de ciclopóides, $M$. mendocinus, T. decipiens, B. deitersi e D. gessneri, assim como táxons que se comportaram independentemente do estado trófico, tais como (. dossuarius, K. cochlearis, T. prasinus, B. hagmanni, D. ambigua e D. birgel, e, portanto, não devem ser utilizados para esta finalidade.

A importância do estabelecimento de correlações entre as densidades numéricas dos táxons que compõem a comunidade zooplanctônica e as características ambientais facilita o entendimento da natureza das respostas dos organismos zooplanctônicos às condições abióticas. 


\subsection{Espécies zooplanctônicas como indicadoras da qualidade da água}

Ao se analisar o predomínio, como também a frequência de ocorrência das espécies zooplanctônicas em reservatórios do Estado de São Paulo, evidenciou-se que certas espécies podem ser utilizadas como indicadoras da qualidade da água.

Entre os rotiferos, Anuraeopsis fissa, Brachionus angularis, B. calyciflorus, C'onochilus dossuarius, Lpiphanes macrourus, Filinia opoliensis, Keratella tecta, $K$. tropica, Trichocerca pusilla e T. stmilis estiveram associadas preferencialmente a condições eutróficas.

Anuraeopsis fissa ocorreu preferencialmente no Alto Tietê, tendo sido predominante no lago das Garças. Foi também registrada na bacia do rio Grande, no Médio Tietê, e na bacia do rio Paraná. De acordo com BERZINS e PEJLER (1989), A. fissa é uma espécie associada a elevadas concentraçòes de fósforo total e valores elevados de condutividade elétrica, característicos de corpos d'água eutróficos.

Brachionus angularis foi registrada nas bacias do rio Paraiba do Sul, Piracicaba, Capivari e Jundiai, Alto e Médio Tietê, e dos rios Grande, Paranapanema, e Paraná. Apesar desta espécie estar preferencialmente associada a condições eutróficas, ocorreu também em corpos d'água mesotróficos.

Brachionus calyciflorus ocorreu preferencialmente no Alto e Médio Tietê, e nas bacias dos rios Piracicaba, Capivari e Jundiaí, Grande, Alto Paranapanema e Paraná. O predomínio de B. calyciflorus associado a condições eutróficas foi evidenciado no braço Taquacetuba (Complexo Billings) por COELHO-BOTELHO et al. (2001), e em Barra Bonita (Médio Tietê) por diversos autores (TUNDISI e MATSUMURA-TUNDISI 1994; ESPINDOLA 1994; RIETZLER 1995; WISNIEWSKI 1998; COELHO-BOTELHO et al. 2001).

Na região temperada, diversos autores (PEJLER 1983; SLÁDECEK 1983; BERZINS E PEJLER 1989; RADWAN E POPIOLEK 1989; PONTIN E LANGLEY 1993) associaram a ocorrência de B. angularis e B. calyciflorus a corpos d'água eutróficos.

Brachionus havanaensis, embora tenha apresentado uma baixa frequência de ocorrência no Estado de São Paulo, esteve relacionada preferencialmente a condições eutróficas. Foi registrada pela primeira vez nos braços Taquacetuba e Rio Pequeno (Complexo Billings), e no reservatório de Barra Bonita (Médio Tietê) por COELí IO- 
BOTELHO et al. (2001). Foi uma espécie importante no lago do PET (Alto Tietê) (DEKER 2000). BLANCHER (1984) constatou que esta espécie ocorreu nos lagos eutróficos da Flórida.

SILVA (1989) constatou o predominio de Epiphanes macrourus no lago Monte Alegre (bacia do rio Pardo). Esta espécie também foi registrada nas bacias do Alto e Médio Tietê, e Paraná. Na lagoa Jota, SENDACZ (1993) constatou que E. macrourus foi uma das espécies adaptadas a elevadas concentrações de nutrientes.

Conochilus dossuarius ocorreu preferencialmente na bacia do Alto Tietê, e Filinia opoliensis, Trichocerca pusilla e T. similis foram registradas principalmente nas bacias do Alto e Médio Tietê. Através da ACP verificou-se que C. dossuarius ocorreu independentemente do gradiente do estado trófico dos lagos do PEFI.

COELHO-BOTELHO et al. (2001) evidenciaram que F. opoliensis predominou nos braços Taquacetuba e Rio Pequeno, no reservatório Rio Grande (Complexo Billings) e em Barra Bonita (Médio Tietê). Foi também registrada nas bacias do Alto Paranapanema e do Paraná.

O predominio de Keratella tropica no reservatório de Barra Bonita (Médio Tietê) foi evidenciado por diversos autores (MATSUMURA-TUNDISI et al. 1990; ESPÍNDOLA 1994; RIETZLER 1995; WISNIEWISKI 1998; COELHO-BOTELHO et al. 2001). Esta espécie também ocorreu no Alto Tietê e em outros corpos d'água do Médio Tietê, nas bacias dos rios Pardo, Piracicaba, Capivari e Jundiai, Alto Paranapanema, e Parana.

Keratella tecta apresentou uma baixa frequência de ocorrência no Estado de São Paulo, tendo sido registrada nas bacias do Alto Tietê e do Pardo. Na região temperada, diversos autores (BERZINS e PEJLER 1989; RADWAN e POPIOLEK 1989, PONTIN e LANGLEY 1993) consideraram $K$. tecta como indicadora de condições eutróficas.

No estudo realizado nos lagos do PEFI, ao se aplicar a análise de componentes principais (ACP) com o objetivo de evidenciar espécies indicadoras da qualidade da água, Anuraeopsis fissa, K. tropica e $K$. tecta estiveram associadas a condições eutróficas. 
Por outro lado, Asplanchna sleboldi, Collotheca ornata, Conochilus coenobasts, Hexarthra mira e Plationus patulus, estiveram associadas preferencialmente a condições oligotróficas.

FONSECA (1996) constatou o predomínio de $H$. mira no reservatório de Jacaré-Pepira (Médio Tietê), oligotrófico. Esta espécie ocorreu em todos os reservatórios da bacia do rio Grande, tendo sido também registrada nas bacias do Pardo, Alto e Médio Tietê, Paranapanema e Paraná

Hexarthra intermedia braziliensis, Ptygura libera e Trichocerca capucina ocorreram preferencialmente em corpos d'água oligo e mesotróficos. O predomínio de $P$. libera foi constatado no reservatório do Broa (Médio Tietê) por diversos autores (OLIVEIRA-NETO 1993; SEGERS e DUMONT 1995; RODRÍGUEZ 1997; RODRIGUEZ e MATSUMURA-TUNDISI 2000). Esta espécie também ocorreu nas bacias dos rios Pardo, Alto, Médio e Baixo Tietê, Grande e Paraná. Trichocerca capucina ocorreu preferencialmente na bacia do rio Paranapanema.

Brachionus falcatus, Conochilus unicornis, Keratella americana, $K$. cochlearis e Polyarthra vulgaris foram registradas na maioria das bacias hidrográficas do Estado de São Paulo, independentemente das condições tróficas. Em relação a $K$. cochlearis, tal fato também foi evidenciado através da ACP aplicada nos lagos do PEFI.

Quanto aos copépodos ciclopóides, Thermocyclops decipiens ocorreu em todas as bacias hidrográficas do Estado de São Paulo, preferencialmente no Alto e Médio Tietê. De acordo com REID (1989), T. decipiens é frequentemente dominante entre os microcrustáceos planctônicos em corpos d'água meso e eutróficos.

Thermocyclops inversus, embora tenha apresentado uma baixa frequència de ocorrência, esteve relacionada a corpos d'água meso e eutróficos. Foi registrada pela primeira vez no Alto Tietê, no reservatório de Guarapiranga por CALEFFI (1994, 2000).

Thermocyclops minutus esteve associada a condições oligo e mesotróficas, evidenciadas nos reservatórios Euclides da Cunha (bacia do rio Pardo), Jaguará e Marimbondo (bacia do rio Grande), Piraju e Xavantes (Alto Paranapanema), e Promissão (Baixo Tietê) (MATSUMURA-TUNDISI 1997b). 
Embora seja uma espécie numericamente dominante entre os copépodos de corpos d'água oligo e mesotróficos (MATSUMURA-TUNDISI e TUNDISI 1976; SENDACZ e KUBO 1982; SENDACZ et al. 1985; REID 1989), pode ocorrer e se desenvolver com sucesso associada a condições eutróficas (REID 1989).

Thermocyclops minutus foi predominante nos reservatórios de Funil (bacia do rio Paraíba do Sul) (SENDACZ e KUBO 1982; SENDACZ et al. 1985), Broa (Médio Tietê) (MATSUMURA-TUNDISI e TUNDISI, 1976), Jurumirim (bacia do rio Paranapanema) (NOGUEIRA 1996; NOGUEIRA e PANARELLI 1997; MITSUKA 1998; PANARELLI 1999), e na lagoa Comprida (bacia do rio Paraná) (SENDACZ 1993).

No reservatório do Broa, segundo MATSUMURA-TUNDISI e TUNDISI (1976), de características oligo-mesotróficas, picos de densidades numéricas de $T$. minutus estão fortemente associados ao carreamento de nutrientes que ocorre no período chuvoso-quente, com consequente aumento da comunidade fitoplanctônica.

Thermocyclops minutus e $T$. decipiens podem ocorrer em corpos d'água em transição, nos quais as condições ambientais estão se modificando (REID 1989); tal fato foi verificado por SENDACZ (1993) nas lagoas associadas ao rio Paraná.

Nos corpos d'água do Estado de São Paulo, a co-ocorrència de T. minutus e $T$. decipiens foi constatada preferencialmente em condições eutróficas, confirmando o verificado por REID e PINTO-COELHO (1994).

De acordo com SENDACZ (1978) e SENDACZ et al. (1985), T. decipiens e Metacyclops mendocinus ocorrem em condições eutróficas. Esta co-ocorrência foi evidenciada principalmente na bacia do Alto Tietê. Foi também registrada nas bacias do Paraiba do Sul, Piracicaba, Capivari e Jundiaí, Médio Tietê, Ribeira de Iguape, e Alto Paranapanema, somente no reservatório São José (SENDACZ e KUBO 1982; SENDACZ et al. 1985).

A co-ocorrência de $T$. decipiens e Mesocyclops longisetus, apesar de constatada em todas as bacias hidrográficas do Estado de São Paulo, ocorreu preferencialmente no Alto e Médio Tietê. Mesocyclops longisetus não é importante quantitativamente no zooplâncton (SENDACZ e KUBO 1982; ARCIFA 1984; SENDACZ et. al. 1985), e desta forma não foi possivel estabelecer associações com o estado trófico. O mesmo se verifica em relação às demais espécies deste gênero 
que apresentaram baixa frequência de ocorrência nos corpos d'água do Estado de São Paulo, inviabilizando associações com as condições tróficas.

Mesocyclops brasilianus e M. kieferi ocorreram em Barra Bonita (TUNDISI e MATSUMURA-TUNDISI 1994; RIETZLER 1995; WISNIEWSKI 1998), e em Jurumirim (Alto Paranapanema) (NOGUEIRA 1996)

Mesocyclops ellipticus ocorreu nas lagoas associadas ao rio Paraná (SENDACZ 1993), e Mesocyclops meridianus foi registrada pela primeira vez no Estado de São Paulo no reservatório Volta Grande (bacia do rio Grande) por ROLLA et al. (1990), ocorrendo também em Paraibuna (bacia do rio Paraiba do Sul) (CABIANCA 1991), e nas lagoas Comprida e Jota (bacia do rio Paraná) (SENDACZ 1993).

Tropocyclops prasinus foi registrada na maioria das bacias hidrográficas do Estado de São Paulo, com exceção do rio Paraná. Esteve relacionada preferencialmente a condições eutróficas, ocorrendo principalmente no Alto Tietê. No entanto, através da ACP evidenciou-se que T. prasinus ocorreu nos lagos do PEFI independentemente do estado trófico.

O predomínio de $T$. prasinus, na ausência de espécies do gênero Thermocyclops, foi associada a condições meso e eutróficas, constatadas nos reservatórios de Ponte Nova (SENDACZ e KUBO 1982; SENDACZ et al. 1985), Pedro Beicht (ARCIFA 1984), lagos do IAG e das Ninféias (Alto Tietê), na lagoa Dourada (Médio Tietê) (MELÃO 1997) e no reservatório Batista (bacia do Alto Paranapanema) (SENDACZ e KUBO 1982; SENDACZ et al. 1985).

No lago Monte Alegre (bacia do rio Pardo) (SILVA 1989; ARCIFA et al. 1992, 1998), e no lago das Garças (Alto Tietê), de condições eutróficas, T. prasinus foi mais importante e co-ocorreu com Thermocyclops decipiens. Já Tropocyclops schubarti só foi registrada na lagoa Dourada (Médio Tietê) (ROCHA e SAMPAIO, 1991).

Em estudo recente realizado nas bacias do Alto e Médio Tietê por COELHOBOTELHO et al. (2001) foram constatadas alterações na composição de espécies de ciclopoides, bem como o registro de novas ocorrências, devido a mudanças na qualidade da água em função das regras operacionais implementadas nos últimos anos, que regulam a operação do sistema de reversão das águas do rio Pinheiros, ora 
para o rio Tietê, ora para o reservatorio Billings, gerando pulsos de enriquecimento (TIJNDISI e MATSUMURA-TUNDISI, 1994). Desta maneira, COELHOBOTELHO et al. (2001) registraram no Complexo Billings (Alto Tietê) pela primeira vez Mesocyclops aspericornis, M. ogunnus, Thermocyclops inversus e T. minutus; M. ogunnus e T. minutus ocorreram no reservatório Guarapiranga (Alto Tietê), e $M$. aspericornis, M. ogunnus e $\%$ inversus no reservatório de Barra Bonita (Médio Tietê). No lago do PET (Alto Tietê), DEKER (2000) evidenciou o predominio de $T$. inversus.

Em 1979, na bacia do Alto Tietê Odontodiaptomus paulistanus foi registrada nos reservatórios de Ponte Nova, Águas Claras, Juqueri e Guarapiranga (SENDACZ e KUBO 1982; SENDACZ et al. 1985), e em Ribeirão do Campo (ARCIFA 1984). Ocorreu também esporadicamente em reservatórios da bacia do rio Ribeira de Iguape (SENDACZ et al., 1985). Na bacia do rio Paraíba do Sul, esta espécie foi registrada nos reservatórios Santa Branca (ARCIFA 1984) e Paraibuna (CABIANCA 1991).

De acordo com DOMINGOS (1993) e CALEFFI (1994, 2000), O. paulistanus não ocorreu em Guarapiranga, verificando-se que com a crescente eutrofização esta espécie não vem sendo registrada em corpos d'água do Estado de São Paulo, encontrando-se atualmente no reservatório de Ponte Nova (SENDACZ comunicação pessoal).

Argyrodiaptomus furcatus tem sido associada preferencialmente a condições oligotróficas: ocorreu no Médio Tietê, nos reservatórios do Broa (MATSUMURATUNDISI e ROCHA 1975; MATSUMURA-TUNDISI e TUNDISI 1976) e JacaréPepira (CLARO 1981; FONSECA 1996).

$\mathrm{Na}$ bacia do rio Paranapanema, A. furcatus ocorreu nos reservatórios Jurumirim, Piraju, Xavantes e Salto Grande (MATSUMURA-TUNDISI 1997b), tendo sido registrada posteriormente no reservatório Jurumirim (NOGUEIRA 1996; NOGUEIRA e PANARELLI 1997; MITSUKA 1998; PANARELLI 1999). Nos reservatórios de Ilha Solteira e Jupiá (bacia do rio Paraná), A. furcatus foi registrada por SENDACZ (1993) e MATSUMURA-TUNDISI (1997b).

SENDACZ et al. (1984) e KUBO (1989), ao estudarem o reservatório Rio Grande (Alto Tietê), após o seu isolamento do corpo central da Billings, registraram A. furcatus e Scolodiaptomus corderoi, indicando uma melhoria das condiçres da 
qualidade da água, pois previamente ao isolamento deste braço do corpo do reservatorio, não havia registros de calanóides (SENDACZ e KUBO 1982; SENDACZ et al. 1985). Como consequência da eutrofizaçào, Argyrodiaptomus furcatus também não vem sendo registrada nos reservatórios Rio Grande (Alto Tietê) e Barra Bonita (Médio Tietê) (COELHO-BOTELHO et al., 2001).

De acordo com MATSUMURA-TUNDISI (1997b), A. furcatus e Scolodiaptomus corderoi ocorreram em todos os reservatórios da bacia do rio Grande, tendo sido registradas posteriormente por ROLLA et al. (1990) no reservatório de Volta Grande.

Nos reservatórios de Graminha e Euclides da Cunha (bacia do rio Pardo), $S$. corderol foi a única espécie de calanóide registrada (MATSUMURA-TUNDISI 1997b). Ocorreu também no Alto Tietê em Águas Claras, Juqueri, Parque Ecológico, braço do Rio Pequeno (Complexo Billings), Guarapiranga (SENDACZ e KUBO 1982; SENDACZ et al. 1985), e Taiaçupeba (ARCIFA 1984). Ainda no Alto Tietê, no PEFI, $S$. corderoi predominou nos lagos do IAG e das Ninféias, ocorrendo esporadicamente no lago das Garças.

Esta espécie também não vem sendo registrada nos reservatórios Guarapiranga (Alto Tietê) e Barra Bonita (Médio Tietê) como consequència da eutrofização. No entanto, $S$. corderol vem ocorrendo no reservatório Rio Grande (Complexo Billings) (COELHO-BOTELHO et al., 2001), devido ao tratamento da água para fins de abastecimento.

Notodiaptomus iheringl foi registrada pela primeira vez no Estado de São Paulo por SENDACZ e KUBO (1982) e SENDACZ et al. (1985) nos reservatórios de Itapeva e Funil (bacia do rio Paraíba do Sul). Foi posteriomente registrada nos reservatórios de Bariri e lbitinga (Médio Tietê), e Promissão e Nova Avanhandava (Baixo Tietê) (TUNDISI et al., 1991), assim como em Volta Grande (bacia do rio Grande) (ROLLA et al., 1990). Por ocasião de alterações no estado trófico no reservatório do Broa (Médio Tietê), RIETZLER (1991) evidenciou a ocorrència de $N$. iheringi. Esta mesma autora verificou que esta espécie foi substituida por $A$. furcutus quando este reservatório retornou a condição oligotrófica.

Notodiaptomus iheringi foi também registrada no Alto Tietê, no reservatório de Guarapiranga por DOMINGOS (1993), CALEFFI (1994, 2000) e COELHO- 
BOTELHO et al. (2001). Ainda no Alto Tietê, Notodiaptomus iheringi foi a única espécie de calanóide registrada no lago do PET (DEKER 2000); no reservatório Billings, foi pela primeira vez registrada por COELHO-BOTELHO et al. (2001), demonstrando bastante tolerância a condições eutróficas. O predomínio desta espécie também tem sido constatado no reservatório de Barra Bonita (Médio Tietê) por diversos autores (FONSECA 1990; GÁVILAN-DIAZ 1990; ESPÍNDOLA 1994; TUNDISI e MATSUMURA-TUNDISI 1994; WISNIEWSKI 1998; COELHOBOTELHO et al. 2001).

Ainda no reservatório de Barra Bonita, ESPINDOLA (1994) constatou que esta espécie superou em abundância os ciclopóides em alguns períodos deslocando Notodiaptomus conifer e Scolodiaptomus corderoi, espécies dominantes entre os calanóides em estudos anteriores.

Além de sua característica competitiva, diversos autores têm frequentemente associado $N$. iheringı a condições eutróficas (SENDACZ e KUBO 1982; REID 1985; MATSUMURA-TUNDISI 1986; RIETZLER 1991: COELHO-BOTELHO et al. 2001). De acordo com MATSUMURA-TUNDISI e ROCHA (1987 apud COELHOBOTELHO et al. 2001), N. iheringi tem se desenvolvido bem nestas condições, muitas vezes suplantando os ciclopóides em locais onde são comuns as florações de cianobactérias.

Apesar de estar adaptado a condições eutróficas, $N$. iheringi também foi registrada associada a condições oligotróficas nos reservatórios de Ilha Solteira e Jupiá (bacia do rio Paraná) (SENDACZ 1993). Na bacia do Alto Paranapanema, diversos autores (NOGUEIRA 1996; NOGUEIRA e PANARELLI 1997; MITSUKA 1998; PANARELLI 1999) constataram que $N$. iheringi foi frequente entre os calanóides no reservatório de Jurumirim, fato este provavelmente relacionado à composição fitoplanctônica deste corpo d'água (PANARELLI 1999).

No Médio Tietê, $N$. conifer foi a única espécie registrada nos reservatórios Bariri e Ibitinga (MATSUMURA-TUNDISI 1997b); SENDACZ e KUBO (1982) e SENDACZ et al. (1985) registraram $N$. conifer no reservatorio de Itupararanga.

Esta espécie ocorreu preferencialmente na bacia do rio Paranapanema, tendo sido registrada na maioria dos reservatórios desta bacia por SENDACZ et al. (1985) e MATSUMURA-TUNDISI (1986). Ocorreu também, juntamente com 
Notodiaptomus transitans, nos reservatórios de Água Vermelha (bacia do rio Grande), e Promissão e Nova Avanhandava (Baixo Tietê) (MATSUMURATUNDISI 1997b). Notodiaptomus transitans também foi registrada no reservatório Capivara (bacia do rio Paranapanema) por MATSUMURA-TUNDISI (1986).

Com a crescente eutrofização no reservatório de Barra Bonita (Médio Tietê), Notodiaptomus conifer não vem sendo registrada (TUNDISI e MATSUMURATUNDISI 1994; WISNIEWSKI 1998; COELHO-BOTELHO et al. 2001), porém foi constatado o aparecimento de Notodiaptomus cearensis (ESPÍNDOLA 1994; TUNDISI e MATSUMURA-TUNDISI 1994; COELHO-BOTELHO et al. 2001). Notodiaptomus conifer ocorreu em lagoas marginais dos rios Paraná (SENDACZ 1993) e Paranapanema (CASANOVA 2000).

Notodiaptomus isabelae, registrada por SENDACZ (1993) nas lagoas associadas ao rio Paraná, ocorre preferencialmente neste tipo de habitat. Esta autora, nesta mesma bacia, registrou Notodiaptomus jatobensis nos reservatorios de Ilha Solteira e Jupiá.

Notodiaptomus spinuliferus ocorreu nos reservatórios de Marimbondo e Água Vermelha (bacia do rio Grande) (MATSUMURA-TUNDISI 1997b), e Ilha Solteira (MATSUMURA-TUNDISI 1986) e Jupiá (SENDACZ 1993; MATSUMURATUNDISI 1997b)

Em relação às demais espécies de calanóides, Argyrodiaptomus azevedoi foi registrada no reservatório Marimbondo (bacia do rio Grande) (MATSUMURATUNDISI 1997b), e na bacia do rio Paraná, em Ilha Solteira (MATSUMURATUNDISI 1986; SENDACZ 1993) e Jupiá (SENDACZ 1993; MATSUMURATUNDISI 1997b). Já Trichodiaptomus coronatus ocorreu exclusivamente no reservatório Guarapiranga (Alto Tietê) (CALEFFI 1994).

As alterações constatadas na composição de espécies de calanóides no Alto e Médio Tietê por COELHO-BOTELHO et al. (2001) foram provavelmente ocasionadas pelas regras operacionais que provocam alterações na qualidade da água. No Alto Tietê, estas autoras registraram pela primeira vez, no Complexo Billings, Notodiaptomus theringi que deslocou Scolodiaptomus corderoi, e no reservatório Guarapiranga, Notodiaptomus cf. cearensis. 
Quanto aos cladóceros, Daphnia gessneri apresentou elevada frequência de ocorrència no Estado de São Paulo, tendo sido registrada em todas as bacias hidrográficas; ocorreu preferencialmente em condições eutróficas, principalmente na bacia do Alto Tietê. Nos lagos do PEFI, através da ACP evidenciou-se que esta espécie também foi associada a condições eutróficas.

O predominio de 1 ). gessneri foi constatado no lago Monte Alegre (bacia do rio Pardo) (SILVA 1989; ARCIFA et al. 1992), no reservatório de Americana (bacia dos rios Piracicaba, Capivari e Jundiaí) (ARCIFA 1984; ESPINDOLA et al. 1998), Ponte Nova (SENDACZ e KUBO 1982; SENDACZ et al. 1985), no reservatório Rio Grande (COELHO-BOTELHO et al, 2001), nos lagos do PET (DEKER 2000), e Garças (bacia do Alto Tietê), e na bacia do rio Paranapanema, em Jurumirim (MITSUKA 1998) e Batista (SENDACZ e KUBO 1982; SENDACZ et al. 1985). ARCIFA et al. (1992) atribuem o sucesso de D. gessneri no lago Monte Alegre à sua eficiência como filltrador, predominando sobre rotíferos e alguns cladóceros.

Daphnia ambigua ocorreu preferencialmente em condições oligo e mesotróficas evidenciadas nos lagos do IAG e das Ninféias (bacia do Alto Tietê), no Médio Tietê, nos reservatórios do Broa (MATSUMURA-TUNDISI 1984, 1997b) e Monjolinho (NOGUEIRA 1990; OKANO 1994; NOGUEIRA e MATSUMURATUNDISI 1996) e lagoa Dourada (TALAMONI 1995), e na lagoa Camargo (bacia do rio Paranapanema) (CASANOVA 2000). Já a co-ocorrência de D. ambigua e $D$. gessneri esteve relacionada preferencialmente a condições eutróficas, evidenciadas principalmente na bacia do Alto Tietê. Através da ACP, evidenciou-se que $D$. ambigua ocorreu independentemente do estado trófico dos lagos do PEFI.

Moina minuta também apresentou uma elevada frequência de ocorrência no Estado de São Paulo, tendo sido registrada na maioria das bacias hidrográficas, com exceção do Baixo Tietê, ocorrendo preferencialmente em condições eutróficas. De acordo com NOGUEIRA (1996), esta espécie prefere corpos d'água de condições eutróficas e turbulentas.

Já a co-ocorrência de Moina micrura e M. minuta foi evidenciada em condições meso e eutróficas, no lago Monte Alegre (bacia do rio Pardo) (SILVA 1989; ARCIFA et al. 1992, 1998), no Alto Tietê, nos braços Taquacetuba e Rio Pequeno (Complexo Billings) (COELHO-BOTELHO et al, 2001), e no lag das 
Garças, no Médio Tietê, em Barra Bonita (GÁVILAN-DIAZ 1990) e Monjolinho (NOGUEIRA 1990; NOGUEIRA e MATSUMURA-TUNDISI 1996), e na lagoa Jota (bacia do rio Paraná) (SENDACZ 1993).

Nos corpos d'água do Estado de São Paulo evidenciou-se que a ocorrência de espécies do gênero Bosmina esteve relacionada ao estado trófico. Bosmina hagmanni foi registrada preferencialmente em condições oligotróficas, principalmente nas bacias do Paranapanema e Médio Tietê; já Bosmina tubicen foi registrada principalmente na bacia do Alto Tietê, associada a condições eutróficas. Bosmina longirostris ocorreu nas bacias dos rios Paraiba do Sul, do Piracicaba, Capivari e Jundiai, do Alto e Médio Tietê, do Grande e do Paranapanema, associada preferencialmente a condições mesotróficas.

O mesmo não foi verificado por EL-MOOR LOUREIRO (1988), que constatou que $B$. longirostris estaria relacionada a corpos d'água eutróficos, $B$. tubicen, oligotróficos, e B. hagmanni, intermediário entre ambos. SENDACZ e KUBO (1999) constataram, no reservatório Rio Grande (Alto Tietê), que $B$. hagmanni foi mais importante na estação que apresentou melhores condições da qualidade da água, ocorrendo o inverso com B. longirostris. Já nos lagos do PEFI, B. hagmanni ocorreu independentemente das condições tróficas. Portanto, maiores estudos são necessários para estabelecer a preferência das espécies de Bosmina em relação à qualidade da água.

Quanto ao gènero Diaphanosoma, do total de espécies registradas (6), somente $D$. birgei apresentou uma elevada frequência de ocorrência no Estado de São Paulo, tendo sido registrada em todas as bacias hidrográficas. Nos lagos do PEFI, evidenciou-se, através da ACP, que a ocorrência de D. birgei foi independente das condições tróficas.

Diaphanosoma hirgei, D. brevireme, D. fluviatile e D. spinulosum coocorreram no Estado de São Paulo somente na lagoa Coqueiral (CASANOVA 2000), e este fato pode ser talvez explicado pela conexão desta lagoa com o rio Paranapanema, propiciando uma maior amplitude de recursos alimentares e, consequentemente, uma maior especialização de nichos.

Bosminopsis deiterst foi registrada na maioria das bacias hidrograficas do Estado de São Paulo, com exceção do Baixo Tietê; segundo NOGUEIRA (1906), é 
uma espécie que tem preferència por regiões de maior influência de condições lóticas.

Ceriodaphnia cornuta foi registrada em todas as bacias hidrográficas do Estado de São Paulo; já Ceriodaphnia silvestrii ocorreu principalmente na bacia do rio Paranapanema preferencialmente em condições oligotróficas, tendo sido também registrada em Ponte Nova (Alto Tietê) (SENDACZ comunicação pessoal). Por outro lado, Ceriodaphnia reticulata foi preferencialmente associada a condições eutróficas, ocorrendo principalmente na bacia do Alto Tietê.

Com base nos dados sobre a ocorrência de espécies zooplanctônicas nos corpos d'água do Estado de São Paulo, evidenciou-se que certas espécies, por estarem associadas a determinado estado trófico, podem ser utilizadas como indicadoras da qualidade da água.

\section{CONCLUSÕES}

- A composição, estrutura e abundância da comunidade zooplanctônica nos três lagos do PEFI variaram de acordo com o estado trófico, dependendo também das diferentes estratégias alimentares de cada grupo zooplanctônico.

- A comunidade zooplanctônica caracterizou-se pelo predomínio de microzooplâncton (rotiferos e náuplios) nos três lagos estudados, independentemente do estado trófico.

- A riqueza foi fortemente influenciada pelos rotíferos, representados por grande número de táxons, e também variou de acordo com o estado trófico.

- Conochilus dossuarius predominou no lago do IAG, e Polyarthra vulgaris, no lago das Ninféias. No lago das Garças, Anuraeopsis fissa, Brachionus angularis chelonis, Keratella americana, K. tecta. K. tropica, P. valgaris e Polyarthra sp. apresentaram abundâncias relativas semelhantes, provavelmente devido a uma 
maior amplitude de recursos alimentares, caracteristica de corpos d'água eutróficos.

- O predomínio de copépodos variou de acordo com o estado trófico; ciclopóides foram mais importantes no lago das Garças, eutrófico, e calanóides nos lagos do IAG e das Ninféias, de características oligo e mesotróficas, respectivamente.

- Tropocyclops prasinus foi a espécie de ciclopóide predominante nos lagos do IAG e das Ninféias, e co-ocorreu com Thermocyclops decipiens e Metacyclops mendocinus no lago das Garças. A única espécie de calanóide registrada nos três lagos do PEFI foi Scolodiaptomus corderoi.

- De modo geral, a flutuação de cladóceros foi inversamente relacionada à variação das concentrações de sólidos totais em suspensão. No entanto, a flutuação das espécies predominantes também dependeu de outros fatores, tais como o tempo de residência dos lagos estudados, e a estratégia alimentar. Bosminopsis deitersi foi mais importante nos lagos do IAG e das Ninféias, de características semi-lóticas, e Daphnia gessneri predominou no lago das Garças, talvez pela grande eficiência em utilizar um amplo espectro de partículas da cadeia microbiana como recurso alimentar.

- A flutuação das densidades numéricas do zooplâncton nos lagos das Ninféias e Garças foi influenciada pela precipitação e, no lago das Garças, foi também relacionada à biomassa algal disponivel. Densidades numéricas mais baixas ocorreram no periodo chuvoso-quente, devido ao efeito diluidor das chuvas.

- A composição fitoplanctônica provavelmente foi um dos fatores determinantes na composição de espécies zooplanctônicas nos lagos do IAG e das Ninféias. A composição no lago das Garças pode ter sido influenciada tanto pela maior variabilidade de recursos alimentares, como também pelas diferentes estratégias dos organismos zooplanctônicos, minimizando os efeitos deletérios das cianobactérias. 
- Através da análise de componentes principais (ACP), evidenciou-se grupos de táxons que podem ser utilizados como indicadores da qualidade da água, tais como náuplios e copepoditos de calanóides, Scolodiaptomus corderoi e Bosminopsis deitersi, que apresentaram uma maior importância nos lagos do IAG e das Ninféias. Anuraeopsis fissa, Brachionus angularis chelonis, Keratella tecta, K. tropica, náuplios e copepoditos de ciclopóides, Metacyclops mendocinus, Thermocyclops decipiens e Daphnia gessneri foram mais importantes no lago das Garças.

- Não foi evidenciada através da ACP uma clara associação entre Conochilus dossuarius, Keratella cochlearis, Tropocyclops prasinus, Bosmina hagmanni, Daphnia ambigua, Diaphanosoma birgei e o estado trófico.

- Valores mais baixos de transparència da água, valores elevados de $\mathrm{pH}$, condutividade elétrica, turbidez, e concentrações também elevadas de sólidos totais em suspensão, fósforo e nitrogènio totais, e clorofila $a$, caracteristicos de corpos d'água eutróficos, foram relacionados ao lago das Garças na ACP. A comunidade zooplanctônica aí verificada apresentou índices de diversidade e densidades numéricas mais elevados

- Através da ACP, evidenciou-se que valores mais elevados de transparência da água, valores mais baixos de $\mathrm{pH}$, condutividade elétrica, turbidez, e baixas concentrações de sólidos totais em suspensão, fósforo e nitrogênio totais, e clorofila $a$, que caracterizam corpos d'água oligotróficos, foram relacionados ao lago do IAG, que apresentou as menores densidades de organismos zooplanctônicos.

- O lago das Ninféias apresentou na ACP uma posição intermediária em relação aos lagos do IAG e Garças quanto ao gradiente do estado trófico; densidades numéricas intermediárias entre os lagos estudados foram observadas neste corpo d'água. 
- O gradiente do estado trófico constatado através da $\mathrm{ACP}$ em relação às variáveis físicas, quimicas e biológicas, foi o maior responsável pela variabilidade das densidades numéricas do zooplâncton nos lagos do PEFI.

- No Estado de São Paulo, Anuraeopsis fissa, Brachionus angularis, B. calyciflorus, Epiphanes macrourus, Filinia opoliensis, Keratella tecta, K. tropica, Trichocerca pusilla, T. similis, Metacyclops mendocinus, Thermocyclops decipiens, Bosmina tubicen, Daphnia gessneri e Moina minuta podem ser utilizadas como indicadoras da qualidade da água, por estarem preferencialmente associadas a condições eutróficas.

- Asplanchna sieboldi, Collotheca ornata, Conochilus coenobasis, Hexarthra mira e Plationus patulus estiveram associadas preferencialmente a condições oligotróficas, e Bosmina longirostris a condições mesotróficas. Hexarthra intermedia braziliensis, Ptygura libera, Trichocerca capucina, Thermocyclops minutus e Argyrodiaptomus furcatus foram relacionadas principalmente a condições oligo e mesotróficas.

- Brachionus falcatus, ('onochilus unicornis, Keratella americana, K. cochlearis e Polyarthra vulgaris não devem ser utilizadas como indicadoras da qualidade da água, por terem ocorrido na maioria dos corpos d'água do Estado de São Paulo, de diferentes bacias hidrográficas, independentemente do estado trófico.

- Brachionus havanaensis, Mesocyclops aspericornis, M. brasilianus, M. ellipticus, M. kieferi, M. longisetus, M. meridianus, M. ogunnus, Thermocyclops inversus, Argyrodiaptomus azevedoi, Notodiaptomus cearensis, N. conifer, N. cf. henseni, N. isabelae, N. jatobensis, $N$. spinuliferus, N. transitans e Trichodiaptomus coronatus, por apresentarem baixas densidades e frequência de ocorrência no zooplâncton, necessitam de mais estudos para serem melhor avaliadas quanto a sua utilização como indicadoras da qualidade da água de corpos d'água do Estado de São Paulo. 
- No Estado de São Paulo, Notodiaptomus iheringi ocorreu na maioria das bacias hidrográficas, demonstrando bastante tolerância a condições eutróficas; Scolodiaptomus corderot vem ocorrendo também em condições eutróficas, embora preferencialmente em condições oligo e mesotróficas. Argyrodiaptomus furcatus e Odontodiaptomus paulistanus ficaram restritos a corpos d'água oligotróficos.

\section{REFERÊNCIAS BIBLIOGRÁFICAS}

Alves VRE, Cavalcanti CGB, Mattos SP. Análise comparativa de parâmetros físicos, químicos e biológicos, em um período de 24 horas, no Lago do Paranoá, Brasília - DF, Brasil. Acta Limnol Brasil 1988; 2: 199 - 218.

Arcifa-Zago MS. Os Cladocera planctônicos e aspectos da eutrofização da Represa de Americana. A ciclomorfose em Daphnia gessneri Herbst 1967. São Paulo (SP); 1972. [Tese de Doutorado - Instituto de Biociências da Universidade de São Paulo].

Arcifa-Zago MS. The planktonic Cladocera (Crustacea) and aspects of the eutrophication of Americana Reservoir, Brazil. Bolm Zool 1976; 1 : 105-45.

Arcifa MS. Zooplankton composition of ten reservoirs in southern Brazil. Hydrobiologia 1984; 113:137-45.

Arcifa MS. Fluctuations and vertical migration of Chaoborus in a tropical brazilian reservoir: lake Monte Alegre. Acta Limnol Brasil 1997; 9: 93-103.

Arcifa MS, Carvalho MAJ, Gianesella-Galvão SMF, Shimizu GY, Froehlich CG, Castro RMC. Limnology of ten reservoirs in Southern Brazil. Verh Internat Verein Limnol 1981; 21 : 1048 - 53. 
Arcifa MS, Gomes EAT, Meschiatti AJ. Composition and flutuactions of the zooplankton of a tropical Brazilian reservoir. Arch Hydrobiol. 1992; 123 (4): $479-95$

Arcifa MS, Silva LHS, Silva MHL. The planktonic community in a tropical brazilian reservoir: composition, fluctuations and interactions. Rev Bras Biol 1998; 58 (2): $241-54$

Arruda JA, Marzolf GR, Faulk RT. The role of suspended sediments in the nutrition of zooplankton in turbid reservoirs. Ecology 1983; 64 (5): 1225-35.

Azevedo SMFO, Evans WR, Carmichael WW, Namikoshi M. First report of microcystins from a Brazilian isolate of the cyanobacterium $M$. aeruginosa. $\mathbf{J}$ Appl Phycol 1994; 6: 261-65.

Berzins B, Pejler B. Rotifer occurrence in relation to $\mathrm{pH}$. Hydrobiologia 1987; 147 : 107-16.

Berzins B, Pejler B. Rotifer occurrence and trophic degree. Hydrobiologia 1989; 182: $171-80$.

Beyruth Z. Fitoplâncton em lagos do Parque Ecológico do Tietê, São Paulo, 1986 1987. Estudo para reabilitação. Rev DAE 1993; 170: 5 - 10.

Beyruth Z, Caleffi S, Rocha AA. Hidrobiologia sanitária e saúde pública em lagos do Parque Ecológico da Zona Leste de São Paulo. Macroinvertebrados bentônicos. Rev DAE 1993; $172: 11-3$.

Bicudo CEM. Tipologia, monitoramento e recuperação dos corpos de água da Reserva Biológica do Parque Estadual das Fontes do Ipiranga, São Paulo. São Paulo; 1996. [Projeto de Pesquisa]. 
Bicudo CEM, Ramirez R JJ, Tucci A, Bicudo DC. Dinâmica de populações fitoplanctônicas em ambiente eutrofizado: O Lago das Garças, São Paulo. In: Henry R, editor. Ecologia de Reservatórios: Estrutura, Função e Aspectos Sociais. Botucatu (SP): FUNDIBIO: FAPESP; 1999. p. 449-508.

Bicudo DC. Algas epífitas do Lago das Ninféias, São Paulo, Brasil. 1: Cyanophyceae. Rev Brasil Biol 1983; 48: 407-19.

Bicudo DC. Algas epífitas (exceto diatomáceas) do Lago das Ninféias, São Paulo: levantamento e aspectos ecológicos. Rio Claro; 1984. [Tese de Doutorado Universidade Estadual Paulista].

Bicudo DC. Algas epífitas do Lago das Ninféias, São Paulo, Brasil. 2: Xanthophyceae. Rev Bras Biol 1989; 49: 851-60.

Bicudo DC. Algas epífitas do Lago das Ninféias, São Paulo, Brasil. 3: Chrysophyceae. Rev Bras Biol 1990; 50: 355-75.

Bicudo DC, Vercellino I S, Carmo CF, Bicudo CEM, Sant'Anna CL, Barcelos EM, Rosa AC. Classificação do estado trófico dos três lagos artificiais da Reserva Biológica do Parque Estadual das Fontes do Ipiranga, SP: Avaliação preliminar. In: Anais do $6^{\circ}$ Congresso Brasileiro de Limnologia. 1997 Jul 22-25; São Carlos (SP). São Carlos: Sociedade Brasileira de Limnologia UFSCar; 1997. p. 61.

Bicudo DC, Carmo CF, Tucci-Moura NA, Ramirez R JJ, Bicudo CFM. Limnologia em um ambiente hipereutrofizzado: um estudo no Lago das Garças, São Paulo. In: Anais do Simpósio: Ecologia de Reservatórios: Estrutura, Função e Aspectos Sociais. 1998; Botucatu (SP). Botucatu: Universidade Estadual Paulista: 1998. p. 25-6. 
Bicudo DC, Tucci A, Ramirez R JJ, Carmo CF, Nogueira NMC, Bicudo CEM. Escala de amostragem e variabilidade de fatores limnológicos em reservatório eutrofizado: (Lago das Garças. São Paulo). In: Henry R, editor. Ecologia de Reservatórios: Estrutura, Função e Aspectos Sociais. Botucatu (SP): FUNDIBIO: FAPESP: 1999. p. 409-48.

Blancher EC. Zooplankton-trophic state relationships in some north and central Florida lakes. Hydrobiologia 1984; 109: 251-63.

Boon PI, Bunn SE, Green JD, Shiel RJ. Consumption of cyanobacteria by freshwater zooplankton: implications for the success of "top-down" control of cyanobacterial blooms in Australia. Aust J Mar Freshwater Res 1994; 45: 875-87.

Branco CWC. A comunidade planctônica e a qualidade da água no Lago Paranoá, Brasília, DF, Brasil. Brasilia (DF); 1991. [Dissertação de Mestrado - Universidade de Brasilia].

Branco CWC, Cavalcanti CGB. A ecologia das comunidades planctônicas no Lago Paranoá. In: Henry R, editor. Ecologia de Reservatórios: Estrutura, Função e Aspectos Sociais. Botucatu (SP): FUNDIBIO: FAPESP; 1999 p. 573-96.

Bueno NC. Ecologia de Nitella furcata subsp. mucronata var. mucronata f. oligospira na região litorânea do lago das Ninféias, município de São Paulo, SP, Brasil. Rio Claro (SP); 2000. [Tese de Doutorado - Universidade Estadual Paulista]

Burns CW. Starvation resistance among copepod nauplii and adults. Verh Internat Verein Limnol 1988; 23: 2087-91.

Cabianca MAA. A Represa de Paraibuna: aspectos do zooplâncton. São Paulo (SP); 1991. [Dissertação de Mestrado - Instituto de Biocièncias da USP] 
Cabianca MAA, Sendacz S. Limnologia do reservatório do Borba (Pindamonhangaba, SP). II - Zooplâncton. B Inst Pesca 1985; 12 (3): 83-95.

Cabianca MAA, Sendacz S. Distribuição vertical do zooplâncton da Represa do Rio Grande - Complexo Billings - SP. In: Anais do $1^{\circ}$ Congresso Brasileiro de Limnologia; 1986 Set 3-5; Belo Horizonte (MG). Belo Horizonte: Sociedade Brasileira de Limnologia - UFMG; 1986. p. 130.

Cairns J, Mc Cormick PV, Niederlehner BR. A proposed framework for developing indicators of ecosystem health. Hydrobiologia 1993; 263: 1-44.

Caleffi S. A Represa de Guarapiranga : Estudo da comunidade zooplanctônica e aspectos da eutrofização. São Paulo (SP); 1994. [Dissertação de Mestrado Faculdade de Saúde Pública da USP].

Caleffi S. Estudo da comunidade zooplanctônica da Represa de Guarapiranga 1991/92. Aspectos ecológicos e qualidade ambiental. São Paulo (SP); 2000. [Tese de Doutorado - Faculdade de Saúde Pública da USP].

Carmo $\mathrm{CF}$. Aporte de nutrientes, $\mathbf{N}$ e $\mathbf{P}$, e sua relação com impactos antropogênicos em um lago urbano, São Paulo, Brasil. São Carlos (SP); 2000. [Dissertação de Mestrado - Escola de Engenharia de São Carlos da USP]

Carpenter SR, Kitchell JF, Hodgson JR. Cascading trophic interactions and lake productivity. BioScience 1985; 35: 634-39.

Carvalho MAJ. A Represa de Americana: aspectos físico-químicos e a variação das populações de Copepoda Cyclopoida de vida livre. São Paulo (SP); 1975. [Tese de Doutorado - Instituto de Biociencias da USP]. 
Casanova SMC. Distribuição longitudinal da comunidade zooplanctônica na região de transição rio-reservatório (Rio Paranapanema - Represa de Jurumirim). Botucatu (SP); 2000. [Dissertação de Mestrado - Universidade Estadual Paulista].

Cavalcanti CGB, Pinto MT, Freitas HJ, Moreira RCA. Paranoá Lake restoration: impact of tertiary treatment of sewage in the watershed. Verh Internat Verein Limnol 1997; 26: 689-93.

CETESB (Cia. Tecnol. Saneamento Ambiental). Monitoramento integrado das bacias do Alto e Médio Tietê (Avaliação da qualidade da água, sedimento e peixes). São Paulo (SP): CETESB. Relatório técnico final; 1999a.

CETESB (Cia. Tecnol. Saneamento Ambiental). Qualidade das águas interiores do Estado de São Paulo. São Paulo (SP): CETESB. Relatório técnico; 1999 b.

Claro SM. Aspectos limnológicos da Represa do Jacaré-Pepira (Brotas - SP) com ênfase na comunidade zooplanctônica. São Carlos (SP); 1981. [Dissertação de Mestrado - Universidade Federal de São Carlos].

Coelho-Botelho MJ, Cabianca MAA, Sendacz S. Alterações na composição da comunidade zooplanctônica em represas do Alto e Médio Tietê (Estado de São Paulo). São Paulo (SP): CETESB. Relatório técnico; 2001.

Crowder LB, Drenner RW, Kerfoot WC, Mc Queen DJ, Mills EL, Sommer U, Spencer CN, Vanni MJ. Food web interactions in lakes. In: Carpenter SR, editor. Complex interactions in lake communities. New York: SpringerVerlag; 1988. p. 141-60.

Dabés MBGS, França RC, Gomes MCS, Junqueira MV, Rolla ME, Rosa SG. Caracterização limnológica na represa de Pontal, Itabira (MG). Acta Limnol Brasil 1990; 3: 173-99. 
De Bernardi R, Giussani G. Are blue-green algae a suitable food for zooplankton? An overview. Hydrobiologia 1990; 200/201: 29-41.

Deker CM. Efeitos da inundação do Rio Tietê na estrutura da comunidade zooplanctônica do lago do Parque Ecológico do Tietê - São Paulo. São Paulo (SP); 2000. [Dissertação de Mestrado - Faculdade de Saúde Pública da USP].

DeMott WR, Kerfoot WC. Competition among cladocerans: nature of the interaction between Bosmina and Daphnia. Ecology 1982; 63 (6): 1949-66.

DeMott WR, Moxter F. Foraging on cyanobacteria by copepods: responses to chemical defenses and resource abundance. Ecology 1991; 72 (5): 1820-34.

Domingos MD. Heterogeneidade espacial (horizontal) da Represa do Guarapiranga (São Paulo) e a distribuição da comunidade zooplanctônica. São Carlos (SP); 1993. [Dissertação de Mestrado - Escola de Engenharia de São Carlos da USP].

Dumont HJ. Zooplankton and the science of biogeography: the example of Africa. In: Kerfoot WC, editor. Evolution and ecology of zooplankton communities. New England: University Press; 1980. p. 685-96.

Dumont HJ, DeRidder M. Rotifers from Turkey. Hydrobiologia 1987; 147: 65-73.

Dussart BH. Some Crustacea Copepoda from Venezuela. Hydrobiologia 1984; 113 : 25-67.

Dussart BH, Matsumura-Tundisi, T. Nouvelles espèces de calanoides du Brésil. Rev Bras Biol 1986; 46(1): 249-55. 
El-Moor Loureiro LMA. O gènero Bosmina (Cladocera) na região do Distrito Federal. Acta Limnol Brasil 1988; 2: 502 - 12.

El-Moor Loureiro LMA. Manual de identificação de cladóceros límnicos do Brasil. Brasilia: Universa; 1997.

Espíndola ELG. Dinâmica de associação congenérica das espécies de Notodiaptomus (Copepoda, Calanoida) no Reservatório de Barra Bonita, São Paulo. São Carlos (SP); 1994. [Tese de Doutorado - Escola de Engenharia de São Carlos da USP].

Espindola ELG, Zanata LH, Grimberg EM, Rios L. Distribuição horizontal de Cladocera em um reservatório hipereutrófico (Reservatório de Salto Grande, São Paulo). In: Anais do $\mathbf{8}^{\circ}$ Seminário Regional de Ecologia; 1998; São Carlos (SP). São Carlos: Programa de Pós-Graduação em Ecologia e Recursos Naturais - UFSCar; 1998. p. 1149-57

Esteves KE, Sendacz S. Relações entre a biomassa do zooplâncton e o estado trófico de reservatórios do Estado de São Paulo. Acta Limnol Brasil 1988; 2: 587 604.

Eysink GGJ, Piva-Bertoletti SAE, Pádua HB de. Caracterização ambiental dos lagos do Parque Ecológico do Tietê - João Khun. São Paulo: CETESB; 1985 (Relatório técnico)

Ferragut $C$. Efeito do en riquecimento por $N$ e $P$ sobre a colonização e sucessão da comunidade de algas perifíticas: biomanipulação em reservatório oligotrófico, São Paulo. Rio Claro (SP); 1999. [Dissertação de Mestrado Universidade Estadual Paulista]. 
Fonseca $C P$. Estudos de flutuações de curta duração na comunidade zooplânctônica, Barra Bonita, Médio Tietê, SP. São Carlos (SP); 1990. [Dissertação de Mestrado - Escola de Engenharia de São Carlos].

Fonseca $C P$. A dinâmica planctônica nas estações de seca e de chuva na Represa do Jacaré-Pepira, Brotas, SP. São Paulo (SP); 1996. [Tese de Doutorado Universidade de São Paulo].

Fonseca CP, Rocha DLP. A ocorrència de Daphnia gessneri e Moina micrura no Lago Paranoá, Brasília, DF. In: Anais do $6^{\circ}$ Congresso Brasileiro de Limnologia; 1997 Jul 22-25; São Carlos (SP). São Carlos: Sociedade Brasileira de Limnologia - UFSCar : 1997. p. 180.

Freire BM, Pinto-Coelho RM. Composição e distribuição horizontal do zooplâncton no Reservatório de Vargem das Flores, Betim/Contagem, Minas Gerais. Ciênc Cult 1986; $38(5): 919-27$.

Freitas JS. Variação sazonal e distribuição vertical de microcrustáceos planctônicos no Lago Paranoá, DF. Brasilia (DF); 1983. [Dissertação de Mestrado- Universidade de Brasília].

Fulton RS, Paerl HW. Effects of colonial morphology on zooplankton utilization of algal resources during blue-green algal (Microcystis aeruginosa) blooms. Limnol Oceanogr 1987a; 32 (3): 634-44.

Fulton RS, Paerl HW. Toxic and inhibitory effects of the blue-green alga Microcystis aeruginosa on herbivorous zooplankton. J Plankton Res 1987b; 9 (5): $837-55$

Gannon JE, Stemberger RS. Zooplankton (especially crustaceans and rotifers) as indicators of water quality. Trans Amer Micros Soc 1978; 97 (1): 16-35. 
Gávilan-Diaz RA. Ciclos nictemerais de fatores ecológicos, biomassa e diversidade de plâncton na Represa de Barra Bonita - Estado de São Paulo. São Paulo (SP); 1990. [Dissertação de Mestrado - Universidade Federal de São Carlos].

Geller W, Müller H. The filtration apparatus of Cladocera: filter mesh-sizes and their implications on food selectivity. Oecologia 1981; 49: 316-21.

Gentil RC. Variação sazonal do fitoplâncton de um lago subtropical eutrófico e aspectos sanitários, São Paulo, SP. São Paulo (SP); 2000. [Dissertação de Mestrado - Faculdade de Saúde Pública da USP].

Giani A. Distribuição horizontal do fitoplâncton e zooplâncton no Lago Paranoá, Brasília, DF, Brasil. Brasília (DF); 1984. [Dissertação de MestradoUniversidade de Brasilia]

Giani A, Pinto-Coelho RM, Oliveira SJM, Pelli A. Ciclo sazonal de parâmetros físicos e químicos da água e distribuição horizontal de nitrogênio e fósforo no Reservatório da Pampulha (Belo Horizonte, MG, Brasil). Ciênc Cult 1988; 40 (1): $69-77$.

Gilbert JJ. Effect of food availability on the response of planktonic rotifers to a toxic strain of the cyanobacterium Anabaena flos-aquae. Limnol Oceanogr 1996; 41(7): 1565-72.

Gilbert JJ, Bogdan KG. Selectivity of Polyarthra and Keratella for flagellate and aflagellate cells. Verh Internat Verein Limnol 1981; 21: 1515-21.

Gilbert JJ, Bogdan KG. Rotifer grazing: in situ studies on selectivity and rates. In: Mevers DG, Strickler JR, editors. Trophic interactions within Aquatic Ecosystems. Boulder: Westview Press; 1984. p. $97-133$. 
Gliwicz ZM. Food size selection and seasonal succession of filter-feeding zooplankton in a eutrophic lake. Ekol Pol 1977; 25 (2): 179 - 225.

Gliwicz ZM. Why do cladocerans fail to control algal blooms? Hydrobiologia 1990; 200/201: 83-97.

Gliwicz ZM. Relative significance of direct and indirect effects of predation by planktivorous fish on zooplankton. Hydrobiologia 1994; 272: 201-10.

Golterman HL, Clymo RS, Ohmstad MAM. Methods for physical and chemical analysis of freshwaters. 2nd ed. Oxford: Blackwell Scientific Publications; 1978. (IPB Handbook n. ${ }^{\circ} 8$ ).

Goodwin KL, Giani A. "Blooms" de cyanobacteria no reservatório da Pampulha: o efeito das macrófitas no seu aparecimento. In: Anais do $8^{\circ}$ Seminário Regional de Ecologia; 1998; São Carlos (SP). São Carlos: Programa de pósGraduação em Ecologia e Recursos Naturais - UFSCar; 1998. p. 1239-45.

Green J. Keratella cochlearis (Gosse) in Africa. Hydrobiologia 1987; 147: 3-8.

Hanazato T, Yasuno M. Population dynamics and production of cladoceran zooplankton in the highly eutrophic Lake Kasumigaura. Hydrobiologia 1985; 124: 13-22.

Hanazato T, Yasuno M. Evaluation of Microcystis as food for zooplankton in a eutrophic lake. Hydrobiologia 1987; 144: $251-59$.

Hanazato T, Yasuno M. Influence of Chaoborus density on the effects of an insecticide on zooplankton communities in ponds. Hydrobiologia 1990; 194 : 183-97. 
Hart RC. Zooplankton feeding rates in relation to suspended sediment content: potencial influences on community structure in a turbid reservoir. Freshwater Biol $1988 ; 19(1): 123-40$

Henry R. Heat budgets, thermal structure and dissolved oxygen in Brazilian reservoirs. In: Tundisi JG, Straskraba M, editors. Theoretical reservoir ecology and its applications. São Carlos (SP): International Institute of Ecology, Brazilian Academy of Sciences and Backhuys Publishers; 1999. p. $125-51$

Infante AG. Vertical and horizontal distribution of the zooplankton in Lake Valencia. Acta Limnol Brasil 1993; 6: 97-105.

Infante $A G$, Riehl W. The effect of Cyanophyta upon zooplankton in a eutrophic tropical lake (Lake Valencia, Venezuela). Hydrobiologia 1984; 113: 293-98.

Kerfoot WC, Kirk KL. Degree of taste discrimination among suspension-feeding cladocerans and copepods: implications for detritivory and herbivory. Limnol Oceanogr 1991; $36(6): 1107-23$.

Kirk KL. Inorganic particles alter competition in grazing plankton: the role of selective feeding. Ecology 1991; 72 (3): 915-923.

Kirk KL, Gilbert JJ. Suspended clay and the population dynamics of planktonic rotifers and cladocerans. Ecology 1990; 71(5): 1741-55.

Korovchinsky NM. On the taxonomy and geographical distribution of the superfamily Sidoidea Baird, 1850 (Crustacea: Cladocera). Hydrobiologia 1986; 140: $243-53$

Koste W. Rotatoria. Die Radertiere Mitteleuropas begrundet von max Voigt. Berlin (GR): Gebruder Borntraeger; 1978. 
Koste W, Shiel RJ. Rotifera from Australian Inland Waters. I. Bdelloidea (Rotifera: Digononta). Austr J Mar Fresh Res 1986; 37: 765-92.

Kubo E. Autodepuração da represa do Rio Grande (Complexo - Billings- SP): Zooplâncton. São Paulo (SP); 1989. [Dissertação de Mestrado - Instituto de Biociências da USP].

Kuczynski D. The rotifer fauna of Argentine Patagonia as a potencial limnological indicator. Hydrobiologia 1987; 150: 3-10.

Lamparelli MC, Kuhlmann ML, Carvalho MC, Salvador, MEP, Souza, RCR de, Coelho-Botelho, MJ et al. Avaliação do Complexo Billings: comunidades aquáticas, água e sedimento. São Paulo (SP): CETESB; 1996. (Relatório técnico).

Lampert W. Laboratory studies on zooplankton-cyanobacteria interactions. New Zealand J Mar Freshw Res 1987; 21 (3): 483-90.

Lazzaro $X$. Do the trophic cascade hypothesis and classical biomanipulation approaches apply to tropical lakes/reservoirs? Verh Internat Verein Limnol 1997; 26: 719-30.

Legendre L, Legendre P. Numerical ecology. New York (USA): Elsevier; 1983.

Lindström K. Changes in growth and size of Keratella cochlearis (Gosse) in relation to some environmental factors in cultures. Hydrobiologia. 1983; 104: 325-28.

Lopes MRM. Eventos perturbatórios que afetam a biomassa, a composição e a diversidade de espécies do fitoplâncton em um lago oligotrófico raso (Lago do Instituto Astronômico e Geofísico, São Paulo, SP). São Paulo (SP); 1999. [Tese de Doutorado - Instituto de Biociências da USP]. 
Ludwig JA, Reynolds JF. Stastistical ecology: a primer on methods and computing. New York (USA) : John Wiley e Sons, Inc.; 1988.

Margalef R. Ecologia. Barcelona: Ed. Ediciones Omega, F.A.; 1991.

Matsumura-Tundisi T. Occurrence of species of the genus Daphnia in Brazil. Hydrobiologia 1984; 112: 161-65.

Matsumura-Tundisi T. Latitudinal distribution of Calanoida Copepods in freshwater aquatic systems of Brazil. Rev Bras Biol 1986; 46 (3): 526-53.

Matsumura-Tundisi T. Composition and vertical distribution of zooplankton in Lake Dom Helvécio. In: Tundisi JG, Saijo Y, editors. Limnological studies on the Rio Doce Valley Lakes, Brazil. Brazil: Brazilian Academy of Sciences; 1997a. p. $265-274$.

Matsumura-Tundisi T. Estudo de diversidade de espécies de zooplâncton lacustre do Estado de São Paulo. Serra Negra (SP); 1997b. [Workshop: "Bases para a Conservação da Biodiversidade do Estado de São Paulo" - 30/07 a 02/08/1997].

Matsumura-Tundisi T. Diversidade de zooplâncton em Represas do Brasil. In: Henry R, editor. Ecologia de Reservatórios: Estrutura, Função e Aspectos Sociais. Botucatu (SP): FUNDIBIO: FAPESP; 1999. p. 39-54.

Matsumura-Tundisi T, Hino K, Rocha O. Características limnológicas da Lagoa do Taquaral (Campinas, SP) - um ambiente hipereutrófico. Ciên Cult 1986; 38 (3): $420-25$ 
Matsumura-Tundisi T, Leitão SN, Aguena LS, Miyahara J. Eutrofização da Represa de Barra Bonita: Estrutura e organização da comunidade de Rotifera. Rev Bras Biol 1990: $50(4): 923-35$.

Matsumura-Tundisi T, Okano W, Tundisi JG. Vertical migration of copepod populations in the tropical monomictic Lake Dom Helvécio. In: Tundisi JG, Saijo Y, editors. Limnological studies on the Rio Doce Valley Lakes, Brazil. Brazil: Brazilian Academy of Sciences. 1997. p. 297-307.

Matsumura-Tundisi $\mathrm{T}$, Rocha $\mathrm{O}$. Ocorrència e abundância relativa do zooplâncton na Represa do Lobo (Broa). Cien Cult 1975; 27(7): 395-6.

Matsumura-Tundisi T, Rocha O. Occurrence of Copepoda (Calanoida, Cyclopoida and Harpacticoida) from "Broa" Reservoir (São Carlos, São Paulo, Brazil). Rev Bras Biol 1983; 43(1): 1-17

Matsumura-Tundisi T, Tundisi JG. Plankton studies in a lacustrine environment. I. Preliminary data on zooplankton ecology of Broa reservoir. Oecologia 1976; $25: 265-70$.

Matsumura-Tundisi T, Tundisi JG. Limnology of a warm monomictic lake at Rio Doce Forest Park (Lake Dom Helvécio, MG, Eastern Brazil). In: Tundisi JG, Bicudo CEM, Matsumura-Tundisi T, editors. Limnology in Brazil. Brazil: Brazilian Academy of Sciences and Brazilian Limnological Society; 1995. p. 245-56.

Matsumura-Tundisi T, Tundisi JG, Tavares LS. Diel migration and vertical distribution of Cladocera in Lake D. Helvécio (Minas Gerais, Brazil). Hydrobiologia 1984; 113: 299-306.

McCune B, Mefford MJ. PC-ORD. Multivariate analysis of ecological data [computer program]. Version 3,0. Oregon: MjM Software Design; 1997. 
Melão MGM. Comunidade planctônica (fitoplâncton e zooplâncton) e produtividade secundária $\mathrm{em}$ um reservatório oligotrófico. São Carlos (SP); 1997. [Tese de Doutorado - Universidade Federal de São Carlos].

Melão MGM, Rocha O. Flutuações populacionais e interações biológicas do zooplâncton em um reservatório raso e oligotrófico (Lagoa Dourada, Brotas, SP). In: Anais do $7^{\circ}$ Congresso Brasileiro de Limnologia; 1999 jul 18-22; Florianópolis (SC). Florianópolis: Sociedade Brasileira de Limnologia -UFSC; 1999. p. 381.

Mercante CTJ. Assimilação de amônio e nitrato no Reservatório do IAG (Instituto Astronômico e Geofísico) - São Paulo. São Carlos (SP); 2000. [Tese de Doutorado - Universidade Federal de São Carlos].

Mercante CTJ, Tucci-Moura A. Comparação entre os indices de Carlson e de Carlson modificado aplicados a dois ambientes aquáticos subtropicais, São Paulo, SP. Acta Limnol Brasil 1999; 11 (1): 1-14.

Mikschi E. Rotifer distribution in relation to temperature and oxygen content. Hydrobiologia 1989; 186/187: 209-14.

Mitsuka PM. Empobrecimento da comunidade zooplanctônica após passagem pela barragem da Represa de Jurumirim (Rio Paranapanema - SP). Botucatu (SP); 1998. [Dissertação de Mestrado - Universidade Estadual Paulista].

Moore MV, Gilbert JJ. Age-specific (haoborus predation on rotifer prey. Freshwater Biol 1987; 17: 223-36.

Moura A N. Estrutura e produção primária da comunidade perifítica durante o processo de colonização em substrato artificial no lago das Ninféias, São 
Paulo, SP: análises comparativas entre períodos chuvoso e quente. Rio Claro (SP); 1997. [Tese de Doutorado - Universidade Estadual Paulista].

Moura ATN. Estrutura e dinâmica da comunidade fitoplanctônica numa lagoa eutrófica, São Paulo, SP, Brasil, a curtos intervalos de tempo: comparações entre épocas de chuvas e secas. Rio Claro (SP); 1996. [Dissertação de Mestrado - Universidade Estadual Paulista].

Nogueira MG. Dinâmica das populações planctônicas e fatores físicos e químicos em um sistema artificial raso. São Paulo (SP); 1990. [Dissertação de Mestrado - Universidade de São Paulo].

Nogueira MG. Composição, abundância e distribuição espacial-temporal das populações planctônicas e das variáveis físicas e químicas na Represa de Jurumirim, Rio Paranapanema - SP. São Paulo (SP); 1996. [Tese de Doutorado - Universidade de São Paulo].

Nogueira MG, Matsumura-Tundisi T. Limnologia de um sistema artificial raso (Represa do Monjolinho - São Carlos, SP). Dinâmica das populações planctônicas. Acta Limnol Bras 1996; 8: 149-68.

Nogueira MG, Panarelli E. Estudo da migração vertical das populações zooplanctônicas na Represa de Jurumirim (Rio Paranapanema - São Paulo, Brasil). Acta Limnol Bras 1997; 9: 55-81.

Nogueira NMC. Dinâmica populacional de Microcystis aeruginosa Kützing (Cyanophyceae/Cyanobacteria) ao longo de um ano no lago das Garcas, São Paulo, SP, Brasil. Rio Claro (SP); 1997. [Dissertação de Mestrado Universidade Estadual Paulista].

Nogueira NMC, Ramirez R JJ. Variação mensal da condição trófica do lago das Garças (São Paulo, SP, Brasil). Acta Limnol Brasil 1998; 10 (2): 21-34. 
Northcote TG. Fish in the structure and function of freshwater ecosystems: a "topdown" view. Can J Fish Aquatic Sci 1988; 45: 361-79.

Nunes MA, Lansac-Tôha FA, Bonecker CC, Roberto MC, Rodrigues L. Composição e abundância do zooplâncton de duas lagoas do Horto Florestal Dr. Luiz Teixeira Mendes, Maringá, Paraná. Acta Limnol Brasil 1996; 8: 207-19.

Odum EP. Ecologia. Lisboa: Fundação Calouste Gulbekian; 1971

Okano WY. Análise da estrutura e dinâmica populacional da comunidade zooplanctônica de um corpo d'água artificial (Reservatório de Monjolinho, São Carlos, SP). São Carlos (SP); 1994. [Tese de Doutorado - Universidade Federal de São Carlos].

Oliveira-Neto AL. Estudo da variação da comunidade zooplanctônica com ênfase na comunidade de rotíferos, em curtos intervalos de tempo (variaçôes diárias e nictemerais) na Represa do Lobo (Broa) - Itirapina - SP. São Paulo (SP); 1993. [Dissertação de Mestrado - Universidade de São Paulo].

Paggi JC. Acerca de algunas especies de la familia Moinidae (Crustacea, Cladocera) de la Republica Argentina. Physis 1973; 32 (85): 269-77.

Paggi JC. Revision de las especies argentinas del genero Diaphanosoma Fischer (Crustacea, Cladocera). Acta Zoologica Lilloana 1978; 33 (1): 44-65.

Panarelli EA. Flutuações de curto prazo das populaçōes zocplanctônicas na Represa de Jurumirim (Zona de Barragem), Rio Paranapanema - SP. Botucatu (SP); 1999. [Dissertação de Mestrado - Universidade Estadual Paulista]. 
Pejler B. Zooplanktic indicators of trophy and their food. Hydrobiologia 1983; 101 : $111-14$

Pinel-Alloul B, Méthot G, Verreault G, Vigneault $Y$. Zooplankton species associations in Quebec lakes: variation with abiotic factors, including natural and anthropogenic acidification. Can J Fish Aquat Sci 1989: 47 (1): 11021.

Pinto-Coelho RM. Efeitos do zooplâncton na composição qualitativa e quantitativa no Lago Paranoá, Brasília, DF, Brasil. Brasília (DF); 1983. [Dissertação de Mestrado - Universidade de Brasília]

Pinto-Coelho RM. Flutuações sazonais e de curta duração na comunidade zooplanctônica do lago Paranoá, Brasilia - DF. Rev Bras Biol 1987; 47 (1/2) : $17-29$

Pinto-Coelho RM. Fundamentos em ecologia. Porto Alegre: Artes Médicas Sul Ltda; 2000.

Pinto-Coelho RM, Grecco MB. Metais pesados em organismos zooplanctônicos e macrófitas aquáticas no Reservatório da Pampulha, Belo Horizonte, MG. In: Anais do $6^{\circ}$ Congresso Brasileiro de Limnologia; 1997 Jul 22-25; São Carlos (SP). São Carlos: Sociedade Brasileira de Limnologia - UFSCar; 1997 p. 117

Pinto-Coelho RM, Lima SS, Pelli A. Estudos experimentais sobre a alimentação em fêmeas adultas de Diaptomus (s.1.) corderoi (Wright, 1936) CopepodaCalanoida, do reservatório da Pampulha, Belo Horizonte- MG. Acta Limnol Brasil. 1988; 2: 605-20.

Pinto-Coelho RM, Coelho MM, Espírito Santo MM, Cornelissen TG. Efeitos da eutrofização na estrutura da comunidade planctônica na Lagoa da Pam rulha, 
Belo Horizonte, MG. In: Henry R, editor. Ecologia de Reservatórios: Estrutura, Função e Aspectos Sociais. Botucatu (SP): FUNDIBIO: FAPESP; 1999. p. 551-72.

Pontin RM, Langley JM. The use of rotifer communities to provide a preliminary national classification of small water bodies in England. Hydrobiologia 1993; 255/256: 411-19.

Porter KG, Paerl H, Hodson R, Pace M, Priscu J, Riemann B, Scavia D, Stockner J. Microbial interactions in lake food webs. In: Carpenter SR, editor. Complex interactions in lake communities. New York: Springer-Verlag; 1988. p. 20927.

Porter KG, Orcutt Jr. D. Nutricional adequacy, manageability, and toxicity as factors that determine the food quality of green and blue-green algae for Daphnia. Am Soc Limnol Oceanogr Spec Symp 1980; 3: 268-81.

Radwan S. The influence of some abiotic factors on the occurrence of rotifers of Leczna and Wlodawa Lake District. Hydrobiologia 1984; 112: 117-24.

Radwan S, Popiolek B. Percentage of rotifers in spring zooplankton in lakes of different trophy. Hydrobiologia 1989; 186/187: 235-38.

Ramirez $R$ JJ. Variação espacial, vertical e nictemeral da estrutura da comunidade fitoplanctônica e variáveis ambientais em quatro dias de amostragem de diferentes épocas do ano no Lago das Garças, São Paulo. São Paulo (SP); 1996. [Tese de Doutorado - Instituto de Biociências da USP].

Reid JW. Chave de identificação e lista de referências bibliográficas para as espécies continentais sulamericanas de vida livre da Ordem Cyclopoida (Crustacea, Copepoda). Bolm Zool 1985; 9: 17-143. 
Reid JW. The distribution of species of the genus Thermocyclops (Copepoda, Cyclopoida) in the western hemisphere, with description of T. parvus, new species. Hydrobiologia 1989; 175: 149-74.

Reid JW, Pinto-Coelho RM. Planktonic Copepoda of Furnas Reservoir: initial survey of species (1993) and review of literature. In: Pinto-Coelho, RM, Giani A, von Sperling E, editors. Ecology and human impact on lakes and reservoirs in Minas Gerais with special reference to future development and manegement strategies. Belo Horizonte (MG): SEGRAC; 1994. p. 93114.

Reid JW, Pinto-Coelho RM, Giani A. Uma apreciação da fauna de copépodos (Crustacea) da região de Belo Horizonte, com comentários sobre espécies de Minas Gerais. Acta Limnol Brasil 1988; 2: 527-47.

Richman S, Dodson SI. The effect of food quality on feeding and respiration by Daphnia and Diaptomus. Limnol Oceanogr 1983; 28 (5): 948-56.

Rietzler AC. Estudo da dinâmica de populações de Copepoda - Calanoida na Represa do Lobo (Broa). São Carlos (SP); 1991. [Dissertação de Mestrado Escola de Engenharia de São Carlos da USP].

Rietzler AC. Alimentação, ciclo de vida e análise da coexistência de espécies de Cyclopoida na Represa de Barra Bonita, São Paulo. São Carlos (SP); 1995. [Tese de Doutorado - Escola de Engenharia de São Carlos da USP].

Rocha AA. A ecologia, os aspectos sanitários e de saúde pública da Represa Billings na região metropolitana de São Paulo, uma contribuição à sua recuperação. São Paulo (SP); 1984. [Tese de Livre-Docència - Faculdade de Saúde Pública da USP]. 
Rocha AA, Merighi Jr. A. Notas sobre o zooplâncton, bentos e fungos na Represa Billings, São Paulo. Rev DAE. 1986: 46 (146): 302-06.

Rocha AA, Merighi Jr. A. Notas sobre o zooplàncton, bentos e fungos na Represa Billings. Ambiente 1987; 1( 1): 18 - 23.

Rocha AA, Narduzzo M. Aspectos ecológicos dos lagos do Parque Zoológico de São Paulo. Rev DAE 1975; 35 (103): 45 - 51.

Rocha DLP, Fonseca CP. Estudo da dinâmica de populações de microcrustáceos no Braço do Riacho Fundo, Lago Paranoá, Brasilia, DF. In: Anais do $6^{\mathbf{0}}$ Congresso Brasileiro de Limnologia; 1997 Jul 22-25; São Carlos (SP). São Carlos: Sociedade Brasileira de Limnologia - UFSCar; 1997. p. 405.

Rocha $O$, Matsumura-Tundisi $T$. Growth rate, longevity and reproductive performance of Daphnia laevis Birge, D. gessneri Herbst and D. ambigua Scourfield in laboratory cultures. Rev Brasil Biol 1990; 50 (4): 915-21.

Rocha O, Matsumura-Tundisi T, Espindola ELG, Roche KF, Rietzler AC. Ecological theory applied to reservoir zooplankton. In: Tundisi JG, Straškraba M, editors. Theoretical reservoir ecology and its aplications. São Carlos (SP): International Institute of Ecology, Backhuys Publishers, Brazilian Academy of Sciences; 1999. p.457-76.

Rocha O, Sampaio A de V. Composição, caracterização e variação sazonal da comunidade zooplanctônica da Lagoa Dourada, bacia hidrográfica do Lobo. In: Anais do $6^{0}$ Seminário Regional de Ecologia; 1991; São Carlos (SP). São Carlos; 1991. p. 23-46.

Rocha $\mathrm{O}$, Sendacz S, Matsumura-Tundisi T. Composition, biomass and productivity of zooplankton in natural lakes and reservoirs of Brazil. In: Tundisi JG, 
Bicudo CEM, Matsumura-Tundisi T, editors. Limnology in Brazil. Rio de Janeiro: ABC/SBL; 1995. p. 151-65.

Rodriguez M P. Análise da dinâmica e produção das espécies dominantes de Rotifera da Represa do Ribeirão do Lobo (Broa), SP, no período seco (inverno). São Carlos (SP); 1997. [Dissertação de Mestrado - Escola de Engenharia de São Carlos da USP].

Rodriguez MP, Matsumura-Tundisi T. Variation of density species composition and dominance of rotifers at a shallow tropical reservoir (Broa Reservoir SP, Brazil) in a short scale time. Rev Bras Biol 2000; 60 (1): 1-9.

Rolla ME, Dabés MBGS, França RC, Ferreira EMVM. Aspectos limnológicos do Reservatório de Volta Grande, Minas Gerais/São Paulo. Acta Limnol Brasil $1990 ; 3(1): 219-44$

Rothhaupt KO. Differences in particle size-dependent feeding efficiences of closely related rotifer species. Limnol Oceanogr 1990; 35 (1): 16-23.

Sanders RW, Porter KG. Bacterivorous flagellates as food resources for the crustacean zooplankter Daphnia ambigua. Limnol Oceanogr 1990; 35 (1): $188-91$

Sanders RW, Leeper DA, King CH, Porter KG. Grazing by rotifers and crustacean zooplankton on nanoplanktonic protists. Hydrobiologia 1994; 288: 167-81.

Sant'Anna CL, Azevedo MTP, Sormus L. Fitoplâncton do Lago das Garças, Parque Estadual das Fontes do Ipiranga, São Paulo, SP, Brasil: Estudo taxonômico e aspectos ecológicos. Hoehnea 1989; 16: 89-131.

Sant'Anna CL, Sormus L, Tucci A, Azevedo MTP. Variação sazonal do fitoplâncton do Lago das Garças, São Paulo, SP. Hoehnea 1997; 24 (1): 67-86. 
Scavia D, Fahnenstiel GL. From picoplankton to fish: complex interactions in the Great Lakes. In: Carpenter SR, editor. Complex interactions in lake communities. New York: Springer-Verlag; 1988. p. 85-97.

Schaden $R$. Sobre rotíferos planctônicos da raia olímpica da Cidade Universitária em São Paulo. São Paulo (SP); 1970. [Dissertação de MestradoInstituto de Biociências da USP].

Segers H, Dumont HJ. 102 + rotifers species (Rotifera Monogonta) in Broa Reservoir (SP, Brazil) on 26 August 1994, with the description on three new species. Hydrobiologia 1995; 316: 183-97.

Seixas MH. Aspectos ecológicos das populações de Cladocera (Crustacea) na Represa do Lobo ("Broa"), São Paulo, SP. São Carlos (SP); 1981. [Dissertação de Mestrado - Universidade Federal de São Carlos].

Sendacz S. Alguns aspectos do zooplâncton da Represa Billings. São Paulo (SP); 1978. [Dissertação de Mestrado - Instituto de Biociências da USP].

Sendacz S. A study of the zooplankton community of Billings Reservoir - São Paulo. Hydrobiologia 1984; 113: $121-27$.

Sendacz S. Estudo da comunidade zooplanctônica de lagoas marginais do Rio Paraná Superior. São Paulo (SP); 1993. [Tese de Doutorado - Instituto de Biocièncias da USP].

Sendacz S, Kubo E. Copepoda (Calanoida e Cyclopoida) de reservatórios do Estado de São Paulo. B Inst Pesca 1982; 9: 51 - 89. 
Sendacz S, Kubo E. Zooplâncton de reservatórios do Alto do Tietê, Estado de São Paulo. In: Henry R, editor. Ecologia de Reservatórios: Estrutura, Função e Aspectos Sociais. Botucatu (SP): FUNDIBIO: FAPESP: 1999. p. 511 -29.

Sendacz S, Kubo E, Cestarolli MA. Limnologia de Reservatórios do Sudeste do Estado de São Paulo, Brasil. VIII. Zooplâncton. B Inst Pesca 1985; 12 (1): 187- 207.

Sendacz S, Kubo E, Fujiara LP. Further studies on the zooplankton community of a eutrofic reservoir in southern Brazil. Verh Internat Verein Limnol 1984; 22: $1625-30$.

Silva JAS, Pinto-Coelho RM. Composição e variação sazonal do zooplâncton no Reservatório da Pampulha (Belo Horizonte, MG). In: Anais do $1^{\circ}$ Congresso Brasileiro de Limnologia; 1986 Set 3-5; Belo Horizonte (MG). Belo Horizonte: Sociedade Brasileira de Limnologia - UFMG; 1986. p. 150.

Silva MHL. Composição e variação da densidade e da biomassa da comunidade zooplanctônica no lago Monte Alegre [Monografia]. Faculdade de Filosofia, Ciências e Letras da Universidade de São Paulo. Ribeirão Preto (SP); 1989.

Silva WM. Caracterização do Reservatório Nova Ponte (MG) nos períodos seco (julho/95) e chuvoso (fevereiro/96) com ênfase na composição e distribuição do zooplâncton. São Paulo (SP); 1998. [Dissertação de Mestrado- Universidade de São Paulo].

Sládecek V. Rotifers as indicators of water quality. Hydrobiologia 1983; 100: 169201.

SMA (Secretaria do Meio Ambiente). Perfil Ambiental do Estado de São Paulo [CD ROM]. São Paulo (SP): Videolar; 1999 
Soto D. Hurlbert SH. Short term experiments on calanoid-cyclopoid-phytoplankton interactions. Hydrobiologia 1991; 215: 83-110.

Stockner JG, Porter KG. Microbial food webs in freshwater planktonic ecosystems. In: Carpenter SR, editor. Complex interactions in lake communities. New York: Springer-Verlag; 1988. p. 69-83.

Struffaldi-de-Vuono Y. Fitossociologia do estrato arbóreo da Floresta da Reserva Biológica do Instituto de Botânica (São Paulo, SP). São Paulo (SP); 1985. [Tese de Doutorado - Universidade de São Paulo].

Talamoni JLB. Estudo comparativo das comunidades planctônicas de lagos de diferentes graus de trofia e uma análise do efeito de Microcystis aeruginosa (Cyanophycea) sobre algumas espécies de microcrustáceos. São Carlos (SP); 1995. [Tese de Doutorado - Universidade Federal de São Carlos].

Toledo Jr AP de, Talarico M, Chinez SJ, Agudo EG. A aplicação de modelos simplificados para a avaliação de processo de eutrofização em lagos e reservatórios tropicais. In: Anais do $12^{\circ}$ Congresso Brasileiro de Engenharia Sanitária e Ambiental; 1983; Camboriú (SC). Camboriú: 1983. p. 1-34.

Toledo LG, Freitas JS, Ferreira CJA. Variações diurnas de parâmetros limnológicos no Lago Paranoà, Brasília, DF, Brasil. Acta Limnol Brasil 1988; 2: 219 - 37.

Tundisi JG, Matsumura-Tundisi T. Limnology and eutrophication of Barra Bonita reservoir, S. Paulo state, Southern Brazil. Arch Hydrobiol Beih Ergebn Limnol 1990; $33: 661-76$.

Tundisi JG, Matsumura-Tundisi T. Plankton diversity in a warm monomictic lake (Dom Helvécio, Minas Gerais) and a polymitic reservoir (Barra Bonita); a comparative analysis of the intermediate disturbance hypothesis. An Acad Bras Ci 1994; 66 (Supl. 1): 15-28. 
Tundisi JG, Matsumura-Tundisi T, Calijuri MC, Henry R, Ibañes MSR de, Nakamoto N. Limnological survey of Lake Anibal. In: Tundisi JG, Saijo Y, editors. Limnological studies on the Rio Doce Valley Lakes, Brazil. Brazil: Brazilian Academy of Sciences; 1997. p.441-47.

Tundisi JG, Matsumura-Tundisi T, Calijuri MC, Novo EML. Comparative limnology of five reservoirs in the Middle Tietê River, S.Paulo State. Verh Internat Verein Limnol 1991; 24: 1489-96

Tundisi JG, Matsumura-Tundisi T, Henry R, Rocha O, Hino K. Comparação do estado trófico de 23 reservatórios do Estado de São Paulo: eutrofização e manejo. In: Tundisi JG, editor. Limnologia e Manejo de Represas (Monografias em Limnologia). São Paulo: Academia de Ciências de São Paulo; 1988. p. $165-204$.

Valderrama JC. The simultaneous analysis of total nitrogen and total phosphorus in natural waters. Mar Chem 1981; $10: 109-12$.

Valentin JL. Agrupamento e Ordenação. In: Peres-Neto PR, Valentin JL, Fernandez FAS, editores. Oecologia Brasiliensis: Tópicos em Tratamento de Dados Biológicos. Rio de Janeiro (RJ): Universidade Federal do Rio de Janeiro; 1995. p. $27-55$.

Zagatto PA. Toxicidade da alga Cylindrospermopsis raciborskii isolada do reservatório Billings, braço Taquacetuba. São Paulo (SP): CETESB; 1998. (Relatório técnico).

Walz N. Comparative population dynamics of the rotifers Brachionus angularis and Keratella cochlearis. Hydrobiologia 1987: $147: 209-13$. 
Weisse T. Structure of microbial food webs in relation to the trophic status of lakes and fish grazing pressure: a key role of cyanobacteria? In: Pinto-Coelho, RM, Giani A, von Sperling E, editors. Ecology and human impact on lakes and reservoirs in Minas Gerais with special reference to future development and management strategies. Belo Horizonte (MG): SEGRAC; 1994. p. 5570 .

Weisse T, Stockner JG. Eutrophication: the role of microbial food webs. Mem Ist Ital Idrobiol $1993 ; 52: 133-50$

Wetzel RG, Likens GE. Limnological analyses. 2nd ed. New York (USA): Springer -Verlag; 1991.

Wisniewski MJS. Distribuição espacial e produção secundária da comunidade zooplanctônica do Reservatório de Barra Bonita, SP. São Carlos (SP); 1998. [Tese de Doutorado - Universidade Federal de São Carlos]. 


\section{TABELAS}


TABELA 1 - Temperaturas do $\operatorname{ar}\left({ }^{\circ} \mathrm{C}\right)$ e precipitação total $(\mathrm{mm})$ (médias mensais) de janeiro a dezembro de 1997.

\begin{tabular}{l|c|c|c|r}
\hline MESES & \multicolumn{3}{|c|}{ TEMPERATURA DO AR } & $\begin{array}{c}\text { PRECIPITAÇÃO } \\
(\mathrm{mm})\end{array}$ \\
\hline & lago do IAG & lago das Ninféias & lago das Garças & 341,4 \\
Janeiro & 20,0 & 23,0 & 22,1 & 108,9 \\
Fevereiro & 21,2 & 21,9 & 22,0 & 67,1 \\
Março & 21,0 & 22,0 & 24,4 & 47,8 \\
Abril & 18,5 & 18,4 & 19,0 & 80,7 \\
Maio & 19,9 & 19,6 & 18,6 & 108,7 \\
Junho & 13,0 & 13,3 & 16,8 & 9,4 \\
Julho & 18,2 & 16,7 & 18,5 & 38,7 \\
Agosto & 16,8 & 17,5 & 17,5 & 130,6 \\
Setembro & 15,6 & 17,5 & 18,6 & 126,4 \\
Outubro & 17,4 & 20,1 & 19,0 & 164,0 \\
Novembro & 21,3 & 22,5 & 23,1 & 206,5 \\
Dezembro & 22,3 & 21,2 & 22,0 & \\
\hline
\end{tabular}


TABELA 2 - Valores e médias mensais das variáveis físicas, químicas e biológicas, no lago do IAG de janeiro a dezembro de 1997.

\begin{tabular}{|c|c|c|c|c|c|c|c|c|c|c|c|c|c|}
\hline & & $17701 / 1997$ & $0402 / 1997$ & $04613 / 1997$ & $0804 / 1997$ & 06061997 & $03 \times 11997$ & 08077997 & \begin{tabular}{|l|}
05081997 \\
\end{tabular} & 02091997 & 07101997 & 14111997 & 02121997 \\
\hline Profundidade $(m)$ & & +6.) & 45 & +5 & +7 & +6 & +51 & 45 & +5. &,+ 4 & 45 & +5 & 44 \\
\hline Transparencia (m) & & $1+4$ & 1,10 & $\therefore(x)$ & 1,70 & 1,60 & 2.15 & 1.85 & 1,70 & 1,30 & 1,25 & 1,52 & 1.15 \\
\hline Temperatura da aqua & $s$ & 220 & 21.11 & 21.6 & 19.4 & 19.6 & 15.5 & 17.8 & 17.0 & 17.2 & 19.2 & 34,1 & 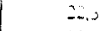 \\
\hline \multirow[t]{5}{*}{$(C)$} & Im & $2: 2$ & $=23$ & 21.6 & 10.7 & 19.4 & 15.5 & 17.4 & 17,0 & 17.8 & 20,0 & 24.6 & $\therefore 21$ \\
\hline & $2 \mathrm{~m}$ & 21,2 & 21.2 & 21.5 & 14,7 & 19,4 & 15.5 & 17,0 & 16,9 & 17,8 & 19.5 & 22.1 & 21,3 \\
\hline & $3 m$ & 20,7 & 20.6 & 21.0 & 19.5 & 19.1 & $|5,4|$ & 16,7 & 16.5 & 17.4 & 18,8 & 19,9 & 20.6 \\
\hline & $\mathbf{F}$ & 19.4 & 19,9 & 20,4 & 19.0 & 18.9 & 15,3 & 16.4 & 16,3 & 17,0 & 18,0 & 18.7 & 19.5 \\
\hline & $x$ & $2 !, 1$ & 21,0 & 21,2 & 19,5 & 19,3 & 15,4 & 17,1 & $16,7]$ & 17,4 & 19,1 & 21,9 & 21,2 \\
\hline Oxagênuo dissolvido & $\mathrm{s}$ & 7.03 & 0.611 & 597 & 7.21 & 7.11 & 6.82 & 7.92 & 8.52 & 8,33 & 0.78[ & 7,42 & 8,45 \\
\hline \multirow[t]{5}{*}{$(\mathrm{mg} / \mathrm{L})$} & im & 6.67 & 6.36 & 5,96 & 7.34 & 6.92 & 6.74 & 7.58 & 8.50 & 8,23 & 0.81 & 7.36 & 8.24 \\
\hline & $2 \mathrm{~m}$ & 5.89 & 5.82 & 5,03 & 7,21 & 6.75 & 7,09 & 7.25 & 8,55 & 8,07 & 0,63 & 7.49 & 5,39 \\
\hline & $3 \mathrm{~m}$ & 4.17 & 4.50 & 572 & 6,77 & 5.62 & 6,77 & 0.75 & 8,03 & 0,33 & 0,23 & 3,86 & 3,74 \\
\hline & $\mathrm{F}$ & 2.94 & 2.24 & 5.40 & 6,54 & $\$ .18$ & 6.88 & 5.35 & 7.58 & 4.78 & 0.12 & 1.56 & 2.24 \\
\hline & $\mathrm{x}$ & 5,34 & 5.11 & 580 & 3,01 & 6,32 & 6,86 & 6,97 & 8,24 & 3,15 & 051 & 5.54 & 5,61 \\
\hline \multirow[t]{6}{*}{ pH } & $\mathrm{s}$ & 5.86 & 5.30 & 5,68 & 5,74 & 5,90 & 0.05 & 6,01 & 6,14 & 6,19 & 5,98 & 6,21 & 6,32 \\
\hline & Im & 5.83 & 5,39 & 5.69 & 5,67 & $\varsigma, 84$ & 6.12 & 5,97 & 0,14 & 6,17 & 593 & 0,11 & 6,25 \\
\hline & $2 m$ & 5.67 & 4.311 & 5.67 & 5.67 & 5,79 & 6.14 & $5 \%$ & 6.05 & 0.16 & 5,81 & 5,97 & 5.87 \\
\hline & $3 \mathrm{~m}$ & 59 & 5.35 & 558 & 5.04 & 5.73 & 6,69 & s.1 & 598 & 599 & 568 & 5.83 & 5.85 \\
\hline & $\mathrm{F}$ & 5.76 & $<<7$ & 53 & $<.63$ & 5.73 & 0.101 & 585 & 5.93 & 5.956 & 5.97 & 5.87 & 597 \\
\hline & $x$ & 54 & $\therefore 38$ & 563 & 5,07 & 5,80 & 0.10 & $\therefore 94$ & 0,05 & 0,09 & 587 & 6,000 & tins \\
\hline Conduturivede eictrica & $\$$ & 41,9 & +2.51 & 38,8 & 30.4 & 31,0 & 35,0 & 30,2 & 33,9 & 34,1 & 30.34 & 31,6 & 28.9 \\
\hline \multirow[t]{5}{*}{$(\mu \mathrm{S} / \mathrm{cm})$} & $\mathrm{Im}$ & 40.9 & 43.7 & 41,0 & 30.6 & 29,8 & 36,1 & 32.3 & 34,4 & 33,7 & 9,4 & 31,6 & 29.1 \\
\hline & $2 m$ & 44.8 & $\$ 9.1$ & +1.1 & 30.1 & 31.4 & 36.4 & 30.4 & 35.2 & $33.1]$ & 31.3 & 31.8 & 32.0 \\
\hline & $3 \mathrm{~m}$ & 4.5 & 44.6 & 4,8 & 30.5 & 31.2 & 36.1 & 31,0 & 34.4 & $35.1]$ & 33.8 & 33.8 & 32,3 \\
\hline & $\mathbf{F}$ & 49.1 & 4.0 & +2.2 & 30,8 & 32,3 & 36.5 & 3211 & 33,8 & 34,9 & 46.11 & 43,7 & $\$ 4.3$ \\
\hline & $x$ & 440 & 48,7 & +13,8 & 30,5 & 31,2 & 36,0 & 31,2 & 34,4 & 34,2 & 34,2 & 34,5 & 33,3 \\
\hline \multirow{6}{*}{$\begin{array}{l}\text { Solidos totals en suspenswo } \\
\text { (mgl) }\end{array}$} & $s$ & 1.0 & 54 & 1.6 & 7.3 & 40 & 40 & 1.8 & 0.3 & 10,0 & 6.8 & 5.9 & 4.8 \\
\hline & $\mathrm{im}$ & 19.6 & 5.3 & $\therefore 1$ & 6,5 & 5.5 & 4.5 & 27 & 3,6 & 8.7 & 0.7 & 5.3 & 7.5 \\
\hline & $2 \mathrm{~m}$ & 5.4 & .7 .8 & 1.4 & 6,8 & 3,7 & 4,7 & $-1,2$ & 5.6 & 8.5 & 6,0 & 5,7 & 7.7 \\
\hline & $3 m$ & 8.6 & 5.7 & 2.3 & 8,0 & 5.2 & 4.7 & 23 & 4,4 & 7,3 & 6,0 & 5,3 & 7.7 \\
\hline & $\mathbf{F}$ & 6.0 & 17,0 & -2.3 & 9.0 & 7.0 & 3.8 & 27.8 & 4.9 & 8.5 & 10.3 & 12.8 & 19). 3 \\
\hline & $\mathrm{x}$ & 1,9 & 5.1 & 1,0 & 7,5 & 5.1 & 4,3 & 6,7 & 5,0 & 8,6 & 7,2 & 7,0 . & 8,6 \\
\hline Turbidez & $s$ & 4.2 & 4.0 & $4,1]$ & 3,2 & 4.3 & 3,2 & 3,1 & 3,8 & 5.4 & 4,9 & 4,8 & 53 \\
\hline \multirow{5}{*}{ (UNT) } & $\operatorname{lm}$ & 4.2 & 4,9 & 4,4 & 3.1 & 4,0 & 3,3 & 3.1 & 4,0 & 5,3 & 5,5 & 4,9 & 5,4 \\
\hline & $2 m$ & 4.4 & 5.2 & 4,4 & 3.2 & 4,2 & 3.4 & 29 & 3.9 & 4,9 & 5,1 & 4,4 & 5,8 \\
\hline & $3 \mathbf{m}$ & 4.9 & 6,3 & 5,3 & 3.5 & 4,7 & 3,8 & 3,0 & 4,3 & 5.4 & 4.5 & 4.2 & 6.4 \\
\hline & $\mathrm{F}$ & 10.5 & 21,0 & 5.6 & 4.1 & 6.0 & 4,3 & 3.5 & 4.7 & 50 & 7,2 & 7.0 & 17,3 \\
\hline & $x$ & 7,4 & 8,3 & 4.8 & 3,4 & 4,7 & 3,6 & 3.11 & 4,1 & 5 & 5.4 & 5.1] & 80 \\
\hline Niurogénio total & $\mathrm{S}$ & 749,37 & 587.99 & 158,66 & 58,19 & 314.58 & 91.10 & $|88,42|$ & 25,25 & 153.72 & 282.70 & 157.93 & 50.76 \\
\hline \multirow[t]{5}{*}{$(\mu \mathrm{g} L)$} & lm & 670.90 & 458,37 & $|81,06|$ & 50,14 & 352.97 & $\mid 10.70$ & 190,52 & 33,30 & 173.23 & 258.58 & $129,60 \mid$ & 43.11 \\
\hline & $2 m$ & 018,34 & 041.55 & $|65,66|$ & 43,49 & 319.99 & 97.40 & $\mid 85.96$ & 40,30 & $|43,00|$ & 26203 & $\mid 08.17$ & 36,60 \\
\hline & $3 \mathrm{~m}$ & 798.31 & 1379.04 & 157.96 & 53.99 & 34,66 & $\infty, \infty, 0$ & 09.51 & 45,20 & 167.11 & 286.52 & 181.65 & 47,32 \\
\hline & $\mathrm{F}$ & 86284 & $|427.44|$ & 173.01 & $0 \pm 39$ & 398.24 & 89.00 & $\mid 78.26$ & 31.90 & $|83.57|$ & +20.10 & 227.97 & 141.85 \\
\hline & $x$ & $7 \times 9.95$ & $9 \times 8,88$ & $i n 7.27$ & $\{3,64$ & 345,29 & 24,84 & 18253 & $3 \times 19$ & $i \theta+13$ & 31199 & $\mid 61.06$ & 0393 \\
\hline Fusforo total & $s$ & 8.61 & 2.40 & 9.89 & 9.25 & 8.50 & 15.17 & {$[11.58$} & $2: .58$ & 16.45 & 23,97 & 14,26 & 31,50 \\
\hline \multirow[t]{5}{*}{$(\mu \mathrm{gL})$} & Im & 200 & 9.30 & 11.49 & 0.04 & 11.76 & 16.24 & 17.06 & 16.03 & 19.93 & 25.55 & 17.35 & 33,86 \\
\hline & Im & 9.14 & $|11,69|$ & $\mid 6.14$ & 10,42 & 11.70 & 17.47 & $11.1=$ & $16.57 \mid$ & 20.49 & 26.11 & 22.12 & 31.39 \\
\hline & $3 m$ & 11.01 & 11.33 & $\mid 3,89$ & 11,38 & 13.68 & $\mid 7,58$ & 1392 & $|7,33|$ & $\therefore t .28$ & 34.47 & 18.81 & 31). 26 \\
\hline & $F$ & 15,07 & 12.83 & 7,36 & 13,41 & 13.41 & 17.95 & $\mid 4.41$ & $|8,84|$ & 2285 & 20.531 & $21, \infty 0$ & 40,03 \\
\hline & $x$ & 10.58 & 10,2 & 13,75 & 1070 & 11,81 & 16.88 & 13,42 & $|6,29|$ & $21, \geq 0$ & 27,93 & 18,71 & 394 \\
\hline "lorotila a lotal & $S$ & 2.31 & 1,03 & 11.41 & 2.89 & 4.82 & 4,34 & 5.21 & 7.59 & 60.74 & 7,44 & 0,83 & +115 \\
\hline \multirow[t]{5}{*}{$(\mu g L)$} & $1 \mathrm{~m}$ & 5.78 & 289 & 1.24 & 4.34 & 6.27 & 4.34 & 0,58 & 1172 & 4,54 & 4.54 & 0.83 & 2.31 \\
\hline & $2 m$ & 1.16 & $2 .+11$ & 289 & 10.12 & 4.82 & 1.93 & 231 & 7.95 & 14.87 & 10.40 & 0.83 & 11,01 \\
\hline & $3 m$ & 7,52 & $11, \infty 6$ & 1,03 & 3.37 & 12,53 & 2,89 & 3.47 & 5.37 & 0,75 & 8.26 & 19.6 & {$[3,01$} \\
\hline & $F$ & 5.78 & 3,611 & $\therefore .17$ & 6.75 & 4,82 & 3,37 & 1,16 & $4 . \%$ & 2,89 & 2,89 & 4.34 & 14.46 \\
\hline & $\mathrm{x}$ & 451 & 236 & 1,73 & 5.49 & 0,65 & 3,37 & $2,55]$ & 532 & 7,96 & 0,711 & 1,561 & 4,17 \\
\hline
\end{tabular}

$s=$ superticie

$F-$ fundo

$x=$ valor medio da coluna d'ápue 
TABELA 3 - Valores e médias mensais das variáveis físicas, químicas e biológicas, no lago das Ninféias de janeiro a dezembro de 1997.

\begin{tabular}{|c|c|c|c|c|c|c|c|c|c|c|c|c|c|}
\hline & & $08.01 / 1997$ & 03021997 & 030131997 & $07+41997$ & $0505 / 1997$ & 02061997 & $07: 07 / 1097$ & |04/081997| & 10109/1997 & K.101997 & 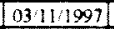 & 011121997 \\
\hline Frofundidade (m) & & 35 & 35 & 3.3 & 3,3 & 3,3 & 3,3 & 3,4 & 3,4 & 3.4 & 3,3 & 3,3 & 34 \\
\hline ransperincie (m) & & $1, \infty$ & 1.45 & 160 & 1.37 & 1,35 & 120 & 1,25 & 1.30 & 1,30 & 0,90 & 0,55 & 11,80 \\
\hline Tenpernaura dil agu & $\mathrm{s}$ & 223 & 320 & 224 & 19.2 & 19.6 & 14.5 & 17.0 & 17.0 & 17.8 & 20.8 & 3.2 & 21.3 \\
\hline \multirow[t]{4}{*}{$\infty$} & im & 22.1 & 21.8 & $=2.4$ & 19.5 & 19.5 & 15.0 & 17.01 & 16.8 & 17.9 & 19,6 & 22.1 & 21.2 \\
\hline & $2 m$ & 20.8 & 20.5 & 21.6 & 19,6 & 19.4 & 15.0 & 16,5 & 16.6 & 17.7 & 18,4 & 19.0 & 20,1 \\
\hline & $\mathrm{F}$ & 19.1 & 8.9 & 20.1 & 19.2 & 19,2 & 15,0 & 16,1 & 16,4 & 16.8 & 17.8 & 17,9 & 19.1 \\
\hline & $x$ & 21,1 & 20,8 & 21.6 & 19.4 & 19.4 & 14,9 & 16,7 & $|6,7|$ & 17,6 & 19,2 & 20,6 & 204 \\
\hline (nugenuo dissolvido & $s$ & 3.65 & 4.42 & 3,34 & 3.64 & 4,84 & 4,80 & 7.00 & 7.36 & 6,72 & 0.65 & 4,96 & 3.49 \\
\hline \multirow[t]{4}{*}{ (mgl) } & $\operatorname{lm}$ & 3.27 & 3.78 & 3,11 & 3,38 & 4.81 & 4,72 & 6.65 & 7,00 & 7.01 & 0,48 & 2,49 & 2,37 \\
\hline & $2 \mathrm{~m}$ & 1.15 & 1.75 & 1,31 & 3.19 & 3,70 & 4.86 & +39 & $\$ .62$ & 3,90 & 0,41 & 0.00 & 0.38 \\
\hline & $\mathrm{F}$ & 0.31 & 0.38 & 0,74 & 3.41 & 2.24 & 4,70 & 1.76 & 1.85 & 4.32 & 0.09 & 1.06 & 0.00 \\
\hline & $\mathrm{X}$ & 210 & 2,58 & 2,13 & 3.41 & 3900 & +77 & +95 & 521 & 549 & (1),41 & 2,13 & 1,56 \\
\hline \multirow[t]{5}{*}{ Fit } & $s$ & 0.10 & 586 & 6.137 & 6,14 & 6.25 & 6.28 & 0.47 & 0,60 & 0.42 & 5.23 & 6.35 & 5.20 \\
\hline & $\mathrm{Im}$ & 6,09 & $\therefore 85$ & 5,11 & $n, n$ & 0.27 & 0,22 & 0.43 & 0.54 & 0.47 & 0,13 & 0.10 & 0.14 \\
\hline & $2 m$ & ऽ97 & ४०ा & 4,93 & 0,04 & 6,17 & 6,24 & 6.32 & 5.40 & 0.261 & 6.15 & 6,131 & 0,21 \\
\hline & $\mathrm{F}$ & 0.34 & .201 & 0,4 & $0, \infty$ & 6,01 & 0.23 & 0.23 & 6321 & 0,31 & 0.21 & 0.33 & 0.41 \\
\hline & $\mathrm{x}$ & 0.13 & $\therefore$ & 305 & 6,04 & 6.18 & 6.24 & 0,30 & 547 & 637 & 6.18 & 6,23 & 6.24 \\
\hline Conduntivise elecrica & $s$ & $\$ 7.10$ & 02.65 & $\$ 5.70$ & 53.77 & 53,93 & 5203 & $\$ 63$ & $\$ 9.43$ & 47.47 & $+4,63$ & +4.77 & $51 .(0)$ \\
\hline \multirow[t]{4}{*}{ ( $\mathrm{S} \mathrm{S}(\mathrm{cm})$} & $\operatorname{lm}$ & 53,95 & 04.75 & 4807 & {$[5,47]$} & 54,20 & 51,50 & +7.18 & 50,87 & 45,93 & $\$ 6,07$ & 49,60 & 5210 \\
\hline & $\mathrm{Im}$ & 99.70 & 7.80 & $\infty .57$ & 55,73 & 55,00 & 52,13 & $\$ 6.00$ & 51.10 & 49.83 & $\$ 9,77$ & 74,43 & 88.20 \\
\hline & $\mathrm{F}$ & $|29,35|$ & 128,001 & $\mid 77,87$ & 6.27 & $\$ 5.93$ & $\{1,97$ & 51.63 & $\$ 1,10\}$ & 48.77 & 89.97 & 9290 & 160.93 \\
\hline & $x$ & 250 & $8 \geq 3$ & 70.6 & 5,3 & 54,7 & 519 & 48,1 & sig. 6 & 0,5 & 47.6 & 65,4 & 88,1 \\
\hline Solidos Lotaus em suspensio & $s$ & 1.7 & 3.2 & 5.8 & 0.2 & 0,8 & 5.6 & 0.0 & 8.5 & 6,7 & 6,6 & 4.7 & 8,7 \\
\hline \multirow[t]{4}{*}{$m \& L$} & $\operatorname{lm}$ & 2,2 & 3,7 & 0,0 & 4,6 & 6,6 & 0,8 & 4,8 & 7,8 & 5.5 & 9.01 & 7.5 & 10,0 \\
\hline & $2 \mathrm{~m}$ & 8,3 & 3,0 & 9.0 & 120 & 3,8 & 7.0 & 5.7 & 7.2 & 0.2 & 17,0 & 123 & 8.3 \\
\hline & $\mathbf{F}$ & 18.3 & 333 & 35.0 & 16.7 & 9,3 & 8.2 & 8.4 & 7.4 & 11.4 & 10.5 & 18.0 & 9.3 \\
\hline & $x$ & 7.6 & 118 & 140 & 110 & 6,6 & 6,9 & 0.4 & 7,7 & 7,5 & 10,8 & 10,6 & 9.1 \\
\hline Tutidez & $\mathrm{s}$ & +4.4 & 6,3 & 5.2 & 7,0 & 4,3 & 5.4 & 5.4 & 4,5 & 4.9 & 8,0 & 4,2 & 7.5 \\
\hline \multirow{4}{*}{ (NT) } & $\operatorname{lm}$ & 4.4 & 6.8 & 5,4 & 6,8 & 4,5 & 5,5 & 5.4 & 4.8 & 50 & 8,2 & 4,8 & 8,3 \\
\hline & $2 m$ & 8.3 & 21,5 & 17.3 & 7.8 & 49 & 5.5 & 6.5 & $\$ 9$ & 6.1 & 9.0 & 7.1 & 7.3 \\
\hline & F & 25,5 & 3,3 & 34,3 & 11,8 & 7.4 & 5,9 & 22.0 & 5.1 & 0.5 & 9.1 & 7,5 & 5,8 \\
\hline & $x$ & 10,7 & 170 & 156 & 84 & 53 & 5,6 & 9.8 & 48 & 56 & 8,6 & $\leq 9$ & 72 \\
\hline Vtronguo LTal & $\mathrm{s}$ & 479.54 & 161.11 & 16499 & 190,56 & 303.35 & 396,86 & $|09.65|$ & 266.09 & $\mid 78.59$ & 212.66 & 194,67 & 51.91 \\
\hline \multirow[t]{4}{*}{$\omega \& \mathrm{~L})$} & $\mathrm{Im}$ & 427.86 & $|+1.86|$ & {$[41.40$} & 11255 & 238.36 & 356,01 & 12225 & 268.89 & 170.94 & 197.73 & 991.61 & 07.22 \\
\hline & $2 m$ & (4)7.59 & 164.61 & 173,09 & 142,08 & 274.80 & 376.68 & 121.90 & 281.84 & $|59.07|$ & 194.28 & 223,37 & 184.33 \\
\hline & $\mathrm{F}$ & 713.31 & 200.13 & 234.46 & $|92.28|$ & 348,63 & 375,20 & 143.96 & 204,93 & $|76.68|$ & 390,24 & $\$ 16.16$ & 316.38 \\
\hline & $x$ & 53208 & 18743 & 17874 & 159.36 & 396,34 & 376,19 & 124,44 & 355,44 & 171,32 & 248,73 & 281,45 & $154 \%$ \\
\hline Fosforo total & 5 & 13.25 & 31 & 1272 & 13.52 & 17.15 & 13,20 & $13, \infty 6$ & 13.71 & $: 7.74$ & 28,07 & 5.84 & 16.95 \\
\hline \multirow[t]{4}{*}{ (we) } & $\mathrm{Im}$ & 12.13 & $\| 1, n \mid$ & 14,48 & $1+, 53$ & 15,87 & $\mid 4.53$ & 13.71 & $\mid 5,87$ & 29.53 & $3 \geq 17$ & 50.26 & 18.30 \\
\hline & $2 \mathrm{~m}$ & 19.91 & 13,92 & $|s(x)|$ & $\mid 6.14$ & $|4 \infty|$ & 14.32 & $\mid 4.79$ & $\mid 9.48$ & 30.21 & 19.86 & $+4,13$ & $2,3.47$ \\
\hline & $\mathrm{F}$ & 16,30 & in 18 & 28.31 & 17,47 & 15,00 & 16,03 & 19,21 & $\{9.70\}$ & 26.11 & 36.50 & $\$ 8.57$ & 32,90 \\
\hline & $x$ & 13,80 & 1.28 & 1778 & 1541 & 15,90 & 14,52 & 15.19 & 1719 & 28,40 & 39,15 & 50,45 & 2291 \\
\hline orofila a totol & $\mathrm{s}$ & 14.22 & 699 & 3.79 & $\times, 72$ & 11.38 & 7.0 & 5.69 & 16,71 & 23.61 & 5.12 & 0,00 & +.98 \\
\hline \multirow{4}{*}{$(4) \mathrm{L})$} & $1 \mathrm{~m}$ & $<69$ & 5.69 & 3,70 & $<.40$ & 8.53 & 8.53 & 13.00 & (1) 31 & $1<.64$ & $7 \%$ & 4.55 & 4.27 \\
\hline & $2 \mathrm{~m}$ & 11,38 & +74 & $\times, 53$ & 4.39 & 0.67 & 9,10 & 17.54 & $=2.75$ & 0.35 & $1, \infty 1$ & 11,00 & 25,00 \\
\hline & $\mathrm{F}$ & 20,86 & 17.54 & 43,61 & 4.74 & 9,48 & 10,24 & $|6,12|$ & 21.05 & 25,60 & 2,84 & 5.69 & 33.42 \\
\hline & $x$ & 17,14 & +41 & 14,93 & $2 \times x_{0}$ & 076 & 8,06 & 13,10 & 1770 & 1780 & +26 & $=56$ & 1716 \\
\hline
\end{tabular}

$F$ - fundo

$X$ - vilor medio da colure déprua 
TABELA 4 - Valores e médias mensais das variáveis fisicas, químicas e biológicas, no lago das Garças de janeiro a dezembro de 1997.

\begin{tabular}{|c|c|c|c|c|c|c|c|c|c|c|c|c|c|}
\hline & & $=03011047$ & $0502 / 1997$ & |05/03/1997 & $090(04 / 1097$ & $0705 / 997$ & (44)6,1997 & 09:07/1997 & $0608 / 1997$ & $03 / 69 / 1997$ & $08: 101997$ & $05 / 111997$ & $03 \quad 1997$ \\
\hline Profundtdade (m) & & 4.7 & +6 & 4.5 & +7 & 49 & +7 & 4,5 & 4,61 & 4,61 & 4,6 & 4.6 & +7 \\
\hline Transparêncis (m) & & 11.55 & 11,40 & $(n, 9)$ & 67.70 & 10.65 & 1.95 & 0,85 & 0,601 & 0,10 & 0,40 & 3,55 & 0,35 \\
\hline Temperatura da iqua & s & 2.81 & 24.4 & 24.1 & 20.5 & 20.4 & 16.7 & 18.8 & 17.5 & 18.8 & 19.8 & 23.4 & 22.4 \\
\hline \multirow{5}{*}{ (क) } & $\operatorname{lm}$ & 24.4 & 24.6 & 23,8 & 20.6 & 20.4 & 16.7 & 18.5 & 17.4 & 18.9 & 20,0 & 24.2 & 22,6 \\
\hline & $2 m$ & 27,81 & 24,0 & 23.5 & 20.6 & 20.4 & 16.6 & 18.0 & 17.5 & $\mid 8.5$ & 20,1 & 24,1 & 225 \\
\hline & $3 \mathrm{~m}$ & 22,5 & 23,3 & 23.1 & 20,5 & 20.4 & 16.5 & 17,6 & 17.4 & $\mid 7.8$ & 20.11 & 20,8 & 22,2 \\
\hline & $\mathrm{F}$ & 20.5 & 21,2 & $\because 21$ & 20.5 & 19,9 & 16.5 & 17,4 & 17.4 & 17.4 & 19.1 & 19.6 & 20,6 \\
\hline & $x$ & $=30$ & 23,5 & 23,3 & 30,51 & $\mathbf{2 0 . 3}$ & 16.6 & 18.1 & 17.4 & {$[8,3$} & 198 & $=4$ & 221 \\
\hline nupeno dissolndo & $\mathrm{s}$ & $x, 02$ & 5.62 & 3.35 & +95 & 3.29 & 5,78 & 7.13 & 6.47 & 10,57 & 0.48 & 5.94 & 5.67 \\
\hline \multirow{5}{*}{$(\mathrm{mgl})$} & $\operatorname{lm}$ & 9.28 & 6.49 & 2.94 & 5.52 & 2.71 & 5.84 & 7.42 & 6.12 & 9.70 & 0,52 & 0.12 & 4.98 \\
\hline & $2 \mathrm{~m}$ & $\therefore \infty$ & 2.85 & 1.64 & 5.46 & 2.85 & 5.86 & 5.47 & 5.97 & 5.64 & 0.51 & $5.71]$ & +.40 \\
\hline & $3 \mathrm{~m}$ & 1.01 & 0.52 & 11.66 & 600 & 3.10 & 5.71 & 2.43 & 6.12 & $1 . \infty$ & 1).55 & $2 . \infty$ & 1.63 \\
\hline & $\mathrm{F}$ & 11.28 & 0,15 & 0,68 & 4,85 & $2: 4$ & 5.15 & 1.20 & 5.99 & 0.74 & 0.12 & 0,52 & 0,38 \\
\hline & $x$ & +36. & 32 & 1,85 & 5,35 & 2,84 & 5,67 & 4,73 & 6,13 & 5,53 & 0.4 &,$+ \infty$ & $3,4]$ \\
\hline \multirow{6}{*}{$\mathrm{FH}$} & $s$ & $7+61$ & 0,99 & 6.72 & 0.80 & 0.78 & 7.02 & 6.92 & 6.92 & 8.77 & 0.93 & 7.14 & 6.87 \\
\hline & Im & 7.42 & 7.12 & 6.67 & 0.85 & 6.72 & 7.011 & 7.03 & 0.78 & 8.77 & 006 & 7.15 & 6.84 \\
\hline & $2 m$ & 102 & 6.68 & 0,6 & +8.88 & 6.78 & 7.08 & 6,81 & 6.83 & 7.311 & 6.6 & 7,10 & 0.86 \\
\hline & $3 m$ & 0.74 & 0.70 & 6,57 & $6, \infty 9$ & 0,77 & 7,07 & 6,71 & 6.91 & 7.25 & 0.97 & 0.93 & 6,64 \\
\hline & $\mathrm{F}$ & 0,080 & 6.60 & 6.54 & 6,96 & 6.71 & 7,00 & 6,65 & 6,91 & 6.93 & 6.77 & 6.70 & 6.54 \\
\hline & $x$ & 3.4 & 6,83 & 6.63 & 6,90 & 0.75 & 704 & 0,82 & $-6,87$ & 7.811 & 6.92 & 7,011 & 6,75 \\
\hline ' undurundade eienna & $\mathrm{s}$ & 118.8 & 110.4 & 117.9 & 134.8 & $13+.5$ & 150.2 & 135.7 & 139,5 & $|36.3|$ & 133.4 & 125.0 & 142.2 \\
\hline \multirow[t]{5}{*}{ ( $\mathrm{SS} \mathrm{cm}$ ) } & $1 \mathrm{~m}$ & $12+6 \mid$ & 1149 & 122.6 & 141.4 & $1+0,6$ & $1+2,1$ & $|35,7|$ & $\mid 39.8$ & 139.7 & $\{32.9$ & $\mid 26.21$ & $1 \$ 1,4$ \\
\hline & $2 \mathrm{~m}$ & $2 ? .04$ & $\mid 6,4,8$ & 125.2 & $1+0.4$ & 135,4 & $1+1.4$ & 138,0 & $\mid 39.1$ & $1 \%, 7$ & 138.0 & 128,4 & $1+3.2$ \\
\hline & $3 \mathrm{~m}$ & $\mid 1 \times, 6\}$ & 171.6 & 147,3 & {$[41,8 \mid$} & $\mid 37.7$ & $\mid 41,2$ & $|38.7|$ & $\mid 39,8$ & $|51,5|$ & $\mid 35,9$ & $|65,0|$ & 165,5 \\
\hline & $\mathrm{F}$ & 409 & 249,0 & 186.0 & 142.1 & $1+4,2$ & 1424 & 43.5 & 139.7 & 164.6 & 152,3 & 171,7 & 213.3 \\
\hline & $x$ & $|x 6|$ & $(6,4)$ & 139.8 & $1+0,1$ & 138,5 & 143.5 & 138,3 & 139.6 & 146,6 & 138.5 & 43,3 & 161,1 \\
\hline Solidos totess em surpentito & $s$ & 0.7 & 8.0 & ne & 12,5 & 7.7 & 7.3 & 8.5 & 9.5 & 19.5 & 10,7 & 9.3 & 140 \\
\hline \multirow[t]{5}{*}{$(\mathrm{mg} h)$} & $\operatorname{lm}$ & $\therefore: 1$ & 7.7 & ne & 11.2 & 8.5 & 7.5 & 9,0 & 8.0 & 14,0 & 11,7 & 8.5 & 125 \\
\hline & Im & $x, 3$ & 11.0 & ne. & 12.0 & 9,8 & 8,3 & 8,2 & 7,7 & 12,3 & 13.3 & 9.0 & 12.5 \\
\hline & $3 \mathbf{m}$ & ne & 12.7 & ne. & 13.2 & 10.3 & 9.2 & 8.8 & 8,7 & 17,3 & 13.0 & 8.5 & 25.0 \\
\hline & $\mathrm{F}$ & $|3,8|$ & 26.3 & ne & 12,8 & 11.7 & 8.7 & 10,0 & 10.8 & 22,0 & 18.3 & 14,7 & 40.5 \\
\hline & $x$ & 0.5 & 13,3 & ne & 12,3 & 9.6 & 8.2 & 89 & 2,0 & 17,0 & 13,4 & 10,0 & 209 \\
\hline Furbidez & $s$ & $x .1$ & 15.5 & 15,0 & $\{6,7$ & 0.4 & 17.7 & 7.6 & 19.0 & 423 & 20.3 & 16.3 & 19,0 \\
\hline \multirow{5}{*}{$(\mathrm{NT})$} & $\operatorname{lm}$ & $x, 0$ & 16,0 & 16,0 & 16,3 & 6.7 & 16.3 & 7.1 & 19,0 & 37,7 & 20,3 & 17,0 & 19.0 \\
\hline & $2 \mathrm{~m}$ & 8.3 & 20,0 & 17,0 & $|6.7|$ & 0.0 & 16,0 & 5.4 & 19,0 & 24.7 & 20,0 & 17,7 & 19.7 \\
\hline & $3 \mathbf{m}$ & 31,0 & 20,5 & 20,3 & 17,3 & 7,8 & $\mid \leq 7$ & 5,1 & 19,0 & 16.0 & 20,0 & $|8,7|$ & 32.3 \\
\hline & $\mathrm{F}$ & -4.5 & 25.5 & 2.27 & 18.7 & 20.0 & 6.0 & 5.7 & 19.3 & 16.0 & 20.0 & 19,3 & 30.3 \\
\hline & $x$ & 48 & 19.5 & 18,2 & 171 & 0.5 & 10,3 & 6,2 & 19,1 & 27.3 & $-0,1$ & 17.8 & 241 \\
\hline$\therefore$ itrogento todal & $s$ & 73137 & 7801.63 & 986,47 & $(a n) 24$ & 849.85 & +71.17 & 436.94 & 770,29 & 313.70 & $|2| 4.50 \mid$ & 581,47 & 159,70 \\
\hline \multirow[t]{5}{*}{$m(2)$} & $\operatorname{lm}$ & 237 & 453,46 & 1007.15 & $4+469$ & 139.421 & 599,63 & 0.32 .89 & 505,00 & $269.68 \uparrow$ & $\{(4), 63\}$ & $\infty 00.31$ & 142.86 \\
\hline & $2 m$ & $\times \times 801$ & $(x) 5,04$ & (2) 95.95 & 023,02 & $2=3.92$ & 592,24 & $5 \mid 6.16$ & 647.05 & $\mid 41,85$ & $8|4,17|$ & 686.33 & 107.35 \\
\hline & $3 \mathrm{~m}$ & 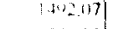 & 1055,36 & 1374.05 & 032.49 & .799 .04 & $\langle i * 9,56$ & 599.21 & 484,78 & $\mid 77.83$ & 863.92 & $|166.28|$ & $\$ 12.79$ \\
\hline & $\mathrm{F}$ & 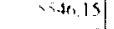 & 2722,79 & $4(4,4,85$ & 635,94 & $\mid 163.35$ & 579.46 & 519.22 & 8013.97 & $2-9.88$ & 1399,74 & $\mid 641.63$ & 775.89 \\
\hline & $x$ & $\mid \sin 97$ & $11,3,46$ & 1681,69 & 628.87 & 071.12 & 540,41 & $5 \$ 1,89$ & $(0,22$ & 226,59 & 3167,90 & 94.20 & 311,2 \\
\hline fosforo total & s & $\mid \ln 512$ & 05,25 & 62.10 & 83.98 & 74,32 & 72.88 & 77,66 & $\mid 11,36$ & 269.221 & 114,16 & $\mid 115,18$ & 222,38 \\
\hline \multirow{5}{*}{ (ag $[$ ) } & $\operatorname{lm}$ & 1408 & 79.87 & $\times 7.83$ & 82.49 & 8), 30) & 75,07 & 79,71 & $\mid 14,22$ & $=21.77$ & 118.26 & $\mid 17.09$ & 171.50 \\
\hline & $2 \mathrm{~m}$ & $|+1,39|$ & 92,74 & 88.10 & 9157 & $91 .+4)$ & 78.75 & 92.23 & 119.84 & $\mid+6.29$ & 120.12 & $|25.62|$ & 15555 \\
\hline & $3 m$ & $n+\infty)$ & 69,78 & $x 2,81$ & 87.45 & $\mid 17.78$ & 76.83 & 100.22 & $\mid 15.18$ & 114.611 & $|26.24|$ & $\mid 21.75$ & 158.31 \\
\hline & $\mathrm{F}$ & $|+x| 04 \mid$ & 71,97 & 82.06 & 106,57 & $\mid 29.73$ & 80,51 & 100,17 & 121.52 & $i 42.13$ & $\mid 35,34$ & $|60.44|$ & 134.78 \\
\hline & $x$ & 41069 & 75,92 & $\mathrm{x} 0,58$ & $\infty, 41$ & 48,711 & 70,81 & $\infty 0,00$ & $\mid 116,42$ & 178,80 & 12282 & $1=8,01$ & $16,8,50$ \\
\hline "Worofiles a totel & $s$ & $\therefore \therefore 5$ & 42,06 & 29.15 & $0,1.86$ & 24.17 & $+1,53$ & 61.86 & 93,86 & $=26,11$ & 21.80 & $49.7 n$ & 137.94 \\
\hline \multirow[t]{5}{*}{$\theta L$} & $\operatorname{lm}$ & $\because 1,10$ & 48.35 & 44,79 & 59,73 & 31.29 & 41.24 & 59,73 & $\times 7,46$ & {$[55,00]$} & $|8,01|$ & $8=48$ & 2599 \\
\hline & $2 m$ & 324 & $\infty .13$ & +4.79 & 59.02 & 33.42 & 37.68 & 40.53 & 78,92 & 99.54 & 48 & 4.79 & 8.83 \\
\hline & $3 m$ & is $13 \mid$ & 37.68 & 33,35 & 94.75 & 36.97 & 38.40 & 35,55 & 71,81 & 36,97 & 8.48 & 20.62 & 78,21 \\
\hline & f & $\therefore|x|$ & 29.86 & $+9,7$ & 44.79 & 22.23 & 30.57 & 25,60 & 17.78 & 33.18 & 0.48 & 13,27 & 51.19 \\
\hline & $\mathrm{x}$ & 404 & 44.94 & +1137 & {$[6,03$} & 31.621 & 37,68 & 44.65 & 0997 & 11016 & 13.65 & 4219 & 22,43 \\
\hline
\end{tabular}


TABELA 5 - Composição de rotíferos nos lagos do IAG, das Ninféias e Garças, de janeiro a dezembro de 1997.

\begin{tabular}{|c|c|c|c|}
\hline & $\begin{array}{c}\text { tago do } \\
\text { LAG }\end{array}$ & $\begin{array}{l}\text { Lago das } \\
\text { Ninf́cies }\end{array}$ & $\begin{array}{l}\text { lago das } \\
\text { Gastions }\end{array}$ \\
\hline Anuraeopses fissa (Gossc. 1851) & $\cdot$ & + & 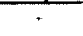 \\
\hline Anurceopsess sp. & . & - & . \\
\hline Ascomorpho ecoudis (Perty, 1859) & & - & . \\
\hline A. saltans Barrach, 1870 & & - & . \\
\hline iscomorpha sp. & - & - & - \\
\hline Asplanchna girodt (De Gueme, 1888) & - & - & . \\
\hline Brachomus angularis bidens (Plate) & - & - & + \\
\hline B. a. cheionss (Ahbstrom 1940) & . & . & + \\
\hline B. bidentata Andenon, 1889 & - & - & + \\
\hline B. caluctflones Pallear 1766 & - & - & + \\
\hline B. candatus Bamois \& Dadry, 1884 & - & - & . \\
\hline B. falcanus Zacherian, 1898 & - & - & + \\
\hline B. mires Dadry, 1905 & - & - & + \\
\hline Brachionus spp. & . & - & + \\
\hline Cephalodella catellina (O.F. Maller, 1786) & - & - & + \\
\hline Cephalodella sp. & - & - & . \\
\hline Collowheca upp. & - & + & - \\
\hline Colurella spp. & . & + & + \\
\hline Conochilus dossuarmus (Hudeon. 1875) & . & + & + \\
\hline C. unucornus Rounceleh, 1892 & - & - & . \\
\hline Conochilus upp. & . & - & + \\
\hline Dipleuchilanes propatula (Gosece. 1886) & - & . & - \\
\hline Dissorrocha aculeata (Ehrenberg 1832) & + & - & - \\
\hline Euchlans dilowata Elurenberg, 1832 & - & . & + \\
\hline Filinia opoliansis (Zacharian, 1891) & . & . & . \\
\hline F. terminalis (Plate, 1886) & - & - & . \\
\hline Hexarthra intermedia Wiesmewaki 1929 & . & - & - \\
\hline H. i. braziliensss (Haver. 1953) & . & - & - \\
\hline H. mira (Hudeon, 1871) & . & - & . \\
\hline Hexarthra app. & . & - & . \\
\hline Keratella amencana Cartin, 1943 & - & - & + \\
\hline$K$ cochlears Gowe, 1851 & + & + & + \\
\hline K. wecla (Gome. 1886) & - & - & + \\
\hline K. tropica (Apetein, 1907) & . & - & + \\
\hline Keratella spp. & - & - & + \\
\hline Lecane bulla (Gonec, 1886) & - & + & + \\
\hline L. curvicornis (Murray. 1913) & - & . & - \\
\hline L. donsssa Haring, 1914 & . & . & - \\
\hline L. leontina (Tumer, 1892) & - & - & - \\
\hline L. signfera (Jernanan 1896) & + & . & - \\
\hline Lecane opp. & - & . & + \\
\hline Lepadalla pareilus (O F Maller. 1786) & . & . & - \\
\hline Lepactilla sp. & - & . & - \\
\hline Macrochoerus ep. & - & - & - \\
\hline Manfrectum oudaciniota (Gosece. 1886) & - & . & . \\
\hline Monommata sp. & - & + & - \\
\hline Myttima busulcata (Lucke, 1912) & - & - & - \\
\hline Potharthra walgaris Cartin, 1943 & - & + & . \\
\hline Polvarthra ap. & - & - & - \\
\hline Sinamiherina sp. & . & . & - \\
\hline Symchaeta pectinata Ehrenberg, 1832 & - & - & - \\
\hline Synchaeta sp. & - & - & - \\
\hline Trichacerca ct. bidens (Lucker 1912) & - & - & - \\
\hline T. groctlis (Temin, 1890) & - & + & . \\
\hline T. of. mus Hauer & . & . & . \\
\hline T. pustlla (I swertion. 1898) & - & - & . \\
\hline$r$ simils (Wierzejatci, 1893) & - & - & . \\
\hline T. sfilata (Gosec, 1851) & . & & - \\
\hline Trichocerca sp. 1 & - & - & - \\
\hline Trichocerca sp. 2 & . & . & - \\
\hline Irichoourca spp. & . & 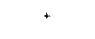 & . \\
\hline Bdelloides & & . & + \\
\hline
\end{tabular}


TABELA 6 - Composição de microcrustáceos nos lagos do IAG, das Ninféias e Garças de janeiro a dezembro de 1997.

\begin{tabular}{|c|c|c|c|}
\hline & $\begin{array}{c}\text { lago do } \\
1 \mathrm{AG} \\
\end{array}$ & $\begin{array}{l}\text { lago das } \\
\text { Vinfteins }\end{array}$ & $\begin{array}{l}1280 \text { des } \\
\text { Garrysos }\end{array}$ \\
\hline \multicolumn{4}{|l|}{ COPEPODA CYCLOPODA } \\
\hline Eucwlops pseudicensifer Dessers. 1984 & . & - & . \\
\hline Fucoclops up. & . & . & . \\
\hline Macraculops sp. & . & . & . \\
\hline Mesococlops longtsernes (Thichaud 191.t) & . & . & . \\
\hline Hetacoclops mendocimus (Wierzejsth. 1892) & + & . & + \\
\hline Mfrrocusiops op. & . & - & - \\
\hline Thermaxiciops dectpiens (Kiefer. 1929) & . & . & . \\
\hline Tropocyclops prassmus (fischer. $186(x)$ ) & . & - & + \\
\hline COPEPODA CALANODA & & & \\
\hline Scolodiaptomus cordenen (Wright, 1936) & . & + & + \\
\hline COPEPODA HARPACICOIDA & . & . & . \\
\hline \multicolumn{4}{|l|}{ (LADOCERA } \\
\hline Hona guttata Sarn, 1862 & . & . & . \\
\hline A. monacantha Sar 1901 & . & + & - \\
\hline thona spp. & . & . & . \\
\hline Buapertura spp. & . & - & - \\
\hline Basmina hagmannu Strngetion, 1904 & . & - & . \\
\hline B. tubicen Bretrm. 1953 & . & . & . \\
\hline Basmina up. & . & . & . \\
\hline Bosminopsis detersi Richurd, 1895 & . & . & . \\
\hline Cumptocercus dadan Stingelin. 1913 & . & + & + \\
\hline Cenodaphmia cornuta cornuta Sars, 1886 & . & . & . \\
\hline c.c. ngaudh (Richend 1894) & . & - & + \\
\hline$\therefore$ of. reficulata (Jurina 1820) & 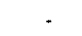 & - & + \\
\hline Chudorus pubescens Sen 1901 & . & + & . \\
\hline C. sphoencus (Muellar, 1785) & . & . & + \\
\hline Chudorus spp. & . & . & + \\
\hline Daphnia ambrgus Scourtickd 1947 & . & . & . \\
\hline D. gessnern Herabea 1967 & . & . & . \\
\hline Daphnua sp. (jorem) & . & . & . \\
\hline Draphanosoma birger Korinock | 1981 & + & . & . \\
\hline Thuphanosoma up. & . & . & . \\
\hline Dispurationa dation (Bige 1910) & . & . & . \\
\hline Tiphemeropones barroest (Richard. 1844) & . & . & . \\
\hline Eirdentatus (Bergamman 1931) & . & & . \\
\hline Giraptolebers lessudinana (Ficher. $1 \times 11$ ) & . & 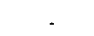 & - \\
\hline Thocryptus spinter Hernck, 1882 & . & . & . \\
\hline levdtgia spp. & . & . & . \\
\hline Hacrothrix Laticornes (Jume. 1820) & - & & . \\
\hline M. spinosa King 1853 & . & . & . \\
\hline Macrothrex sp. & . & . & . \\
\hline Mona micrue Kurz 1874 & . & . & . \\
\hline If mimuta Hansen 1899 & . & . & . \\
\hline Mona sp. & - & . & . \\
\hline Simocophajus ep. & . & . & . \\
\hline Thydoridue &. & - & - \\
\hline
\end{tabular}


TABELA 7 - Densidades numéricas $\left(\mathrm{n}^{\circ} \mathrm{org} / \mathrm{m}^{3}\right)$ e abundàncias relativas $(\%)$ de rotiferos, copépodes ciclopoides e calanóides, e cladóceros, no lago do IAG de janeiro a dezembro de 1997.

\begin{tabular}{|c|c|c|c|c|c|c|c|c|c|c|}
\hline & \multicolumn{2}{|c|}{ ROTIFERA } & \multicolumn{2}{|c|}{ CYCLOPOIDA } & \multicolumn{2}{|c|}{ CALANOIDA } & \multicolumn{2}{|c|}{ CLADOCERA } & \multicolumn{2}{|c|}{ TOTAL } \\
\hline & D & $A R$ & D & $A R$ & D & $\mathrm{AR}$ & D & $\mathrm{AR}$ & D & $\mathrm{AR}$ \\
\hline Janeiro & 153891 & 87.00 & 7712 & 4,36 & 13449 & 7.60 & 1839 & 1.04 & 176891 & 100,00 \\
\hline Fevereiro & 191072 & 69.33 & 56838 & 20,62 & 25914 & 9.40 & 1790 & 0.65 & 275614 & 100,00 \\
\hline Março & 53572 & 56.71 & 10438 & 11,05 & 20331 & 21.52 & 10122 & 10,72 & 94463 & 100,00 \\
\hline Abril & 177551 & 88.92 & 8890 & 4.45 & 10592 & 5.30 & 2660 & 1.33 & 199693 & 100.00 \\
\hline Maio & 133162 & 73.17 & 5729 & 3,15 & 9995 & 5.49 & 33101 & 18,19 & 181987 & 100,00 \\
\hline Junho & 315307 & 78.91 & 12671 & 3.17 & 15929 & 3.99 & 55662 & 13,93 & 399569 & 100,00 \\
\hline Julho & 182398 & 0.1 .35 & 6776 & 2,28 & 24552 & 8.26 & 83578 & 28,11 & 297304 & 100.00 \\
\hline Agosto & 39030 & 39.52 & 7127 & 7,22 & 13061 & 13,23 & 39530 & 40,03 & 98748 & 100,00 \\
\hline Setembro & 90815 & 54.38 & 5654 & 3,38 & 12939 & 7.75 & 57602 & 34.49 & 167010 & 100,00 \\
\hline Outubro & 210969 & 56.61 & 145217 & 38.97 & 6847 & 1.84 & 9620 & 2,58 & 372653 & 100,00 \\
\hline Novembro & 79975 & +2.99 & 83199 & 44,72 & 15623 & 8.40 & 7233 & 3,89 & 186030 & 100.00 \\
\hline Dezembro & 154974 & 80.61 & 9761 & 5.46 & 12495 & 6.98 & 1700 & 0.95 & 178930 & 100,00 \\
\hline$x$ & & 60.29 & & 12.40 & & 8.31 & & 12,99 & & 100.00 \\
\hline
\end{tabular}

$D=$ Densidade numerica

$\mathrm{AR}=$ Abundância relatıa

$\mathrm{X}=$ Valor médio 
TABELA 8 - Densidades numericas $\left(\mathrm{n}^{\circ} \mathrm{org} / \mathrm{m}^{3}\right)$ e abundâncias relativas $(\%)$ de rotiferos, copépodes ciclopóides e calanóides, e cladóceros, no lago das Ninféias de janeiro a dezembro de 1997.

\begin{tabular}{|c|c|c|c|c|c|c|c|c|c|c|}
\hline & \multicolumn{2}{|c|}{ ROTIFERA } & \multicolumn{2}{|c|}{ CYCLOPOIDA } & \multicolumn{2}{|c|}{ CALANOIDA } & \multicolumn{2}{|c|}{ CLADOCERA } & \multicolumn{2}{|c|}{ TOTAL } \\
\hline & $\mathrm{D}$ & $\mathrm{AR}$ & D & AR & $\mathrm{D}$ & $\mathrm{AR}$ & $\mathrm{D}$ & $\mathrm{AR}$ & $\mathrm{D}$ & AR \\
\hline Janeiro & 41837 & 86.65 & 1333 & 2,76 & 4919 & 10,19 & 191 & 0.40 & 48280 & 100,00 \\
\hline Fevereiro & 40704 & 83.02 & 3824 & 7,80 & 4111 & 8.38 & 387 & 0.80 & 49026 & 100,00 \\
\hline Março & 92347 & 85,44 & 5048 & 4,67 & 10156 & 9,40 & 530 & 0,49 & 108081 & 100.00 \\
\hline Abril & 168775 & 84.48 & 5047 & 2.53 & 22327 & 11,18 & 3614 & 1,81 & 199763 & 100.00 \\
\hline Maio & 174491 & 79.01 & 15946 & 7.22 & 17782 & 8,05 & 12639 & 5,72 & 220858 & 100.00 \\
\hline Junho & 448408 & 85.24 & 9951 & 1.89 & 55119 & 10,48 & 12569 & 2.39 & 526047 & 100.00 \\
\hline Julho & 191496 & 90.59 & 2693 & 1.27 & 15220 & 7,20 & 1988 & 0,94 & 211397 & 100,00 \\
\hline Agosto & 1741495 & 99,53 & 2670 & 0.15 & 5186 & 0,30 & 402 & 0,02 & 1749753 & 100,00 \\
\hline Setembro & 69557 & 76,71 & 3423 & 3,78 & 16374 & 18,06 & 1317 & 1,45 & 90671 & 100,00 \\
\hline Outubro & 20239 & 46.32 & 2354 & 5,39 & 17402 & 39,83 & 3695 & 8,46 & 43690 & 100.00 \\
\hline Novembro & 2211 & 12.22 & 1615 & 8,93 & 7565 & 41,83 & 6696 & 37,02 & 18087 & 100,00 \\
\hline Dezembro & 5781 & 74.98 & 299 & 3.88 & 1319 & 17,11 & 311 & 4,03 & 7710 & 100,00 \\
\hline$X^{x}$ & & 75.35 & & 4.19 & & 15,17 & & 5.29 & & 100.00 \\
\hline
\end{tabular}

$\mathrm{D}=$ Densidade numérica

$\mathrm{AR}=$ Abundância relativa

$\mathrm{X}=$ Valor medio 
TABELA 9 - Densidades numéricas $\left(\mathrm{n}^{\circ} \mathrm{org} / \mathrm{m}^{3}\right)$ e abundâncias relativas $(\%)$ de rotiferos, copépodes ciclopóides e calanóides, e cladóceros no lago das Garças de janeiro a dezembro de 1997

\begin{tabular}{|c|c|c|c|c|c|c|c|c|c|c|}
\hline & \multicolumn{2}{|c|}{ ROTHIRA } & \multicolumn{2}{|c|}{ CYCLOPOIDA } & \multicolumn{2}{|c|}{ CALANOIDA } & \multicolumn{2}{|c|}{ CLADOCERA } & \multicolumn{2}{|c|}{ TOTAL } \\
\hline & D) & $A R$ & D & $\mathrm{AR}$ & D & $\mathrm{AR}$ & D & $\mathrm{AR}$ & D & $A R$ \\
\hline Janeiro & 141070 & 73,90 & 49801 & 26,09 & () & 0,00 & 25 & 0.01 & 190896 & 100,00 \\
\hline Fevereiro & 3175090 & 88.60 & $4(1) 774$ & 11,38 & 5 & 0,00 & 71 & 0,02 & 358449 & 100.00 \\
\hline Março & 1358.419 & 8,31 & 23026 & 1,67 & 10 & 0,00 & 290 & 0,02 & 1381745 & 100,00 \\
\hline Abril & 1261.482 & 60,00 & 820823 & 39,04 & 10 & 0,00 & 20250 & 0.96 & 2102565 & 100,00 \\
\hline Maio & 1653063 & 85,28 & 265316 & 13,69 & 92 & 0,00 & 19843 & 1.02 & 1938314 & 100,00 \\
\hline Junho & 911480 & 76,79 & 259016 & 21,82 & 127 & 0.01 & 16356 & 1,38 & 1186979 & 100,00 \\
\hline Julho & 1082910 & 60.94 & 661193 & 37,21 & 15 & 0,00 & 32826 & 1,85 & 1776944 & 100,00 \\
\hline Agosto & 893877 & $\times 2,68$ & 172031 & 15.91 & 15 & 0,00 & 15261 & 1,41 & 1081184 & 100,00 \\
\hline Setembro & 638132 & 52,45 & 552181 & $+5,38$ & 597 & 0,05 & 25780 & 2,12 & 1216690 & 100,00 \\
\hline Outubro & $113928+$ & 91,65 & 99907 & 8,04 & 178 & 0,01 & 3694 & 0,30 & 1243063 & 100,00 \\
\hline Novembro & 431632 & 67,52 & 183251 & 28,66 & 103 & 0.02 & 24318 & 3,80 & 639304 & 100,00 \\
\hline Dezembro & 134437 & 25.00 & 5040 & 3,56 & 5 & 0,00 & 2030 & 1,43 & 141512 & 100,00 \\
\hline$x$ & & 77,76 & & 21,04 & & $0,01]$ & & 1,19 & & 100,00 \\
\hline
\end{tabular}

$D=$ Densidade numenca

$A R=A$ bundância relatiıa

$\mathrm{X}=$ Valor médio 
TABELA 10 - Densidades numéricas $\left(\mathrm{n}^{\circ} \mathrm{org} / \mathrm{m}^{3}\right)$ de rotiferos e microcrustáceos, no lago do IAG de janeiro a dezembro de 1997.

\begin{tabular}{|c|c|c|c|c|c|c|c|c|c|c|c|c|c|}
\hline Butrevas & & $\frac{1-01: 1007}{209}$ & in 0210947 & 94.031999 & a & 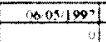 & 030001007 & \begin{tabular}{|l|l|}
$-1807 ; 0991$ \\
\end{tabular} & [14:08:1909] & $02: 08 / 1909$ & 07101999 & Q.11:10997 & 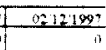 \\
\hline 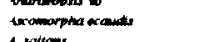 & & 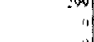 & , & 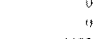 & & of & & 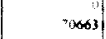 & 1020 & $\sin \mid$ & 100868 & iit & \\
\hline 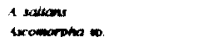 & & & & 11082 & 0.18 & 6012 & $8+18$ & $8+18$ & 65 & 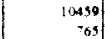 & t. & 930. & 1088 \\
\hline 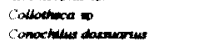 & & (0139\%" & 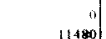 & 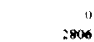 & 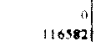 & and & 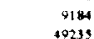 & 3 & 30 & . & 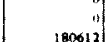 & (4) & 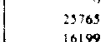 \\
\hline 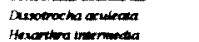 & & 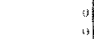 & . & " & & of & & o & & & o & : $: 2$ & 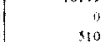 \\
\hline Hit inmertionests & & nva & (6122) & & & & & & & & . & of & $\begin{array}{l}100 \\
4+40\end{array}$ \\
\hline Hexporara $=0$ & & 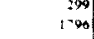 & 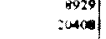 & & & of & & of & & & ? & : & $\begin{array}{l}510 \\
2100\end{array}$ \\
\hline 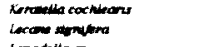 & & o:25? & 82163 & 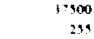 & 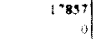 & "'s! & $=2933 \%$ & $=$ & 6378 & 60,33 & 16709 & {$[1399$} & 8 \\
\hline 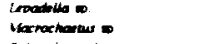 & & & 时 & 8 & 359 & & & & of & is & : & : & \\
\hline 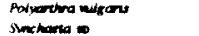 & & $14 \%$ & 1.86 & 1, 180 & 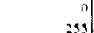 & 1049 & 215091 & satsent & 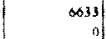 & $\mid \begin{array}{l}3001 \\
0\end{array}$ & :4003 & 6 & $\begin{array}{c}14031 \\
1: 3\end{array}$ \\
\hline 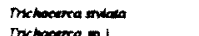 & & 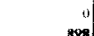 & of & 0 & 30 & . & : & a) & of & 0 & of & of & 10 \\
\hline 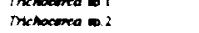 & & 20106 & 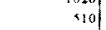 & 1911 & 10200 & $\infty$ & 29 & of & of & . & a) & ? & 3129 \\
\hline & & 3:93 & $20+1$ & (137? & 1.897 & 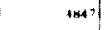 & & 1 & & & ) & iit & 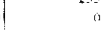 \\
\hline 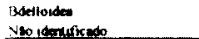 & & (w) & 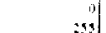 & & $+8+7$ & 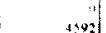 & 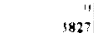 & $\begin{array}{cc}0 \\
26\end{array}$ & 80 & (3) & 1. & . & 7:19, \\
\hline 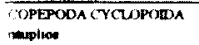 & & 3449 & 488781 & & $-8,3]$ & + & $1114 ;$ & 8.204 & $6: 45$ & $\$ 429$ & 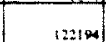 & thent & \\
\hline coposonos & & {$[483$} & $=+49$ & +18 & 年 & $\%$ & 9.92 & (390 & :as & 230 & $1=310$ & $+\infty \times 1$ & $: 312$ \\
\hline Survesone of & (m) & a) & y. & a & ? & of & 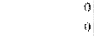 & of & of & & i] & d) & \\
\hline 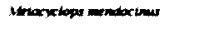 & (7) & . & a) & 8 & ) & of & 10 & {$[1,1]$} & o) & 9 & 0 & 1) & 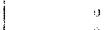 \\
\hline 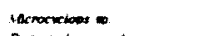 & $(F=\infty)$ & & & & 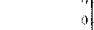 & ot & 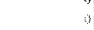 & -8 & & 10 & & & \\
\hline 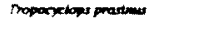 & $\underset{m}{M}$ & 象 & in: & $x_{100}$ & 济 & 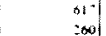 & $\therefore$ & 101 & 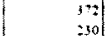 & 列 & 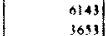 & answit & $\begin{array}{l}1041 \\
: 10\end{array}$ \\
\hline ОРPPODA CA ANOADA & If ow 2 & & $\pi \times 4$ & & $1: 2$ & 8. & & & -14 & & & . & $n$ \\
\hline Dos & & 10200 & : & $1000+1$ & 2000 & $\| m \mid$ & \$16 & 0.96 & 3244 & tomen & 3 & -999 & \\
\hline 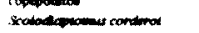 & (M) & $\infty$ & (184] & $11 \%$ & $\begin{array}{r}19,100 \\
309\end{array} \mid$ & 8326 & $\begin{array}{l}6939 \\
1031\end{array}$ & 8604 & 6336 & st69 & $20 \times 4$ & 1809 & 918 \\
\hline & (n) & 24 & 1122 & iss & 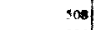 & 147 & 1286 & 2347 & $\infty$ & +39 & 311 & 208 & 48 \\
\hline TPFEPODA HARPACTKKOD & & & & & & & & & & & & & \\
\hline Nom & & : & : & i & o. & 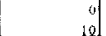 & : & : & : & {$\left[\begin{array}{r}10 \\
138\end{array}\right.$} & 3 & 8 & 20 \\
\hline ZnDocksh & & & 0 & & of & & & & & 4 & & & \\
\hline 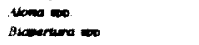 & & (1) & i) & : & & & 0 & ? & i & 10. & of & & . \\
\hline 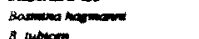 & & $2+6$ & $\therefore$ & 19 & 11 & $"$ & 102 & 31 & 291 & 13607 & $\infty$ & $\times 3]$ & 8 \\
\hline 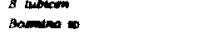 & & as! & 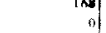 & 16 & isto & [1343] & ${ }^{3}$ & & & & d. & $\begin{array}{l}193 \\
0\end{array}$ & 19 \\
\hline 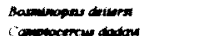 & & +1 & $\cos \mid$ & 4 & $: 34$ & s102: & "s? & $: 64$ & 26,200 & $4: 3633$ & 4918 & $1 \times 0$ & 1011 \\
\hline 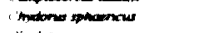 & & a) & 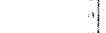 & 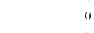 & 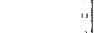 & of & . & 3 & ") & . & i) & 3 & 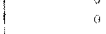 \\
\hline mans & & : & (⿻) & $\because$ & $1+4$ & | & 31 & $\cdots 306$ & $3+1$ & 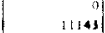 & ? & ;inol & 3 \\
\hline manest & & iil & 80,3 & $=028$ & {$[\mathrm{sen}]$} & $x+4$ & in:360? & $: 2: 100$ & is:49] & {$[+1]$} & .009 & (418) & $1: 2+2+20$ \\
\hline 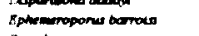 & & (I) & 4 & 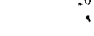 & ? & is & " & of & . & a & (1) & & \\
\hline 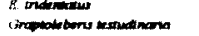 & & "." & 3 & ") & of & at & " & of & , & . & : & & \\
\hline 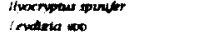 & & ". & of & $\because$ & : & 11 & & of & 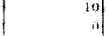 & (10.0 & in & & \\
\hline 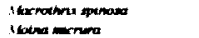 & & .) & if & " & (11) & :39. & 30 & 1.960 & 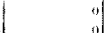 & . & H. & & \\
\hline & & & (5) & 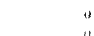 & & 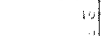 & & & 14) & $: 0$ & 10 & & \\
\hline 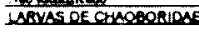 & & & & & & & & & & & $a 2$ & & \\
\hline
\end{tabular}

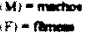

(F ivi-forem and 
TABELA 11 - Densidades numéricas $\left(\mathrm{n}^{\circ} \mathrm{org} / \mathrm{m}^{3}\right)$ de rotiferos e microcrustáceos, no lago das Ninféias de janeiro a dezembro de 1997.

\begin{tabular}{|c|c|c|c|c|c|c|c|c|c|c|c|c|c|}
\hline RUTTIFERA & & $1801 / 1997$ & $0302 / 1997$ & $03 / 03 / 1997$ & $07 / 04 / 1997$ & $05 / 05 / 1997$ & $02 / 06 / 1997$ & \begin{tabular}{|l|l|}
07071997 \\
\end{tabular} & $04 / 08 / 1997$ & $0109 / 1997$ & $06 / 10 / 1997$ & $03 / 11 / 1997$ & $01 / 121997$ \\
\hline Anuraecupsis fisso & & 5612 & 1474 & 310 & o) & 0 & 245 & 2211 & $\mid 380952$ & 1701 & 170 & 0 & 0 \\
\hline Collotheca sp. & & (1) & 0 & o) & 204 & of & 0 & 0 & 0 & i) & 170 & 0 & i) \\
\hline Colurello spo & & 11 & "1) & i) & 14) & 204 & .1) & i) & 2551 & (1) & 0 & 4) & ;) \\
\hline Conachilus dosnuarius & & $r \infty$ & $(80)$ & 2959 & $|+14490|$ & 12041 & 1) & of & , & 4 & 0) & 1) & $3 \times 1$ \\
\hline Diplouchionis propacula & & 14 & (1) & i) & 0 & 4 & o) & 1 & i) & 1) & 1.0 & a) & 100 \\
\hline Karatella cechlearss & & 2653 & 3855 & 1492 & 1834 & $\mid 24082$ & $\mid 13878$ & $8-95$ & $\mid 16258$ & 6633 & $1 \leqslant 31$ & 100 & $:$ \\
\hline Lecane bulla & & 0 & i) & of & 1) & a) & 11 & 1001 & of & i) & 0 & it & i) \\
\hline Li. cumcornus & & (1) & ") & 0) & 1020 & i) & (1) & of & i) & of & of & of & $a$ \\
\hline L. doryesa & & 0 & i. & a) & 0 & 1) & 245 & 1) & (i) & i) & o) & ol & a) \\
\hline L. Leontrina & & i) & if & (a) & 612 & o) & 0 & 01 & i) & of & 0 & 0] & 0 \\
\hline L. stgutifora & & 0 & 11) & 1) & 204 & 0 & 1) & 0 & (1) & 0 & o) & 0 & 0 \\
\hline Lecane upp. & & (1) & 1) & 102 & 204 & 612 & 0) & 0 & o) & 0 & 0 & o) & 0 \\
\hline Lepadella paselia & & (1) & 227 & 0 & of & 0 & 0 & o) & i) & 0 & 0 & a) & 0 \\
\hline Lepadella no. & & t) & 0 & 1) & 0 & of & 0 & of & 850 & 0 & 0 & of & 0 \\
\hline Manfredicom oudactplosts & & b) & (1) & 0 & 0 & 0 & 0 & of & of & of & of & 85 & 0 \\
\hline Monommate up. & & of & f) & 1) & D) & 0 & 0 & 100 & 0 & 170 & 0 & o) & 0 \\
\hline Polvarthra milgaris & & 20510 & $|6204|$ & 8674 & 11837 & 33674 & 332571 & 100170 & 207483 & 55102 & 14116 & $|616|$ & $10: 0$ \\
\hline Sinantherina ep. & & c) & i) & 102 & 1)] & 0 & (1) & 0 & 1) & o) & 0 & of & 0 \\
\hline Trichocerco of bidens & & a) & () & 0) & 204 & 0 & i) & 0 & of & o) & 0 & of & 1) \\
\hline T. gracilis & & 162 & o) & o) & a) & of & 0 & 0 & of & 0 & 0 & 0 & 0 \\
\hline Trichocerea ip. 1 & & 1531 & 5556 & 1735 & 1837 & 408 & 0 & 0 & o) & of & o) & of & 0 \\
\hline Trichocerea sp. 2 & & 2551 & 5556 & 108 & 408 & 1837 & 1) & 0) & 0 & 0 & 0) & 0 & 340 \\
\hline Trichocurce nop. & & 24.49 & $124: 2$ & 510 & 012 & o) & a) & 0 & of & 1) & 0 & i) & if \\
\hline Butellordea & & 11 & 11 & 0) & 1429 & i) & (1) & 50 & 4 & i) & a & 85 & n) \\
\hline Văo sdentuficedo & & 1633 & 180 & $\because \leqslant 5$ & 3877 & 633 & $\mid+469$ & 510 & 3401 & 5951 & 482 & 255 & 1100 \\
\hline \multicolumn{14}{|l|}{ COPEPODA CYCLOPOIDA } \\
\hline nauplico & & 836 & 2494 & 2449 & to2 7 & 8109 & $9|43|$ & 2326 & 2517 & 2531 & 1578 & 782 & $!^{-7}$ \\
\hline copepoditoe & & 326 & 688 & 2340 & 571 & 4517 & +411 & 320 & 119 & 694 & 449 & 789 & 119 \\
\hline \multirow[t]{2}{*}{ Encrelops op } & $\because$ & in & of & 0 & (1) & of & $\theta$ & 3 & (日) & a) & of & 9 & "1 \\
\hline & - & if & in & of & a) & a) & (4) & 3 & (1) & 0) & in & i) & (1) \\
\hline Macrocyelops up. & & -1 & i) & of & 0 & o) & 0 & (1) & f) & (1) & 0) & iof & is \\
\hline \multirow[t]{3}{*}{ Tropacociops prasinus } & $\because$ & 1,7 & 306 & 228 & 381 & 2667 & 286 & $2=$ & 34 & $|36|$ & 286 & 17 & $n$ \\
\hline & $\therefore$ & 4 & 91 & 24 & 54 & 381 & 57 & o) & 1) & 48 & $4 t$ & 17 & 3 \\
\hline & 1 & if & 45 & 1 & 14 & $=2$ & 24 & 14 & o) & 14 & 0) & 10 & 0 \\
\hline \multicolumn{14}{|l|}{ COPEPODA CALANODA } \\
\hline neuphion & & 435 & $3 \div 49$ & 9197 & 13823 & 13224 & 42449 & 14122 & 4109 & $\mid 4748$ & $\mid 4803$ & 6939 & 482 \\
\hline copepoditor & & $\mid 50$ & 234 & 636 & 5252 & 3483 & 8229 & 993 & 1034 & 993 & 2435 & 558 & 333 \\
\hline \multirow{3}{*}{ Scolodiaptomus corderot } & $\because$ & 14 & 60 & 190 & 1374 & 578 & 2922 & 61. & 37 & 347 & .5 & 34 & 136 \\
\hline & $=$ & 20 & 45 & 85 & 898 & 320 & 980 & 1": & 3 & $1+7 \mid$ & -5 & 20 & 61 \\
\hline & $\because \quad \cdots$ & 4 & 23. & 48 & 980 & 17 & 539 & $=21$ & 3 & 109 & 14 & 14 & E \\
\hline \multirow{3}{*}{$\begin{array}{l}\text { COPEPODA HARPACTICOIDA } \\
\text { nauplion } \\
\text { Nao idenuficado }\end{array}$} & & & & & & & & & & & & & \\
\hline & & (1) & 0) & 0 & 0 & of & 0 & 0 & a) & 116 & ol & o) & 0 \\
\hline & & 0 & t) & (a) & of & of & (i) & 14 & of & of & 0 & i) & 0 \\
\hline \multicolumn{14}{|l|}{ CLADOCERA } \\
\hline Alona guntala & & 0 & 0 & 0 & 7 & 0 & 65: & 218 & -5 & 54 & 14 & 0 & 0 \\
\hline 1. monecranthe & & (1) & 0 & of & 0 & 0 & 0 & 190 & 20 & 0 & (1) & 0 & - \\
\hline flone & & a & 0 & 0 & ) & 0 & 8 & 54 & 14 & 89 & 48 & $10 \mid$ & 3 \\
\hline Sirapertura epp. & & il & of & 0 & 1) & a) & a) & b) & - & 108 & 34 & 13 & $\therefore$ \\
\hline Bosminopsis destersi & & 10 & $3+n$ & 31 & 3388 & $\approx 231$ & 5 & o) & i) & 1 & 3483 & $6 \infty 67$ & $\because 2$ \\
\hline ¿amplacercul dadayn & & 11) & $\because$ & a & 1) & 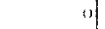 & (1) & $2=1$ & 3 & 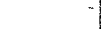 & 0) & 11 & $\because$ \\
\hline Chydonus pubescens & & i) & 8 & of & 1) & 0 & 1) & i) & 1) & , & a) & (9) & $" 1$ \\
\hline$\therefore$ sphaerices & & 11. & 8 & 1) & $=$ & 0) & (1) & 54 & 11) & 1)! & 7 & 0 & () \\
\hline 'hudons no. & & 7 & (1) & 3 & 0 & (1) & (日) & 0 & (1) & vi & (1) & of & $"$ \\
\hline Daphnia ambigua & & n & of & 3 & 116 & 10286 & $1: 212$ & 3 & 1) & 1) & 0) & 0 & 3 \\
\hline Draphanosoma ap. & & i) & 11) & 9) & 18 & 14 & in) & i) & 11) & "1 & (3) & 9) & " \\
\hline Disparalona dodayn & & + & 15) & 7 & -1 & 54 & $|63|$ & 653 & 218 & 816 & 48 & $3:$ & [is \\
\hline Ephemeroporws barroist & & in & " & 0 & 0 & (1) & 8 & (1) & if & of & (1) & if & $\because$ \\
\hline E. tndentafur & & 0 & (1) & 0 & 7 & a) & $16)$ & o) & 1 & t. & 1) & of & is \\
\hline Alrocryptus spinifor & & i) & i) & o) & 201 & $=7$ & $8 \mid$ & (9) & 3 & ) & -1 & 1) & $o$ \\
\hline Macrothrix laticomus & & it & .1 & (1) & & is & 81 & . & 1) & i) & a) & 1) & $\therefore$ \\
\hline 14. spimasa & & 11) & 1) & $\theta$ & 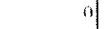 & 2 & 24 & 599 & 11 & $\ln 9$ & 54 & 3 & 0 \\
\hline Macrothrix ap & & - & 0 & 0 & 0 & a) & 0 & 0 & 0 & i) & 0 & o) & $\theta$ \\
\hline Moina micrura & & 11 & $\$$ & f) & a) & (1) & $\because$ & (1) & 1:) & i) & 9 & i) & $\therefore$ \\
\hline Hoina ip & & 11) & 8 & d) & 0 & 0 & a) & (1) & 11 & $"$ & (1) & ") & " \\
\hline Thydorideo & & 1 & 11. & a) & 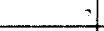 & (1) & i) & a) & 14 & 1.13 & 0 & o] & II \\
\hline LARVAS DE CHAOBORIDAI: & & 396 & 378 & 1031 & 245 & 204 & 49 & o & 3 & 74 & 271 & 425 & 187 \\
\hline
\end{tabular}

(3) - mechoo

if $r=$ ferneas

if ov $1=$ femen ovade 
TABELA 12 - Densidades numéricas $\left(\mathrm{n}^{\circ} \mathrm{org} / \mathrm{m}^{3}\right)$ de rotíferos, no lago das Garças de janeiro a dezembro de 1997.

\begin{tabular}{|c|c|c|c|c|c|c|c|c|c|c|c|c|}
\hline ROTIFERA & $09 / 01 / 1997$ & $05 / 02 / 1997$ & $05 / 03 / 1997$ & $09 / 04 / 1997$ & \begin{tabular}{|l|}
$07 / 05 / 1997$ \\
\end{tabular} & $04 / 06 / 1997$ & \begin{tabular}{|l|}
$09 / 07 / 1997$ \\
\end{tabular} & $06 / 08 / 1997$ & $03 / 09 / 1997$ & $08 / 10 / 1997$ & $05 / 11 / 1997$ & $03 / 12 / 1997$ \\
\hline Amuroeopsis fissa & 255 & 16071 & 529337 & 340561 & 979592 & 3826 & 6378 & 1020 & 1493 & 31122 & 510 & 16582 \\
\hline Asplanchna ginodt & 0 & 0 & 0 & 0 & 0 & 0 & 6378 & 0 & 0 & 0 & 0 & 0 \\
\hline Brachionus angulars & 0 & 0 & 0 & 0 & 0 & 0 & 0 & 1020 & 498 & 1020 & 0 & 510 \\
\hline$B$ a budens & 7143 & 0 & 2551 & 0 & 21684 & $9 \mid 837$ & 22959 & 0 & 0 & 0 & 0 & 5357 \\
\hline B a chelons & 11735 & 3061 & 705357 & 368622 & 1276 & 0 & 0 & 0 & 0 & 0 & 3061 & 13265 \\
\hline$B$ budentato & 255 & 0 & 0 & 0 & 0 & 0 & 0 & 0 & 0 & 0 & 0 & 0 \\
\hline B. calyeflorus & 0 & 0 & 0 & 0 & 0 & 0 & 0 & 2551 & 4978 & 0 & 0 & 0 \\
\hline B. condatus & 0 & 5357 & 10204 & 0 & 3826 & 0 & 0 & o) & 0 & 0 & 0 & 0 \\
\hline B falcarus & 11735 & 0 & 0 & 15306 & 2551 & $\mid 2245$ & 0 & 0 & 0 & 0 & 0 & 510 \\
\hline$B$ minus & 0 & 0 & 0 & 0 & 0 & 0 & 0 & 0 & 0 & 510 & 0 & $\$ 10$ \\
\hline Brachionus spp. & 0 & 765 & 3826 & 0 & 0 & 0 & o) & 0 & 0 & 0 & 510 & 1276 \\
\hline (ephaliodella catellimo & 0 & 0 & 0 & 17857 & 17857 & 0 & 0 & 510 & 498 & 1020 & 7653 & 0 \\
\hline Cephalodella sp. & o) & 3061 & 0 & 0 & 0 & 0 & 0) & 0 & 0 & 0 & 0 & 0 \\
\hline Collocheca spp. & 2806 & 0 & 0 & 0 & 6378 & 112500 & 24235 & 17347 & 1493 & 7653 & 8674 & 510 \\
\hline Colunelia sp. & 0 & 0 & 0 & 0 & 0 & & 0 & 0 & 0 & 510 & 0 & 255 \\
\hline Conachilus dossuarius & $\theta$ & 3826 & 3826 & 16582 & 31888 & 44388 & 28061 & $\mid 5816$ & 3982 & 2041 & 0 & 3061 \\
\hline ( wenicomis & 0 & 0 & 0 & 0 & 0 & 0 & 0 & 204082 & 0 & 0 & 0 & 0 \\
\hline Comochulus spp. & 0 & 0 & 0 & & 0 & 0 & 0 & 2551 & 0 & 0 & 0 & 0 \\
\hline Euchlonks dilauta & 0 & 0 & 0) & 0 & 0 & 0 & 0 & 0 & 0 & 510 & 0 & 0 \\
\hline Filunia opoliensis & 0 & 0 & 0 & 10204 & 52296 & 79592 & 8929 & 10714 & 187696 & 179592 & 6633 & 14541 \\
\hline Fiterminals & o) & $0)$ & 0 & o) & 0 & 0 & of & 0 & 0 & 0 & 1020 & 255 \\
\hline Hexarthra mira & 259 & 13010 & 0 & 2551 & 0 & 0 & 0 & 0 & 0 & 0 & 0 & 0 \\
\hline Keratella amencona & 78571 & 141582 & 1276 & 1276 & 8929 & 22194 & 24235 & 0 & 498 & 8674 & 65816 & 1786 \\
\hline K. cochleans & 0 & 7653 & 0 & 63776 & 59949 & 109439 & 386480 & 34694 & 10453 & 37755 & 31122 & 50765 \\
\hline K. lecta & 2806 & 14541 & 2551 & 25510 & 38265 & 39031 & 150510 & 179592 & 149826 & 225510 & 29592 & 1020 \\
\hline K. tropica & 15561 & 2296 & 6378 & $|4031|$ & 38265 & 189031 & 251276 & 34694 & 196118 & 30612 & 13265 & 3826 \\
\hline Kenatella spp. & 510 & 0 & 0 & 1276 & 0 & 5357 & 43367 & 2551 & 41812 & 41326 & 67347 & 8929 \\
\hline Lecone bulla & 0 & 0 & 0 & 0 & 0 & 0 & 0 & 0 & 0 & 1020 & 1531 & 0 \\
\hline 1. curvicomis & 0 & 0 & 0 & 이 & 0 & 0 & of & 0 & 0 & 0 & 510 & 0 \\
\hline Lecane $\mathbf{s p}$ & 0 & 0 & 0 & 0 & 0 & 0 & 0 & 0 & 498 & 0 & 0 & 0 \\
\hline Manfredium eudocrylora & 0 & 0 & 0 & 0 & 0 & 0 & ol & 0 & $a$ & 510 & 0 & 0 \\
\hline Mvenima besuicata & 0 & 0 & 1276 & 0 & 0 & 0 & 0 & 0 & 0 & 0 & 0 & 0 \\
\hline Polvarthra vulgarts & 6633 & 61224 & 28061 & 308674 & 201531 & 120918 & 85459 & 236224 & 19413 & 0 & 0 & 255 \\
\hline Poluanthra SD. & 0 & & 0 & 0 & 0 & 0 & 0 & 0 & 0 & 531633 & 144898 & 7908 \\
\hline Sinchacta pectunata & 0 & 22194 & 2591 & -653 & 0 & 6122 & 0 & 139796 & 1493 & 0 & 0 & 0 \\
\hline Sinchoeta $\$ p$ & 0) & 0 & 0 & 17857 & 10204 & 54337 & 12755 & o] & 498 & 9184 & 0 & 0 \\
\hline Thenocerca grocils & 0 & 3061 & 12755 & .653 & 7653 & 0 & o) & 0 & 0 & 0 & 0 & 0 \\
\hline I sf mus & 0 & 0 & 0 & 1276 & 0 & 0 & 0 & 0 & 0 & 0 & 0 & 0 \\
\hline l pusilla & 510 & 6122 & 2591 & $14031 \mid$ & 56122 & 2296 & 2551 & 0 & 0 & 4082 & 12245 & 0 \\
\hline$T$ sumths & 1020 & 6122 & 3826 & 5102 & 1276 & 9184 & 5102 & 8674 & $\$ 978$ & 12245 & 28061 & 0 \\
\hline Irichocera $\mathrm{spp}$ & 255 & 0 & 24235 & 12755 & 73980 & 4592 & 2551 & 510 & 996 & 4992 & 4082 & 0 \\
\hline Bdellordea & 765 & 5397 & 1276 & 0 & 2551 & 765 & 0 & 0 & 8462 & 2041 & 0 & 510 \\
\hline Nolo identificado & 259 & 2296 & 16582 & 8929 & 36990 & 3826 & 21684 & 1531 & 2489 & 6122 & 5102 & 2806 \\
\hline
\end{tabular}


TABELA 13 - Densidades numéricas $\left(\mathrm{n}^{\circ} \mathrm{org} / \mathrm{m}^{3}\right)$ de microcrustáceos, no lago das Garças de janeiro a dezembro de 1997.

\begin{tabular}{|c|c|c|c|c|c|c|c|c|c|c|c|c|c|}
\hline COPEPODA CYCLOPOIDA & & $09 / 01 / 1997$ & $05 / 02 / 1997$ & $05 / 03 / 1997$ & $09 /(04 / 1997$ & $07 / 05 / 1997$ & $04 / 06 / 1997$ & $009 / 07 / 1997$ & $0608 / 1997$ & $03 / 09 / 1997$ & 08/10/1997| & \begin{tabular}{|l|}
$05 / 11 / 1997$ \\
\end{tabular} & $03 / 12 / 1997$ \\
\hline nauplios & & 37551 & 17269 & 21143 & 729765 & 145408 & $\mid 69133$ & 477040 & 139286 & 496267 & 54209 & 124235 & $\$ 418$ \\
\hline copepoditos & & 9184 & 19061 & 1608 & 7837 & 107908 & 59265 & 107781 & 17857 & 34943 & 39372 & 28997 & 439 \\
\hline \multirow[t]{3}{*}{ liucxiops psewdoenstifer } & (M) & $0)$ & & 0 & 0 & 0 & of & 6) & of & 40 & 0 & 0 & 0 \\
\hline & (F) & a) & 0 & 0 & of & o. & of & 20 & ol & o) & 0 & of & 0 \\
\hline & (Fov.) & 0 & o) & o) & o) & 0 & o) & 5 & 0 & 0 & 0 & 0 & 0 \\
\hline \multirow[t]{2}{*}{ Hesocyciops ionytsenus } & (M) & 0 & 0 & 5 & of & o) & 61 & 20 & 0 & ol & 0 & 0 & 0 \\
\hline & (F) & 0 & 0 & 0 & 5 & 0 & 20 & 10 & o & 5 & 0 & 0 & 5 \\
\hline \multirow[t]{3}{*}{ Metaky<lops mendocumes } & (M) & +1 & 346 & 0 & 332 & 01 & 837 & 1724 & 684 & 338 & 269 & 1168 & 311 \\
\hline & (f) & 20 & 199 & 0 & 87 & 26 & 497 & 1214 & $\mid 48$ & 249 & 980 & 633 & 76 \\
\hline & (F ov.) & 5 & 219 & 0 & 112 & 51] & 1068 & 918 & 281 & 110 & 1071 & 862 & 276 \\
\hline Micmaculops sp & (M) & 0 & 0) & 0 & o] & 0 & 0 & 5 & 0 & 0 & 0 & 0 & 0 \\
\hline \multirow[t]{3}{*}{ Thermocyciops decipiens } & (M) & 1602 & 255 & 0 & 898 & 1031 & 714 & 449 & 199 & 1224 & 1367 & 17918 & 102 \\
\hline & (F) & 505 & 143 & 0 & 3214 & 505 & 1265 & 1245 & 174 & 936 & 1347 & 6000 & 224 \\
\hline & (Fov) & 158 & 107 & 0 & 980 & 315 & 605 & 537 & 76 & 110 & 398 & 2571 & 189 \\
\hline \multirow[t]{3}{*}{ Tropocyciops prasimus } & (M) & 444 & 2321 & 143 & 6939 & $\$ 612$ & 14898 & 36531 & 10816 & $13121 \mid$ & 1439 & 286 & 0 \\
\hline & (F) & 194 & 434 & 31 & 3674 & 1786 & 4653 & 19143 & $\mid 388$ & 2400 & 510 & 321 & 0 \\
\hline & (Fov) & 97. & 224] & 36) & 2980 & 2612 & 6000 & 14490 & 1122 & 2429 & 245 & 260 & 0 \\
\hline \multirow{3}{*}{$\begin{array}{l}\text { COPEPODA CALANOIDA } \\
\text { copepoditos } \\
\text { Solochaptomas conderoi }\end{array}$} & & & ;3) & 10 & o & & $61]$ & 5 & & $3|9|$ & 66 & 4) & \\
\hline & (M) & 0 & : & $\begin{array}{r}10 \\
0\end{array}$ & $\begin{array}{r}0 \\
0\end{array}$ & $\begin{array}{r}82 \\
9\end{array}$ & $\begin{array}{l}61 \\
51\end{array}$ & $\begin{array}{r}5 \\
10\end{array}$ & 5 & $\begin{array}{l}319 \\
134\end{array}$ & $\begin{array}{l}66 \\
97\end{array}$ & 31 & $\begin{array}{l}3 \\
0\end{array}$ \\
\hline & (F) & (1) & 5 & a) & 1) & 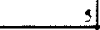 & 15 & 0 & 5) & 44 & 15) & 3i) & 0 \\
\hline \multirow{2}{*}{$\begin{array}{l}\text { COPEPODA HARPACTICOIDA } \\
\text { nduplios } \\
\text { Nlo identificado }\end{array}$} & & o] & 0 & of & 0 & 0 & of & 26 & 0 & 15 & 5 & 0 & 0 \\
\hline & & o) & 0 & 0 & ol & 0 & 0 & 0 & o. & 0 & s) & 0 & 0 \\
\hline \multicolumn{14}{|l|}{ CLADOCERA } \\
\hline Aloma guntrata & & 0 & 0 & 0 & 0 & 0 & 0 & 10 & 0 & 0 & 0 & 0 & 0 \\
\hline A. monacantina & & of & 0 & 0 & 0 & 0 & 0 & 0 & 0 & 0 & 5 & (1) & 0 \\
\hline Aloma $4 \mathrm{p}$ & & 0 & 0 & 0 & 0 & 0 & 0 & 0 & 9 & 0 & 0 & 0 & 0 \\
\hline Blaperiuma spp & & 9 & 0 & 0 & 0 & 0 & 5 & of & ㅁ) & 0 & 0 & 0 & 0 \\
\hline Bosmina mgmom & & of & 5 & 0 & 41 & 61 & 92 & 36 & 148 & 498 & 704 & 5 & 0 \\
\hline B. mabicen & & 0 & 0 & 0 & 143 & 97 & 26 & o] & 0 & o] & 41 & 0) & 0 \\
\hline Bosmina no. & & 0 & 0 & 0 & 5 & 0 & s) & 0 & 0 & 30 & 0 & 0 & 0 \\
\hline Bosmimopses detiens & & 0 & 0 & 0 & 0 & 62 & 201 & of & of & 10274 & 1582 & 31 & 5 \\
\hline Compurencess dodont & & 0 & 0 & 0 & 0 & 0 & 5 & 0 & 요 & $s$ & 0 & 0 & 0 \\
\hline Cenadaphrua comula comuta & & 0 & 0 & 0 & 0 & 0 & 0 & 5 & o) & o) & of & 0 & 0 \\
\hline C. c. mgande & & 0 & 0 & 0 & 0 & 0 & 0 & o) & 0 & 5 & o] & of & 0 \\
\hline C. cf renculora & & 0 & 0 & 0 & 0 & 0 & o) & 0 & of & 0 & 15 & 9102 & 92 \\
\hline Chydorw pubescen & & 0 & 0 & 0 & 0 & 0 & 0 & 10 & 0 & 0 & 0 & of & 0 \\
\hline C. of sprocencus & & 0 & 0 & 0 & 0 & 0 & 0 & 153 & 10 & 20 & 0 & 5 & 0 \\
\hline Chydons spp. & & 0 & 0 & 0 & 0 & of & of & 10 & 0 & 55 & 0 & 0 & 0 \\
\hline Daphnia ambirsa & & 0 & 0 & 0 & 184 & 429 & 3000 & 11714 & 1388 & $1 \mid 45$ & 776 & 566 & 372 \\
\hline D. gessmen & & o & 0 & 0 & 14633 & 10612 & 9531 & 13959 & 214 & 164 & 20 & 14082 & 1510 \\
\hline Daphosua sp (fovem) & & of & $\infty 6$ & 269 & 5163 & 2235 & 993 & 1929 & 0 & 0 & $s \mid$ & 163 & 41 \\
\hline Diaphemasoma burget & & 0 & 0 & 10 & 46 & 76 & 1015 & $\$ 786$ & 13306 & 13021 & 276 & 0 & 0 \\
\hline Diaphemasoms ap & & of & c) & of & o. & 0 & is) & 0 & 0 & 0 & of & of & 9 \\
\hline Oispanaiono dadont & & 0 & o) & 0 & o) & 0 & 5 & 36 & 26 & 35 & 20 & 5 & 5 \\
\hline thecroptus spinfer & & 0 & of & 5 & 0 & 10 & 26 & 36 & 28 & 29 & 0 & o) & 0 \\
\hline Macrothrux spinosa & & 0) & .1) & 0 & 0 & 0 & 5 & 0 & 56 & 10 & 5 & 0 & ; \\
\hline Macrothrs sp. & & 0 & of & 0 & 0 & 0 & 5 & 0 & 31 & 0 & 0 & 0 & 0 \\
\hline Moma micruna & & 0 & of & 5 & 15 & 71) & $10 \times 1$ & 112 & 10 & 0 & 102 & 252 & $s$ \\
\hline M. mimuta & & 0 & 0 & 0 & 10 & 41 & 174 & 0 & 0 & 5 & 31 & 36 & 0 \\
\hline Moma $\mathrm{sp}$. & & 0 & of & 0 & o) & 148 & 378 & 10 & 0 & 0 & 112 & t.6 & 0 \\
\hline Simacephalus sp & & o) & 0 & 0 & 0 & 0 & 0 & o) & 0 & 0 & of & 5 & 0 \\
\hline Chydondue & & 0 & 0 & 0) & 0 & 0 & 0 & 20 & 41 & 40 & of & of & 0 \\
\hline Cledocera jovem & & 19 & 0 & 5 & 10 & 0 & 15 & 0 & 0 & $0)$ & of & of & 0 \\
\hline No identificado & & 5 & o] & o & o] & 0 & 0 & o. & 0 & 48 & of & o) & 0 \\
\hline LARVAS DE CHAOBORIDAE & & 153 & 168 & 107 & 485 & 269 & 184 & 138 & 411 & 458 & \begin{tabular}{|l|l|}
776 \\
\end{tabular} & 79 & 883 \\
\hline
\end{tabular}


TABELA 14 - Valores mensais de diversidade (bits/ind) e diversidade média (H' média), nos lagos do IAG, das Ninféias e Garças de janeiro a dezembro de 1997

\begin{tabular}{l|c|c|c}
\hline DIVERSIDADE & LAGO DO IAG & LAGO DAS NINFÉIAS & LAGO DAS GARCุAS \\
\hline JANEIRO & 2,39 & 2,81 & 2,81 \\
FEVEREIRO & 3,01 & 3,12 & 3,17 \\
MARÇO & 2,94 & 1,90 & 1,74 \\
ABRIL & 2,31 & 1,79 & 2,90 \\
MAIO & 2,83 & 2,31 & 2,86 \\
JUNHO & 2,46 & 1,63 & 3,79 \\
JULHO & 3,07 & 1,64 & 3,25 \\
AGOSTO & 3,15 & 1,02 & 3,14 \\
SETEMBRO & 2,75 & 2,00 & 2,71 \\
OUTUBRO & 2,07 & 2,53 & 2,78 \\
NOVEMBRO & 2,89 & 2,21 & 3,56 \\
DEZEMBRO & 2,80 & 2,76 & 3,30 \\
\hline H' MEDIA & 2,72 & 2.14 & 3,00 \\
\hline
\end{tabular}


TABELA 15 - Valores mensais de equitatividade e equitatividade média (E média), nos lagos do IAG, das Ninféias e Garças de janeiro a dezembro de 1997.

\begin{tabular}{l|c|c|c}
\hline EQUITATIVIDADE & LAGO DO IAG & LAGO DAS NINFÉIAS & LAGO DAS GARÇAS \\
\hline JANEIRO & 0,54 & 0,65 & 0,60 \\
FEVEREIRO & 0,66 & 0,71 & 0,67 \\
MARÇO & 0,65 & 0,44 & 0,36 \\
ABRIL & 0,48 & 0,36 & 0,55 \\
MAIO & 0,59 & 0,53 & 0,54 \\
JUNHO & 0,53 & 0,37 & 0,69 \\
JULHO & 0,65 & 0,36 & 0,60 \\
AGOSTO & 0,71 & 0,22 & 0,60 \\
SETEMBRO & 0,57 & 0,46 & 0,49 \\
OUTUBRO & 0,44 & 0,59 & 0,50 \\
NOVEMBRO & 0,64 & 0,55 & 0,68 \\
DEZEMBRO & 0,57 & 0,68 & 0,65 \\
\hline E MEDIA & 0,59 & 0,49 & 0,58 \\
\hline
\end{tabular}


TABELA 16 - Valores mensais de riqueza e riqueza média ( $\mathrm{S}$ média), nos lagos do IAG, das Ninféias e Garças de janeiro a dezembro de 1997.

\begin{tabular}{l|c|c|c}
\hline RIQUEZA & LAGO DO IAG & LAGO DAS NINFEIAS & LAGO DAS GARÇAS \\
\hline Janeiro & 22 & 20 & 25 \\
Fevereiro & 24 & 21 & 26 \\
Março & 23 & 20 & 28 \\
Abril & 29 & 30 & 38 \\
Maio & 27 & 21 & 39 \\
Junho & 25 & 21 & 46 \\
Julho & 26 & 24 & 43 \\
Agosto & 22 & 23 & 37 \\
Setembro & 29 & 20 & 46 \\
Outubro & 26 & 20 & 46 \\
Novembro & 23 & 16 & 38 \\
Dezembro & 30 & 21 & 34 \\
\hline S MEDIA & 26 & 17 & 37 \\
\hline
\end{tabular}


TABELA 17 - Correlações das variáveis fĩsicas, químicas e biológicas $(\mathrm{n}=36$ ) com os eixos 1 e 2.

\begin{tabular}{l|cc}
\hline \multirow{2}{*}{ Variáveis } & \multicolumn{2}{|c}{ Componentes principais } \\
\cline { 2 - 3 } & \multicolumn{1}{|c}{1} & 2 \\
\hline Clorofila $a$ total (Clor) & $\mathbf{- 0 , 8 9 0}$ & 0,130 \\
Condutividade elétrica (CE) & $\mathbf{- 0 , 9 5 2}$ & $-0,004$ \\
Fósforo total (Ptot) & $\mathbf{- 0 , 9 3 4}$ & 0,168 \\
Oxigênio dissolvido (OD) & 0,303 & $\mathbf{0 , 7 6 7}$ \\
pH & $\mathbf{- 0 , 8 9 8}$ & 0,121 \\
Profundidade (Prof) & $-0,277$ & $\mathbf{0 , 8 0 7}$ \\
Nitrogênio total (Ntot) & $\mathbf{- 0 , 6 4 9}$ & 0,089 \\
Sólidos totais em suspensão (STS) & $\mathbf{- 0 , 6 9 4}$ & $-0,438$ \\
Transparência da água (Tran) & $\mathbf{0 , 9 0 3}$ & 0,032 \\
Turbidez (Turb) & $\mathbf{- 0 , 8 7 0}$ & $-0,109$ \\
\hline Variância explicada & $60,2 \%$ & $15,1 \%$ \\
\hline
\end{tabular}


TABELA 18 - Correlações das densidades numéricas dos táxons da comunidade zooplanctônica $(n=36)$ com os eixos 1 e 2 .

\begin{tabular}{l|cc}
\hline & \multicolumn{2}{|c}{ Componentes principais } \\
\cline { 2 - 3 } Táxons & 1 & 2 \\
\hline Anuraeopsis fissa (Afis) & $\mathbf{- 0 , 7 1 6}$ & 0,420 \\
Ascomorpha spp. (Asco) & 0,484 & $\mathbf{- 0 , 6 0 9}$ \\
Bosmina hagmanni (Bhag) & $-0,112$ & $\mathbf{- 0 , 8 8 3}$ \\
Bosminopsis deitersi (Bdei) & $\mathbf{0 , 6 0 1}$ & $-0,476$ \\
Brachionus angularis chelonis (Banc) & $\mathbf{- 0 , 6 3 9}$ & 0,364 \\
Conochilus dossuarius (Cdos) & 0,006 & $\mathbf{- 0 , 6 5 6}$ \\
Copepoditos de calanóides (coCa) & $\mathbf{0 , 8 7 4}$ & $-0,347$ \\
Copepoditos de ciclopóides (coCy) & $\mathbf{- 0 , 8 1 8}$ & $-0,354$ \\
Daphnia ambigua (Damb) & $-0,048$ & $\mathbf{- 0 , 8 4 8}$ \\
Daphnia gessneri (Dges) & $\mathbf{- 0 , 8 3 3}$ & $-0,206$ \\
Diaphanosoma birget (Dbir) & $-0,041$ & $\mathbf{- 0 , 8 7 7}$ \\
Keratella cochlearis (Kcoc) & $-0,079$ & $\mathbf{- 0 , 5 2 0}$ \\
Keratella tecta (Kcot) & $\mathbf{- 0 , 9 7 1}$ & $-0,098$ \\
Keratella tropica (Ktrop) & $\mathbf{- 0 , 9 7 2}$ & $-0,074$ \\
Metacyclops mendocinus (Mmen) & $\mathbf{- 0 , 8 7 8}$ & $-0,228$ \\
Náuplios de calanóides (naCa) & $\mathbf{0 , 9 5 5}$ & 0,002 \\
Náuplios de ciclopóides (naCy) & $\mathbf{- 0 , 7 4 7}$ & $\mathbf{- 0 , 5 4 0}$ \\
Scolodiaptomus corderoi (Scor) & $\mathbf{0 , 7 3 8}$ & $\mathbf{- 0 , 5 2 6}$ \\
Thermocyclops decipiens (Tdec) & $\mathbf{- 0 , 9 4 3}$ & $-0,100$ \\
Tropocyclops prasinus (Tpra) & $-0,379$ & $\mathbf{- 0 , 6 9 8}$ \\
\hline Variância explicada & $46,9 \%$ & $26,5 \%$ \\
\hline
\end{tabular}


TABELA 19 - Relação dos autores e ano de publicação dos estudos realizados nos corpos d'água das Unidades de Gerenciamento de Recursos Hídricos (UGRHI) do Estado de São São Paulo.

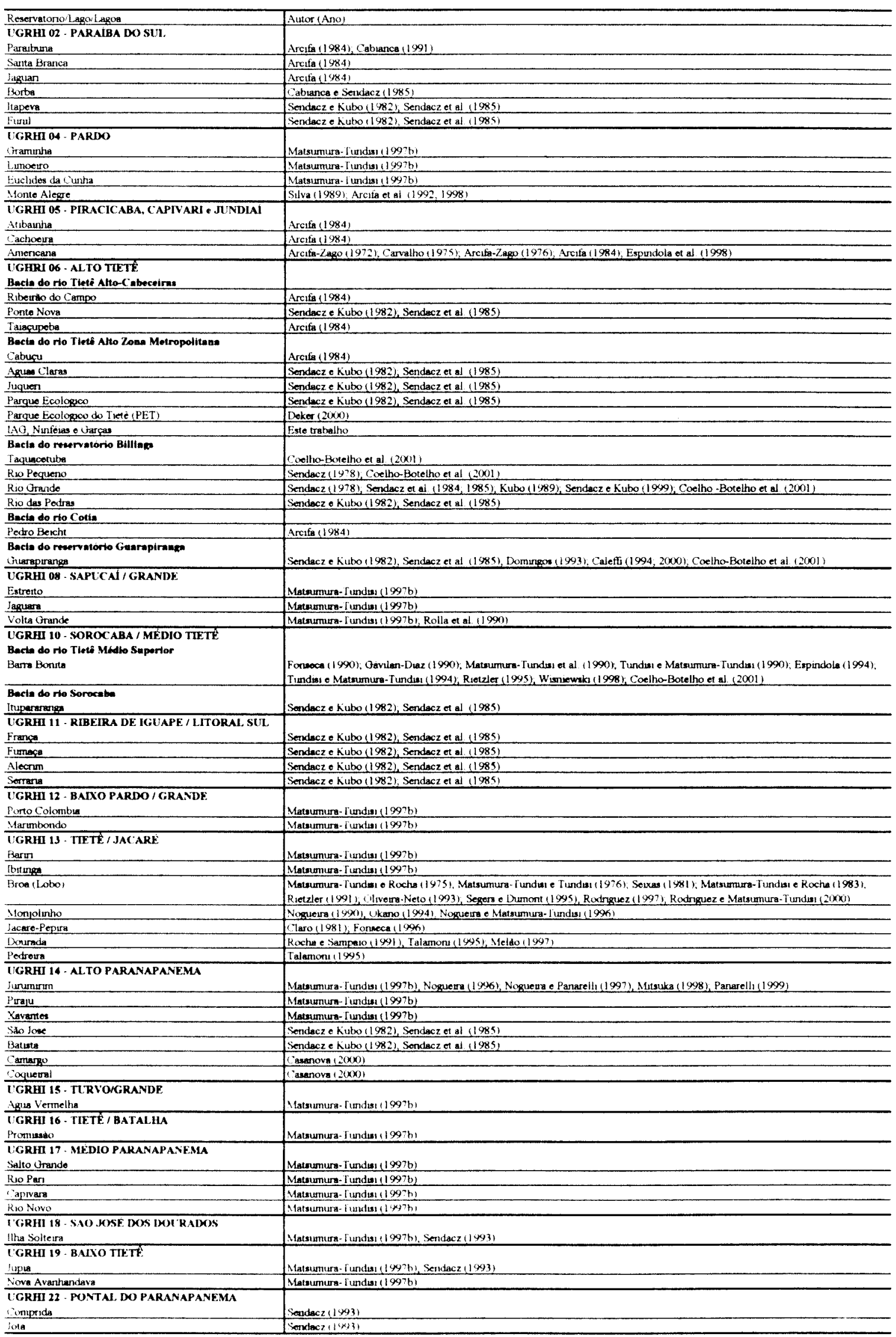


TABELA 20 - Ocorrência de rotiferos. média das concentrações de clorofila $a$ total $(\mu \mathrm{g} / \mathrm{L})$ e Indice de Estado Trófico (IET) de Carlson modificado, em cada corpo d'água, com o respectivo autor e epoca de estudo, por Unidade de Gerenciamento de Recursos Hidricos (UGRHI) do Estado de São Paulo

\begin{tabular}{|c|c|c|c|c|}
\hline topecos & Remonationo Legox Laso & Gorotib a $\left(\mu \mathrm{g}_{\mathrm{L}} \mathrm{L}\right.$ & $\mathrm{EET}$ & Autoren \\
\hline 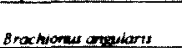 & $\begin{array}{l}\text { EGRHI O2 - PARALA DOO SLC } \\
\text { Punebera }\end{array}$ & $\therefore 0$ & ND & Cubuasa $(1 \infty \infty 1)$ \\
\hline Fithoopeliert & Parabums & $\therefore D$ & $\times D$ & Cabeenca $(1 \omega)\}$ \\
\hline 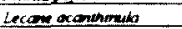 & Persabuan: & 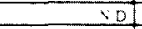 & $M D$ & Caberce: \\
\hline soulo & Permberne & 50 & $N D$ & Calrencen $\left(19 \log _{1}\right)$ \\
\hline Larroxorms & Parsabure & 50 & $\mathrm{ND}$ & Cobuenca $(1 \omega)$ \\
\hline Grontion & Perethere & $\times 0$ & $\triangle D$ & Cubronat $(190)$ \\
\hline i heother & Barabona: & SD & No & Cabanas $\left(\left|\omega_{1}\right|\right)$ \\
\hline$i$ ang & Parabung & 50 & $N D$ & Orbenca $(1091)$ \\
\hline i. hangris & Paratanua & SD & ND & Cobrangen $(19901)$ \\
\hline$\angle$ manounka & Penatense & . & ND & Cotansu(1)*11) \\
\hline Lof man & Parubuma & Sol & $\mathrm{ND}$ & Cabuasa $(1991)$ \\
\hline L worvicas & Perature & VD & $N D$ & Celvapan $(1 \omega)$ \\
\hline Testactimeilo potano & Parubuene & YOD & $\mathrm{ND}$ & Cobrence $(1991)$ \\
\hline$I_{\text {indenean }}$ & Parnberse & ND & $N D$ & Cothunge $(1091)$ \\
\hline 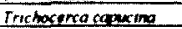 & Parribana & YD. & $\mathrm{ND}$ & Catanca (1vel) \\
\hline I chement & Parcibuate & ND & ND & Crbancal (1991) \\
\hline T poulo & Paraberna & जD & ND & Cabrence $(1901)$ \\
\hline$r$ simuls & Parabane & vo & $N D$ & 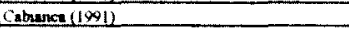 \\
\hline$I_{\text {snckeno }}$ & Peraberna & YD & ND & Cathers: (19091) \\
\hline Bnax maves dohborans & $\begin{array}{l}\text { UGRHI OA - PARDO } \\
\text { Mosto ANove }\end{array}$ & $\begin{array}{c}18,6 \\
40\end{array}$ & $\begin{array}{l}59,9 \\
90\end{array}$ & Sulva (1999) \\
\hline A fakcones & 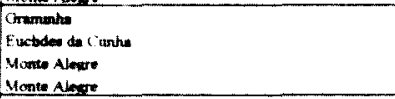 & $\begin{array}{r}7.7 \\
83 \\
8.6 \\
\times 0 \\
\end{array}$ & $\begin{array}{r}48,0 \\
36.5 \\
59,9 \\
\times D \\
\end{array}$ & 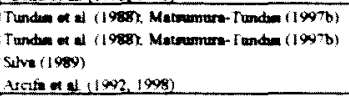 \\
\hline ollostrea muntils & $\begin{array}{l}\text { Monte Aleque } \\
\text { Mogite Nerge }\end{array}$ & $\begin{array}{l}86 \\
00 \\
0\end{array}$ & $\begin{array}{r}59,9 \\
\times 0 \\
\end{array}$ & $\begin{array}{l}\operatorname{sing}(1989) \\
\text { Axgiten al (1992, 1998) }\end{array}$ \\
\hline ampero comenso & Cremuntu & $5-3$ & 48,0 & 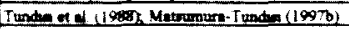 \\
\hline Conocheru coenobats & Orvonghe & 5 & 480 & 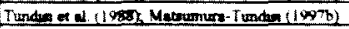 \\
\hline Cof dosenarner & $\begin{array}{l}\text { Monte Neore } \\
\text { Monte Negre }\end{array}$ & $\begin{array}{c}18.6 \\
\times 0\end{array}$ & 39,9 & 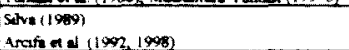 \\
\hline 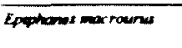 & Morte Aleven & $\begin{array}{c}\mid 8,6 \\
40\end{array}$ & $\begin{array}{l}59,9 \\
\text { ND }\end{array}$ & $\begin{array}{l}\text { Sulve (1909) } \\
\text { Arafin ot al (1992, 1998) }\end{array}$ \\
\hline Eucheos deflese & Euchdee de ourin & $\frac{8}{83}$ & 365 & 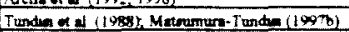 \\
\hline Fillimb longerseses & Eucbere de Cunie & 1.80 & $\begin{array}{l}36.5 \\
48,3\end{array}$ & 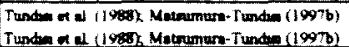 \\
\hline Hexorthra mbermectia & Monte Alepre & $\begin{array}{c}\mid 8.0 \\
\times 0\end{array}$ & $\begin{array}{l}99.9 \\
10\end{array}$ & Sidva (1989) \\
\hline H. Anzzitientis & Oremenha & -3 & 60 & 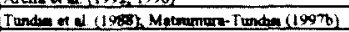 \\
\hline$H \min$ & Orementum & $\begin{array}{l}5,-3 \\
1.86\end{array}$ & $\begin{array}{l}48,0 \\
48,3\end{array}$ & 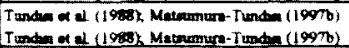 \\
\hline 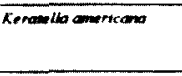 & 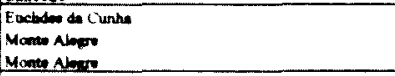 & $\begin{array}{r}1.83 \\
180 \\
\times D \\
\end{array}$ & $\begin{array}{l}36.5 \\
999 \\
\times 1 \\
\end{array}$ & 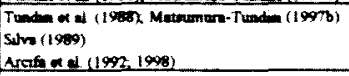 \\
\hline K sechlowary & $\begin{array}{l}\text { Oremuahe } \\
\text { Lunowers }\end{array}$ & $(-3)$ & $\begin{array}{l}48,0 \\
183\end{array}$ & 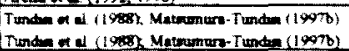 \\
\hline K CExracaute & $\begin{array}{l}\text { Momes Nows: } \\
\text { Mome Alors: }\end{array}$ & $\begin{array}{c}13.6 \\
\vee 0 \\
\end{array}$ & $\begin{array}{l}39,9 \\
\text { ND }\end{array}$ & $\begin{array}{l}\text { Sivno }(1909) \\
\operatorname{Arah} 21\end{array}$ \\
\hline$x \ln$ & 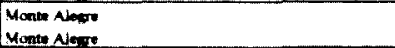 & 18.6 & $\begin{array}{l}59.9 \\
\text { No }\end{array}$ & $\begin{array}{l}\text { Simn }(1989) \\
\text { Arofinet al (1902, 1998) }\end{array}$ \\
\hline$K$ troptaca & Oraminst & 5 & 480 & 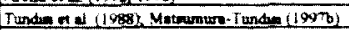 \\
\hline Cocase buila & Eustede do ciurte & s3] & 365 & 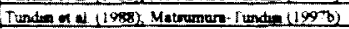 \\
\hline$i \tan$ & Monue Alose & 18.0 & $\frac{59.9}{40}$ & 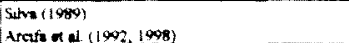 \\
\hline sstencoan & Euchdea de cunhe & 180 & 305 & 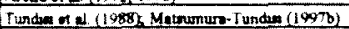 \\
\hline 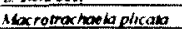 & Eastuden de ciurha & 1.83 & 365 & 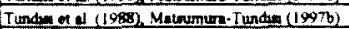 \\
\hline Okatrones posives & $\begin{array}{l}\text { Eucheres do Curthe } \\
\text { Limoento }\end{array}$ & 1.83 & $\begin{array}{l}36.5 \\
48.3\end{array}$ & 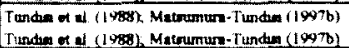 \\
\hline Phanker anextricomen & Lamoero & $4,8+1$ & 483 & 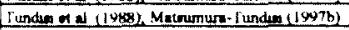 \\
\hline Potheratron vilearis & Monta Alever & 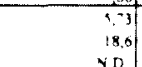 & $\begin{array}{l}48,0 \\
90,0\end{array}$ & 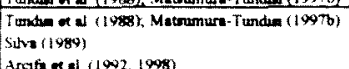 \\
\hline pricé & $\begin{array}{l}\text { Monte Aloge: } \\
\text { Growerihe }\end{array}$ & $\frac{20}{9+3}$ & 480 & 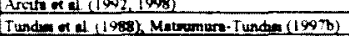 \\
\hline Pregena libera & 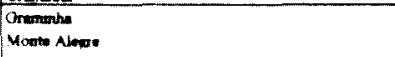 & $\begin{array}{l}3 \\
18.0\end{array}$ & $\begin{array}{l}48.0 \\
59.9\end{array}$ & 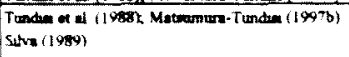 \\
\hline & Monte Alor: & $\times 0$ & Yo & 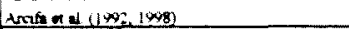 \\
\hline 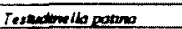 & Eocteden de Cunpe & {$[, 8$} & 369 & 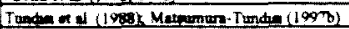 \\
\hline Frichocercapatilka & Monte Alexese & 186 & 59.9 & $\sin (1909)$ \\
\hline & 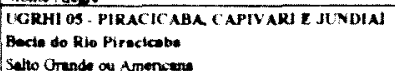 & & $\checkmark D$ & \\
\hline$\frac{\text { Braxmoner anowaris }}{8 \text { cathrithons }}$ & 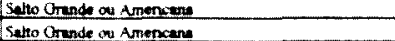 & $\frac{10}{S D}$ & $\frac{S D}{S D}$ & $\frac{\operatorname{trah}(1980)}{\operatorname{trath}(1980)}$ \\
\hline 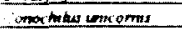 & Selto cinende ou Amencuse & 60 & $\times 0$ & Arath (1):44) \\
\hline Aeraselto cachisaris & Solto Conende ou Amencane & (D) & ND & traficicas \\
\hline Siropera & Solito Onende ou Amensuse & $\therefore D$ & $5 D$ & Anathil1984 \\
\hline Patererchora mazor & 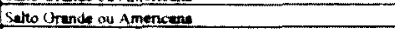 & 50 & 50 & Arafaliyse \\
\hline Pryeans & Salto Qrende de Amoncentu & $\times D$ & ND & Aratialioge \\
\hline
\end{tabular}


Continuanito

TABELA 20 - Ocorrència de rotiferos, média das concentrações de clorofila $a$ total $(\mu \mathrm{g} / \mathrm{L})$ e Indice de Estado Trófico (IET) de Carlson modificado, em cada corpo d'água, com o respectivo autor e época de estudo, por Unidade de Gerenciamento de Recursos Hidricos (UGRHI) do Estado de São Paulo

\begin{tabular}{|c|c|c|c|c|}
\hline Especioes & Reservatono L Lzoplayor & Clorofila a ugL L & EI & Autores: \\
\hline Anuraeopses fisso & 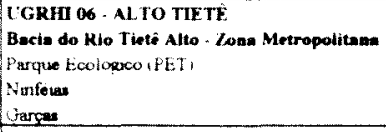 & $\begin{array}{l}91,15 \\
11,24 \\
53,22\end{array}$ & $\begin{array}{r}7.9 \\
54.8 \\
70.4 \\
\end{array}$ & $\begin{array}{l}\text { Deker } 12(x), 4 \\
\text { Este trabaiho } \\
\text { Este trabalho }\end{array}$ \\
\hline iscomorpho eccandis & $1 \mathrm{AO}$ & 437 & 45,2 & Ente trabaiho \\
\hline 1. saltans & $\begin{array}{l}\text { P'urque bcolopico (PET) } \\
\text { LAO }\end{array}$ & $\begin{array}{r}91,15 \\
4,37 \\
\end{array}$ & $\begin{array}{l}75,9 \\
45,2 \\
\end{array}$ & \begin{tabular}{|l|} 
Deker $(2000)$ \\
Este trabalho
\end{tabular} \\
\hline Asplanchno siradis & Uarcas & 53,22 & 30,4 & Ente crabualino \\
\hline Brachiones angularis & Parque Ecologeco (PET) & 91,15 & 75,9 & Deker $(2000)$ \\
\hline B. a bidens & Larcas & 53,22 & 70,4 & Esto trabs ho \\
\hline B. a. chrionis & $\begin{array}{l}\text { Purque Ecologaco (PET) } \\
\text { Garcas }\end{array}$ & $\begin{array}{l}91,15 \\
53,22 \\
\end{array}$ & $\begin{array}{r}75,9 \\
20,4 \\
\end{array}$ & $\begin{array}{l}\text { Deker (2000) } \\
\text { Este trabeilho }\end{array}$ \\
\hline B. bidentata & Garcen & 53,22 & 20,4 & Ense trabaliho \\
\hline B. calleiflons & $\begin{array}{l}\text { Parque Ecologico (PET) } \\
\text { Garcas }\end{array}$ & $\begin{array}{l}91.15 \\
53.22 \\
\end{array}$ & 75,9 & $\begin{array}{l}\text { Doker (2000) } \\
\text { Este trabalho }\end{array}$ \\
\hline B. c. dorcas & Parque Eoologaco (PET) & 91,15 & 759 & Deker 12000) \\
\hline B. coudatury & Jarcas & 53,22 & 70,4 & Enc rrabelho \\
\hline B. falcatus & $\begin{array}{l}\text { Parque Ecologeo (PET) } \\
\text { Jarrea }\end{array}$ & $\begin{array}{l}91,15 \\
53,22\end{array}$ & $\begin{array}{r}75,9 \\
20,4 \\
\end{array}$ & $\begin{array}{l}\text { Deker (2000) } \\
\text { Este trabalho }\end{array}$ \\
\hline B. hovanagnsis & Parque Ecologico (PET) & 91,15 & 55,9 & Deker (2000) \\
\hline B. minus & Garran & 53,22 & 704 & Este trabaiho \\
\hline B. unadindontatus & Parque Ecologico & 91,151 & $\quad 359$ & Deker $(2000)$ \\
\hline Sephalodella catellina & Jarcas & 53,22 & 704 & Este trabalho \\
\hline onachilus dosmerins & $\begin{array}{l}\text { Parque Ecolopoco PET } \\
\text { IAO } \\
\text { Vunfens } \\
\text { Garca }\end{array}$ & $\begin{array}{r}91.15 \\
4.37 \\
11,24 \\
53,22 \\
\end{array}$ & $\begin{array}{r}75.9 \\
45.2 \\
54.8 \\
70.4 \\
\end{array}$ & $\begin{array}{l}\text { Deker } 12000) \\
\text { Este trabatho } \\
\text { Este trabaito } \\
\text { Este trabaiho }\end{array}$ \\
\hline C. untoomis & $\begin{array}{l}\text { Parque Ecoloveo iPET) } \\
\text { tarces }\end{array}$ & $\begin{array}{l}91,15 \\
43,22 \\
\end{array}$ & $\begin{array}{l}75,9 \\
20.4 \\
\end{array}$ & $\begin{array}{l}\text { Deker } 20000 \\
\text { Este grabaho }\end{array}$ \\
\hline Depienchlanis proparula & Sinfelas & .11 .24 & 54.8 & Este urabelho \\
\hline Duspomacha eculeata & IAO & 4,37 & 45,2 & Este trabstho \\
\hline Epiphanes machourus & Parque kcoloquon (PET) & 91,15 & 59 & Deiker $(2000)$ \\
\hline Euchlanis dilatata & tearges & 53,22 & 0,4 & Ente trabaiho \\
\hline Filima opalienens & $\begin{array}{l}\text { Perque Ecolopeo APET) } \\
\text { Garcas }\end{array}$ & $\begin{array}{l}91,15 \\
53,22\end{array}$ & $\begin{array}{r}75,9 \\
70,4 \\
\end{array}$ & $\begin{array}{l}\text { Deker } 120001 \\
\text { Este trabelho }\end{array}$ \\
\hline F. terminalus & $\begin{array}{l}\text { Parque Ecolopyoo (PET) } \\
\text { Oarces }\end{array}$ & $\begin{array}{l}91,15 \\
53,22 \\
\end{array}$ & $\begin{array}{l}75,9 \\
70,4 \\
\end{array}$ & $\begin{array}{l}\text { Deker (2000) } \\
\text { Este trabel ho }\end{array}$ \\
\hline Hexorthro intermedta & $1 \mathrm{AO}$ & 4,37 & 45,2 & Esee inbalho \\
\hline H. i. brasiliensts & IAO & 4,37 & 45,2 & Ene trabalho \\
\hline H. mero & $\begin{array}{l}\text { LAO } \\
\text { Garces } \\
\end{array}$ & $\begin{array}{r}4,37 \\
53,22 \\
\end{array}$ & $\begin{array}{l}45,2 \\
? 0,4 \\
\end{array}$ & $\begin{array}{l}\text { Esto tratalino } \\
\text { Esto trabelho }\end{array}$ \\
\hline Keratsila americana & $\begin{array}{l}\text { Perque Ecoloquco (PEI) } \\
\text { Tarcas }\end{array}$ & $\begin{array}{l}91,15 \\
53,22 \\
\end{array}$ & $\begin{array}{r}75,9 \\
70,4 \\
\end{array}$ & $\begin{array}{l}\text { Deker } 12000) \\
\text { Ente trabalho }\end{array}$ \\
\hline K cocklearis & $\begin{array}{l}\text { Parque kcolokxo IPETI } \\
\text { IAu } \\
\text { Ninforas } \\
\text { atarce }\end{array}$ & $\begin{array}{r}91,15 \\
4,37 \\
11,24 \\
6,2,2 \\
\end{array}$ & $\begin{array}{r}75.9 \\
45,2 \\
54.8 \\
70.4 \\
\end{array}$ & $\begin{array}{l}\text { Deker }(200) \text { ) } \\
\text { Este trabaiho } \\
\text { Este trabalho } \\
\text { Este trabaiho }\end{array}$ \\
\hline K.c. huspida & Parque Ecolosico (PH & 91.15 & -59 & Deker $(2000)$ \\
\hline K. tecto & 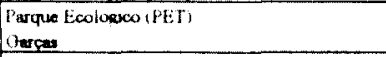 & \begin{tabular}{r|}
91.15 \\
43.22 \\
\end{tabular} & $\begin{array}{r}-5,9 \\
7.4 \\
\end{array}$ & $\begin{array}{l}\text { Deker } 12000) \\
\text { Este vabaiho }\end{array}$ \\
\hline A. tropica & Garces & 63,22 & 90.4 & Este rrabalho \\
\hline Lecane bulla & $\begin{array}{l}\text { Ninfeles } \\
\text { Garcas }\end{array}$ & $\begin{array}{l}11,24 \\
53,22\end{array}$ & $\begin{array}{l}54,8 \\
50.4\end{array}$ & $\begin{array}{l}\text { Ere trabatho } \\
\text { Ente trabelho }\end{array}$ \\
\hline Le curvicarnis & $\begin{array}{l}\text { Nonfens } \\
\text { Garcan }\end{array}$ & $\begin{array}{l}11,24 \\
43,22\end{array}$ & $\begin{array}{r}54.8 \\
9.1,4 \\
\end{array}$ & $\begin{array}{l}\text { Este trabalho } \\
\text { Este trabelho }\end{array}$ \\
\hline L. donesso & Ninfenes & 11,24 & 54,8 & Este trabedho \\
\hline L. Iunaris & Parque trologico (PET) & 91,15 & -59 & Deker $2(0,0)$ \\
\hline L. signtfora & $\begin{array}{l}\text { LAO } \\
\text { Nonferes }\end{array}$ & $\begin{array}{r}4,37 \\
11,24 \\
\end{array}$ & $\begin{array}{l}45,2 \\
54,8\end{array}$ & $\begin{array}{l}\text { Ente tribalho } \\
\text { Ente trabalho }\end{array}$ \\
\hline Lepadelia patella & Linfores & 11,24 & 5.8 & Este trataino \\
\hline Manfredtien exdactylota & $\begin{array}{l}\text { Vinforess } \\
\text { Garcas }\end{array}$ & $\begin{array}{l}11,24 \\
63,22\end{array}$ & $\begin{array}{r}54,8 \\
-0,4 \\
\end{array}$ & $\begin{array}{l}\text { Este trabeitho } \\
\text { Este trabeltho }\end{array}$ \\
\hline Mynilins bisulceta & Oercas & 53,22 & 70 & Ento trabalho \\
\hline Folyarthra na/garts & Sintem & $\begin{array}{r}4,37 \\
11,24 \\
53,27\end{array}$ & $\begin{array}{l}45.2 \\
54,8 \\
0.4\end{array}$ & $\begin{array}{l}\text { Esto tribaliho } \\
\text { Ente tratseiho }\end{array}$ \\
\hline Pompholyx sulcuta & Parque Ecologeo (PET) & 4115 & .99 & Deker 2 2(xom) \\
\hline Synchaeta pectimata & $\begin{array}{l}\text { Parque trologoo (PET) } \\
\text { Garre }\end{array}$ & $\begin{array}{l}91,15 \\
53,22 \\
\end{array}$ & $\begin{array}{r}399 \\
704 \\
\end{array}$ & $\begin{array}{l}\text { Deker }\{2000) \\
\text { Este trubatho }\end{array}$ \\
\hline Trichacerou cf bidens & Nertom & $11,2+1$ & 548 & Este trabelho \\
\hline rgraciiss & 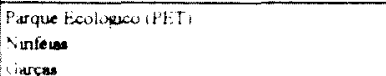 & $\begin{array}{l}11.15 \\
1.24 \\
3.24\end{array}$ & $\begin{array}{r}-5,9 \\
5.8 \\
-1.9\end{array}$ & $\begin{array}{l}\text { Deker (2) } \\
\text { Este trabaltho } \\
\text { Este trabatho }\end{array}$ \\
\hline T. of mus & tarceas & 63,22 & 7,4 & Fiste trabatho \\
\hline r. pussila & 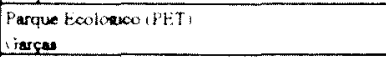 & $\begin{array}{l}1.151 \\
43.2\end{array}$ & $\begin{array}{r}359 \\
-114 \\
\end{array}$ & $\begin{array}{l}\text { Deket } 20001 \\
\text { Este trabaino }\end{array}$ \\
\hline T. stmilss & $\begin{array}{l}\text { Perque Ecolotaco (PET) } \\
\text { Iiarcas }\end{array}$ & $\begin{array}{l}91.15 \\
63.2\end{array}$ & $\begin{array}{r}-59 \\
-144 \\
\end{array}$ & $\begin{array}{l}\text { Deker } 12000) \\
\text { Este tratalho }\end{array}$ \\
\hline I sciata & 1817 & $a+1$ & $45=$ & Itste tratuitho \\
\hline
\end{tabular}


TABELA 20 - Ocorrência de rotiferos, média das concentrações de clorofila $a$ total $(\mu \mathrm{g} / \mathrm{L})$ e Índice de Estado Trófico (IET) de Carlson modificado, em cada corpo d'água, com o respectivo autor e época de estudo, por Unidade de Gerenciamento de Recursos Hidricos (UGRHI) do Estado de São Paulo.

\begin{tabular}{|c|c|c|c|c|}
\hline Especies & Reservatono Lagoal Lago & Corofila a ugallu & LET & Autores \\
\hline inuraeopsis fissa & $\begin{array}{l}\text { UGRHI 06 - AL TO TLETÊ } \\
\text { Bacia do Reservetorio Bitlings } \\
\text { Taquacetubs } \\
\text { Rio Orande }\end{array}$ & $\begin{array}{r}22.63 \\
38,48 \\
\end{array}$ & $\begin{array}{l}61.9 \\
672\end{array}$ & $\begin{array}{l}\text { CETESB (1999a): Coetho-Boteiho et al } 2001 \\
\text { CETESB (1999a); Cueiho-Botelho et al (20M1) }\end{array}$ \\
\hline Brachionus angwiaris & Rio Crande & ND & ND & Kubo (1989) \\
\hline B. a.cheilonis. & Rw Grande & YDD & ND & Kubo (1989) \\
\hline B. calpeyllorus & $\begin{array}{l}\text { Taquacetuba } \\
\text { Rio Pequeno } \\
\text { Rio Orande } \\
\text { Rio Orande }\end{array}$ & $\begin{array}{r}22.63 \\
7.61 \\
\mathrm{~N} D \\
38.48 \\
\end{array}$ & $\begin{array}{l}61,9 \\
50,9 \\
\text { ND } \\
67,2\end{array}$ & $\begin{array}{l}\text { CETESB (1999a); Coelho-Botetho et al (2001) } \\
\text { CETESB (1999a); Coelho-Botelho et al } 120011 \\
\text { Kubo (1989) } \\
\text { CETESB (1999a); Coelho-Botelho et al }(2001\end{array}$ \\
\hline B. coudatus & Rw Grande & ND & ND & Kubo(1989) \\
\hline B. dolabratus & $\begin{array}{l}\text { Taquacetuba } \\
\text { Rro Poqueno } \\
\end{array}$ & $\begin{array}{r}22,63 \\
2,61 \\
\end{array}$ & $\begin{array}{l}61,9 \\
50,9 \\
\end{array}$ & $\begin{array}{l}\text { CETESB (1999a); Coetho-Boteiho et al }(2001 \\
\text { CETESB (1999, a), Coelho-Botelho or al }(2001\end{array}$ \\
\hline B. falcuatur & $\begin{array}{l}\text { Taquacetube } \\
\text { Rio Pequeno } \\
\text { Rwo Grande } \\
\text { Rio irrande }\end{array}$ & $\begin{array}{r}2.63 \\
? .61 \\
N .0 \\
38,48 \\
\end{array}$ & $\begin{array}{l}61.9 \\
50,9 \\
\text { N.D } \\
6 ? 2\end{array}$ & 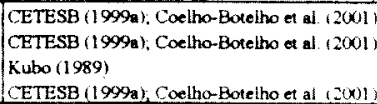 \\
\hline B. havanaensis & $\begin{array}{l}\text { Taquacetubo } \\
\text { Rio Pequeno }\end{array}$ & $\begin{array}{r}22.63 \\
.61 \\
\end{array}$ & $\begin{array}{l}61.9 \\
50,9 \\
\end{array}$ & $\begin{array}{l}\text { CETESB (1999a); Cue ho-Botetho et al (2001) } \\
\text { CETESB (1999a); Coe ho-Botelho et al (2001) }\end{array}$ \\
\hline B. mirus & Rwo Grande & $\because 0$ & $\mathrm{ND}$ & Kubo (1989) \\
\hline$\frac{\text { B. guadridentarus }}{\text { Comactilus dossuartus }}$ & $\begin{array}{l}\text { Rio Grande } \\
\text { Taquacerube } \\
\text { Rio Pequeno } \\
\text { Ro Grande }\end{array}$ & $\begin{array}{r}\text { YD } \\
22,63 \\
7,61 \\
38,48 \\
\end{array}$ & $\begin{array}{l}\text { ND } \\
61.9 \\
50,9 \\
67,2\end{array}$ & 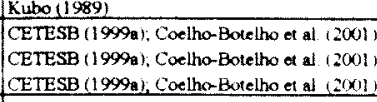 \\
\hline C. unscornts & $\begin{array}{l}\text { Tequacotutro } \\
R_{10} \text { Pequeno } \\
R_{10} \text { Omende }\end{array}$ & $\begin{array}{r}72.63 \\
7.61 \\
38,48 \\
\end{array}$ & $\begin{array}{l}61,9 \\
50,9 \\
67,2 \\
\end{array}$ & 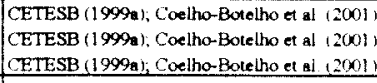 \\
\hline Euchlanis dilotata & Rwo Pequeno & -611 & 509 & CETESB (1999), Coe iho-Botelho ef al (200) \\
\hline Filinia longiseta & $\begin{array}{l}\text { Trequacetubs } \\
\text { Rio Pequeno } \\
\text { R10 Orande } \\
\end{array}$ & $\begin{array}{r}22.63 \\
7,61 \\
38,48 \\
\end{array}$ & $\begin{array}{l}61.9 \\
50,9 \\
67,2 \\
\end{array}$ & 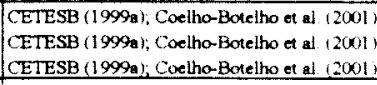 \\
\hline F. opoliensus & $\begin{array}{l}\text { Trquacerubs } \\
\text { Ro Poqueno } \\
\text { Rio Orande } \\
\end{array}$ & $\begin{array}{r}22,63 \\
7.61 \\
38,48 \\
\end{array}$ & $\begin{array}{l}61,9 \\
50,9 \\
67,2 \\
\end{array}$ & $\begin{array}{l}\text { CETESB (1999a); Coe tho-Botelho ef al } 12001) \\
\text { CETESB (1999a); Coe tho-Botelho et al ( } 2001) \\
\text { CETESB (1999), Coe tho-Botelho er al. } 12001)\end{array}$ \\
\hline $\begin{array}{l}\text { E cerminalis } \\
\text { Hexarthra iniermedia }\end{array}$ & $\begin{array}{l}\text { Roo Orande } \\
\text { Rwo Grande }\end{array}$ & $\begin{array}{ll}38,48 \\
38,48\end{array}$ & 67,2 & 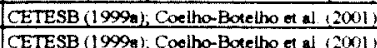 \\
\hline H. mira & $\begin{array}{l}\text { Taquacetuba } \\
\text { Ro Pequeno } \\
\end{array}$ & $\begin{array}{r}22.40 \\
2.61 \\
\end{array}$ & $\begin{array}{l}61,9 \\
50,9 \\
\end{array}$ & 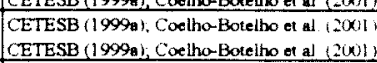 \\
\hline Kellicottio bostoniensis & $\begin{array}{l}\text { Ro Pequeno } \\
\text { Rio Orande }\end{array}$ & $\begin{array}{r}7.61 \\
38,48 \\
\end{array}$ & $\begin{array}{l}50,9 \\
67,2\end{array}$ & $\begin{array}{l}\text { CETESB (1999a); Coetho-Botelho en al } 12001 \\
\text { CETESB (1999a); Coelho-Botelho et al } 22001\end{array}$ \\
\hline$\overline{\text { Keralella americand }}$ & $\begin{array}{l}\text { Tarquacotube } \\
\text { Rio Pequeno } \\
\text { Rio Grande } \\
\end{array}$ & $\begin{array}{r}72,63 \\
-, 61 \\
38,48 \\
\end{array}$ & $\begin{array}{l}61,9 \\
50,9 \\
67,2 \\
\end{array}$ & 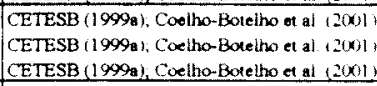 \\
\hline Ki cochiearis & $\begin{array}{l}\text { Taquencotuba } \\
\text { Rio Orande }\end{array}$ & $\begin{array}{l}32,63 \\
38,48 \\
\end{array}$ & $\begin{array}{l}61,9 \\
67,2 \\
\end{array}$ & 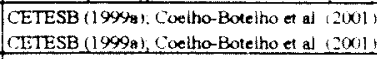 \\
\hline K ef cochloaris & Rio Grande & ND & ND & Kubo (1989) \\
\hline$K$ ef lensi & Rwo Grande & ND & $\mathrm{ND}$ & Kubo (1989) \\
\hline$k$ of proaurow & Rio Urande & $\triangle D$ & ND & Kubo (1989) \\
\hline Es tecta & $\begin{array}{l}\text { Ro Pequeno } \\
\text { Rio Orande }\end{array}$ & $\begin{array}{r}r .61 \\
38,48 \\
\end{array}$ & $\begin{array}{l}50,9 \\
67,2 \\
\end{array}$ & 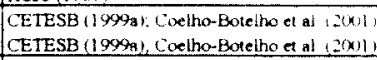 \\
\hline K. tropica & $\begin{array}{l}\text { Taquacetub: } \\
\text { Rwo Pequeno } \\
\text { Ro Orande } \\
\end{array}$ & $\begin{array}{r}22,63 \\
7,61 \\
38,48 \\
\end{array}$ & $\begin{array}{l}61,9 \\
50,9 \\
67,2 \\
\end{array}$ & 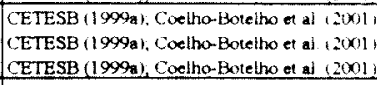 \\
\hline Lecane bulla & Rio Pequeno & 361 & 50,9 & CETESB (1999a), Coelho Botetho et al $(200)$ \\
\hline L. cf lunaris & Rıo Orande & 38,48 & 672 & CETESB (1999a), Coeiho-Botelho et al (2001) \\
\hline Sfynlina ventralis & $\begin{array}{l}\text { Tequacertubn } \\
\text { Rio Pequeno } \\
\end{array}$ & $\begin{array}{r}2263 \\
-61 \\
\end{array}$ & $\begin{array}{l}61,9 \\
50,9 \\
\end{array}$ & 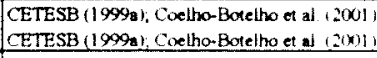 \\
\hline Plansonus porulus & Rio Orande & ND & ND & Kubo (1989) \\
\hline Pogura libera & Rio Poqueno & 61 & 50,9 & 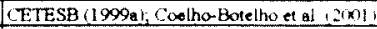 \\
\hline Sinchosets oflonga & $\begin{array}{l}\text { Rio Pequeno } \\
\text { Rio Grande } \\
\end{array}$ & $\begin{array}{r}.61 \\
38,48 \\
\end{array}$ & $\begin{array}{l}50,9 \\
672 \\
\end{array}$ & 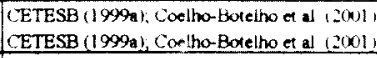 \\
\hline S stylata & Rw Pequeno & .611 & 50,9 & CFTESB (1999a), Coelho-Borelho of al 12001 \\
\hline Trichocercice capusing & Rio Crande & 38,48 & 67,2 & CETESB (l 999 a); Coel ho-Botelho ef al $12(x)]$ \\
\hline Tucharron & Ro Pequeno & 361 & 50,9 & CETESB (1999an, Cuelho-Botelho ef al :2001 \\
\hline T. cylindrica & $\begin{array}{l}\text { Rio Pequeno } \\
\text { Rio Grande }\end{array}$ & $\begin{array}{r}7.61 \\
38,48 \\
\end{array}$ & $\begin{array}{l}50,9 \\
67,2\end{array}$ & 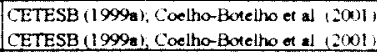 \\
\hline$T_{\text {muliticrinis }}$ & Ro itrande & 38,48 & 67,2 & CETESB (1999a) Coelho-Botelho ot al i2001) \\
\hline Ipusillo & Ro thande & 28,48 & $6+2$ & 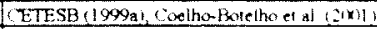 \\
\hline T. similis & $\begin{array}{l}\text { Pequacetuba } \\
\text { Ris Pequeno } \\
\text { Ro Orando } \\
\text { Rio Grande }\end{array}$ & $\begin{array}{r}2.63 \\
-61 \\
N 0 \\
38.48 \\
\end{array}$ & $\begin{array}{l}61,9 \\
519 \\
\text { No } \\
672\end{array}$ & 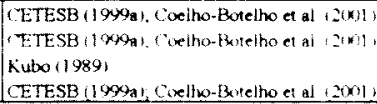 \\
\hline
\end{tabular}


TABELA 20 - Ocorrència de rotiferos. média das concentraçōes de clorofila $a$ total $(\mu \mathrm{g} / \mathrm{L})$ e Indice de Estado Trófico (IET) de Carlson modificado. em cada corpo d'água. com o respectivo autor e época de estudo. por Unidade de Gerenciamento de Recursos Hidricos (UGRHI) do Estado de São Paulo.

\begin{tabular}{|c|c|c|c|c|}
\hline Eppecom & hestrenolosoilyo & 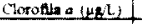 & IET & Aruare \\
\hline tmuraroposu fused & 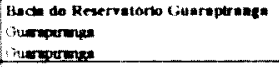 & $\begin{array}{l}\because 0 \\
\vee 0 \\
\end{array}$ & $\begin{array}{l}N D \\
N D \\
N\end{array}$ & 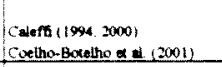 \\
\hline Bractiomus anproturese & 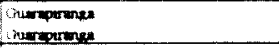 & $\begin{array}{r}7 \\
1\end{array}$ & $\begin{array}{l}512 \\
Y \mathrm{D}\end{array}$ & 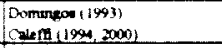 \\
\hline B a buden & Therporive & 80 & $\mathrm{ND}$ & 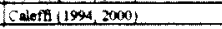 \\
\hline 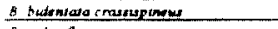 & 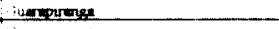 & $\therefore 0$ & $\triangle D$ & I. alefor 19504 \\
\hline is calscyone & 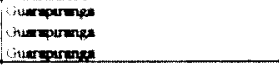 & $\begin{array}{r}7 \\
\times 0 \\
\times 0 \\
\end{array}$ & $\begin{array}{l}S 1.2 \\
\text { ND } \\
\text { ND }\end{array}$ & 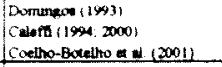 \\
\hline$B c$ camphemons & Durrorresea & XD & $N D$ & ICalem 11990,20001 \\
\hline$B<$ anunuriformus & Sinerourenga & ज्D & $\mathrm{ND}$ & Caleft 11094,2000 \\
\hline$B<$ dorces & Siutrepirenga & Y. & ND & Caleff 11994,20001 \\
\hline 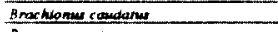 & Sinumgersuge & ND & ND & Caleff $(1094,2000)$ \\
\hline Biperiomatur & 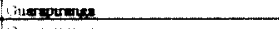 & Yof & ND & Coterin (2000) \\
\hline 9 dolubrapus & cinerounge & YD & $N D$ & Coedho-Boxeftio on (2001) \\
\hline B falcons & 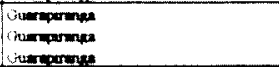 & $\begin{array}{ll} \\
\text { ND } \\
\text { VD } \\
\end{array}$ & $\begin{array}{l}51.2 \\
\text { ND } \\
\text { ND }\end{array}$ & 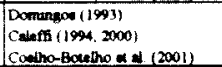 \\
\hline B c forficula & Suervermen & vo & ND & 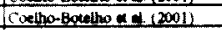 \\
\hline menes & 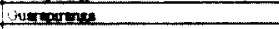 & VD & $N D$ & Colatp 11990,2000$)$ \\
\hline Bn anroule & conconinge & YD & ND & 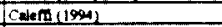 \\
\hline$B$ quendiatare & 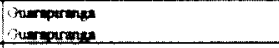 & $\begin{array}{c}7 \\
v 0 \\
\end{array}$ & $\begin{array}{r}51.2 \\
N \text { D } \\
\end{array}$ & 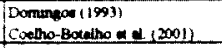 \\
\hline Collothere onmeas & ourrorene: & -3 & 5.2 & Donremeo: $\left[1993_{3}\right)$ \\
\hline 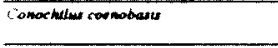 & 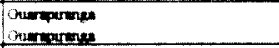 & $\begin{array}{r}7.7 \\
\times D \\
\end{array}$ & $\begin{array}{l}91.2 \\
\text { NDD }\end{array}$ & 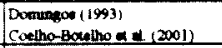 \\
\hline doervamus & cuerovinga & $\begin{array}{l}\text { ND } \\
\text { YD }\end{array}$ & $\begin{array}{l}\text { ND } \\
\text { ND }\end{array}$ & 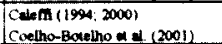 \\
\hline Inkamis & 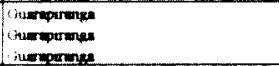 & $\begin{array}{l}7.8 \\
20 \\
20 \\
20\end{array}$ & $\begin{array}{l}51.2 \\
\mathrm{ND} \\
\mathrm{ND}\end{array}$ & 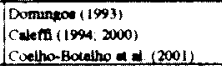 \\
\hline 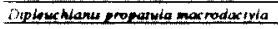 & 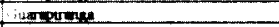 & vol & ND & Calem (1994) \\
\hline Exphaneci marrouru & 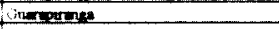 & ⿶0 & ND & Cotens 20000$)$ \\
\hline 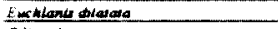 & forevinese & aㅣ & ND & 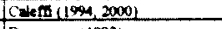 \\
\hline 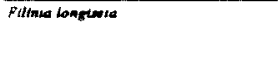 & Conerorange & $\begin{array}{c}7 \\
40 \\
40\end{array}$ & $\begin{array}{l}-1.2 \\
40 \\
40\end{array}$ & $\begin{array}{l}\text { Domanged (1993) } \\
\text { Cults (2000) }\end{array}$ \\
\hline Fopoitrins & 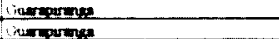 & $\begin{array}{ll}Y 0 \\
D\end{array}$ & $\frac{N D}{N D}$ & 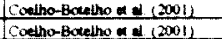 \\
\hline Epsilert & Gencrarte: & So & $\frac{N D}{N D}$ & $\operatorname{logient}_{1}(1904,2000)$ \\
\hline F termmais & 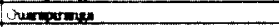 & VD & SD & Calet $(2000)$ \\
\hline Bexanhmo ineormedes & 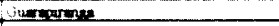 & 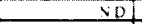 & $S D$ & Crism $(2000)$ \\
\hline Hordilla thom mon & nrrarate & Sp & $\mathrm{ND}$ & 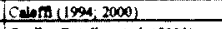 \\
\hline 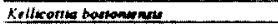 & Guergarmen: & No & ND & Coepho-Botelino e 12001$)$ \\
\hline 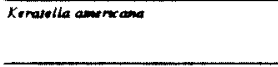 & 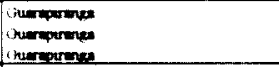 & $\begin{array}{r}7 \\
\times 0 \\
\times 0 \\
N 0\end{array}$ & $\begin{aligned} 91,2 \\
N D \\
N 0\end{aligned}$ & 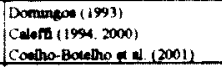 \\
\hline$K$ cocklourt & 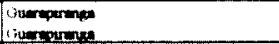 & $\begin{array}{r}7.7 \\
\times 10 \\
\end{array}$ & $\begin{array}{l}51.2 \\
40\end{array}$ & 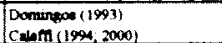 \\
\hline$l^{\prime}$ lonat & 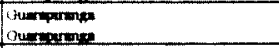 & $\begin{array}{r}7.7 \\
\times 0 \\
\end{array}$ & $\begin{array}{l}31.2 \\
\text { N. } \\
\end{array}$ & 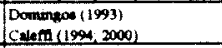 \\
\hline E. necta & crumporese & $\times D$ & ND & Colom 110042000$)$ \\
\hline K. loopke & 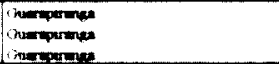 & $\begin{array}{l}7.78 \\
y 0 \\
40\end{array}$ & $\begin{array}{l}1.2 \\
N D \\
N D\end{array}$ & 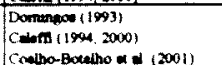 \\
\hline Lecantoulde & 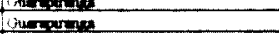 & (a) & ND & $16 \cos (199)$ \\
\hline L. clanerocerera & Comerenese & -7 & 51,2 & Domenen $(1993)$ \\
\hline Scompere & Nexpen & $-\pi$ & 91,2 & 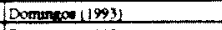 \\
\hline L cumcormes & 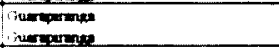 & $\begin{array}{l}78 \\
40\end{array}$ & $\begin{array}{l}91.2 \\
\mathrm{ND}\end{array}$ & $\begin{array}{l}\text { Dommenot (1993) } \\
\text { Casert }(1994,2000)\end{array}$ \\
\hline ineverbom & rivereparense & पD & ND & $\left.\operatorname{cole}_{1}+2000\right)$ \\
\hline If if lavierosom & inerpanes: & id & $N D$ & Conots 10904$)$ \\
\hline I iedara & Doroune & 40 & $N D$ & Conem 10ent \\
\hline liven & Ciknemprimea & ND & ND & Coleft $(2000)$ \\
\hline & i herexprense & $V_{D}$ & $N D$ & Coetho-Botetho as 20001 \\
\hline E af luma & 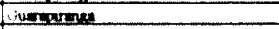 & vD. & ND & Coedho-bocelho a d. 120011 \\
\hline L denaru ormave & Couecorrever & vo & $\times D$ & Colefn $(2000)$ \\
\hline 1 momotopre & ingerprenge & 40 & $\mathrm{ND}$ & Calens 20000$)$ \\
\hline Lequana & 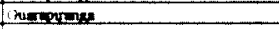 & VD & ND & Caleft $(1994,2000)$ \\
\hline Lelormans. & Cingereverese & vo & $N D$ & Congen (1904) \\
\hline 1. Alennoast & itancrereve & vof & Yo & $\operatorname{cosem}_{120001}$ \\
\hline L, linnereas & 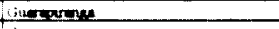 & $\times 0$ & No & colofo 11904$)$ \\
\hline 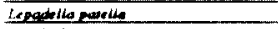 & Linerourese & -3 & 51.2 & 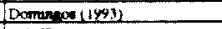 \\
\hline 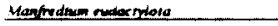 & intervorive & 40 & $\checkmark D$ & Colem (199+1) \\
\hline 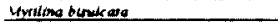 & Tun pormen & sol & No & Calnm (1994) \\
\hline Plattamun perives & Sterverove & VD & $\times 0$ & Coeff 11904$)$ \\
\hline 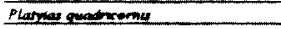 & congreneses & 40 & ND & Conem \\
\hline Polvertion bescerious & Ciuncorrese: & -3 & 952 & Dernmatos (1993) \\
\hline Fivigure & 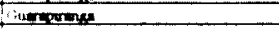 & 3 & 91,2 & 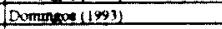 \\
\hline Pumpeolua rompionala & Dinerenes & $\times 0$ & $\times D$ & $\operatorname{coln} m(1900), 2000)$ \\
\hline Perroristere & Ansorenes & 3 & 91,2 & Domingen log? \\
\hline 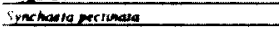 & incorose & 7 & 912 & Domuneas $\{993\}$ \\
\hline 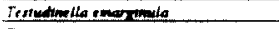 & homporeve & $\times D$ & ND & Calen 1000$)$ \\
\hline$I$ mucromate & inturpourenese & 40 & ND & Colom (1994) \\
\hline$T$ pertives & 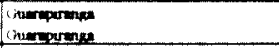 & . & $\begin{array}{l}31,2 \\
N D \\
\end{array}$ & 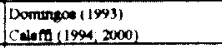 \\
\hline 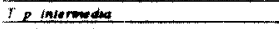 & necporenes & \begin{tabular}{c|c|}
$* 0$ \\
\end{tabular} & $\mathrm{ND}$ & Calen 11998,2000$)$ \\
\hline Inchorema betentals & theroman & $\mathrm{ND}$ & ND & Colffo $(194)$ \\
\hline$T$ capercona & cionerpormenes & SD & ND & Colont (1994:2000) \\
\hline & innererente & vo & No & Cootho-Boxelho $\approx 0120011$ \\
\hline$Y$ chattont & iturgorowe & 40 & $\times D$ & Coxho-Buxetho a \& 130013 \\
\hline 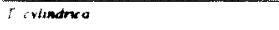 & nempermentan & VD & No & Caleth (1904, 2000) \\
\hline & Sumermen & 40 & $\times 0$ & 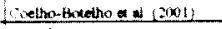 \\
\hline sructis & Lertoverye & $\div 01$ & $\therefore 0$ & 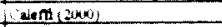 \\
\hline Thonewera & nimpane & 3 & 51,2 & 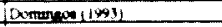 \\
\hline$I$ mulikman & inererene & 8 & $x D$ & 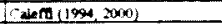 \\
\hline$I \mathrm{men}$ & 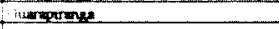 & (.0) & No & $\operatorname{cosen} 120001$ \\
\hline$T$ esmeits & churapormes & चा & 31.2 & Domanque $(1993)$ \\
\hline & ingerome & 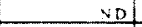 & ND & Coven 11994,2000$)$ \\
\hline Fuyiara & 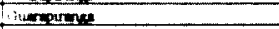 & $\therefore$ & ND & colem $(1994,2000)$ \\
\hline Prochoina & inyerourenes & -7 & $51: 2$ & Damungon $\{1599\}$ \\
\hline
\end{tabular}


Cont Inuacio

TABELA 20 - Ocorrència de rotiferos, média das concentraçoos de clorofila $a$ total $(\mu \mathrm{g} / \mathrm{L})$ e Índice de Estado Trófico (IET) de Carlson modificado, em cada corpo d'água, com o respectivo autor e época de estudo, por Unidade de Gerenciamento de Recursos Hídricos (UGRHI) do Estado de São Paulo.

\begin{tabular}{|c|c|c|c|c|}
\hline Especies & Resenvatorio Lagoe Lago & Gonofila o (ug $L)$ & ET & Autores \\
\hline & UGRHI OB - SAPUCAL/GRANDE & & & \\
\hline inuramopsis fissa & Volta Grande & 3,78 & 43,8 & Tundun et al (1988): Matnumum-Tundus (1997b) \\
\hline 4. navicula & Yolta Grande & ND. & N.D & Rolla ef al $(19 \times x)$ \\
\hline Ascomorpha rcaudts & Volla Srande & ND & ND & Rolla et al $(1990)$ \\
\hline A. owalis & Volte Grande & N.D. & N.D & Rolla et al (1990) \\
\hline \multirow[t]{3}{*}{ Brachiomus angularks } & Estretto & 1,26 & 32.8 & 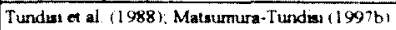 \\
\hline & Voltu Orande & 3.78 & 43.8 & Tundiss ef al (1988). Mataumura-Tundsas (1997b) \\
\hline & Voltea orande & ND. & ND & Roliset al $(1990)$ \\
\hline B. calyciforus & Volus Orande & ND & ND & Rolla et al $(1990)$ \\
\hline B. candanes & Volte Orande & ND. & $\triangle D$ & Rolla et al $(1990)$ \\
\hline \multirow[t]{3}{*}{ B. dolabranus } & Estretro & 1.26 & 32,8 & 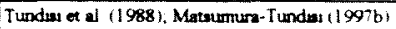 \\
\hline & Voltu Orande & 3,78 & 43.8 & Tundan at al (1988). Matsurnura-Tundan (1997b) \\
\hline & Volte Grande & ND & ND & Rolla et al $(1990)$ \\
\hline \multirow[t]{3}{*}{ B. falcaks } & Estreto & 1,26 & 32,8 & Tunder ef al. (1988), Matrumura-Tunda $11997 \mathrm{~b})$ \\
\hline & Volte Orande & 3.78 & 43,8 & Tundies of al. (1988): Matsumurn-Tundien (1997b) \\
\hline & Volus Grande & ND. & ND & Rolla et al (1990) \\
\hline \multirow[t]{3}{*}{ Collothe co ornata cornuta } & Eistretio & 1,26 & 32.8 & Tundses of al. ( (1988), Matsumura-Tundian (1997b) \\
\hline & Gaguarn & 2,13 & 38.1 & Tundise et al (1988); Matrumure-Tundian (1997b) \\
\hline & Volta chande & 3,78 & 43,8 & Tundwe et al (1988) Massumura-Tundian (1997b) \\
\hline \multirow[t]{3}{*}{ Conachilus coenobasis } & Estretio & 1,26 & 32.8 & Tundus ef al (1988), Matsumura-Tunda : $(1997$ b) \\
\hline & Jagauma & 2.13 & 38.1 & Tundwi of al (1988): Matsumura-Tundes (1997b) \\
\hline & Volue Crande & 3,78 & 43,8 & Tundist of al $(1988)$, Massumurn-Tundui (1997b) \\
\hline \multirow[t]{3}{*}{ C. natans } & Estreto & 1.26 & 32,8 & Tundas of al ( $(1988)$, Matrumura-Tunden $\left(199^{7}\right.$ b) \\
\hline & Volte Grande & 3.78 & 43.8 & 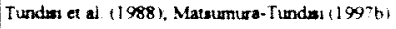 \\
\hline & Volta utande & ND & $\therefore \mathrm{D}$ & Rolla of al 1990 \\
\hline C.unicornis & Volta Grande & ND & ND & Rolla et al $(1990)$ \\
\hline Epuphanes brachionus & Voits Grande & ND & ND & Roilset al 19900 \\
\hline Euchlanis deflexa & Voltu Urande & 3,8 & 43,8 & Tundes of of (1988), Maturmure-Tundew (19976) \\
\hline \multirow[t]{2}{*}{ Filinia longisota } & Volte Orande & 3,78 & 43,8 & Tundis et al $(1988$, Matsumurn-Tundwa (1997b) \\
\hline & Volte Orande & ND. & ND & Rolle et al $(1990)$ \\
\hline F.termingies & Volts Grande & ND. & ND & Rolleet al $(1990)$ \\
\hline Hexarthro inturmedio & Volug Orande & ND. [ & ND & Rolla of al $(1990)$ \\
\hline \multirow{4}{*}{$\frac{H .1 . \text { brasiliensis }}{\text { H. mira }}$} & Volta Urande & 3,78 & 43.8 & 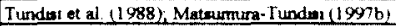 \\
\hline & Estretio & $\mid, 26$ & 32.8 & Tundins et al (1988). Metrunaura-Tundian $(1997 \mathrm{~b})$ \\
\hline & Jazuman & 2.13 & 38.1 & Tunden ec al (1988). Mateumurn-Tundsi (1997b) \\
\hline & Volu ohande & 3,78 & 43,8 & 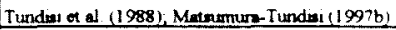 \\
\hline Horaella thomassoni & Volla Orande & ND. & ND & Rollo ex al $(1990)$ \\
\hline \multirow[t]{4}{*}{ Keratella ementicono } & Estretto & 1.26 & 32,8 & Tundes ef af (1988), Matrumurn-Tundra (1997b) \\
\hline & loguery & 2,13 & 38.1 & Tundrs et al (1988), Metromura-Tundw (1997b) \\
\hline & Volu Orande & 3,78 & 43,8 & Tundas et al $(1988)$. Matumure-Tundwa (1997b) \\
\hline & Volus Grande & ND & ND & Rollig et al $(1990)$ \\
\hline \multirow[t]{4}{*}{ K. casiniearss } & Estretio & 1.26 & 32.8 & 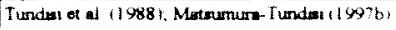 \\
\hline & Jakumara & $2,13 \mid$ & 38.1 & 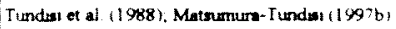 \\
\hline & Volts itrande & 3.78 & 43,8 & Tundul et al 119881 . Matsumurs- Tundat $1199^{7} \mathrm{~b}$ : \\
\hline & Volle orande & $\therefore D$ & ND & Rolls et al $(1990)$ \\
\hline K. $\operatorname{len} 31$ & Volte Orande & ND & ND & Rolla ef al (1990) \\
\hline$K$. ef quadrate & Volte Grando & ND. & ND & Rolln of al $(1990)$ \\
\hline Lecone et crapida & Volta Grande & ND & ND & Rolla et al $(1990)$ \\
\hline L. lunaras & \begin{tabular}{|l} 
Volta Grande \\
\end{tabular} & $\because D$ & $\because \mathrm{D}$ & Rolla et al (1999) \\
\hline Lepadella actuminata & Volten cirande & ND & $\mathrm{ND}$ & Rolla of al $(1900)$ \\
\hline Plattonus parsius & Vulta Chande & $\mathrm{ND}$ & $\sqrt{N D}$ & Rolls at al 11900! \\
\hline Ploesoma truncanum & Volts Urande & ND & $\mathrm{ND}$ & Rolla et ai 199001 \\
\hline \multirow[t]{3}{*}{ Polyarthra migaris } & Eutrerto & 1.26 & 32,8 & 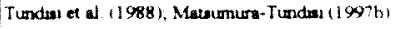 \\
\hline & Volta irande & 3.38 & 43.8 & 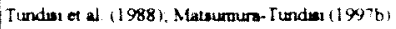 \\
\hline & Volua Orunde & No. & $\mathrm{ND}$ & Rolla et al $(1990)$ \\
\hline P. tripla & Volth Urande & 3,78 & 438 & Tunding et al (1988), Matsumura -Tundwe (1997b) \\
\hline \multirow[t]{3}{*}{ Pogura likera } & Fureno & 1.26 & 32.8 & Tundes ef at (1988). Matsumura-Tundwo 1 1997b) \\
\hline & Japuera & 2.13 & 38.1 & 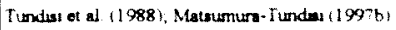 \\
\hline & Volun Urande & $3,-8$ & 43,8 & 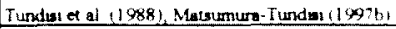 \\
\hline Rhinogiens al rontaiss & Folfen Grande & $\therefore D$ & $\times D$ & Rollin et al $(19 \times x)$ \\
\hline Synchotso stylata & Volts Girande & ND & ND & Rolla of 11990 \\
\hline Trichacerca chattoni & Colle chrande & ND & $\mathrm{ND}$ & Rollact al 11996$)$ \\
\hline$T$ muitrorints & Voles urande & ND & $\mathrm{ND}$ & Rolla et al $(1990)$ \\
\hline T. pusilia & Volta urande & ND & ND & Rolla ef al $(1990)$ \\
\hline T. semilis & Volu urande & ND & ND & Rollin et al $(1990)$ \\
\hline I. shilara & Volta chrande & ND [ & ND & Rollin of al $(1990)$ \\
\hline
\end{tabular}


Contimuag o

TABELA 20 - Ocorrência de rotiferos, média das concentrações de clorofila $a$ total $(\mu \mathrm{g} / \mathrm{L})$ e Índice de Estado Trófico (IET) de Carlson modificado, em cada corpo d'água, com o respectivo autor e época de estudo, por Unidade de Gerenciamento de Recursos Hidricos (UGRHI) do Estado de São Paulo.

\begin{tabular}{|c|c|c|c|c|}
\hline Espociez & Reservat tho Lasparlago & Corofila a (ugL) & IET & Autoren \\
\hline Amurasopsys fissa & $\begin{array}{l}\text { UGRHI } 10 \text { - SOROCABAMMEDIO TIETÉ } \\
\text { Bacia do Rio Tieté Médio Superior } \\
\text { Barra Bonta }\end{array}$ & ent & 65,4 & CETESB, $199 \%$ a): Coetho-Botetho ot at 12001 , \\
\hline Ascomorpha ovalys & $\begin{array}{l}\text { Barra Bonta } \\
\text { Barra Bonts } \\
\text { Barra Bonts } \\
\text { Barra Bontata }\end{array}$ & $\begin{array}{r}5.56 \\
5.96 \\
N 0 \\
2.58 \\
\end{array}$ & $\begin{array}{l}47.7 \\
46,8 \\
\mathrm{ND} \\
61,3 \\
\end{array}$ & 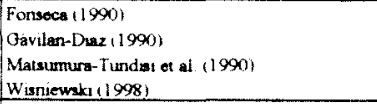 \\
\hline A sollons & Barra Bonuta & 5.56 & $47, ?$ & Fonsece 1990$)$ \\
\hline Asplanchna sieboldi & Barra Bonita & N.D. & ND. & Matsumura Tundusi et al , 1990 ) \\
\hline Brachonus angularis & $\begin{array}{l}\text { Barre Bonuta } \\
\text { Barra Bonita } \\
\end{array}$ & $\begin{aligned} \text { N.D. } \\
32,18 \\
\end{aligned}$ & $\begin{array}{l}\text { ND. } \\
65,4 \\
\end{array}$ & 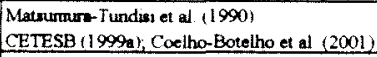 \\
\hline B. Bidentata & Barra Bonta & 32,18 & 65.4 & CETESB (1999a); Coctho-Botelho et al (2001) \\
\hline B. calycifiorus & 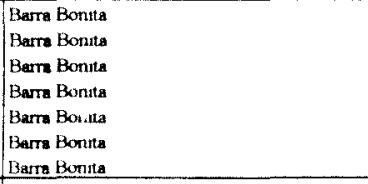 & $\begin{array}{r}5,56 \\
5,06 \\
\text { N.D } \\
\text { N.D } \\
\text { N.D } \\
21,58 \\
32,18 \\
\end{array}$ & $\begin{array}{l}47.7 \\
46,8 \\
\text { ND. } \\
\text { N.D } \\
\text { N.D. } \\
61.3 \\
65.4 \\
\end{array}$ & 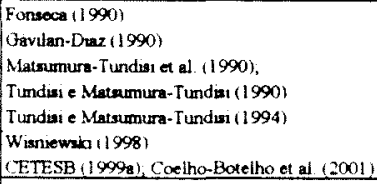 \\
\hline B. caudotus & \begin{tabular}{|l|} 
Ramra Bonnts \\
Berra Bonta \\
Barra Bonna \\
\end{tabular} & \begin{tabular}{rl|} 
N. D. \\
21,58 \\
32,18 \\
\end{tabular} & $\begin{array}{l}N D \\
61.3 \\
65.4 \\
\end{array}$ & 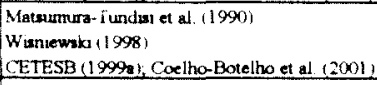 \\
\hline B.:. vulgans & Barra Bonita & 21,58 & 61,3 & Wianuewakia (1998) \\
\hline B. dolabratus & $\begin{array}{l}\text { Bams Bonits } \\
\text { Barra Bonita }\end{array}$ & $\begin{array}{l}21,58 \\
32,18 \\
\end{array}$ & $\begin{array}{l}61.3 \\
65.4 \\
\end{array}$ & $\begin{array}{l}\text { Wismewaik (1998) } \\
\text { CETESB (1999, Coelho-Botoliho et al }(2001)\end{array}$ \\
\hline B. falcatus & $\begin{array}{l}\text { Barra Bomita } \\
\text { Barra Bonth } \\
\text { Barra Bontata } \\
\text { Barra Bonuta }\end{array}$ & \begin{tabular}{r|r|}
5,56 \\
$N D$ \\
21,58 \\
32,18 \\
\end{tabular} & $\begin{array}{l}47.7 \\
N D \\
61,3 \\
65,4\end{array}$ & 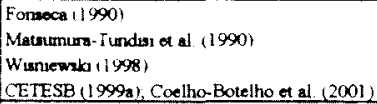 \\
\hline B. havamaensis & Barre Bonuta & 32,18 & 65,4 & CETESB 11999 a), Coetho-Botelho et al $(2001)$ \\
\hline B. mimus & $\begin{array}{l}\text { Barra Bconta } \\
\text { Barma Bonuta }\end{array}$ & $\begin{array}{r}21,58 \\
32,18 \\
\end{array}$ & $\begin{array}{l}61,3 \\
65,4 \\
\end{array}$ & $\begin{array}{l}\text { Wirnewsik }+1998 \text { ) } \\
\text { CETESB (1999), Coelho-Botelho of al (2001) }\end{array}$ \\
\hline B. quadriculata & Bemra Bonita & N.D. & ND & Tundua e Matsonura-Tundiss (1990) \\
\hline B. quadridentatus & $\begin{array}{l}\text { Berra Boruts } \\
\text { Berra Bortuta }\end{array}$ & $\begin{aligned} & \\
& 32.18 \\
&\end{aligned}$ & $\begin{array}{l}\text { ND. } \\
65,4 \\
\end{array}$ & 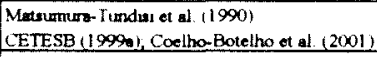 \\
\hline Copholodalla gibba & Bearra Bonuta & ND. & ND. & Massunum-Tundies at al (1990) \\
\hline Conochilus coemabasis & $\begin{array}{l}\text { Berra Bontata } \\
\text { Barra Bonta } \\
\text { Barna Bonits } \\
\text { Berre Bonita } \\
\end{array}$ & $\begin{array}{r}5,56 \\
\text { N.D } \\
\text { N.D. } \\
32,18 \\
\end{array}$ & $\begin{array}{l}47 . ? \\
\text { ND } \\
\text { ND. } \\
65,4 \\
\end{array}$ & 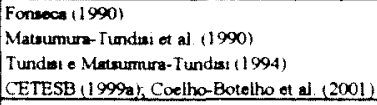 \\
\hline C. of cormobasys & Barra Bonila & 32,18 & 65.4 & CETESB (1999); Coelho-Botelho et al. 2001$)$ \\
\hline C. dosmarius & Bam Bonuta & 32,18 & 65,4 & C(ETESB (1 999a), Cuelho-Botelho et al $(2001)$ \\
\hline C. unicornis & 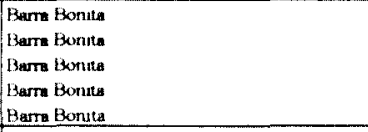 & $\begin{array}{l}5.56 \\
5.06 \\
\times D \\
N D \\
33,18\end{array}$ & $\begin{array}{l}4.9 \\
46.8 \\
\because D \\
\therefore D \\
65.4\end{array}$ & 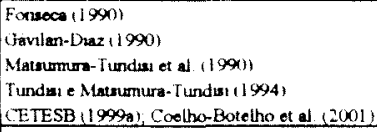 \\
\hline Eosphora anthadus & Harra Bomita & Nof & ND & Matsumura-Tundian et af (1990) \\
\hline Epiphanes macrourus & Barra Honita & 32,18 & 654 & CETESB (1999); Coelho-Botelho et al $(2001)$ \\
\hline Euchlanis dilatata & $\begin{array}{l}\text { Harra Honth } \\
\text { Barra Bonita } \\
\text { Barra Berita }\end{array}$ & $\begin{array}{r}10 \\
21,58 \\
3,18 \\
\end{array}$ & $\begin{array}{l}N D \\
61,3 \\
654 \\
\end{array}$ & 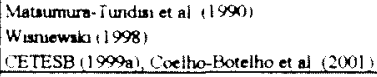 \\
\hline Filinia longiseta & $\begin{array}{l}\text { Batra Bonta } \\
\text { Barra Bonuta }\end{array}$ & $\begin{array}{rl}N & D \\
21,58 \\
\end{array}$ & $\begin{array}{l}N D \\
B 1,3\end{array}$ & 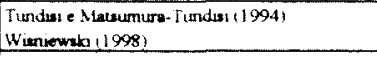 \\
\hline F. opoliensis & $\begin{array}{l}\text { Bharra Bonita } \\
\text { Bamz Bonita }\end{array}$ & $\begin{array}{l}21,58 \\
32,18 \\
\end{array}$ & $\begin{array}{r}61.3 \\
65.4 \\
\end{array}$ & 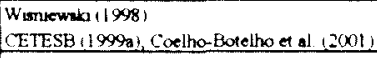 \\
\hline E.terminalis & Barre Bonute & $N D$ & N.D. & Matunura-I Indiss of al (1990) \\
\hline Hecorthro intermedio & Barma Bonita & 32,18 & 65,4 & CETESB (1999a, Coelho-Boxelho of al 12001 ) \\
\hline H. mira & Barra Bonta & 32,18 & 654 & CETESB, i 909 a), Cuetho-Botetho of at (200) 1) \\
\hline Kallicoma bostoniomsis & Barra Bomite & $3,2,18$ & 654 & CETESB $(1999$ a), Coelho Bore itho et al $(2001)$ \\
\hline Keratella americona & 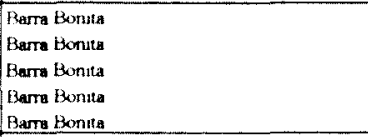 & \begin{tabular}{rl|}
5,56 \\
5,06 \\
$N D$ \\
$N D$ \\
3,18 \\
\end{tabular} & $\begin{array}{l}47 \\
46,8 \\
N D \\
X i D \\
654\end{array}$ & 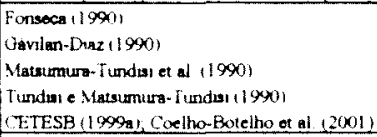 \\
\hline $\bar{K}$. cochiearis & 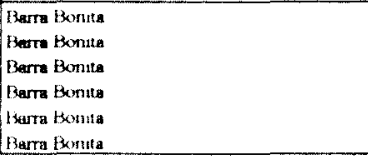 & \begin{tabular}{r|}
5.56 \\
506 \\
$N D$ \\
$N D$ \\
$\therefore D$ \\
$\therefore 2.18$ \\
2.18
\end{tabular} & $\begin{array}{l}4.7 \\
+6.8 \\
N D \\
N D \\
\therefore D \\
6.4\end{array}$ & 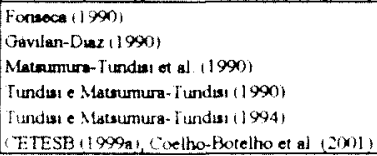 \\
\hline
\end{tabular}


TABELA 20 - Ocorrència de rotiferos, média das concentrações de clorofila $a$ total $(\mu \mathrm{g} / \mathrm{L}$ ) e Índice de Estado Trófico (IET) de Carlson modificado, em cada corpo d'água, com o respectivo autor e época de estudo, por Unidade de Gerenciamento de Recursos Hidricos (UGRHI) do Estado de São Paulo

\begin{tabular}{|c|c|c|c|c|}
\hline Especies & Reservatonoilasoa Lago & Clorofila a (1egL) & IET & Autores \\
\hline Kerateila lenst & $\begin{array}{l}\text { Barra Bonita } \\
\text { Barra Bonita } \\
\text { Barra Bonita } \\
\text { Barra Bonita }\end{array}$ & $\begin{array}{l}5.56 \\
N D \\
N D \\
21.58\end{array}$ & $\begin{array}{l}47 \\
\text { ND } \\
\text { ND } \\
61,3\end{array}$ & $\begin{array}{l}\text { Fonseca }(1990) \\
\text { Matsumura-Tundss of al (1990) } \\
\text { Tundisi e Matsumura-Tundws (1994) } \\
\text { Wisnewsio (1998) }\end{array}$ \\
\hline K. tropica & 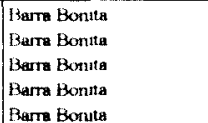 & \begin{tabular}{r|r|}
5.56 \\
$N D$ \\
$N$ & 0 \\
21,58 \\
32,18
\end{tabular} & $\begin{array}{l}47,7 \\
\text { ND } \\
\text { ND. } \\
61,3 \\
65,4\end{array}$ & 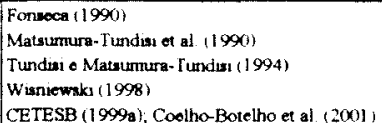 \\
\hline K. tropica & Barra Bonita & 21,58 & 61,3 & Wisnjewnki (1998) \\
\hline K. valga & Barre Bonta & ND & ND & Tundisi e Matsumura-Tunden (1990) \\
\hline Lecane cormuta & $\begin{array}{l}\text { Barra Bonta } \\
\text { Barra Bonta }\end{array}$ & $\begin{array}{l}\text { ND. } \\
\text { ND. }\end{array}$ & $\begin{array}{l}\text { ND } \\
\text { ND }\end{array}$ & $\begin{array}{l}\text { Matsumura-Tundssi et al. (1990) } \\
\text { Tundist e Matsurnura-Tundiss (1994) }\end{array}$ \\
\hline L. curncomis & Barri Bonita & 32,18 & 65,4 & CETESB (1999), Coetho-Botelho of al (2001) \\
\hline L donyssa & Barm Bonita & ND & $\mathrm{ND}$ & Matmenure fundrsi of al (1990) \\
\hline L. Koontina & Barra Bonita & ND. & ND & Matsumurg-Tundiat et al $(1990)$ \\
\hline LLeng & Barra Bunia & 32,18 & 65,4 & CETESB (1999a); Coctho-Botelho et al (2001) \\
\hline L. lunaris & Barra Bontra & ND & ND & Matsumura-Tindwis et al 11990$)$ \\
\hline Dapuana & Barra Bemta & 21,58 & 61,3 & Wisnicwak 1 (1998) \\
\hline i. quadridentata & Barra Bomita & ND. & ND & Matsumura-Tundssi et al $[1990\}$ \\
\hline Lepadalia patella & Barre Bonita & 5,56 & $47 ?$ & Fonsoca $(1990)$ \\
\hline Mantredium eudactviota & Barrm Bonita & ND. & ND. & Matsumura- [undwe1 ot al. (1990) \\
\hline Aptilina bisulcata & Barra Bonta & 32,18 & 65,4 & CETESB (19999), Coelho-Botetho et al. $20(01)$ \\
\hline Plationus paridus & $\begin{array}{l}\text { Barra Bonita } \\
\text { Barra Bonita } \\
\text { Barre Bonnta }\end{array}$ & $\begin{array}{r}5,56 \\
N D \\
32,18 \\
\end{array}$ & $\begin{array}{l}47,7 \\
\text { ND. } \\
65,4\end{array}$ & $\begin{array}{l}\text { Forsoci }(1990) \\
\text { Matsumura-Tundwi et al. }(1990) \\
\text { CETESB (1999a, Coelho-Botelho et al }(2001)\end{array}$ \\
\hline P.p. macracanther & Barre Bomita & 21,58 & 613 & Wuinewak $(1998)$ \\
\hline Planvias quadricornis & $\begin{array}{l}\text { Barra Bonita } \\
\text { Berra Bonta } \\
\text { Barra Bonta }\end{array}$ & \begin{tabular}{r|} 
ND \\
21,58 \\
32,18 \\
\end{tabular} & $\begin{array}{l}\text { N.D. } \\
61.3 \\
65.4 \\
\end{array}$ & 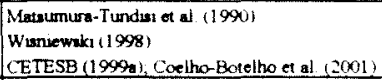 \\
\hline Polyarthra nelgarts & $\begin{array}{l}\text { Barra Bonnta } \\
\text { Barre Bonnta } \\
\text { Barrs Bonita }\end{array}$ & $\begin{array}{l}5,56 \\
\text { ND } \\
\text { ND }\end{array}$ & $\begin{array}{l}47, ? \\
\text { ND } \\
\text { ND }\end{array}$ & $\begin{array}{l}\text { Fonsocio (1990) } \\
\text { Matrumura-Tundisi et al }(1990) \\
\text { Tundias e Matsurnura-Tundesi (1994) }\end{array}$ \\
\hline Pompholyx complanata & $\begin{array}{l}\text { Barte Eonna } \\
\text { Barme Bonnta }\end{array}$ & ND & ND. & 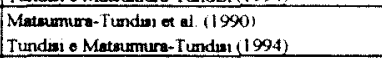 \\
\hline Ptygura libera & $\begin{array}{l}\text { Ftarm Bonnta } \\
\text { Parra Bonita }\end{array}$ & $\begin{array}{l}\text { ND } \\
\text { ND } \\
\end{array}$ & $\begin{array}{l}\text { ND } \\
\text { ND } \\
\end{array}$ & $\begin{array}{l}\text { Matsumurn-Tundut of al }(1990) \\
\text { Tundien o Matsumura-Fundasi (1994) }\end{array}$ \\
\hline Synchaste longupes & Bems Bonta & 5,06 & 46,8 & Grvilan-Diaz $(1990)$ \\
\hline S. ablonge & Barra Borme & 32.18 & 65,4 & CETESB (1999, Coelho-Botelho et al (2001) \\
\hline S pectrnato & $\begin{array}{l}\text { Barta Bonna } \\
\text { Barra Bonita }\end{array}$ & $\begin{array}{l}\text { ND } \\
\text { ND } \\
\end{array}$ & $\begin{array}{l}\text { ND } \\
\text { ND }\end{array}$ & 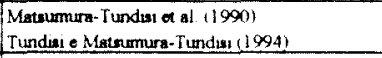 \\
\hline S. striata & $\begin{array}{l}\text { Parre Bonts } \\
\text { Berm Bonta } \\
\text { Barm Bonuta } \\
\text { Barm Bontut } \\
\text { Barra Bonta } \\
\end{array}$ & $\begin{array}{l}5,56 \\
5,06 \\
N D \\
N D \\
N 2,18 \\
32,18\end{array}$ & $\begin{array}{l}47.7 \\
46,8 \\
N D \\
N D \\
65,4\end{array}$ & 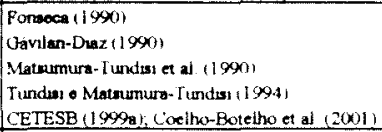 \\
\hline Testudinelila potina & $\begin{array}{l}\text { Barna Bonta } \\
\text { Farra Bonta } \\
\text { Parra Bonta }\end{array}$ & $\begin{array}{r}5,56 \\
N D \\
21,58 \\
\end{array}$ & $\begin{array}{l}47,7 \\
\text { ND } \\
6 ! 3\end{array}$ & $\begin{array}{l}\text { Fonsoca (1990) } \\
\text { Matsumura-Tundsel et al (1990) } \\
\text { Wianiewrik } 1998)\end{array}$ \\
\hline Trichocerca bicristata & $\begin{array}{l}\text { Barna Bonte } \\
\text { Barra Bonta }\end{array}$ & $\begin{array}{ll}5,06 \\
\text { ND } \\
\end{array}$ & $\begin{array}{l}46.8 \\
N D\end{array}$ & 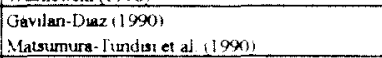 \\
\hline T. tapucina & 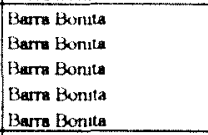 & $\begin{array}{r}5.56 \\
5,06 \\
\text { ND } \\
\text { ND } \\
3218 \\
\end{array}$ & $\begin{array}{l}47 . ? \\
46,8 \\
\text { N.D. } \\
\text { ND. } \\
65,4\end{array}$ & 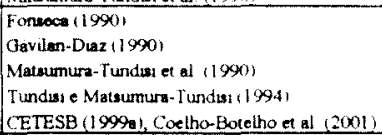 \\
\hline T. chattont & $\begin{array}{l}\text { Plame Bonits } \\
\text { Rame Bonits }\end{array}$ & ND & $\begin{array}{l}\text { ND } \\
\text { ND }\end{array}$ & 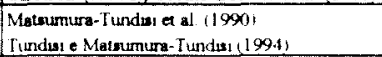 \\
\hline$T$ Exelindrica & Darra Bonitn & 32,18 & 65,4 & CETESB (1999)a, Coeltho-Botelhoet al $(7001)$ \\
\hline T. juxon-muttallit & Bamta Botuta & 32,18 & 65.4 & CETESB (1999a) Leeiho-Buteiho et al $Z(x) 1\}$ \\
\hline T. elongata & Barre Benita & ND. & $\mathrm{ND}$ & Matsumura - Tundwi et al 119901 \\
\hline T. longeseta & $\begin{array}{l}\text { Barra Bonuta } \\
\text { Barn Bomia } \\
\text { Barra Bonnas }\end{array}$ & $\begin{array}{r}5,56 \\
N D \\
21,58\end{array}$ & $\begin{array}{l}473 \\
N D \\
61,3\end{array}$ & 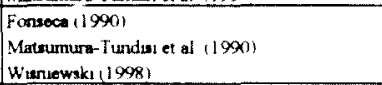 \\
\hline$T$ mus & Barra Bonts & $\mathrm{ND}$ & $\mathrm{ND}$ & Matsumura- Fundac ef al (19900) \\
\hline r. pussilla & $\begin{array}{l}\text { Barrs Bonts } \\
\text { Berra Bonth }\end{array}$ & $\begin{array}{r}\mathrm{ND} \\
3 \geq 18 \\
3 \geq 18\end{array}$ & ND & $\begin{array}{l}\text { Matmamura-Tundua et al } 11990) \\
\text { CETESB (1999a), Coelho-Botelho et ai }(2001)\end{array}$ \\
\hline T. simitus & $\begin{array}{l}\text { Barra Bonta } \\
\text { 13arta Bonta } \\
\text { Parra Bonta } \\
\text { Berra Bonita }\end{array}$ & \begin{tabular}{r|}
$N D$ \\
$N D$ \\
21.58 \\
32,18
\end{tabular} & $\begin{array}{l}\text { ND } \\
\text { ND } \\
61.3 \\
6.5 .4\end{array}$ & 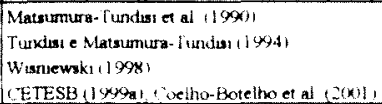 \\
\hline Irichoria istractes & Perra Bonita & ND & $\mathrm{ND}$ & Matumurra- $\mathrm{f}$ indulat et al, 1990 \\
\hline ionovella globosa & Itarra Basuica & 566 & 47 & Fonneca $(1 \times \times \times) !$ \\
\hline
\end{tabular}


Continuario

TABELA 20 - Ocorrència de rotiferos, média das concentrações de clorofila $a$ total $(\mu \mathrm{g} / \mathrm{L}$ ) e Índice de Estado Trófico (IET) de Carlson modificado, em cada corpo d'água, com o respectivo autor e epoca de estudo, por Unidade de Gerenciamento de Recursos Hídricos (UGRHI) do Estado de São Paulo

\begin{tabular}{|c|c|c|c|c|}
\hline Espectes & Reservatono Lapos Lago & Corofila a (U. L L) & IET & Autores \\
\hline Brachiowess anpularis & 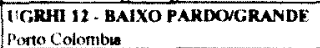 & $4,3^{-1}$ & 45,2 & 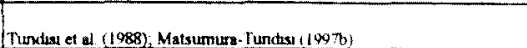 \\
\hline Oullothec ca conasa commita & Mlanmbondo & $\therefore$ & $40 ?$ & 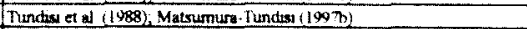 \\
\hline \multirow[t]{2}{*}{ Cumochums comobarss } & Porto colombia & 47 & 49.2 & 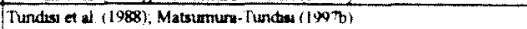 \\
\hline & Marmbondo & $\therefore$ & $\$ 0,7$ & 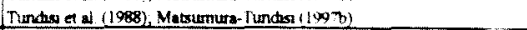 \\
\hline Euchelanes deflexa & Ponto Cocomber & 4,79 & 452 & 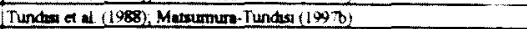 \\
\hline Fthenta lenquesta & Ponto Cochombua & 4,3 & 592 & 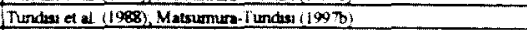 \\
\hline 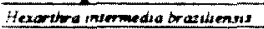 & Pento Cobmba & 43 & 45,2 & 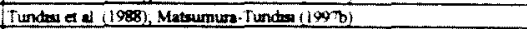 \\
\hline \multirow[t]{2}{*}{ it mira } & Porto Lalombu & 4.37 & 45,2 & 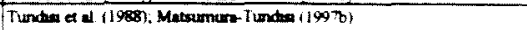 \\
\hline & Mermbondo & $2 \rightarrow$ & $40^{3}$ & 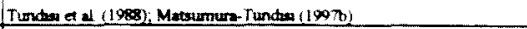 \\
\hline Keratella ememcona & Perto Cokomitue & 437 & 45,2 & 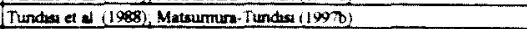 \\
\hline A cochinerese & $\begin{array}{l}\text { Ponto Colombre } \\
\text { Mermbondo }\end{array}$ & 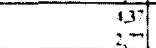 & 45,2 & 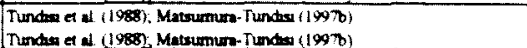 \\
\hline Lecane owils & Menmbendo & $2=1$ & $\$ 0,7$ & 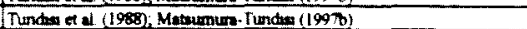 \\
\hline Fyewedibere & Pomo Colombe & 4,3 & 452 & 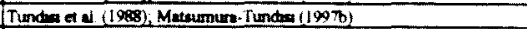 \\
\hline imeracopon fiess & $\begin{array}{l}\text { UCWHO 13 - TIETE/JACARE } \\
\text { Renn } \\
\text { Lobo (Afod) }\end{array}$ & $\because+\infty$ & $\begin{array}{l}50,7 \\
50,9\end{array}$ & 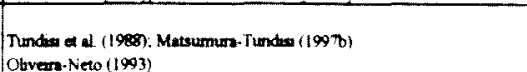 \\
\hline A nemoda & Latoo groe & $-\infty$ & 509 & Otven-Nero $(1993)$ \\
\hline Accimarpha omates & Jucure-Pepura & 2,50 & 39,7 & Forteose $(1990)$ \\
\hline & LNo Amo & vo & ND & Segen e Dumont (1995) \\
\hline i Bandist & topo (Brou) & 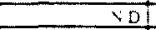 & $\checkmark D$ & Seqes \& Dumona (1995) \\
\hline Sgedisa rimrinator & Leto (Bron & $\because 0$ & $\mathrm{ND}$ & Soners e Dhumont (1995) \\
\hline 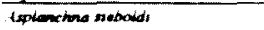 & Baenn & -6 & $50 . ?$ & 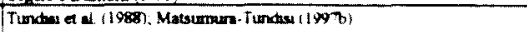 \\
\hline & Monjelento & 0.38 & $\$ 3,0$ & 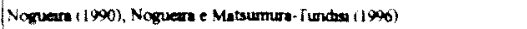 \\
\hline & Mominhinho & $\checkmark$ & ND & OKano (1994) \\
\hline Brachiones on pularts & Monolinho & 0,38 & 330 & 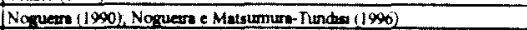 \\
\hline$B$ catwothons & Dounden & N.D. & ND & Rochs e Sernpero (I99) \\
\hline & Monjoimho & 9,38 & 530 & Nozuenn (1990) Noguenn e Mutsumurn-Tundws (1996) \\
\hline 8 condans & Tacoure Pepros & 1.0 & 35.8 & Chro (1981) \\
\hline 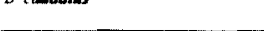 & lacert. Pepra & $\therefore 30$ & 39.7 & Fonseca $1(1096)$ \\
\hline$B$ c persongans & Moninterho & 0,38 & 33,0 & Noguers (1990); Noguease e Mutsumure-f unchsis (1990) \\
\hline 8 falcanus & Dournde & Nol & $\mathrm{ND}$ & Roche \& Sanpewo (1991) \\
\hline & iscare pepurs: & 2,5 & 39,7 & Fenence $1(10 \times 0)$ \\
\hline & Lobo (Brow) & $\checkmark \mathrm{D}$ & ND & 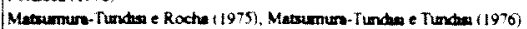 \\
\hline & Loto (Brow) &.$\infty$ & $\infty .9$ & Obvers-Newo (1993\} \\
\hline & Labo (Brot) & ND & ND & Segens e Dumont (1999) \\
\hline & Monjotenho & 9.8 & 53,0 & 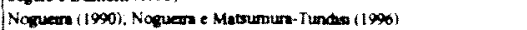 \\
\hline & Monotmino & ND & ND & Otwen (1994) \\
\hline & Pentera & $\therefore 0$ & $\mathrm{No}$ & Taiminon (1995) \\
\hline 8 manes & Lobo (Brou) & 10.19 & 93.8 & 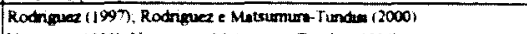 \\
\hline & Moniohnto & 0,38 & 330 & 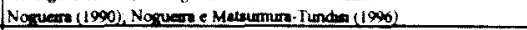 \\
\hline Dplicatulit & Monicturino & 9,38 & 53,0 & 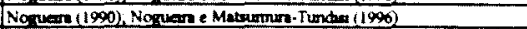 \\
\hline B. eved dentarss & Pedrem & Vo & ND & Telazsons (1995) \\
\hline 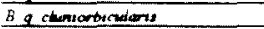 & Lobo (Bros) & . & VD & Senen e Dumont (1995) \\
\hline Bg memabilis & Labor Broes & VD & ND & 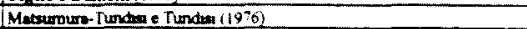 \\
\hline Copheladeris evriculaso & Petrera & $\checkmark D$ & ND & Telamern (1905) \\
\hline C cf arpo & Loto (Broe) & ND. & ND & Seter e Dumomt (1995) \\
\hline cmo & Lobo (Broes & vol & ND & Segme Dumam (1995) \\
\hline C fortacua & Wobo itroes & $\because D$ & $\mathrm{ND}$ & Segen e Lumbont (1995) \\
\hline Costos & Lobolaroul & $-\infty$ & $\$ 0.9$ & Otvers-Nero (1993) \\
\hline & Lato (Broe) & $\therefore D$ & ND & Segen e Dumont (199n) \\
\hline hoods & Wobo (Broes & VD & $\sqrt{N D}$ & Segerte Damont (1995) \\
\hline$C$ meronese & Downde & 3.46 & 48,2 & Melbo (1997) \\
\hline & Loto (Broe) & $\checkmark D$ & ND. & Segen * Dumont (1995) \\
\hline & Manjouthio & vo & ND & Okeno $(1994)$ \\
\hline Fallothera ambigua & Pedreve & $\mathrm{VD}$ & $\mathrm{ND}$ & Talemony 1099s \\
\hline if campanemita & Lobo $\{$ Brow & . & 50,9 & Otrvern-Neto! (1903) \\
\hline Comata & Loto i Broe & $\therefore D$ & ND & 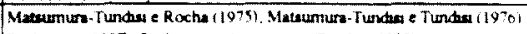 \\
\hline & 1,060 (Broe) & 10,19 & 53,8 & 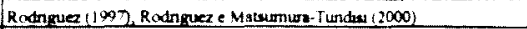 \\
\hline ocromia & LotoniBrow & (1) & 50 & 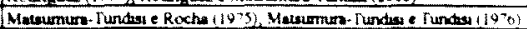 \\
\hline Colorela ot neag & Monpatingo & ⿶D & vo & Otero $(1994)$ \\
\hline C serentiate & Loto (Alace) & 40 & . 0 & Segere Dumont (1995) \\
\hline Eekinale brougpidafa & Lobor Broel & $\therefore 0$ & $\triangle D$ & Segen e Dumont (1909) \\
\hline Comochikis remobasis & Lobo r Brom & -.00 & $\$ 0,9$ & Orvern-Neo (1993) \\
\hline & Lobo (Brou) & ND & ND & Seten e Durnorn (1995) \\
\hline & Loto i Hros & 1019 & 53.8 & 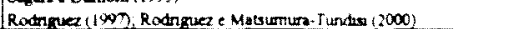 \\
\hline$\therefore$ unicomis & Lobo (Arot) & .00 & 50.9 & Obvers-Newo(1993) \\
\hline & Wobotiriat: & VD & ND & Sexers e Durnom (1995) \\
\hline & Lobol Broes) & 10.19 & 53,8 & Rodingues (1997), Rodinguez \& Matsumurn-Iurdear (12000) \\
\hline & Monpotento & 4.38 & $\$ 3,0$ & Nonuara $(1900)$, Noguan e Mussumun Fundes $(19 \times 0)$ \\
\hline Dtcrenophonus qucheris & Latoo Brous & VD & $\mathrm{ND}$ & Segen e Dumont (1999) \\
\hline$P$ hutitent & Wotoro(Broa) & 40 & $\mathrm{ND}$ & Seren e Durnont (i9es) \\
\hline D robusmis & Lobo (Bro) & 80 & $\triangle D$ & Sogers e Dumont (1909) \\
\hline Eoshunte etion tale & Labo (Brou) & $\because D$ & $\mathrm{ND}$ & Segerse Dumont (19y9) \\
\hline Euchionis dikatore & Momplentio & $\therefore D$ & $\operatorname{~} \mathrm{D}$ & Ox=0 $(1004)$ \\
\hline Ex proatim & Labo (finos) & SD & $\mathrm{ND}$ & Segen e Dumpont 1 logs \\
\hline E ocouersa & Loborturos & VD & ND & Segers e Durnoni (1909) \\
\hline Hineo kmgizeta & Dotrace & 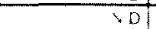 & $\therefore D$ & Ruchu e sarnpeos i | wall \\
\hline & Monjoleritio & .38 & 590 & 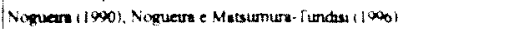 \\
\hline & Nomedentw & $\therefore 0$ & (1) & oksro $\{1004\}$ \\
\hline F T tomnesica & Tacoure-Pepose & 2.50 & $34:$ & Fonsocen $(15 \times 0)$ \\
\hline & lobororos) & $\therefore \infty$ & $\$ 0,9$ & Otvern-Neto (1993) \\
\hline Fperion & LolmitBroal & vD & $\mathrm{ND}$ & Segers e Dumbrt ( $(1995)$ \\
\hline & Watho (Brou) & 10,19 & 338 & Rodnguez (199), Rodngueze Matsumurn-I Iundan (2000) \\
\hline Fantropous enviloer & Lobor (Brous &.$\infty$ & 50.9 & Orvern-Nero (1993) \\
\hline & Latoo(Bros) & $\therefore$ D & $\mathrm{No}$ & Sogeas \& Dumorat (1945) \\
\hline
\end{tabular}


Contimuacín

TABELA 20 - Ocorrència de rotiferos, media das concentrações de clorofila $a$ total $(\mu \mathrm{g} / \mathrm{L})$ e Indice de Estado Trófico (IET) de Carlson modificado, em cada corpo d'água, com o respectivo autor e época de estudo, por Unidade de Gerenciamento de Recursos Hidricos (UGRHI) do Estado de São Paulo.

\begin{tabular}{|c|c|c|c|c|}
\hline Espoceses & Reservatono Lagoa Lazo & Clorotin a 4 gLL & $\mathrm{EI}$ & Autores \\
\hline \multirow[t]{4}{*}{ Hexarthro insermedia } & Dourada & ND & ND & 7 adamoqu (1995) \\
\hline & Dourada & $3 .+6$ & 48,2 & Melino (1997) \\
\hline & Monyolinho & $\therefore \mathrm{D}$ & $\therefore D$ & OKano $(1 \times 94)$ \\
\hline & Pachera & ND & $v_{0}$ & Talanoru $(1005)$ \\
\hline H, browiliensts & Harn & +40 & $60^{\circ}$ & Turchas et al (1988), Matsumura - Turdisi ( $(190)$ b) \\
\hline & Pectere & $Y 0$ & $\because 0$ & Talamomilyas \\
\hline 11 longucornecula & twho, Broa? & 10,19 & 57.8 & 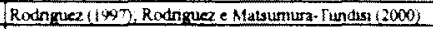 \\
\hline 11 mira & hacase-Pepin & 2.80 & 30.7 & Fonsecen $(1996)$ \\
\hline & Laborotion & $-\infty$ & 50.9 & Otvern-Neto [1993) \\
\hline & Itimpolatio & 0.38 & 530 & Noguen (1900), Noguetra e Matsumura- [undwa (1950) \\
\hline Horaetlo chemanomit & Litbol broat & $+\infty$ & 50 & Olwern-Neto $(1093)$ \\
\hline Aeratello americana & Itcare-Peptra & 2,50 & क्ष.? & Fimsect +1996$)$ \\
\hline & Labo i Brous & $-\infty$ & $\$ 0.9$ & Otvan-Nete (1993) \\
\hline & Lobor (Bres) & $\checkmark D$ & ND & Segers e Durnont (1995) \\
\hline & Lobo (Brow & 10.19 & 53,8 & 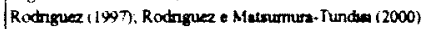 \\
\hline & Monjolunho & 9,38 & 53.0 & Noguena (1990), Noguent e Matsumum-Tundes (1996) \\
\hline & Monnoturne & ND & $N D$ & (Otano $(1974)$ \\
\hline & Poctren & ND & $\times 0$ & I lumom (1995) \\
\hline A tockleors & Dotrade & जo & No & Roche S Sempeno $($ Wy $\}$ \\
\hline & bounda & ND) & ND & 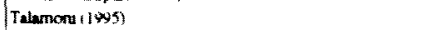 \\
\hline & Dourade & 3.46 & 482 & Mallo $(1 \times)$ \\
\hline & iacare-Pepin & 2,50 & $39 ?$ & Fonsoca $(1990)$ \\
\hline & Libo (Brou) & No & ND & Maturnure-Tundis e Roche (1975) \\
\hline & $1.0 \mathrm{bo}(\mathrm{Bros})$ &. .00 & $\$ 0.9$ & Ohvan-Neto (1993) \\
\hline & Lubor Broes & $\times 0$ & $\therefore D$ & Segers e Dumbent (1995) \\
\hline & Lotho (Brios) & 10.19 & 338 & 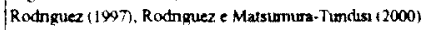 \\
\hline & Monpotintor & 0.38 & 93,0 & (Nogicare (1990): Noguctra e Matsumusz-fundiss (1990) \\
\hline & Monjoetrito & ND. & ND & Otano (1994) \\
\hline & Peatren & VD & ND & Talemoru (1995) \\
\hline A couciformis & Mompolintio & 0,38 & 930 & Noguerra $(1090)$, Nogueria e Matsurnura- - Iundisi (1996) \\
\hline A tropica & ham & -.40 & $50 ?$ & Tundari et al (1988); Matsumure Tundess $(1997 \mathrm{~b})$ \\
\hline & Douradra & No & $\therefore 0$ & Rocha e Surmpeso (1991) \\
\hline & facare-Pepina & 2,00 & $39+$ & Fonseca $(1990)$ \\
\hline Lecone aqueara & hourade & $N D$ & $\times 0$ & Talamora $(11995)$ \\
\hline Logus & Labol Rxoes & ND & $\because 0$ & Segers e Damont (1909) \\
\hline Lancula & Labolara) & ND & SD & Segerse Dhument (1005) \\
\hline L bylantigata & Dournde & Not & 50 & Tilangore (1995) \\
\hline L. bitive & Lobol(Bros) & vo & ND & Segers e Dument (1909) \\
\hline$L$ aropilioniss & Labo (Broe) & XD & ND & Segers e Dumomt 1.1995) \\
\hline Ltroaensts & LabolBroe & ND & ND & Segens e Dumomi (1909) \\
\hline L toulo & Dourain & ND & No & Roche e Sampono (1991) \\
\hline & Wourack & No & ND & Talemora i (1995) \\
\hline & Labo (Brow) & 3.0 & 50,9 & Otvera-Neto (1993\} \\
\hline & Latho (Bros) & ND & ND & Segens e Durncont (1999) \\
\hline & Monpoterito & No & $\therefore D$ & $\operatorname{lok}(1,0,0)$ \\
\hline L clara & Wounde & $3,+\infty$ & $\$ .2$ & Metholison \\
\hline & What Brow & ND & so & Sogene Dument (1995) \\
\hline L clueteroserca & Lato (Broe) & ND & ND & Segene Dernomin (1905) \\
\hline L commia & intoribroel & ND & $\mathrm{ND}$ & Sogen $<$ Oumont (19) S \\
\hline tromramis & l, whor Broes & 300 & 80 & Olvean-Neto $(1 \times 9)$ \\
\hline I c mindo & L Lubo (Bros) & 40 & $\mathrm{SD}$ & Sagen e Durnom (1909) \\
\hline 1. derceions & Cobo(Btoe) & NDI & $\times 0$ & Segers e Dumonn (1995) \\
\hline 1. doryssa & Thournd & $\because D$ & $N D$ & Rocha e Sernpano (1991) \\
\hline & ibourads & $\therefore D$ & No & Tolamon (1995) \\
\hline Sexplys & Lubor (Bros) & पDD & $\therefore D$ & Segers e Dumiont (1995) \\
\hline Lurcata & Loto (Bros) & VD & $\therefore D$ & Segers e Dumnent (1995) \\
\hline L ghpta & Dournda & NDI & $\therefore B$ & Talantions (1995) \\
\hline & herrade & $3 .+$ & 48,2 & Meläo,1997) \\
\hline hamata & ! wbolBroa) & $\because 0$ & $\because D$ & Segers e Lumont (1005) \\
\hline Lhomemennt & LubotBroul & ND & $\times D$ & Segerse i Irment (1995) \\
\hline t. inermis & 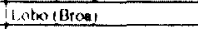 & $\mathrm{ND}$ & $\therefore 0$ & Sexers e Dutront il iwos \\
\hline t. bontina & thoutuade & $\therefore 0$ & $\times D$ & Roche e Sampero $(199)$ \\
\hline & Luboibroes & $\therefore 0$ & $\times D$ & Segen e Dumans (1095) \\
\hline 1. Levestiva & Dourede & VD & $\times 0$ & Thlameru (1999) \\
\hline & Brounde & 3,6 & $\$ 2.2$ & Melioulan \\
\hline 1. hedoryt & Lobo (frow) & $-\infty$ & 6.9 & Obvesn - Neto $\{(00,3\}$ \\
\hline & Monjobentio & No & $N D$ & Otano $(1904)$ \\
\hline & Predrem & $\because 0$ & $\checkmark D$ & Talamona (1 14095 \\
\hline i. encodes & Cobol(Aroe) & $\times 0$ & 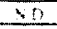 & Segers e Luments (jous) \\
\hline 1. 1 Laticaudata & thitho (Bras) & $\therefore 0$ & 50 & Segars e Dument (1005) \\
\hline it inuvensis & Nobolerose & 01 & 80 & Segerse e Dhumont iluos \\
\hline Sung & hournde & 40 & 50 & Roche e sempeoul(oo) \\
\hline 1. Exnams & Whourade & $N D$ & $\therefore D$ & 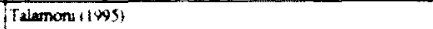 \\
\hline & I ikutrada & $3, \infty$ & 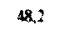 & Meikorisot] \\
\hline & 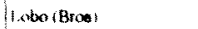 & 19,19 & 9.8 & 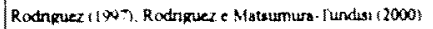 \\
\hline & Fatrear & $\mathrm{n}$ & $\because$ & Talamono i wots \\
\hline 1. I crenata & Wontrende & VD & $\mathrm{ND}$ & 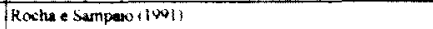 \\
\hline & Luther (Brne) & ND & ND & Segene e Dumbant (149) \\
\hline $\operatorname{mins}$ & Lubo (Broo) & ND & $\therefore D$ & Segers e Dumont (1095) \\
\hline monostiva & mouradm & $8 \mathrm{DI}$ & $\sqrt{n}$ & Raxha e Sampaor rout\} \\
\hline & | thourada & $\vee D$ & $\therefore 0$ & Talamons tives \\
\hline & 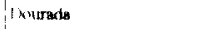 & 7.6 & $16:$ & Meläollowt \\
\hline & L who (Btion) & $v 0$ & $\therefore D$ & Sogers e Lumont (1995) \\
\hline & Mimjounte & (2) 38 & 30 & 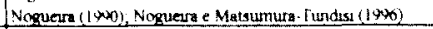 \\
\hline pertica & I keurade & $\therefore 0$ & $\times 0$ & Richa e Sartipao ( $(20)\}$ \\
\hline & Invurade & $\triangle D$ & $\mathrm{No}$ & Talamonu (1609) \\
\hline parilla & Lwbolbroe & VD & $\times 0$ & 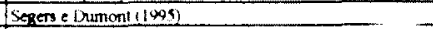 \\
\hline Derdionnis & 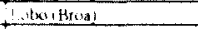 & 4.01 & 90 & Seyerse e Drumont (199) \\
\hline Susudrideniara & 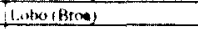 & $\therefore 0$ & $\therefore 0$ & Segerae Dummel (ings \\
\hline Stitutaia & Conads & $\because 0$ & $\therefore$ & Rexhac sempasos $\mid$ wit \\
\hline
\end{tabular}


Continuaciso

TABELA 20 - Ocorrència de rotiferos, media das concentrações de clorofila $a$ total $(\mu \mathrm{g} / \mathrm{L})$ e Indice de Estado Trófico (IET) de Carlson modificado, em cada corpo d'água, com o respectivo autor e época de estudo, por Unidade de Gerenciamento de Recursos Hídricos (UGRHI) do Estado de São Paulo.

\begin{tabular}{|c|c|c|c|c|}
\hline Espectes & Reservalmo Lazca ingo & Cloroüh a [uRL] & IET & Autores \\
\hline \multirow[t]{3}{*}{ Lecane signifera } & Jacare-Pepus & 2,50 & 39.7 & Fonseca $1(10 \%)$ \\
\hline & Labo i Bron & No & ND & Serers e Dumont t toys \\
\hline & Lobo Broas & .0 .19 & 538 & 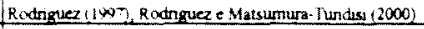 \\
\hline Is plomentss & Lotoc $\operatorname{Br}(\mathrm{e})$ & $-\infty 0$ & 50,9 & Ohvers: Neto $(1993)$ \\
\hline \multirow{2}{*}{ L sichoes } & Lobo i Broat & $\therefore D$ & ND & Segers e Dumont (1995) \\
\hline & Dounede & $3,+6$ & 48,2 & Meläo(1900) \\
\hline L subritut & Lobo Broal & $\therefore \mathrm{D}$ & $\mathrm{ND}$ & Segers e Dhumont (10ys) \\
\hline Luenot & Labou Broas & ND & $\mathrm{ND}$ & Segere e Dumont 11095 \\
\hline \multirow[t]{2}{*}{ L. ungulata } & Dourath & ND & $\mathrm{ND}$ & Taliamonn (19995) \\
\hline & Labo Broes & ND & ND & Segen e Dumorat (1995) \\
\hline Lapadella benyamins & Loto (Bros) & NDI & ND & Seseres e Dumorat (1995) \\
\hline L. cortatoldes & Loho (bros) & ND & $\mathrm{ND}$ & Segers e Dhumont (1995) \\
\hline \multirow[t]{4}{*}{ L. cristata } & Dotrnech & N.D. & ND & Rocha e Sermpeas (1991) \\
\hline & Dotrads & N.D. & N.D. & Talamont (1995) \\
\hline & Dourach & $3, \infty$ & 48,2 & Metbo (1997) \\
\hline & Labo $\operatorname{Brcc}$ & ND & ND & Sogers e Dumont (1995) \\
\hline Ldactusesa & Labo (Brou) & ND & $\mathrm{ND}$ & Segers e Dumont ily9s) \\
\hline Lefongola & L.obo(Broa) & ND & $\mathrm{ND}$ & Sogers $\&$ Dumbont (1905) \\
\hline L. labusinus anericana & Lobo (Broe) & 200 & 50,9 & Otvera-Neto (1993) \\
\hline L. minemia & Labo i Bros & ND & $\mathrm{ND}$ & Segere e Dumoni (ixy) \\
\hline L nesiecta & Lato Brou & $\mathrm{ND}$ & $\mathrm{ND}$ & Segerse Dumont (1909) \\
\hline Lovalss & Lobo iBroa & VD & $\mathrm{ND}$ & Segerse Dumont (199) \\
\hline \multirow[t]{4}{*}{ L postella } & Doundu & ND & ND & Tralamorn $(1499)$ \\
\hline & Incure-Pepan & 2.50 & $39, ?$ & Fonsect $(1000)$ \\
\hline & Lobo (Brou) & N.D & ND & (Segers e Durnona (1 (Y)s) \\
\hline & Podrems & ND. & N.D. & Talamon : 1095 \\
\hline L quadicarinata & Labo (Brou) & ND & $\mathrm{ND}$ & Segen e Dumont (1995) \\
\hline L. guedricoudo & Pedrent & ND & $\mathrm{ND}$ & Talumon (1999) \\
\hline Ir rombordes & Dounede & ND & $\mathrm{ND}$ & Roche e Sampero (199) I] \\
\hline$L_{\text {mabo }}$ & Lator (Brous & vD & $\mathrm{ND}$ & Segerse Dumont (1999) \\
\hline \multirow[t]{2}{*}{ L. mpiera } & Labo (Brous & ND & $\mathrm{ND}$ & Segers e Dumons (1995) \\
\hline & Monolarato & 0,38 & 53,0 & Noquere (1990), Noxuera e Malsumuma-Turdua (1996) \\
\hline Lendia torulosa & Latho (Arroe) & ND & $\mathrm{ND}$ & Segerse e Dhumont (1995) \\
\hline Macrochaesu aitamiral & Lobo $(8500)$ & ND & ND & Sereers e Dumoni (1995) \\
\hline \multirow[t]{3}{*}{ M. collinst } & Lobo (Broes & N.D. & $\mathrm{ND}$ & Segers e Dumont (1995) \\
\hline & Lobo (Broe) & 10,19 & 53,8 & Rodrguez (1997), Rodnguez e Matsumurn. Tundwi (2000) \\
\hline & Peatreara & ND & N.D & Tatancon (1999) \\
\hline$M$ longipes & Dourada & 3,40 & 48,2 & Melibo $(1097)$ \\
\hline M. enquadratus & Douracin & ND & ND & Telumons (1999) \\
\hline & Jeare Pagen & 1,0 & 35.8 & Claro $(1981)$ \\
\hline Monommaja end $t_{t}$ & Labo, Aroos & VD & ND & Sogem e Dumont $(1995)$ \\
\hline$M$ cendoro & Monpontro & ND & ND & Otano $(1994)$ \\
\hline 4 mariala & Dourrectu & ND & ND & Rocha e Sampeno (1901) \\
\hline & Dowrad & 3.46) & 48.2 & Mellorigen \\
\hline & Lober Brou & No & ND & Segers e Dumont (1909) \\
\hline$M$ macromata & Dournode & ND & $\mathrm{ND}$ & Talurioro (1909) \\
\hline Myalina bessukato & Monjodurtio & Not & ND & Ottano $(1994)$ \\
\hline$M$ micronata & Doungen: & ND & $\mathrm{ND}$ & Rocha e Sermpens 19001$]$ \\
\hline$M$ wertrats & Lobo (Broa & ND & $\mathrm{ND}$ & Segers e Dumont (1995) \\
\hline & Monolunto & ND. & ND. & lokeno $(1944)$ \\
\hline Voromomaja certionus & Loto Broes & ND & $\mathrm{ND}$ & Segense Dumont (1909s\} \\
\hline$N_{\text {curtopus }}$ & Labo (Hros) & ND & $\mathrm{ND}$ & Sogers e Dhemont (1 wos) \\
\hline N. pachyura & Lobo (Brina) & ND & $N D$ & Sogerse Dumont (1995) \\
\hline$\therefore$ saccigera & Lobo (Aroes) & पD & $\mathrm{ND}$ & Sogers e Drmignt $(19 \times 5)$ \\
\hline Plattomus paries & Jacere-Peprire & 2.50 & 39.7 & Fonseca 1996$)$ \\
\hline & Momplentho & 0.98 & 53.0 & 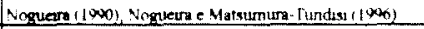 \\
\hline Pe macracanthus & Douradin & 3,46 & 4,2 & Melao (199) \\
\hline Plapued letoupt & Lobalibros & $\because D$ & ND & Segers e Damont (1995) \\
\hline Pquadricomis & Tacase Payru & 1,0 & 35,8 & Cleso $(1981)$ \\
\hline & Loto (Bras) & N.D. & ND & Segers e Dumont ( (1995) \\
\hline & Monkilunto & 0,38 & 53,0 & 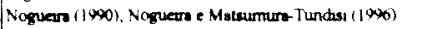 \\
\hline & Monpointo & No. & ND & okeno $(1094)$ \\
\hline & Potrane & No & ND & Talamonu (1995) \\
\hline Ploesome enonkanum & Lobo (Broe) & ND & ND & Seger e Dumomt (1909) \\
\hline Polperthro longersmis & Monjobrno & 0.38 & 50 & 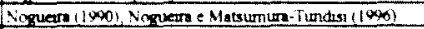 \\
\hline Pquadrata & Mompintio & ND & $\times D$ & Okano $1(094$ \\
\hline$P$ wears & Dounde & NDI & $\times D$ & Rocha e sempaso ||$\infty|+|\}$ \\
\hline & Dowrada & $\mathrm{ND}$ & $\times 0$ & Thamona liken \\
\hline & Imacare.Pequre & 2,50 & 39 , ? & Fonsece $10 \times 0$ ) \\
\hline & Lobo i Biou) & $7, \infty$ & $\$ 0,9$ & Otvers-Neto (1993) \\
\hline & Lobo (Broe) & 10.19 & 53.8 & 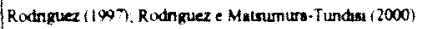 \\
\hline & Lobo (Mrow & ND & ND & Segers e Dumons (1495) \\
\hline & Momolustho & 0.38 & 53,0 & 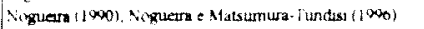 \\
\hline & Monjodurho & ND & NO & Okano $(1 \times 94)$ \\
\hline & Pedrem & No & ND & Themora(1405) \\
\hline P cf mugaris & Ixnarada & $3+\infty$ & 48,2 & Mellof 1997 \\
\hline Prixales decipiens & 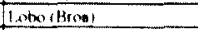 & VD & $\therefore$ & 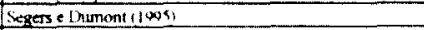 \\
\hline Pfalloctiosa & Lubotbrous & $\mathrm{NO}$ & $\mathrm{ND}$ & Segers e Lumbont (1)iss) \\
\hline
\end{tabular}


Continumarto

TABELA 20 - Ocorrència de rotiferos, media das concentrações de clorofila $a$ total $(\mu \mathrm{g} / \mathrm{L})$ e Indice de Estado Trófico (IET) de Carlson modificado, em cada corpo d'água, com o respectivo autor e época de estudo, por Unidade de Gerenciamento de Recursos Hidricos (UGRHI) do Estado de São Paulo

\begin{tabular}{|c|c|c|c|c|}
\hline Espeases & Reservatoncl Lagoa Lago & Chroth a ing L L & IET & Autores \\
\hline \multirow[t]{5}{*}{ Prypure havere } & acare-Pepura & 201 & $39=$ & Fonsece $(1996)$ \\
\hline & i. stoo i Brow & $-\infty$ & $\mathbf{\infty}, 9$ & Otvern-Neto (1993) \\
\hline & $(6, \infty)$ (Arros) & 10.19 & 53.8 & 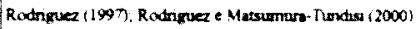 \\
\hline & Monketrita & 9.38 & 53,0 & 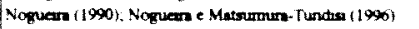 \\
\hline & preatreme & ND & ND & Tolumorn (1909) \\
\hline P\&f & I.tei, Broul & 1. & $\mathrm{ND}$ & Segens e Dumont (1999) \\
\hline 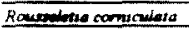 & Liteon Broe & $\mathrm{ND}$ & $\mathrm{ND}$ & Segers e Durmont (1995) \\
\hline 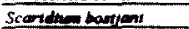 & S Abo I Broel & ND & $\therefore D$ & Seress e Dumbont (1999) \\
\hline Shentecenden & Honpounto & ND & $\mathrm{ND}$ & Okno $(1994)$ \\
\hline Squariente mences & Laboibroes & ND & $\mathrm{ND}$ & Segen e Dumomi (1905) \\
\hline 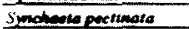 & Sompolanho & 938 & 530 & 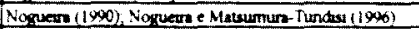 \\
\hline S cf pectumere & 1kunde & 346 & 48 & Mello 1909 \\
\hline \multirow[t]{2}{*}{ sonime } & Honfountho & 9.38 & 53.0 & 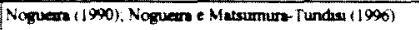 \\
\hline & Monkinuto & No & ND & Oteno (1994) \\
\hline 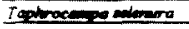 & Inove Broes & vo & No & Seron e Drmona (1995) \\
\hline 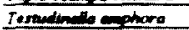 & Bulbor Aroes & $\therefore D$ & No & Serense Drampont (1909) \\
\hline$T=\operatorname{mon}$ & Hoor Bros & $\triangle D$ & $\mathrm{ND}$ & Segene e Dumont (1909) \\
\hline Ineconeres & Tompentio & ND & $\mathrm{ND}$ & Otano (1994) \\
\hline Iperm & Sentos Broal & vD & $\mathrm{ND}$ & Sarerse f Dumome (1995) \\
\hline I patine & 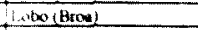 & No & ND & Sepess e Dumont 1909 \\
\hline 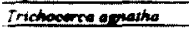 & Mempobenho & 98 & 530 & 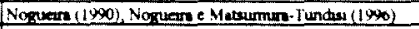 \\
\hline \multirow{3}{*}{ T bierisuose } & Dourmata & NDI & ND & Tolamonu (1995) \\
\hline & Labo i Brous &. .00 & 50,9 & Otvera-Neto (1993) \\
\hline & Latero(Bros) & ND. & ND & Sexers e Dumont [1999, \\
\hline \multirow[t]{2}{*}{$T$ bidones } & Laborbtros) & $7, \infty$ & 50,9 & Otivern-Neto $(1993)$ \\
\hline & wabo Brous & ND & ND & Seren e Dumont i1999) \\
\hline I brentienes & Tatoo Broes & $\therefore D$ & $\mathrm{ND}$ & Segers e Chumorn 1999s \\
\hline \multirow[t]{3}{*}{$T$ capareven } & Thern & .4 & 30. & 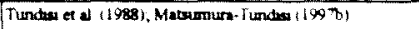 \\
\hline & 1acere Pepon & 1,0 & 35.8 & Cluro (1981) \\
\hline & sotwo Broes & $+\infty$ & $\infty, 9$ & Obvem-Neto (1993) \\
\hline$I$ chathons & tho Bros & -80 & 0,9 & O(veess-Neto (1993) \\
\hline \multirow{3}{*}{$T$ colime } & Desurate & $\mathrm{ND}$ & $\mathrm{ND}$ & Racha e Serupeso [1991) \\
\hline & bouradis & $\times D$ & ND & Talempon (i (1995) \\
\hline & sourade & 36 & 48.2 & 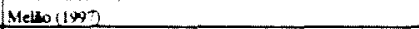 \\
\hline telonew & tototo faroul & 7,00 & 50,9 & Otwem-Nero (1993) \\
\hline & Lintos Bros & 7,00 & 89 & Otvern-Neto $(1993)$ \\
\hline \multirow{2}{*}{$\frac{T \text { lomes }}{T \text { heteradente }}$} & Labo Broul & -60 & 309 & Otrean-Neto $(1993)$ \\
\hline & Monokdertio & No & ND & Otweno (1994) \\
\hline & Petren & ND & $\mathrm{ND}$ & Tulumon: (1999) \\
\hline I temenes & Intoo Brous & ND & ND & Segen : Durnort $(1909)$ \\
\hline T lonetsende & intor Bros & $-\infty$ & 509 & Otvent-Neto (1993\}) \\
\hline \multirow[t]{4}{*}{$T$ bongiones } & Aknurede & $\mathrm{ND}$ & ND & 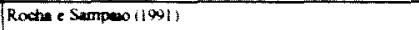 \\
\hline & Dowarada & Nol & ND & Thlemose i (1995) \\
\hline & I invirnde & 3.4 & 48.2 & Mello (1907) \\
\hline & S, the Aroses & $\therefore \mathrm{D}$ & ND & Segen e Dumani $\{1999$ ) \\
\hline I moneren & bou, Aroe & 40 & $\mathrm{No}$ & Segare e Drathent $1100 \%$ \\
\hline$I \mathrm{mom}$ & totho Arew & 70 & $\mathrm{ND}$ & Segers e Dhimont (1995) \\
\hline porrellue & abolBros & $\triangle D$ & No & Segers e Dhumkre 1999 \\
\hline \multirow{2}{*}{$\frac{\text { porresus }}{\text { T purits }}$} & Thenof Brose & 7.00 & 80,9 & Otvern-Neto $(1993)$ \\
\hline & 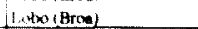 & $\mathrm{ND}$ & ND & Segers c D Demmont (1999) \\
\hline In neleta & Butho Broal & $\times D$ & $\mathrm{ND}$ & Segen e Dumont (1999) \\
\hline \multirow[t]{3}{*}{$I$ mimils } & Therrada & $\mathrm{ND}$ & ND & Thenernova (1999) \\
\hline & I hoturatio & 3.10 & 48.2 & Melso $(\mid \alpha)$ ) \\
\hline & Poo Broses & 10.19 & 938 & 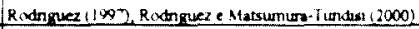 \\
\hline & intolarme & SD & $\mathrm{NO}$ & 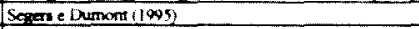 \\
\hline \multirow{2}{*}{ 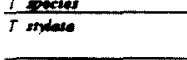 } & Sotbo itroe & .00 & 9.9 & Otvarn-Neto $\{(y) 3\}$ \\
\hline & Pedran & $\mathrm{SD}$ & ND & 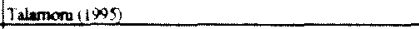 \\
\hline \multirow[t]{2}{*}{ Tners } & ind bothrowi & $-\infty$ & 50,9 & Utrvern-Neto $\{[\$ 93\}$ \\
\hline & Wato Brow & $\therefore 0$ & No & Segers e Dumont (1999) \\
\hline \multirow[t]{2}{*}{ Trichoore woress } & 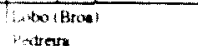 & जD & $\begin{array}{l}\text { ND } \\
\forall 0\end{array}$ & 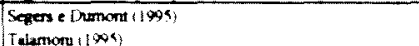 \\
\hline & inteatra & & & \\
\hline
\end{tabular}


Continuacho

TABELA 20 - Ocorrència de rotiferos, media das concentraçōes de clorofila $a$ total $(\mu \mathrm{g} / \mathrm{L})$ e Índice de Estado Trófico (IET) de Carlson modificado, em cada corpo d'água, com o respectivo autor e epoca de estudo, por Unidade de Gerenciamento de Recursos Hidricos (UGRHI) do Estado de São Paulo.

\begin{tabular}{|c|c|c|c|c|}
\hline Especies & 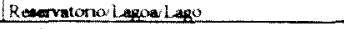 & Goofila a ug L L I & IET & Autores \\
\hline Ascomorpha ecaudis & $\begin{array}{l}\text { IGRHI I4 - AL TO PARANAPANEMA } \\
\text { JuRumuryn }\end{array}$ & 1 & 414 & Mutsula i 1998 \\
\hline \multirow[t]{2}{*}{ Aspianchna sieboldi } & Jurumeran & 2,00 & 37,4 & 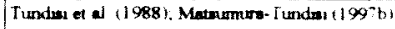 \\
\hline & Xavantea & 165 & 35.5 & 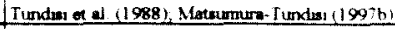 \\
\hline \multirow[t]{3}{*}{ Brachiomus angularis } & Jurumuruta & 2.18 & 38,3 & Paruareliti (1999) \\
\hline & Coquera! & 10.63 & 54,2 & Cananova $(2000)$ \\
\hline & Camuono & 982 & 51,2 & Catanowa 2000$)$ \\
\hline \multirow[t]{2}{*}{ B. bidentata } & Copueral & 10,63 & 54.2 & Casenova $(2000)$ \\
\hline & Cannerso & 32 & 51,2 & Cosanown 2000$)$ \\
\hline B. calperitons & $\begin{array}{l}\text { Jurumirm } \\
\text { Juruminn }\end{array}$ & $\begin{array}{l}2.46 \\
3,00\end{array}$ & $\begin{array}{l}39.6 \\
41.4 \\
\end{array}$ & $\begin{array}{l}\text { Noguere }(1996) \\
\text { Miltudta (1998) }\end{array}$ \\
\hline \multirow[t]{2}{*}{ B. dolabratus } & Coquern: & 10,63 & 54,2 & Camenowa $(2000)$ \\
\hline & Camango & 82 & 51,2 & Cananove 120001 \\
\hline \multirow[t]{4}{*}{ B. falcatus } & Jurimuran & 2,46 & 39,6 & Nogueira: $(1996)$ \\
\hline & Jurumurum & 2.18 & 38,3 & Parareill (1999) \\
\hline & Coqueral & 10.63 & 54,2 & Cammova $(2000)$ \\
\hline & Camerno & .82 & 51,2 & Camonove 2000$)$ \\
\hline \multirow[t]{2}{*}{ B. forficuia } & Coquential & 10.63 & 54.2 & Caunova 12000 \\
\hline & Camango & .821 & 51,2 & Canoman 2000 \\
\hline Ollother m mulabilis & Jurumierm & 2.18 & 38,3 & Fanarelin 1999 : \\
\hline Sornats & Jurunerm & 2.181 & 38,3 & Panarelin (1999) \\
\hline \multirow[t]{6}{*}{ Conachilus conobasis } & furumurem & 2001 & 37.4 & Tundes ef al (1988). Matsumure Tundas ( $1997 \mathrm{~b})$ \\
\hline & Jurumeram & 3.00 & 41.4 & Mrtaina (1998) \\
\hline & Junumirm & 2.18 & 38.3 & Panarelin (1999) \\
\hline & Coquernal & 10,63 & 54.2 & Casmova $: 2000)$ \\
\hline & Carnarno & .82 & $5 ! .2$ & Cacanova $(2000)$ \\
\hline & Prope & 3,59 & 400 & Tundus of at (1988), Matsimura- Tundpi (1997 bi \\
\hline \multirow[t]{2}{*}{ C. natant } & Junurnerun & 3.00 & 41,4 & Mrtukan (1998) \\
\hline & Jurumirm & 2,18 & 38.3 & Panmelli (1999) \\
\hline \multirow[t]{6}{*}{ Cunicornis } & Surumurum & 2.46 & 39,6 & Noguern $(1996)$ \\
\hline & Junumurum & $1, \infty$ & 31,3 & Noguers o Parmelis (199?) \\
\hline & Juremurum & 3,00 & 41,4 & Mrenda (1998) \\
\hline & Jurumurnm & 2.18 & 38,3 & Penereill (1999; \\
\hline & Coqueral & 10.63 & 54.2 & Camanova $(2000)$ \\
\hline & Comese & .82 & 51,2 & Ceneman 2000$)$ \\
\hline Epiphanessonia & Jurumurma & 2,46 & 39,6 & Nonverc 1996 \\
\hline Filinia longisete & Jurumurm & 3,00 & 41,4 & Mteruka (19988) \\
\hline & Jưmum mn & 2.18 & 38,3 & Parnarelli (1999) \\
\hline & Coquent & 10.63 & 54.2 & Cananova 12000 \\
\hline & Camaroso & 7.82 & 51.2 & Casumova : 2000 ) \\
\hline & Piraju & 2,59 & 40.0 & 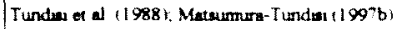 \\
\hline & Yaventees & 1,65 & 35.5 & Tundus of al (1988). Mateumura-Tundan i 199 b) \\
\hline Evopodiensis & Junemirm & $3, \infty$, & 41,4 & Mitsula $(1998)$ \\
\hline F torminals & Iunvenurm & 3,00 & 41,4 & Mitmuka (1998) \\
\hline & Jurimirm & 2.18 & 38.3 & Parnelin 11999, \\
\hline & Coqueral & $10,63 \mid$ & 54.2 & Camonova 22000 \\
\hline & Camargo & 7,82 & 51,2 & Casanova 12000 ) \\
\hline Hexarthro infermedio & Jurumsrum & 3,00 & 41,4 & Mitsuka ( I 998 ) \\
\hline & Jurumentm & 2,18 & 38,3 & Panarelli +19999 \\
\hline If. t. brasiliensis & Jisumurum & 2,18 & 38,3 & Panarelili (19999) \\
\hline Rellircotria longuspina & Coquesse & {$[0,63$} & 54,2 & Casanova 12000: \\
\hline Aerateilla americanas & Jurumarum & 2.00 & $3: 4$ & 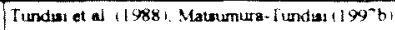 \\
\hline & furrumurm & 2.46 & 39,6 & Nopaere 119961 \\
\hline & furumurus & 1,08 & 31,3 & Nopuera e Parareihi : 199?', \\
\hline & Jurumuram & 300 & 41.4 & Mrouka (1998) \\
\hline & furumurm & 2,18 & 38.3 & Panarelli (1999) \\
\hline & Coquerra: & $\mid 0,63$ & 54.2 & Canemove 2000 ) \\
\hline & Carnaryo & -82 & 51.2 & Cananove 20001 \\
\hline & Prafuju & 2.59 & 4),0 & Tundus et al (1988), Matsumura - Tundus $1199^{\circ} b$ : \\
\hline & Xavantes & 1.55 & 35.9 & 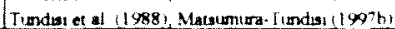 \\
\hline A. tochlearis & Jurvenurun & 2.46 & 39,6 & Nopuera il I996: \\
\hline & funumuran & $1, \infty$ & 31.3 & 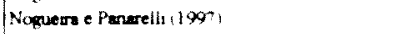 \\
\hline & ftarumurm & 3.00 & 41.4 & Masuka 11098 \\
\hline & Surummerm & 2.18 & 38.3 & Panarelin (1999) \\
\hline & Compueral & 10.63 & $4: 2$ & (caunovatians \\
\hline & Carrumso & .82 & 51.2 & Cannorm 2000 ) \\
\hline & Prape & 2,59 & 4) 0 & 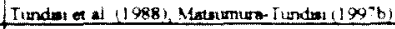 \\
\hline R ients & Surumurm & 2.46 & 39.6 & Noquers 19996 \\
\hline & Coquerral & 10,63 & 54.2 & Canown if $\left(\mathrm{CO}_{0}\right) \mathrm{s}$ \\
\hline & Camergo & -82 & 912 & Casanova f Zianois \\
\hline A. irspica & Lurumurun & $\therefore 46$ & 39.6 & 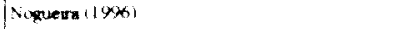 \\
\hline & incunarem & 1.08 & 31,3 & 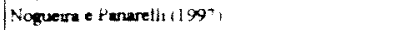 \\
\hline & Surimerm & 3,00 & 414 & Mntsukn I 1998 \\
\hline & Lusumuram & 2,18 & 38.3 & Panarelin II $x x y$ \\
\hline & Converna & in) 63 & 342 & Canonove 20000 \\
\hline
\end{tabular}


Contmunguo

TABELA 20 - Ocorrència de rotiferos, média das concentrações de clorofila $a$ total $(\mu \mathrm{g} / \mathrm{L})$ e Índice de Estado Trófico (IET) de Carlson modificado, em cada corpo d'água, com o respectivo autor e epoca de estudo, por Unidade de Gerenciamento de Recursos Hidricos (UGRHI) do Estado de São Paulo.

\begin{tabular}{|c|c|c|c|c|}
\hline Especies & Reservitono Lago Lapo & Clorofila a (ukl. & IET & Auturea \\
\hline \multirow[t]{3}{*}{ Lecane bullo } & Strumirm & 3.00 & 41.4 & Mnsuka (1998) \\
\hline & Sumumurum & 2.18 & 38.3 & Panarelih (1999) \\
\hline & Curnargo & 2.82 & 51,2 & Casanove 2000 \\
\hline Euturviconis & Surumerns & 518 & 38,3 & Panareilh (1999) \\
\hline \multirow[t]{3}{*}{ 2. Iunaris } & funumersn & 3,00 & 41.4 & Mitsuka (1998) \\
\hline & hurumorm & 2,18 & 38.3 & Panareilh (1999) \\
\hline & Camngo & 582 & 51,2 & Cassonove 2000$)$ \\
\hline L. manomila & Siunmarem & 218 & 38,3 & Panereilh (1999) \\
\hline If obrusa & Junumirm & 318 & 38,3 & Panarellh (1999) \\
\hline L. ef pertica & flurumirmm & 2,18 & 383 & Paneroih (1999) \\
\hline L- ef priformis & firremirm & 218 & 38,3 & Panurelis (1999) \\
\hline \multirow[t]{2}{*}{ L. Scutato } & furuenrern & 3,00 & 41,4 & Mitruika (1998) \\
\hline & Junumbern & 2,18 & 38,3 & Pararelili (1999) \\
\hline issenfora & Juscumirm & 218 & 38,3 & Panuredili (1999) \\
\hline \multirow[t]{2}{*}{ L. stenroosi } & Jurumurive & 3,00 & 41,4 & Mtsula (1998) \\
\hline & Lurumirm & 2.18 & 38,3 & Panarelli (1999) \\
\hline \multirow[t]{2}{*}{ Ln stichaea } & lirumurm & 2.18 & 38.3 & [Panarelli (1999) \\
\hline & Camerno & 282 & 51,2 & Carenove $(2000)$ \\
\hline I- of sthehose & Junuminn & 300 & 41,4 & Mrrula (1998) \\
\hline \multirow[t]{2}{*}{ Lo thuenemenns } & huremurem & 2,18 & 38,3 & Panarelli (1999) \\
\hline & Cogueral & 10,63 & 54,2 & Casanom (2000) \\
\hline Macrachaent collins & Jurumoron & 3,00 & 41.4 & Mitouka (1998) \\
\hline & furumurm & 2.18 & 38,3 & Panereih (19999) \\
\hline & Coqueral & 1063 & 54,2 & Casanave 20001 \\
\hline Plationus paruins & Jurumuram & $\therefore, 46$ & 39,6 & Noguerra $(1996)$ \\
\hline Platyias quadricormis & Jurumberm & 2.46 & 39,6 & Nopueara (1996) \\
\hline & Jurunurum & 1,08 & 31,3 & Noguerse of Panerelli a (1997) \\
\hline & Jyngrarm & 218 & 38,3 & Panmeilis (1999) \\
\hline Plossome iruncarum & Jisugnenm & 3,00 & 41,4 & Mitsuka (19981 \\
\hline Polyarthro ci mojor & Jinumerem & 300 & 41.4 & Masula (1998) \\
\hline Pingaris & Jurumirm & 2.46 & 39.6 & Nontora 1 ( 9960 \\
\hline & furumanm & $3, \infty 0$ & 41.4 & Mitouka (1998, \\
\hline & Jumunirm & 2.18 & 38,3 & Pannereilin (1999) \\
\hline Pompholix compianda & Coquerral & 10,63 & 54.2 & Casanove 12000$)$ \\
\hline & Camerno & .82 & 51,2 & Camenova 2000 ) \\
\hline P sulcata & hrumerm & 246 & 39,6 & Noguern $(1996)$ \\
\hline P.ntoba & Jumumirm & 300 & 41,4 & Mrtula (1998) \\
\hline Simchourla parcinate & Jurummerm & 218 & 38,3 & Panerelit,1999) \\
\hline S strdaen & funumarem & 2.18 & 38,3 & Panereill (1999) \\
\hline Tesmuanella pation & furumarm & 2,18 & 38,3 & Panereli1 (1999) \\
\hline Itridemato & Junumirm & $\therefore 18$ & 38,3 & Panarelli (1999) \\
\hline Trichacerce capuirina & furumurom & 2.00 & 37.4 & 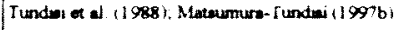 \\
\hline & Coquernal & 10.63 & 54,2 & Conson $(2000)$ \\
\hline & Cannerso & 2.82 & $\$ 1,2$ & Cenenove $(2000)$ \\
\hline & Keventes & 1,65 & 35,5 & Tundus el al (1988), Matsumura- I undas (199"b) \\
\hline Towitindico & Jurunarem & 3,000 & 41,4 & Mitsuke (1998) \\
\hline & Jurumerm & $=18$ & 38,3 & [Panurethi 1999) \\
\hline T. durom-mutfailis & furumerun & 3,00 & 41.4 & Mitruke (1998) \\
\hline & Surumum & $\therefore 18$ & 38,3 & Panare:li (1999) \\
\hline I. fopellota & Junumam & 318 & 38,3 & Paneretifi(1999) \\
\hline I cf iernis & Sirumerum & 2,38 & 38,3 & Pankrellin(1999) \\
\hline Tlonguseria & furumurum & 2.18 & 38,3 & Panarelli $(19999$ \\
\hline I. cf rousselem & Surumrum & 2.18 & 38,3 & Panarelli 19999 \\
\hline T. similis & lurumurum & 3.00 & 41.4 & Mitsuka (1998) \\
\hline & Lierumurem & 2,18 & 383 & Panareilit (19099) \\
\hline & UGRHI IS TURVORGRANDE & & & \\
\hline Asplanitua sueboldi & Anue Vermelhe & 2.74 & 40,6 & 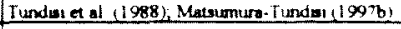 \\
\hline Keractllo - ochiearis & Arue Vermeing & 2,4 & 40,6 & 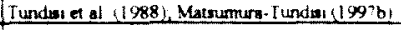 \\
\hline Hexerthra mire & Agne Vermeiha & $=4$ & 406 & Tundise ef al (1988), Matsumura. Tundus (199" b) \\
\hline Lecane currionomis & Apu Vemelthe & 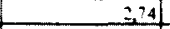 & 40,6 & 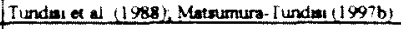 \\
\hline & UGRH I6 - TIETE/BATALAA & & & \\
\hline Meratella cantiearis & Promuanedo & 8,62 & 92 & 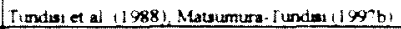 \\
\hline Poveraicibera & Promisedo & 8,621 & 522 & 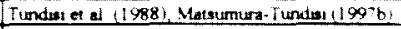 \\
\hline Friknarerod iopelina & Promusaio & 862 & $52:$ & 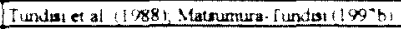 \\
\hline & UGRHI 17 MEDIO PARANAPANEMA & & & \\
\hline Asplancinna sieboids & Salto Orande & $1, \mathbf{3} 1$ & 36.4 & 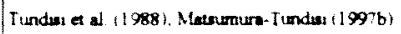 \\
\hline & Capmen & 2,83 & 40,9 & 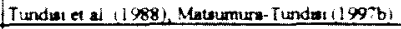 \\
\hline Brachionms falourur & Roo Part & 2,88 & 40,4 & 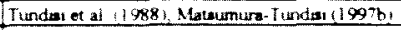 \\
\hline allotheca ornata carmuta & Ro Pan & $\therefore, 68$ & $4 \div 4$ & 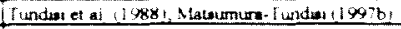 \\
\hline Conochitur counobasts & $R \times P_{\text {an }}$ & 2,68 & 40,4 & 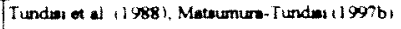 \\
\hline & Rso Novo & 3,32 & 42,5 & I undan a al (1988), Matcumure- Tunda (1997b) \\
\hline Euchlones deflexo & Capivere & 2,83 & 419 & 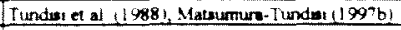 \\
\hline Finnio longisera & Rto Par: & $\therefore 68$ & $4 i+4$ & 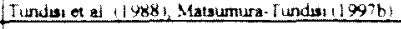 \\
\hline Sexarthra incermedia brartiensis & Rio Par & 268 & $4 \div 4$ & 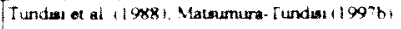 \\
\hline & Ron Nowo & 3,32 & 425 & 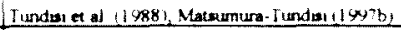 \\
\hline ii. mura & RюPar & 2.68 & 40.4 & T Tunder ef ad (1988), Matsumura - Tundun (1997b) \\
\hline & RoNowo & 3,32 & 425 & 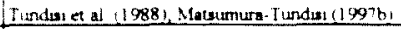 \\
\hline Aerabillo anericiano & Salto Grende & 81 & 364 & 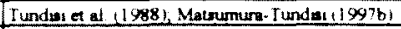 \\
\hline$K_{\text {vivachiearis }}$ & Rw Pan & $\therefore, 68$ & 40,4 & 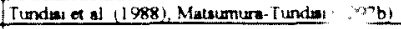 \\
\hline Inchaxerco capewina & Capivana & 283 & 409 & 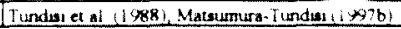 \\
\hline
\end{tabular}


comonuxars

TABELA 20 - Ocorrència de rotiferos. media das concentrações de clorofila $a$ total $(\mu \mathrm{g} / \mathrm{L})$ e Indice de Estado Trófico (IET) de Carlson modificado. em cada corpo d'água. com o respectivo autor e época de estudo. por Unidade de Gerenciamento de Recursos Hidricos (UGRHI) do Estado de São Paulo

\begin{tabular}{|c|c|c|c|c|}
\hline Expeace & 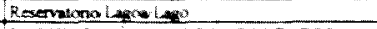 & orosin o 14 & IET & Autive \\
\hline Camoxitulus composass & 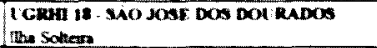 & .0 & 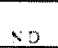 & $\operatorname{Sen} \omega_{\alpha}\left(1 \omega_{3}\right)$ \\
\hline dovenerws & Fiha Sodterere & $\sqrt{90}$ & $\therefore 0$ & 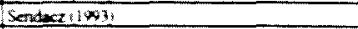 \\
\hline Cutcome & The Solvern & .0 & $\mathrm{~N}$ & $\operatorname{sen} 2010 \times 3)$ \\
\hline 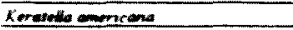 & fine Sohen & $\therefore$ & $\mathrm{ND}$ & Sender 11003 \\
\hline K recheory & $\begin{array}{l}\text { The Solvers } \\
\text { inu Solvers: }\end{array}$ & $\begin{array}{ll}204 \\
\because 0\end{array}$ & 3 & 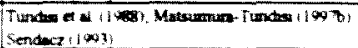 \\
\hline Iims & Tha Sotitera & 40 & $\therefore p$ & Sendec $1 / \infty x_{3}$ \\
\hline 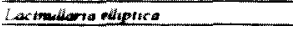 & Fis Soleres: & +0 & $\triangle 8$ & Serdeczllaviy \\
\hline Favertiva miple & Ihu Solkers & 204 & $3=$ & 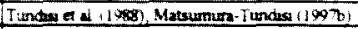 \\
\hline Pomphobiat conplemato & Illine Soltern & $\therefore D$ & $\times D$ & Sendera 11903 \\
\hline \multirow[t]{2}{*}{ Pevere where } & Tha Soltere & $\times 0$ & $\mathrm{ND}$ & Sendaxz $(1043)$ \\
\hline & $\begin{array}{l}\text { TICRH IS- BAIXO IIETE } \\
\text { Juph }\end{array}$ & 3,20 & 423 & 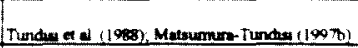 \\
\hline Brachiones espoveris & Jupu & $\sqrt{D}$ & ND & Sende $=(1003)$ \\
\hline B cadrofony & Seppes & ND & ND & Sendect $[(9093)$ \\
\hline B cendens & Jupen & $\mathrm{ND}$ & No & Sendezz $(1943)$ \\
\hline 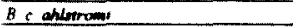 & Jupa & 3,20 & 43.3 & 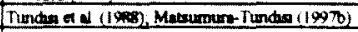 \\
\hline B fokems & Jupin & 3,26 & 42,3 & 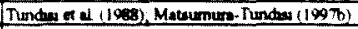 \\
\hline A quedidentans & luppon & ND & ND & $\operatorname{sendex}(190,3)$ \\
\hline 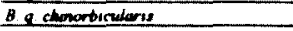 & Jupus & 3,26 & 42,3 & 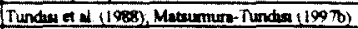 \\
\hline Conochicive comolobers & Jupu & 40 & ND & Senderz $(19093)$ \\
\hline C dovenering & Jupm & VD & $\mathrm{ND}$ & Sendect $(10043)$ \\
\hline Cunicomus & Jupe & V. & ND & Sendeze $(1043)$ \\
\hline Heserveremiro & Jupe & 3,20 & 423 & 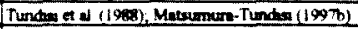 \\
\hline Keratedo enemrane & $\operatorname{ling} 4$ & $\therefore$ DI & $\mathrm{ND}$ & $\operatorname{sen} 2(1993)$ \\
\hline A coskearis & Inpe & 3,26 & 42,3 & 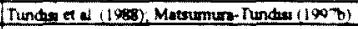 \\
\hline A Lon:i & 3 supu & $\therefore 0$ & $\mathrm{ND}$ & $\operatorname{sendesz}(1003)$ \\
\hline 1 mopica & lapes & $\begin{array}{l}3.20 \\
40\end{array}$ & $\begin{array}{ll}423 \\
40\end{array}$ & 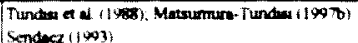 \\
\hline 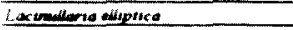 & Jipu & $\therefore D$ & VD & Sendez: $\{\mid x<3\}$ \\
\hline Laran belle & Heve & (.) & $\mathrm{ND}$ & $\operatorname{senderzi(\infty )3)}$ \\
\hline L Lowentina & lopen & पOL & ND & $\operatorname{Senciez}(10 \times 2)$ \\
\hline Plationer parivers & Heapen & $\begin{array}{c}3.20 \\
10 \\
\end{array}$ & $\begin{array}{l}423 \\
\$ 0 \\
\end{array}$ & 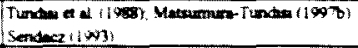 \\
\hline 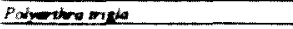 & logon & 3,20 & 42,3 & 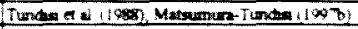 \\
\hline 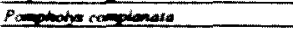 & Hupen & $\therefore 0$ & No & Sendiozil1097 \\
\hline 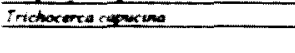 & Tem Averstemater & 9.81 & 99 & 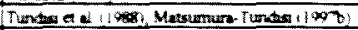 \\
\hline Amemopons fien & 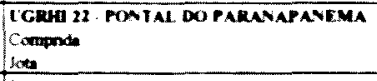 & $\begin{array}{r}9,13 \\
41,4 \\
\end{array}$ & $\begin{array}{l}5.8 \\
306\end{array}$ & 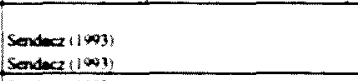 \\
\hline \multirow{2}{*}{ 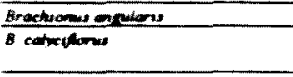 } & $\lim$ & 43,4 & 280 & Sencera $[10 \times 3)$ \\
\hline & Componde & $\begin{array}{ll}19,13 \\
43.4\end{array}$ & 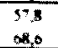 & $\operatorname{sendmat}\{(x)$ \\
\hline 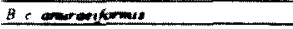 & Ton & $3+4$ & og 0 & $\operatorname{Sendecz}(y * 3)$ \\
\hline \multirow{2}{*}{$\begin{array}{l}\text { B cendans } \\
\text { doledrabus }\end{array}$} & Compnos & 15,33 & 5.8 & Sender $[1043\}$ \\
\hline & Coxapondin & $\begin{array}{l}15,13 \\
43,7.4\end{array}$ & $\begin{array}{l}57,8 \\
0,6\end{array}$ & $\begin{array}{l}\operatorname{Sendez}(1093) \\
\operatorname{Senduz}(1 \times 93)\end{array}$ \\
\hline B farenen & $\begin{array}{l}\text { Contonde } \\
\text { sere }\end{array}$ & $\begin{array}{l}5,13 \\
6,4,4\end{array}$ & $\begin{array}{l}5.8 \\
58\end{array}$ & 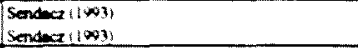 \\
\hline 8 and & Componde & $\begin{array}{l}15.13 \\
434\end{array}$ & $\begin{array}{r}578 \\
080\end{array}$ & 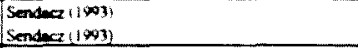 \\
\hline A meticundans & $\begin{array}{l}\text { Conponde } \\
\text { loe }\end{array}$ & $\begin{array}{l}15.13 \\
13.4\end{array}$ & 5 & 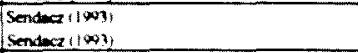 \\
\hline Comochutes dossuerme & $\begin{array}{l}\text { Componde } \\
\text { one }\end{array}$ & $\begin{array}{l}19,134 \\
41,44\end{array}$ & $\begin{aligned} 10.3 \\
0 \times 0\end{aligned}$ & $\begin{array}{l}\text { Sendera } 11003 ! \\
\text { Sendect i } 1003\}\end{array}$ \\
\hline Tunicomis & Componde & $\begin{array}{l}\mid 9.13 \\
13,4\end{array}$ & 19.8 & 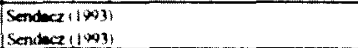 \\
\hline 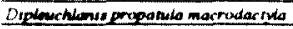 & Ciompnds & $1,9,13$ & 58 & Sendec $2[10903$ \\
\hline Epuphenes mecrounsus & Jone & 43,94 & 00,0 & Sendece $(1099)$ \\
\hline 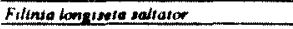 & Cormpnde & 15,33 & 578 & Sendaci $[(x) 3)$ \\
\hline Fpeliors & Comprida & $\begin{array}{l}19.13 \\
41.44\end{array}$ & 5.8 & 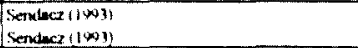 \\
\hline F apodemitt & $\begin{array}{l}\text { Compnis } \\
\text { lote }\end{array}$ & $\begin{array}{l}19,13 \\
19 * 4\end{array}$ & $\begin{array}{l}5.8 \\
0 \times 10\end{array}$ & 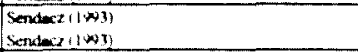 \\
\hline Reractedia merrions & $\begin{array}{l}\text { Compride } \\
\text { Inete }\end{array}$ & 39,13 & 5 & 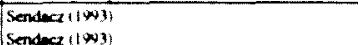 \\
\hline$\overline{x \text { ractibers }}$ & $\begin{array}{l}\text { Componde } \\
\text { hene }\end{array}$ & $\begin{array}{l}19,13 \\
1,+4\end{array}$ & 5.8 & 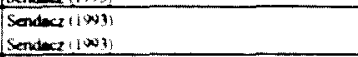 \\
\hline$x \operatorname{long}$ & Compnde & 3,13 & 5 & Sendice $11 \times 43$ \\
\hline$x_{\text {monce }}$ & Componde & 15,3 & 5 & Sontez $[\mid(\phi)\}$ \\
\hline & sone & 13,4 & No & Sendea w w \\
\hline 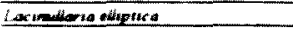 & Conponste & 9,13 & 5 & Sendere ine? \\
\hline Leram trente & Componde & $\mid \begin{array}{ll}\mid c, 3 \\
314\end{array}$ & 18 & 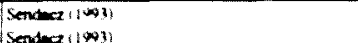 \\
\hline Lancomes & Compense & $\frac{15,13}{4,13}$ & 98 & 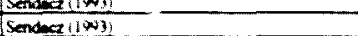 \\
\hline Lne & line & 43,9 & 080 & $\operatorname{sen} 400\{19093$ \\
\hline$t$ manang & Componde & 8 & 5 & Sendeg:you \\
\hline 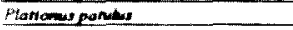 & Componde & 5 & 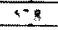 & Sendectionis \\
\hline 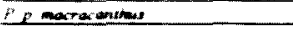 & Componak & 19,13 & 9.8 & Senderctisut 3 \\
\hline 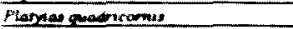 & Compras & 19,3 & 8.8 & Sendecilisis \\
\hline Fomplatha remperele & Conponde & 19,13 & 58 & Sendea $(1993)$ \\
\hline & Won & $43-4$ & \& & Senden: \\
\hline Propurathoure & iampricts & 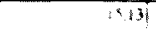 & 5.8 & Sersidez: $\{w\}$ \\
\hline & sone & 194 & no & Senmana $(x)$ \\
\hline 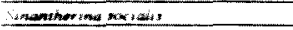 & mponda & 43 & 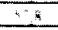 & sendenzisury \\
\hline 5 stomonos & inemponin & 9,13 & 58 & Sander:ing: \\
\hline Inchocerra chation & lise & 19.4 & $\infty 0$ & Sendez $+1 \omega_{3}$ \\
\hline Trematis & Conapriat & $(x, 13$ & $x+8$ & $\operatorname{sen} d x z$ inven \\
\hline & lise & 194 & a.o & Sendeza il 1000 : \\
\hline Tinderes & Componite & 9.13 & 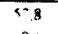 & Senders $: 1104\}$ \\
\hline & Son & $x+4$ & 0.0 & Sendera $(\mid \omega) y$ \\
\hline 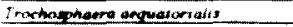 & Campress & 9,91 & 5.8 & Sendmat 140 in \\
\hline
\end{tabular}


TABELA 21 - Ocorrència de copepodos ciclopóides, média das concentrações de clorofila $a$ total $(\mu \mathrm{g} / \mathrm{L})$ e Índice de Estado Trófico (IET) de Carlson modificado, em cada corpo d'água, com o respectivo autor e epoca de estudo, por Unidade de Gerenciamento de Recursos Hídricos (UGRHI) do Estado de São Paulo.

\begin{tabular}{|c|c|c|c|c|}
\hline Eprecies & Tenotvmtinno Lague Lago & (7orofih $a(4 \mathrm{KL})$ & IET & Alutoren \\
\hline Hesocurlops merutiones & $\begin{array}{l}\text { UGRHI OQ - P'ARAIBA DO SCL } \\
\text { Paraturg }\end{array}$ & 更 & ND & Cabuence $(1991)$ \\
\hline$M$ langisenest & $\begin{array}{l}\text { Sants Branck } \\
\text { Borbu } \\
\text { Itapena } \\
\text { fiund }\end{array}$ & $\begin{array}{l}21.20 \\
\times D \\
44.92 \\
40,10 \\
\end{array}$ & $\begin{array}{l}61.2 \\
0.0 \\
68.7 \\
6.7\end{array}$ & 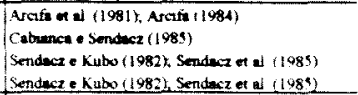 \\
\hline 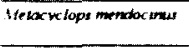 & $\begin{array}{l}\text { Itapeva } \\
\text { Furul }\end{array}$ & $\begin{array}{r}4.92 \\
40,10\end{array}$ & 88 & 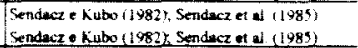 \\
\hline Istrocuclops af anceps & Parabura & YD & $\times 0$ & Cabraxea $(1 \times 0 \times 1)$ \\
\hline Thermacrelops dec anengy & 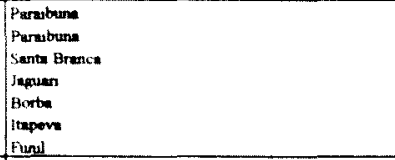 & \begin{tabular}{r|r|}
16,80 \\
$N D$ \\
21.20 \\
20,90 \\
$N D$ \\
44.92 \\
40,10 \\
\end{tabular} & $\begin{array}{l}58.3 \\
N D \\
61.2 \\
61.0 \\
N D \\
68.7 \\
6 \%\end{array}$ & 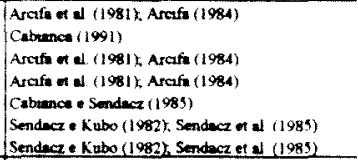 \\
\hline$T$ maniax & $\begin{array}{l}\text { Parabuna } \\
\text { Borbu } \\
\text { Furil }\end{array}$ & \begin{tabular}{r|} 
ND \\
ND \\
10,10 \\
\end{tabular} & $\begin{array}{l}\text { N.D. } \\
\text { N.D. } \\
67 ?\end{array}$ & 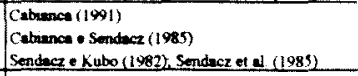 \\
\hline Tropocuriops prasumes & Fund & 40,10 & 679 & Sendecze Kubo $(1982)$ Sendecz of al 11989$)$ \\
\hline Mesockitiops longiserius & 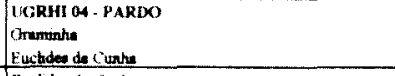 & $\begin{array}{r}5,73 \\
{[, 83} \\
\end{array}$ & $\begin{array}{r}48,0 \\
365 \\
\end{array}$ & 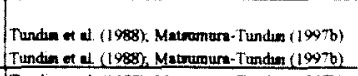 \\
\hline Aficrackiopt ancept & $\begin{array}{l}\text { Euclides de Cornha } \\
\text { Limoaro }\end{array}$ & $\begin{array}{l}1,83 \\
9,86\end{array}$ & $\begin{array}{l}36,5 \\
48,3\end{array}$ & 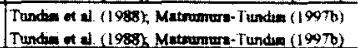 \\
\hline Thermocyetiopes dectpiens & $\begin{array}{l}\text { Coumunhe } \\
\text { Lumoero } \\
\text { Monte Aleare } \\
\text { Wonte Alggre }\end{array}$ & $\begin{array}{r}5,73 \\
5.86 \\
18, \infty \\
190 \\
\end{array}$ & $\begin{array}{l}48.0 \\
48,3 \\
99.9 \\
\text { N. } \\
\end{array}$ & 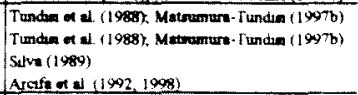 \\
\hline$T$ mamens & 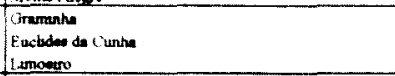 & $\begin{array}{l}5,3 \\
1,83 \\
586\end{array}$ & $\begin{array}{l}48,0 \\
36,9 \\
48,3 \\
\end{array}$ & 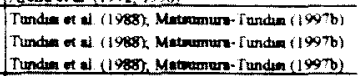 \\
\hline Froposweriops poresunes & $\begin{array}{l}\text { Graminhu } \\
\text { Lumouro } \\
\text { Motibe Alogere } \\
\text { Mante Alsege }\end{array}$ & $\begin{array}{r}5,73 \\
5,80 \\
18,60 \\
N D \\
\end{array}$ & $\begin{array}{l}48,0 \\
48,3 \\
59,9 \\
N D\end{array}$ & 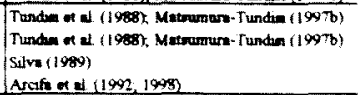 \\
\hline Ectocplopt nubetrens & 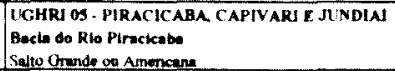 & ND & No & Cavalho (1979) \\
\hline 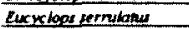 & Sulgo Qrende ou Ameracept & N.D. & N.D. & Conve (1975) \\
\hline 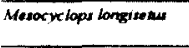 & 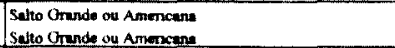 & $\begin{array}{r}\text { N.D } \\
113,80 \\
\end{array}$ & $\begin{array}{l}\text { N.D. } \\
78,1\end{array}$ & $\begin{array}{l}\text { Carvalho (1975) } \\
\text { Areff of el (1981), Argfi (1984) }\end{array}$ \\
\hline 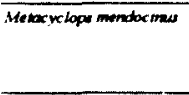 & 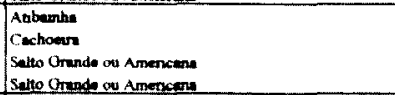 & $\begin{array}{r}38,50 \\
97,20 \\
N D \\
113,80 \\
\end{array}$ & $\begin{array}{l}67.2 \\
76.5 \\
N .0 \\
78.1 \\
\end{array}$ & 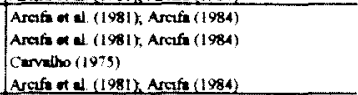 \\
\hline Aftcrockilope varticans & 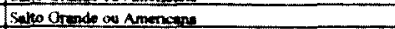 & ND & ND & Carvidho (1995) \\
\hline 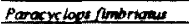 & Selto Chende on Armencems & ND. & ND & Canzlho(1999) \\
\hline 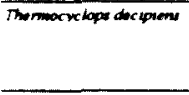 & 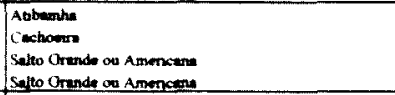 & $\begin{array}{r}38,50 \\
97,20 \\
N D \\
113,80 \\
\end{array}$ & $\begin{array}{r}67.2 \\
96.9 \\
\times 0 \\
78.1 \\
\end{array}$ & 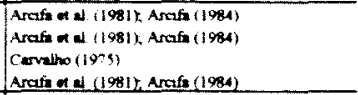 \\
\hline 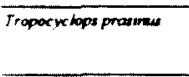 & 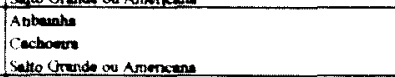 & $\begin{array}{l}38.50 \\
97,20 \\
\times 0 \\
\end{array}$ & $\begin{array}{l}6.1 \\
7.2 \\
6,5 \\
N 0\end{array}$ & 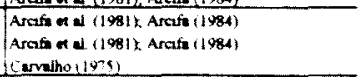 \\
\hline Euxuctoper terrulatass & 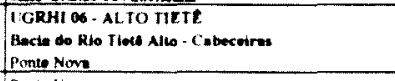 & 41,97 & $\Delta 8,1$ & 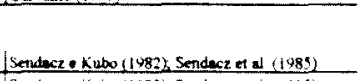 \\
\hline 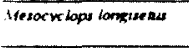 & Ponie Novit & $\begin{array}{l}51.97 \\
59,40\end{array}$ & $\begin{array}{l}68.1 \\
70.9\end{array}$ & 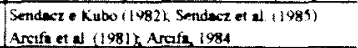 \\
\hline Aticrocyclopi ancopy & Ruberto do Campo & 14,00 & $2 \div 0$ & Arafin of al (1981) Arati (1984) \\
\hline Thermackiopt dec lpiens & Reborito do $t$ empo & $\begin{array}{l}14,00 \\
49,0\end{array}$ & 97,0 & Ascifin of al (1981), Aretin 1984 \\
\hline Tropocreciopes preationeat & $\begin{array}{l}\text { Riburto do Campo } \\
\text { Ponse Nove } \\
\text { Truesupeba }\end{array}$ & $\begin{array}{r}14,00 \\
11,97 \\
9,40 \\
\end{array}$ & $\begin{array}{l}5.0 \\
7.0 \\
70,9\end{array}$ & 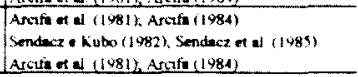 \\
\hline 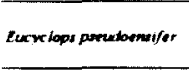 & 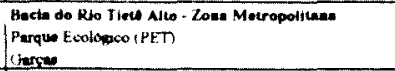 & $\begin{array}{l}91,19 \\
33,22\end{array}$ & $\begin{array}{r}79.9 \\
70,4\end{array}$ & $\begin{array}{l}\text { Deker (2000) } \\
\text { Ene trabaliho }\end{array}$ \\
\hline Mesoryciops bongremun & 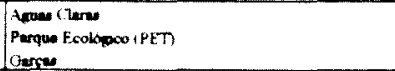 & $\begin{array}{l}39.26 \\
91.19 \\
9322\end{array}$ & $\begin{array}{r}56,4 \\
75.9 \\
90,4\end{array}$ & $\begin{array}{l}\text { Sondecz \& Kubo (1982). Sendecz of ai (1988) } \\
\text { Detike (2000) } \\
\text { Ene tratulho }\end{array}$ \\
\hline Thescruclopet mentios ind & 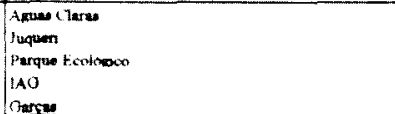 & $\begin{array}{r}35.26 \\
31.99 \\
24.90 \\
4,37 \\
9,22\end{array}$ & $\begin{array}{l}\infty 0.4 \\
85,4 \\
02.6 \\
4,2 \\
70,4\end{array}$ & 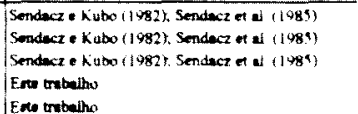 \\
\hline Microcyciopu ancopt & 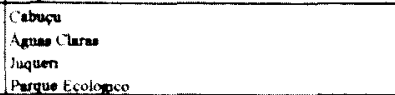 & $\begin{array}{l}3,00 \\
35.26 \\
11.95 \\
24,50\end{array}$ & $\begin{array}{l}65.9 \\
6.9 \\
69.4 \\
62.6\end{array}$ & 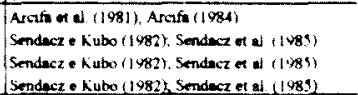 \\
\hline Thermocyciops dectprens & 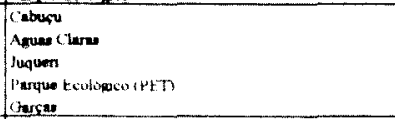 & $\begin{array}{r}34,00 \\
35,26 \\
31,99 \\
41,19 \\
3,22\end{array}$ & $\begin{array}{l}65.9 \\
56,4 \\
65.4 \\
3.9 \\
0.9 \\
\end{array}$ & 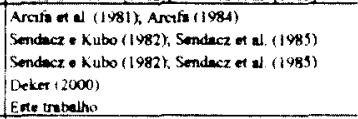 \\
\hline Envermu & 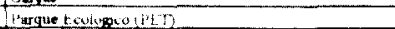 & 4.19 & $\frac{6}{x y}$ & Deker $(2000)$ \\
\hline$I_{\text {money }}$ & Avencl laus & 19.26 & $\infty, 4$ & 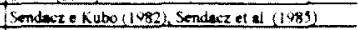 \\
\hline 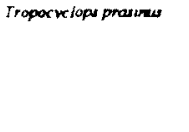 & 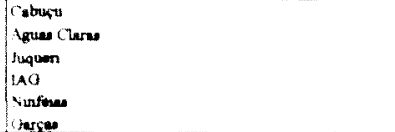 & 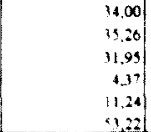 & $\begin{array}{l}65.9 \\
6.4 \\
69.4 \\
4.2 \\
34.8 \\
0.4\end{array}$ & 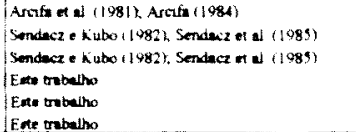 \\
\hline
\end{tabular}


TABELA 21 - Ocorrência de copépodos ciclopóides, média das concentrações de clorofila $a$ total $(\mu \mathrm{g} / \mathrm{L})$ e Índice de Estado Trófico (IET) de Carlson modificado, em cada corpo d'água com o respectivo autor e epoca de estudo, por Unidade de Gerenciamento de Recursos Hidricos (UGRHI) do Estado de São Paulo.

\begin{tabular}{|c|c|c|c|c|}
\hline Enposes & Feservatonol Lae Lape & Turofile o (uRL) & IET & Tutores \\
\hline & Bacis do Reservalorto Billinge & & & \\
\hline \multirow{4}{*}{ Excociopusernibass } & Ros Pequeno & ND & ND & Sendeca (1978) \\
\hline & Rro Chaide & No & ND & Sendeca 11478 \\
\hline & Fro Crende & $\$ 99.39$ & 86,2 & Sendecte Rubo (1982), Sendecz ef at (i985) \\
\hline & Ro doo Podre & 289,21 & $8 \div$ & Sendere \& Kabo (1982, Sendecz et a (1985) \\
\hline Berocinteps appericonms & Ro Poqueno & $\because 61$ & 50,9 & ICETESB $(190 \%)$ a , Coelho-Botetho of a $(2001)$ \\
\hline \multirow[t]{2}{*}{16 otoment } & Taquevertibe & 22.63 & 61,9 & CETESB (1999) Coetho-Botelho of at 12001$)$ \\
\hline & Ro Poqueno & -561 & 30,9 & CETESB (190), Coetho-Botel ho of at (2001) \\
\hline is donguesue & $\begin{array}{l}\text { Ro Crande } \\
\text { Ro Grande }\end{array}$ & $\begin{array}{r}25539 \\
\times D\end{array}$ & $\begin{array}{l}86.2 \\
\text { N D }\end{array}$ & $\begin{array}{l}\text { Sendece e Kubo (1982x. Sendecz et al (1989) } \\
\text { Kubo (1989) }\end{array}$ \\
\hline \multirow{10}{*}{ Mekackiope mendortmis } & Thequecerube & 22.63 & 61.9 & CETESB (1909) Coetho-Botolito of al $(2001)$ \\
\hline & Ris Pequeno & ND. & ND & Sendear (1978) \\
\hline & Rio Pequano & 7.01 & 50,9 & CETESB (19990), Coetho-Botetho of at (2001) \\
\hline & Rio Orande & ND & N D & Sendeca (1978) \\
\hline & Ruo Crande & 259,39 & 86,2 & Sendecz e Kubo (1982). Sendecz et al (1985) \\
\hline & Rio Orande & 10,24 & 339 & Sendect of al $(1984)$ \\
\hline & Rio Crende & ND & ND. & Kubo (1989) \\
\hline & Ris Croundo & 0,46 & 49,3 & Sendecx o Kuto (1999) \\
\hline & Row Onende & 38,48 & 07,2 & CETESB (1909), Coetho-Botalho of at (200) \\
\hline & Rio deu Podrus & 289,21 & 879 & Sendecz Kubo (1982), Sendecz of 21 (1985) \\
\hline \multirow[t]{9}{*}{ 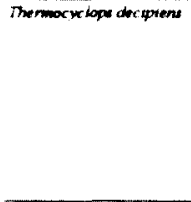 } & Tequecortube & 22,63 & 61,9 & 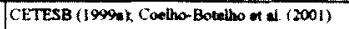 \\
\hline & Rio Pequeno & ND. & ND & Sendece (1978) \\
\hline & Ris Poqueno & -81 & so, 9 & CETESB (1909), Coetho-Botelho of al $1200 \mathrm{n}$ \\
\hline & Roo Chunde & ND & ND & Sendeca (1978) \\
\hline & Ruo Orende & 259.39 & 86.2 & Sendecz o kubo (1982) Sendecz of al (1985) \\
\hline & Rwo Orende & 10,24 & 93.9 & Sendecez of al. (1984) \\
\hline & Roo Orende & 0.46 & 49,3 & Seedeca = Kubo $(1 \times \infty \times)$ \\
\hline & Rwo Orande & 38,48 & 67.2 & CETRSB (1909), Coetho-Boceltho on al (2001) \\
\hline & Pro den Padre & 289,21 & 8,5 & Sondeco o kubo (1982k Sendacz et of (1989) \\
\hline Is decpoiens & Roo Orendo & YD & ND & Kubo (1989) \\
\hline Tirmeres & Rro Pequenso & .041 & 50,9 & 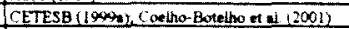 \\
\hline \multirow[t]{2}{*}{$T$ monesis } & Reo Pequeveso & 7.61 & 50,9 & 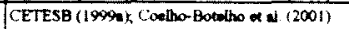 \\
\hline & Ren Orende & 18,49 & 672 & CETESB (1909re, Coetho-Boteine of al (200) \\
\hline \multirow[t]{10}{*}{ Tropecyec lopes prosirasus } & Tequencertuban & 23,69 & 61.9 & CETESB (1909) Cootho-Boreitro of at (200) \\
\hline & Ros Propeno & ND & ND & Sendeca $(1978)$ \\
\hline & Rso Pequeno & 4.01 & $\$ 0.9$ & CETESB (1900), Coelho-Bowetro of at (2001) \\
\hline & Rw Orende & Nol & ND & Sendecz (1978) \\
\hline & Ros Chende & 23539 & 36.2 & 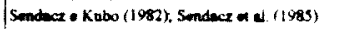 \\
\hline & Rio Onenters & 10.24 & 53.9 & Sendect of of (1984) \\
\hline & Ruo Ohande & ND. & ND & Kubo (1989) \\
\hline & Rwo Onende & 0.46 & $\$ 9,3$ & Sendece o Kubo (1959) \\
\hline & Reo Orende & 38,18 & 67,2 & CETESB (1909), Condho-Boteltho on at (2001) \\
\hline & Ro def Peotres & 209,21 & 85 & Sendera e Kubo (19820, Sendera of el (1989) \\
\hline \multirow[b]{2}{*}{ Ipromen } & Bercen do Rio Cocitis & & & \\
\hline & Pedro Benihs & 04,00 & 225 & 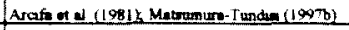 \\
\hline & 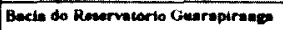 & & & \\
\hline \multirow[t]{3}{*}{ 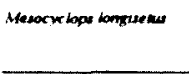 } & Oumerperange: & 18.57 & 59.7 & Sendere o Kubo (1982), Sendece of al (1989) \\
\hline & 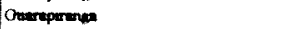 & 7.78 & 51,2 & Domingeos (1993) \\
\hline & Orenoperan: & ND. & $\mathrm{ND}$ & Calieff $(1994,2000)$ \\
\hline Honeme & Cuerveringe & vo & ND & Coe ho-Botwho of e (2001) \\
\hline 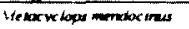 & Oterrapsersen & 18,37 & 19.7 & Sendere o kubo (1982), Sendecz of ai (1986) \\
\hline & Guereprange: & Nop & No & Coedhorbotertho of ell (2001) \\
\hline 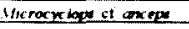 & Coureperenge & VD & $\mathrm{ND}$ & Calefín (2000) \\
\hline The rmocre hapes dec ipuens & Oetersparane: & $\mid 8,37$ & 99,7 & Sendect o kubo (1982k Sendect et al (1989) \\
\hline & Oturreparenes &,- 9 & 31.2 & Domureses (1999) \\
\hline & Oumaprement & Not & ND & Caleffi (1994, 2000) \\
\hline & Oupropresia & Y. & ND & Coedho-Borelhe at w. $1200 \mathrm{H}$ \\
\hline Itmernga & Imerropiange & VD & ND & Calefth $(1994 ; 2000)$ \\
\hline$I$ minaves & Ohareperenge & NDD & $\mathrm{ND}$ & Cosiho-Botetho of al $(2001)$ \\
\hline 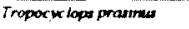 & Chearmptrenge & 18,37 & 59,7 & Sondect o Kubo (1982), Sendect of al (1985) \\
\hline & Ounenperese & $\therefore D$ & ND & Coetho-Boreibo of w (2001) \\
\hline & UGRHI OA - SAPUCAL/GRANDE & & & \\
\hline 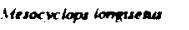 & Eversinto & 1,26 & 32.8 & 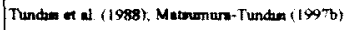 \\
\hline & Jaguens & 2.13 & 38.1 & 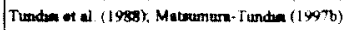 \\
\hline & Votth urande & 3,78 & 43,8 & Turdan of af (1988), Metrumera $\mathrm{T}$ unctan $(1497 \mathrm{~b})$ \\
\hline & Volmenende & so & ND & Rollen at $(1990)$ \\
\hline 11 merabonay & Volte Orende & ND & ND & Rothen a $(1000)$ \\
\hline 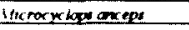 & Encosto & 1,20 & 328 & 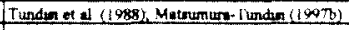 \\
\hline Thempork tapes dec priens & Exostio & 1,26 & 32.8 & 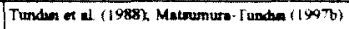 \\
\hline & voise Onende & 3.7 & 41.8 & 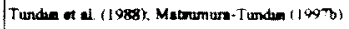 \\
\hline & Volen urende & Y D & $\times D$ & Rallien as $(1 \times \infty)$ \\
\hline$r$ manemax & Eartemiso & 1,26 & 32,8 & 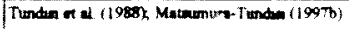 \\
\hline & Inenen & 2.13 & 38.1 & 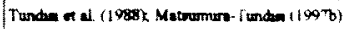 \\
\hline & Volte Chande & $3,+8$ & 43.8 & 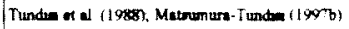 \\
\hline & Volm Onende & vol & No & Rollh en ef $(1 \times 00)$ \\
\hline Propecreliogs prasmat & Jaquen & 2,13 & 183 & 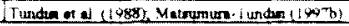 \\
\hline
\end{tabular}


Continuerio

TABELA 21 - Ocorrència de copépodos ciclopóides, média das concentrações de clorofila $a$ total $(\mu \mathrm{g} / \mathrm{L})$ e Índice de Estado Trófico (IET) de Carlson modificado, em cada corpo d'água, com o respectivo autor e epoca de estudo, por Unidade de Gerenciamento de Recursos Hídricos (UGRHI) do Estado de São Paulo.

\begin{tabular}{|c|c|c|c|c|}
\hline Espocies & Revervatono Lagoe Lago & 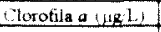 & ET & Alifores \\
\hline 11esockilops aspericormis & 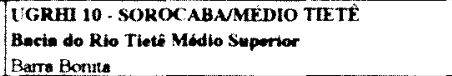 & 32,18 & 65.4 & CETESB $\left(1999_{\mathrm{B}}\right.$ ), Coelho-Botelho of ai (2001) \\
\hline 1. brasilianus & $\begin{array}{l}\text { Berra Bonta } \\
\text { Bearra Bonta } \\
\text { Berru Bonts } \\
\text { Berre Bonta } \\
\end{array}$ & \begin{tabular}{r|}
5,06 \\
$N \mathrm{D}$ \\
13,17 \\
21,58 \\
\end{tabular} & $\begin{array}{l}46,8 \\
\text { N D } \\
56,4 \\
61,3 \\
\end{array}$ & 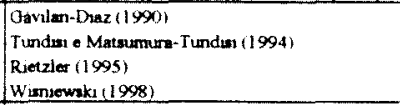 \\
\hline M. kester & $\begin{array}{l}\text { Bwrre Bonuta } \\
\text { Bearre Bonsts } \\
\text { Berra Bonita }\end{array}$ & $\begin{array}{r}N . D \\
13,17 \\
21,58 \\
\end{array}$ & $\begin{array}{l}\text { N.D } \\
56.4 \\
61.3 \\
\end{array}$ & $\begin{array}{l}\text { Jundwi e Metsurnura-Tundsa (1994) } \\
\text { Rietzler (1995) } \\
\text { Wisniewala (1998) }\end{array}$ \\
\hline M. longiserus & $\begin{array}{l}\text { Berra Bonta } \\
\text { Berra Bontta } \\
\text { Barra Bonta } \\
\text { Barra Bonta } \\
\text { Barra Bonta }\end{array}$ & $\begin{array}{c}5.56 \\
5.06 \\
N . D \\
13,17 \\
21,58\end{array}$ & $\begin{array}{l}47,7 \\
46,8 \\
N \mathrm{D} \\
56,4 \\
81,3 \\
\end{array}$ & $\begin{array}{l}\text { Fonwoce (1990) } \\
\text { Gavian-Diaz (1990) } \\
\text { Tundius o Matsumura-Fundias (1994) } \\
\text { Rietzler (1995) } \\
\text { Wianiewaku (1998) }\end{array}$ \\
\hline M. ogunnus & Barra Bonite & 32,18 & 65,4 & CETESB (1999a), Coelho-Botelho ef al $(2001)$ \\
\hline Melachiops mendiocinus & 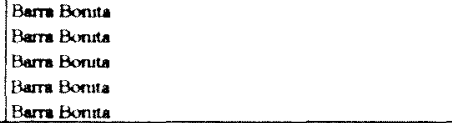 & $\begin{array}{r}5,06 \\
N D \\
13,1 \\
21,58 \\
32,18\end{array}$ & $\begin{array}{l}46,8 \\
N D \\
56,4 \\
61,3 \\
65,4\end{array}$ & 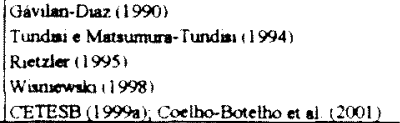 \\
\hline Tiermayxiops decipiens & 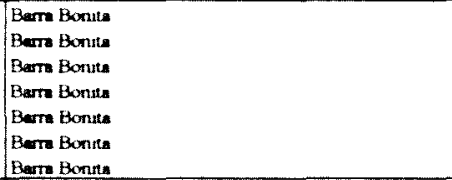 & $\begin{array}{c}5,56 \\
5.06 \\
\text { ND } \\
\text { VD } \\
13,17 \\
21,58 \\
32,18\end{array}$ & $\begin{array}{l}47.7 \\
46.8 \\
N D \\
N . D \\
56,4 \\
61.3 \\
69.4\end{array}$ & 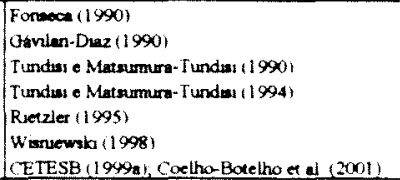 \\
\hline T. inversus & Bamra Bonite & 32,18 & 65.4 & CETESB (1999a); Coetho-Botetho ef a 12001 ) \\
\hline T. minumus & 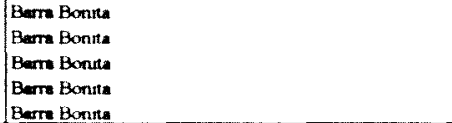 & \begin{tabular}{c|c}
$N D$ \\
$N D$ \\
13,17 \\
21,58 \\
32,18
\end{tabular} & $\begin{array}{l}\text { ND } \\
\text { ND } \\
56,4 \\
61,3 \\
65,4\end{array}$ & 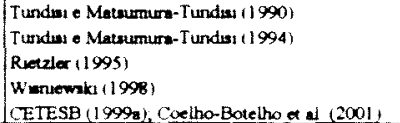 \\
\hline Mosococlops longuertus & $\begin{array}{l}\text { Bimetio do Rlo Sorocrabe } \\
\text { ltupenorerese }\end{array}$ & 15,81 & 58,3 & Sendecz e Kubo (1982), Sendecz of ad (1985) \\
\hline Ifetoogolops mendacinus & Iinpararane & 15,81 & 58,3 & Sendacz o Kubo (1982); Sendecz ef of (1985) \\
\hline Thermocxilops decapiens & fituperarange & 15,81 & 58,3 & Sendacze Kubo (1982), Sendec $z$ of af (1985) \\
\hline T. miminus & Jituperaranges & 15,81 & 58,3 & Sendec $z$ e Kubo (1982), Sendec $z$ ef al (1985) \\
\hline Tropoopclops prasinus & Ihupererene & 15,81 & 58,3 & Sendecz e hubo (1982), Seadec zet a (1985) \\
\hline Mesocyclops iongisenus & 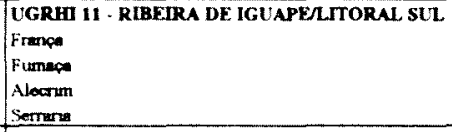 & $\begin{array}{l}40,91 \\
32,30 \\
16.87 \\
44,41 \\
\end{array}$ & $\begin{array}{l}67.8 \\
65.5 \\
58.8 \\
68 . \\
\end{array}$ & 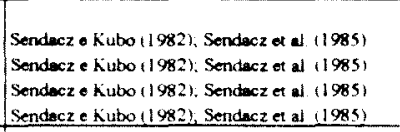 \\
\hline Hetachileps mondocinus & $\begin{array}{l}\text { France } \\
\text { Fumeca } \\
\text { Alocrun } \\
\text { Serrarns } \\
\end{array}$ & $\begin{array}{l}40,91 \\
32.30 \\
16,87 \\
+4,41 \\
\end{array}$ & $\begin{array}{l}67.8 \\
65.5 \\
58.8 \\
68.7\end{array}$ & $\begin{array}{l}\text { Sendacz e Kubo (1982), Sendacz of al (1985) } \\
\text { Sendecz e Kubo (1982). Sendacz et al (1985) } \\
\text { Sendecz e Kubo (1982): Sendecz ef al (1985) } \\
\text { Sendacz o Kubo (1982); Sendacz of al (1985) }\end{array}$ \\
\hline Hhorocydops anarps & $\begin{array}{l}\text { France } \\
\text { Fumeca } \\
\text { Alecrum } \\
\text { Serrerne }\end{array}$ & $\begin{array}{r}\$ 1,91 \\
32,30 \\
16.87 \\
44,41 \\
\end{array}$ & $\begin{array}{l}67.8 \\
65.5 \\
58.8 \\
68.7 \\
\end{array}$ & 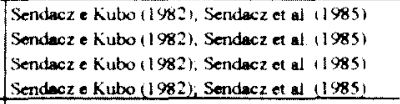 \\
\hline Thermayclops dicipiens & $\begin{array}{l}\text { Franca } \\
\text { Fumacia } \\
\text { Alecrun } \\
\text { Serranin }\end{array}$ & $\begin{array}{r}40,91 \\
32,30 \\
16.87 \\
44,41 \\
\end{array}$ & $\begin{array}{l}67.8 \\
65,5 \\
58,8 \\
68,7 \\
\end{array}$ & $\begin{array}{l}\text { Sendacz e Kubo (1982): Sendacz ex al (1985) } \\
\text { Sendacz o Kubo (1982): Sendacz et al (1985) } \\
\text { Sendacz e Kubo (1982). Sendacz et al (1985) } \\
\text { Sendecz o Kubo (1982), Sendecz et al (1985) }\end{array}$ \\
\hline T. minurus & 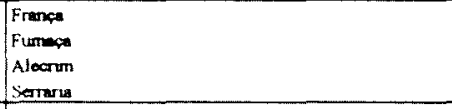 & $\begin{array}{r}40,91 \\
32,30 \\
16,87 \\
44,41 \\
\end{array}$ & $\begin{array}{l}67.8 \\
65.5 \\
58.8 \\
68 . \\
\end{array}$ & 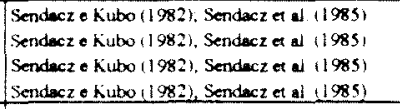 \\
\hline Tropocyctops prasimus & 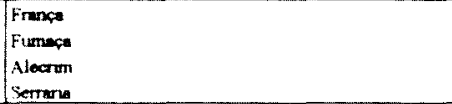 & $\begin{array}{l}40,91 \\
32,30 \\
16,87 \\
44,41\end{array}$ & $\begin{array}{l}67,8 \\
65,5 \\
58,8 \\
68\end{array}$ & 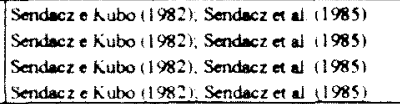 \\
\hline Mesogelops iongiserus & $\begin{array}{l}\text { UGRHI } 12 \text { - BAXX PARDO/GRANDE } \\
\text { Porto Colombla }\end{array}$ & 4,37 & 45,2 & Iunder ef al (1988), Matsumaura-Tunden (1997b) \\
\hline Thermaculogi decipiens & Ponto Colonibu & 4,37 & 452 & 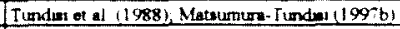 \\
\hline$r$ minurus & $\begin{array}{l}\text { Porto Colombu } \\
\text { Ylarunbondo }\end{array}$ & 4.37 & $\begin{array}{l}15: ? \\
411 ?\end{array}$ & 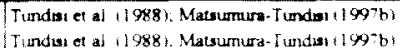 \\
\hline
\end{tabular}


Contunuacto

TABELA 21 - Ocorrência de copépodos ciclopóides, média das concentrações de clorofila $a$ total $(\mu \mathrm{g} / \mathrm{L})$ e Índice de Estado Trófico (IET) de Carlson modificado, em cada corpo d'água, com o respectivo autor e época de estudo, por Unidade de Gerenciamento de Recursos Hídricos (UGRHI) do Estado de São Paulo.

\begin{tabular}{|c|c|c|c|c|}
\hline Enecen & 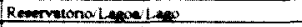 & Goratha (uRL) & LET & Aatures \\
\hline 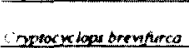 & 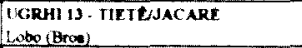 & $\leqslant 0$ & $\mathrm{ND}$ & 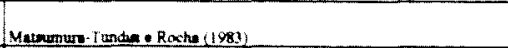 \\
\hline 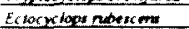 & Latoo (Bros) & YD & $\mathrm{ND}$ & Metumpure- Tuntane Roche (1983) \\
\hline Eurukept mover & 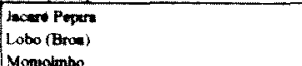 & $\begin{array}{ll}1,70 \\
\times 0 \\
Y \\
\end{array}$ & $\begin{array}{l}39.8 \\
N D \\
N D\end{array}$ & 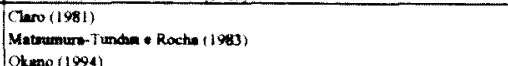 \\
\hline 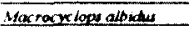 & Manobintio & S. & $\mathrm{ND}$ & Okeno $(19994)$ \\
\hline 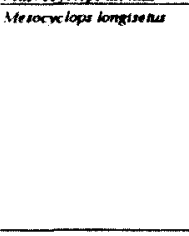 & 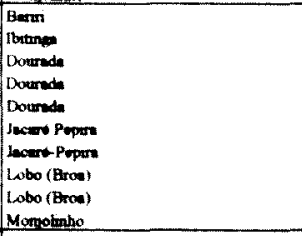 & \begin{tabular}{r|}
7,46 \\
10,38 \\
$N D$ \\
$N D$ \\
3.46 \\
1,70 \\
2.50 \\
ND \\
ND \\
ND \\
\end{tabular} & $\begin{array}{l}30,7 \\
34.1 \\
\text { N D } \\
\text { N D } \\
48,2 \\
35,8 \\
39,7 \\
\text { N D } \\
\text { N D } \\
\text { ND } \\
\end{array}$ & 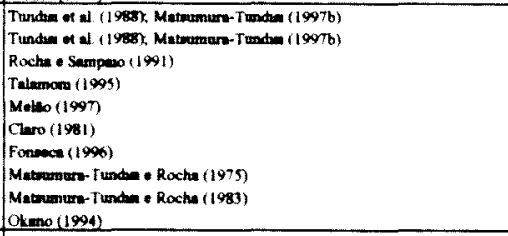 \\
\hline 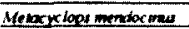 & Momiolumo & N.D. & N.D & olems $(1994)$ \\
\hline Ascrock lope ancept & $\begin{array}{l}\text { Labo (Broe) } \\
\text { Moriobinho }\end{array}$ & $\begin{array}{lll} & 0 \\
\text { Y } & 0 \\
\end{array}$ & $\begin{array}{l}\text { ND } \\
\text { ND }\end{array}$ & 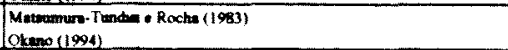 \\
\hline M foretomess & Dorruch & $\begin{array}{ll} & 0 \\
\text { Y } & 0 \\
\end{array}$ & $\begin{array}{l}\text { ND } \\
\text { ND }\end{array}$ & $\begin{array}{l}\text { Tulwionu (1909) } \\
\text { Okene (1994) }\end{array}$ \\
\hline Paraxwe lope fimborames & 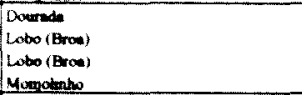 & $\begin{array}{l}1.60 \\
\times 0 \\
\vee 0 \\
Y 0 \\
\end{array}$ & $\begin{array}{l}48,2 \\
N D \\
N D \\
N D\end{array}$ & 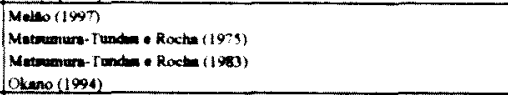 \\
\hline 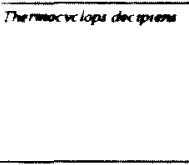 & 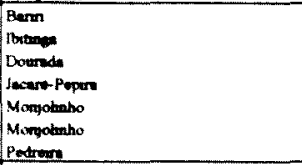 & \begin{tabular}{r|}
7.46 \\
10.38 \\
$\times 0$ \\
2.50 \\
9,38 \\
$\times 0$ \\
$\times 0$ \\
\end{tabular} & $\begin{array}{l}30.7 \\
54.1 \\
\text { N D } \\
39.7 \\
93.0 \\
\text { ND } \\
\text { ND }\end{array}$ & 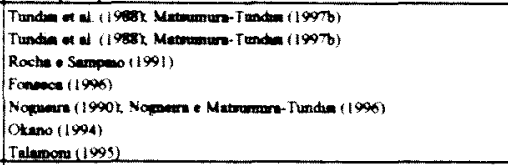 \\
\hline$T$ monas & 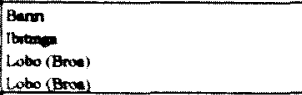 & $\begin{array}{r}7.46 \\
10.38 \\
\times 0 \\
\times D \\
\end{array}$ & $\begin{array}{l}50.7 \\
54.1 \\
N D \\
N D\end{array}$ & 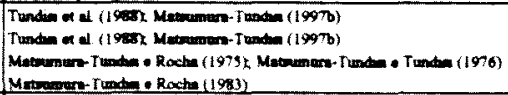 \\
\hline 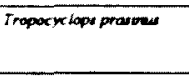 & 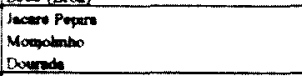 & $\begin{array}{l}1.70 \\
\times 0 \\
3.16\end{array}$ & $\begin{array}{l}3.3 \\
N D \\
48.2\end{array}$ & 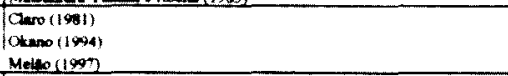 \\
\hline Inchoort & Dowente & NDI & ND & Raxhe : Sompen $(1 \times 911$ \\
\hline 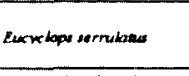 & 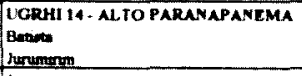 & $\begin{array}{r}48,91 \\
2,46 \\
\end{array}$ & $\begin{array}{l}69.6 \\
39,6 \\
\end{array}$ & 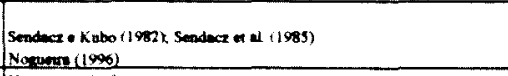 \\
\hline Meenxychay bratthones & Lureturme & 2,46 & 39.6 & $\operatorname{Nag}(1996)$ \\
\hline Mhefert & Jureansing & 2,46 & 39,6 & Nereane (1900) \\
\hline 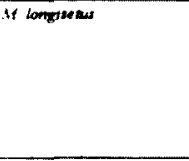 & 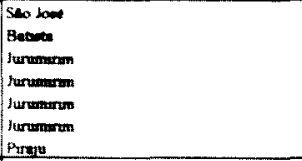 & \begin{tabular}{r|}
39,74 \\
48,91 \\
2,00 \\
2.40 \\
1.00 \\
2,18 \\
2,59 \\
\end{tabular} & $\begin{array}{l}67.5 \\
69.6 \\
37.4 \\
39.6 \\
31.3 \\
18.3 \\
40.0\end{array}$ & 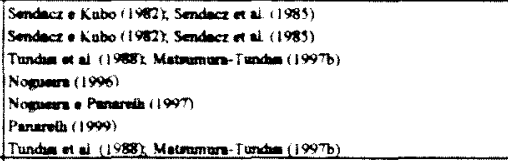 \\
\hline It of longenes & furumpion & 3,00 & 41.4 & Mitakikn (10\%s) \\
\hline 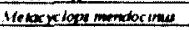 & Sto tooe & 89,74 & 875 & Sendeczo Kubo (1982) Senderca a ni (1985) \\
\hline 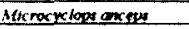 & Beare & 48,914 & 69.6 & 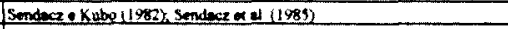 \\
\hline 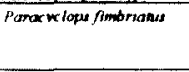 & 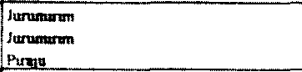 & $\begin{array}{r}2,00 \\
2,46 \\
2,59 \\
\end{array}$ & $\begin{array}{r}37,4 \\
39,6 \\
+0,0\end{array}$ & 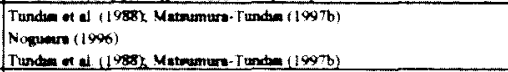 \\
\hline Thermox ch lopu dociprens & 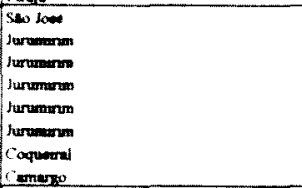 & $\begin{array}{r}39,74 \\
2.00 \\
2,46 \\
1.08 \\
3.00 \\
2.18 \\
10.63 \\
7.82 \\
\end{array}$ & $\begin{array}{l}67.5 \\
37.4 \\
39.6 \\
31.3 \\
41.4 \\
38.3 \\
94.2 \\
31.2\end{array}$ & 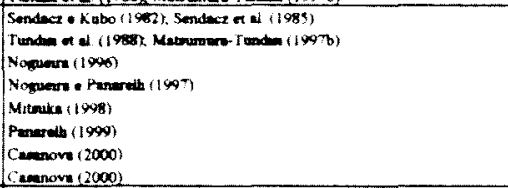 \\
\hline$r$ mineme & 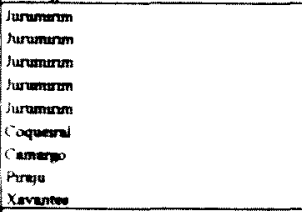 & \begin{tabular}{r|}
2.00 \\
2.06 \\
1,08 \\
3.00 \\
2.18 \\
10,63 \\
-.8 \\
2.59 \\
1.65 \\
\end{tabular} & $\begin{array}{l}37.4 \\
19.6 \\
31.3 \\
11.4 \\
38.3 \\
54.2 \\
1.2 \\
40.0 \\
39.5\end{array}$ & 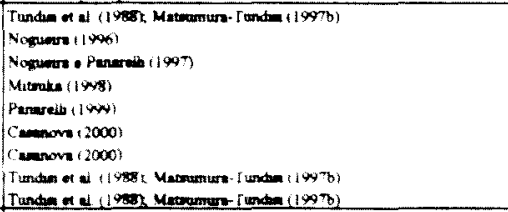 \\
\hline 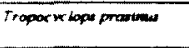 & Solowe & $\begin{array}{ll}39.74 \\
48.91\end{array}$ & 67.5 & 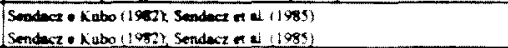 \\
\hline 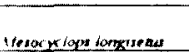 & 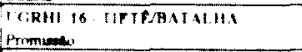 & $x \rightarrow 02$ & 132 & 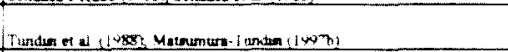 \\
\hline 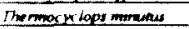 & Promm & ․․․ & 22 & 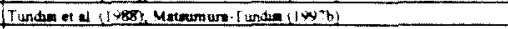 \\
\hline Fropocor sops posasires & ATomenas & 8021 & 22 & 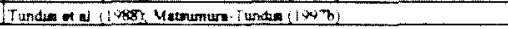 \\
\hline
\end{tabular}


Contimuegio

TABELA 21 - Ocorrência de copépodos ciclopóides, média das concentrações de clorofila $a$ total $(\mu \mathrm{g} / \mathrm{L})$ e Índice de Estado Trófico (IET) de Carlson modificado, em cada corpo d'água, com o respectivo autor e época de estudo, por Unidade de Gerenciamento de Recursos Hídricos (UGRHI) do Estado de São Paulo.

\begin{tabular}{|c|c|c|c|c|}
\hline Esposios & Reservationo/Lapoed Lago & Clorofila a $(4 \mathrm{R} / \mathrm{L})$ & ET & Autores \\
\hline Mosayclops longusotus & $\begin{array}{l}\text { UGRHA 17 - MÉDIO PARANAPANEMA } \\
\text { Capiver: } \\
\text { Rio Novo }\end{array}$ & $\begin{array}{l}2,83 \\
3,32\end{array}$ & $\begin{array}{l}40,9 \\
42,5\end{array}$ & 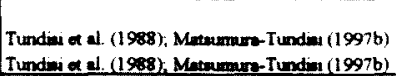 \\
\hline Parasxiops finbrianus & Selto Orande & 1,81 & 36,4 & 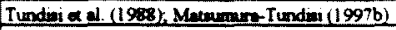 \\
\hline Thermacyciops decipiens & $\begin{array}{l}\text { Rio Pen } \\
\text { Capivern } \\
\text { Ro Novo }\end{array}$ & $\begin{array}{l}2,68 \\
2,83 \\
3,32 \\
\end{array}$ & $\begin{array}{l}40,4 \\
40,9 \\
42,5 \\
\end{array}$ & 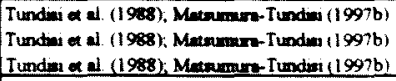 \\
\hline$T$ minuma & $\begin{array}{l}\text { Cappivan } \\
\text { Ro Novo }\end{array}$ & $\begin{array}{r}2,83 \\
3,32 \\
\end{array}$ & $\begin{array}{r}40,9 \\
42,5 \\
\end{array}$ & 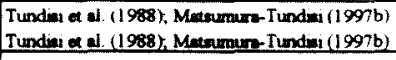 \\
\hline Mesocpelops longuners & $\begin{array}{l}\text { UGRHI IS - SȦO JOSÉ DOS DOURADOS } \\
\text { IThe SOltere }\end{array}$ & 2,04 & 37,7 & Tundiei et al (1988): Mutarmurn-Tundrici (1997b) \\
\hline Thermacyclops docipiens & $\begin{array}{l}\text { Ithe Solteirs } \\
\text { The Solterra }\end{array}$ & $\begin{array}{l}2,04 \\
\text { ND. }\end{array}$ & $\begin{array}{l}37,7 \\
\text { N.D. }\end{array}$ & $\begin{array}{l}\text { Tundian of al. (1988); Matmumure-Tundiai (1997b) } \\
\text { Sendecz (1993) }\end{array}$ \\
\hline$I_{\text {mimiose }}$ & Ima solteira & 204 & 37,7 & Tundin of al $(1988)$, Metormure Tundiai $(1997 \mathrm{~b})$ \\
\hline Mesocyclops longusetur & $\begin{array}{l}\text { UGREI } 19 \text { - BADXO TIETE } \\
\text { Nove Avanhandeve } \\
\text { Jupie } \\
\end{array}$ & $\begin{array}{l}9,87 \\
\mathbf{3 , 2 6} \\
\end{array}$ & $\begin{array}{l}53.5 \\
42.3 \\
\end{array}$ & 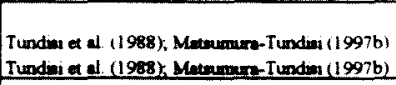 \\
\hline Thermacyclops decipiens & $\begin{array}{l}\text { Non Avenhandeve } \\
\text { fupit } \\
\text { fuppe } \\
\end{array}$ & \begin{tabular}{r|r|}
9,87 \\
3,26 \\
$N D$. \\
\end{tabular} & $\begin{array}{l}53.5 \\
42.3 \\
N D \\
\end{array}$ & 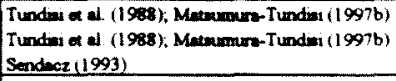 \\
\hline T. mimanus & $\begin{array}{l}\text { Nove Avanhendeve } \\
\text { Jupie } \\
\text { Jupie }\end{array}$ & $\begin{array}{l}9.87 \\
3,26 \\
\text { N.D. }\end{array}$ & $\begin{array}{l}53,5 \\
42,3 \\
\text { N.D. }\end{array}$ & 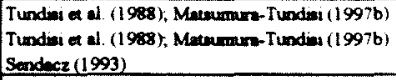 \\
\hline Tropacyclop: prasimus & Nove Averitienders: & 9,87 & 53,5 & 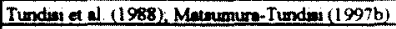 \\
\hline Masacosiopr allipticus & $\begin{array}{l}\text { UGRER } 22 \text { - PONTAL DO PARANAPANEMA } \\
\text { Compnde } \\
\text { lohe }\end{array}$ & $\begin{array}{l}15,13 \\
43,74 \\
\end{array}$ & $\begin{array}{l}57,8 \\
68,6 \\
\end{array}$ & $\begin{array}{l}\text { Sendecz (1993) } \\
\text { Sendecz (1993) }\end{array}$ \\
\hline M. moridianus & $\begin{array}{l}\text { Compride } \\
\text { low }\end{array}$ & $\begin{array}{r}15,13 \\
43,74 \\
\end{array}$ & $\begin{array}{l}57,8 \\
68,6 \\
\end{array}$ & $\begin{array}{l}\text { Sendecz }(1993) \\
\text { Sendecz }(1993)\end{array}$ \\
\hline Thermacyclops deccpiens & $\begin{array}{l}\text { Comprida } \\
\text { bot }\end{array}$ & $\begin{array}{r}15,13 \\
43,74 \\
\end{array}$ & $\begin{array}{l}57,8 \\
68,6 \\
\end{array}$ & $\begin{array}{l}\text { Sendecz }(1993) \\
\text { Sendecz }(1993)\end{array}$ \\
\hline T. minumes & $\begin{array}{l}\text { Compride } \\
\text { jote }\end{array}$ & $\begin{array}{l}15,13 \\
43,74 \\
\end{array}$ & $\begin{array}{l}57,8 \\
68,6\end{array}$ & $\begin{array}{l}\text { Sendecz (1993) } \\
\text { Sendecz (1993) }\end{array}$ \\
\hline
\end{tabular}

ND $=$ NGo determinado 
TABELA 22 - Ocorrência de copépodos calanóides, media das concentrações de clorofila $a$ total $(\mu \mathrm{g} / \mathrm{L})$ e Indice de Estado Trófico (IET) de Carlson modificado, em cada corpo d'água, com o respectivo autor e época de estudo, por Unidade de Gerenciamento de Recursos Hidricos (UGRHI) do Estado de São Paulo.

\begin{tabular}{|c|c|c|c|c|}
\hline Entere & 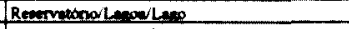 & Corofina (nelu) & IET & Autean \\
\hline 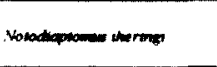 & $\begin{array}{l}\text { UGGRHI OR - PARA BA DO SUL } \\
\text { lemper } \\
\text { Fund }\end{array}$ & $\begin{array}{l}44.92 \\
40,10\end{array}$ & $\begin{array}{l}68.7 \\
67.7\end{array}$ & 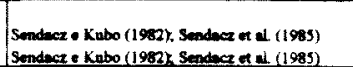 \\
\hline 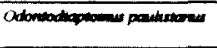 & Pencibuna & $\begin{array}{c}0 \\
21,20\end{array}$ & $\begin{array}{l}\text { N.D } \\
61,2\end{array}$ & $\begin{array}{l}\text { Cabone (1991) } \\
\text { Arafin of al (1981) Arcift (1994) }\end{array}$ \\
\hline Scoladiqpenem conderot & 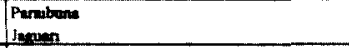 & $\begin{array}{r}16,8 \\
20,00 \\
\end{array}$ & $\begin{array}{l}88.8 \\
61.0 \\
\end{array}$ & 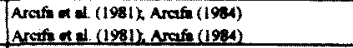 \\
\hline$S$ controut & 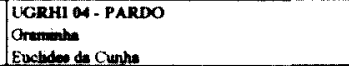 & $\left.\begin{array}{l}3,73 \\
1,83\end{array}\right]$ & $\begin{array}{l}48.0 \\
36.5\end{array}$ & 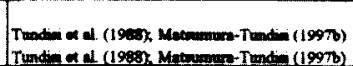 \\
\hline 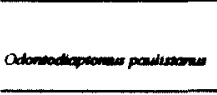 & 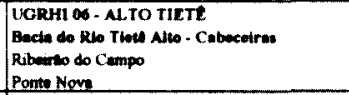 & $\begin{array}{r}14,0 \\
41,97 \\
\end{array}$ & $\begin{array}{l}57,0 \\
68,1 \\
\end{array}$ & 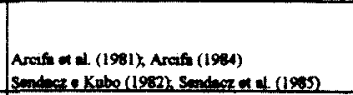 \\
\hline 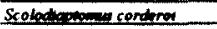 & Triverpen & 35,4 & 70.9 & 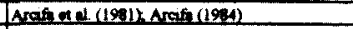 \\
\hline 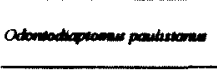 & 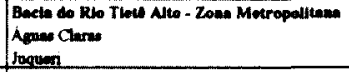 & $\begin{array}{l}35,26 \\
31,95 \\
\end{array}$ & $\begin{array}{l}66,4 \\
65,4 \\
\end{array}$ & 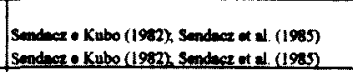 \\
\hline 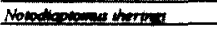 & Pureue Esoldwoo (PED & 9.15 & 79,9 & $D o k=(2000)$ \\
\hline 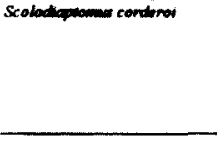 & 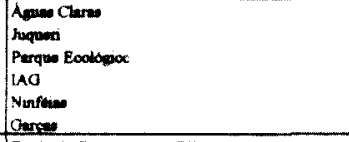 & $\begin{array}{r}35,26 \\
31,95 \\
24,30 \\
4,37 \\
11,24 \\
33,22 \\
\end{array}$ & $\begin{array}{l}66,4 \\
65,4 \\
62,6 \\
45,2 \\
5,8 \\
70,4 \\
\end{array}$ & 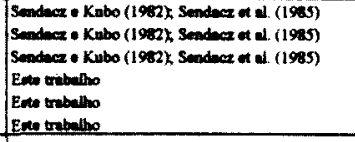 \\
\hline 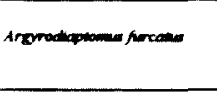 & 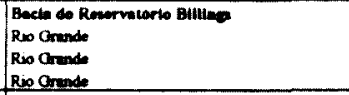 & $\begin{array}{r}10,24 \\
\times .0 \\
6,46 \\
\end{array}$ & $\begin{array}{l}33,9 \\
N D \\
49,3\end{array}$ & 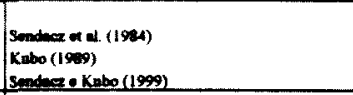 \\
\hline 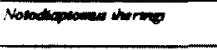 & Tequacomerise & $\begin{array}{r}22.63 \\
7.61 \\
\end{array}$ & $\begin{array}{l}61,9 \\
30,9 \\
\end{array}$ & 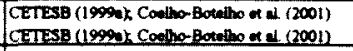 \\
\hline 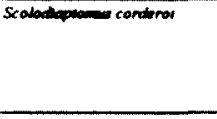 & 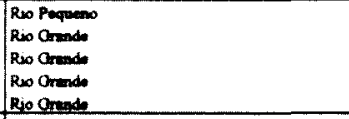 & \begin{tabular}{r|}
$N .0$ \\
10.24 \\
$N . D$ \\
6.46 \\
38.49 \\
\end{tabular} & $\begin{array}{l}\text { N.D } \\
33.9 \\
\text { N D } \\
49.3 \\
672 \\
\end{array}$ & 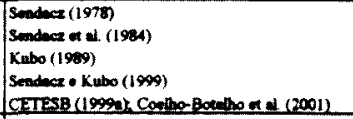 \\
\hline 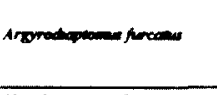 & 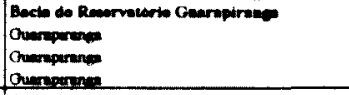 & $\begin{array}{l}7.9 \\
\times 0 \\
\times .0 \\
\end{array}$ & $\begin{array}{r}51.2 \\
\text { N.D } \\
\text { N.D } \\
\end{array}$ & 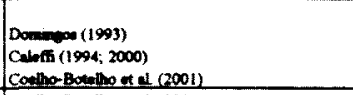 \\
\hline 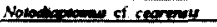 & Open:man & N.D. & $N . D$ & 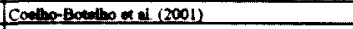 \\
\hline$N$ anrove & 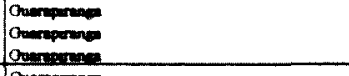 & $\begin{array}{l}7,7 \\
N .0 \\
N .0 . \\
\end{array}$ & $\begin{array}{r}31.2 \\
\text { N.D } \\
\text { N.D } \\
\end{array}$ & 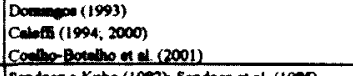 \\
\hline 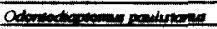 & 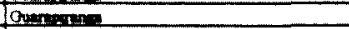 & | 187 & 597 & 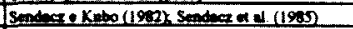 \\
\hline 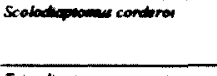 & 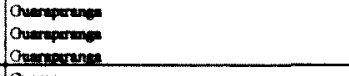 & $\begin{array}{r}18,57 \\
7,79 \\
N \mathrm{p} \\
\end{array}$ & $\begin{array}{l}39,7 \\
31,2 \\
\mathrm{ND} \\
\end{array}$ & 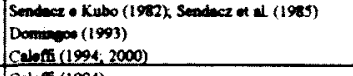 \\
\hline 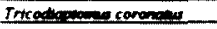 & Oyenerean & N.D. & ND & Colen (1994) \\
\hline 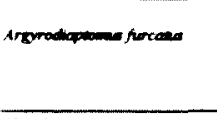 & 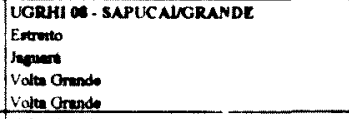 & $\begin{array}{l}1.26 \\
2,13 \\
3,7 \\
\mathrm{v} \\
\end{array}$ & $\begin{array}{r}32,8 \\
38,1 \\
43,8 \\
\text { N D } \\
\end{array}$ & 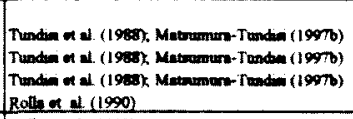 \\
\hline 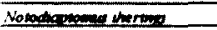 & Volte Grende & YOD & ND & Rollh of al $(1990)$ \\
\hline 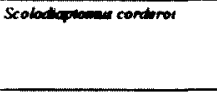 & 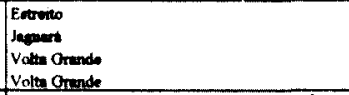 & $\begin{array}{r}1,26 \\
2,13 \\
3,78 \\
\times \\
\end{array}$ & $\begin{array}{l}32,8 \\
38,1 \\
43,8 \\
\text { N.D } \\
\end{array}$ & 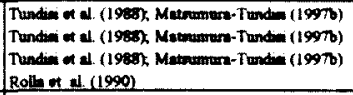 \\
\hline 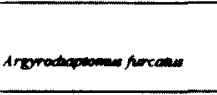 & 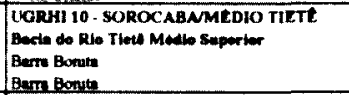 & $\begin{array}{c}N \\
13.17 \\
13.19\end{array}$ & $\begin{array}{l}N D \\
364\end{array}$ & 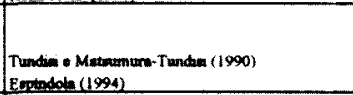 \\
\hline 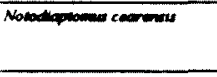 & $\begin{array}{l}\text { Bem Bowut } \\
\text { Barn Bontw } \\
\text { Bam Bonin }\end{array}$ & $\begin{aligned} 13.17 \\
N D \\
12,18 \\
\end{aligned}$ & $\begin{array}{l}96,4 \\
N D \\
65,4\end{array}$ & 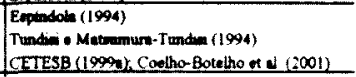 \\
\hline N. conver & $\begin{array}{l}\text { Berm Bonsu } \\
\text { Bem Bonte }\end{array}$ & $\begin{array}{r}5.60 \\
13,17 \\
\end{array}$ & $\begin{array}{r}46,8 \\
96,4 \\
\end{array}$ & 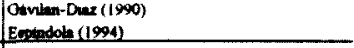 \\
\hline Nof them & Benn Bonten & 32.18 & 654 & CETESB (1999) Coethor Botes the of \& 12001 ) \\
\hline N thermon: & 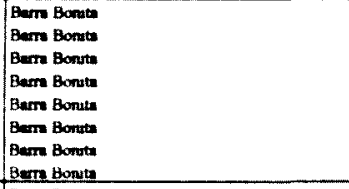 & 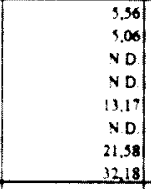 & $\begin{array}{l}47,7 \\
46.8 \\
N D \\
N D \\
56,4 \\
N D \\
61,3 \\
65.4\end{array}$ & 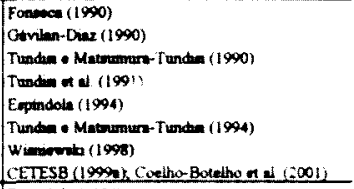 \\
\hline 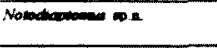 & 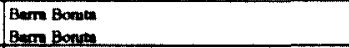 & $\begin{array}{l}13.17 \\
21.98\end{array}$ & $\begin{array}{l}56,4 \\
61,3\end{array}$ & 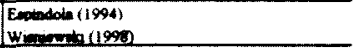 \\
\hline 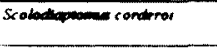 & $\begin{array}{l}\text { Bewe Bontit } \\
\text { Pene Berpte }\end{array}$ & $\begin{array}{ll} & 0 \\
Y & 0 \\
\end{array}$ & $\begin{array}{l}\text { ND } \\
\text { ND } \\
\end{array}$ & 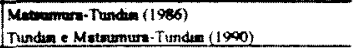 \\
\hline 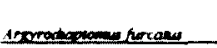 & 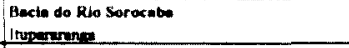 & 15.81 & 98,3 & Sendecto Kubo (1982), Sendecz of \& (1485) \\
\hline 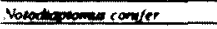 & Ituparinere & 15.81 & 18.3 & Sondect o Rabo (1982), Senderzet of (1986) \\
\hline
\end{tabular}


Continusacio

TABELA 22 - Ocorrência de copépodos calanóides, média das concentraçōes de clorofila $a$ total $(\mu \mathrm{g} / \mathrm{L})$ e Índice de Estado Trófico (IET) de Carlson modificado, em cada corpo d'água, com o respectivo autor e época de estudo, por Unidade de Gerenciamento de Recursos Hidricos (UGRHI) do Estado de São Paulo.

\begin{tabular}{|c|c|c|c|c|}
\hline Endoin & 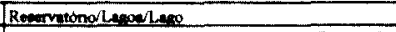 & Gorofilis a GakLL & IET & Autown: \\
\hline 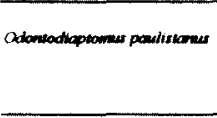 & 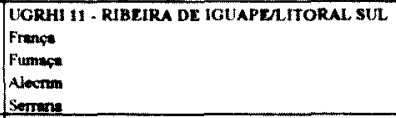 & $\begin{array}{l}10,91 \\
32,30 \\
16,8 \\
4,31\end{array}$ & $\begin{array}{r}67.8 \\
65.5 \\
98,8 \\
68.7 \\
\end{array}$ & 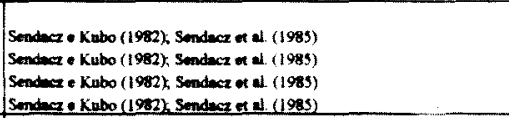 \\
\hline 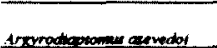 & $\begin{array}{l}\text { UGRHI } 12 \text { - BANXO PARDOUGRANDE } \\
\text { Marnmbondo }\end{array}$ & $2+7$ & 40.7 & 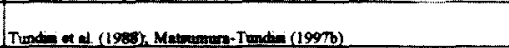 \\
\hline A Mrenotur & $\begin{array}{l}\text { Porto Colombu } \\
\text { Mormabondo }\end{array}$ & 4,39 & $\begin{array}{l}45,2 \\
40,7\end{array}$ & 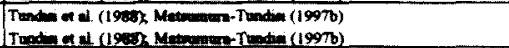 \\
\hline 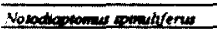 & Mannibondo & $\rightarrow 2$ & 40,7 & 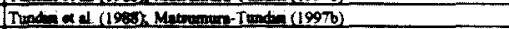 \\
\hline Scolock topome conderat & $\begin{array}{l}\text { Porto Colombua } \\
\text { Marnibondo }\end{array}$ & $\begin{array}{l}4,37 \\
2,77 \\
\end{array}$ & $\begin{array}{c}45,2 \\
40,7\end{array}$ & 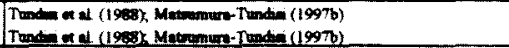 \\
\hline 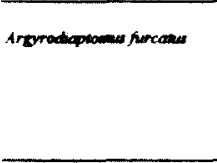 & 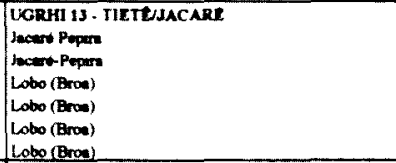 & $\begin{array}{l}1,70 \\
2,50 \\
N \\
N \\
N \\
N \\
N \\
N \\
N\end{array}$ & $\begin{array}{l}35,8 \\
39,7 \\
\text { N.D. } \\
\text { N.D. } \\
\text { N.D. } \\
\text { ND. }\end{array}$ & 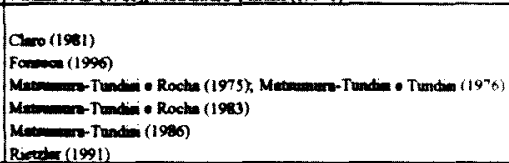 \\
\hline 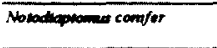 & Beming & $\begin{array}{r}7,46 \\
10.38\end{array}$ & $\begin{array}{l}30,7 \\
34,1\end{array}$ & 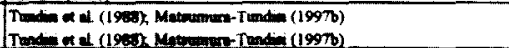 \\
\hline N. thenthe & $\begin{array}{l}\text { Lobo (Broe) } \\
\text { Bern } \\
\text { Ithitine } \\
\end{array}$ & \begin{tabular}{ll|l}
$N$ & 0 \\
$\times$ & 0 \\
$\times$ & 0 \\
\end{tabular} & $\begin{array}{l}\text { N.D } \\
\text { N.D } \\
\text { N.D. } \\
\end{array}$ & 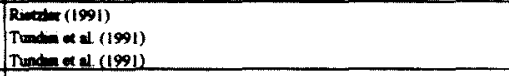 \\
\hline 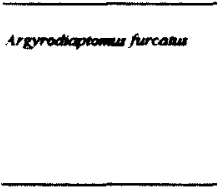 & 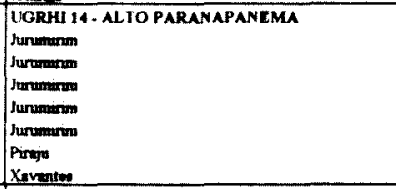 & $\begin{array}{l}2,00 \\
2,46 \\
1,08 \\
3,00 \\
2.18 \\
2.99 \\
1,69\end{array}$ & $\begin{array}{l}37,4 \\
39,6 \\
31,3 \\
41,4 \\
38,3 \\
40,0 \\
39,5 \\
\end{array}$ & 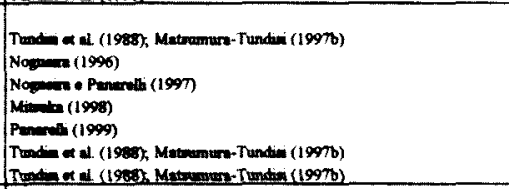 \\
\hline 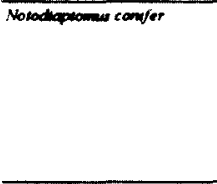 & 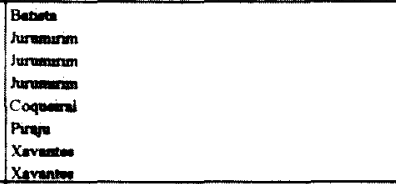 & \begin{tabular}{r|}
4.91 \\
2.00 \\
2.40 \\
3.00 \\
10,63 \\
2.59 \\
$N .0$ \\
1.65 \\
\end{tabular} & $\begin{array}{l}69,6 \\
3,4,4 \\
39,6 \\
41,4 \\
34,2 \\
40,0 \\
N D \\
39,9 \\
\end{array}$ & 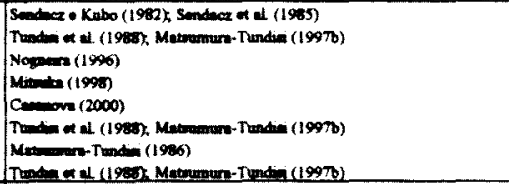 \\
\hline N wertary & 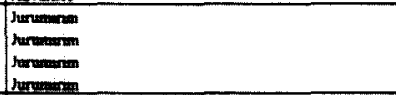 & $\begin{array}{l}2,46 \\
1,06 \\
3,00 \\
2,18\end{array}$ & $\begin{array}{r}39,6 \\
31,3 \\
4,4 \\
38,3\end{array}$ & 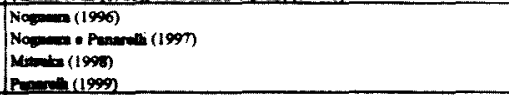 \\
\hline 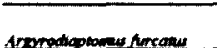 & $\begin{array}{l}\text { UGRHI IS - TURVONGRANDE } \\
\text { AGU Vermelte }\end{array}$ & 2,4 & 40.6 & Tunda a d (1900) Mutrumure Tandin (1997b) \\
\hline 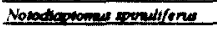 & Am Vongmelle & 234 & 40.6 & 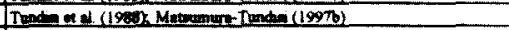 \\
\hline 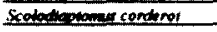 & Aeve Vomede & 2.24 & 40,6 & 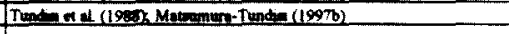 \\
\hline 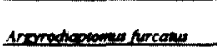 & $\begin{array}{l}\text { UGRHI 16 - TIETEAATALHA } \\
\text { Protime }\end{array}$ & 8,62 & -52.2 & 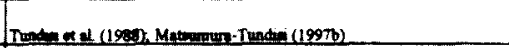 \\
\hline Nopodiopeonu center & Promene & 8.62 & 522 & In \\
\hline Nimeries & Promente & YरD & N.D. & $T \operatorname{Tom} a d(1991)$ \\
\hline$N$ tonimens & Promien & 8.62 & 92.2 & 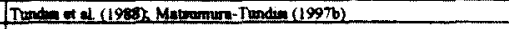 \\
\hline Arroradteplones furconus & $\begin{array}{l}\text { UGRHI 17 - MEDIO PARANAPANEMA } \\
\text { Sollo Onende }\end{array}$ & 181 & 36,4 & 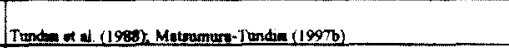 \\
\hline 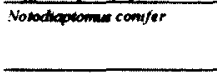 & $\begin{array}{l}\text { Salto Grende } \\
\text { Rio Pan } \\
\text { Copiven }\end{array}$ & $\begin{array}{l}1,81 \\
2,00 \\
2,89\end{array}$ & $\begin{array}{r}36,4 \\
40,4 \\
40,9 \\
\end{array}$ & 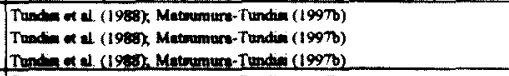 \\
\hline$N$ mantioner & Coperen: & $\begin{array}{l}2.80 \\
Y D \\
\end{array}$ & $\begin{array}{l}10.9 \\
\text { ND } \\
\end{array}$ & 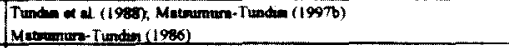 \\
\hline 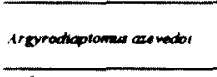 & $\begin{array}{l}\text { WGRHII 18 - SAO JOSE DOS DOURADOS } \\
\text { The Solters } \\
\text { the Soltern }\end{array}$ & $\begin{array}{ll}Y & 0 \\
\times & 0 \\
\end{array}$ & $\begin{array}{l}\text { ND } \\
\text { ND } \\
\end{array}$ & 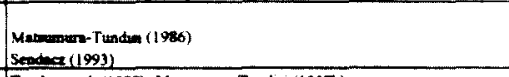 \\
\hline A Mreatur & $\begin{array}{l}\text { The Soltern: } \\
\text { Ithe solumen }\end{array}$ & $\begin{array}{l}2,04 \\
\text { So } \\
\end{array}$ & $\begin{array}{l}37, \\
\text { ND. }\end{array}$ & 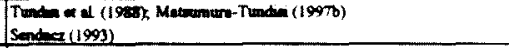 \\
\hline 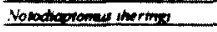 & Ithe Solters: & $\times D$ & ND & Senderz $(1993)$ \\
\hline 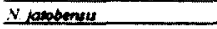 & filha Saltron & $\times D$ & ND & $\operatorname{sen} a(1 \% 93)$ \\
\hline$N$ posediferus & $\begin{array}{l}\text { fhe Solverse } \\
\text { the Solture } \\
\text { the Solterse } \\
\text { lithe Soltern }\end{array}$ & \begin{tabular}{l|}
2,04 \\
$\times 0$ \\
$\times 0$ \\
$\times 1$ \\
\end{tabular} & $\begin{array}{l}37 \\
\text { ND } \\
\text { ND } \\
\text { N D }\end{array}$ & 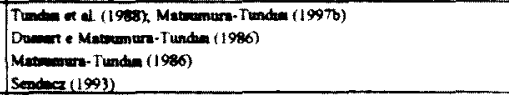 \\
\hline Argmostipposenes aermodot & $\begin{array}{l}\text { UGRHI 19-BADXO TIETE } \\
\text { SupaA } \\
\text { lupR }\end{array}$ & $\begin{array}{r}3.26 \\
\times D \\
\end{array}$ & $\begin{array}{l}\$ 2,3 \\
\text { ND }\end{array}$ & 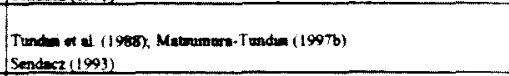 \\
\hline 1. Merrotury & $\begin{array}{l}\text { Nove Averheradove } \\
\text { Jupes } \\
\text { fupen }\end{array}$ & $\begin{array}{r}7.87 \\
3.26 \\
\because 0 \\
\end{array}$ & $\begin{array}{l}53,5 \\
12,3 \\
\times 10 \\
\end{array}$ & 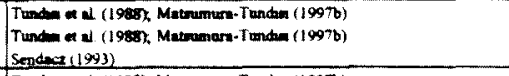 \\
\hline Nopode proment conster & Nove aveninenden & 980 & 53,5 & 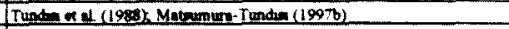 \\
\hline$N$ inarow & $\begin{array}{l}\text { Nove Averibenderve } \\
\text { lupes }\end{array}$ & $\begin{array}{ll}D \\
\times D \\
\end{array}$ & $\begin{array}{ll}\text { ND } \\
\text { N.D } \\
\end{array}$ & 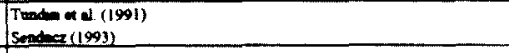 \\
\hline N japobensti & Juput & 90 & YD & Senderi:1999) \\
\hline S spunilifers & $\begin{array}{l}\text { lupe } \\
\text { lupe }\end{array}$ & $\begin{array}{l}1.20 \\
\mathrm{D} \\
\end{array}$ & $\begin{array}{l}42.3 \\
\text { ND } \\
\end{array}$ & 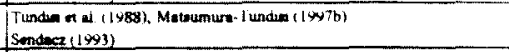 \\
\hline$N$ manions & Nown Avenhenden: & 0.87 & 53,5 & 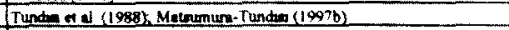 \\
\hline Argorachoptomew furcanus & $\begin{array}{l}\text { GGRHI } 22 \text {, POVTAL DO PARANAPANEMA } \\
\text { Compende } \\
\text { boue }\end{array}$ & $\begin{array}{l}i s, 13 \\
0,24 \\
\end{array}$ & $\begin{array}{r}578 \\
68,6 \\
\end{array}$ & 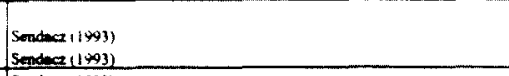 \\
\hline Nopoptopeomes center & Comonda & 15,13 & $5+8$ & Sendecz $(1993)$ \\
\hline$\overline{S i \text { inerimg }}$ & Compride & $\begin{array}{ll}0,5,3 \\
11,4\end{array}$ & $\begin{array}{l}57.8 \\
08,6\end{array}$ & $\begin{array}{l}\text { Sendecz }(1993) \\
\text { Sendiaz }(1999)\end{array}$ \\
\hline visention & $\begin{array}{l}\text { Compride } \\
\text { Wuen }\end{array}$ & \begin{tabular}{|c|c|}
4,13 \\
$3+1$
\end{tabular} & $\begin{array}{l}5.8 \\
08.6 \\
\end{array}$ & 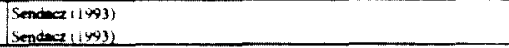 \\
\hline
\end{tabular}


TABELA 23 - Ocorrència de cladóceros, média das concentrações de clorofila $a$ total $(\mu \mathrm{g} / \mathrm{L})$ e Índice de Estado Trófico (IET) de Carlson modificado, em cada corpo d'água, com o respectivo autor e época de estudo, por Unidade de Gerenciamento de Recursos Hidricos (UGRHI) do Estado de São Paulo.

\begin{tabular}{|c|c|c|c|c|}
\hline Extan & Reorveonol & Gorofine a $(4: 2)$ & ETT & Ainofe \\
\hline Eropene temper & 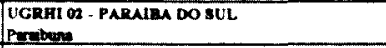 & ND. & ND & comonand) \\
\hline Slam pentere & Proberan & N.D. & ND. & $\alpha_{\operatorname{mon}}(1991)$ \\
\hline A norearitas & Peribues & ND. & N.D. & 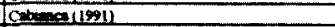 \\
\hline 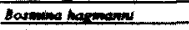 & Patome & ND. & ND & Comanil 19911 \\
\hline B. londroutrey & $P=$ & ND. & N.D. & cobana 1911 \\
\hline Basmeopesu dituterst & 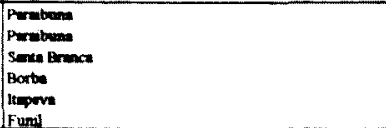 & $\begin{array}{c}16.80 \\
N .0 \\
21.20 \\
N .0 . \\
4.92 \\
40.10\end{array}$ & $\begin{array}{l}38.8 \\
\text { N.D. } \\
61.2 \\
\text { N.D } \\
68.7 \\
67\end{array}$ & 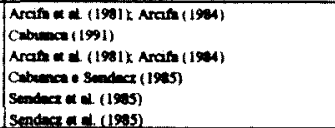 \\
\hline Conodaphnta comula & 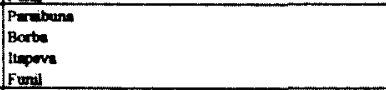 & $\begin{array}{l}16,00 \\
N D \\
4.92 \\
40,10\end{array}$ & $\begin{array}{l}\text { S. } \\
\text { ND. } \\
6.7 \\
67.7\end{array}$ & 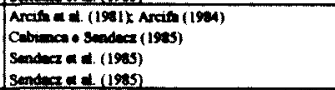 \\
\hline Cr.comple & $P_{m a \text { mans }}$ & N.D. & ND. & cotionalopin \\
\hline C.c. anomene & Jemi & 20,0 & 61.0 & 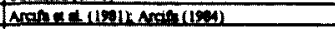 \\
\hline C. a. mente & Pmilen & N.D. & ND. & 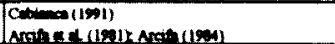 \\
\hline Cnitaleng & ing & 20,90 & 60 & 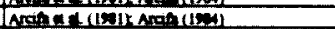 \\
\hline 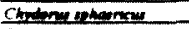 & Pan & N.D. & ND. & $c^{\prime}$ \\
\hline Deopen ention & $P_{1}=$ & ND. & ND. & $\operatorname{com}(1091)$ \\
\hline D. exement & 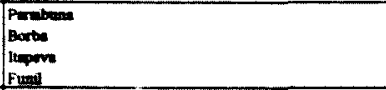 & 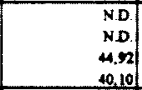 & $\begin{array}{l}\text { ND } \\
\text { ND. } \\
647 \\
677\end{array}$ & 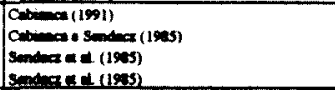 \\
\hline 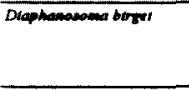 & 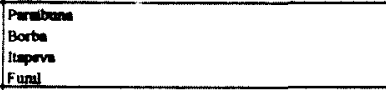 & $\begin{array}{l}N . \mathrm{D} \\
N \mathrm{D} \\
44,92 \\
40,10\end{array}$ & $\begin{array}{l}\text { N.D. } \\
\text { N.D. } \\
68.7 \\
67.7\end{array}$ & 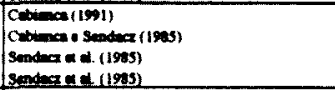 \\
\hline 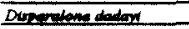 & Perimas & ND & N.D & $c=2(19 \theta 1)$ \\
\hline 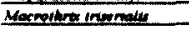 & Pensume & ND. & N.D. & $\cos 2(1901)$ \\
\hline 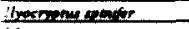 & Paribenes & N.P. & N.D. & Camanation \\
\hline 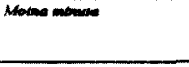 & 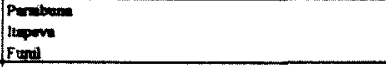 & $\begin{array}{l}N .8 . \\
4.92 \\
+0.10\end{array}$ & $\begin{array}{l}\text { N.D. } \\
66.7 \\
67.7\end{array}$ & 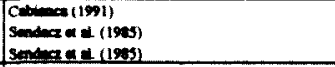 \\
\hline 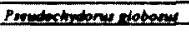 & P. Plathen & NDP & N.D. & cebiea (1) \\
\hline 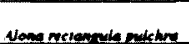 & UGRH OA - PARDO & 1,00 & 36.5 & 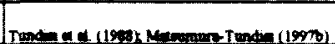 \\
\hline Dandere to & Oanmente & 37 & 40 & 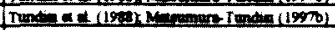 \\
\hline andenten & Monom & $\begin{array}{l}12600 \\
N . D .\end{array}$ & N.9. & $\operatorname{sivn}(190)$ (190) \\
\hline Soosmonowe determ & 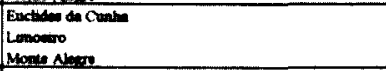 & $\begin{array}{c}1.80 \\
5.06 \\
N D P\end{array}$ & $\begin{array}{l}3.5 \\
44,3 \\
\text { N.P. } \\
\end{array}$ & 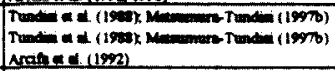 \\
\hline 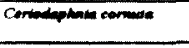 & Moto Alos & $\begin{array}{l}18.60 \\
\text { N.D. } \\
\end{array}$ & $\begin{array}{l}59,9 \\
\text { ND. }\end{array}$ & $\sin (1000)$ \\
\hline 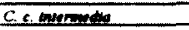 & On & 5,5 & 48,0 & 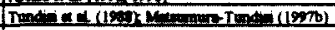 \\
\hline C.c.n $=1$ & onn & 5.75 & 4,0 & 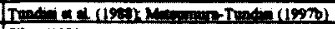 \\
\hline 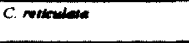 & Mom $N$ & $\begin{array}{l}12,60 \\
N D\end{array}$ & SP.9. & Sime (ISO) \\
\hline 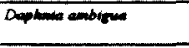 & $\operatorname{mom}_{0} A \operatorname{sen}$ & $\begin{array}{l}12.0 \\
\text { ND. }\end{array}$ & $\begin{array}{l}\text { N9.9 } \\
\text { M.D. }\end{array}$ & $\sin (160)$ \\
\hline$D$ encenen & 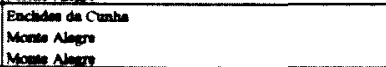 & $\begin{array}{c}1.03 \\
18.60 \\
\times .0\end{array}$ & $\begin{array}{l}3.9 \\
39.9 \\
N . D\end{array}$ & 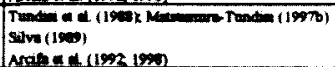 \\
\hline 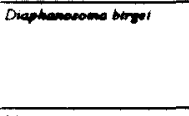 & 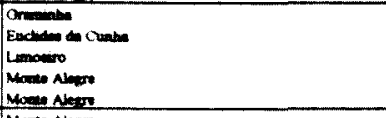 & \begin{tabular}{r|}
5.73 \\
1.3 \\
3.8 \\
18.60 \\
$v 0$ \\
\end{tabular} & $\begin{array}{l}4.0 \\
36.5 \\
48.3 \\
59.9 \\
N . D \\
\end{array}$ & 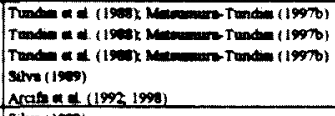 \\
\hline Alomo morane & Monom Never & $\begin{array}{c}12.60 \\
N D\end{array}$ & $\begin{array}{l}59.9 \\
\text { ND }\end{array}$ & 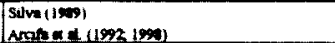 \\
\hline$M_{\text {manera }}$ & 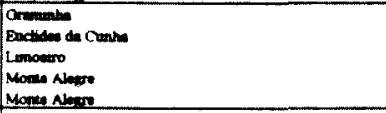 & $\begin{array}{r}3.73 \\
1.83 \\
3.85 \\
18.60 \\
v 0 \\
\end{array}$ & $\begin{array}{r}48.0 \\
36.9 \\
48.3 \\
59.9 \\
\text { N.D }\end{array}$ & 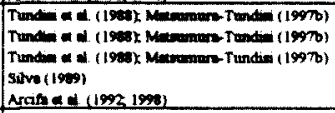 \\
\hline 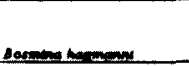 & 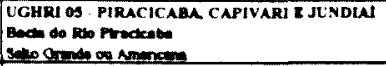 & No. & N.D. & 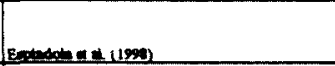 \\
\hline S Lentereming & Siro on ou Amencen & 710 & 74.2 & $\operatorname{Aran}-2$ Q $(19721976)$ \\
\hline Bosmmoperes detienst & 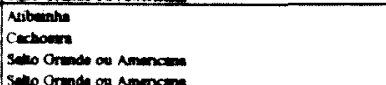 & $\begin{array}{r}7.30 \\
97.20 \\
7.10 \\
N D\end{array}$ & $\begin{array}{l}6.9 .2 \\
76.5 \\
74.2\end{array}$ & 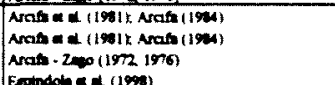 \\
\hline Certolephata comenta & 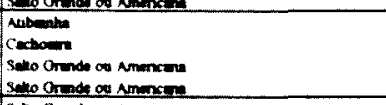 & 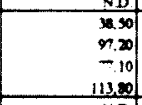 & $\begin{array}{l}N .0 \\
67.2 \\
76.5 \\
74.2 \\
7.2 .1 \\
\end{array}$ & 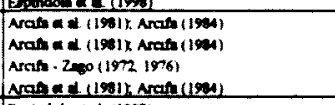 \\
\hline Creormila & Soporende on Amercins & No. & ND & Ependateres (1990) \\
\hline 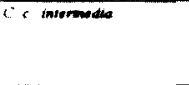 & 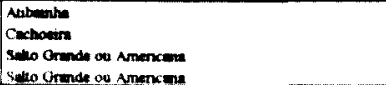 & $\begin{array}{r}31.50 \\
97.20 \\
113.80 \\
\text { v. }\end{array}$ & $\begin{array}{l}67.2 \\
76.9 \\
7.1 \\
\text { Y.D. }\end{array}$ & 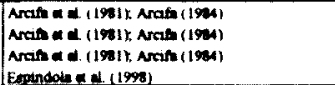 \\
\hline C c. noradt & 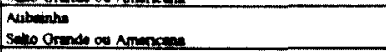 & $\begin{array}{l}30.50 \\
N .0\end{array}$ & $\begin{array}{l}67.2 \\
N D\end{array}$ & $\begin{array}{l}\text { Arah a d (1901: Arafe (199) } \\
\text { E }\end{array}$ \\
\hline C roukweres & 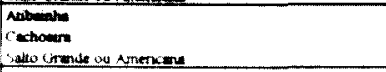 & $\begin{array}{r}3.50 \\
97.20 \\
-10 \\
\end{array}$ & $\begin{array}{r}67.2 \\
76.9 \\
-4.2 \\
\end{array}$ & 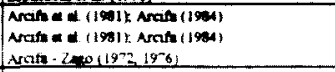 \\
\hline rimelins & 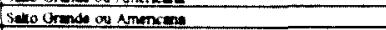 & No & $\frac{1}{N D}$ & Eondenes \\
\hline Daphem greston & 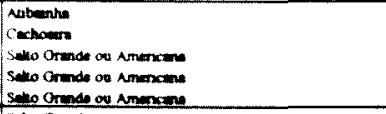 & 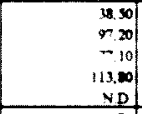 & $\begin{array}{l}67.2 \\
78.3 \\
74.2 \\
7.1 \\
\text { N.D } \\
\end{array}$ & 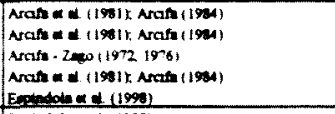 \\
\hline 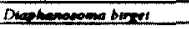 & 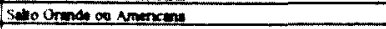 & ND & ND & 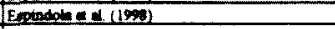 \\
\hline D Brmarm & 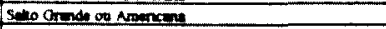 & -50 & 742 & Arat - 20011973 1976) \\
\hline Moceremimire & 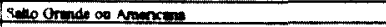 & ND & No & Eorindot ne 1.1900$)$ \\
\hline 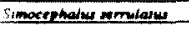 & 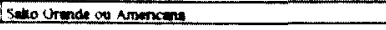 & $\mathrm{xD}$ & N.D. & 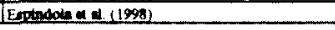 \\
\hline
\end{tabular}


Continuacilo

TABELA 23 - Ocorrência de cladóceros, média das concentrações de clorofila $a$ total $(\mu \mathrm{g} / \mathrm{L})$ e Índice de Estado Trófico (IET) de Carlson modificado, em cada corpo d'água, com o respectivo autor e época de estudo, por Unidade de Gerenciamento de Recursos Hidricos (UGRHI) do Estado de São Paulo.

\begin{tabular}{|c|c|c|c|c|}
\hline Espocion & Reservatonol agoa/Lago & Clorofila a $(\mu \alpha)$ & IET & Autores \\
\hline Bosminopsus detefersi & 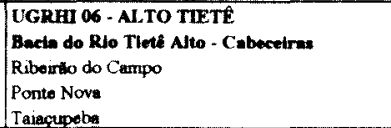 & $\begin{array}{l}14,00 \\
41,97 \\
55,40\end{array}$ & $\begin{array}{l}57,0 \\
68,1 \\
70,9\end{array}$ & $\begin{array}{l}\text { Arcifa ot al. (1981); Arcifa (1984) } \\
\text { Sendecz et at. (1985) } \\
\text { Arcifa et al. (1981): Arcifa (1984) }\end{array}$ \\
\hline Ceriodaphnio cornuto & $\begin{array}{l}\text { Riberito do Campo } \\
\text { Ponto Nove } \\
\text { Taiagupebe }\end{array}$ & $\begin{array}{l}14,00 \\
41,97 \\
55,40 \\
\end{array}$ & $\begin{array}{l}57,0 \\
68,1 \\
70,9\end{array}$ & 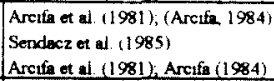 \\
\hline C. reticulata & $\begin{array}{l}\text { Ribeirto do Campo } \\
\text { Taiacupebe }\end{array}$ & $\begin{array}{l}14,00 \\
55,40 \\
\end{array}$ & $\begin{array}{l}57,0 \\
70,9\end{array}$ & 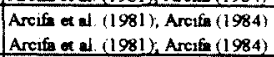 \\
\hline Daphnio gesment & $\begin{array}{l}\text { Ribeirto do Campo } \\
\text { Ponte Nova }\end{array}$ & $\begin{array}{r}14,00 \\
41,97 \\
\end{array}$ & $\begin{array}{l}57,0 \\
68,1 \\
\end{array}$ & $\begin{array}{l}\text { Arcifi ox al. (1981). Arcifis (1984) } \\
\text { Sendecz ex al (1985) }\end{array}$ \\
\hline Diaphanosome birgei & Ponto Noys & 41,97 & 68,1 & Sendacz of al (1985) \\
\hline Moino minuta & Ponte Nove & 41,97 & 68,1 & Sendecz ea ai. (1985) \\
\hline Alona guttata & 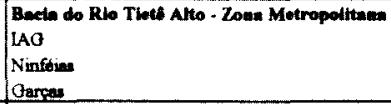 & $\begin{array}{r}4,37 \\
11,24 \\
53,22 \\
\end{array}$ & $\begin{array}{l}45,2 \\
54,8 \\
70,4 \\
\end{array}$ & $\begin{array}{l}\text { Esto trabatho } \\
\text { Este trabulho } \\
\text { Esto trabalho }\end{array}$ \\
\hline A. monacantina & $\begin{array}{l}\text { Ninfoum } \\
\text { Gercen }\end{array}$ & $\begin{array}{l}11,24 \\
53,22 \\
\end{array}$ & $\begin{array}{l}54,8 \\
70,4 \\
\end{array}$ & $\begin{array}{l}\text { Ente trabaiho } \\
\text { Este trabalho }\end{array}$ \\
\hline Bosmina hagmanni & $\begin{array}{l}\text { IAO } \\
\text { Garcean }\end{array}$ & $\begin{array}{r}4,37 \\
53,22 \\
\end{array}$ & $\begin{array}{l}45,2 \\
70,4 \\
\end{array}$ & $\begin{array}{l}\text { Ente tribalho } \\
\text { Ente trabelho }\end{array}$ \\
\hline B. cubicen & $\begin{array}{l}\text { LAO } \\
\text { garyas }\end{array}$ & $\begin{array}{r}4,37 \\
53,22 \\
\end{array}$ & $\begin{array}{l}45.2 \\
70.4 \\
\end{array}$ & $\begin{array}{l}\text { Este trabatho } \\
\text { Einte tnabelho }\end{array}$ \\
\hline Bosminopsss deterss & 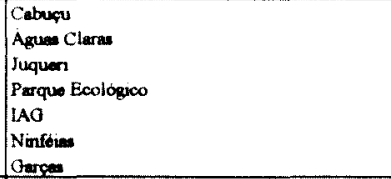 & $\begin{array}{r}34,00 \\
35,26 \\
31,95 \\
24,50 \\
4,37 \\
11,24 \\
53,22 \\
\end{array}$ & $\begin{array}{l}65,9 \\
66,4 \\
65,4 \\
62,6 \\
45,2 \\
54,8 \\
70,4 \\
\end{array}$ & 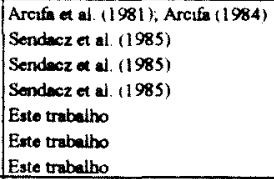 \\
\hline Comptacercus dadayi & $\begin{array}{l}\text { IAO } \\
\text { Ninfétias } \\
\text { Orerceses } \\
\end{array}$ & $\begin{array}{r}4,37 \\
11,24 \\
53,22 \\
\end{array}$ & $\begin{array}{r}45.2 \\
54,8 \\
70,4 \\
\end{array}$ & $\begin{array}{l}\text { Este trabsilho } \\
\text { Este trabalho } \\
\text { Este trabalho }\end{array}$ \\
\hline Ceriodophnea cormuta & $\begin{array}{l}\text { Cabupu } \\
\text { Ague Clara } \\
\text { Juquen }\end{array}$ & $\begin{array}{l}34,00 \\
35,26 \\
31,95 \\
\end{array}$ & $\begin{array}{l}65,9 \\
66,4 \\
65,4 \\
\end{array}$ & $\begin{array}{l}\text { Arctsis of al. (1981); Arcifin (1984) } \\
\text { Sendacz et al (1985) } \\
\text { Sendecz et al (1985) } \\
\end{array}$ \\
\hline C.c.cormute & Oarcan & 53,22 & 70,4 & Ene Unbaliho \\
\hline C. en rugandi & Oarpese & 53,22 & 70,4 & Este trabel the \\
\hline C. ef. reticutiona & Gerrese & 53,22 & 904 & Ence trabatho \\
\hline Chydonus puberceress & $\begin{array}{l}\text { Ninfione } \\
\text { Gercen }\end{array}$ & $\begin{array}{l}11,24 \\
53,22 \\
\end{array}$ & $\begin{array}{l}54,8 \\
70,4\end{array}$ & $\begin{array}{l}\text { Ente trabalho } \\
\text { Ento trabeilho }\end{array}$ \\
\hline C. sphaencus & $\begin{array}{l}\text { IAO } \\
\text { Ninfoine } \\
\text { Oerpes }\end{array}$ & $\begin{array}{r}4,37 \\
11,24 \\
53,22 \\
\end{array}$ & $\begin{array}{l}45,2 \\
54.8 \\
70.4 \\
\end{array}$ & $\begin{array}{l}\text { Eare trabalho } \\
\text { Eare trabalho } \\
\text { Erre trabaiho }\end{array}$ \\
\hline Daphnia ambigua & $\begin{array}{l}\text { LAO } \\
\text { Ninfoive } \\
\text { Oarrea }\end{array}$ & $\begin{array}{r}4,37 \\
11,24 \\
53,22 \\
\end{array}$ & $\begin{array}{r}45,2 \\
54,8 \\
70,4 \\
\end{array}$ & \begin{tabular}{|l|} 
Este trabalho \\
Ente trabalho \\
Este trabalho
\end{tabular} \\
\hline D. gessmen & 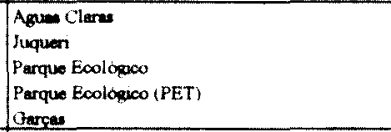 & $\begin{array}{l}35,26 \\
31,95 \\
24,50 \\
91,15 \\
53,22 \\
\end{array}$ & $\begin{array}{l}66,4 \\
65,4 \\
62,6 \\
75,9 \\
70,4 \\
\end{array}$ & 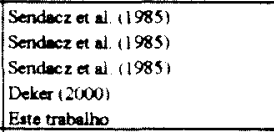 \\
\hline Diaphanosame bregei & $\begin{array}{l}\text { Aqua Claras } \\
\text { Juquen } \\
\text { Parque Ecologoo } \\
\text { Parque Ecologico (PET) } \\
\text { LAO } \\
\text { Oerrea }\end{array}$ & $\begin{array}{r}35,26 \\
31,95 \\
24,50 \\
91,15 \\
4,37 \\
53,22 \\
\end{array}$ & $\begin{array}{l}66,4 \\
65,4 \\
62,6 \\
75,9 \\
45,2 \\
70,4 \\
\end{array}$ & 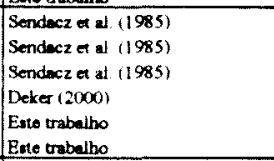 \\
\hline D. brevireme & Parque Ecologico (PET) & 91,15 & 75,9 & Deker 2000$)$ \\
\hline Diaparalona dadoy! & $\begin{array}{l}\text { LAG } \\
\text { Ninfeleat } \\
\text { Oance }\end{array}$ & $\begin{array}{r}4,37 \\
11,24 \\
53,22 \\
\end{array}$ & $\begin{array}{l}45.2 \\
54,8 \\
70,4 \\
\end{array}$ & $\begin{array}{l}\text { Este trabalho } \\
\text { Ente trabaliho } \\
\text { Este trabeliho }\end{array}$ \\
\hline Ephemeroponst barroist & $\begin{array}{l}\text { IAO } \\
\text { Nanfoias }\end{array}$ & $\begin{array}{r}4,37 \\
11,24 \\
\end{array}$ & $\begin{array}{l}45,2 \\
54,8\end{array}$ & $\begin{array}{l}\text { Este trabulho } \\
\text { Este trabal ho }\end{array}$ \\
\hline E. Lridentatus & $\begin{array}{l}\text { LAO } \\
\text { Ninfóing }\end{array}$ & $\begin{array}{r}4,37 \\
11,24 \\
\end{array}$ & $\begin{array}{l}45.2 \\
54,8\end{array}$ & $\begin{array}{l}\text { Este trabeliho } \\
\text { Este trabaino }\end{array}$ \\
\hline iroptoleberis iesrudinario & LAO & 4,37 & 452 & Este trabalho \\
\hline Ilvacryprus spinifer & \begin{tabular}{|l|} 
LAO \\
Nunfeime \\
Uarcas \\
\end{tabular} & $\begin{array}{r}4,37 \\
11,24 \\
53,22 \\
\end{array}$ & $\begin{array}{r}45,2 \\
54,8 \\
-4,4 \\
\end{array}$ & $\begin{array}{l}\text { Este trabaitho } \\
\text { Este trabaitho } \\
\text { Este trabaino }\end{array}$ \\
\hline Legdigra caliato & Parque Ecologyoo (PET) & 91,15 & 759 & Deker (2000) \\
\hline Macrothrux laticomis & Ninfoim & 11,24 & 54,8 & Esto trabalho \\
\hline 14. spinosa & $\begin{array}{l}\text { Parque Ecolópjoo (PETi } \\
\text { Lito } \\
\text { Nunfelas } \\
\text { Oarcas }\end{array}$ & $\begin{array}{r}91.15 \\
1.3 \\
11.24 \\
53.22 \\
\end{array}$ & $\begin{array}{r}-5.9 \\
54.2 \\
548 \\
-0.4 \\
\end{array}$ & 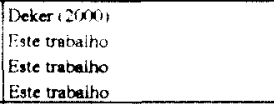 \\
\hline Tauna micura & $\begin{array}{l}\text { LAO } \\
\text { Ninfeleas } \\
\text { Crarcas }\end{array}$ & $\begin{array}{r}1,3 \\
11.24 \\
53,22\end{array}$ & $\begin{array}{l}45.9 \\
54,8 \\
904\end{array}$ & $\begin{array}{l}\text { Este trabaiho } \\
\text { Este trabs tho } \\
\text { Ente trabatho }\end{array}$ \\
\hline U. minuia & $\begin{array}{l}\text { Aguas Clarbs } \\
\text { Juquers } \\
\text { Parquo Ecologroo } \\
\text { iarcas }\end{array}$ & $\begin{array}{l}35.26 \\
31,95 \\
24.50 \\
93.22\end{array}$ & $\begin{array}{r}66.4 \\
65.4 \\
62.6 \\
-6.4\end{array}$ & $\begin{array}{l}\text { Sendecz et af (1985) } \\
\text { Sendacz et al (1985) } \\
\text { Sendacz et of (1985) } \\
\text { Este trabaino }\end{array}$ \\
\hline
\end{tabular}


Continumpio

TABELA 23 - Ocorrência de cladóceros, média das concentrações de clorofila $a$ total $(\mu \mathrm{g} / \mathrm{L})$ e Índice de Estado Trófico (IET) de Carlson modificado, em cada corpo d'água, com o respectivo autor e época de estudo, por Unidade de Gerenciamento de Recursos Hidricos (UGRHI) do Estado de São Paulo.

\begin{tabular}{|c|c|c|c|c|}
\hline Espoceses & Resenvatonol aquad Laso & Corofila a las L L & ET & Autores \\
\hline \multirow{5}{*}{ Bosmina hagmanns } & 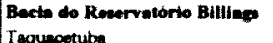 & $2263]$ & 61,9 & CETESB (1999) Coelho-Botel ho of al $(2001$ ) \\
\hline & Rio Pequeno & 7,61 & 50,9 & CETESB (1999), Coelho-Botolho et al (2001) \\
\hline & Rio Orande & ND & N.D. & Kubo (1989) \\
\hline & Rio Orande & 6,46 & 49,3 & Sendacz o Kubo (1999) \\
\hline & Ro Grende & 38,48 & 67,2 & CETESB (1999), Coolho-Botetho of al (2001) \\
\hline \multirow[t]{4}{*}{ B. longunastris } & Rio Orande & 10.24 & 53,9 & Sendecz et of (1984) \\
\hline & Rio Orande & ND. & N.D. & Kubo (1989) \\
\hline & Rio Orande & 6.46 & 49,3 & Sendecz \& Kubo (1999) \\
\hline & Rio Grende & 38,48 & 67,2 & CETESB (1999); Coelho-Botetho of al $(2001)$ \\
\hline \multirow[t]{4}{*}{ B. nubicon } & Rso Pequeno & 3.61 & 50,9 & CETESB (19992), Coelho-Boteltho of al (2001) \\
\hline & Ro Orende & N.D. & N.D. & Kubo (1989) \\
\hline & Rio Chende & 6.46 & 49,3 & Sendecz o Kubo (1999) \\
\hline & Rso Orande & 38,48 & 67,2 & CETESB (1999); Coelho-Botelino a al (2001) \\
\hline \multirow[t]{4}{*}{ Bominopsis dettersi } & Taquecotube & 22,63 & 61.9 & CETESB (1999a); Coelho-Botelito of al (2001) \\
\hline & Rio Pequeno & 7,61 & 50,9 & CETESB (1999a); Coetho-Botetho of al (2001) \\
\hline & Rio Orande & ND. & N.D. & Kubo (1989) \\
\hline & Roo Onnde & 6,46 & 49,3 & Sendacze Kubo (1999) \\
\hline \multirow[t]{8}{*}{ Coriodaphnia cormula } & Tequecotuba & 22,63 & 61,9 & CETESB (1999a); Coelho-Botel hio of al. (2001) \\
\hline & Rso Pequeno & ND. & N.D. & Sendacz (1978) \\
\hline & Rio Pequento & ?.61 & 50,9 & CETESB (1999); Coelho-Botelho of al (2001) \\
\hline & Rio Orance & N.D. & N.D. & Sendecz (1978) \\
\hline & Rio Orende & 255.39 & 86.2 & Sendecz ot al. (1985) \\
\hline & Rio Grende & 6.46 & 49.3 & Sendacz e Kubo (1999) \\
\hline & Rio Onende & 38.48 & 67.2 & CETESB (1999), Coeltro-Botelho et al (2001) \\
\hline & Ro din Pedras & 289,21 & 87.5 & Sendacz et al (1985) \\
\hline \multirow[t]{2}{*}{ C. c. cormuta } & Rio Orande & 10,24 & 53,9 & Sender et af (1984) \\
\hline & Rio Orende & ND & ND & Kubo (1989) \\
\hline C.cintermedia & Roo Orande & ND. & ND & Kubo (1989) \\
\hline \multirow{2}{*}{ C. c. rganedi } & Rio Orande & 10,24 & 53,9 & Senderez of al. (1984) \\
\hline & Rio Orande & ND. & N.D. & Kubo (1989) \\
\hline C. reticulata & Rio Orande & ND. & ND & Kubo (1989) \\
\hline \multirow[t]{5}{*}{ Daphnia ambigua } & Tequecentube & 2263 & 61.9 & CETESB (1999a), Coetho-Bocetho et al (2001) \\
\hline & Rio Pequeco & 7,61 & 50,9 & CBTESB (1999), Coelho-Botelho of al (2001) \\
\hline & Rio Grende & N.D. & N.D. & Kubo (1989) \\
\hline & Rio Grande & 6.46 & 49.3 & Sendecz o Kubo (1999) \\
\hline & Rio Onende & 38,48 & 67,2 & CETESB (1999a), Coetho-Boxol ho of al $(2001)$ \\
\hline \multirow[t]{10}{*}{ D. gessmeri } & Tequesetube & 22.63 & 61,9 & CETRSB (1999), Coelho-Botelho of al (2001) \\
\hline & Rio Poqueno & ND. & ND. & Sendex $(1978)$ \\
\hline & Roo Pequeno & 7.61 & 50.9 & CETESB (1999), Coelho-Boteitho of al $(2001)$ \\
\hline & Rso Grande & ND. & N.D. & Sendecz (1978) \\
\hline & Rio Grande & 10.24 & 53,9 & Sendecz ot ad (1984) \\
\hline & Riso Orende & 255,39 & 86.2 & Sendecz of al (1985) \\
\hline & Roo Orande & ND & ND. & Kubo (1989) \\
\hline & Reo Orende & 6.46 & 49.3 & Sendercz \& Kubo (1999) \\
\hline & Rwo Orande & 38.48 & 67,2 & CETESB (1999a), Coetho-Boretho of al $\{2001\}$ \\
\hline & Rio das Peatras & 899,21 & 87,5 & Sendacz of af (1985) \\
\hline \multirow[t]{8}{*}{ Diaphanasoma birger } & Tequacetuba & 22,63 & 61,9 & CETESB (1999a), Coelho-Boteithe ef al ( 2001$)$ \\
\hline & Rio Pequeno & 7,61 & 50.9 & CETESB (1999); Coolho-Botelino et at (2001) \\
\hline & Rio Orende & 10,24 & 53,9 & Sendercz ot al (1984) \\
\hline & Rio Orande & 255,39 & 86,2 & Sendecz ot al (1985) \\
\hline & Rio Orande & ND. & N.D. & Kubo (1989) \\
\hline & Rso Grande & 6.46 & 49,3 & Sendacz o Kubo (1999) \\
\hline & Rio Grande & 38,48 & 67,2 & CETESB (1999); Cooltho-Boteiho at (2001) \\
\hline & Roo den Podre: & 289,21 & 875 & Sondez et al (1985) \\
\hline \multirow[t]{2}{*}{ D. brevireme } & Rro Orande & $\mathrm{ND}$ & ND. & Kubo (1989) \\
\hline & Ro Paqueno & .61 & 50,9 & (CETESB (1999a), Coetho-Botetho of af (900) \\
\hline \multirow[t]{2}{*}{ D. spimalarem } & Traquectube & 22.63 & 61.9 & CETESB (1999), Coeltho-Botelibo of al. (2001) \\
\hline & Ro Pegueno & -61 & 509 & CETESB (199\%), Coelho-Boleitho of al (2001) \\
\hline Maina micrura & Taquecortube & 2263 & 61.9 & CETESB $(1999$ ): Coetho Bote iho of al 12001 ) \\
\hline & Ruo Pequeno & .61 & 50,9 & CETESB (1999), Coelho-Borelho of al $(2001)$ \\
\hline M. minuta & Taquecetuba & 2263 & 61.9 & CETESB (1999a), Coetho-Bote tho et al $(2001)$ \\
\hline & Rio Pequeno & 7.61 & 50,9 & CETESB (1999), Comiho-Botetho ef at 12001 ) \\
\hline & Roo Orande & 255.39 & 86,2 & Sendacz et af. (1985) \\
\hline & Roo Grende & 38.48 & 67.2 & CETESB (1999a); Coelho-Botelho of al (2001) \\
\hline & Rio das Pedra & 289,21 & 87,5 & Sendecz ef al $(1985)$ \\
\hline & Bacta do Rio Cotion & & & \\
\hline Bosmunopgry deivern & Peatro Bonchi & 64,80 & 725 & Areifin of al (1981), Arcifin (1984) \\
\hline Ileocrypous spinifor & Podro Beich & 64.80 & 725 & Arets a al (1981), Arafin (1984) \\
\hline
\end{tabular}


Continumacio

TABELA 23 - Ocorrência de cladóceros, média das concentrações de clorofila $a$ total $(\mu \mathrm{g} / \mathrm{L})$ e Índice de Estado Trófico (IET) de Carlson modificado, em cada corpo d'água, com o respectivo autor e época de estudo, por Unidade de Gerenciamento de Recursos Hídricos (UGRHI) do Estado de São Paulo.

\begin{tabular}{|c|c|c|c|c|}
\hline Espocies & Reservetiono/Laxon/Laqo & Clorofla a (p)L) & EEI & Autores \\
\hline Alona of recrensula & $\begin{array}{l}\text { Bacta do Reservatório Guarmpirnass } \\
\text { Guarnogrengas }\end{array}$ & N.D. & N.D & Caleffi $(1994 ; 2000)$ \\
\hline Bosmina hogmanns & 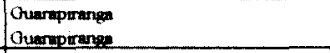 & $\begin{array}{l}\text { N.D. } \\
\text { N.D. } \\
\end{array}$ & $\begin{array}{l}\text { N.D. } \\
\text { ND. } \\
\end{array}$ & $\begin{array}{l}\text { Caleff }(1994 ; 2000) \\
\text { Coelho-Botelho ot al (2001) }\end{array}$ \\
\hline B. longinastrs & 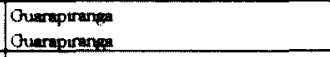 & $\begin{array}{l}3,78 \\
\mathrm{ND} \\
\end{array}$ & $\begin{array}{l}\$ 1,2 \\
\text { N.D. } \\
\end{array}$ & \begin{tabular}{|l} 
Donninges $(1993)$ \\
Caleffi $(1994,2000)$
\end{tabular} \\
\hline B. mbicen & $\begin{array}{l}\text { Ouaruprange } \\
\text { Gherporeng: }\end{array}$ & $\begin{array}{l}\text { N.D. } \\
\text { N.D. } \\
\end{array}$ & $\begin{array}{l}\text { N.D. } \\
\text { N.D } \\
\end{array}$ & $\begin{array}{l}\text { Caleffi }(1994,2000) \\
\text { Coelho-Botelto en al (2001) }\end{array}$ \\
\hline Bosminopsis deluern & 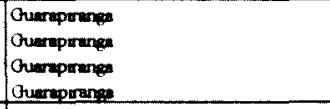 & $\begin{array}{r}18.39 \\
7,78 \\
N D \\
N D \\
\end{array}$ & $\begin{array}{l}59.7 \\
51,2 \\
\text { ND } \\
\text { ND. } \\
\end{array}$ & $\begin{array}{l}\text { Sendecz of al (1985) } \\
\text { Donireoe (1993) } \\
\text { Caleff (1994; 2000) } \\
\text { Coelho-Botelho of al (2001) }\end{array}$ \\
\hline Ceriodaphnsa carmuta & 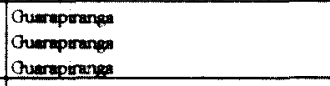 & $\begin{array}{r}18,37 \\
7,78 \\
\mathrm{ND} \\
\end{array}$ & $\begin{array}{l}59,7 \\
51,2 \\
\text { ND. } \\
\end{array}$ & $\begin{array}{l}\text { Sendecz of al. (1985) } \\
\text { Doningow (1993) } \\
\text { Coeltho-Botelho ot al (2001) } \\
\end{array}$ \\
\hline C. c. cornuta & Outerpiremeg & N.D. & ND & Caleffi $(1994 ; 2000)$ \\
\hline C.c. niroudl & Guareprangeg & N.D. & N.D & Caleffi $(1994,2000)$ \\
\hline C. of reticulate & Guarepiranga & ND. & N.D. & Caleffi (1994) \\
\hline Daphnia ambiguo & Orumeprenge & $\begin{array}{l}\text { ND. } \\
\text { ND. } \\
\end{array}$ & $\begin{array}{l}\text { N.D. } \\
\text { N.D. }\end{array}$ & $\begin{array}{l}\text { Caleffir (1994; 2000) } \\
\text { Coelho-Botelho ot al (2001) }\end{array}$ \\
\hline D. gassmert & 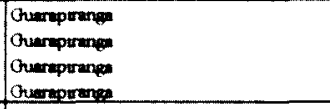 & $\begin{array}{r}18.37 \\
7,78 \\
\text { N.D. } \\
\text { ND. } \\
\end{array}$ & $\begin{array}{l}59,7 \\
51,2 \\
\text { ND } \\
\text { ND } \\
\end{array}$ & $\begin{array}{l}\text { Sendecz of al (1985) } \\
\text { Domingos (1993) } \\
\text { Caleff (1994, 2000) } \\
\text { Coelho-Botelho of al (2001) }\end{array}$ \\
\hline Diaphanasoma birges & 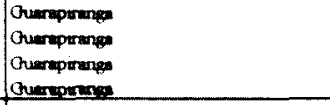 & $\begin{array}{r}18,37 \\
7,78 \\
\text { N.D. } \\
\text { N.D. } \\
\end{array}$ & $\begin{array}{l}59,7 \\
51,2 \\
\text { ND } \\
\text { ND. } \\
\end{array}$ & $\begin{array}{l}\text { Sendecz of al (1985) } \\
\text { Doringoes (1993) } \\
\text { Caloffi (1994; 2000) } \\
\text { Coelho-Botelho of al (2001) }\end{array}$ \\
\hline D. Brevirem & Ounereprens: & N.D. & ND. & Caleffi (1994) \\
\hline Dusparalona dadogi & Ounerpirenese & N.D. & ND. & Caieffi (1994) \\
\hline Eurpalone of orrentalis & Oumpoprenese & N.D. & N.D & Calefi (1994) \\
\hline lyeaspypess spenifor & Gueropinenes & N.D. & ND. & Calefif $(1994 ; 2000)$ \\
\hline Moima minuta & 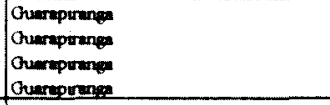 & $\begin{array}{r}18.37 \\
7.78 \\
\text { N.D. } \\
\text { N.D. } \\
\end{array}$ & $\begin{array}{l}59,7 \\
51,2 \\
\text { N.D. } \\
\text { ND. } \\
\end{array}$ & $\begin{array}{l}\text { Sendecz of al. (1985) } \\
\text { Domirgon (1993) } \\
\text { Calefis (1994: 2000) } \\
\text { Coelho-Botelbo of al (2001) }\end{array}$ \\
\hline Simacepholus sermilerus & Ouersprangs & ND. & ND & Caleffi (1994; 2000) \\
\hline Basmina hagmarnt & 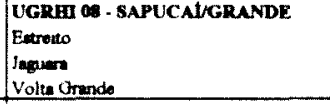 & $\begin{array}{r}1.26 \\
2.13 \\
3,78 \\
\end{array}$ & $\begin{array}{l}32,8 \\
38,1 \\
43,8 \\
\end{array}$ & 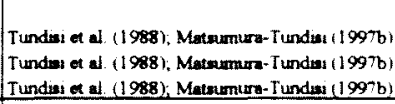 \\
\hline 8. tongirastors & $\begin{array}{l}\text { Volte Grande } \\
\text { Voltu Grande } \\
\end{array}$ & $\begin{array}{l}3,78 \\
\mathrm{ND} \\
\end{array}$ & $\begin{array}{l}43,8 \\
\mathrm{ND} \\
\end{array}$ & $\begin{array}{l}\text { Tundus et al (1988), Mecmumure Tundisi } 1997 \mathrm{~b}) \\
\text { Rolis a al (1990) }\end{array}$ \\
\hline Bosminopns dritern & $\begin{array}{l}\text { Eatreito } \\
\text { Inquar: } \\
\text { Volt Orande } \\
\text { Voltu Orando } \\
\end{array}$ & $\begin{array}{r}1,26 \\
2,13 \\
3,78 \\
\mathrm{ND} \\
\end{array}$ & $\begin{array}{l}32,8 \\
38,1 \\
43,8 \\
N D \\
\end{array}$ & 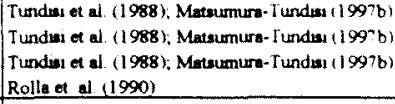 \\
\hline Ceriadaphnea cornuto & Volth Urande & ND. & ND & Rolle et al. $(1990)$ \\
\hline C. C. Intermedia & \begin{tabular}{|l} 
Estretto \\
Volta Orande \\
\end{tabular} & $\begin{array}{l}1.26 \\
3,78 \\
\end{array}$ & $\begin{array}{l}32,8 \\
43,8 \\
\end{array}$ & 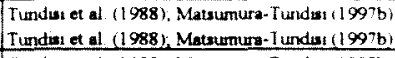 \\
\hline C.c. ngoud & \begin{tabular}{|l} 
Evtretio \\
Volth Orande
\end{tabular} & $\begin{array}{r}1,26 \\
3,78 \\
\end{array}$ & $\begin{array}{l}32,8 \\
43,8 \\
\end{array}$ & 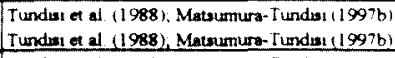 \\
\hline Daphnio gessmen & \begin{tabular}{|l|} 
Eutretto \\
Volts Orande \\
Volte Orande \\
\end{tabular} & $\begin{array}{r}1.26 \\
3,78 \\
\text { VD } \\
\end{array}$ & $\begin{array}{l}32,8 \\
43,8 \\
N D \\
\end{array}$ & 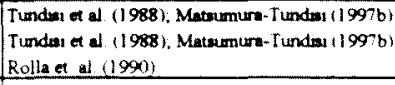 \\
\hline Diaphanoscoma birges & $\begin{array}{l}\text { Eatrento } \\
\text { Jequers } \\
\text { Volts Grande } \\
\end{array}$ & $\begin{array}{l}1,26 \\
2,13 \\
3,78 \\
\end{array}$ & $\begin{array}{r}32,8 \\
38,1 \\
43,8 \\
\end{array}$ & 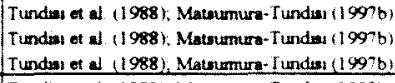 \\
\hline Moina minuea & $\begin{array}{l}\text { Joguara } \\
\text { Volta Orande } \\
\text { Volta Grande }\end{array}$ & $\begin{array}{r}2,13 \\
3,78 \\
\mathrm{~N} \mathrm{D}\end{array}$ & $\begin{array}{l}38,1 \\
43,8 \\
\text { ND }\end{array}$ & 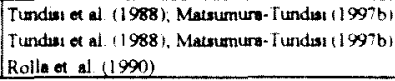 \\
\hline
\end{tabular}


Contimuacio

TABELA 23 - Ocorrência de cladóceros, média das concentrações de clorofila $a$ total $(\mu \mathrm{g} / \mathrm{L})$ e Índice de Estado Trófico (IET) de Carlson modificado, em cada corpo d'água, com o respectivo autor e época de estudo, por Unidade de Gerenciamento de Recursos Hídricos (UGRHI) do Estado de São Paulo.

\begin{tabular}{|c|c|c|c|c|}
\hline Espocies & Reuervatonol Lespellapo & Glorofis a $\left(\mu \Omega^{2}\right)$ & IET & Autores \\
\hline Alom rectangula & 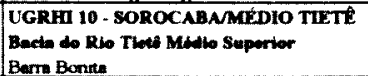 & 32,18 & 65,4 & CETESB (1999a), Coeiho-Botetho of af (2001) \\
\hline \multirow[t]{5}{*}{ Bosmina hagmannt } & Berme Bonta & 5,56 & 47,7 & Fonecos $(1990)$ \\
\hline & Barta Bonts & 5,06 & 46,8 & Oavilon-Dinaz (1990) \\
\hline & Burra Bonits & N.D & ND & Tundiai o Matrumura-Tundrai $(1990 ; 1994)$ \\
\hline & Barme Bonuto & 21,58 & 61,3 & Wimiomba (1998) \\
\hline & Berrs Bonita & 32,18 & 65,4 & CETESB (1999), Coolho-Botelho of al. (2001) \\
\hline \multirow[t]{3}{*}{ B. longirastiris } & Bamra Botuta & 5,56 & 47.7 & Foneoca $(1990)$ \\
\hline & Berre Bonts & 5,06 & 46,8 & Oavilm-Dien (1990) \\
\hline & Bern Bonirs & ND & ND & Tundrie Mntoumun-Tundiai (1990) \\
\hline \multirow[t]{3}{*}{ Boseminopsis doitersi } & Bemen Bonits & 5,06 & 46,8 & Oavilan-Diaz (1990) \\
\hline & Berm Bonta & 21,58 & 61,3 & Wirniewalo (1998) \\
\hline & Bam Bontu & 32,18 & 65,4 & CETESB (1999), Coetho-Botelho of al (2001) \\
\hline \multirow[t]{5}{*}{ Ceriodaphnia cornuto } & Berre Bonita & 5.56 & $47 ?$ & Forwace $(1990)$ \\
\hline & Barre Bonita & 5,06 & 46,8 & Otevimon-Dhea (1990) \\
\hline & Berre Bontra & N.D & N.D & Tundint o Mentsumura-Tundwi (1990) \\
\hline & Burm Bonita & 21,58 & 61,3 & Wirniomak (1998) \\
\hline & Berte Bonit: & 32,18 & 65,4 & CETESB (1999); Coelho-Boteltho of al (2001) \\
\hline C.c. cormuto & Berme Bonits & N.D. & N.D & 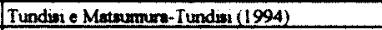 \\
\hline C.c. intermadia & Bem Bonts & N.D. & ND. & Tundiai o Metoumun-Tundiai (1994) \\
\hline C. a.rigaudi & Beme Bonits & N.D & N.D. & Tundiaie Mnenumun-Tundivi (1994) \\
\hline \multirow[t]{3}{*}{ C. silwestrii } & Bum Bonina & 5,06 & 46,8 & Oavilen-Diaz $(1990)$ \\
\hline & Bern Bonta & N.D & ND & Tundien e Motsumura-Tundies (1990, 1994) \\
\hline & Bern Bonne & 21,58 & 61,3 & Wimiemila $(1998)$ \\
\hline \multirow[t]{4}{*}{ Daphnia ambigma } & Barm Bonith & 5,06 & 46,8 & Otvilm-Dine (1990) \\
\hline & Berre Boruts & ND & ND. & Roche e Metbumura-Tundas (1990) \\
\hline & Berm Bonta & ND & ND. & Tunden e Metmunnme-Tundwi $(1990,1994)$ \\
\hline & Bems Bonts & 21,58 & 61,3 & Wrimionata $(1998)$ \\
\hline \multirow[t]{6}{*}{ D. gesemeri } & Bem Bontin & 5,56 & 47.7 & Fonvecos (1990) \\
\hline & Beme Bonit: & 5,06 & 46,8 & Otvilan-Dnaz (1990) \\
\hline & Berne Borut: & N.D. & N.D. & Rocha e Mrtsumus-Tundisi (1990) \\
\hline & Berre Bonts & N.D. & N.D. & Tundian o Minumure-Tundiai (1990; 1994) \\
\hline & Barme Borita & 21,58 & 61,3 & Wiuniomata (1998) \\
\hline & Berm Bonute & 32,18 & 65,4 & CETESB (1999); Coetho-Botelho of al. (2001) \\
\hline \multirow[t]{5}{*}{ Diaphanosoma birget } & Berro Bonzta & 5,56 & 47.7 & Foreace (1990) \\
\hline & Berra Bornta & 5.06 & 46,8 & Otivimn-Duaz (1990) \\
\hline & Bem Bonita & N.D. & ND. & Tundrai e Mersumun-Tundies (1990, 1994) \\
\hline & Bemra Bonuta & 21.58 & 61,3 & Wmiomia (1998) \\
\hline & Bem Bonrs & 32,18 & 65,4 & CETESB (1999): Coe tho-Bonetho et al $(2001)$ \\
\hline \multirow[t]{3}{*}{ D. spinulorem } & Berme Bonta & ND. & ND. & 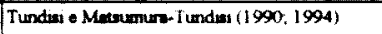 \\
\hline & Bem Bonns & 21,58 & 61.3 & Wimiowrika (1998) \\
\hline & Berm Bonits & 32,18 & 65,4 & CETESB (1999); Coetho-Boteltho of al $(2001)$ \\
\hline Eurpalona axidentalis & Berme Bonits & 32,18 & 65,4 & CETESB (1999): Coctho-Boteltho of al (2001) \\
\hline \multirow[t]{2}{*}{ Moina micrura } & Berrm Bonita & 5,06 & 46,8 & Gavilen-Dinx $(1990)$ \\
\hline & Berm Bonts & 32,18 & 65,4 & CETESB (1999a); Coelho-Botelho of al (2001) \\
\hline \multirow[t]{3}{*}{ M. minuta } & Plems Bonsts & 5.56 & 47,7 & Fonnece $(1990)$ \\
\hline & Berre Bonita & 5,06 & 46,8 & Gavilan-Dhaz (1990) \\
\hline & Bam Boruta & 21,58 & 61,3 & Wuniemato (1998) \\
\hline \multirow[t]{2}{*}{ Simacophaiues serrilames } & Bern Bonts & 21,58 & 61,3 & Wieniewain (19988) \\
\hline & Bacte do Rlo Sorrecebs & 1581 & 583 & Sendacz et al (1985) \\
\hline $\begin{array}{l}\text { Basminopsis doulersi } \\
\text { Ceriodophnia cormuta }\end{array}$ & Ituperarenge & $\frac{15,81}{15,81}$ & $\frac{58,3}{58,3}$ & $\frac{\text { Sendacz et al (1985) }}{\text { Seadecz ot al (1985) }}$ \\
\hline Dophnio gessmern & Ithourerese & 15,81 & 58,3 & Sendecz of al $(1985)$ \\
\hline Drophanosoma birger & Itupararenge & 15,81 & 58,3 & Sendacz of ei (1985) \\
\hline Moina minula & Ituperrange & 15,81 & 58,3 & Sendecz of al (1985) \\
\hline
\end{tabular}


Contmumeno

TABELA 23 - Ocorrència de cladóceros, média das concentraçðes de clorofila $a$ total $(\mu \mathrm{g} / \mathrm{L})$ e Índice de Estado Trófico (IET) de Carlson modificado, em cada corpo d'água, com o respectivo autor e época de estudo, por Unidade de Gerenciamento de Recursos Hidricos (UGRHI) do Estado de Såo Paulo.

\begin{tabular}{|c|c|c|c|c|}
\hline Enson & 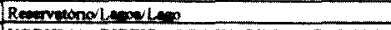 & Comofih a (axil) & IET & Autan \\
\hline Sommopen ditorsi & 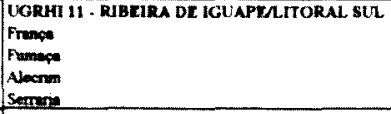 & $\begin{array}{l}40,91 \\
32,30 \\
16,87 \\
44,41\end{array}$ & $\begin{array}{r}67.8 \\
65,5 \\
58.8 \\
68,7 \\
\end{array}$ & 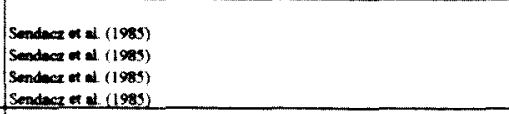 \\
\hline Centodiponsona comeso & 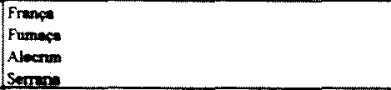 & $\begin{array}{l}50,91 \\
32.30 \\
10,85 \\
44,41\end{array}$ & $\begin{array}{l}67,8 \\
69,5 \\
38,8 \\
68,7\end{array}$ & 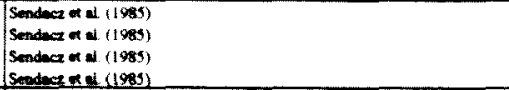 \\
\hline Dephion gexomeri & 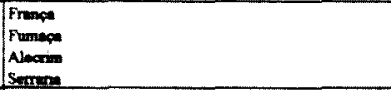 & $\begin{array}{r}40.91 \\
32.30 \\
16.87 \\
4.41\end{array}$ & $\begin{array}{l}67,8 \\
69,5 \\
58,8 \\
68,7\end{array}$ & 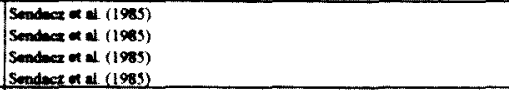 \\
\hline Draphenosema birgori & $\begin{array}{l}\text { Frampe } \\
\text { Pumeace } \\
\text { Alecrim } \\
\text { Seming }\end{array}$ & $\begin{array}{l}40,91 \\
32,30 \\
16,87 \\
44,41 \\
\end{array}$ & $\begin{array}{l}67,8 \\
69,5 \\
58,8 \\
68,7 \\
\end{array}$ & 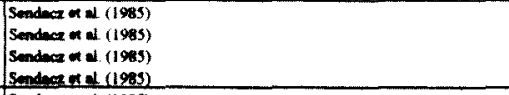 \\
\hline Moing menenes & 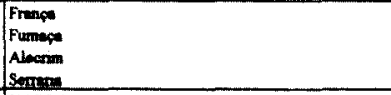 & $\begin{array}{r}40,91 \\
32,30 \\
16,87 \\
44,41 \\
\end{array}$ & $\begin{array}{l}67,8 \\
65,5 \\
58,8 \\
68.7 \\
\end{array}$ & 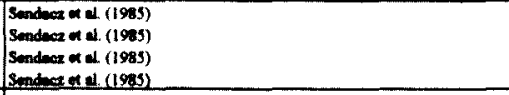 \\
\hline Aomolomats & $\begin{array}{l}\text { UCRRII } 12 \text { - BADXO PARDOKGRUNDE } \\
\text { Pono Colonge }\end{array}$ & 4,37 & 15,2 & 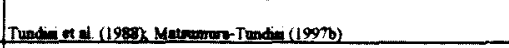 \\
\hline B. lon dpoutry & Porto Colonatus & $\frac{4,37}{4,37}$ & $\frac{432}{432}$ & 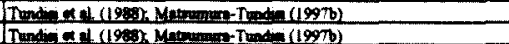 \\
\hline 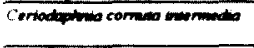 & $\begin{array}{l}\text { Porto Colorat } \\
\text { Mermingondo }\end{array}$ & 4,37 & $\begin{array}{l}452 \\
40,7\end{array}$ & 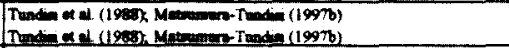 \\
\hline Centomed & 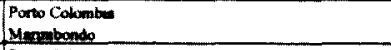 & $\begin{array}{ll}4,37 \\
2,77 \\
\end{array}$ & $\begin{array}{l}15,2 \\
60.7 \\
\end{array}$ & 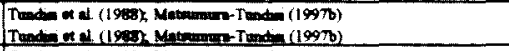 \\
\hline 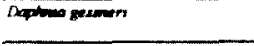 & $\begin{array}{l}\text { Pono Colomber } \\
\text { Marimbendo }\end{array}$ & $\begin{array}{l}0,37 \\
2,77 \\
\end{array}$ & $\begin{array}{l}45,2 \\
40,7\end{array}$ & 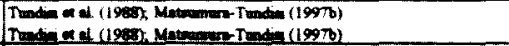 \\
\hline 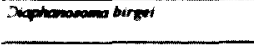 & 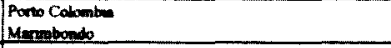 & 2,37 & $\begin{array}{l}49.7 \\
40.7 \\
\end{array}$ & 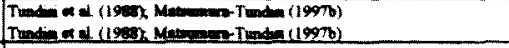 \\
\hline 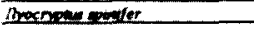 & Merminbondo & $2 \pi$ & 0.7 & 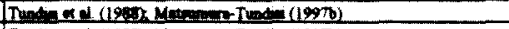 \\
\hline Mone & Pono coloman & $\frac{4,37}{27}$ & 45,2 & 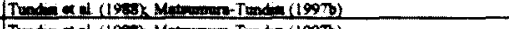 \\
\hline 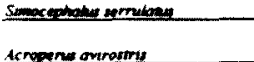 & 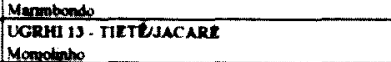 & 2.77 & 30.9 & 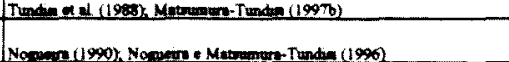 \\
\hline Acropermo hapo & 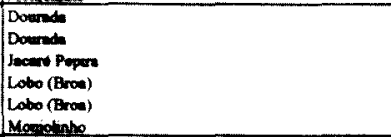 & $\begin{array}{l}\text { N. } \\
3.46 \\
1.70 \\
N . D \\
N . D \\
N .0 \\
\end{array}$ & $\begin{array}{l}\text { ND } \\
48.2 \\
33.8 \\
\text { N.D } \\
\text { N.D. } \\
\text { N. }\end{array}$ & 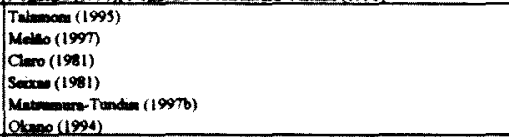 \\
\hline Aknesemens & Loberan (Ban & ND & N.D. & $\sin (1901)$ \\
\hline A bromentu & Lober (non & NDI & N.D & 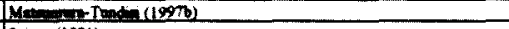 \\
\hline Acantion & 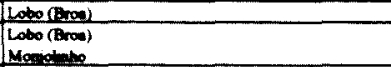 & $\begin{array}{ll}\text { No } \\
N D \\
938 \\
938\end{array}$ & $\begin{array}{l}\text { N.D } \\
\text { N.D } \\
530\end{array}$ & $\frac{\operatorname{sen}(1981)}{\operatorname{sen}}$ \\
\hline 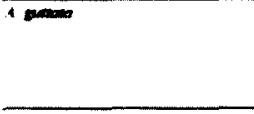 & 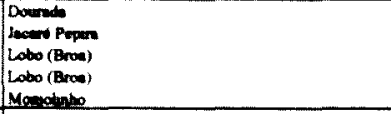 & \begin{tabular}{ll|l} 
N. & \\
1.70 \\
N \\
N \\
N \\
\end{tabular} & $\begin{array}{l}\text { N.D. } \\
39.8 \\
\text { N.D. } \\
\text { N.D } \\
\text { N.D. }\end{array}$ & 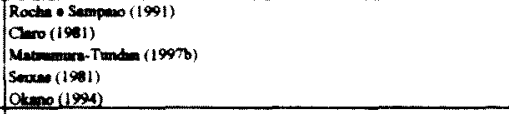 \\
\hline A Doppen & 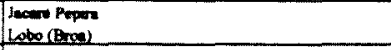 & $\begin{array}{r}1,70 \\
\times 0 \\
\end{array}$ & $\begin{array}{l}35,8 \\
\mathrm{ND} \\
\end{array}$ & $\begin{array}{l}C \cos (19801) \\
\sin (1980)\end{array}$ \\
\hline 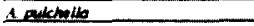 & Loteo(Broes) & ND & $\mathrm{ND}$ & $\operatorname{sen} x=19811$ \\
\hline 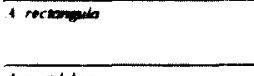 & 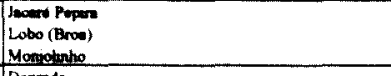 & $\begin{array}{l}1,70 \\
\times \mathrm{D} \\
\mathrm{N} \\
\end{array}$ & $\begin{array}{l}35,8 \\
N D \\
N D \\
\end{array}$ & $\begin{array}{l}\text { Cimo (1988) } \\
\text { Sexwe (1981) } \\
\text { Okemo (1990) }\end{array}$ \\
\hline A pavichro & $\begin{array}{l}\text { Dournate } \\
\text { Lobo (Brow) } \\
\text { Monivanho }\end{array}$ & $\begin{array}{ll}\text { ND } \\
\text { ND } \\
Q, 38\end{array}$ & $\begin{array}{l}\text { N.D. } \\
\text { N.D. } \\
530\end{array}$ & 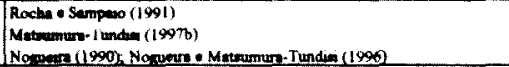 \\
\hline Alosella reticulats & $\begin{array}{l}\text { Dournde } \\
\text { Doured } \\
\text { Lobo(Boos) }\end{array}$ & 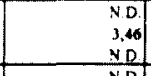 & $\begin{array}{r}N .0 . \\
48,2 \\
N . D \\
N D\end{array}$ & $\begin{array}{l}\text { Talemora (1995) } \\
\text { Meleo (1997) } \\
\text { Matounen-Tundian (1997b) }\end{array}$ \\
\hline 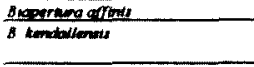 & 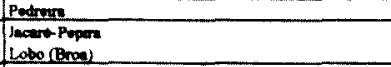 & $\begin{array}{ll}N 0 & \\
230 \\
N D\end{array}$ & $\begin{array}{l}\text { ND. } \\
39.7 \\
\text { N.D. }\end{array}$ & 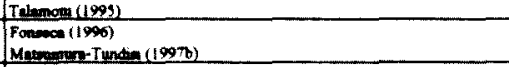 \\
\hline$B$ remuxpea & Labo (Bral & ND & ND & $\sin x=(1081)$ \\
\hline Bament corrom & $\begin{array}{l}\text { Lobo (Brow) } \\
\text { Lobosos) }\end{array}$ & ND & $\begin{array}{l}\text { ND. } \\
\text { ND. }\end{array}$ & 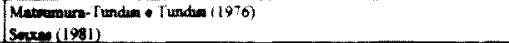 \\
\hline 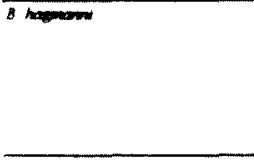 & 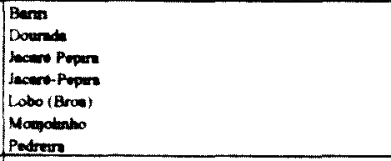 & \begin{tabular}{r|}
7.66 \\
$\times 0$ \\
1.90 \\
2.90 \\
$\times 0$ \\
9.38 \\
$\times 0$ \\
\end{tabular} & $\begin{array}{l}30.7 \\
N 0 \\
39,8 \\
39,7 \\
N D \\
93.0 \\
N D \\
\end{array}$ & 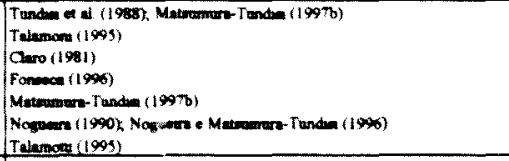 \\
\hline A bonstantre & $\begin{array}{l}\text { Bem } \\
\text { limame } \\
\text { tomo (Bron) }\end{array}$ & $\begin{array}{r}7.66 \\
10.38 \\
\times 0 \\
\end{array}$ & $\begin{array}{l}50,7 \\
54,1 \\
\text { ND }\end{array}$ & 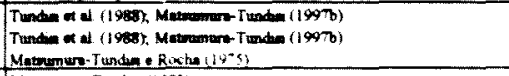 \\
\hline B macrongin & Labo (Brou) & VDDI & ND & TMavere Tundan $(1983)$ \\
\hline A modrem & $\begin{array}{l}\text { Lobo (Bhow) } \\
\text { Pothene }\end{array}$ & $\begin{array}{ll}\mathrm{ND} \\
\mathrm{ND} \\
\end{array}$ & $\begin{array}{l}\text { ND } \\
\text { ND } \\
\end{array}$ & 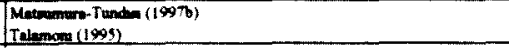 \\
\hline 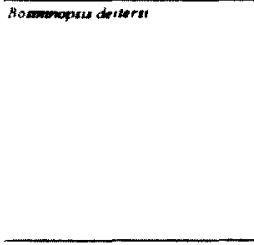 & 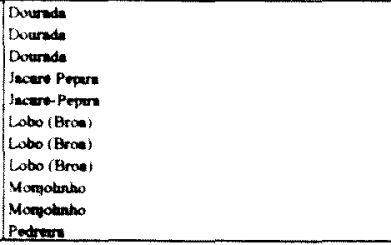 & 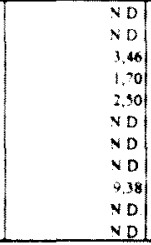 & $\begin{array}{l}\text { ND } \\
N D \\
48,2 \\
39.8 \\
19.7 \\
N D \\
N D \\
N D \\
93.0 \\
N D \\
N D \\
\end{array}$ & 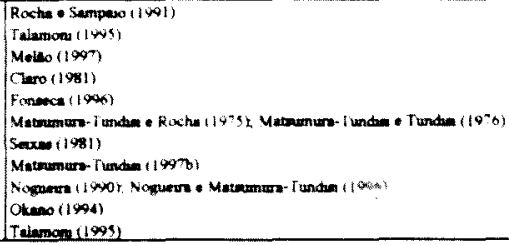 \\
\hline
\end{tabular}


TABELA 23 - Ocorrència de cladóceros. média das concentrações de clorofila $a$ total $(\mu \mathrm{g} / \mathrm{L})$ e Índice de Estado Trófico (IET) de Carlson modificado. em cada corpo d'água. com o respectivo autor e época de estudo, por Unidade de Gerenciamento de Recursos Hidricos (UGRHI) do Estado de São Paulo.

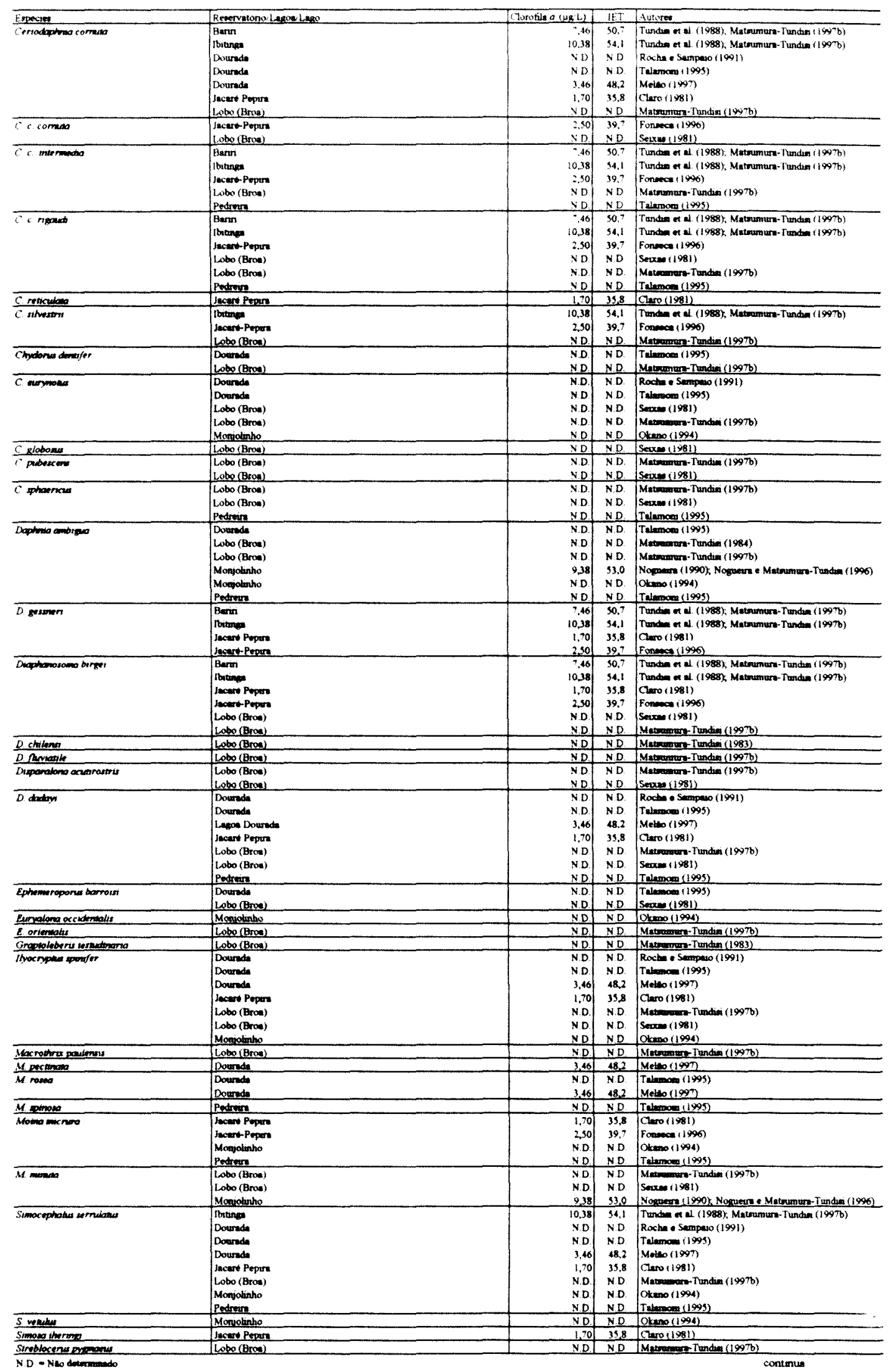


Contrnuacio

TABELA 23 - Ocorrência de cladóceros. média das concentraçóes de clorofila a total ( $\mu \mathrm{g} / \mathrm{L}$ ) e Índice de Estado Trófico (IET) de Carlson modificado, em cada corpo d'água, com o respectivo autor e época de estudo, por Unidade de Gerenciamento de Recursos Hidricos (UGRHI) do Estado de São Paulo.

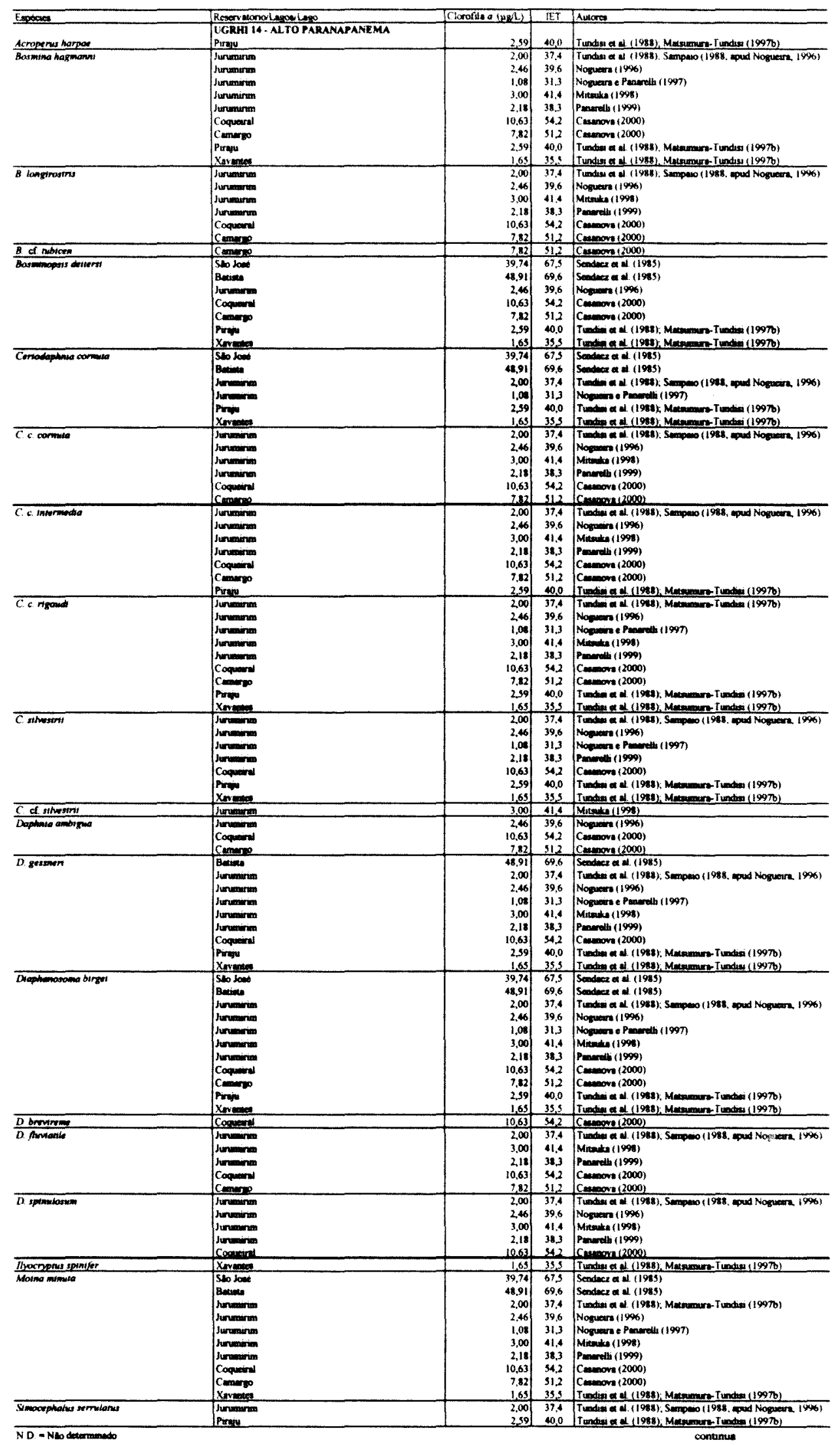


ominued

TABELA 23 - Ocorrència de cladóceros. média das concentrações de clorofila $a$ total $(\mu \mathrm{g} / \mathrm{L})$ e Índice de Estado Trófico (IET) de Carlson modificado, em cada corpo d'água. com o respectivo autor e época de estudo, por Unidade de Gerenciamento de Recursos Hidricos (UGRHI) do Estado de São Paulo.

\begin{tabular}{|c|c|c|c|c|}
\hline Expen & 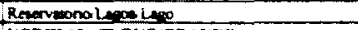 & 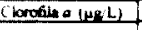 & iET & Autare \\
\hline & IGRHI IS . T RVOGRANDE & & & \\
\hline Brimug haxmone & Arian Vemeitse & 27.4 & Ans & 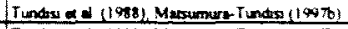 \\
\hline 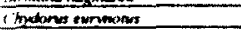 & Ave Vertethe & 2,74 & 406 & 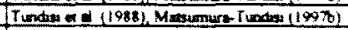 \\
\hline Sphoserexs & Saevermith & 34 & 406 & 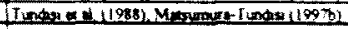 \\
\hline 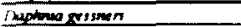 & Axue vermethe & 2.7 & 40,0 & 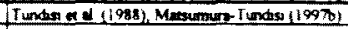 \\
\hline 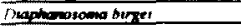 & Aruev Vomedre & 2.34 & 40,6 & 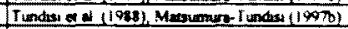 \\
\hline 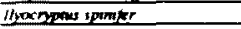 & Doun vermethe & 2.4 & 40,6 & 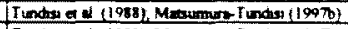 \\
\hline \multirow{2}{*}{ 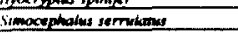 } & Arue Vermosthe & 2,74 & 40,6 & 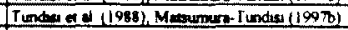 \\
\hline & CGRHI 16- TIETESATALAA & 8,62 & 52,2 & 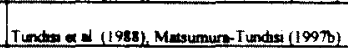 \\
\hline Cemodrotme compria & Promenes & 8,62 & 52 & 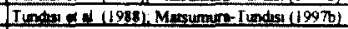 \\
\hline Cᄃnxouch & Promianes & 8,62 & 32,2 & 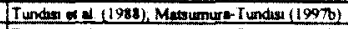 \\
\hline Thutoung epherencus & Promassto & 8,62 & 52 & 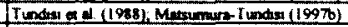 \\
\hline Dapenew sersuen & Proconsasto & 8,62 & 52,2 & 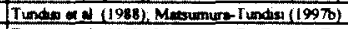 \\
\hline Demphesosoma bioxa & Promisato & 8,62 & 52,2 & 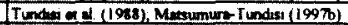 \\
\hline 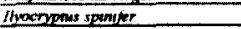 & Promisalo & 8.62 & 32,2 & 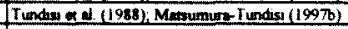 \\
\hline \multirow[t]{2}{*}{ Simoxophalus serrukans } & Promianilo & 8,62 & 522 & 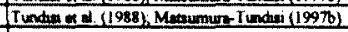 \\
\hline & 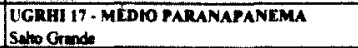 & 1,81 & 36,4 & 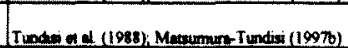 \\
\hline Bosmina hapemani & $R_{0} \operatorname{Pan}_{n+1}$ & 2,68 & $\begin{array}{l}20,4 \\
40,9\end{array}$ & 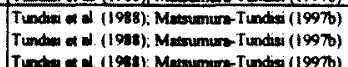 \\
\hline B. honverung & comen & 2,6 & 409 & 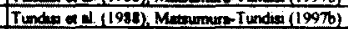 \\
\hline \multirow{2}{*}{ Basmopses diverst } & Roo Nowo & 3,32 & 42.3 & 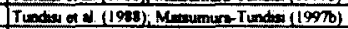 \\
\hline & $\lim _{\log } \lim _{\lim }$ & $\begin{array}{l}1,210 \\
2,64 \\
2,13 \\
3,32\end{array}$ & $\begin{array}{l}16,4 \\
10,4 \\
40,9 \\
42,3\end{array}$ & 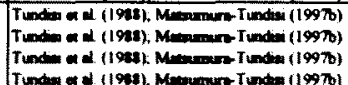 \\
\hline \multirow{2}{*}{ 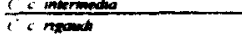 } & Com & 2,3 & $\$ 0.9$ & 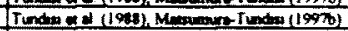 \\
\hline & 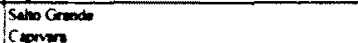 & $\begin{array}{l}1.18 \\
2.81\end{array}$ & $\begin{array}{ll}36,4 \\
409\end{array}$ & 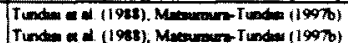 \\
\hline thesen & $\begin{array}{l}\text { Seloc Grend } \\
\text { Repin }\end{array}$ & $\frac{1,11}{2,68}$ & $\begin{array}{ll}36,4 \\
40,4\end{array}$ & 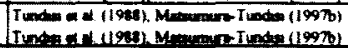 \\
\hline 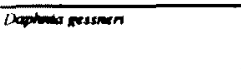 & 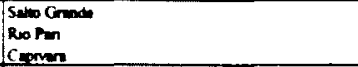 & $\begin{array}{l}1.1 \\
2,64 \\
2,8,\end{array}$ & $\begin{array}{l}36,4 \\
40,4 \\
40.9\end{array}$ & 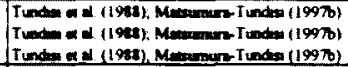 \\
\hline Deapheasoma birnet & $\operatorname{lom}_{\mathrm{Con}}$ & $\begin{array}{ll}2,649 \\
2,83\end{array}$ & 40.9 & 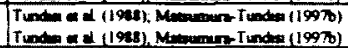 \\
\hline \multirow{2}{*}{ 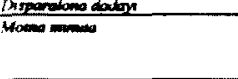 } & Shac Crente & I.II & 36,4 & 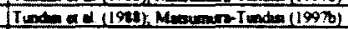 \\
\hline & 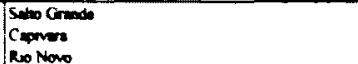 & $\begin{array}{l}1.11 \\
2.13 \\
1,3.2\end{array}$ & $\begin{array}{l}36.4 \\
40.9 \\
42.9\end{array}$ & 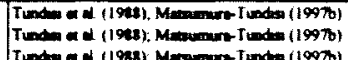 \\
\hline 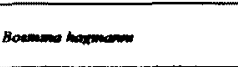 & 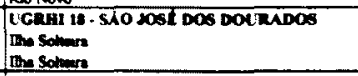 & $\begin{array}{ll}2,04 \\
2,0 \\
N\end{array}$ & M? & 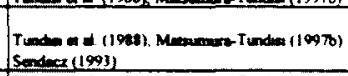 \\
\hline 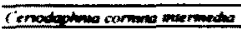 & thes Sohen & 309 & $m 7$ & 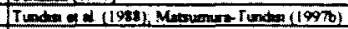 \\
\hline \multirow{2}{*}{ 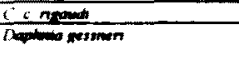 } & The Solewers & 2,09 & $\pi$ & 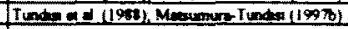 \\
\hline & $\begin{array}{l}\text { ine Solwers } \\
\text { B. Solvers }\end{array}$ & $\begin{array}{ll}2,04 \\
\text { N D }\end{array}$ & $\begin{array}{l}37.7 \\
\mathrm{ND}\end{array}$ & 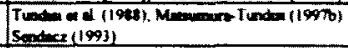 \\
\hline 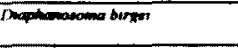 & the Solwen & ND & $\begin{array}{l}37,7 \\
N D\end{array}$ & 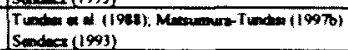 \\
\hline$D$ breniven & The Soltwern & ND. & $\mathrm{ND}$ & $\operatorname{send\operatorname {cos}(1993)}$ \\
\hline D sperares & the solewe & ND & ND & Sendexi $(1993)$ \\
\hline Inocropeut spealer & the Sotern & 2,04 & 37 & 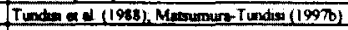 \\
\hline Arovea minowed & $\begin{array}{l}\text { Ithe Solvarn } \\
\text { Iha Sotwein }\end{array}$ & $\begin{array}{ll}2,04 \\
\text { N D }\end{array}$ & $\begin{array}{l}37.7 \\
\mathrm{ND}\end{array}$ & 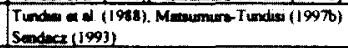 \\
\hline Simastpenimg semulans & The Soteen & 2,0 & 377 & 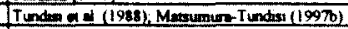 \\
\hline & UGRHI 19-BADXO TITE & & & \\
\hline Barmuma haman & $\begin{array}{l}\text { Now Averthendon } \\
\text { Sugut }\end{array}$ & $\begin{array}{l}9,87 \\
N D\end{array}$ & $\begin{array}{l}93.5 \\
\mathrm{ND} \\
\end{array}$ & $\begin{array}{l}\text { Tumber of (1988): Menumure- Tumdisis (1997) } \\
\text { Sendes (1993) }\end{array}$ \\
\hline Bosmomopest detuerst & Jupin & ND & ND & Sendese $(1993)$ \\
\hline Conoedruthio cornutes & Non Averhanden & 9,87 & 335 & 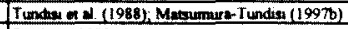 \\
\hline Cccomies & Jupis & N.D & ND & Sendiez $(1993)$ \\
\hline Cc conernedo & Nons Aventoden & 9,82. & 53,5 & 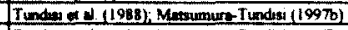 \\
\hline CC ngand & $\begin{array}{l}\text { Nova Avernhendon } \\
\text { lepor }\end{array}$ & $\begin{array}{l}9,87 \\
\text { ND }\end{array}$ & $\begin{array}{l}53,9 \\
\text { ND }\end{array}$ & 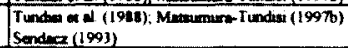 \\
\hline Chedonew yphournows & 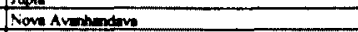 & 9,87 & 33,9 & 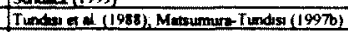 \\
\hline 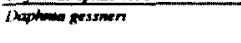 & lopid & $\begin{array}{ll}3.26 \\
N D\end{array}$ & $\begin{array}{ll}2.3 \\
N D\end{array}$ & 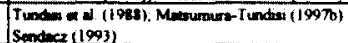 \\
\hline Thaphasonoma binget & Nowe Avempendon & $\begin{array}{l}9,87 \\
3,26 \\
90\end{array}$ & $\begin{array}{l}53,3 \\
2,3 \\
\mathrm{ND}\end{array}$ & 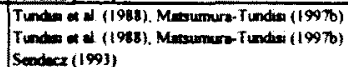 \\
\hline D bromingme & Gupat & ND & ND & Sendwa (1993) \\
\hline 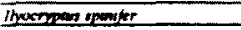 & hom & 3,26 & 23 & 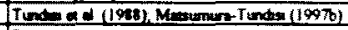 \\
\hline 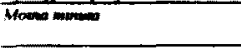 & Supot & $\begin{array}{r}3.26 \\
\text { V. } \\
\end{array}$ & $\begin{array}{l}2.3 \\
\mathrm{ND}\end{array}$ & 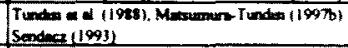 \\
\hline 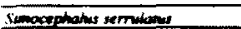 & Thom Aventensen & 9,87 & 335 & 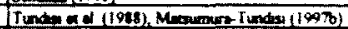 \\
\hline & UGEAI 22 - POSTAL DO PATANAPANEML & & & \\
\hline Banmono hasmanm & Componde & $\begin{array}{l}15.13 \\
43,74\end{array}$ & $\begin{array}{l}37.8 \\
646\end{array}$ & $\begin{array}{l}\text { Sendece }(199)\} \\
\operatorname{Sendx}(1993)\end{array}$ \\
\hline$B=$ & Conepond & 13.13 & 57. & Sendera $\{1903\}$ \\
\hline & & $+3,74$ & Qbo & [Sondea $(1993\}$ \\
\hline Bo numiogons detierst & Compinde & 19,13 & 57.8 & Sendera $(\mid 99) \mid$ \\
\hline & $\log$ & 43,74 & 03,6 & $\operatorname{sen}(1092)$ \\
\hline 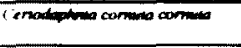 & $\begin{array}{l}\text { Cortonde } \\
\text { low }\end{array}$ & $\begin{array}{l}19,13 \\
43,74 \\
\end{array}$ & $\begin{array}{l}3.8 \\
080\end{array}$ & $\begin{array}{l}\text { Send }(1993) \\
\text { Sondea }(1993)\end{array}$ \\
\hline Cangued & Compinde & 15,13 & 99.8 & Sendwa $(1091)$ \\
\hline & lon & 43,74 & 086 & Sensuza $(100)$ \\
\hline 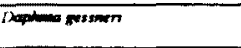 & compende & $\begin{array}{l}5.13 \\
637.74\end{array}$ & $\begin{array}{l}37.8 \\
88.6\end{array}$ & \begin{tabular}{|l|} 
Sendera (1993) \\
Seoducx (1993)
\end{tabular} \\
\hline Thaphemoremo binner & Compondm & 19.13 & 97.8 & Sendeca $\{(1993)$ \\
\hline & & 4,74 & 886 & Sondea $(1993)$ \\
\hline D bermener & Componde & $\frac{15,13}{15}$ & 998 & $\operatorname{sen} x=(1093)$ \\
\hline D spipulasen & Compond & 19,13 & 97,8 & Sendera $(1093)$ \\
\hline & $\log$ & 9.74 & 68.6 & Sendere (1993) \\
\hline Hanem morume & Lete & 4.74 & 68,6 & $\operatorname{sendan}(1997)$ \\
\hline 4 mantous & Componde & $\begin{array}{l}19,13 \\
4374\end{array}$ & $\begin{array}{l}97.8 \\
68.6\end{array}$ & Sendera $(1993)$ \\
\hline
\end{tabular}


TABELA 24 - Relaçào das especies de rotteros regıstradas nas ( nidades de Gerenciamento de Recursos Hidricos (LGRHIs) do Estado de São Paulo e seu respectivo numero de identuticaçào

\begin{tabular}{|c|c|}
\hline ESPECIES & NLMERO \\
\hline Amuraeopss fissa (Gosse. 1851 ) & 1 \\
\hline A. navicula Rousselet. 1910 & 2 \\
\hline Ascomorpha ecaudis (Pertv. 1859) & 3 \\
\hline A. ovalis (Bergendal, 1892) & 4 \\
\hline A. saltans Bartsch. 1870 & 5 \\
\hline A. tundısu Segers e Dumont (1995) & 6 \\
\hline Aspelia circinator (Gosse. 1886) & 7 \\
\hline Asplanchna girodi (De Guerne, 1888) & 8 \\
\hline A. sieboldi (Leydıg, 1854) & 9 \\
\hline Brachionus angularıs Gosse, 1851 & 10 \\
\hline B. a. bidens (Plate) & 11 \\
\hline B. a. chelonis (Ahlstrom, 1940) & 12 \\
\hline B. bidentata Anderson, 1889 & 13 \\
\hline B.b. crassispineus Hauer & 14 \\
\hline B. calyciflonis Pallas, 1766 & 15 \\
\hline B.c. amphiceros (Ehrenberg. 1838) & 16 \\
\hline B. c. anuraelformis (Brehm. 1909) & 17 \\
\hline B.c. dorcas (Gosse) & 18 \\
\hline B. caudatus Barrois e Daday, 1884 & 19 \\
\hline B. c. ahlstrom (Lindeman) & 20 \\
\hline B. c. personatus Ahistrom. 1940 & 21 \\
\hline B. c. vulgaius Ahlstrom, 1940 & 22 \\
\hline B. dolabrams Harring. 1915 & 23 \\
\hline B. falcanus Zacharıas. 1898 & 24 \\
\hline B. forficula Wierzejski & 25 \\
\hline B. havanaensts Rousselet. 1911 & 26 \\
\hline B. minus Daday, 1905 & 27 \\
\hline B. m. angusta (Koste. 1972) & 28 \\
\hline B. m. laticaudatus Paggi, 1973 & 29 \\
\hline B. plicatilis (O F Müler, 1786) & 30 \\
\hline B. quadriculata & 31 \\
\hline B. quadridentatus Hermann. 1783 & 32 \\
\hline B. q. clumiorticularis (Skorikov, 1894) & 33 \\
\hline B. q. mirabilis (Daday, 1897) & 34 \\
\hline (ephalodella auriculata (O F Muller, 1773) & 35 \\
\hline (. catellina (OF Muller, 1786) & 36 \\
\hline C. eva (Gosse. 1886) & 37 \\
\hline (. cf exigua (Gosse. 1886) & 38 \\
\hline ( forficula (Ehrenberg. 1838) & 39 \\
\hline C.gibba (Ehrenberg. 1838) & 40 \\
\hline (. hoodi (Gosse) & 41 \\
\hline C. mucronala Myers. 1924 & 42 \\
\hline
\end{tabular}


Contınuação

TABELA 24 - Relação das especies de rotiferos registradas nas Unidades de Gerenciamento de Recursos Hidricos (UGRHIs) do Estado de São Paulo e seu respectivo número de identificaçào

\begin{tabular}{|c|c|}
\hline ESPECIES & NUMERO \\
\hline Collotheca ambigua (Hudson. 1883) & 43 \\
\hline (. cf. campanulata (Dobie, 1849) & 44 \\
\hline C. mutabilis (Hudson, 1885) & 45 \\
\hline C. ornata (Ehrenberg, 1832) & 46 \\
\hline C. ornata cornuta (Dobie) & 47 \\
\hline Colurella obtusa (Gosse, 1886) & 48 \\
\hline C. tesselata (Glascott, 1893) & 49 \\
\hline C. uncinata bicuspidata (Ehrenberg, 1832) & 50 \\
\hline Conochilus coenobasis Skorikov, 1914 & 51 \\
\hline C. dossuarius (Hudson, 1875) & 52 \\
\hline C. natans (Seligo, 1900) & 53 \\
\hline C. unicornis Rousselet, 1892 & 54 \\
\hline Dicranophorus epicharis Harring e Myers, 1928 & 55 \\
\hline D. lutkeni (Bergendal, 1892) & 56 \\
\hline D. robustus Harring e Myers, 1928 & 57 \\
\hline Dipleuchlanis propatula (Gosse, 1886) & 58 \\
\hline D. p. macrodactyla (Hauer, 1965) & 59 \\
\hline Dissotrocha aculeata (Ehrenberg, 1832) & 60 \\
\hline Eosphora anthadis Harring e Myers, 1922 & 61 \\
\hline Eothinia elongata (Ehrenberg) & 62 \\
\hline Epiphanes brachionus (Ehrenberg, 1837) & 63 \\
\hline E. macrourus (Barrois e Daday, 1894) & 64 \\
\hline E. senta (O. F. Müller, 1773) & 65 \\
\hline Euchlanis deflexa (Gosse, 1851) & 66 \\
\hline E. dilatata Ehrenberg, 1832 & 67 \\
\hline E. proxima Myers & 68 \\
\hline E. triquetra Ehrenberg, 1838 & 69 \\
\hline Filinia longiseta (Ehrenberg, 1834) & 70 \\
\hline F. I. limnetica (Zacharias, 1893) & 71 \\
\hline F.l. saltator (Gosse, 1886) & 72 \\
\hline F. opoliensis (Zacharias, 1891) & 73 \\
\hline F. pejleri Hutchinson, 1964 & 74 \\
\hline F.terminalis (Plate, 1886) & 75 \\
\hline Gastropus stylifer Imhof, 1891 & 76 \\
\hline Hexarthra intermedia Wieszniewski, 1929 & 77 \\
\hline H.i.braziliensis (Hauer, 1953) & 78 \\
\hline H. longicornicula Turner, 1987 & 79 \\
\hline H. mira (Hudson, 1871 ) & 80 \\
\hline Horaella thomassoni Koste 1973 & 81 \\
\hline Kellicottia bostoniensis (Rousselet) & 82 \\
\hline K. longispina (Kellicott, 1879) & 83 \\
\hline
\end{tabular}


Continuaçào

TABELA 24 - Relação das especies de rotiferos registradas nas Unidades de Gerenciamento de Recursos Hidricos (UGRHIs) do Estado de São Paulo e seu respectivo número de identificação.

\begin{tabular}{|c|c|}
\hline ESPECIES & NUMERO \\
\hline Keratella americana Carlin, 1943 & 84 \\
\hline K. cochlearis Gosse, 1851 & 85 \\
\hline K. c. hispida Lauterborn & 86 \\
\hline K. c. macracantha (Lauterborn) & 87 \\
\hline K. cruciformis (Thompson) & 88 \\
\hline K. lenzi (Hauer, 1953) & 89 \\
\hline K. cf. procurva (Thorpe, 1891) & 90 \\
\hline K. cf. quadrata ( O. F. Müller, 1786) & 91 \\
\hline K. tecta (Gosse, 1886) & 92 \\
\hline K. tropica (Apstein, 1907) & 93 \\
\hline K. valga Ahlstrom & 94 \\
\hline Lacinullaria elliptica Shephard, 1897 & 95 \\
\hline Lecane acanthinula (Hauer, 1938) & 96 \\
\hline L. aculeata (Jakubski, 1912) & 97 \\
\hline L. agilis (Bryce, 1892) & 98 \\
\hline L. arcula Harring, 1914 & 99 \\
\hline L. bifastigata Hauer, 1938 & 100 \\
\hline L. bifurca (Bryce, 1892) & 101 \\
\hline L. braziliensis Segers, 1993 & 102 \\
\hline L. broaensis Segers e Dumont (1995) & 103 \\
\hline L. bulla (Gosse, 1886) & 104 \\
\hline L. clara (Bryce, 1892) & 105 \\
\hline L. closterocerca (Schmarda, 1859) & 106 \\
\hline L. cf. crepida Harring, 1914 & 107 \\
\hline L. cornuta (O. F. Müller, 1786) & 108 \\
\hline L. curvicornis (Murray, 1913) & 109 \\
\hline L.c. nitida (Murray, 1913) & 110 \\
\hline L. decipiens (Daday, 1913) & 111 \\
\hline L. doryssa Harring, 1914 & 112 \\
\hline L. flexilis (Gosse, 1886) & 113 \\
\hline L. furcata (Murray, 1913) & 114 \\
\hline L. glypta Harring e Myers, 1926 & 115 \\
\hline L. hamata (Stockes, 1896) & 116 \\
\hline L. hornemanni (Ehrenberg, 1838) & 117 \\
\hline L. inermis (Bryce, 1892) & 118 \\
\hline L. lauterboni Hauer, 1924 & 119 \\
\hline L. leontina (Turner, 1892) & 120 \\
\hline L. levistyla (Olofsson, 1917) & 121 \\
\hline L. luctwigi (Eckstein, 1893) & 122 \\
\hline L. l. ercodes Harring & 123 \\
\hline L. l. laticaudata Hauer & 124 \\
\hline L. l. ohioensis (Herrick) & 125 \\
\hline
\end{tabular}


Continuação

TABELA 24 - Relação das especies de rotiferos registradas nas Unidades de Gerenciamento de Recursos Hidricos (UGRHIs) do Estado de São Paulo e seu respectivo número de identificação

\begin{tabular}{|c|c|}
\hline ESPECIES & NUMERO \\
\hline Lecane luna (O.F. Müller, 1776) & 126 \\
\hline L. lunaris (Ehrenberg, 1832) & 127 \\
\hline L. l. crenata (Harring, 1913) & 128 \\
\hline L. mitis Harring e Myers, 1926 & 129 \\
\hline L. monostyla (Daday, 1897) & 130 \\
\hline L. cf. obtusa (Murray, 1913) & 131 \\
\hline L. papuana (Murray, 1913) & 132 \\
\hline L. pertica Harring \& Myers, 1926 & 133 \\
\hline L. ploenensis (Voigt, 1902) & 134 \\
\hline L. pusilla Harring, 1914 & 135 \\
\hline L. pyriformis (Daday, 1905) & 136 \\
\hline L. quadridentata (Ehrenberg, 1892) & 137 \\
\hline L. cf. rhytida Harring e Myers, 1926 & 138 \\
\hline L. scutata (Harring e Myers, 1926) & 139 \\
\hline L. signifera (Jennings, 1896) & 140 \\
\hline L. s. ploenensis (Voigt, 1909) & 141 \\
\hline L. stenroosi (Meissner, 1908) & 142 \\
\hline L. s. lineata (Wulfert, 1966) & 143 \\
\hline L. stichaea Harring, 1913 & 144 \\
\hline L. subtilis Harring e Myers, 1926 & 145 \\
\hline L. thienemanni (Hauer, 1938) & 146 \\
\hline L. uenoi Yamamoto, 1951 & 147 \\
\hline L. ungulata (Gosse, 1887) & 148 \\
\hline Lepadella acuminata (Ehrenberg, 1834) & 149 \\
\hline L. benjamini Harring, 1916 & 150 \\
\hline L. costatoides Segers, 1992 & 151 \\
\hline L. cristata (Rousselett, 1893) & 152 \\
\hline L. dactyliseta (Stenroos, 1898) & 153 \\
\hline L. elongata Koste, 1991 & 154 \\
\hline L. latusinus americana (Myers) & 155 \\
\hline L. minuta (Montet) & 156 \\
\hline L. neglecta sp.n. & 157 \\
\hline L. ovalis (O. F. Müller, 1786) & 158 \\
\hline L. patella (O.F. Müller, 1786) & 159 \\
\hline L. quadricarinata (Stenroos, 1898) & 160 \\
\hline L. quadricauda & 161 \\
\hline L. rhomboides (Gosse, 1886) & 162 \\
\hline L. triba Myers, 1934 & 163 \\
\hline L. triptera Ehrenberg, 1830 & 164 \\
\hline Lindia torulosa Dujardin, 1841 & 165 \\
\hline
\end{tabular}


Continuação

TABELA 24 - Relação das especies de rotiferos registradas nas Unidades de Gerenciamento de Recursos Hidricos (UGRHIs) do Estado de São Paulo e seu respectivo número de identificação

\begin{tabular}{|c|c|}
\hline ESPECIES & NUMERO \\
\hline Macrochaetus altamirai (Arevalo, 1918) & 166 \\
\hline M. collinsi (Gosse, 1867) & 167 \\
\hline M. longipes Myers, 1934 & 168 \\
\hline M. subquadratus Perty, 1850 & 169 \\
\hline Macrotrachaela plicata & 170 \\
\hline Manfredium eudactylota (Gosse. 1886) & 171 \\
\hline Monommata arndti Remane. 1933 & 172 \\
\hline M. caudata Myers & 173 \\
\hline M. maculata Harring e Myers, 1924 & 174 \\
\hline M. mucronata & 175 \\
\hline Mytilina bisulcata (Lucks, 1912) & 176 \\
\hline M. mucronata (O. F. Müller, 1773) & 177 \\
\hline M. ventralis (Ehrenberg, 1832) & 178 \\
\hline Notommata cerberus (Gosse, 1886) & 179 \\
\hline N. cyrtopus Gosse, 1886 & 180 \\
\hline N. pachyura (Gosse, 1886) & 181 \\
\hline N. saccigera Ehrenberg, 1832 & 182 \\
\hline Plationus patulus (O.F. Müller, 1786) & 183 \\
\hline P.p. macracanthus (Daday, 1905) & 184 \\
\hline Platyias leloupi (Gillard, 1957) & 185 \\
\hline P. quadricornis (Ehrenberg, 1832) & 186 \\
\hline Ploesoma truncatum (Levander, 1894) & 187 \\
\hline Polyarthra longiremis (Carlin, 1943) & 188 \\
\hline P. major Burckhardt, 1900 & 189 \\
\hline P. quadrata & 190 \\
\hline P. vulgaris Carlin, 1943 & 191 \\
\hline P. trigla (Ehrenberg) & 192 \\
\hline Pompholyx complanata Gosse, 1851 & 193 \\
\hline P. sulcata (Hudson, 1885) & 194 \\
\hline P. triloba Pejler & 195 \\
\hline Proales decipiens Ehrenberg, 1831 & 196 \\
\hline P. fallaciosa Wulfert, 1937 & 197 \\
\hline Ptygura libera Myers, 1934 & 198 \\
\hline Rhinoglena cf. frontalis Ehrenberg, 1953 & 199 \\
\hline Rousseletia corniculata Harring & 200 \\
\hline Scaridium bostjani Daems e Dumont, 1974 & 201 \\
\hline S. longicaudum (O. F. Müller, 1786) & 202 \\
\hline Sinantherina socialis (Linné, 1758) & 203 \\
\hline S. spinosa (Thorpe, 1893) & 204 \\
\hline Squatinella mutica (Ehrenberg) & 205 \\
\hline
\end{tabular}


Continuação

TABELA 24 - Relação das especies de rotiferos registradas nas Unidades de Gerenciamento de Recursos Hidricos (UGRHIs) do Estado de São Paulo e seu respectivo número de identificação.

\begin{tabular}{|c|c|}
\hline ESPECIES & NUMERO \\
\hline Synchaeta longipes Gosse. 1887 & 206 \\
\hline S. oblonga Ehrenberg, 1831 & 207 \\
\hline S. pectinata Ehrenberg, 1832 & 208 \\
\hline S. stylata Wiezejski, 1893 & 209 \\
\hline Taphrocampa selenura (Gosse, 1887) & 210 \\
\hline Testudinella amphora Hauer, 1938 & 211 \\
\hline T. emarginula (Stenroos) & 212 \\
\hline T. mucronata (Gosse, 1886) & 213 \\
\hline T. parva (Ternetz, 1892) & 214 \\
\hline T. patina (Hermann, 1783) & 215 \\
\hline T.p. intermedia (Anderson) & 216 \\
\hline T. tridentata Smirnov, 1931 & 217 \\
\hline Trichocerca agnatha Wulfert, 1939 & 218 \\
\hline T. bicristata (Gosse, 1887) & 219 \\
\hline T. bidens (Lucks, 1912) & 220 \\
\hline T. braziliensis (Murray, 1913) & 221 \\
\hline T. capucina Wierzejski e Zacharias, 1893 & 222 \\
\hline T. chattoni De Beauchamp, 1907 & 223 \\
\hline T. collaris (Rousselet, 1896) & 224 \\
\hline T. cylindrica (Imholf, 1891) & 225 \\
\hline T. dixon-nuttalli Jennings, 1903 & 226 \\
\hline T. elongata (Hudson e Gosse, 1886) & 227 \\
\hline T. flagellata Hauer, 1937 & 228 \\
\hline T. gracilis (Tessin, 1890) & 229 \\
\hline T. heterodactyla (Tschug.) & 230 \\
\hline T. iernis (Gosse, 1887) & 231 \\
\hline T. jenningsi Voigt, 1957 & 232 \\
\hline T. longicauda (Tschug.) & 233 \\
\hline T. longiseta (Schrank, 1802) & 234 \\
\hline T. montana Hauer & 235 \\
\hline T. multicrinis (Kellicott, 1897) & 236 \\
\hline T.mus Hauer & 237 \\
\hline T. myersi (Hauer, 1931) & 238 \\
\hline T. porcellus (Gosse, 1886) & 239 \\
\hline T. pusilla (Lauterborn, 1898) & 240 \\
\hline T. relicta Donner & 241 \\
\hline T. cf. rousseletti (Voigt, 1902) & 242 \\
\hline T. similis (Wierzejski, 1893) & 243 \\
\hline T. species & 244 \\
\hline T. stylata (Gosse, 1851) & 245 \\
\hline T. tigris (O. F. Müller, 1786) & 246 \\
\hline Trichotria tetractis (Ehrenberg, 1830) & 247 \\
\hline Trochosphaera aequatorialis Semper, 1872 & 248 \\
\hline Vonoyella globosa & 250 \\
\hline
\end{tabular}


TABELA 25 - Relação das espécies de copépodos ciclopóides registradas nas Unidades de de Gerenciamento de Recursos Hidricos (UGRHIs) do Estado de São Paulo e seu respectivo número de identificação.

\begin{tabular}{l|c}
\hline ESPECIES & NU'MERO \\
\hline Cryptocyclops brevifurca Lowndes, 1934 & 1 \\
\hline Ectocyclops rubescens Brady, 1904 & 2 \\
\hline Eucyclops ensifer Kiefer, 1936 & 3 \\
\hline Eucyclops pseudoensifer Dussart, 1984 & 4 \\
\hline E. serrulatus (Fischer, 1851) & 5 \\
\hline Macrocyclops albidus (Jurine, 1820) & 6 \\
\hline Mesocyclops aspericornis (Daday, 1906) & 7 \\
\hline M. brasilianus Kiefer, 1933 & 8 \\
\hline M. ellipticus Kiefer, 1936 & 9 \\
\hline M. kieferi Van de Velde, 1984 & 10 \\
\hline M. longisetus (Thiébaud, 1914) & 11 \\
\hline M. meridianus (Kiefer, 1926) & 12 \\
\hline M. ogunmus Onabamiro, 1957 & 13 \\
\hline Metacyclops mendocinus (Wierzejski, 1892) & 14 \\
\hline Microcyclops anceps (Richard, 1897) & 15 \\
\hline M. finitimus Dussart & 16 \\
\hline M. varicans (G.O. Sars, 1863) & 17 \\
\hline Paracyclops fimbriatus (Fischer, 1853) & 18 \\
\hline Thermocyclops decipiens (Kiefer, 1929) & 19 \\
\hline T. inversus Kiefer, 1936 & 20 \\
\hline T. minutus (Lowndes, 1934) & 21 \\
\hline Tropocyclops prasinus (Fischer, 1860) & 22 \\
\hline T. schubarti Kiefer, 1935 & 23 \\
\hline
\end{tabular}


Continuação

TABELA 25 - Relação das espécies de copépodos calanóides registradas nas Unidades de de Gerenciamento de Recursos Hídricos (UGRHIs) do Estado de São Paulo e seu respectivo número de identificação.

\begin{tabular}{l|c}
\hline ESPECIES & NUMERO \\
\hline Argyrodiaptomus azevedoi (Wright, 1935) & 24 \\
\hline A. furcatus (Sars, 1901) & 25 \\
\hline Notodiaptomus cearensis (Wright, 1936) & 26 \\
\hline N. conifer (Sars, 1901) & 27 \\
\hline N. cf. henseni (Dahl, 1891) & 28 \\
\hline N. iheringi (Wright, 1935) & 29 \\
\hline N. isabelae (Wright, 1936) & 30 \\
\hline N. jatobensis (Wright, 1936) & 31 \\
\hline N. spinuliferus Dussart e Matsumura-Tundisi, 1986 & 32 \\
\hline N. transitans (Kiefer, 1929) & 33 \\
\hline Notodiaptomus sp. n. & 34 \\
\hline Odontodiaptomus paulistanus (Wright, 1936) & 35 \\
\hline Scolodiaptomus corderoi (Wright, 1936) & 36 \\
\hline Trichodiaptomus coronatus (Sars, 1901) & 37 \\
\hline
\end{tabular}


Continuação

TABELA 25 - Relação das especies de cladoceros registradas nas Unidades de Gerenciamento de Recursos Hidricos (UGRHIs) do Estado de São Paulo e seu respectivo numero de identificação.

\begin{tabular}{|c|c|}
\hline ESPECIES & NÚMERO \\
\hline Acroperus avirastris Henr. 1919 & 38 \\
\hline Acroperus harpae Baird. 1843 & 39 \\
\hline Alona broanensis Matsumura-Tundisi e Smimov. 1984 & 40 \\
\hline A. costata Sars. 1862 & 41 \\
\hline A davidi Richard. 1895 & 42 \\
\hline A. guttata Sars. 1862 & 43 \\
\hline A monacantha Sars. 1901 & 44 \\
\hline A. poppei Richard. 1897 & 45 \\
\hline A. pulchella King, 1853 & 46 \\
\hline A. rectangula Sars. 1861 & 47 \\
\hline A. r. pulchra Hellick, 1874 & 48 \\
\hline Alonella reticulata Henry, 1919 & 49 \\
\hline Biapertura affinis (Leydig, 1860) & 50 \\
\hline B. kendallensis (Henry, 1919) & 51 \\
\hline B. verrucosa (Sars, 1901) & 52 \\
\hline Bosmina coregoni Baird. 1857 & 53 \\
\hline B. hagmanni Stingelin, 1904 & 54 \\
\hline B. longirostris (O.F. Maller, 1785) & 55 \\
\hline B. macrosnla Daday, 1905 & 56 \\
\hline B. mubicen Brehm, 1953 & 57 \\
\hline Bosminopsis deitersi Richard, 1895 & 58 \\
\hline Camptocercus dadayi Stingelin, 1913 & 59 \\
\hline Ceriodaphnia cormuta Sars. 1886 & 60 \\
\hline C. c. comuta Sars, 1886 & 61 \\
\hline C.c. intermedia & 62 \\
\hline C. c. rigandi (Richard, 1894) & 63 \\
\hline C. reticulata (Jurine, 1820) & 64 \\
\hline C. silvessrii Daday, 1902 & 65 \\
\hline Chydorus dentifer Daday, 1905 & 66 \\
\hline C. eurmotus Sars. 1901 & 67 \\
\hline C. globasus & 68 \\
\hline C. pubescens Sars, 1901 & 69 \\
\hline C. sphaericus (Mueller. 1785) & 70 \\
\hline Daphnia ambigua Scourtield, 1947 & 71 \\
\hline D. gesmeri Herbst. 1967 & 72 \\
\hline Diaphanosoma birgei Korineck, 1981 & 73 \\
\hline D. brevireme Sars, 1901 & 74 \\
\hline D. chilensi Daday & 75 \\
\hline D. fuviatile Hansen. 1899 & 76 \\
\hline D. spimulosum Herbst, 1967 & 77 \\
\hline Disparalona acutirostris (Birge, 1879) & 78 \\
\hline D. dadayi (Birge, 1910) & 79 \\
\hline Ephemeroporus barroisi (Richard. 1894) & 80 \\
\hline E. bridentatus (Bergamin, 1931) & 81 \\
\hline Euryalona occidentalis (Sars. 1901) & 82 \\
\hline E. orientalis (Daday, 1898) & 83 \\
\hline Graptoleberis testudinaria (Fischer, 1851) & 84 \\
\hline Ilyocroptus spinifer Herrick. 1882 & 85 \\
\hline Leydigia ciliata Gauthier. 1939 & 86 \\
\hline Macrothrix laticomis (Junine. 1820) & 87 \\
\hline M. paulensis (Sars, 1901) & 88 \\
\hline M. pectinata & 89 \\
\hline M. rasea (Liévin. 1848) & 90 \\
\hline M. spinosa King. 1853 & 91 \\
\hline M. Eriserialis (Brady. 1886) & 92 \\
\hline Moma micrura Kur. 1874 & 93 \\
\hline M. mimuta Hansen. 1899 & 94 \\
\hline Pseudochudorus globosus (Baird. 1850) & 95 \\
\hline Simocephalus serrulatus (Koch. 1841) & 96 \\
\hline S. vetulus (O.F. Muller, 1776) & 97 \\
\hline Simosa iheringi & 98 \\
\hline Streblocerus pygmaeus Sars. 1901 & 99 \\
\hline
\end{tabular}

